\title{
Paramagnetisch markierte Oligonukleotide
}

\author{
Dissertation \\ zur Erlangung des Doktorgrades \\ der Mathematisch-Naturwissenschaftlichen Fakultäten \\ der Georg-August-Universität zu Göttingen
}

vorgelegt von

Edith Wöltjen

aus

Braunschweig

Göttingen 2009 
D 7

Referent:

Prof. Dr. Christian Griesinger,

Max-Planck-Institut für biophysikalische Chemie, Göttingen

Koreferent:

Prof. Dr. Ulf Diederichsen,

Georg-August-Universität, Göttingen

Tag der mündlichen Prüfung: 01.07.2009 
meiner Familie 



\section{Danksagung}

Mein besonderer Dank gilt Herrn Prof. Griesinger für die interessante Themenstellung, sein reges Interesse an dieser Arbeit und die sehr gute Betreuung. Er hat mich stets zielführend unterstützt.

Herrn Prof. Diederichsen möchte ich für die Betreuung meiner Doktorarbeit von Seiten der Universität Göttingen danken. Ohne seine Unterstützung wäre diese Arbeit nicht möglich gewesen.

Bei Dr. Andrei Leonov bedanke ich mich herzlich für die Betreuung des experimentellen Teils und die aufmunternden Worte.

Herrn Fabian Peters, Frau Kerstin Overkamp, Dr. Volker Klaukien und Dr. Mate Erderlyi danke ich für die gemeinschaftliche Arbeit im Büro und die unzähligen wissenschaftlichen Diskussionen.

Dr. Jörg Fohrer danke ich für die Zusammenarbeit bei der TAR-RNA-Strukturanalyse und den NMR-spektroskopischen Messungen.

Bei Dr. Edward D'Auvergne bedanke ich mich für die zahlreichen Diskussionen über Pseudokontaktshifts und dipolare Kopplungen und die Erklärungen zum Programm Relax.

Mein Dank gilt Dr. Dirk Bockelmann, Dr. Jochen Junker und Herr Jürgen Arve für die Unterstützung beim Lösen von Computerproblemen.

Der gesamte Arbeitskreis sorgte für ein kreatives Arbeitsklima in äußerst freundlicher Atmosphäre.

Herrn Johannes Lehmann danke ich für die liebevolle Begleitung meines gesamten Studiums, wegen dem das Privatleben oft zurückstehen mußte.

Meine Familie und Freunde haben meine Arbeit immer mit Interesse und reger Anteilnahme verfolgt.

Für die finanzielle Unterstützung danke ich dem Fonds der Chemischen Industrie. 



\section{Inhaltsverzeichnis}

1 Zusammenfassung $\quad 1$

2 Einleitung $\quad 9$

2.1 Strukturbiologie . . . . . . . . . . . . . . . . . . . 9

2.2 Nukleinsäurestruktur . . . . . . . . . . . . . . . . . . . . . . . . 11

2.3 Biologische Bedeutung von Nukleinsäuren . . . . . . . . . . . . . . 12

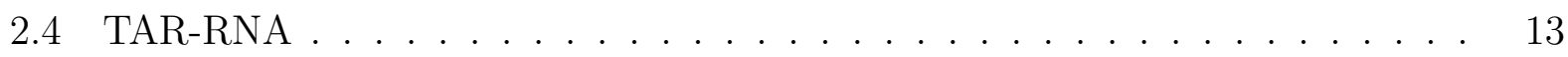

3 NMR-Spektroskopie $\quad 17$

3.1 Strukturaufklärungsmethoden . . . . . . . . . . . . . . . . 17

3.2 2D-NMR-Spektroskopie . . . . . . . . . . . . . . . . 18

3.3 Zur NMR-Strukturaufklärung von Oligonukleotiden . . . . . . . . . . . . . . 20

3.4 Zuordnung der Resonanzen . . . . . . . . . . . . . . . . . . . . . . . 21

3.5 Strukturrechnung . . . . . . . . . . . . . . . . . 27

3.6 NMR-Spektroskopie an partiell ausgerichteten Molekülen . . . . . . . . . . . 29

3.7 Paramagnetische NMR-Spektroskopie . . . . . . . . . . . . . . . . . . . 30

3.8 Pseudokontaktverschiebung . . . . . . . . . . . . . . . . . . 32

3.9 Residuale dipolare Kopplungen . . . . . . . . . . . . . . . . . . 38

3.10 Relaxation durch Paramagnetismus . . . . . . . . . . . . . . . . 43

$\begin{array}{lll}4 & \text { Tagging } & 47\end{array}$

4.1 Das Konzept des Taggings von Biomolekülen . . . . . . . . . . . . . . . 47

4.2 Chelatisierende DNA-Tags in der Literatur . . . . . . . . . . . . . . . 49

4.3 Anforderungen an paramagnetisch getaggte DNA $\ldots \ldots \ldots \ldots$

5 Synthese paramagnetisch markierter DNA $\quad 59$

5.1 Festphasensynthese . . . . . . . . . . . . . . . . 60 
5.2 Methoden zur Modifizierung von DNA-Basen . . . . . . . . . . . . . 62

5.3 Synthese eines EDTA-funktionalisierten Phosphoramidits . . . . . . . . . . 63

5.4 Sonogashira-Reaktionen an DNA . . . . . . . . . . . . . . 67

5.5 Clickchemie . . . . . . . . . . . . . . . . . . . . 69

5.6 Tagging über eine Disulfidbrücke . . . . . . . . . . . . . . . . 81

6 Analyse der Oligonukleotide $\quad 87$

6.1 Zur Auswahl der Sequenzen . . . . . . . . . . . . . . . . . 88

6.2 HPLC von Oligonukleotiden . . . . . . . . . . . . . . . . . . . . . . . 90

6.3 Die Beladung der getaggten DNA mit Lanthanoidionen . . . . . . . . . . . 95

6.4 NMR-Messungen der Hairpin-DNA mit EPTE-Tag . . . . . . . . . . . . . . 98

6.5 Chimäre TAR-RNA . . . . . . . . . . . . . . . . . 107

6.6 Chimäre TAR-RNA mit einem EPTE-Tag . . . . . . . . . . . . . . 111

6.7 Vergleich des paramagnetischen Alignments mit anderen Verfahren . . . . . 118

$\begin{array}{llr}7 & \text { Ausblick } & 121\end{array}$

8 Experimenteller Teil $\quad 123$

8.1 Material und Methoden . . . . . . . . . . . . . . . . . 123

8.2 Versuchsvorschriften . . . . . . . . . . . . . . . 126

$\begin{array}{ll}\text { Literaturverzeichnis } & 173\end{array}$

9 Anhang $\quad 183$

9.1 Abkürzungsverzeichnis . . . . . . . . . . . . . . . 183

9.2 Abbildungsverzeichnis . . . . . . . . . . . . . . . . 186

9.3 Macromodelparameter . . . . . . . . . . . . . . . . . . . 190

9.4 Weitere Versuchsvorschriften . . . . . . . . . . . . . . . . . . 190

9.5 Pulssequenz des NOESY-Spektrums . . . . . . . . . . . . . . . 193

9.6 Pulssequenz des COSY-Spektrums . . . . . . . . . . . . . . . . . . 194

9.7 Pulssequenz des TOCSY-Spektrums . . . . . . . . . . . . . . 196

9.8 NOESY-Pulssequenz mit watergate-Wasserunterdrückung . . . . . . . . . . 198

9.9 HSQC-Pulssequenz der C1'-H1'-Kreuzsignale . . . . . . . . . . . . . . . . 199

9.10 HSQC-Pulssequenz der C8-H8- und C2-H2-Kreuzsignale . . . . . . . . . . 203 
9.11 HSQC-Pulssequenz der gekoppelten C1'-H1'-Kreuzsignale . . . . . . . . . . 207

9.12 HSQC-Pulssequenz der gekoppelten C8-H8- und C2-H2-Kreuzsignale . . . . 211

9.13 CNS-Skripte und Tabellen . . . . . . . . . . . . . . . . 215

9.14 Relax-Skript und die zugehörige PCS-Tabelle . . . . . . . . . . . . . . 244

9.15 Lebenslauf . . . . . . . . . . . . . . . . . . . 246 



\section{Kapitel 1}

\section{Zusammenfassung}

Die Strukturbiologie von Nukleinsäuren ist von großem Interesse in der modernen Biochemie. Die NMR-spektroskopische Analyse (nuclear magnetic resonance) von Oligonukleotiden mit konventionellen Methoden auf der Basis von NOE-Messungen (nuclear Overhauser enhancement) und skalaren Kopplungen führt aufgrund der geringen Protonendichte oft zu fehlerbehafteten Ergebnissen [1]. Neuere Methoden verbessern diese durch die partielle Ausrichtung der Nukleinsäuren im Magnetfeld, wodurch wertvolle zusätzliche Strukturparameter zugänglich werden [2,3]. Bisher erfolgte dies zumeist mit Hilfe externer Alignmentmedien [4]. Die in dieser Arbeit entwickelten Methoden ermöglichen es, Desoxyribonukleinsäuren (DNA) und auch Ribonukleinsäuren (RNA) durch eine paramagnetische Markierung im Magnetfeld auszurichten und somit zusätzliche Strukturinformationen zu generieren. Darüber hinaus lässt sich damit auch die Dynamik von Nukleinsäuren untersuchen [5].

In dieser Arbeit wurden zwei Methoden zur paramagnetischen Markierung von Oligonukleotiden entwickelt. Dabei wurden ethinyl- und thiolhaltige Oligonukleotide per Festphasensynthese dargestellt und anschließend modifiziert. Die Markierung von Makromolekülen mit kleinen funktionalen Einheiten bezeichnet man als Tagging. Im Fokus stand die Verwendung 
der paramagnetischen DNA für NMR-Studien, aber auch für MRI, künstliche DNAsen und molekulare Magnete sind paramagnetisch markierte Oligonukleotide von Interesse [6-10].

Um ein paramagnetisches Zentrum in einem Biomolekül zu erhalten, muss entweder ein Metallion oder ein Radikal eingeführt werden. Als stabile Radikale bieten sich Nitrosylradikale wie TEMPO (2,2,6,6-Tetramethylpiperidinyloxyl) an. Neben einem TEMPO-basierten Radikal wurden in dieser Arbeit Lanthanoid(III)ionen (im Folgenden kurz Lanthanoidionen genannt) als paramagnetische Zentren genutzt. Lanthanoidionen werden sehr stark von EDTA (Ethylendiamintetraacetat) komplexiert $\left(K_{B} \approx 10^{18}\right)[11]$. Diese starke Wechselwirkung erlaubt eine selektive Bindung von Lanthanoidionen an die Chelatfunktion anstelle von unselektiven Wechselwirkungen mit Phosphatfunktionen des DNA-Rückgrats.

Die EDTA-Tags wurden auf zwei verschiedene Arten an die DNA gebunden. Die erste Methode basiert auf einer Anbindung über eine Disulfidbrücke. Dazu wurde ein S-Acetyl-5mercaptomethyl-2'-desoxyuridin via Phosphoramiditchemie in eine DNA-Sequenz eingebaut. Anschließend wurde die Thiolfunktion entschützt und reagierte mit einem Thiosulfonat 36 zum gewünschten Oligonukleotid (Abb. 1.1).

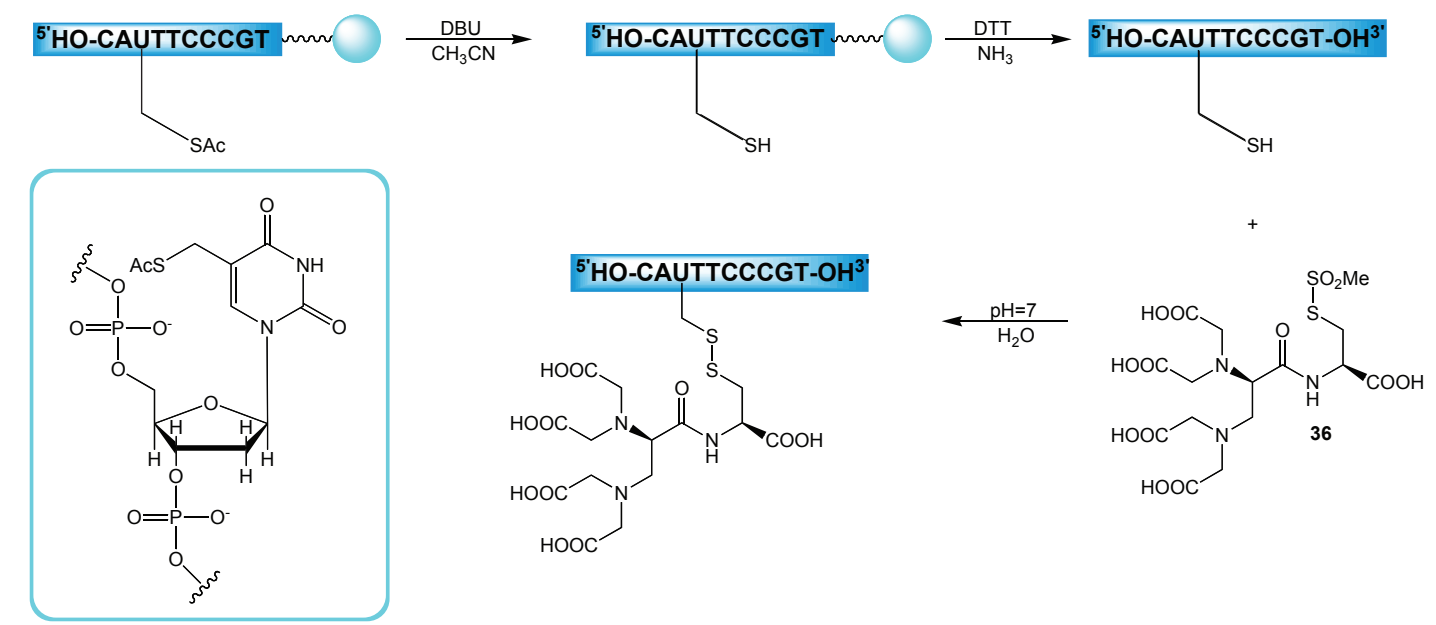

Abb. 1.1: Tagging über eine Disulfidbrücke. Die DNA-Sequenzen sind dunkelblau unterlegt. Die hellblauen Kugeln stellen die CPG-Festphase (controlled pore glas) dar.

Analog wurden ebenfalls Proteine und Peptide modifiziert. Mit dem gleichen Thiosulfonat wurden bereits Calmodulin, Triggerfaktor und Ubiquitin derivatisiert [12-14]. 
Die zweite Methode zur paramagnetischen Markierung basiert auf der Clickreaktion [15, 16], einer Kupfer(I)-katalysierten Huisgen 1,3-dipolaren Cycloaddition. Dabei reagieren ein Azid mit EDTA-Funktion und eine ethinylmodifizierte DNA. Clickreaktionen an DNA-Sequenzen haben ein breites Anwendungsspektrum, da sie unter milden, neutralen Bedingungen durchgeführt werden können und dabei diverse funktionelle Gruppen tolerieren. Die Clickreaktion an Oligonukleotiden mit 5-Ethinyl-2'-desoxyuridin erwies sich als sterisch teilweise gehindert (Abb. 1.2). Das sehr flexible radikalische Azid reagierte mit diesem Oligonukleotid, aber das sterisch etwas anspruchsvollere Cyclohexylazid 32-S lieferte nur eine Mischung aus Eduktund Produktoligonukleotid. Eine Reaktion der Ethinylfunktion mit dem weniger reaktiven aromatischen Azid 26-S fand nicht statt.

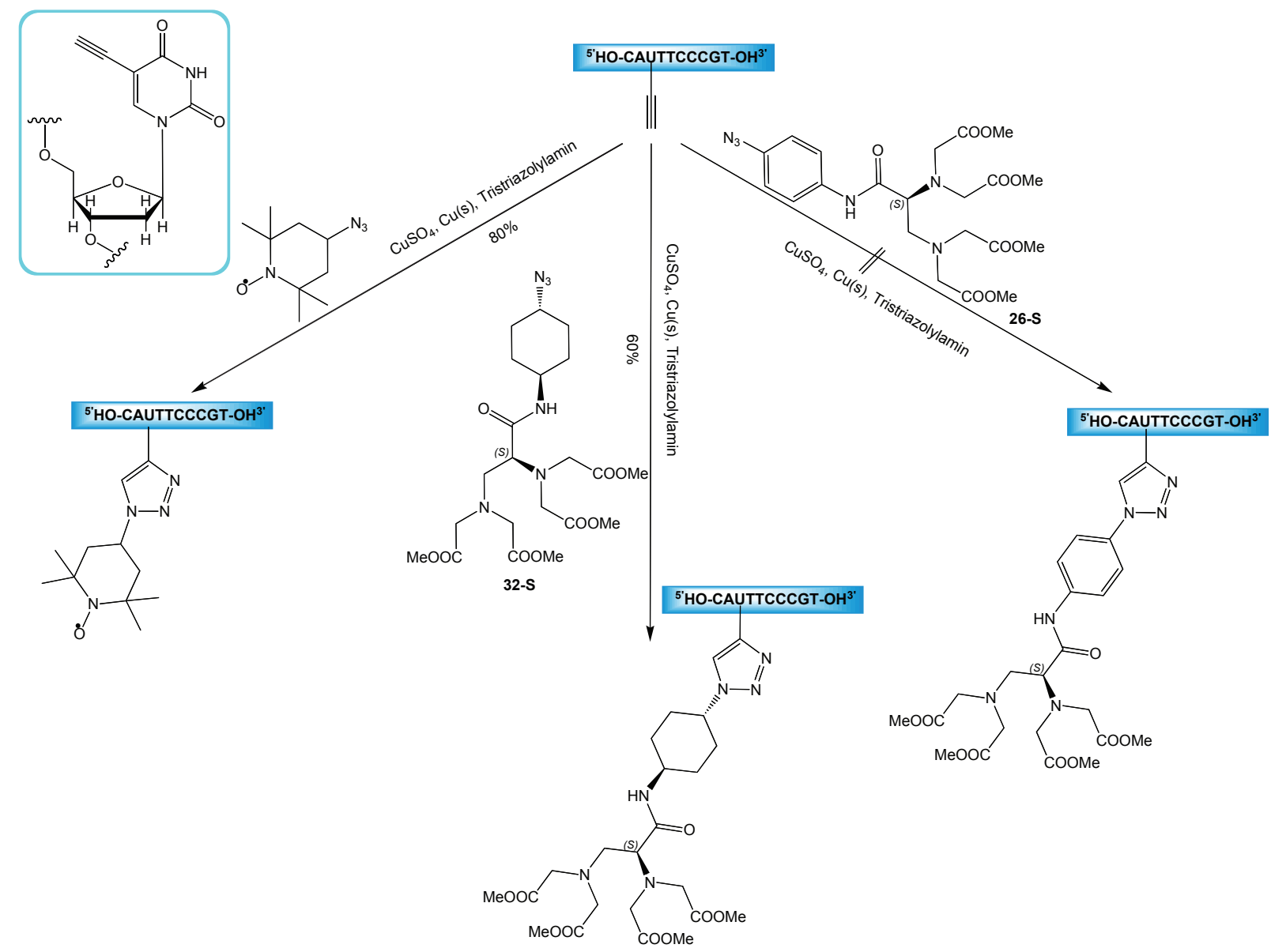

Abb. 1.2: Methodenübersicht: Clickreaktionen an ethinylmodifizierter DNA mit einem radikalischen TEMPO-Derivat (links), einem alkylischen Azid mit EDTA-Funktion (Mitte) und einem aromatischen Azid mit EDTA-Funktion (rechts). 
Durch die Verwendung des verlängerten 5-[[(4-Ethinyl)phenyl]ethinyl]-2'desoxyuridin wurde dieses Problem gelöst. Auf diese Art konnte auch das aromatische Azid mit der DNA verbunden werden (EPTE-Tag). Die Clickreaktion an derart modifizierten Oligonukleotiden war dabei sowohl in Lösung als auch an festphasengebundenen Oligonukleotiden möglich (Abb. 1.3). Der Vorteil hierbei ist die einfachere Aufarbeitung, da die festphasengebundene DNA durch Waschen mit verschiedenen Lösungsmitteln von überschüssigem Azid, Ligand und Kupferionen gereinigt werden kann.

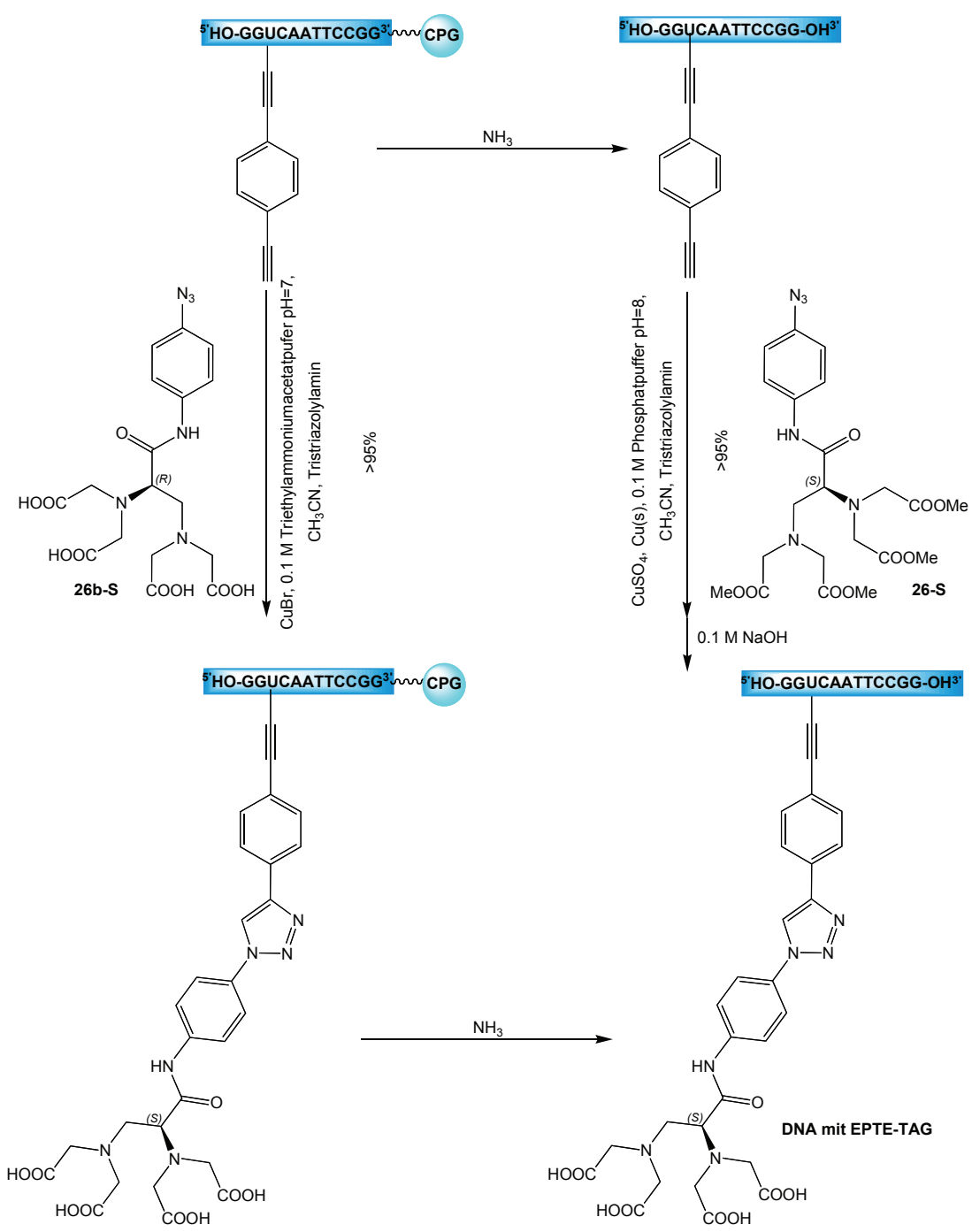

Abb. 1.3: Methodenübersicht: Clickreaktionen an verlängerter ethinylmodifizierter DNA. Synthese einer DNA mit EPTE-Tag durch eine Clickreaktion an der Festphase (links) und in Lösung (rechts). 
Lanthanoidhaltige paramagnetische Tags sind für die NMR-Spektroskopie von großem Interesse, weil sie einerseits die Strukturberechnungen verfeinern können und andererseits auch Informationen über die Dynamik von Molekülen liefern. Dabei treten drei verschiedene Effekte in den Spektren auf: Paramagnetische Relaxationsverstärkung (PRE), Pseudokontaktverschiebungen (PCS) und residuale dipolare Kopplungen (rdc). Erstere ist abhängig von der Distanz des betrachteten Atomkerns zum paramagnetischen Zentrum und wird oft für Bindungsstudien von Proteinkomplexen genutzt. Pseudokontaktverschiebungen sind ebenfalls abstandsabhängig, unterliegen aber zudem noch einer Winkelabhängigkeit. Die meist genutzten Effekte sind residuale dipolare Kopplungen, die es erlauben die Orientierung des Vektors zweier benachbarter Atomkerne im Alignmenttensor zu bestimmen. Dies kann nur gelingen, wenn das getaggte Molekül durch die magnetische Anisotropie des Lanthanoidions eine Vorzugsausrichtung im Raum besitzt. Neben dem Tagging existieren auch andere Methoden, um eine Vorzugsausrichtung im Molekül zu generieren, z. B. durch die Nutzung von Phagen oder gestreckten Polyacrylamidgelen, welche allerdings nur rdcs und keine PCSs liefern [17].

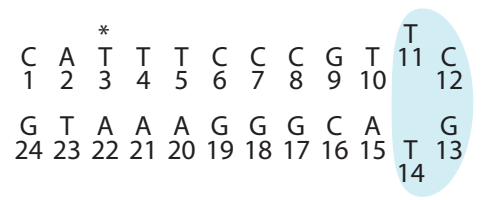

Abb. 1.4: DNA-Hairpinsequenz. Das Sternchen markiert die Position des Tags.

In dieser Arbeit wurde die Struktur eines 24meren DNA-Hairpins durch NMR-spektroskopische Messungen ermittelt. Dazu wurden NOE-Daten und das Strukturberechnungsprogramm CNS (Crystallography \& NMR System) genutzt [18,19]. Die Sequenz des Hairpins basiert dabei auf einem Ausschnitt einer STAT-Protein bindenden Sequenz (Abb. 1.4) [20-22]. An der dritten Position der DNA wurde ein paramagnetischer Tag mit Hilfe einer Clickreaktion angebracht, der anschließend mit Dysprosiumionen beladen wurde. Aus dem NOESYSpektrum konnten dreiunddreißig Pseudokontaktshifts extrahiert werden. Mit dem Programm Macromodel [23] wurde ein Set von mehreren Tag-Konformationen an der Hairpinsequenz erstellt. Das Programm Relax [24,25] benutzte diese als Basis zur Berechnung des Alignmenttensors aus den Pseudokontaktshifts. 
Die erwarteten rdcs können damit maximal die Größe von $13.8 \mathrm{~Hz}$ bei $700 \mathrm{MHz}$ erreichen. Der q-Faktor, der die Güte der Messwerte bestimmt, betrug 0.086. Die Größe des Tensors und damit auch der erwarteten rdes entspricht in etwa den Werten der EDTA-Tags für Proteine $[12,14]$.

Des Weiteren wurde ein Konstrukt entwickelt, das das Alignment der HIV2-TAR-RNA ermöglicht. Dazu wurde eine TAR-RNA-Sequenz am 3'-Ende um einen Überhang von 11 Basen verlängert. Anschließend wurde ein komplementärer decamerer DNA-Gegenstrang zur RNA titriert (Abb. 1.5). Dabei wurde durch NMR-spektroskopische Messungen beobachtet, dass sich bei $25{ }^{\circ} \mathrm{C}$ ein stabiler chimärer Duplex bildet. Essentiell dabei ist, dass dadurch die Signale der ursprünglichen RNA nicht beeinflusst wurden und somit auch nicht deren Konformation.

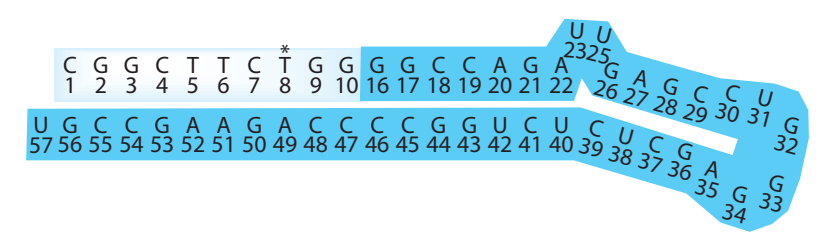

Abb. 1.5: Verlängerte TAR-Sequenz des HIV2.

dunkelblau: RNA, hellblau: DNA, Sternchen: getaggte Base.

Der DNA-Gegenstrang kann durch eine der oben genannten Methoden mit einem paramagnetischen Zentrum modifiziert werden. Dazu wurde ein EPTE-Tag verwendet. Die DNA wurde mit Dysprosium komplexiert und anschließend zur RNA titriert. Bei $900 \mathrm{MHz}$ und 298 K wurden rdes bis zu $10 \mathrm{~Hz}$ gemessen. Die $\mathrm{Dy}^{3+}$-haltige DNA hydrolysierte dabei die RNA nicht, was durch eine Gelelektrophorese nachgewiesen wurde. Der EPTE-Tag bewirkte also eine Vorzugsausrichtung des gesamten Konstrukts im Magnetfeld.

Die NMR-Spektroskopie und auch die Röntgenstrukturanalyse setzen sehr saubere DNAProben voraus. Dies führt bei nicht palindronischen DNA-Duplexen zu der Anforderung, dass Strang und Gegenstrang genau im Verhältnis eins zu eins vorliegen müssen. Meist werden dazu UV-Absorptionspektren der ssDNA-Lösungen gemessen, um deren Konzentrationen zu bestimmen. Diese Methode führt jedoch oft zu fehlerbehafteten Ergebnissen, besonders 
falls modifizierte Oligonukleotide vorliegen, deren Modifikation das UV-Absorptionspektrum beeinflusst. Dies ist z. B. beim EPTE-Tag der Fall, deshalb wurde in dieser Arbeit nachfolgende Hochleistungsflüssigkeitschromatographie-Methode (HPLC, high performance liquid chromatography) zur Behebung dieses Problems entwickelt.

Mit Hilfe der Anionenaustauscher-HPLC können ds- und ssDNA-Gemische untersucht werden, da bei dieser Chromatographie unter nativen Bedingungen in wässrigen Lösungen bei neutralem pH-Wert gearbeitet wird. Die Trennung basiert dabei auf der unterschiedlichen Anzahl an Phosphatresten im Rückgrat, die mit dem positivgeladenen Säulenmaterial wechselwirken. Dabei kann nicht nur das Verhältnis von ssDNA zu dsDNA ermittelt werden, sondern auch die Art des im Überschuss vorliegenden Einzelstranges. Proben mit ausschließlich gepaarter DNA lassen sich so einfach herstellen. 
KAPITEL 1. ZUSAMMENFASSUNG 


\section{Kapitel 2}

\section{Einleitung}

\subsection{Strukturbiologie}

Mit der Strukturbiologie werden die Prozesse des Lebens auf der molekularen oder atomaren Ebene verständlich. Die Eigenschaften biologischer Makromoleküle wie Proteine, DNA und RNA und deren Wechselwirkungen bestimmen die auf der makroskopischen Ebene phänomenologisch zugänglichen biologischen Prozesse.

Die Erkenntnisse der Strukturbiologie sind für die biotechnologische und pharmazeutische Industrie wichtig. Im menschlichen Organismus ist eine Vielzahl von Proteinen und $\mathrm{Nu}-$ kleinsäuren vorhanden, die potenzielle Wirkungsorte für Medikamente darstellen. Durch die Kenntnis der Struktur dieser Moleküle können Bindungsstellen und Bindungspartner analysiert werden. Mit Hilfe dieser Informationen können Computersimulationen potentielle Bindungspartner aus Moleküldatenbanken identifizieren und anschließend in einem screening deren Bindungsaffinität untersuchen. Dadurch werden potentielle Medikamente aus Moleküldatenbanken herausgefiltert, deren Wirksamkeit dann überprüft werden kann. Vor allem 
seit der Einführung der ersten kommerziellen Biopharmazeutika erlebt die Strukturbiologie ein noch stärkeres Wachstum (Abb. 2.1).

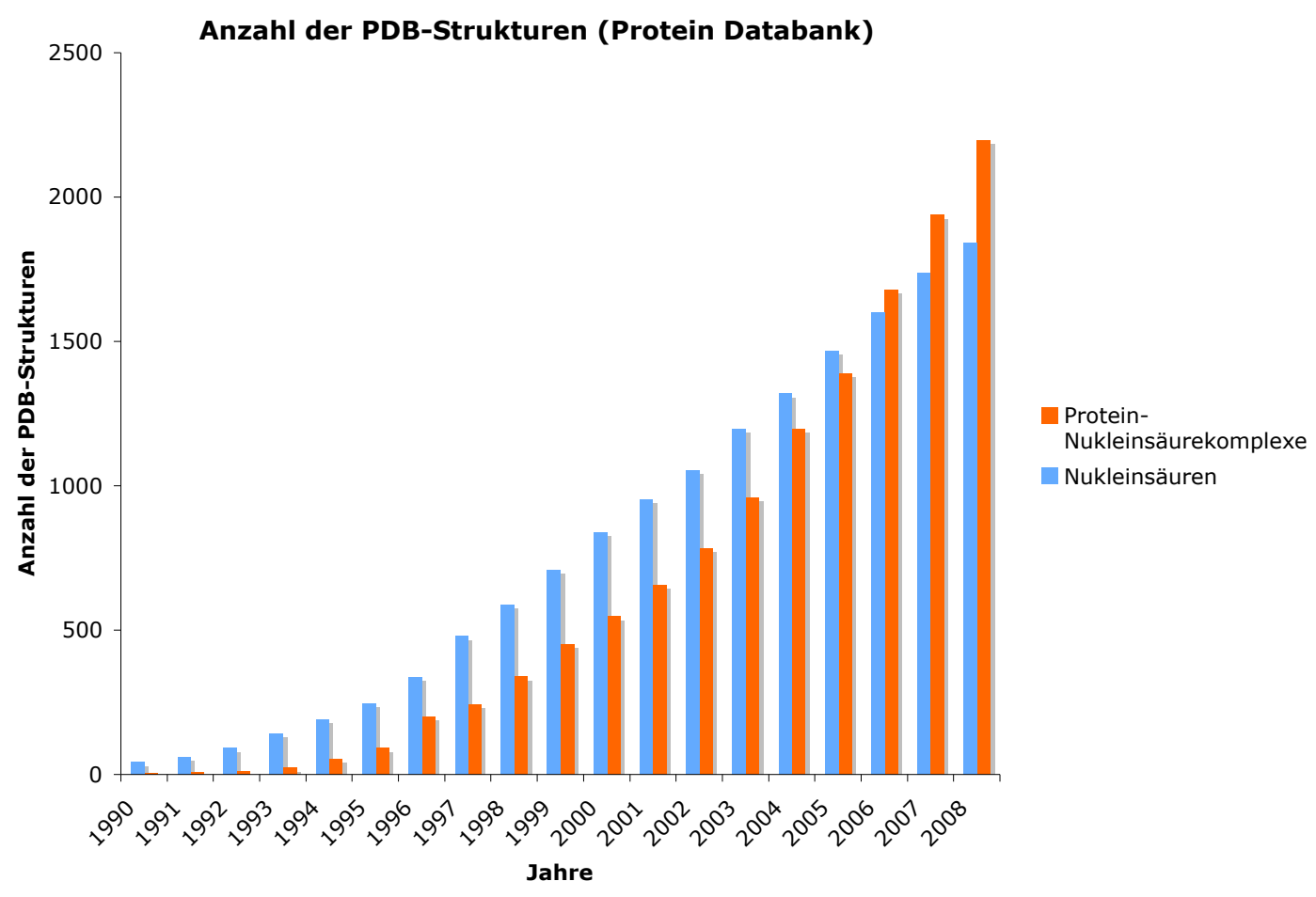

Abb. 2.1: Entwicklung der Nukleinsäurestrukturaufklärungen anhand der PDB-Daten.

Im letzten Jahrzehnt hat die Forschung auf dem Bereich der Nukleinsäuren stark zugenommen. Initialzündung war 1992 die Entdeckung, dass die Genexpression des LIN-14-Proteins durch kurze RNA-Stränge (20-25 Nukleotide lang) reguliert wird [26]. In den folgenden Jahren stellte sich heraus, dass diese kurzen RNA-Stränge, short interfering RNA (siRNA) oder microRNA (miRNA) genannt, die Expression vieler Gene (geschätzte 20-30\%) regulieren $[27,28]$. Diese regulatorische Aktivität wurde von Tuschl et al. zum Knockdown spezieller Gene in Säugetierzellen genutzt [29]. Dabei wurde siRNA in die Zelle eingebracht, die gezielt die mRNA eines Proteins abbaut. Dadurch wurde das Gen nicht oder stark vermindert expremiert und man konnte beobachten, welche biologischen Prozesse beeinflusst werden, also welche Funktion ein Gen hat. 


\subsection{Nukleinsäurestruktur}

Pyrimidinbasen<smiles>[R]c1c[nH]c(=O)[nH]c1=O</smiles>

$\mathrm{R}=\mathrm{Me} / \mathrm{H}$

Thymin/Uracil<smiles>Nc1cc[nH]c(=O)n1</smiles>

Cytosin

\section{Purinbasen}<smiles>Nc1nc2[nH]cnc2c(=O)[nH]1</smiles>

Guanin<smiles>Nc1ncnc2[nH]cnc12</smiles>

Adenin

Abb. 2.2: Abbildung der Nukleobasen.

DNA und RNA bestehen aus den fünf Nukleosiden Adenosin, Guanosin, Cytidin und Thymidin bzw. Uridin (Abb.2.2), die über Phosphatdiesterbindungen miteinander verknüpft sind. Jedes Nukleosid besteht aus einem Zuckerring, der am anomeren Zentrum glykosidisch mit einer Nukleobase verknüpft ist. RNA basiert auf dem Zucker Ribose, DNA auf 2'-Desoxyribose. In DNA nimmt die 2'-Desoxyribose mit C2'-endo meist eine andere Vorzugskonformation ein als die Ribose mit C3'-endo in RNA-Helices (Abb. 2.3).
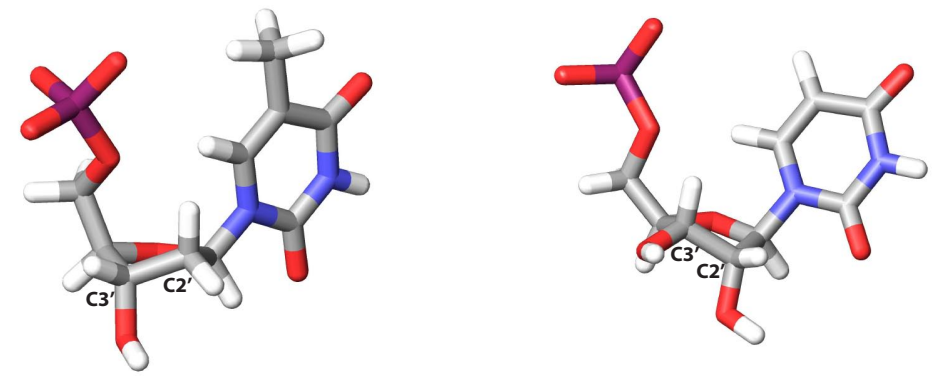

Abb. 2.3: Die beiden Zuckerkonformationen von DNA (links) und RNA (rechts).

Nukleinsäuren speichern die genetische Information eines Organismus, codiert in der Abfolge der einzelnen Nukleotidbausteine. Sie sind spiralförmig gewundene Ketten, die meist doppelsträngig vorliegen und über Watson-Crick-Wasserstoffbrückenbindungen verbunden sind [30]. Unter physiologischen Bedingungen liegt RNA in Form einer A-Helix, DNA in Form einer B-Helix vor (Abb. 2.4). 

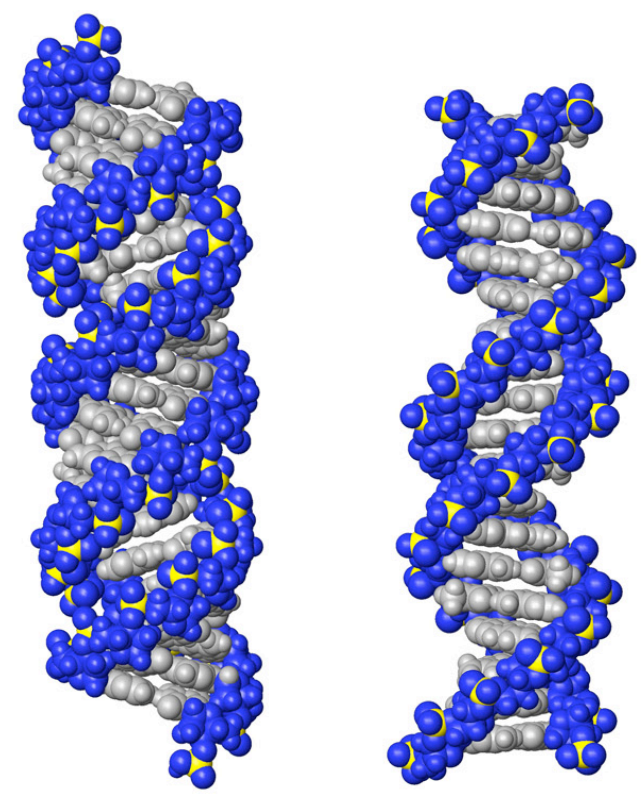

Abb. 2.4: Die verschiedenen Nukleinsäurehelices: A-Form (links), B-Form (rechts) [31].

\subsection{Biologische Bedeutung von Nukleinsäuren}

Neben der Funktion der genetischen Informationsspeicherung besitzen Nukleinsäuren noch weitere Funktionen, wie die Umwandlung dieser Informationen zu Proteinen. RNAs, die Enzymfunktionen besitzen, nennt man Ribozyme. 1989 bekamen Sidney Altman und Thomas R. Cech den Nobelpreis für Chemie für die Entdeckung des Enzympotentials der RNA, die heute zu dem Postulat der RNA world als Ursprung allen Lebens führte. Ein besonders bekanntes Ribozym ist die 23 S-RNA, die zuständig für die Knüpfung der Peptidbindung bei der Translation ist. Spliceosome katalysieren die Entfernung der Introns aus der pre-mRNA unter Erhalt der fertigen mRNA aus den Exonsequenzen. Auch als Energielieferanten und -speicher spielen Nukleinsäuren eine wichtige Rolle. Adenosintriphosphat (ATP) ist beispielsweise das Trinukleotid des Adenosins, das unter Energieabgabe zu Adenosindiphosphat (ADP) und Adenosinmonophosphat (AMP) umgewandelt werden kann. Diese Energie wird vom Organismus für die verschiedensten zellulären Vorgänge genutzt, wie Transport durch Membranen und chemische Reaktionen. siRNAs sind Teil des RNA-Interferenz-Mechanismus (RNAi). Hierbei binden die siRNAs an ein Argonaute-Protein und an die komplementäre mRNA, die 
dann durch das Protein abgebaut wird. Dies führt zur Regulation der Expression der in der mRNA kodierten Gene.

Die verschiedensten Funktionen der Nukleinsäuren beruhen dabei nicht nur auf der konstitutionellen Verknüpfung der jeweiligen unterschiedlichen Bausteine, sondern auch auf deren Anordnung im Raum (Konformation). So bilden sich Bindungsstellen, die sowohl spezifisch für bestimmte Molekülklassen als auch hochspezifisch für einzelne Moleküle sein können. DNAund RNA-Moleküle besitzen per se meist eine helikale doppelsträngige Struktur, die aber durch kleine Unterschiede zu den verschiedenen Funktionen und Bindungsmotiven führt. Häufige Bindungsstellen sind die Furchen der Helices (Abb. 2.5), aber auch die Nukleobasen und Strukturelemente wie Schlaufen (loops) und Vorwölbungen (bulges) [33].

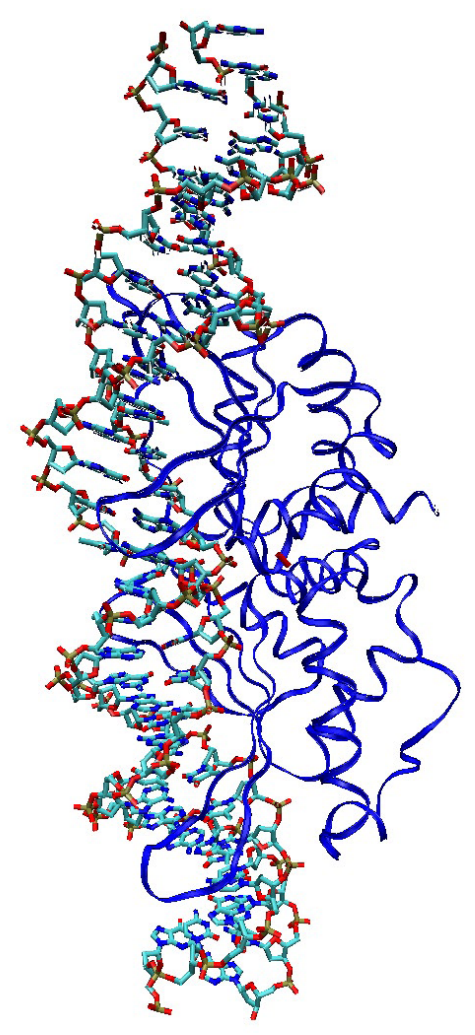

Abb. 2.5: Eine Endonuclease gebunden an die DNA-Zielsequenz [32].

\subsection{TAR-RNA}

Human immunodeficiency virus (HIV) ist ein Retrovirus, der die Immunschwächekrankheit AIDS (acquired immunodeficiency şyndrome) auslöst (Abb. 2.6). Obwohl sich der Virus immer stärker verbreitet, ist seit seiner Entdeckung 1983 noch kein Heilmittel gefunden worden. Unter anderem besteht die Schwierigkeit der Medikamentenentwicklung darin, dass es verschiedene Formen von HI-Viren gibt, die relativ schnell mutieren. Retroviren speichern ihre Erbinformation in Form von RNA, die aufgrund der zusätzlichen 2'-Hydroxylgruppe schneller mutiert als DNA. 


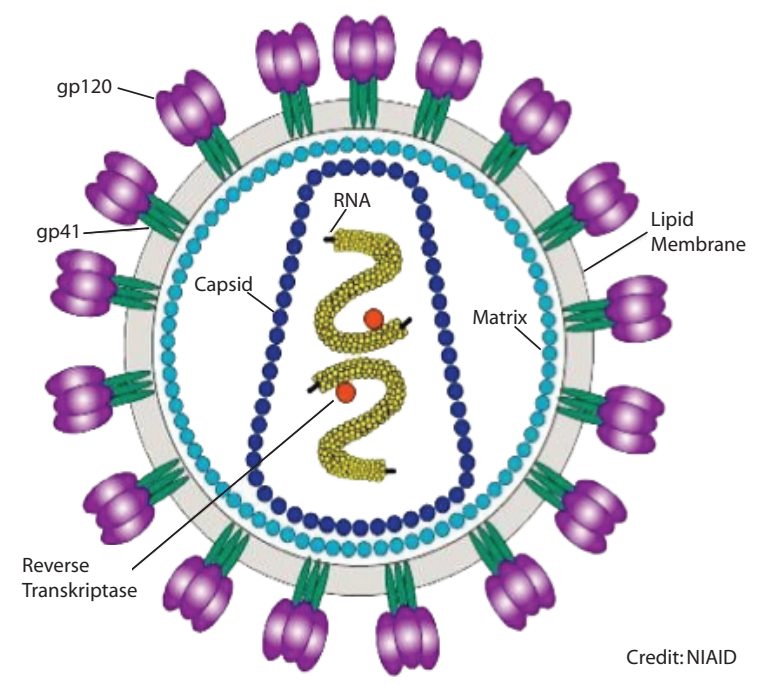

Abb. 2.6: Schematische Darstellung des HI-Virus.

Das Genom der HI-Viren wird in verschiedene codierende Bereiche, die Gene, aufgeteilt. Das tat-Gen des HI-Virus codiert das 86 bis 101 aminosäurelange TAT-Protein (transactivator of transcription), das an die ursprüngliche Haarnadelstruktur (hairpin) der HIV-RNA bindet und in ssRNA entfaltet. Diese ssRNA wird wesentlich effizienter transkribiert. Durch die effizientere Transkription wird auch mehr TAT-Protein gebildet, das wiederum die Transkriptionsgeschwindigkeit noch weiter erhöht. Das TAT-Protein wird von infizierten Zellen abgegeben und im Blut von AIDS-Patienten gefunden. Es ist toxisch und führt deshalb zur Apoptose von noch uninfizierten T-Zellen.

Das TAT-Protein bindet zur Transkriptionsaktivierung an den stem-loop der TAR-RNA

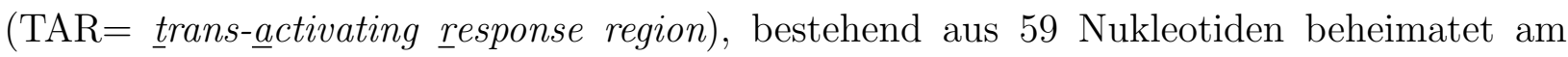
5'-Ende der HIV-Transkripte. Die bulge-Region des stem-loops ist wichtig für die TATBindung und Transaktivierung, während die loop-Region nur für die Transaktivierung wichtig ist. NMR-Studien haben gezeigt, dass die zentrale Bindungsregion zwischen TAT und TAR aus dem bulge und den beiden benachbarten Basenpaaren besteht [34]. Durch Anbindung eines Arginins oder Argininanalogas wird eine Strukturänderung im bulge induziert [35,36]. In den meisten NMR-Studien verwendet man Konstrukte aus den vier funktionell wichtigen Domänen: lower stem, bulge, upper stem, loop (siehe Abb. 2.7). 


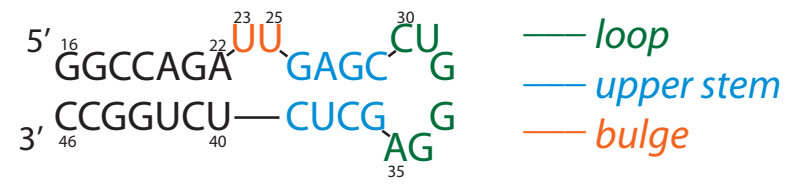

Abb. 2.7: Untersuchte TAR-Sequenz des HIV2.

Durch die Inhibition der TAT-TAR-Wechselwirkung lässt sich die Ausbreitung des Virus im Körper verlangsamen, weshalb verschiedene Inhibitoren auf ihre Medikamententauglichkeit überprüft werden, wie zum Beispiel TAT peptid mimetics, Argininaminoglykoside und RNAAptamere [37]. Beim Menschen wurden zwei verschiedene Typen von HI-Viren gefunden, Typ 1 und Typ 2, die auf Aminosäureebene nur knapp 50\% Sequenzhomologie aufweisen. Die TAR-Sequenzen dieser beiden HIV-Typen unterscheiden sich nur geringfügig in der Bindungsregion [38]. Obwohl sich die Sequenzen des bulges durch die Substitution der zwei Nukleotide UU durch die drei Nukleotide UCU unterscheiden, binden beide in gleicher Weise an das TAT-Protein [36].

CyclinT1 ist ein Transkriptionsfaktor, der zusammen mit TAR und TAT einen Komplex bildet. Mutationsstudien haben dabei gezeigt, dass TAT an die bulge-Region von TAR bindet, während CycT1 an die loop-Region bindet. Designte Inhibitoren sollten also beide Wechselwirkungen gleichermaßen behindern und die gesamte Region von bulge bis upper stem blockieren, um die Transkription des Virus zu verhindern.

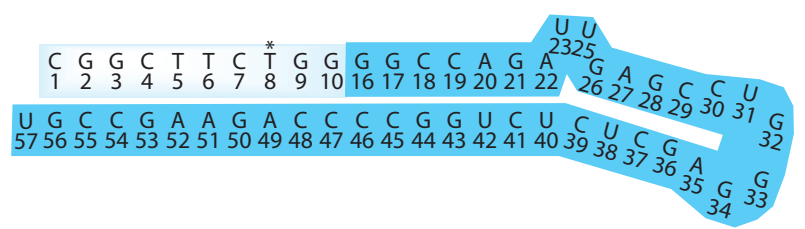

Abb. 2.8: Verlängerte TAR-Sequenz des HIV2.

dunkelblau: RNA, hellblau: DNA, Sternchen: getaggte Base

Obiger Ausschnitt der TAR-Sequenz des HIV-Typ 2 wurde in dieser Arbeit verwendet, um das Alignment von RNA durch paramagnetisch getaggte DNA zu überprüfen (Abb. 2.8). 
KAPITEL 2. EINLEITUNG 


\section{Kapitel 3}

\section{NMR-Spektroskopie}

\subsection{Strukturaufklärungsmethoden}

Die NMR-Spektroskopie stellt eine wichtige Strukturanalysemethode dar. Die zu untersuchenden Moleküle werden dazu in einem Lösungsmittel gelöst und einem starken externen, homogenen Magnetfeld ausgesetzt. Detektierbar sind dabei nur Atomkerne mit einem Kernspin ungleich null. ${ }^{1} \mathrm{H}$-Wasserstoffatome haben einen Kernspin von $1 / 2$ und sind deshalb mit der NMR-Spektroskopie gut analysierbar, aber das häufigste Kohlenstoffisotop ${ }^{12} \mathrm{C}$ hat einen Kernspin von null und ist nicht detektierbar. In der Natur kommt das ${ }^{13} \mathrm{C}-$ Kohlenstoffisotop mit dem Kernspin 1/2 nur zu 1,1\% vor [39]. Die Sensitivität von Kohlenstoffspektren mit natürlicher Häufigkeit ist deshalb sehr gering. Um das zu umgehen verwendet man oft markierte Proben, d. h. Proben, die mit dem Kohlenstoffisotop ${ }^{13} \mathrm{C}$ angereichert sind.

Das Hauptstickstoffisotop ${ }^{14} \mathrm{~N}$ ist mit einem Kernspin von 1 ein Quadrupolkern, der zwar detektierbar ist, aber sehr schnell relaxiert. Das zu 0,37\% vorkommende Kernspin-1/2- Isotop ${ }^{15} \mathrm{~N}$ wird deshalb meist auf $95 \%$ angereichert um Stickstoffspektren aufzunehmen [39]. 
Neben der NMR-Spektroskopie spielt vor allem die Röntgenstrukturanalyse eine große Rolle innerhalb der Strukturbiologie. Hierbei wird ein kristallisiertes Molekül mit Hilfe von Röntgenbeugungsmustern analysiert, so dass eine dreidimensionale Elektronendichtekarte des Moleküls und damit seine Struktur errechnet werden kann. Je nach Kristallqualität bietet diese Methode eine Auflösung bis maximal $1 \AA$ [40]. Strukturaufklärungen von größeren Systemen (>200 kDa) kann die moderne Elektronenmikroskopie leisten, aber die Auflösung beträgt meist maximal $4 \AA[41]$.

Viele DNA- und RNA-Strukturen wurden durch Röntgenstrukturanalyse aufgeklärt. Ihr Nachteil besteht darin, dass nur die starre Struktur in der Kristallform ermittelt werden kann, aber nicht die Struktur, die in der Lösung, also physiologisch, vorliegt. Mit Hilfe der NMR-Spektroskopie dagegen können Moleküle in Lösung und deren dynamische Eigenschaften untersucht werden [42].

\section{$3.2 \quad$ 2D-NMR-Spektroskopie}

Die Entwicklung der zweidimensionalen NMR-Spektroskopie in den 80er Jahren erlaubte die detaillierte Untersuchung von biomolekularen Systemen [43]. In eindimensionalen Spektren sind die Resonanzpeaks von Makromolekülen wie DNA oder Proteinen stark überlagert. Bei der 2D-NMR-Spektroskopie erfolgt die Auflösung in zwei Zeitdomänen, die durch FourierTransformation in die Frequenzdomänen überführt werden. Die eine Zeitdomäne, meist $t_{1}$ genannt, ist ein Zeitintervall zwischen zwei Pulsen, das inkrementiert wird. Das Signal der zweiten, direkten Zeitdomäne $t_{2}$ wird direkt am Ende der Pulssequenz detektiert. Ein Resonanzsignal in einem zweidimensionalen Spektrum besitzt also zwei Frequenzen $\omega_{1}$ und $\omega_{2}$ entsprechend $t_{1}$ und $t_{2}$. Generell unterscheidet man zwischen homonuklearen und heteronuklearen NMR-Spektren, je nachdem ob sich in $t_{1}$ und $t_{2}$ dieselbe oder verschiedene Kernarten, beispielweise ${ }^{1} \mathrm{H}$ und ${ }^{13} \mathrm{C}$, entwickeln [44]. 


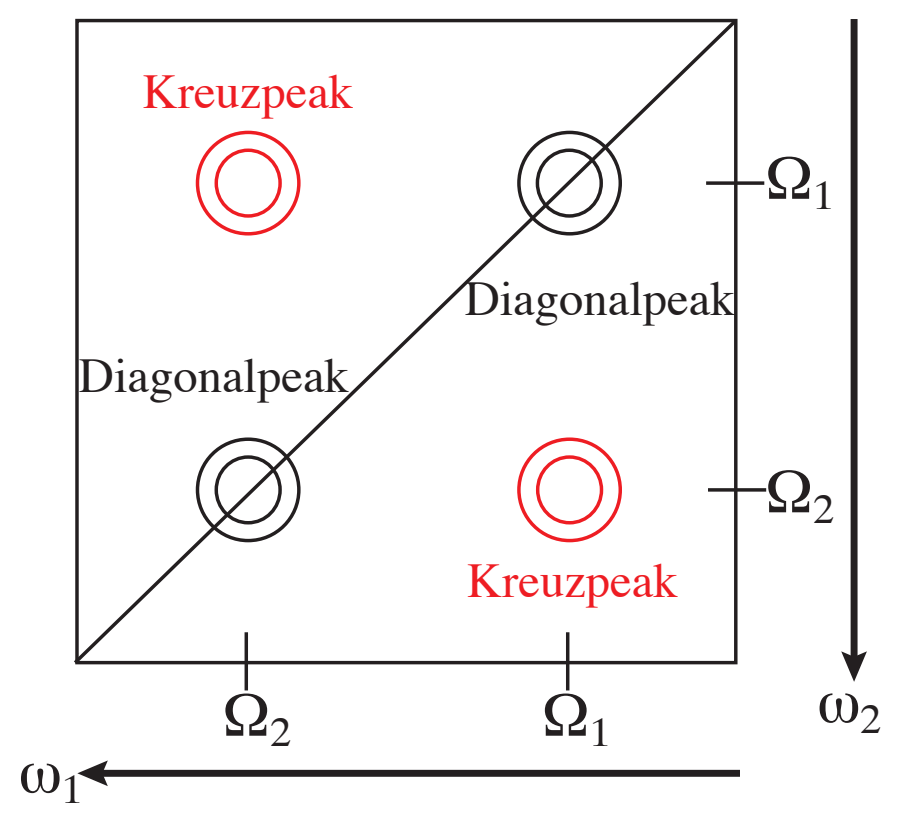

Abb. 3.1: Schematische Darstellung eines homonuklearen zweidimensionalen NMR-Spektrums.

Bei homonuklearen Experimenten ergibt sich schematisch folgendes Spektrum (Abb. 3.1), das aus Kreuz- und Diagonalpeaks besteht. Von einem Diagonalpeak spricht man immer dann, wenn das Signal in $\omega_{1}$ und $\omega_{2}$ die gleiche chemische Verschiebung $\Omega$ auftritt, also dem gleichen Atom zugeordnet ist. Kreuzpeaks haben in den beiden Frequenzdomänen eine unterschiedliche chemische Verschiebung. Sie korrelieren zwei Atome. Diese Korrelation beinhaltet je nach Pulssequenz Informationen über die Verknüpfung der Atome im Molekül oder deren räumliche Nähe zueinander. Eine Pulssequenz ist eine Abfolge radiofrequenter Einstrahlungen, die die Kernspins anregen.

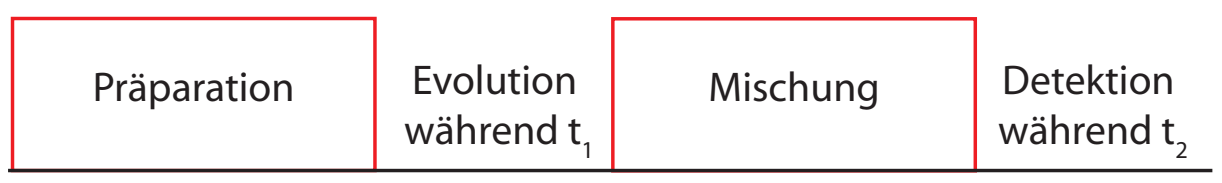

Abb. 3.2: Schema zum Aufbau zweidimensionaler NMR-Pulsprogramme. Die roten Boxen symbolisieren verschiedene Abfolgen von Pulsen.

Eine Pulssequenz eines zweidimensionalen Spektrums ist wie folgt aufgebaut (Abb. 3.2). In einem ersten Schritt wird die longitudinale Boltzmannmagnetisierung in die gewünsch- 
te transversale Magnetisierung transferiert (Präparation), die sich dann meist in Form der chemischen Verschiebung in $t_{1}$ entwickelt (Evolution). Anschließend wird diese codierte Magnetisierung auf einen anderen Kern übertragen, in die zu detektierende Form umgewandelt (Mischung) und in $t_{2}$ detektiert. Dabei ist anzumerken, dass auch während $t_{1}$ und $t_{2}$ Pulse beziehungsweise Pulssequenzen auftreten können, wie zum Beispiel die häufig verwendete Breitbandentkopplung in $t_{2}$ auf den nicht detektierten Kern.

\subsection{Zur NMR-Strukturaufklärung von Oligonukleoti- den}

Um Strukturen eines Moleküls mit Hilfe der NMR-Spektroskopie zu bestimmen, werden zuerst eine Reihe verschiedener Spektren aufgenommen. Anschließend werden die detektierten Daten prozessiert: das beinhaltet in erster Linie eine Fourier-Transformation, aber auch die Minimierung von störenden Lösungsmittelsignalen und eine Basislinienkorrektur. Im folgenden Schritt werden die einzelnen Resonanzsignale den entsprechenden Kernen zugeordnet (Assignment). Aus NOESY-Spektren werden durch Integration der Kreuzsignale Abstandsinformationen gewonnen [45]. Zusätzlich können aus Kopplungskonstanten Bindungswinkel erhalten werden. Aus all diesen Bedingungen, im Folgenden restraints genannt, erstellt man eine Tabelle, die zur Strukturrechnung verwendet wird [46].

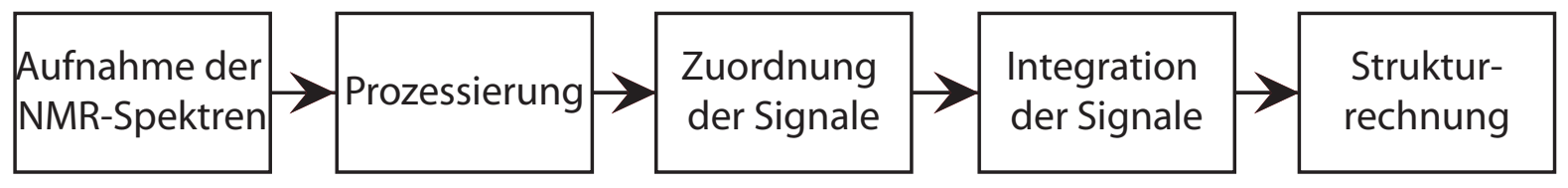

Abb. 3.3: Schema zum Ablauf einer NMR-Strukturaufklärung mit NOE-Daten. 


\subsection{Zuordnung der Resonanzen}

Bei der Strukturbestimmung von DNA-Sequenzen spielt das NOESY-Spektrum eine essentielle Rolle. NOESY-Spektren liefern Informationen über räumlich benachbarte Kerne mit einem Abstand von bis zu $6 \AA$ [47-49]. Die Intensität des Integrals ist indirekt proportional zur sechsten Potenz des Protonenabstands. Um Distanzinformationen zu erhalten, müssen jedoch zuerst die verschiedenen Resonanzfrequenzen den entsprechenden Protonen der DNA zugeordnet werden. Zusätzlich zum NOESY-Spektrum werden COSY- und TOCSY-Spektren benötigt, um die Zuordnung zu vervollständigen. Im COSY-Spektrum werden Protonen korreliert, die eine skalare Kopplung über 1 bis 3 Bindungen miteinander aufweisen [50]. Idealerweise lassen sich alle Kerne eines Spinsystems aus TOCSY-Spektren extrahieren [51].
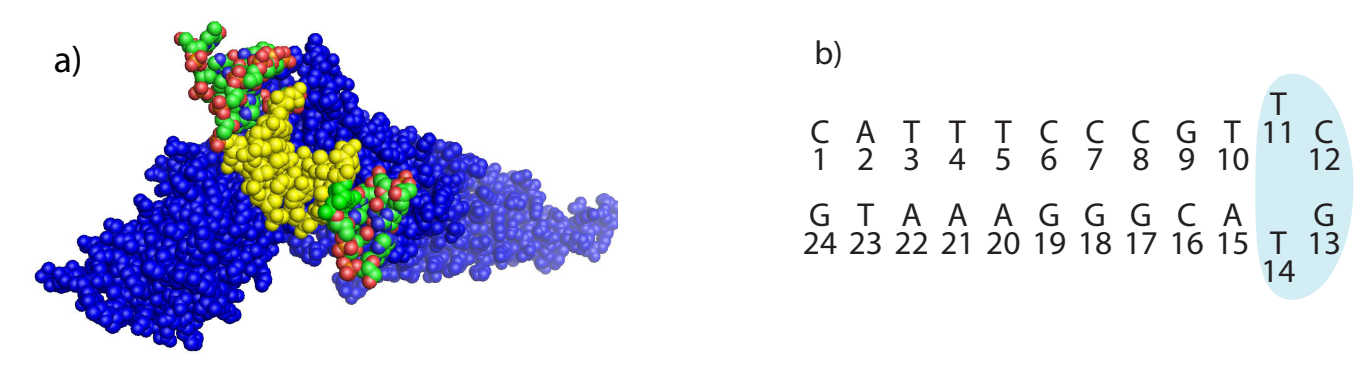

Abb. 3.4: a) STAT1 mit DNA-Doppelstrang, in gelb die untersuchte Sequenzregion.

b) DNA-Hairpin, der auf einer STAT bindenden Sequenz basiert. [20-22]

In Abb. 3.4 ist die Basenfolge des analysierten DNA-Hairpins dargestellt, der auf einer STATProteinbindenden Sequenz basiert. Soweit als möglich erfolgte die Zuordnung der Basen duch einen sogenannten „NOESY-Walk“, d. h. die Kreuzpeaks zwischen den H1'-Resonanzen und den H6/H8-Resonanzfrequenzen der eigenen Base und der $\mathrm{n}+1$ Base in 3'-Richtung werden identifiziert (Abb. 3.5) [52-55]. Von letzterer erfolgte die Zuordnung der H1'( n+1)-Resonanz. Bei stark überlagerten Bereichen wurde die Region der H2" /H2' und

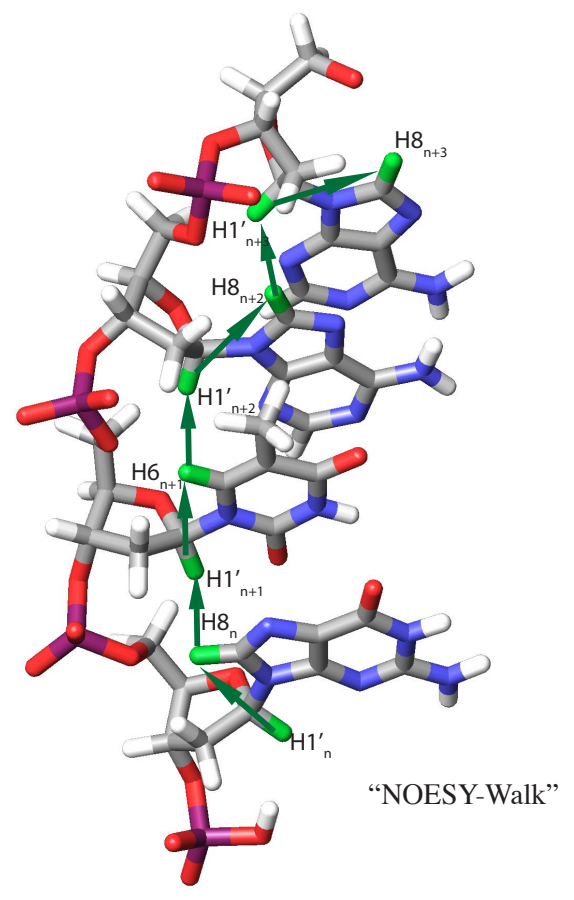




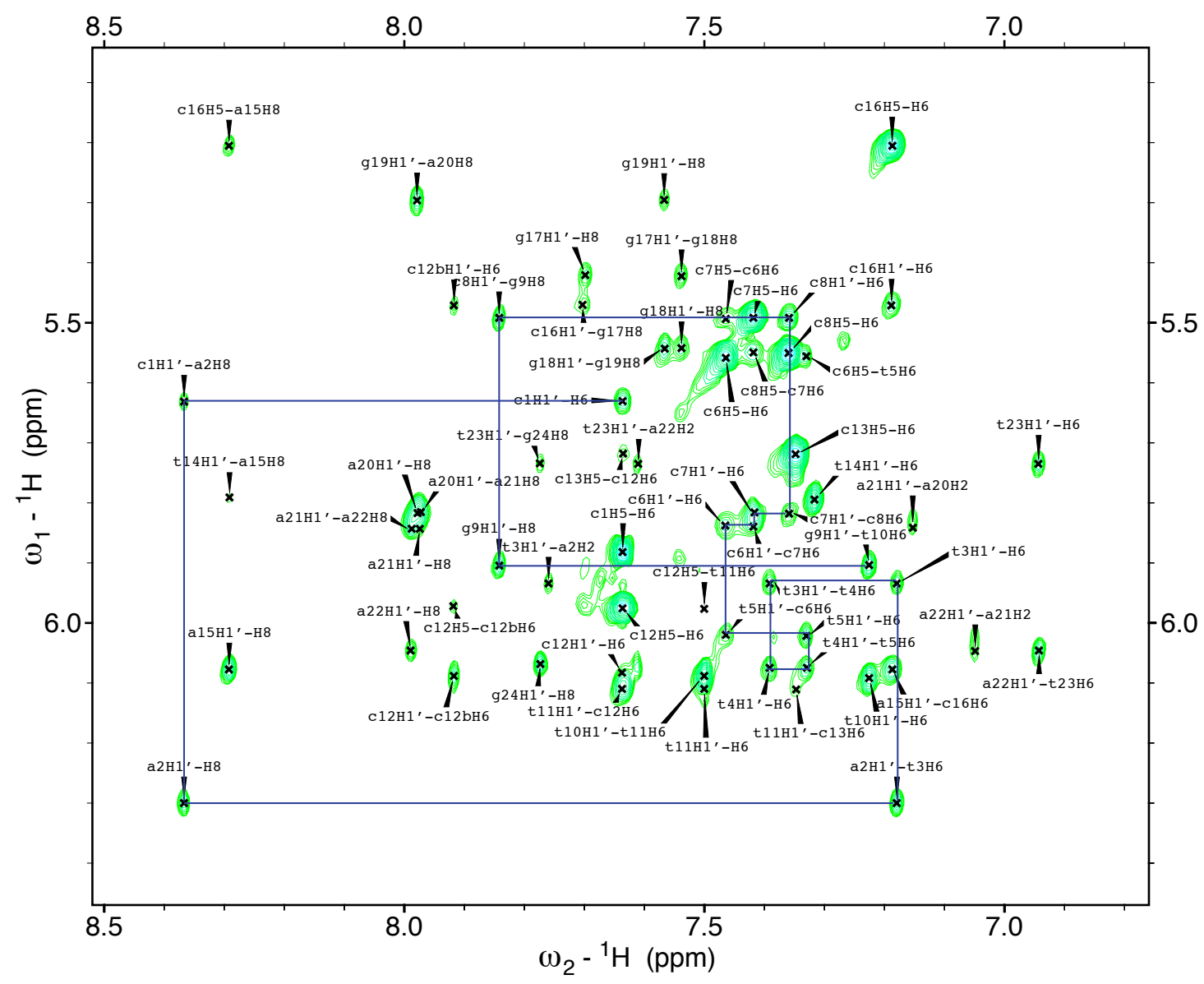

Abb. 3.5: „NOESY-Walk“der ersten zehn Basen vom 5'- in Richtung 3'-Ende. NOESY-Spektrum mit einer Mischzeit von $250 \mathrm{~ms}$ bei $25^{\circ} \mathrm{C}$ in $\mathrm{D}_{2} \mathrm{O}$ mit $10 \mathrm{mM}$ Natriumphosphatpuffer $(\mathrm{pH}=7), 600 \mathrm{MHz}$.

H6/8 Kreuzpeaks hinzugenommen. Verifiziert wurde die Zuordnung soweit möglich durch Kreuzpeaks von H6/H8-Frequenzen aufeinander folgender Basen. Da diese Peaks jedoch nur eine sehr schwache Intensität aufweisen, wurde zudem die Region der Kreuzpeaks zwischen H2" /H2'- und H1'-Resonanzen analysiert.

Thymin und Cytosin, die Pyrimidinbasen, lassen sich leicht durch ergänzende Informationen des COSY- und TOCSY-Spektrums bestimmen. Thymine erkennt man an den Kreuzpeaks zwischen der Methylgruppe und dem H6 des Thymins. Obwohl diese Kreuzpeaks in den über skalare Kopplungen korrelierten Spektren sehr schwach sind, sind sie gut erkennbar, da in diesem Frequenzbereich von 1 bis 2 ppm keine anderen Signale auftreten. Dabei ist zu beachten, dass in den NOESY-Spektren auch Kreuzpeaks der Methylgruppen zu H6/H8 der 


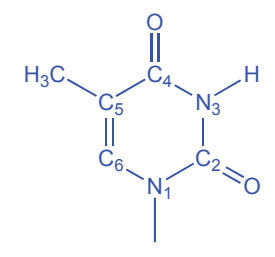

Thymin

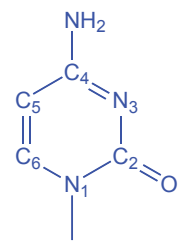

Cytosin

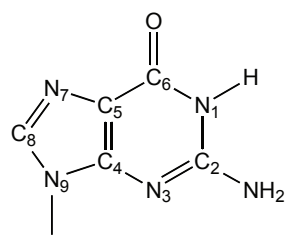

Guanin

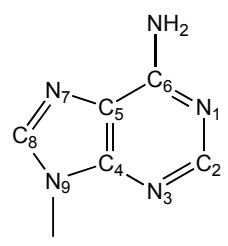

Adenin

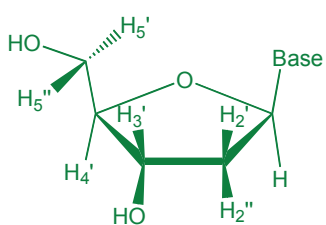

2"-Deoxy- $\beta$-D-ribose

Abb. 3.6: Abbildung der Nukleobasen und der 2'Desoxyribose inklusive ihrer Nomenklatur [56].

benachbarten Base in 5'-Richtung existieren. Die Cytosine erkennt man im COSY-Spektrum an den starken Kreuzpeaks zwischen dem H5 und H6, während sie im NOESY-Spektrum in der Regel im gleichen Bereich wie die H1'-H6/H8-Signale liegen und dort nur schlecht extrahiert werden können.

Um zwischen internukleosiden und intranukleosiden Protonenkorrelationen zu unterscheiden, wurde zur Zuordnung der Zuckersignale innerhalb eines Nukleotids TOCSY- und COSYSpektren zum Assignment hinzugezogen. Die Resonanzen von H4', H5' und H5" konnten oft nicht eindeutig identifiziert werden, da dieser Frequenzbereich sehr stark überlagert war und somit nicht bestimmt werden konnte, ob die betreffende Frequenz einem H4' , H5' oder einem H5" Signal zuzuordnen war. 20 der 24 Zucker (nicht C8, A20-A22) konnten jedoch je drei Signale in diesem Bereich zugeordnet werden. Die Region der Adenoside A20 bis A22 war die am stärksten überlagerte Region. Unter anderem lagen die Resonanzen der H8-Protonen sehr nah beieinander. Eine Tabelle der chemischen Verschiebungen ist in Abb. 3.7 abgebildet.

Die NMR-Messungen der nicht austauschbaren Protonen erfolgte in deuteriertem Wasser, um aber die Signale der austauschbaren Imino- und Aminoprotonen aufnehmen zu können, erfolgte eine weitere Messung in nicht-deuteriertem Wasser $\left(\mathrm{H}_{2} \mathrm{O} / \mathrm{D}_{2} \mathrm{O}: 9 / 1\right)$. Um das starke Wassersignal zu unterdrücken wurde eine watergate-Sequenz (water suppression by gradient tailored excitation) verwendet [57]. Presaturation als Wasserunterdrückung ist hier nicht geeignet, da mit Wasser austauschende Protonen ebenfalls unterdrückt werden. Sichtbar waren dabei alle Iminoprotonen im Stamm des Hairpins. Bei den Aminoprotonen waren nur die 


\begin{tabular}{|c|c|c|c|c|}
\hline & H1' & H2' & H2" & H3' \\
\hline c1 & 5,63 & 1,91 & 2,38 & 4,64 \\
\hline a2 & 6,30 & 2,73 & 2,95 & 4,97 \\
\hline t3 & 5,93 & 2,03 & 2,55 & 4,78 \\
\hline t4 & 6,08 & 2,12 & 2,57 & 4,82 \\
\hline t5 & 6,02 & 2,10 & 2,52 & 4,82 \\
\hline c6 & 5,84 & 2,10 & 2,37 & 4,77 \\
\hline c7 & 5,82 & 2,05 & 2,35 & 4,76 \\
\hline c8 & 5,49 & 1,99 & 2,30 & 4,75 \\
\hline g9 & 5,90 & 2,55 & 2,64 & 4,89 \\
\hline t10 & 6,09 & 2,18 & 2,39 & 4,83 \\
\hline t11 & 6,11 & 2,08 & 2,35 & 4,75 \\
\hline c12 & 6,09 & 1,97 & 2,20 & 4,49 \\
\hline c13 & 5,74 & 1,80 & 2,30 & 4,54 \\
\hline t14 & 5,79 & 2,01 & 2,23 & 4,57 \\
\hline a15 & 6,08 & 2,67 & 2,78 & 4,89 \\
\hline c16 & 5,47 & 1,77 & 2,18 & - \\
\hline g17 & 5,42 & 2,51 & 2,61 & 4,87 \\
\hline g18 & 5,54 & 2,41 & 2,59 & 4,88 \\
\hline g19 & 5,30 & 2,42 & 2,55 & 4,88 \\
\hline a20 & 5,82 & - & 2,80 & 4,96 \\
\hline a21 & 5,84 & 2,53 & 2,80 & 4,96 \\
\hline a22 & 6,05 & 2,41 & 2,79 & 4,89 \\
\hline t23 & 5,74 & 1,76 & 2,25 & 4,75 \\
\hline g24 & 6,07 & 2,38 & 2,38 & 4,59 \\
\hline
\end{tabular}

Abb. 3.7: Chemische Verschiebungen der 2'-Desoxyriboseprotonen in ppm. In blau unterlegt ist die Loopregion.

H41 und H42 Protonen der Cytosine sichtbar, allerdings mit Ausnahme des endständigen Cytosins C1. Dort befinden sich die Aminoprotonen wohl schon im schnellen Austausch mit dem Lösungsmittel, da die endständige Wasserstoffbrückenbindung nicht sehr stark ist. Das Vorliegen von Wasserstoffbrückenbindungen ist jedoch nicht nur an den sichtbaren Iminoprotonenresonanzen des NOESY erkennbar, sondern auch durch 1D-Spektren. Nicht über Wasserstoffbrücken gebundene Iminoprotonen können bei einer chemische Verschiebung von etwa 10 ppm auftreten. Durch die Wasserstoffbrücke verschiebt sich die Resonanz ins Tieffeld auf bis zu 14 ppm [58]. Eine Tabelle der chemischen Verschiebungen der Basenprotonen ist in Abb. 3.8 abgebildet.

Die NOESY-Peaks wurden mit Hilfe der Software SPARKY integriert. Dabei wurden die zu integrierenden Signale mit einer Ellipse zur Deckungsgleichheit gebracht und über diese Fläche integriert. Es wurde zwischen drei verschiedenen Kategorien von NOE-Kreuzpeaks unterschieden: stark $(2.2 \AA \pm 0.4 \AA)$, mittel $(2.6 \AA \pm 0.8 \AA)$, schwach $(3.6 \AA \pm 1.5 \AA)$. 


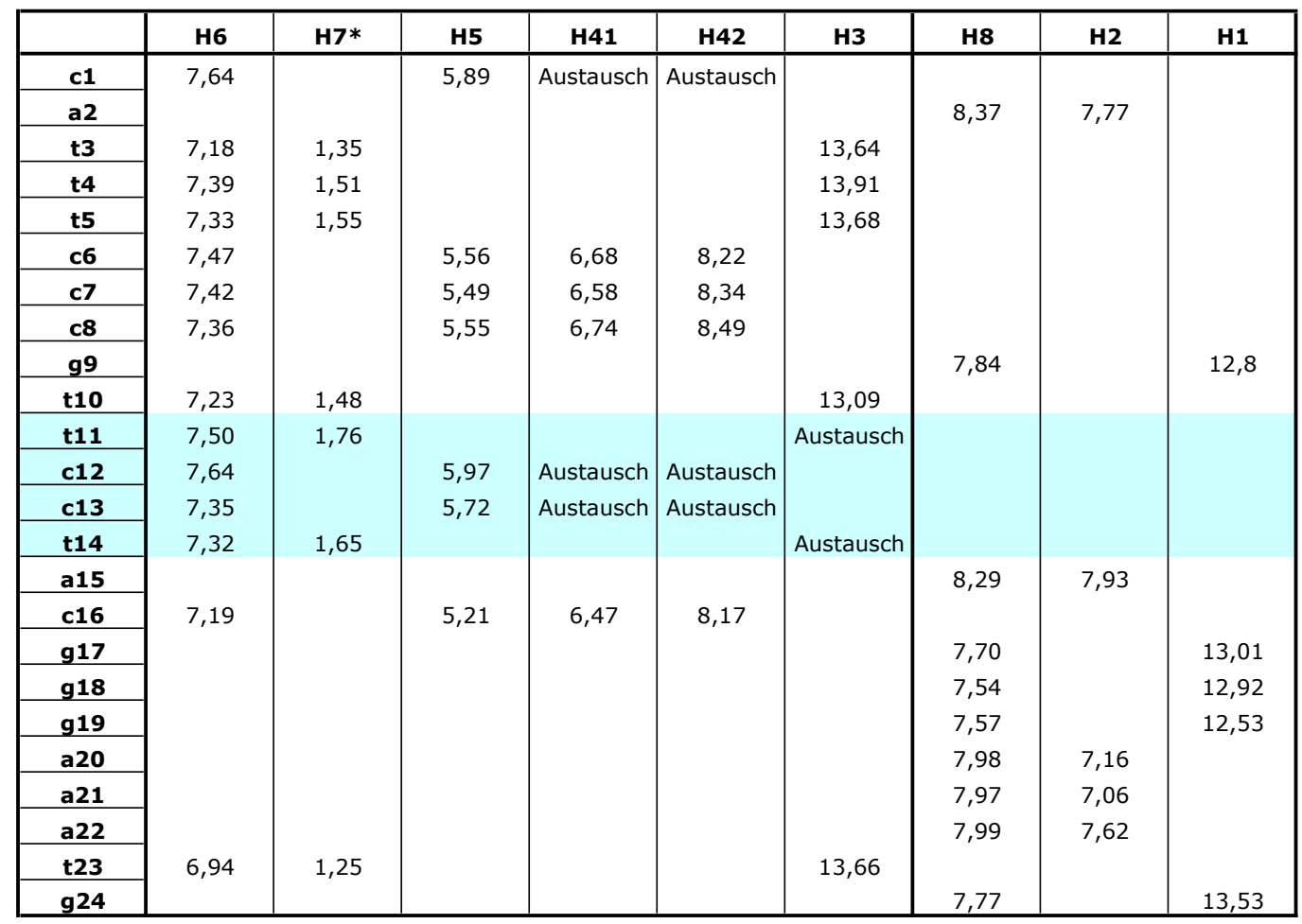

Abb. 3.8: Chemische Verschiebungen der Basenprotonen in ppm. Die Loopregion ist blau unterlegt.

Die detaillierte NOE-Tabelle mit allen Abständen und Fehlergrenzen befindet sich im Anhang. Die NOE-Signale, die in Verbindung mit den Methylgruppen H7* der Thymidine stehen, wurden stets mit größeren Fehlergrenzen $( \pm 2 \AA)$ belegt und zudem das Integral auf ein Drittel skaliert. Einen weiteren Sonderfall stellen die Kreuzpeaks aus dem Iminound Aminospektrum dar. Auch sie wurden mit einem größeren Fehler belegt, der auf der stärkeren Signalverbreiterung basiert. Des Weiteren wurden im Bereich von A20 bis A22 die Peaks des „NOE-Walks“ manuell hinzugefügt, da die Kreuzpeaks zwar sichtbar waren, aber aufgrund der starken Überlagerung nicht einzeln integriert werden konnten. Auf der folgenden Abbildung 3.9 sind die verwendeten internukleotidischen NOE-Kreuzpeaks schematisch dargestellt. 


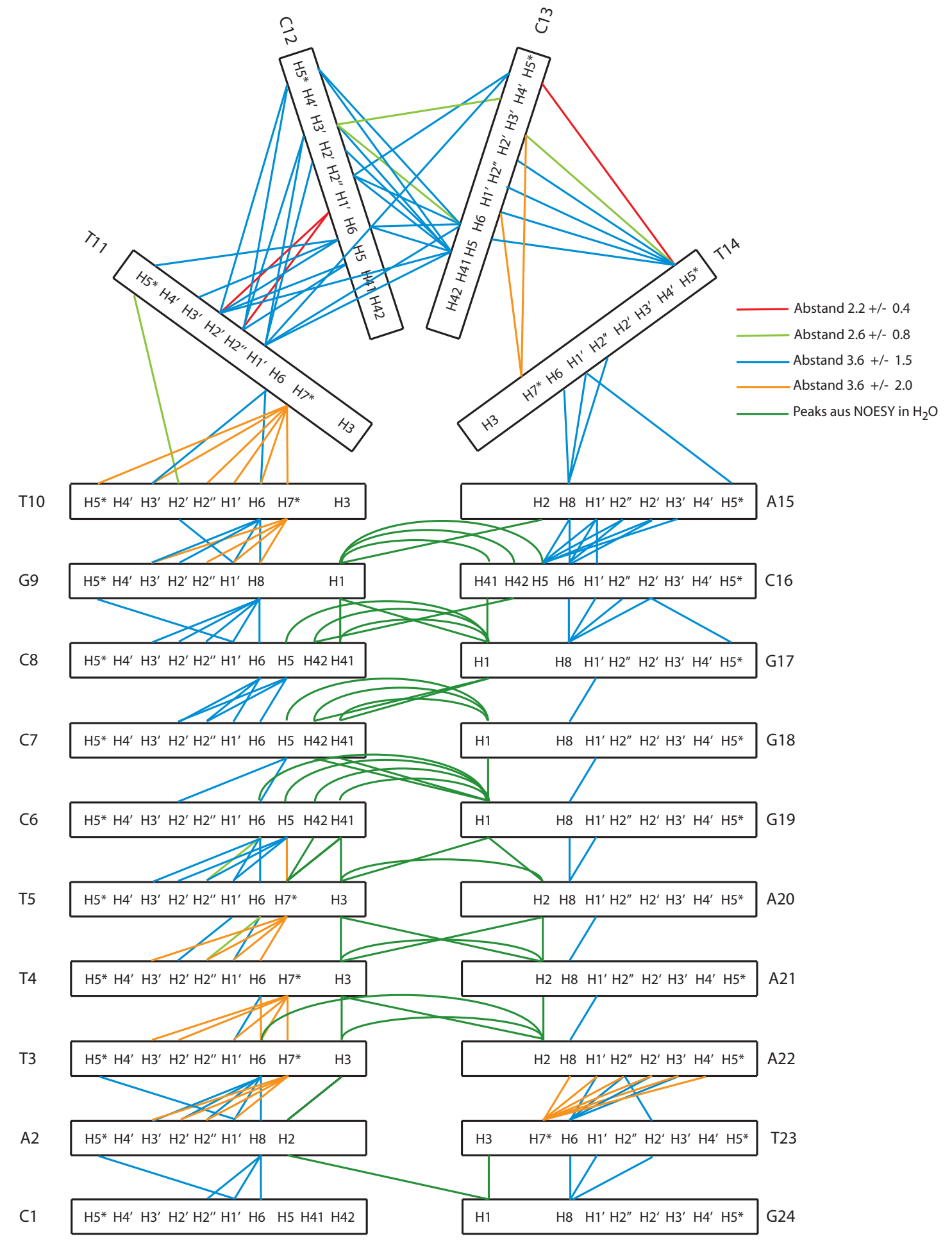

Abb. 3.9: Abbildung der Internukleotid-NOE-Restraints. 


\subsection{Strukturrechnung unter Berücksichtigung von Ab- standsinformationen}

Aus den Abstandsinformationen der NOESY-Spektren wurde mit Hilfe des Programms CNS (Crystallography $\&$ NMR System) der Yale Universität die DNA-Struktur berechnet $[18,19]$. Die restraints fungieren dabei als Energiebarrieren. Zudem verwendet das Programm ein Kraftfeld, eine analytische Funktion, die theoretische Energiebarrieren simuliert. In dieser Arbeit wurde ein Standard-Charmm-Kraftfeld für Nukleinsäuren verwendet, wie es in CNS implementiert ist $[18,19]$. Zusätzlich zu den NOE-Daten wurde eine Tabelle mit Wasserstoffbrückenbindungsrestraints in die Rechnung mit einbezogen. Sie generiert Abstände zwischen Stickstoff- und Sauerstoffatomen, die dem Standardwasserstoffbrückenbindungsabstand entsprechen. Diese restraints wurden allerdings nur bei den Basen verwendet, bei denen Iminound Amino-Resonancen im WatergateNOESY gefunden wurden. Außerdem wurden sogenannte planarity restraints hinzugefügt, die das pi stacking der Basen simulieren. In dem Programmpaket CNS kann man all diesen restraints verschiedene Gewichtungen geben. Dabei sollten die Abstandsinformationen natürlich das höchste Gewicht haben, die Wasserstoffbrückenbindungen eine ebenfalls recht hohe Wichtung, während die Planaritätsbedingungen eine untergeordnete Rolle spielen.

Die Berechnung der dreidimensionalen Struktur eines Biomoleküls erfolgte dabei in mehreren Schritten. Im ersten Schritt wurde eine Ausgangsstruktur generiert und die benötigen Topologie- und Parameterdateien ausgewählt. Diese enthalten Informationen über die Art und Verknüpfung der Atome, die Bindungsstärken, Bindungswinkel, stereochemische Konfiguration und deren Gewichtung über Kraftkonstanten. Für die in dieser Arbeit verwendete Hairpin-DNA wurde als Startstruktur der korrespondierende lineare Einzelstrang verwendet. Diese Startstruktur wurde in einem zweiten Schritt unter Berücksichtigung der oben erwähnten restraints dem Kraftfeld unterworfen. In dem hier verwendeten Skript „Anneal.inp“ wurde der Strang zunächst sehr hoch erhitzt und anschließend langsam abgekühlt. Daraus erhielt man eine Auswahl an Rohstrukturen, deren energetisch günstigsten dann verglichen wurden. 
Eine Überlagerung der fünf energetisch günstigsten Strukturen ist in Abb. 3.10 dargestellt. Aus Gründen der Übersichtlichkeit werden nur fünf Strukturen anstatt der gängigen zehn Strukturen abgebildet.
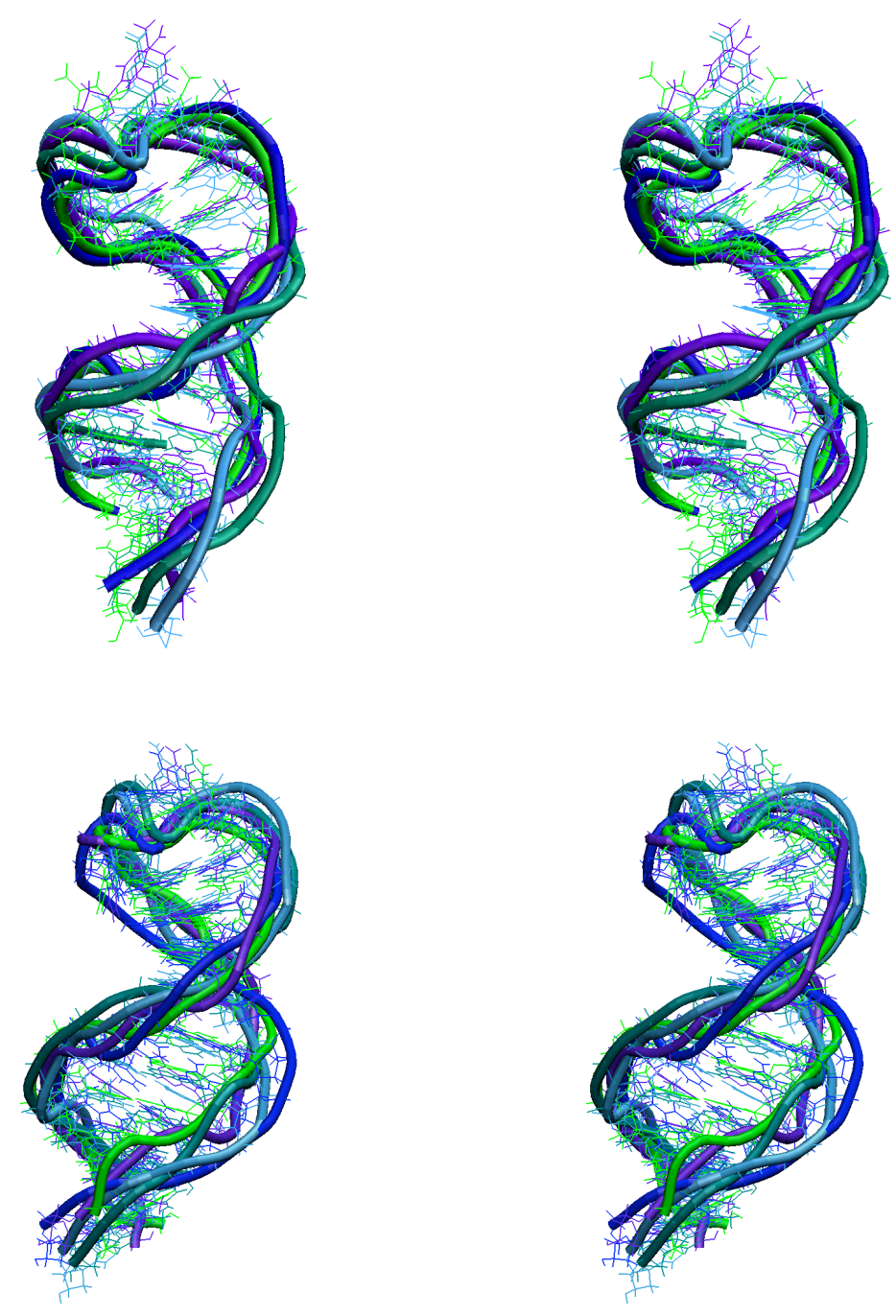

Abb. 3.10: Die fünf energieniedrigsten Strukturen (Stereobilder) nach der ersten (oben, RMSD: $2.31 \AA$ ) und der zweiten (unten, RMSD: $1.87 \AA$ ) Rechnung

Ausgehend von der Struktur mit der geringsten Energie wurde dann eine weitere AnnealingBerechnung vorgenommen und man erhält eines neues Strukturenensemble (Abb. 3.10).

Dies wurde einer letzten Rechnung unterworfen, bei der die Temperaturschritte wesentlich feiner gewählt sind als in den vorigen Schritten. Daraus erhält man fünf Endstrukturen (Abb. $3.11)$ 

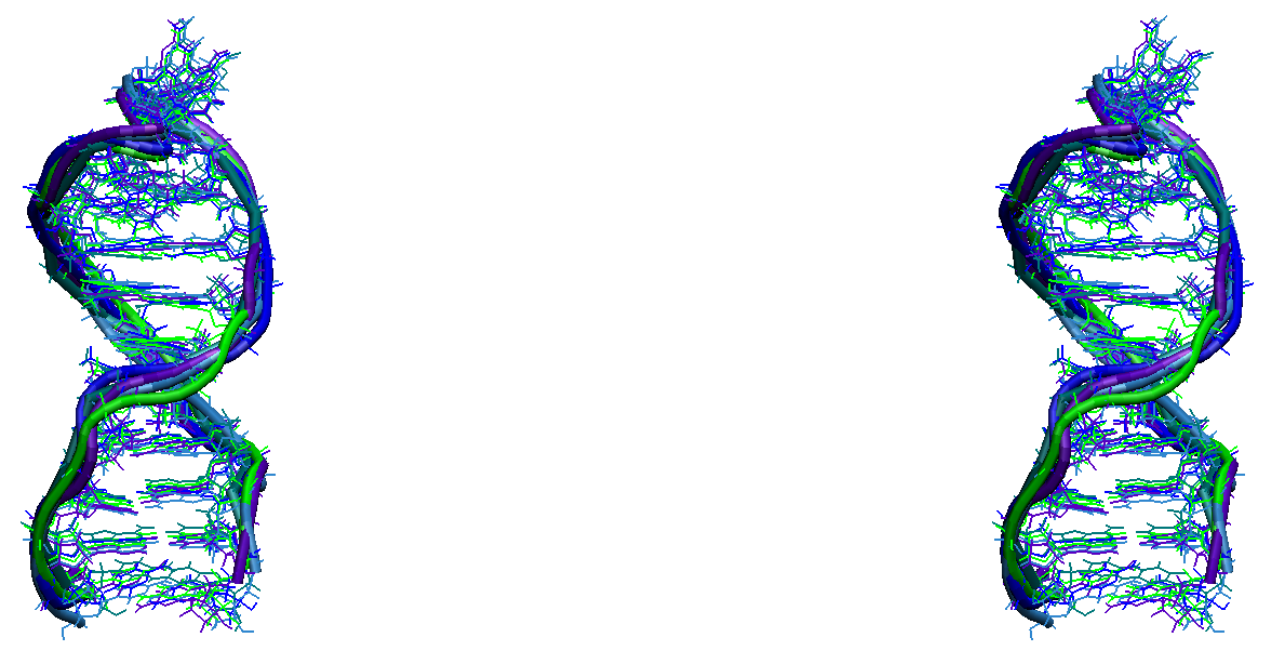

Abb. 3.11: Die fünf energieniedrigsten Strukturen, wie sie aus den verfeinerten Moleküldynamikrechnungen mit CNS erhalten wurden (RMSD: $0.97 \AA$ ).

Die verwendeten Tabellen und Protokolle finden sich im Anhang.

\subsection{NMR-Spektroskopie an partiell ausgerichteten Mo- lekülen}

Herkömmliche NMR-Methoden korrelieren nur nah benachbarte Kerne, was zu relativ großen Unsicherheiten in der Gesamtstruktur führt. Besonders bei Systemen mit einer geringen Spindichte, wie Nukleinsäuren, addieren sich die Unsicherheiten im Abstand und Winkel zweier aufeinander folgender Nukleobasen zu fehlerhaften Gesamthelixkrümmungen auf. Dieser Effekt ist bei Proteinen oft weniger eklatant, da die Krümmung der $\alpha$ - Helices durch Abstandsinformationen zu rückgefalteten $\alpha$ - Helices oder $\beta$-Faltblättern verfeinert werden können. Eine Ausnahme stellen $\alpha$-helical bundle Strukturmotive dar, bei denen die Gesamtkrümmung ebenfalls nur sehr ungenau aus Abstandsinformationen gewonnen werden kann. 
Neuere NMR-Techniken erlauben es, relative Richtungsinformationen zwischen weiter entfernten Kernen zu erhalten, was die Strukturbestimmung der Biomoleküle verfeinert. Hierbei muss die isotrope Rotation der Biomoleküle eingeschränkt werden, wodurch diese eine Vorzugsausrichtung zum Magnetfeld erreichen. Durch diese Vorzugsausrichtung werden dipolare Kopplungen initiiert, die Informationen über die geometrische Anordnung der betrachteten koppelnden Atomkerne im Raum beinhalten. Eine Vorzugsausrichtung des Biomoleküls im Magnetfeld kann durch Orientierungsmedien [17,59-61] wie Phagen und gestreckte Polyacrylamidgele aber auch durch paramagnetische Zentren erreicht werden [17,62, 63]. Bei letzteren werden beispielsweise die Bindungsstellen von Metalloproteinen mit Lanthanoid(III)ionen beladen. Lanthanoide besitzen besonders günstige magnetische Eigenschaften für die NMR-Spektroskopie, eine relativ hohe magnetische Anisotropie gepaart mit einer relativ geringen Relaxationsbeschleunigung im Vergleich zu den Übergangsmetallionen. Viele Biomoleküle besitzen aber keine starke oder spezifische Bindungsstelle für Metallionen, deshalb werden sie mit metallchelatisierenden Liganden modifiziert, z. B. über Cysteindisulfidbrückenbindungen. Diese Art der Modifizierung bezeichnet man in der NMRSpektroskopie als Tagging [14].

\subsection{Paramagnetische NMR-Spektroskopie}

NMR-Spektren paramagnetischer Proben weisen einige Unterschiede gegenüber diamagnetischen Spektren auf. Da das Elektronenspinmoment 658 mal stärker als das Kernspinmoment eines Protons ist, haben ungepaarte Elektronen einen sehr großen Einfluss auf die magnetischen Eigenschaften einer Probe. Bei gepaarten Elektronen hebt sich das Elektronenspinmoment genau auf, aber der Spin ungepaarter Elektronen ( $S$ ungleich 0) induziert ein zusätzliches Magnetfeld, das das Aussehen des NMR-Spektrums stark verändert (Abb. 3.12). Viele Übergangsmetallionen, aber auch Lanthanoidionen besitzen ungepaarte Elektronen, sowie radikalische Verbindungen [64]. 


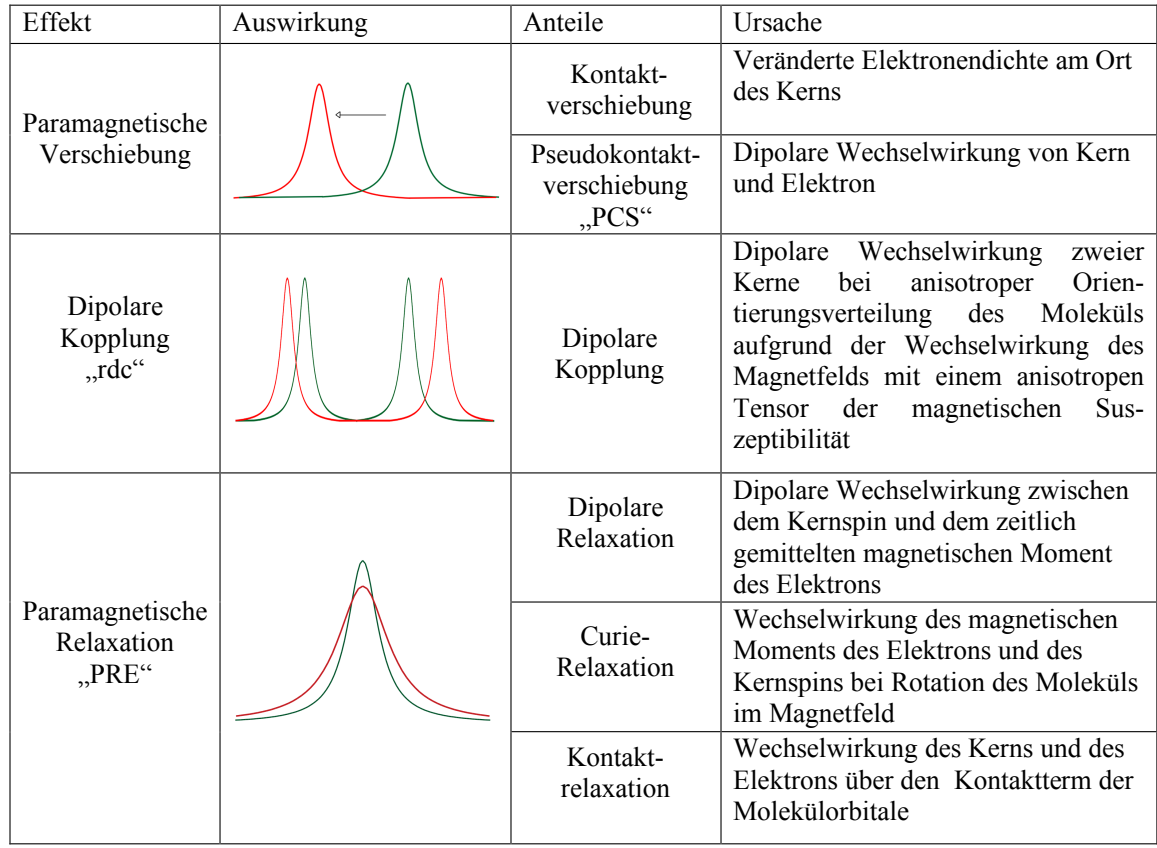

Abb. 3.12: Überblick über die paramagnetischen Effekte und ihre Ursachen. Die diamagnetischen Spektren sind grün, die paramagnetischen Spektren sind rot dargestellt.

Einige dieser Effekte sind bei der Untersuchung von lanthanoidhaltigen Proben von untergeordneter Bedeutung. Ursache dafür sind die teilgefüllten f-Orbitale der Lanthanoide, die sich von d-Orbitalen der Übergangsmetalle und auch den teilgefüllten Orbitalen der organischen Radikale unterscheiden. Lanthanoid(III)ionen besitzen folgende Elektronenkonfiguration: [Xe] $4 \mathrm{f}^{1-14} 6 \mathrm{~s}^{0}$. Dabei fällt auf, dass die ungepaarten Elektronen in der drittäußersten 4f-Schale liegen. Dies führt dazu, dass die f-Elektronen zu weit im Atominneren lokalisiert sind, als dass sie Bindungen zu den Ligandorbitalen aufweisen. Damit ist auch ihre Aufenthaltswahrscheinlichkeit am Ort der nah benachbarten Kerne gering und sowohl die Kontaktverschiebung als auch die Kontaktrelaxation für Lanthanoide vernachlässigbar klein [65]. Daneben ist der Tensor der magnetischen Suszeptibilität für einige Lanthanoidionen sehr anisotrop, was im Vergleich zu Übergangsmetallionen zu einer stärkeren Ausrichtung im Magnetfeld und damit größeren dipolaren Effekten führt (Abb. 3.13) [66].

Im Folgenden wird näher auf einzelne wichtige Effekte eingegangen. 


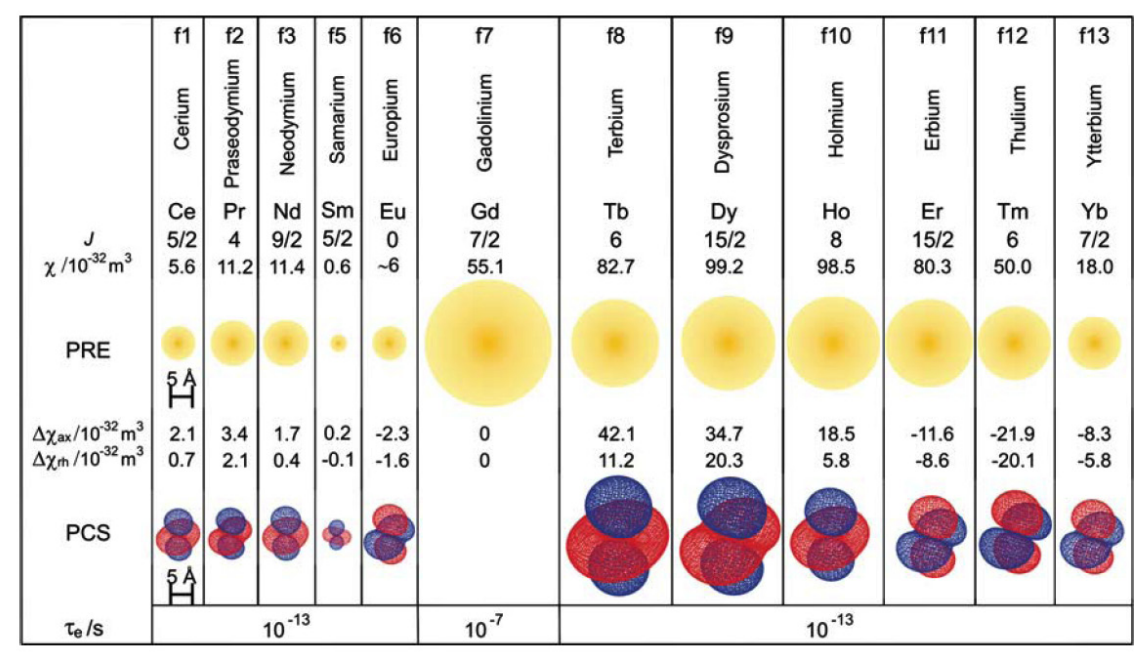

Abb. 3.13: Übersicht der NMR-Eigenschaften der Lanthanoide, $J$ Spinquantenzahl, PRE: Die gelben Kugeln geben die Distanz zwischen Metallzentrum und Proton an, bei der das Signal bei $18.8 \mathrm{~T}$ und einer Korrelationszeit von $15 \mathrm{~ns}$ um $80 \mathrm{~Hz}$ verbreitert ist, $\Delta \chi_{a x}$ und $\Delta \chi_{r h}$ : Axialer und rhombischer Anteil der magnetischen Anisotropie, PCS: Isoflächen mit einem PCS von \pm 5 ppm, $\tau_{e}$ Elektronenrelaxationszeit [66].

\subsection{Pseudokontaktverschiebung}

\subsubsection{Herleitung}

Durch die Anisotropie der magnetischen Suszeptibilität kommt es zu einer Veränderung der chemischen Verschiebung der benachbarten Kerne, da sich deren lokales, effektives Magnetfeld durch das magnetische Moment des paramagnetischen Zentrums verändert.

Die Herleitung der folgenden Formel lehnt sich soweit nicht anders angegeben an Bleaney et al. [67] und Bertini et al. [68] an. Betrachten wir nun einen Suszeptibilitätstensor $\chi$ mit den Hauptachsen $\mathrm{x}, \mathrm{y}, \mathrm{z}$ zentriert im Ursprung des Koordinatensystems. $\chi_{x x}, \chi_{y y}, \chi_{z z}$ sind die Komponenten der Suszeptibilität entlang der Achsen des Koordinatensystems in einer Probe mit N paramagnetischen Zentren. Die Richtung des äußeren Magnetfelds $\overrightarrow{H_{0}}$ in diesem 

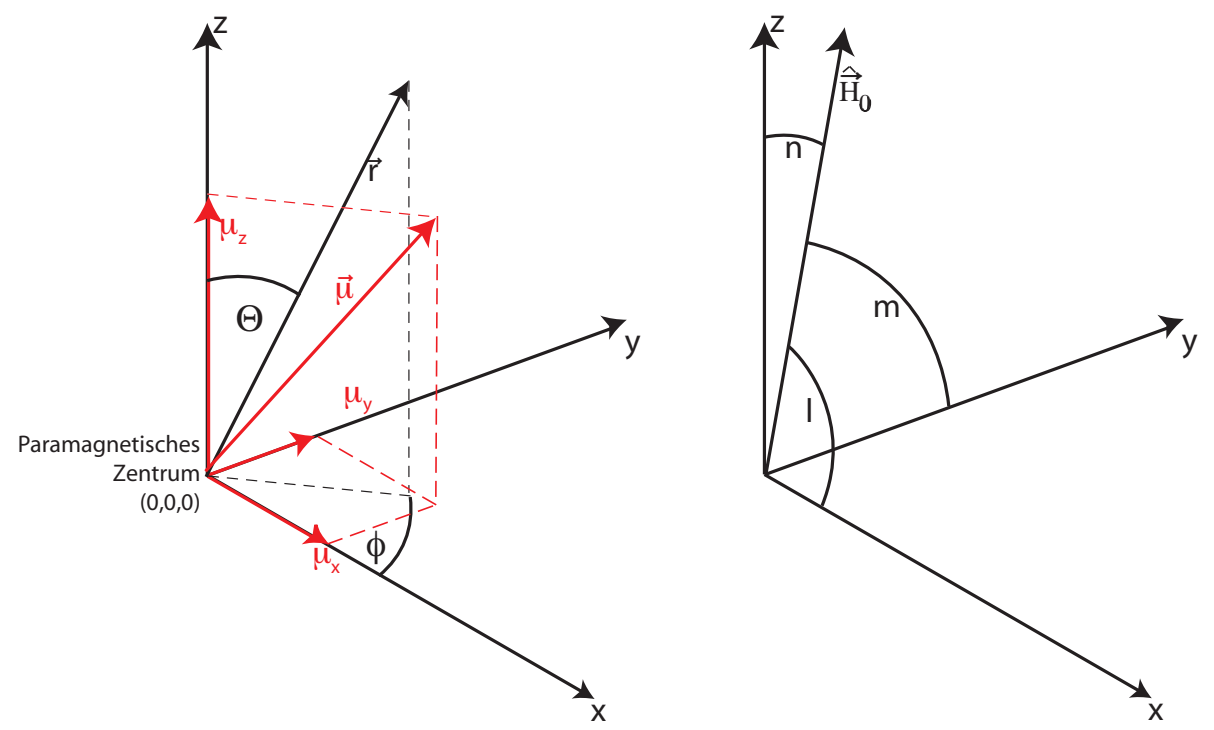

Abb. 3.14: Abbildung des Koordinatensystems des Anisotropietensor mit dem Vektor $\vec{r}$ zwischen Kern und paramagnetischen Zentrum und dem magnetischen Moment $\vec{\mu}$

Koordinatensystem wird durch die Richtungskosinus $l, m, n\left(\widehat{\overrightarrow{H_{0}}}\right.$ ist der Einheitsvektor von $\overrightarrow{H_{0}}$ und $H_{0}=\left|\overrightarrow{H_{0}}\right|$ ) beschrieben (Abb. 3.14). Das magnetische Moment ist dabei:

$$
\vec{\mu}^{\top}=\left(\mu_{x}, \mu_{y}, \mu_{z}\right)
$$

Das magnetische Dipolfeld eines Elektronenspins im Raum lässt sich folgendermaßen beschreiben:

$$
\Delta \vec{H}=\vec{H}-\overrightarrow{H_{0}}=\left(\begin{array}{c}
\Delta H_{x} \\
\Delta H_{y} \\
\Delta H_{z}
\end{array}\right)=\frac{\mu_{0}}{4 \pi}\left[\frac{3(\vec{r} \cdot \vec{\mu}) \vec{r}}{r^{5}}-\frac{\vec{\mu}}{r^{3}}\right]
$$

Dabei ist $\vec{r}$ der Vektor zwischen dem paramagnetischen Zentrum und dem Ort x, y, z. $\vec{H}$ ist das effektive Magnetfeld an dem Ort. $\mu_{0}$ ist die magnetische Feldkonstante. Die Veränderung des Magnetfeldes $\Delta \vec{H}$ lässt sich dabei auch beschreiben als:

$$
\begin{aligned}
\Delta \vec{H} & =\frac{\mu_{0}}{4 \pi}\left[\frac{3 \vec{r} \otimes \vec{r} \vec{\mu}}{r^{5}}-\frac{\vec{\mu} \mathbf{I}}{r^{3}}\right] \\
& =\frac{\mu_{0}}{4 \pi}\left(\begin{array}{ccc}
\left(3 x^{2}-r^{2}\right) & (3 x y) & (3 x z) \\
(3 x y) & \left(3 y^{2}-r^{2}\right) & (3 y z) \\
(3 x z) & (3 y z) & \left(3 z^{2}-r^{2}\right)
\end{array}\right) \vec{\mu}
\end{aligned}
$$


mit $\vec{r}^{\top}=(x, y, z)$. Im Koordinatensystem des Suszeptibilitätstensors $\left(\mu_{0} \| \overrightarrow{H_{0}}\right)$ gilt dabei :

$$
\chi=\left(\begin{array}{ccc}
\chi_{x x} & 0 & 0 \\
0 & \chi_{y y} & 0 \\
0 & 0 & \chi_{z z}
\end{array}\right)=\frac{N}{H_{0}}\left(\begin{array}{ccc}
\mu_{x} & 0 & 0 \\
0 & \mu_{y} & 0 \\
0 & 0 & \mu_{z}
\end{array}\right)
$$

und damit

$$
\Delta \mathbf{H}=\frac{\mu_{0}}{4 \pi} \frac{H_{0}}{N}\left(\begin{array}{ccc}
\chi_{x x}\left(3 x^{2}-r^{2}\right) & \chi_{y y}(3 x y) & \chi_{z z}(3 x z) \\
\chi_{x x}(3 x y) & \chi_{y y}\left(3 y^{2}-r^{2}\right) & \chi_{z z}(3 y z) \\
\chi_{x x}(3 x z) & \chi_{y y}(3 y z) & \chi_{z z}\left(3 z^{2}-r^{2}\right)
\end{array}\right)
$$

Da $H_{0} \gg \Delta \mathbf{H}$, gibt nur der Anteil von $\Delta \mathbf{H}$ parallel zu $H_{0}$ den Ausschlag für die Pseudokontaktverschiebung:

$$
\begin{aligned}
\Delta H_{\| \overrightarrow{H_{0}}} & ={\widehat{\overrightarrow{H_{0}}}}^{\top} \cdot \Delta \mathbf{H} \cdot \widehat{\overrightarrow{H_{0}}}=l^{2} \Delta H_{x x}+m^{2} \Delta H_{y y}+n^{2} \Delta H_{z z} \\
& =\frac{\mu_{0}}{4 \pi} \frac{H_{0}}{3 N r^{3}}\left[\chi_{x x}\left(3 \frac{x^{2}}{r^{2}}-1\right)+\chi_{y y}\left(3 \frac{y^{2}}{r^{2}}-1\right)+\chi_{z z}\left(3 \frac{z^{2}}{r^{2}}-1\right)\right] .
\end{aligned}
$$

Dabei gilt $<l^{2}>=<m^{2}>=<n^{2}>=1 / 3$ und $<l m>,<m n>,<n l>=0$, angenommen wird, dass sich $H_{0}$ isotrop im Molekülkoordinatensystem bewegt. Diese Annahme ist eine Näherung. Die Erweiterung der Gleichung um einen anisotropen Term führt aber nur zu geringfügig unterschiedlichen Ergebnissen [69]. Die Pseudokontaktverschiebung ergibt sich somit $\mathrm{zu}$ :

$$
\begin{aligned}
\delta_{p c}=\frac{\Delta \nu}{\nu_{0}} & =\frac{\Delta H_{\| \overrightarrow{H_{0}}}}{H_{0}}=\frac{\mu_{0}}{4 \pi} \frac{1}{N r^{3}}\left[\chi_{x x}\left(\frac{x^{2}}{r^{2}}-\frac{1}{3}\right)+\chi_{y y}\left(\frac{y^{2}}{r^{2}}-\frac{1}{3}\right)+\chi_{z z}\left(\frac{z^{2}}{r^{2}}-\frac{1}{3}\right)\right] \\
& =\frac{\mu_{0}}{4 \pi} \frac{1}{2 N r^{3}}\left[\left(\chi_{z z}-\bar{\chi}\right)\left(3 \cos ^{2} \theta-1\right)+\left(\chi_{x x}-\chi_{y y}\right) \sin ^{2} \theta \cos 2 \phi\right]
\end{aligned}
$$

mit $\bar{\chi}=1 / 3\left(\chi_{x x}+\chi_{y y}+\chi_{z z}\right), x / r=\sin \theta \cos \phi, y / r=\sin \theta \sin \phi, z / r=\cos \theta$ und $\cos 2 \phi=$ $\cos ^{2} \phi-\sin ^{2} \phi$. 
Die Suszeptibilität ist in erster Ordnung abhängig von der Spinquantenzahl $S$, vom $g$-Tensor, der die Anisotropie beschreibt, und ist indirekt proportional zur Temperatur T. Somit ist die Suszeptibilität gegeben durch:

$$
\chi=\frac{N \mathbf{g}^{2} \mu_{B}^{2} S(S+1)}{3 k T}
$$

Die Naturkonstanten dabei sind die Boltzmannkonstante $k$ und das Bohrsche Magneton $\mu_{B}$. Analog zur obigen Formel lassen sich die Suszeptibilität als Funktion der Spinquantenzahl darstellen. Damit ergibt sich für den Pseudokontaktshift folgende Abhängigkeit:

$$
\delta_{p c}=\left[\frac{\mu_{0}}{4 \pi} \frac{\mu_{B}^{2} S(S+1)}{6 k T r^{3}}\right]\left[\left(g_{z z}^{2}-\bar{g}^{2}\right)\left(3 \cos ^{2} \Theta-1\right)+\left(g_{x x}^{2}-g_{y y}^{2}\right)\left(\sin ^{2} \Theta \cos 2 \phi\right)\right] .
$$

Paramagnetische Zentren mit einer Spinquantenzahl $S>\frac{1}{2}$ weisen eine Entartung des Grundzustandes auf. Auch in Abwesenheit eines externen magnetischen Feldes können diese Zustände aufspalten. Der Hamiltonoperator muss in solchen Fällen um den Term der Nullfeldaufspaltung $D$ erweitert werden:

$$
\hat{H}=\mu_{B}\left(g_{x x} H_{x} S_{x}+g_{y y} H_{y} S_{y}+g_{z z} H_{z} S_{z}+D_{x x} S_{x}^{2}+D_{y y} S_{y}^{2}+D_{z z} S_{z}^{2}\right)
$$

Die Zeeman-Wechselwirkung wird durch den ersten Term beschrieben, dabei ist $g$ der Tensor des Landé-Faktors. Der Tensor $D$ beschreibt die Nullfeldaufspaltung.

Lanthanoide, als schwere Atome, besitzen eine starke Spin-Bahn-Kopplung ( Kernladungs$z_{\text {zahl }}^{4}$ ), also setzt sich ihr Gesamtdrehimpuls $J$ nicht linear aus Spinquantenzahl $S$ und Gesamtbahndrehimpuls $L$ zuammen $(J \neq L+g S)$. Lanthanoide besitzen einen Gesamtdrehimpuls $J>\frac{1}{2}$ (erfüllt für alle Lanthanoidionen außer $\mathrm{Eu}^{3+}$ ), und somit eine Nullfeldaufspaltung. Da diese bei den Lanthanoiden wesentlich größer ist als ihre Ligandenfeldaufspaltung, überwiegt der Einfluss des Nullfeldterms, so dass man annäherungsweise folgenden Hamiltonoperator verwenden kann [65].

$$
\hat{H}=\mu_{B}\left(D_{x x} J_{x}^{2}+D_{y y} J_{y}^{2}+D_{z z} J_{z}^{2}\right) .
$$


Dadurch ergibt sich eine Suszeptibilität $\chi_{z}^{D}$ als Funktion des Gesamtdrehimpulses $J$ :

$$
\chi^{D}=-\left[\frac{N g_{j}^{2} \mu_{B}^{2}}{30(k T)^{2}}\right] D J(J+1)(2 J-1)(2 J+3),
$$

mit

$$
g_{j}=1+\frac{J(J+1)+S(S+1)-L(L+1)}{2 J(J+1)} .
$$

Neuere Untersuchungen [70] zeigten, dass bei Raumtemperatur auch Terme höherer Ordnung eine Rolle spielen, die an dieser Stelle nicht genauer behandelt werden.

Zudem untersuchten Mironov et al. [71,72] den Einfluss des Koordinationspolyeders auf die Größe der magnetischen Anisotropie. Dabei ist zu beachten, dass die Geometrie der Komplexe im Kristall sowohl vom Lanthanoidion abhängt als auch von den Gegenionen [73]. Hervorzuheben ist der neunfach koordinierte kubische Fall, der unverzerrt zu einer Auslöschung der Anisotropie führt. Schon geringe Verzerrungen führen aber aufgrund der Symmetrieänderung zu erheblichen Anisotropien. Die Anisotropie der schweren Lanthanoide ist stets größer als die der leichten Lanthanoide. Die Anisotropie innerhalb der Seltenerdmetalle zeigt bei selber Geometrie meist etwa denselben Verlauf, der in Abbildung 3.15 gezeigt wird [74]. Lanthanoidkomplexe besitzen in der Regel eine große Nullfeldfeldaufspaltung mit $D>100 \mathrm{~cm}^{-1}$.

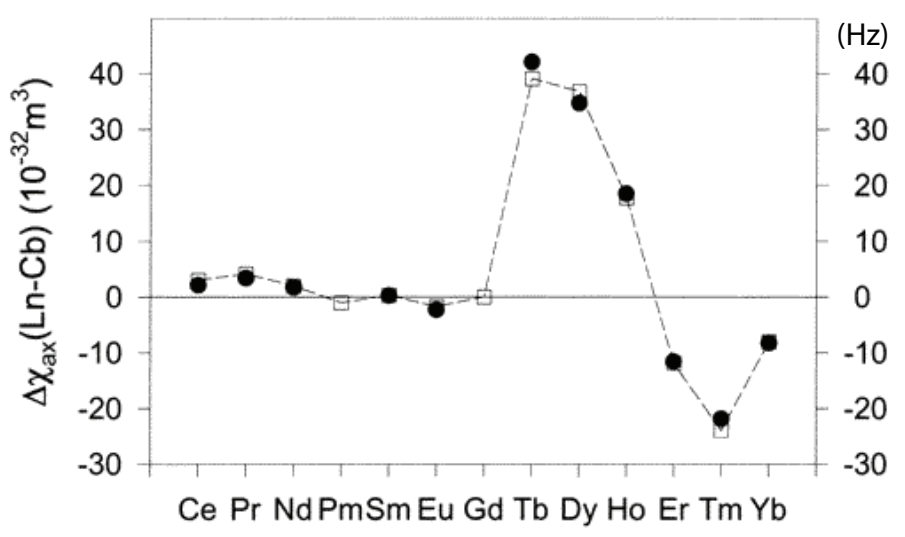

Abb. 3.15: Experimentelle und berechnete Werte der axialen Suszeptibilitätsanisotropie für eine Ligandenfeldaufspaltung von $169 \mathrm{~cm}^{-1}$. Die rechte Skala repräsentiert die daraus resultierenden dipolaren Kopplungen bei $800 \mathrm{MHz}$ und $298 \mathrm{~K}$ [74]. 
Die Formel für die Pseudokontaktverschiebung von Lanthanoiden ergibt sich demzufolge zu:

$\delta_{p c}=-\frac{\mu_{0}}{4 \pi} \frac{g_{j}^{2} \mu_{B}^{2} J(J+1)(2 J-1)(2 J+3)}{60(k T)^{2} r^{3}}\left[\left(D_{z z}-D\right)\left(3 \cos ^{2} \Theta-1\right)+\left(D_{x x}-D_{y y}\right)\left(\sin ^{2} \Theta \cos 2 \phi\right)\right]$.

Dabei wurde der Gesamtspin $S$ durch den Gesamtdrehimpuls $J$ ersetzt, da für schwere Atome die Spin-Bahn-Kopplung zwischen Gesamtbahndrehimpuls $L$ und Gesamtspin $S$ stark ist, d. h. größer als $k T$.

\subsubsection{Praktische Auslegung der Formel}

$\delta_{p c}=-\frac{\mu_{0}}{4 \pi} \frac{g_{j}^{2} \mu_{B}^{2} J(J+1)(2 J-1)(2 J+3)}{60(k T)^{2} r^{3}}\left[\left(D_{z z}-D\right)\left(3 \cos ^{2} \Theta-1\right)+\left(D_{x x}-D_{y y}\right)\left(\sin ^{2} \Theta \cos 2 \phi\right)\right]$.

Die Anisotropie der Suszeptibilität ist temperaturabhängig, da aufgespaltene Energieniveaus bei höherer Temperatur nach Boltzmann gleichmäßiger besetzt sind und die Anisotropie somit abnimmt [75]. Der Pseudokontaktshift der Lanthanoide ist damit proportional zu $T^{-2}$, nimmt also mit sinkender Temperatur zu, während der Effekt mit $r^{-3}$ zum Abstand des paramagnetischen Zentrums abnimmt.

Eine besondere Rolle nimmt $\mathrm{Eu}^{3+}$ ein, das den Gesamtdrehimpuls $J=\frac{1}{2}$ als Grundzustand besitzt, aber dennoch bei Raumtemperatur eine Nullfeldaufspaltung zeigt. Ursache dafür ist der energetisch geringe Unterschied des Grundzustand zu den ersten beiden angeregten Zuständen ( $J$ gleich 1 bzw. 2), die somit teilweise besetzt sind und die Nullfeldaufsplatung verursachen [76]. 


\subsection{Residuale dipolare Kopplungen}

Der Hamiltonian der Kopplungen von Kernspins im externen Magnetfeld $\hat{H}_{\text {Kop }}$ setzt sich aus zwei Komponenten zusammen, der skalaren Kopplung $\hat{H}_{\text {sca }}$ und der dipolaren Kopplung $\hat{H}_{\text {dip }}$.

$$
\hat{H}_{K o p}=\hat{H}_{s c a}+\hat{H}_{d i p}
$$

Die skalare Kopplung $J$ entsteht durch die Wechselwirkung der zwei Kernspins über die Fermikontaktwechselwirkung, damit ist sie von Molekülorbitalen abhängig. Sie ist nur bei Kernen messbar, die direkt oder über maximal drei weitere Kerne verbunden sind. Je mehr Bindungen dabei zwischen den betrachteten Kernspins $I_{1 z} I_{2 z}$ liegen, desto schwächer ist die Wechselwirkung. Die skalare Kopplung besitzt folgende Form:

$$
\hat{H}_{s c a}=2 \pi J \widehat{I_{1 z}} \widehat{I_{2 z}} \text {. }
$$

Kopplungen führen zur Aufspaltung des Resonanzsignals eines Kerns in Multipletts, aus denen sich die Kopplungen extrahieren lassen.

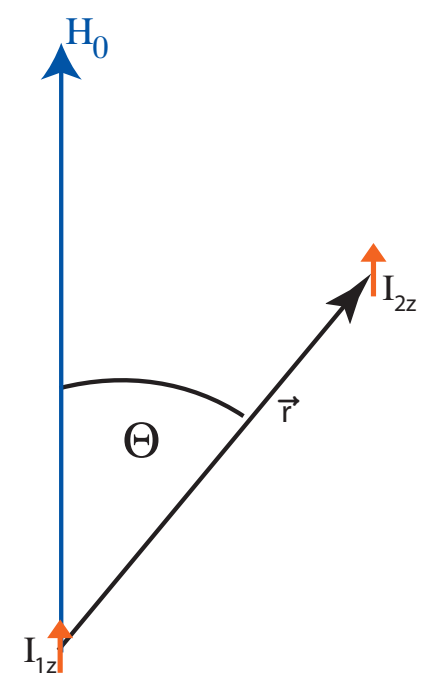

Abb. 3.16: Der Winkel $\Theta$ zwischen dem externen Magnetfeld und dem Kernverbindungsvektor. 
Die dipolare Kopplung existiert unabhängig von Molekülorbitalen und beruht einzig und allein auf der dipolaren Wechselwirkung zweier Kernspinmomente im Raum. Die Größe der dipolaren Kopplung ist dabei abhängig von der Orientierung des internuklearen Vektors zum statischen Magnetfeld. Die dipolare Energie $E_{\text {dip }}$ eines Kernspin $I_{1}$ mit dem gyromagnetischen Verhältnis $\gamma_{1}$ im Feld eines Kernspins $I_{2}$ mit dem gyromagnetischen Verhältnis $\gamma_{2}$ ist wie folgt definiert:

$$
E_{d i p}=\frac{\mu_{0}}{4 \pi} \frac{\gamma_{1} \gamma_{2}}{r^{3}}\left[\overrightarrow{I_{1}} \cdot \vec{I}_{2}-3 \frac{\left(\overrightarrow{I_{1}} \cdot \vec{r}\right)\left(\vec{I}_{2} \cdot \vec{r}\right)}{r^{2}}\right]
$$

Im heteronuklearen Fall ist die Differenz der Larmorfrequenzen groß im Vergleich zur Kopplung $(J+D)$, so dass die transversalen Komponenten des Kernspins vernachlässigt werden dürfen. Es ergibt sich folgende Formel mit dem Winkel $\Theta$ (Abb. 3.16):

$$
\begin{aligned}
E_{\text {dip }}^{\text {hetero }} & =\frac{\mu_{0}}{4 \pi} \frac{\gamma_{1} \gamma_{2} \hbar^{2}}{r^{3}}\left[I_{1 z} I_{2 z}-3\left(I_{1 z} \cos \Theta\right)\left(I_{2 z} \cos \Theta\right)\right] \\
& =-\frac{\mu_{0}}{4 \pi} \frac{\gamma_{1} \gamma_{2} \hbar^{2}}{r^{3}} I_{1 z} I_{2 z}\left(3 \cos ^{2} \Theta-1\right)
\end{aligned}
$$

Die dipolare Kopplung resultiert aus den Differenzen der Frequenzen $\nu$ zwischen den Energieniveaus zweier Spins.

$$
\nu_{\text {dip }}^{\text {hetero }}=-\frac{1}{2 \pi} \frac{\mu_{0}}{4 \pi} \frac{\gamma_{1} \gamma_{2} \hbar}{r^{3}} I_{1 z} I_{2 z}\left(3 \cos ^{2} \Theta-1\right)
$$

Dadurch folgt für die dipolare Kopplung $D$ :

$$
D=D_{\max }\left(\frac{3 \cos ^{2} \Theta-1}{2}\right)
$$

mit

$$
D_{\max }=-\frac{1}{\pi} \frac{\mu_{0}}{4 \pi} \frac{\gamma_{1} \gamma_{2} \hbar}{r^{3}}
$$

$D_{\max }$ ist die maximale Größe der dipolaren Kopplung, die nur dann auftritt, wenn keine Beweglichkeit des Moleküls vorhanden ist. Im Festkörper beträgt sie für eine CH-Kopplung mit einer Bindungslänge von 1.1 Angstöm -45,4 kHz.

In isotroper Lösung rotieren die Moleküle so schnell, dass sich die messbare dipolare Kopplung über alle gleichmäßig populierte Orientierungen zu null mittelt. Dadurch verschwinden 
die dipolaren Kopplungen. Sobald die Verteilung nicht mehr vollständig isotrop ist, mitteln sich die verschiedenen Orientierungen nicht mehr komplett und es entsteht eine Vorzugsausrichtung. Daraus resultieren kleine messbare dipolare Kopplungen. Bildet man den Durchschnitt über alle Orientierungen des Kernverbindungsvektors $\vec{r}$ im Raum und über die Zeit, d. h. über $\Theta$, und erhält somit:

$$
D=D_{\max }\left\langle\frac{3 \cos ^{2} \Theta-1}{2}\right\rangle
$$

Weiterhin gilt:

$$
D=D_{\max } P_{2}(<\cos \Theta>)
$$

mit

$$
P_{2}(<\cos \Theta>)=\frac{3\left\langle\cos ^{2} \Theta\right\rangle-1}{2} .
$$

Dabei ist $P_{2}(x)$ das zweite Legendrepolynom mit zwei Nullstellen.

Um den Winkel $\Theta$ zu berechnen, wird das Bezugssystem auf ein Koordinatensystem $x^{\prime}, y^{\prime}, z^{\prime}$ geändert, das dem Molekülkoordinatensystem entspricht (Abb. 3.17). Dabei ist $\cos \Theta=\widehat{\overrightarrow{H_{0}}} \cdot \widehat{\vec{r}}$, wobei $\widehat{x}$ auf die Normierung der Vektorlänge hinweisen soll. Im Molekülkoordinatensystem lässt sich das Skalarprodukt umwandeln zu:

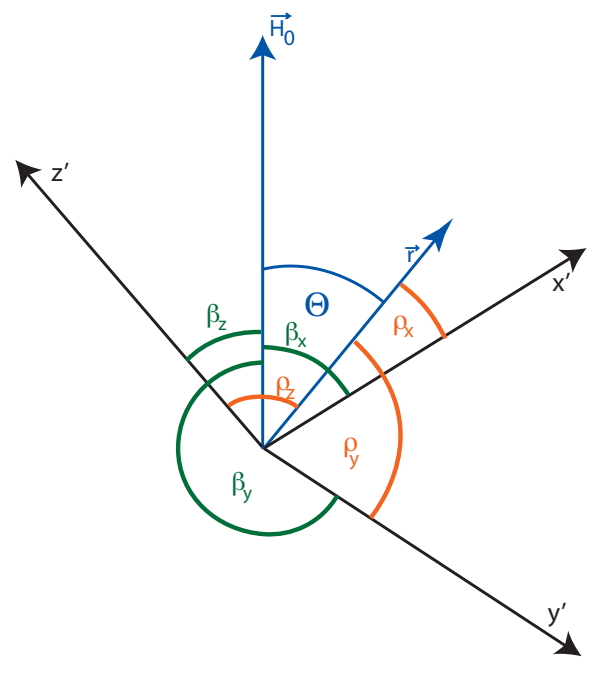

Abb. 3.17: Abbildung des Winkel $\Theta$ im Molekülkoordinatensystem (x', y', z'). $\vec{H}_{0}$ ist das externe Magnetfeld, $\vec{r}$ der Kernverbindungsvektor der zwei koppelnden Kerne. 


$$
\cos \Theta=\widehat{\overrightarrow{H_{0}}} \cdot \widehat{\vec{r}}=\left(\begin{array}{lll}
\cos \beta_{x^{\prime}} & \cos \beta_{y^{\prime}} & \cos \beta_{z^{\prime}}
\end{array}\right) \cdot\left(\begin{array}{c}
\cos \rho_{x^{\prime}} \\
\cos \rho_{y^{\prime}} \\
\cos \rho_{z^{\prime}}
\end{array}\right)=\sum_{i=x^{\prime}, y^{\prime}, z^{\prime}} \cos \beta_{i} \cos \rho_{i}
$$

deshalb:

$P_{2}(<\cos \Theta>)=\frac{3}{2}\left(\sum_{i=x^{\prime}, y^{\prime}, z^{\prime}} \cos \beta_{i} \cos \rho_{i}\right)^{2}-\frac{1}{2}=\frac{3}{2} \sum_{i=x^{\prime}, y^{\prime}, z^{\prime}} \cos \beta_{i} \cos \rho_{i} \sum_{j=x^{\prime}, y^{\prime}, z^{\prime}} \cos \beta_{j} \cos \rho_{j}-\frac{1}{2}$.

Da mit den normalisierten Vektoren gearbeitet wurde, gilt, dass die Summe der quadrierten Richtungskosinus 1 ergibt $\left(\cos ^{2} \rho_{x^{\prime}}+\cos ^{2} \rho_{y^{\prime}}+\cos ^{2} \rho_{z^{\prime}}=1\right)$. Mit

$$
\sum_{i=x^{\prime}, y^{\prime}, z^{\prime}} \cos ^{2} \beta_{i}=1
$$

und

$$
\sum_{i, j=x^{\prime}, y^{\prime}, z^{\prime}} \cos \beta_{i} \cos \beta_{j}=\delta_{i j}
$$

ergibt sich

$$
P_{2}\langle\cos \Theta\rangle=\frac{3}{2} \sum_{i, j=x^{\prime}, y^{\prime}, z^{\prime}} \cos \beta_{i} \cos \rho_{i} \cos \beta_{j} \cos \rho_{j}-\frac{1}{2} \sum_{i, j=x^{\prime}, y^{\prime}, z^{\prime}} \cos \rho_{i} \cos \rho_{j} \delta_{i j} .
$$

Für die dipolare Kopplung gemittelt über die Zeit $(\cos \beta(t))$ ergibt sich nun folgende Gleichung im Molekülkoordinatensystem:

$$
D=-\frac{1}{\pi} \frac{\mu_{0}}{4 \pi} \frac{\gamma_{1} \gamma_{2} \hbar}{r^{3}} \sum_{i, j=l, m, n} A_{i j} \cos \rho_{i} \cos \rho_{j}
$$

mit dem Alignmenttensorelementen:

$$
A_{i j}=\left\langle\frac{3}{2} \cos \beta_{i} \cos \beta_{j}-\frac{1}{2} \delta_{i j}\right\rangle .
$$


Die Alignmentmatrix ist real, symmetrisch und spurlos, was dazu führt, dass sie nur fünf voneinander unabhängige Elemente besitzt. Demzufolge reicht es theoretisch aus, fünf dipolare Kopplungen einer bekannten Molekülstruktur zu messen, um die Alignmentmatrix zu bestimmen (falls die fünf Interspinvektoren der korrespondierenden Kerne eine hinreichend große Winkelstreuung besitzen). Eine weitere Folge dessen ist, dass die Alignmentmatrix durch Überführung in ein anderes Koordinatensystem (genannt Alignmentkoordinatensystem x, y, z) diagonalisiert werden kann. In einem solchen System ergibt sich:

$$
\sum_{i, j=x, y, z} A_{i j} \cos \rho_{i} \cos \rho_{j}=A_{x x} \cos ^{2} \vartheta_{x}+A_{y y} \cos ^{2} \vartheta_{y}+A_{z z} \cos ^{2} \vartheta_{z}
$$

$\vartheta_{i}$ ist dabei der Winkel zwischen der Kernverbindungsachse $r$ und den Koordinatensystemsachsen $i$. In Kugelkoordinaten ergibt sich damit:

$$
\begin{aligned}
\cos \vartheta_{l} & =\sin \Theta \cos \Phi, \\
\cos \vartheta_{m} & =\sin \Theta \sin \Phi, \\
\cos \vartheta_{n} & =\cos \Theta .
\end{aligned}
$$

Die residualen dipolaren Kopplungen hängen somit von $r^{-3}$ und den Winkeln $\Theta$ und $\Phi$ in folgender Weise ab:

$$
\sum_{i, j=x, y, z} A_{k l} \cos \rho_{i} \cos \rho_{j}=A_{x x} \sin ^{2} \Theta \cos ^{2} \Phi+A_{y y} \sin ^{2} \Theta \sin ^{2} \Phi+A_{z z} \cos ^{2} \Theta
$$

und damit

$$
\begin{aligned}
D & =-\frac{1}{\pi} \frac{\mu_{0}}{4 \pi} \frac{\gamma_{1} \gamma_{2} \hbar}{r^{3}}\left[A_{x x} \sin ^{2} \Theta \cos ^{2} \Phi+A_{y y} \sin ^{2} \Theta \sin ^{2} \Phi+A_{z z} \cos ^{2} \Theta\right] \\
& =-\frac{1}{2 \pi} \frac{\mu_{0}}{4 \pi} \frac{\gamma_{1} \gamma_{2} \hbar}{r^{3}}\left[\left(A_{z z}-\bar{A}\right)\left(3 \cos ^{2} \Theta-1\right)+\left(A_{x x}-A_{y y}\right) \sin ^{2} \Theta \cos 2 \Phi\right] .
\end{aligned}
$$


Anmerkung:

Das Alignmenttensorkoordinatensystem und das Molekülkoordinatensystem hängen anschaulich folgendermaßen miteinander zusammen (Abb. 3.18) [77]. Außerdem lassen sich der Suszeptibilitätstensor $\boldsymbol{\chi}$, der Alignmenttensor $\mathbf{A}$ und der Wahrscheinlichkeitstensor $\mathbf{P}$ direkt ineinander überführen [68].

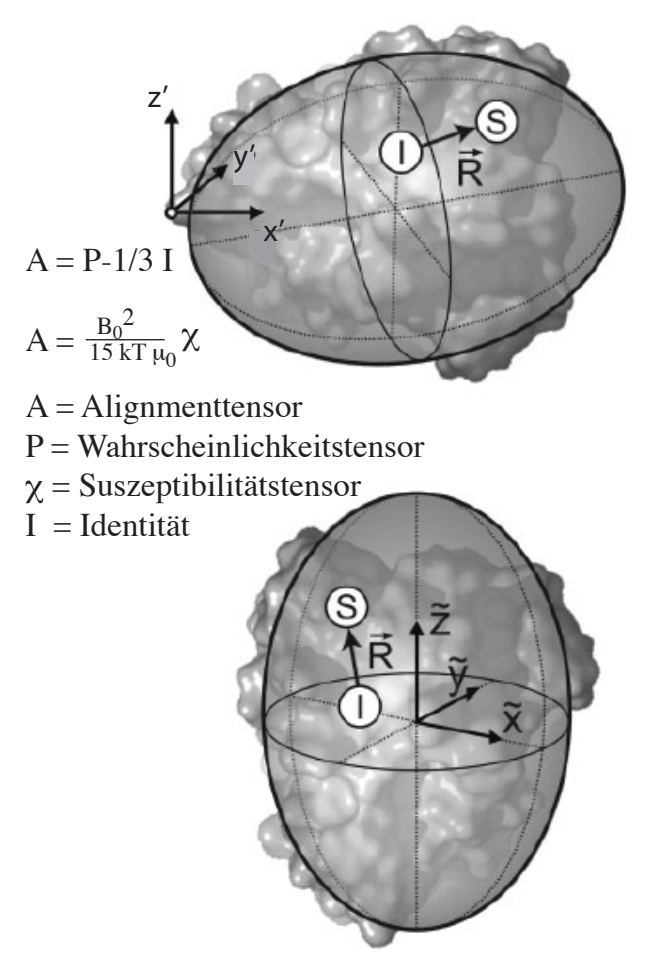

Abb. 3.18: Abbildung des Molekülkoordinatensystem x', y', z' im Vergleich zum Alignmenttensorkoordinatensystem x, y, z [77] und der Zusammenhang zwischen Alignmenttensor A, Suszeptibilitätstensor $\chi$ und Wahrscheinlichkeitstensor $\mathbf{P}$.

\subsection{Relaxation durch Paramagnetismus}

Als Relaxation bezeichnet man den Prozess, der einen Nichtgleichgewichtszustand wieder in den Gleichgewichtszustand bringt. In der NMR-Spektroskopie bedeutet das einerseits, dass die x-, y-, bzw. -z-Magnetisierung nach Abschalten des rf-Pulses (radio frequency) wieder zu z-Magnetisierung relaxiert (longitudinale Relaxationzeit $\mathrm{T}_{1}$ ) und andererseits, dass sich x,y-Magnetisierung abbaut (transversale Relaxationszeit $\mathrm{T}_{2}$ ). Ein Mechanismus, der zu 
beiden Arten der Relaxation führt, ist die sogenannte Spin-Gitter-Wechselwirkung. Dabei tauscht ein Spin Energie mit seiner Umgebung (Gitter) über einen Wechsel des Energieniveaus aus. Zur transversalen Relaxation trägt zusätzlich eine Spin-Spin-Wechselwirkung bei. Dabei wechselwirken zwei Spins benachbarter Kerne. Die transversale Relaxation hängt mit der Linienbreite $\Delta \nu_{1 / 2}$ der Resonanzfrequenz wie folgt zusammen:

$$
\frac{1}{T_{2}}=\pi \Delta \nu_{1 / 2}
$$

Bei paramagnetischen Substanzen spüren sich Kern- und Elektronenspin, denn obwohl die makroskopische Magnetisierung der Probe konstant ist, wechseln die einzelnen Elektronenspins bzw. die Gesamtdrehmomente $J$ ihre Zustände ständig unter Erhalt der Boltzmannverteilung (Elektronenspinrelaxation $T_{e}$ ). So sieht jeder Kern den Elektronenspin $m_{s}$ in der Umgebung umklappen, womit sich auch das Magnetfeld der Umgebung ändert. Diese paramagnetische Relaxationsvergrößerung bezeichnet man mit PRE (paramagnetic relaxation enhancement). Die Länge der Elektronenrelaxation $T_{e}$ nimmt bei abnehmender Temperatur und zunehmender Ligandenfeldaufspaltung zu. Die Ligandenfeldaufspaltung der Lanthanoidkomplexe ist sehr gering, da die f-Orbitale in der drittäußersten Schale nur geringe Wechselwirkungen mit der Ligandorbitalen aufweisen. Demzufolge sind die Elektronenrelaxationszeiten der Lanthanoide sehr kurz (Abb. 3.19). Bei NMR-spektroskopischen Messungen von Biomolekülen in Lösung wird meist bei Temperaturen um die $300 \mathrm{~K}$ gemessen.

Einzige Ausnahme stellt $\mathrm{Gd}^{3+}$ dar. Gadolinium besitzt bei einem Gesamtbahndrehimpuls $L=0$ einen Kernspin $S=7 / 2$. Für derartige Ionen in kubischer Umgebung sollten alle anisotropen magnetischen Terme wie der $g$-Tensor und die Nullfeldaufspaltung verschwinden. Aber wie der Vergleich von Experimenten und theoretischen Berechnungen zeigt, fluktuiert die geometrische Anordnung der Komplexe durch Lösungsmitteleffekte, was zu einer verzerrten Symmetrie und somit zu Anisotropien führt [80]. Anschaulich betrachtet relaxiert ein $\mathrm{Gd}^{3+}$-Ion so viel langsamer, weil jedes f-Orbital genau mit einem Elektron gefüllt ist. Bei allen anderen paramagnetischen Elektronen ist die Elektronenrelaxationszeit $T_{e}$ so kurz im Vergleich zur Korrelationszeit $\tau_{c}$ des gesamten Moleküls, dass benachbarte Kerne nur ein gemitteltes magnetisches Moment der Elektronen spüren, das sich aus der Boltzmann- 


\begin{tabular}{|c|c|c|}
\hline Metallion & Konfiguration & $\mathbf{T}_{\mathbf{e}}$ in $[\mathbf{s}]$ \\
\hline $\mathrm{Cr}^{3+}$ & $\mathrm{d}^{3}$ & $10^{-9}-10^{-10}$ \\
\hline $\mathrm{Cr}^{2+}$ & $\mathrm{d}^{4}$ & $10^{-11}-10^{-12}$ \\
\hline $\mathrm{Cu}^{2+}$ & $\mathrm{d}^{9}$ & $10^{-9}$ \\
\hline $\mathrm{Ce}^{3+}$ & $\mathrm{f}^{1}$ & $4 \cdot 10^{-13}-1 \cdot 10^{-13}$ \\
\hline $\mathrm{Pr}^{3+}$ & $\mathrm{f}^{2}$ & $3 \cdot 10^{-16}-6 \cdot 10^{-14}$ \\
\hline $\mathrm{Nd}^{3+}$ & $\mathrm{f}^{3}$ & $8 \cdot 10^{-13}-2 \cdot 10^{-13}$ \\
\hline $\mathrm{Sm}^{3+}$ & $\mathrm{f}^{5}$ & $2 \cdot 10^{-12}-5 \cdot 10^{-14}$ \\
\hline $\mathrm{Eu}^{3+}$ & $\mathrm{f}^{6}$ & $5 \cdot 10^{-14}-1 \cdot 10^{-14}$ \\
\hline $\mathrm{Gd}^{3+}$ & $\mathrm{f}^{7}$ & $10^{-8}-10^{-9}$ \\
\hline $\mathrm{Tb}^{3+}$ & $\mathrm{f}^{8}$ & $8 \cdot 10^{-13}-2 \cdot 10^{-13}$ \\
\hline $\mathrm{Dy}^{3+}$ & $\mathrm{f}^{9}$ & $1 \cdot 10^{-12}-4 \cdot 10^{-13}$ \\
\hline $\mathrm{Ho}^{3+}$ & $\mathrm{f}^{10}$ & $8 \cdot 10^{-13}-2 \cdot 10^{-13}$ \\
\hline $\mathrm{Er}^{3+}$ & $\mathrm{f}^{11}$ & $8 \cdot 10^{-13}-3 \cdot 10^{-13}$ \\
\hline $\mathrm{Tm}^{3+}$ & $\mathrm{f}^{12}$ & $2 \cdot 10^{-12}-5 \cdot 10^{-13}$ \\
\hline $\mathrm{Yb}^{3+}$ & $\mathrm{f}^{13}$ & $5 \cdot 10^{-13}-2 \cdot 10^{-13}$ \\
\hline
\end{tabular}

Abb. 3.19: Die Elektronenrelaxationszeiten der Übergangsmetalllionen und von Gadolinium stammen aus [78], die übrigen aus [79]. Die gelb unterlegten Felder stellen dabei Relaxationszeiten dar, die unpraktikabel für NMR-Messungen sind.

verteilung ergibt. Dieses Phänomen der Kernspinrelaxation wird als Curie-Spin-Relaxation bezeichnet. Dadurch ergeben sich schmalere Linien als bei höheren $T_{e}$ im Bereich von $\tau_{c}$ [81]. 
KAPITEL 3. NMR-SPEKTROSKOPIE 


\section{Kapitel 4}

\section{Tagging}

\subsection{Das Konzept des Taggings von Biomolekülen}

Als Tagging bezeichnet man die Modifizierung von Makromolekülen mit kleinen funktionalen Einheiten, den so genannten Tags. Tag bedeutet aus dem Englischen übersetzt Markierung. In der biomolekularen Chemie ist ein Tag also eine Markierung eines Biomoleküls. Für das Tagging ist es eine Voraussetzung, dass die eingeführte Markierung die Funktion der Proteine möglichst wenig beeinflusst und idealerweise klein im Vergleich zum Biomolekül ist. Der Tag birgt dabei neue spektroskopische Eigenschaften, die zur Analyse des Biomoleküls genutzt werden, beispielsweise zur Bestimmung des Aufenthaltsortes des Proteins in der Zelle. Eine Strukturaufklärung kann nur funktionieren, wenn durch die Modifizierung die native Struktur des Biomoleküls nicht zerstört wird. Der Ort der Modifizierung muss demnach so gewählt sein, dass der Tag vom Biomolekül weg zeigt. Zudem darf er nicht mit Funktionen des Biomoleküls reagieren oder starke Wechselwirkungen eingehen, beispielsweise über Wasserstoffbrückenbindungen. Häufig werden fluoreszenzaktive Proteine eingefügt, z. B. das Green Fluorescent Protein (GFP), dessen Entwicklung im Jahr 2008 mit dem Nobelpreis für 
Osamu Shimomura, Martin Chalfie und Roger Tsien ausgezeichnet wurde [82]. Mit Hilfe des GFPs können die getaggten Proteine in der Zelle durch Fluoreszenz detektiert werden.

Es existieren verschiedene Taggingkonzepte: Einerseits das globale Tagging, d. h. das Modifizieren von verbreiteten Funktionen in Biomolekülen, u. a. von Aminogruppen in Peptiden; andererseits das selektive Labeling, beispielsweise die Reaktion an Cysteinen in Peptiden.

Tagging hat einen hohe Stellenwert für verschiedene biochemische Methoden. In der Massenspektroskopie von Peptiden verwendet man das iTRAQ-Tagging (isobaric tag for r relative and $\underline{a} b s o l u t e ~ q u a n t i f i c a t i o n)$, eine Modifizierung, die zur quantitativen MS/MS-Analyse verwendet wird [83].

Um die Aufreinigung von Proteinen zu erleichtern, werden im Rahmen der Expression HisTags an das Protein gehängt. His-Tags sind Peptidtags, die aus mindestens sechs Histidinresten bestehen. Polyhistidine besitzen eine Affinität gegenüber Nickel $^{2+}$-NTA-modifiziertem Chromatographiematerial, welches diese mit einer Bindungkonstante von $K_{d}=10^{-13}$ bindet (siehe Abb. 4.1). Erst durch Elution mit Imidazol wird das getaggte Protein wieder abgegeben. So erreicht man, dass Proteine mit His-Tag von allen anderen getrennt werden [84].

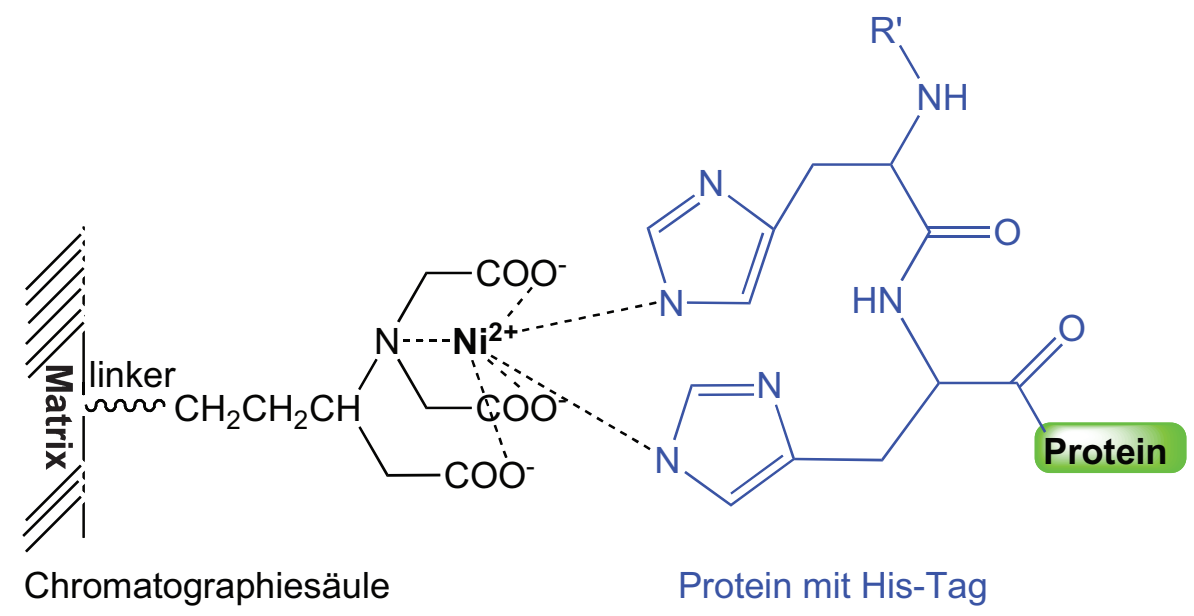

Abb. 4.1: Die schematische Darstellung der His-Tag-Affinitätschromatographie an einer Nickel ${ }^{2+}$ NTA-Säule. 
In der ESR- und NMR- Spektroskopie sind spin labels als Tags für Proteine sehr verbreitet. Spin labels sind Moleküle mit ungepaarten Elektronen, die in NMR-Spektren zu einer lokalen Signalverbreiterung (PRE) führen (siehe Kapitel 3.10). Häufig genutzt wird beispielsweise der MTSSL-Tag ((1-Oxyl-2,2,5,5-tetramethylpyrrolin-3-methyl) methanthiosulfonat spin label), ein stabiles zyklisches Nitroxyl-Radikal. Der MTSSL-Tag ist sehr selektiv und reagiert nur mit Thiolen, also z. B. den Cysteinen eines Proteins (Abb. 4.2) [85,86].

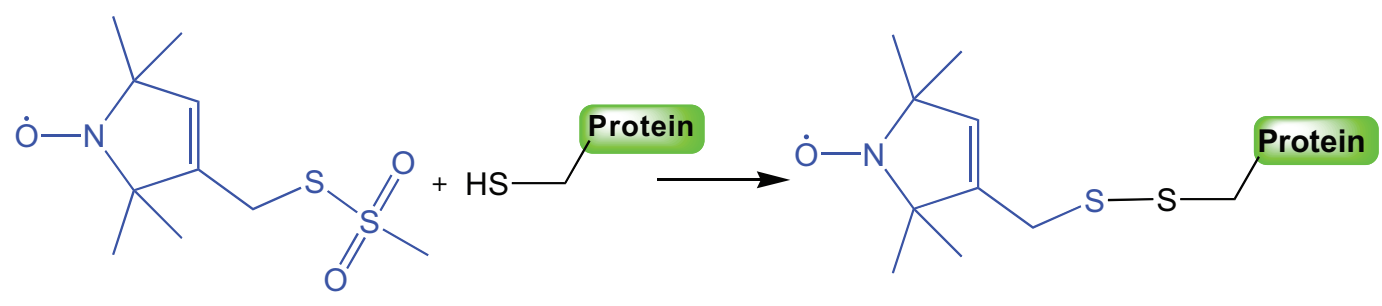

\begin{abstract}
Abb. 4.2: Die schematische Darstellung der Einführung eines MTSSL-Tags in ein Protein mit oberflächenexponiertem Cystein.
\end{abstract}

In der ESR-Spektroskopie sind spin labels essentiell, da nur ungepaarte Elektronen detektiert werden können. Demzufolge kann man allein solche Proteine untersuchen, die ein paramagnetisches Zentrum in Form eines Metallions oder eines Radikals aufweisen.

\title{
4.2 Chelatisierende DNA-Tags in der Literatur
}

In der Literatur wurden bereits einige metallionenchelatisierende Tags für Nukleinsäuren beschrieben. Dabei lag anfangs der Schwerpunkt auf der ortspezifischen Hydrolyse der Oligonukleotide, also auf künstlichen, ortsspezifischen Nukleasen [7]. Mit der Zeit wurden diese chelatisierenden Oligonukleotide zunehmend auch für NMR-Studien genutzt, um paramagnetische Zentren in DNA einzubauen [87-89]. Zudem verwendet man Lanthanoid(III)EDTA-Komplexe für Fluoreszenzstudien [90]. Im Folgenden werden einige chelatisierende Nukleinsäuretags und ihre Anwendungen kurz vorgestellt. 


\subsubsection{Der BABE-Tag}

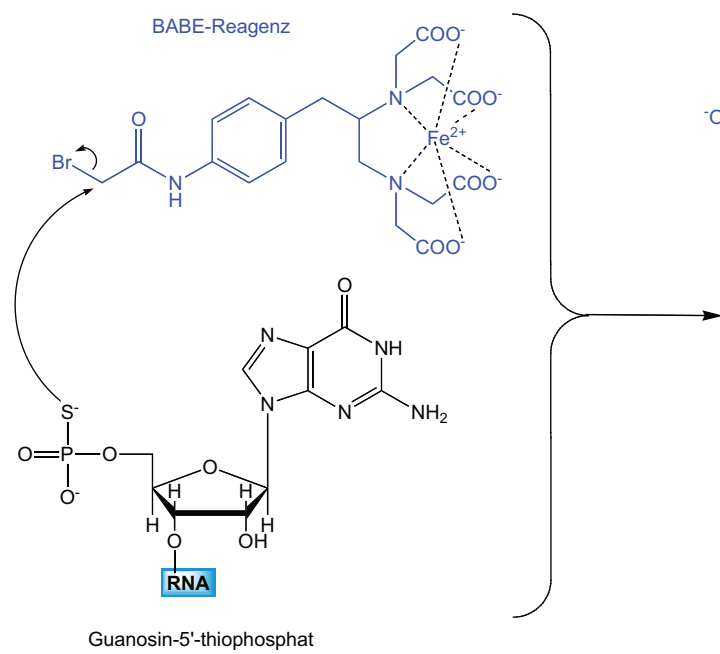

Guanosin-5'-thiophosphat

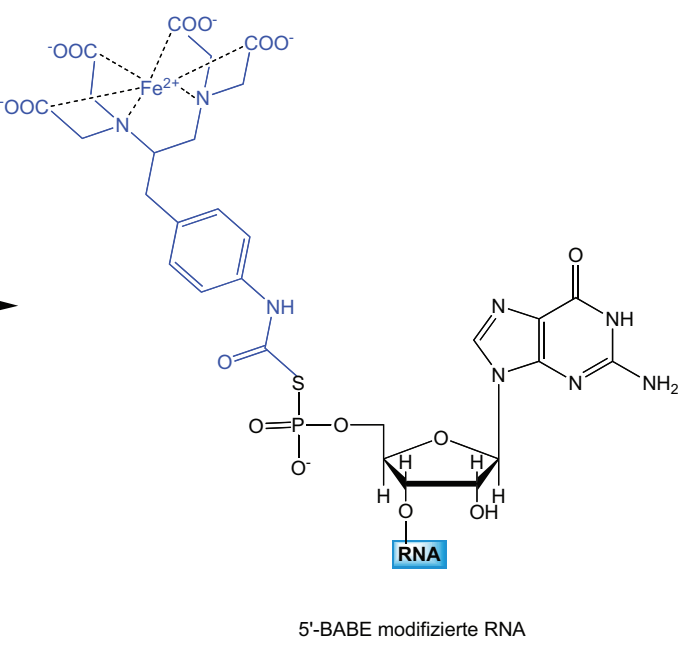

5'-BABE modifizierte RNA

Abb. 4.3: Die Einführung eines endständigen Fe-BABE-Tags in RNA (1-(p-romacetamidㅁenzyl)-EDTA) [7].

Eisen(II)-EDTA-Komplexe bilden in Anwesenheit von Wasserstoffperoxid Hydroxylradikale (Fenton-Reaktion). Diese Eigenschaft nutzt man in der Biochemie, um Peptide aber auch RNA ortsspezifisch zu hydrolysieren. Dazu wird ein Eisen(II)-EDTA-Komplex kovalent an ein Biomolekül gebunden (BABE-Tag), indem man eine Thiolfunktion modifiziert (siehe Abb. 4.3). Anschließend wird Wasserstoffperoxid zugegeben, wodurch sich v. a. in der Nähe des Eisenzentrums Hydroxylradikale bilden, die im Fall von RNA die Ribose angreifen und dabei die Phosphodiesterbindung spalten. Durch die Analyse der entstanden Bruchstücke können dann Rückschlüsse auf die Tertiärstruktur der RNA gezogen werden. Normalerweise erfolgt die Modifizierung am 5'-Ende der RNA. Neuere Methoden ermöglichen zudem die Einbringung einer BABE-Modifizierung an nichtendständigen Basen (Abb. 4.4), was das Anwendungsspektrum des Tags stark erweitert hat [8]. 


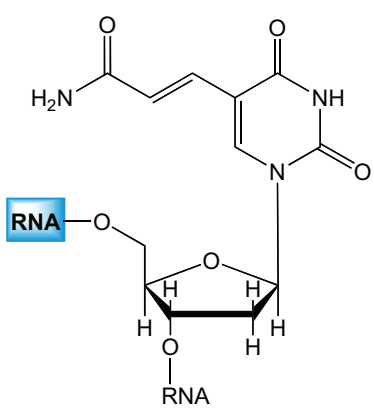

RNA mit
5-Acrylamido-2'-deoxyuridin
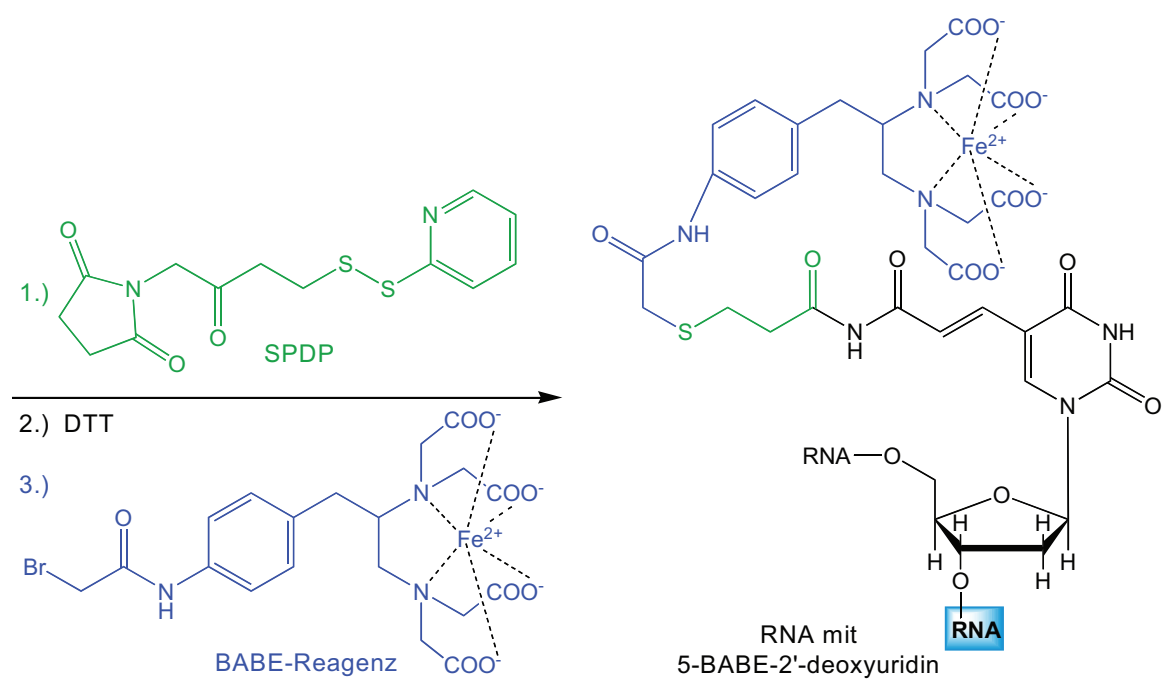

Abb. 4.4: Alternative nichtendständige BABE-Modifizierung von RNA.

\subsubsection{Fluoreszenztags}

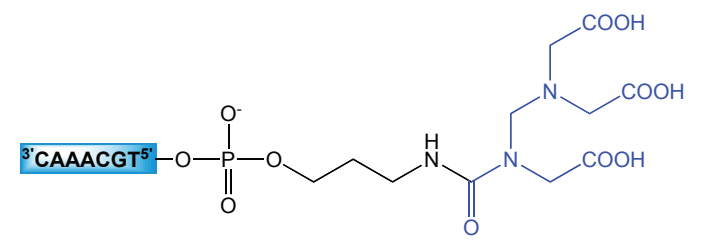

Abb. 4.5: 5'-EDTA modifizierte DNA mit Aminoalkyllinker. Durch Terbium(III)ionenKomplexierung entsteht ein Fluoreszenztag.

Wie in Abb. 4.5 dargestellt kann DNA am 5'-Ende über einen Aminoalkyllinker mit EDTA modifiziert werden [91,92]. Neben EDTA kann so auch DTPA als funktionelle Gruppe eingeführt werden (Abb. 4.8). Anfangs erfolgte diese Derivatisierung zum Komplexieren von Eisen(II)-Ionen, die zusammen mit Wasserstoffperoxid eine ortsspezifische Spaltung von DNA ermöglichten, später wurde der Tag zur Komplexierung mit Terbium(III)-ionen genutzt, um sich die Fluoreszenzeigenschaften des Lanthanoidkomplexes in Hybridisierungsstudien zunutze zu machen. 


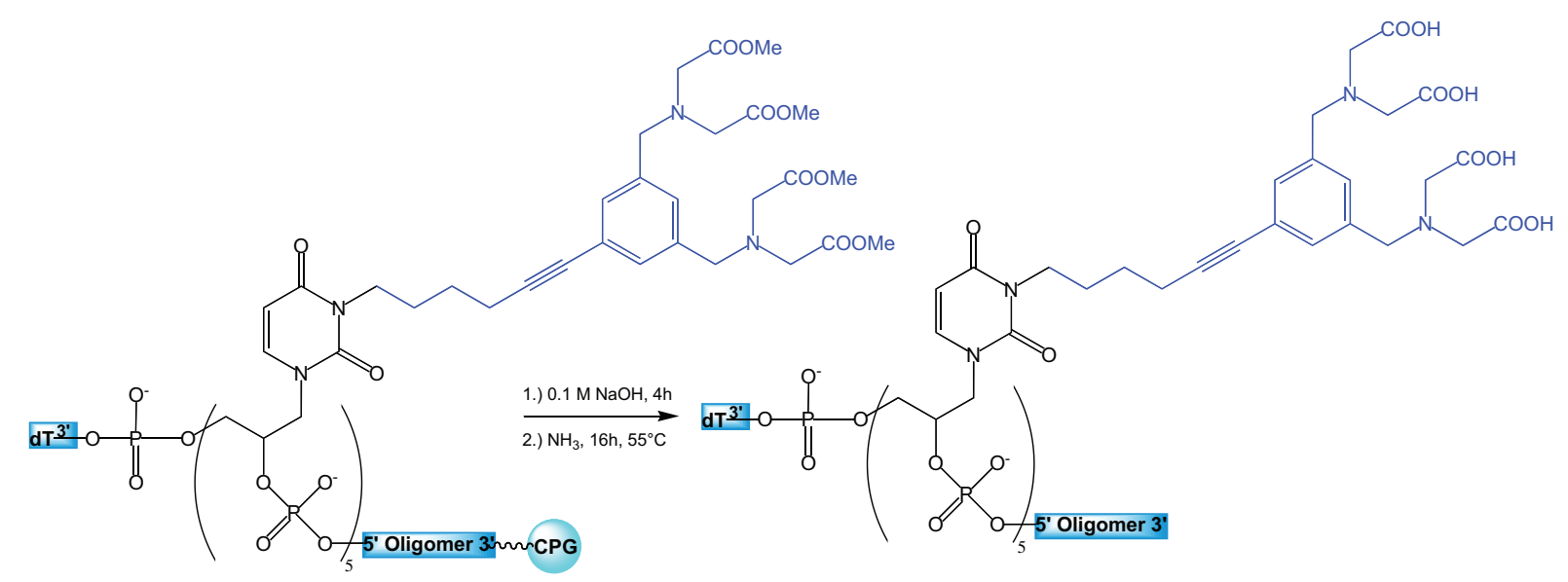

Abb. 4.6: Einbau des Hovinen-Tags via Festphasensynthese mit dem entsprechenden Phosphoramidit und anschließender Vorentschützung mit Natronlauge [90].

Ein weiterer chelatisierender DNA-Tag, der nicht auf der Struktur von EDTA beruht, wurde von Hovinen et al. synthetisiert und analog zu obigem Tag zu fluoreszenzbasierten Hybridisierungsassays verwendet (Abb. 4.6) [90].

\subsubsection{PRE-Tags}

1985 wurde von Dervan et al. ein EDTA-modifiziertes Phosporamidit synthetisiert, das per Festphasensynthese in DNA eingebaut werden konnte [93].
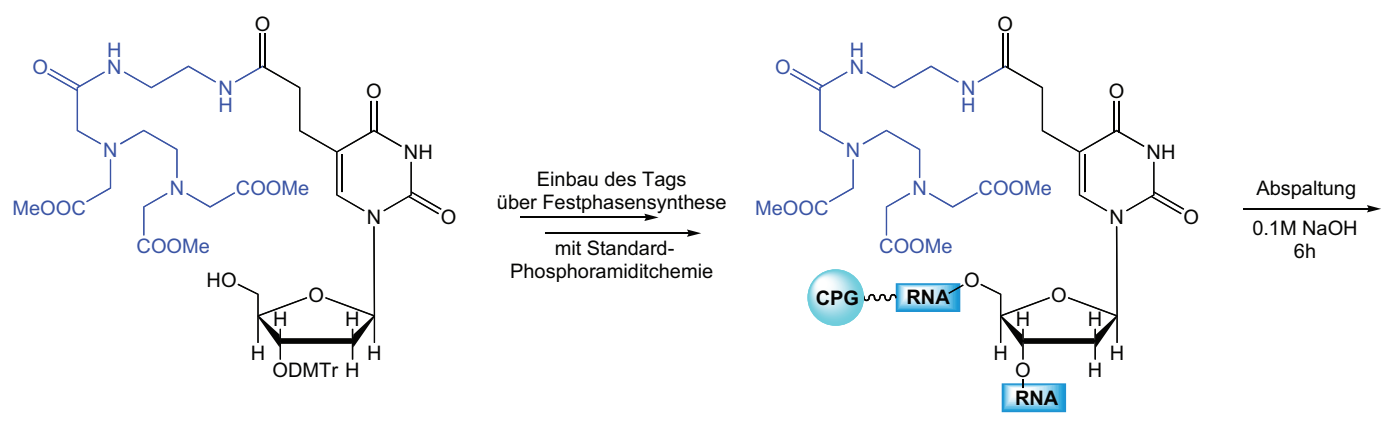

Abb. 4.7: Kommerziell erhältlicher EDTA-Tag für DNA (dT-EDTA). 
Dieses Phosporamidit ist mittlerweile kommerziell erhältlich und wird von Clore et al. zu NMR-Studien genutzt. Dabei werden PRE-Raten gemessen, um Bindungsstellen zwischen DNA und Proteinen zu bestimmen [87-89].

\subsubsection{PRE-Tags für Magnetresonanz-Imaging}

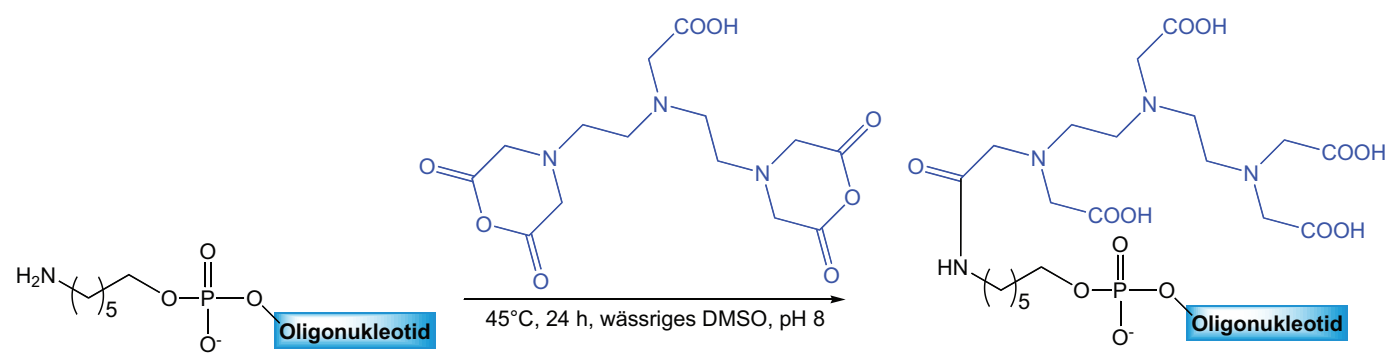

Abb. 4.8: DTPA-Derivatisierung eines Oligonukleotids für MRI-Studien.

Paramagnetische Komplexe werden auch in der Medizin für bestimmte MagnetresonanzImaging-Verfahren (MRI) genutzt. Ein gängiges MRI-Kontrastreagenz ist der GadoliniumDTPA-Komplex. Neben der Verwendung des reinen Komplexes wurden auch Derivate für Spezialanwendungen entwickelt. Beispielsweise wird der Komplex kovalent über einen Aminolinker an ein DNA-Hexamer gebunden, das mit dem Loop C der 5S-rRNA wechselwirkt. Durch die gemessene paramagnetische Relaxationverstärkung werden 5S-rRNA-reiche Bereiche im Körper visualisiert [6].

\subsection{Anforderungen an paramagnetisch getaggte DNA für rdc-Messungen}

Die im Abschnitt 4.2 vorgestellten EDTA- und DPTA-Tags sind zu flexibel für rdc-Messungen, einerseits da die Verknüpfung über Alkylketten erfolgt, andererseits weil sie an endständigen Phosphatresten der DNA gebunden sind. Zudem sind sie auch stereochemisch ungeeignet, da 
das getaggte Biomolekül ein eindeutiges Diastereomer sein muss [94]. EDTA-basierte Modifizierungen, die an einem Stickstoffatom angebracht sind, führen zu zwei verschiedenen diastereomeren Komplexen und somit zu zwei verschiedenen Alignments. Bei Modifizierungen, die über die $\mathrm{CH}_{2}$-Gruppen des Diethylamin des EDTA verknüpft sind, ist es wichtig, dass selektiv nur ein Enantiomer vorliegt, das anschließend mit dem Biomolekül verbrückt wird.

Natürlich darf die Modifizierung auch keine reaktiven Komponenten besitzen, die chemische Reaktionen mit Funktionen des Biomoleküls eingehen können. Diese Einschränkung spielte beim Design der Tags jedoch keine große Rolle, da Biomoleküle recht inert sind und mit vielen funktionellen Gruppen wie z. B. Säuren, Aziden, Alkinen keine Reaktion eingehen. Bei den Modifizierungsreaktionen muss auf den pH-Wert geachtet werden, da im stark alkalischen Bereich RNA hydrolysiert [95] und es in sehr saurem Milieu zu Nebenreaktionen wie Deadenolysierungen kommen kann [96].

Sehr wichtig ist auch die Tatsache, dass die Bindungsaffinität des Lanthanoidions zum Tag wesentlich höher sein muss als die zum Biomolekül. Bei der DNA bedeutet dies, dass die Bindungskonstante zwischen EDTA und Lanthanoid viel größer als die Bindungskonstante zu den Phosphatresten des DNA-Rückgrats sein muss. Die Komplexbildungskonstante des Gadolinium-EDTA-Komplexes beträgt $\mathrm{K}_{B}=10^{17.7}$ [97], während Phosphate in der Regel ein unlösliches Salz mit Lanthanoiden formen. Burai et al. haben die Bildung von ternären Komplexen aus $\mathrm{Gd}^{3+}$, EDTA und kleinen Liganden untersucht [98]. Die Komplexbildungskonstante des $\left[\mathrm{Gd}(\mathrm{EDTA})\left(\mathrm{HPO}_{4}\right)\right]^{3-}$-Komplexes betrug $10^{2.84}$, die von $[\mathrm{Gd}(\mathrm{EDTA})(\mathrm{Citrat})]^{4-}$ Komplexes sogar $10^{3.56}$. Die kleinen Liganden sollten jedoch nicht in der Lage sein einzelne Arme oder das gesamte EDTA-Molekül aus dem Komplex zu verdrängen.

Das Tagging von Biomolekülen zur Strukturaufklärung kann nur funktionieren, wenn durch die Modifizierung die native Struktur des Biomoleküls nicht zerstört wird. Wie in Kapitel 4.1. erwähnt müssen dazu zusammenfassend folgende Bedingungen erfüllt sein: 
- Der Tag muss wesentlich kleiner als die DNA sein.

- Der Tag reagiert nicht mit DNA.

- Der Tag wechselwirkt nicht mit DNA.

- Der Tag zeigt vom Biomolekül weg.

- Der Tag erzeugt keine neuen Stereozentren.

Diese Kriterien wurden mit Hilfe des Programms Macromodel untersucht [23]. Dazu wurde eine B-DNA-Doppelhelix energieminimiert und anschließend modifiziert, um danach eine erneute Energieoptimierung durchzuführen. Dabei wurde ersichtlich, dass Modifizierungen an der 5-Position von Thyminen in Richtung der großen Furche zeigen und damit das Grundgerüst der DNA nicht verändern. Untersuchungen an 5-Ethinyl-2'desoxyuridinhaltiger DNA haben gezeigt, dass diese Modifizierung sogar zu einer Stabilisierung der Doppelhelix führt [99].

In Abb. 4.9 sind die in der Arbeit erfolgreich synthetisierten Tags mit ihren Abkürzungen dargestellt. Vor seiner Synthese wurde die Struktur des EPTE-Tags (EthinylphenyltriazolylEDTA) mit Hilfe des Programms Macromodel untersucht. Die gesamte Modifizierung bestehend aus zwei Phenylringen, einer Dreifachbindung, einem 1,2,3-Triazol, einer Amidbindung und der EDTA-Funktion liegt in Richtung der großen Furche. Vergleicht man aber das Rückgrat der getaggten und der unmodifizierten DNA, so sind nur marginale Unterschiede zwischen den beiden Strukturen feststellbar (Abb. 4.10). Auch die Wasserstoffbrückenbindungen zwischen der modifizierten Base und ihrem Adenosinbindungspartner bleiben erhalten.

Die B-helikale Struktur der DNA bleibt auch bei DSE (못ulfid-EDTA)- und TE (TriazolylEDTA)-Modifizierungen erhalten (Abb. 4.11). Ein Grund für die nur minimalen Strukturunterschiede liegt im Erhalt der Wasserstoffbrückenbindungen der veränderten Basen.

Zusätzlich zu den Tagginganforderungen müssen noch spezielle Bedingungen erfüllt werden, um residuale dipolare Kopplungen im NMR-Spektrum messen zu können. Die EDTA- 

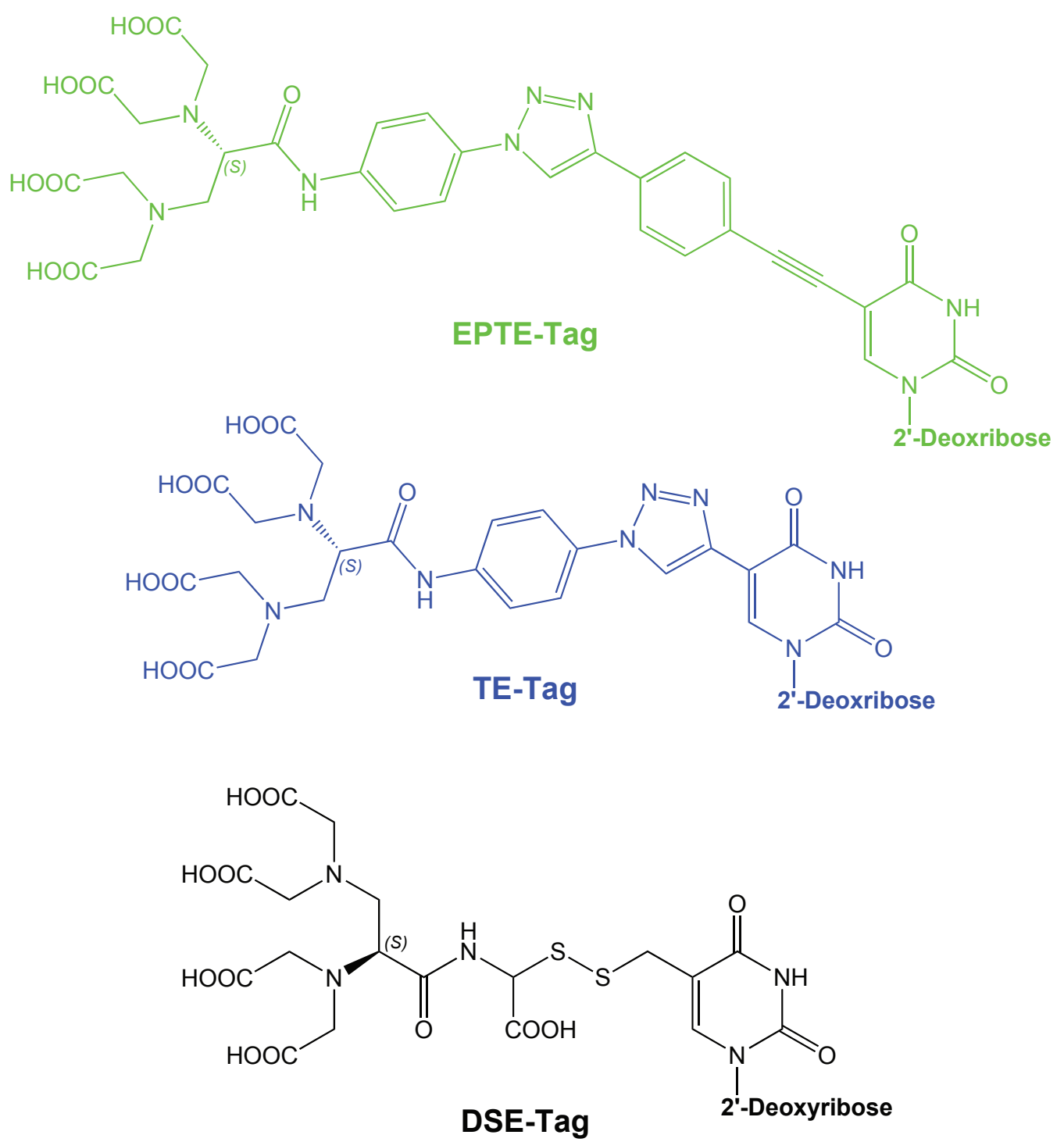

Abb. 4.9: Strukturformeln und Abkürzungen der drei verschiedenen Tags.

Funktion muss möglichst starr mit dem Biomolekül verbunden sein, da nur so eine ausreichende Übertragung des Alignments vom Lanthanoid auf die DNA erreicht werden kann. Beim EPTE-Tag wird dies durch ein mehrgliedriges aromatisches System realisiert, das mit einer Amidbindung endet, die durch ihren planaren Charakter gut als Verbindung zur EDTAFunktion geeignet ist. Bezüglich der Rigidität ist auch ein kürzerer Tag sehr geeignet, wie der TE-Tag. Bei ihm ist jedoch die sterische Hinderung etwas größer. Dies garantiert zwar eine gute Stabilität, aber die Taggingreaktion ist teilweise gehindert (siehe Abschnitt 5.5). 

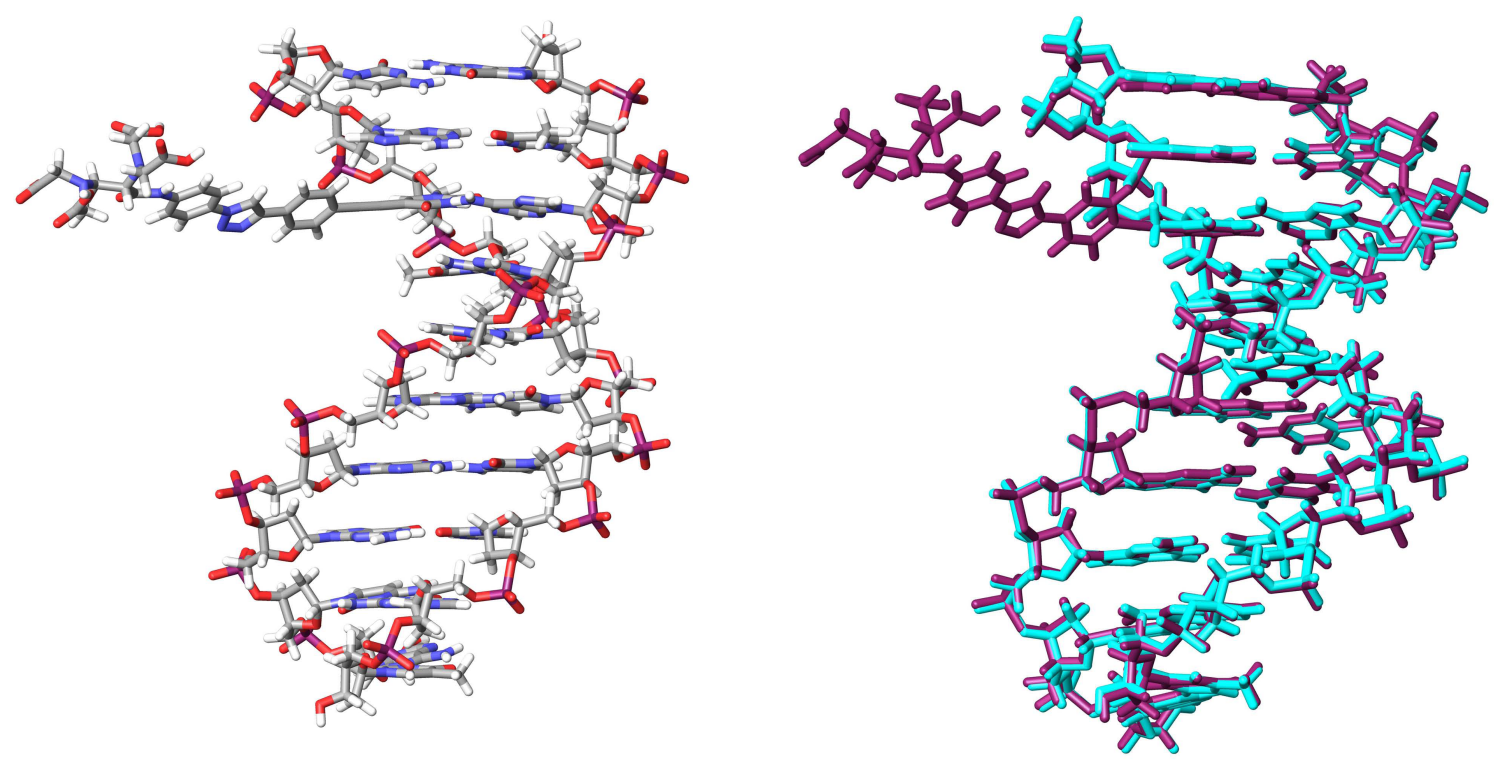

Abb. 4.10: links: Die energieoptimierte Struktur der EPTE-modifizierten DNA und rechts der Vergleich zur unmodifizierten Sequenz (türkis). Die verwendeten Macromodelparameter finden sich im Anhang.
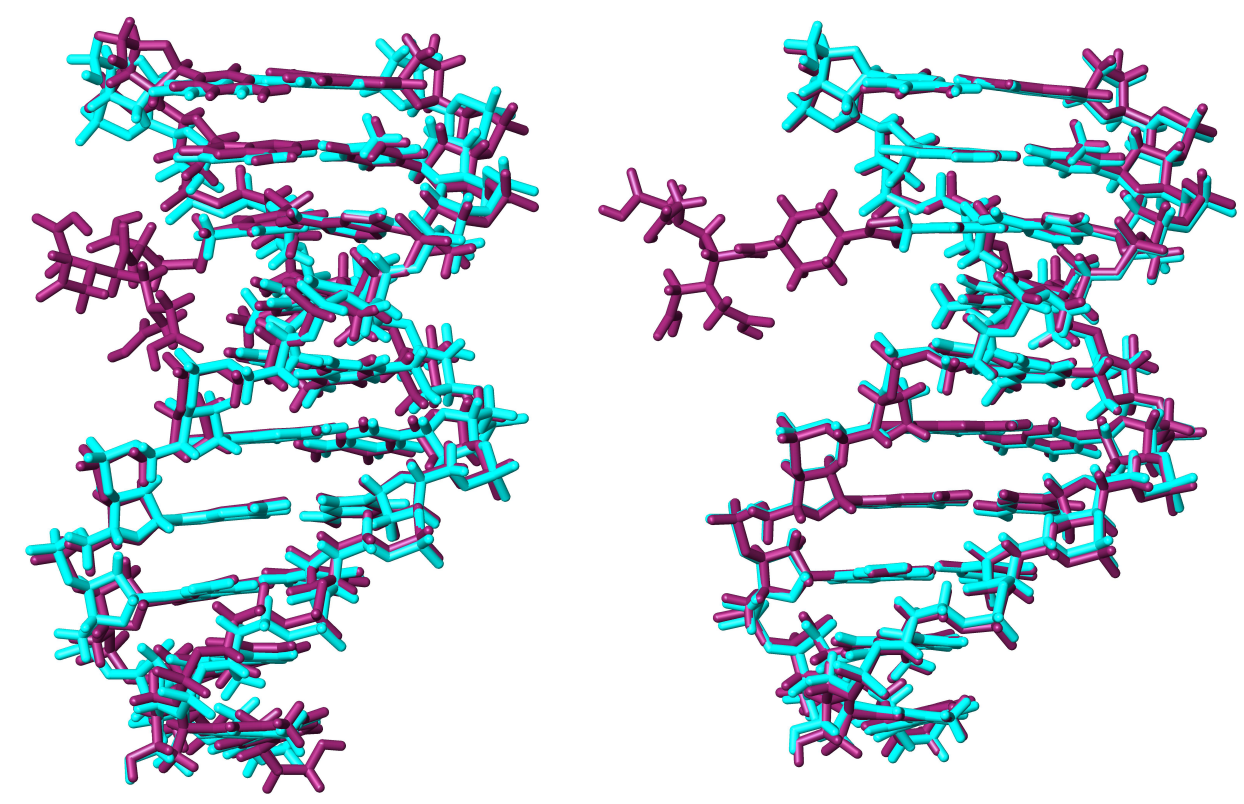

Abb. 4.11: Vergleich der energieoptimierten Struktur modifizierter DNAs (violett) mit der unmodifizierten Sequenz (türkis). Links ist die eine DNA mit DSE-Tag, rechts eine DNA mit TE-Tag dargestellt. Die verwendeten Macromodelparameter finden sich im Anhang. 
Eine etwas weniger starre Struktur, aber eine sehr effiziente Taggingreaktion bietet der DSETag. Besonders die Disulfidbrücke und die beiden benachbarten Methylengruppen sorgen für ein partielles Rotationspotential. Allerdings wird dies durch die kleine Struktur der Modifikation teilweise wieder ausgeglichen, denn die gesamte Modifizierung befindet sich innerhalb der großen Furche, was dazu führt, dass die Mobilitätsgrade vermindert werden (Abb. 4.11). Zudem existiert eine zusätzliche Säurefunktion, die potentiell als Ligand agieren kann und somit die Struktur des komplexierten Tags noch kompakter und starrer werden lässt. Leider ist es mit dem Programm Macromodel nicht möglich Lanthanoidionen (oder auch Übergangsmetallionen) in der Strukturberechnung zu berücksichtigen.

Den letzten Aspekt des Tagdesigns stellt das variable Anwendungspotential dar. Prinzipiell ist es möglich, sowohl die Clickreaktion als auch die Disulfidbindungsbildung an den unterschiedlichsten DNA-Sequenzen sowie an RNA durchzuführen. Letztere findet bereits Anwendung in der Modifizierung von Proteinen. Aber auch mit Hilfe der Clickchemie sollte das Tagging von Peptiden möglich werden. Des Weiteren bietet die Festphasensynthese von DNA die Möglichkeit bei einer Stranglänge von bis zu 60 Basen die modifizierte Base an jeder erdenklichen Stelle im Strang zu positionieren. Essentiell für die breite Verwendung sind die milden Reaktionsbedingungen der beiden Taggingreaktionen, die bei Raumtemperatur und in wässrigen Lösungen bei neutralem pH-Wert durchgeführt werden können. Zudem sind sie sehr spezifisch, so dass nur die modifizierten Basen mit dem entsprechenden Tag reagieren. Durch die zwei verschiedenen Taggingmethoden ist es möglich zwei verschiedene Tags sequenzspezifisch in ein Oligonukleotid einzubauen. 


\section{Kapitel 5}

\section{Synthese paramagnetisch markierter DNA}

Nukleinsäuren können auf biologischem und auf chemischem Wege synthetisiert werden. Beide Verfahren sind etabliert und finden Anwendung auf verschiedenen Gebieten. Die biologische Synthese findet mit Hilfe von Enzymen und einem sog. Templatstrang statt, der die komplementäre Basensequenz besitzt. Dabei bezeichnet man die Synthese von DNA mit Hilfe von DNA-Polymerasen als Replikation, die Synthese von RNA mit RNA-Polymerasen ausgehend von einem DNA-Template als Transkription. Durch biologische Synthese können besonders gut sehr lange Nukleinsäuresequenzen erhalten werden. Dazu wird eine Promotorregion am 5'-Ende des Stranges benötigt, die nach der Synthese noch entfernt werden muss [100,101]. Die verwendeten Enzyme tolerieren jedoch nicht jede Art der Nukleotidmodifizierung, somit ist der Einbau von nicht natürlichen Nukleotidtriphosphaten (NTPs) nicht immer möglich. Dabei gilt: je größer die Modifizierung, desto schwieriger ist der Einbau [102].

Die chemische Synthese hingegen erlaubt meist den Einbau von modifizierten Phoshoramiditen gegebenfalls mit entsprechenden Schutzgruppen, aber die Länge der zu synthetisierenden Nukleinsäuren ist begrenzt. Mit Standardmethoden sind DNAs mit bis zu 100 Nukleotiden 
und RNAs mit bis zu 60 Nukleotiden kommerziell erhältlich. Die häufigsten Isotope ${ }^{12} \mathrm{C}$ und ${ }^{14} \mathrm{~N}$ sind keine Spin-1/2-Kerne, und somit nicht bzw. nicht gut geeignet für NMR-Messungen. Um eine bessere Sensitivität zu erhalten werden deshalb häufig gelabelte Proben zu NMRUntersuchungen verwendet. Gelabelte NTPs können aus Bakterienkulturen isoliert werden, die in gelabelten Medien gezüchtet werden. Der Einbau gelabelter NTPs via Transkription wird deshalb häufig angewandt [103]. Die gelabelten Phosphoramidite sind nicht so leicht zugänglich. Prinzipiell können sie aus den gelabelten NTPs, NDPs und NMPs synthetisiert werden. Diese Methode ist aber sehr ineffizient, v. a. auch weil bei jeder Festphasenkopplung ein großer Überschuss an Phosphoramidit benötigt wird (etwa 20 Äquivalente).

\subsection{Festphasensynthese}

Die einfachste Methode basenmodifizierte DNA zu erhalten besteht in der Synthese entsprechender Phosphoramidite und ihrem anschließenden Einbau in die DNA. Die Festphasensynthese ist eine sehr effiziente Art kettenförmige Biomoleküle zu produzieren. Dabei wird der erste Molekülbaustein über einen Linker mit dem Feststoffträger verbunden. Anschließend wird je ein weiterer Baustein an den Grundbaustein gekuppelt, dabei wird mit Überschuss an löslichen Reagenzien gearbeitet, die nach vollendeter Reaktion durch Waschen mit Lösungsmitteln entfernt werden. Durch optimierte Verfahren erreicht man sehr hohe Kupplungsausbeuten $(>98 \%$ ) bei sehr kurzen Kupplungszeiten (wenige Minuten). Eventuelle Reste unverlängerter Moleküle werden durch das capping aus dem Zyklus entfernt. Dabei wird die freie reaktive Gruppe mit einer Schutzgruppe versehen, bevor eine weitere Kupplung erfolgt. Nach dem Ablauf der Synthese wird das kettenförmige Molekül vom Träger abgespalten und anschließend noch chromatographisch gereinigt. Nach diesem Prinzip erfolgt die Synthese kettenförmiger Moleküle wie DNA, RNA und Peptide. Dabei ist zu beachten, dass die einzelnen Kupplungsausbeuten sehr hoch sein müssen, um eine hohe Gesamtausbeute zu erhalten. Bei einer Synthese von einem Decamer macht eine Kupplungsausbeutenreduzierung von 98 auf $97 \%$ bereits einen Unterschied in der Gesamtausbeute von 82 auf $74 \%$ aus. 


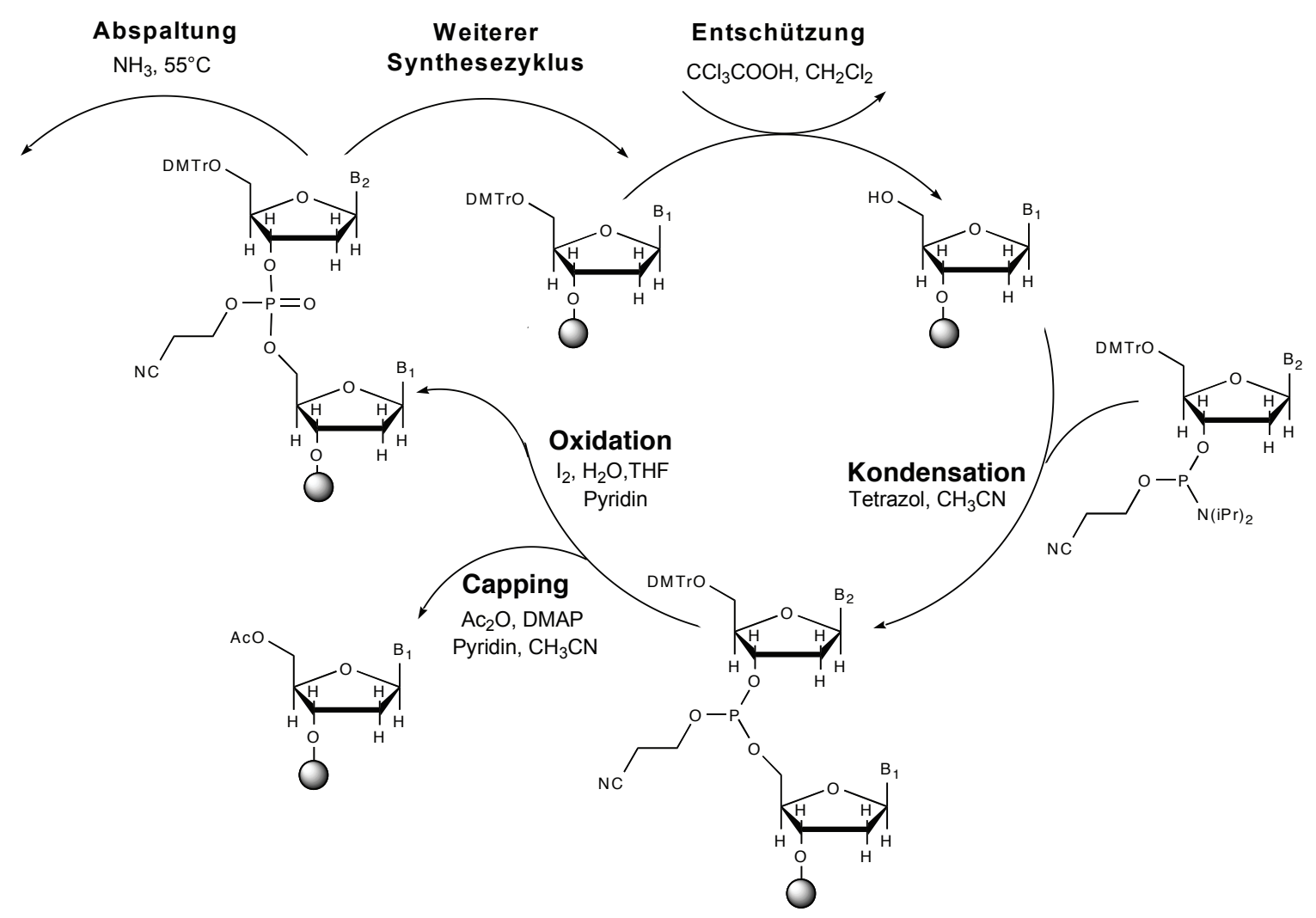

Abb. 5.1: Der Synthesezyklus der sogenannten Phosphoramiditmethode entworfen von R. Letsinger und M. Caruthers

Der Synthesezyklus der DNA ist in Abb. 5.1 dargestellt. Im ersten Schritt wird die 5'Dimethoxytrityl-Schutzgruppe (DMTr) der wachsenden Oligonukleotidkette sauer abgespalten. Anschließend kann die freigewordene 5'-Hydroxylgruppe an das 3'-Phosphoramidit des nächsten Bausteins kuppeln. Tetrazol protoniert dabei die Isopropylgruppe des Phosphoramidits und greift dann das Phosphoramidit unter Abspaltung von Diisopropylamin an. Das intermediär entstandene Tetrazolid reagiert dann mit der 5'-Hydroxylgruppe zum Phosphittriester. Beim capping, dem dritten Schritt, werden alle 5'-Hydroxylgruppen, die bei der Kupplung nicht reagiert haben, durch Acetylierung inaktiviert und so aus dem Synthesezyklus entfernt. Der bei der Kupplungsreaktion entstandene Phosphittriester wird im vierten Schritt zum Phosphotriester oxidiert, dazu wird als mildes Oxidationsmittel Iod genutzt. Dabei entsteht das um einen Baustein verlängerte Oligonukleotid, das erneut den Synthesezyklus durchlaufen kann. 


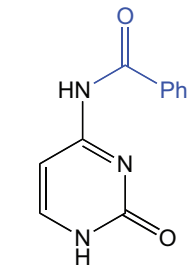

Cytosin mit Benzoylschutzgruppe

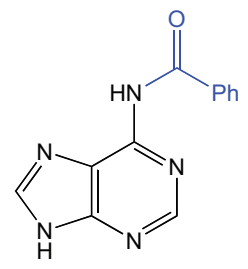

Adenin mit Benzoylschutzgruppe<smiles>CC(C)C(=O)Nc1nc2[nH]cnc2c(=O)[nH]1</smiles>

Guanin mit

Isobutyrylschutzgruppe

Abb. 5.2: Basenlabile Aminoschutzgruppen.

Ist die gewünschte Kettenlänge erreicht, spaltet man das Oligonukleotid mit konzentriertem Ammoniak $\left(55^{\circ} \mathrm{C}, 16 \mathrm{~h}\right)$ von der Festphase ab. Dabei werden auch die Aminoschutzgruppen der Basen (Abb. 5.2) entfernt und man erhält die so genannte DMTr-on DNA, die sich per reversed phase HPLC leicht aufarbeiten lässt. In einem letzten Schritt wird die DMTrSchutzgruppe noch sauer abgespalten und beispielsweise durch Waschen der wässrigen Phase mit Diethylether entfernt. Der Verlauf der Festphasensynthese kann auf der Stufe der sauren Abspaltung der DMTr-Schutzgruppe kontrolliert werden. Die Effizienz der Kopplung korreliert dabei mit der Menge des freiwerdenden DMTr-Kations, die mittels UV-Absorption bei $494 \mathrm{~nm}$ bestimmt wird.

\subsection{Methoden zur Modifizierung von DNA-Basen}

Die Modifizierung von DNA kann auf zwei prinzipiell verschiedenen Wegen erfolgen. Einerseits kann die gewünschte Modifizierung direkt an das entsprechende Phosphoramidit gekuppelt sein, das anschließend in einer Festphasensynthese als ein Baustein verwendet wird. Andererseits kann ein Linker an ein Phosphoramidit angebracht werden, der nach der Festphasensynthese zur Anbringung der eigentlichen Modifizierung verwendet werden kann.

In dieser Arbeit wurde anfangs die erste Methode verwendet, die jedoch nicht das gewünschte Ergebnis lieferte. Anschließend wurde deshalb die zweite postsynthetische Modifizierungsmethode angewandt, darunter verschiedene Konzepte, wie Sonogashira-Reaktion, Click-Reaktion 
und Disulfidbrücken. Die beiden letzteren Herangehensweisen lieferten die gewünschten chelatisierenden Oligonukleotide. Im Folgenden wird auf die verschiedenen Ansätze näher eingegangen.

\subsection{Synthese eines EDTA-funktionalisierten Phospho- ramidits}

Ein EDTA-funktionalisiertes Phosphoramidit besteht aus drei Bausteinen, dem Nukleosid, dem Linker und der EDTA-Funktion. Die EDTA-Funktion wurde in diesem Teil der Arbeit sequenziell auf den Linker aufgebaut und anschließend mit dem Nukleosid verbunden.

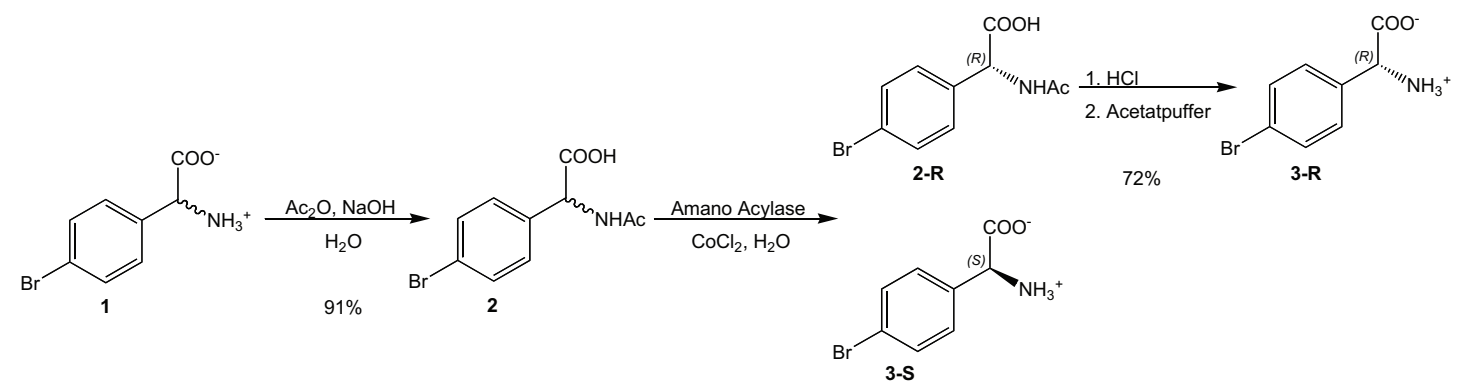

Abb. 5.3: Enantiomeren selektive Synthese von $(R / S)$-(4-Bromphenyl)-glycin.

Ausgegangen wurde dabei von racemischen (4-Bromphenyl)-glycin, das acetyliert wurde, um es danach mit Hilfe des Enzyms Amano Acylase in ( $R$ )- $N$-Acetyl-(4-bromphenyl)-gycin und $(S)$-(4-Bromphenyl)-glycin enzymatisch zu spalten. Um ee-Werte von $>98 \%$ für beide Enantiomere zu erhalten, wurden zwei unterschiedliche Reaktionsbedingungen zur Synthese des $S$ - und des $R$-Enantiomers entwickelt. Details zu diesen Synthesen finden sich in $[31,104]$.

Die Synthese des $S$ - und des $R$-Enantiomers verläuft ab Verbindung 3 analog. In Abb. 5.4 ist exemplarisch die Synthese der S-EDTA-Verbindung dargestellt. Dabei wurde das 


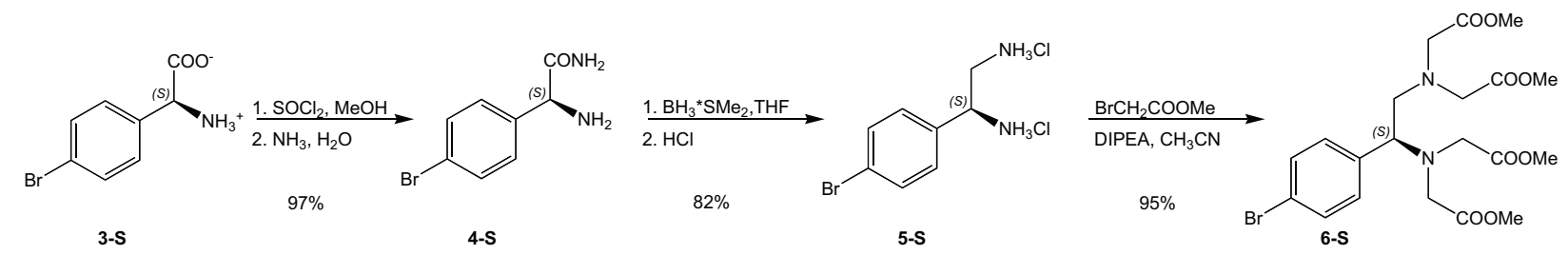

Abb. 5.4: Aufbau der EDTA-Funktion.

(4-Bromphenyl)-glycin erst als Methylester aktiviert, um dann mit Ammoniak zum Amid umgewandelt zu werden. Anschließend wurde das Amid unter milden Bedingungen mit Boran zum Amin reduziert unter Erhalt des Bromids am Phenylring. Eine Alkylierung mit Bromessigsäuremethylester ergab die gewünschte EDTA-Funktion als Tetramethylester. Die Methylesterschutzgruppen werden sowohl für die folgende Sonogashira-Reaktion als auch bei der DNA-Festphasensynthese benötigt und erst beim Abspalten der DNA von der Festphase mit Natronlauge entfernt.
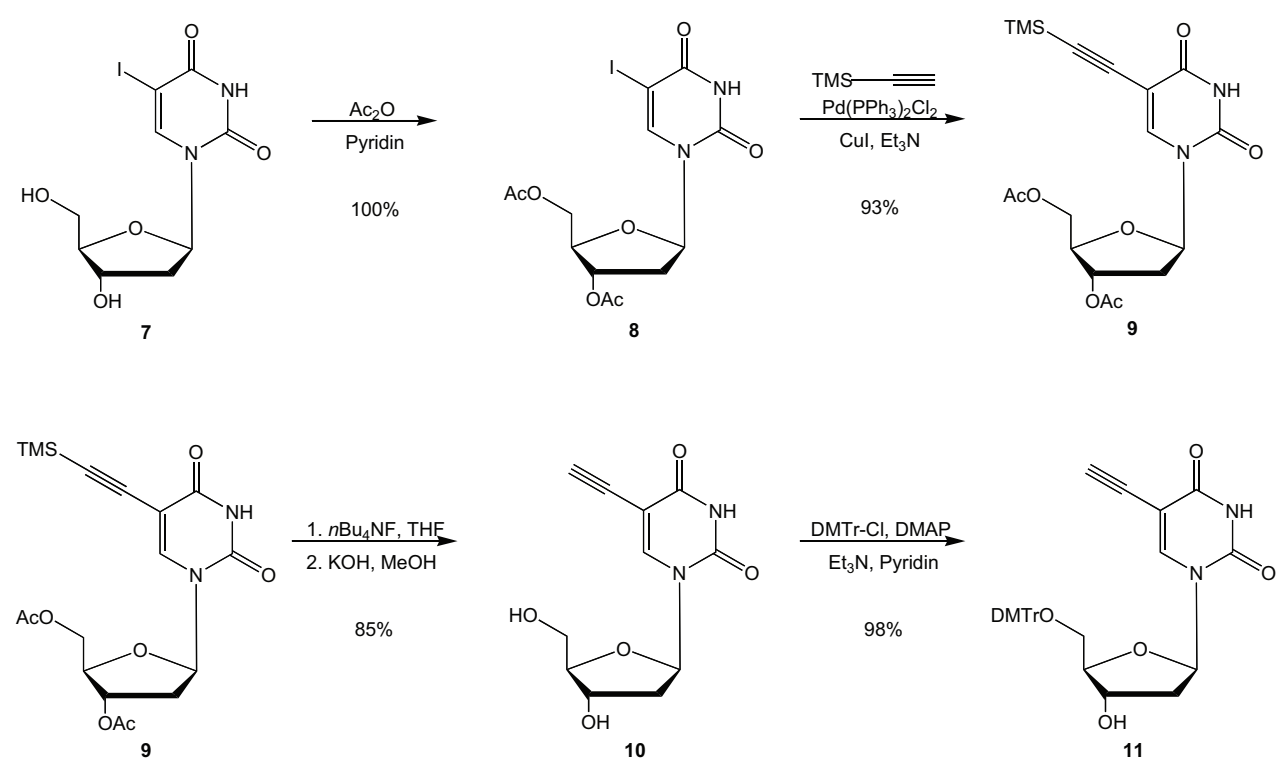

Abb. 5.5: Aufbau des 5-Ethinyl-2'-desoxyuridins.

Der Nukleosidbaustein wurde anhand der folgenden fünfstufigen Synthese mit 77\% Ausbeute hergestellt, dabei wurde das 5-Iod-2'-desoxyuridin erst an 3'- und 5'-Position acetyliert und danach über eine Sonogashira-Reaktion zum diacetylierten 5-Trimethylsilylethinyl-2'- 
desoxyuridin umgewandelt. Anschließend wurde das Ethin mit Fluorid entschützt und die Acetylschutzgruppen abgespalten (Abb. 5.5). Zuletzt wurde das 5-Ethinyl-2'-desoxyuridin an der 5'-Position mit der Dimethoxytritylgruppe geschützt, die für die DNA-Festphasensynthese benötigt wird.

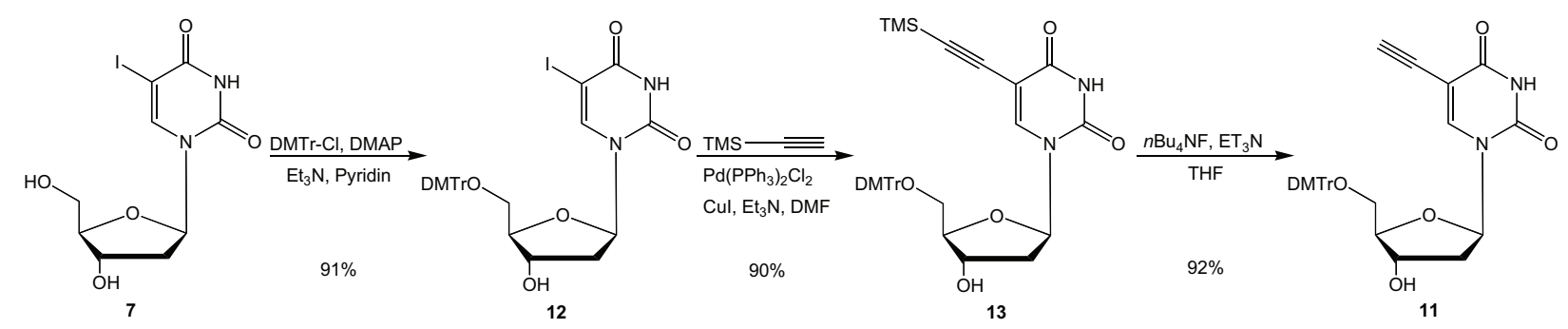

Abb. 5.6: Verkürzte Synthese des 5-Ethinyl-2'-desoxyuridins.

Die Synthese des 5-Ethinyl-3'-dimethoxytrityl-2'-desoxyuridins wurde im Laufe der Arbeit umgestellt auf eine nur dreistufige Synthese (Abb. 5.6). Das 5-Iod-2'-desoxyuridin wurde dabei sofort mit Dimethoxytrityl geschützt und anschließend in einer Sonogashira-Reaktion umgesetzt, dann wurde die Trimethylsilylschutzgruppe mit Fluorid in Anwesenheit von Triethylamin abgespalten. Die Ausbeute betrug dabei $75 \%$.

Im letzten Teil der Synthese wurden der EDTA-Baustein und das Nukleosid über eine Palladium-katalysierte Kreuzkupplung verbunden. Für diese Sonogashira-Reaktion am Bromid benötigte man einen speziellen, sehr reaktiven Palladiumkatalysator, der sich in situ aus dem Palladiumsalz und Tri-tert-butylphosphoniumtetrafluoroborat bildet. Anschließend wird mit Hilfe von 2-Cyanoethyl- $N, N$-diisopropylchlorophosphoramidit das Phosphoramidit gebildet (Abb. 5.7). Dies wurde bei verschiedenen Firmen (Biospring, IBA) und am MPI für experimentelle Medizin bei der Festphasensynthese eingesetzt, erzielte aber nur sehr geringe Kupplungsausbeuten ( $<15 \%$ DMTr-Assay). Dabei war zu beachten, dass unter Standardbedingungen die Abspaltung mit konzentriertem Ammoniak zu Ethylendiamintetraethylamid führt, und somit statt dessen als Abspaltungsbedingung 0.4 M NaOH in Methanol/Wasser $=5 / 1$ genutzt wurde. 


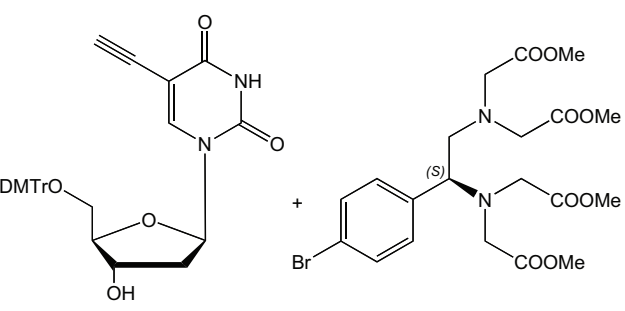

11

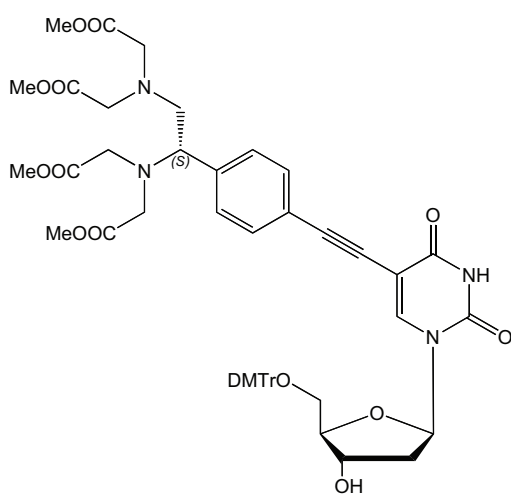

14-S
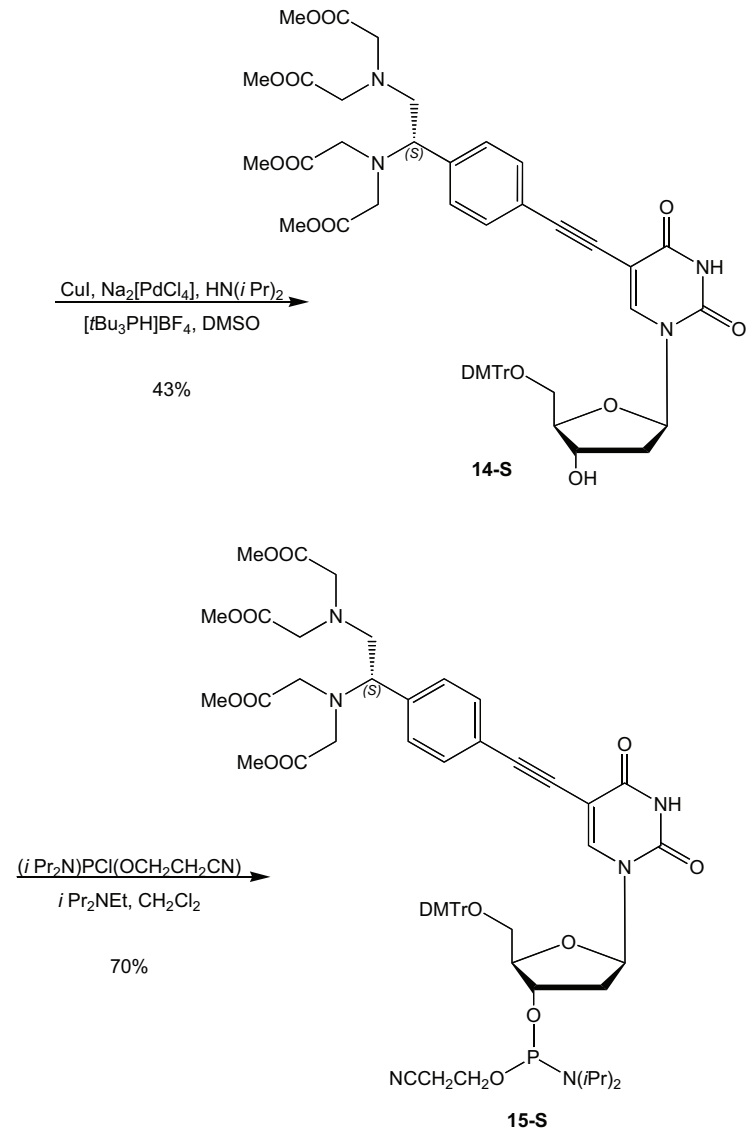

Abb. 5.7: Synthese des Phosphoramidits.

Da auch die Kupplungsausbeuten der Phosphoramidite im Anschluss an das modifizierte Nukleotid stark abgesunken waren, stellte sich diese Methode zur Synthese getaggter DNA als unpraktikabel heraus, besonders weil für die NMR-Spektroskopie sehr reine Proben aus mindestens 100 nmol Oligomer benötigt werden. 


\subsection{Sonogashira-Reaktionen an DNA}

In den letzten Jahren wurden verstärkt Reaktionen an festphasengebundenen Molekülen durchgeführt, da sie eine leichtere Trennung von den Reaktanden und Lösungsmitteln ermöglichen als herkömmliche Ein-Phasen-Reaktionen. Besonders zur Synthese von Biomolekülen wie Peptiden oder DNA wird eine solche Synthesetaktik bevorzugt, da nur so sehr hohe Ausbeuten erreicht werden können. Darüber hinaus können durch Festphasenreaktionen postsynthetische Modifikationen der Biomoleküle erreicht werden. 1999 entwickelten Grinstaff et al. eine Palladium(0)katalysierte Sonogashira-Reaktion an festphasengebundener DNA [105]. Das Schema ist in Abb. 5.8 dargestellt. Diese Reaktion wurde in den folgenden Jahren weiter entwickelt und $\mathrm{u}$. a. von Prof.

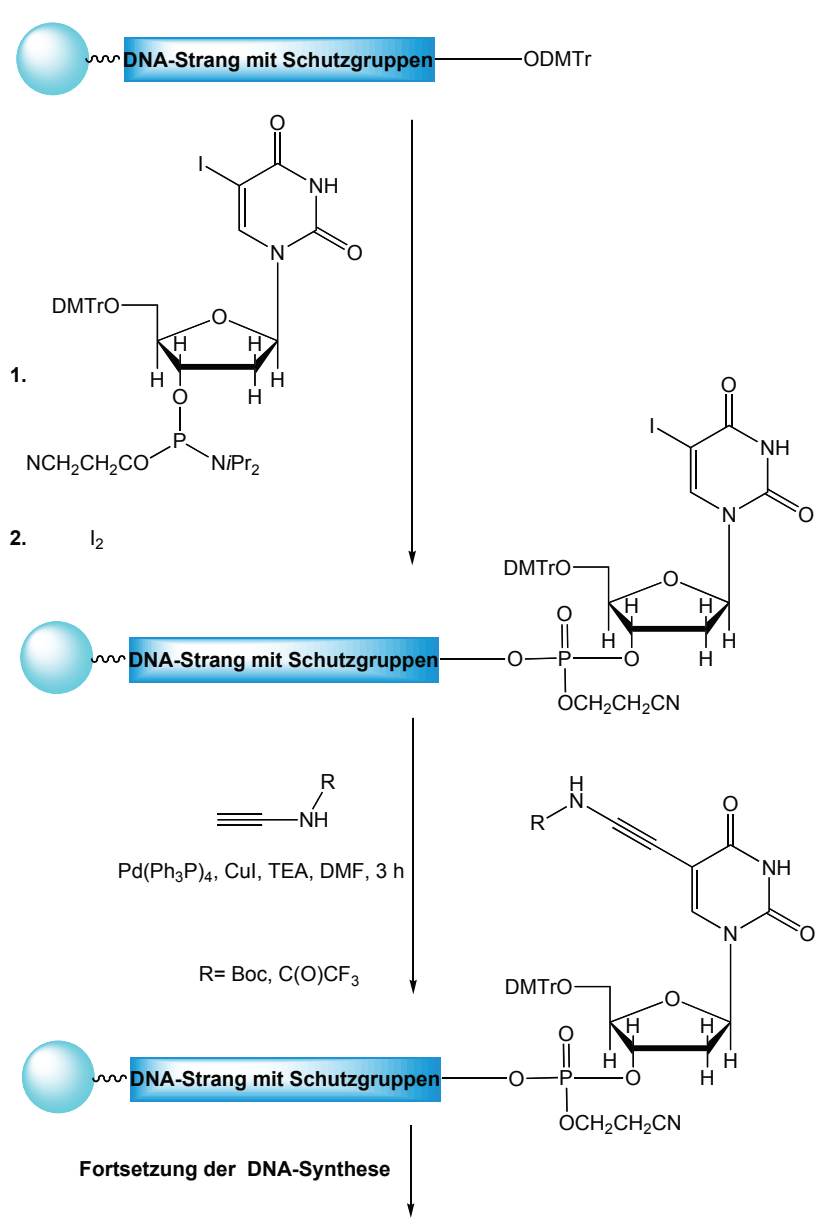

Abb. 5.8: Übersicht zur $\operatorname{Pd}(0)$-katalysierten Reaktion nach Grinstaff.

Liebscher und Prof. Wagenknecht zur Synthese lipidmodifizierter und photoaktiver Oligonukleotide genutzt $[106,107]$. Um eine mögliche Nebenreaktion auszuschließen, die GlaserKupplung (Abb. 5.9) - eine Kupfer(I)-katalysierte, oxidative Dimerisierung von terminalen Alkinen zu Bisacetylenen - müssen die Reaktionen unter Abwesenheit von Sauerstoff durchgeführt werden [108].

Zur EDTA-Modifizierung von DNA per Sonogashira-Reaktion an der Festphase wurden zwei Strategien getestet. Zum ersten wurde 5-Iod-2'-desoxyuridin in die DNA-Sequenz einge- 


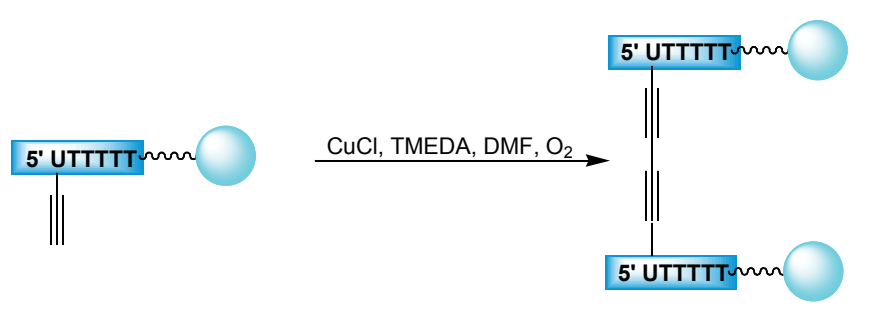

Abb. 5.9: Übersicht zur Glaser-Kupplung.

baut, um es mit chelatisierenden Ethinderivaten zu kuppeln. Zum zweiten wurde 5-Ethinyl2'-desoxyuridin in die DNA eingebaut, um es mit chelatisierenden Bromiden zu kuppeln (Abb. 5.11). Für ersteren Ansatz wurden das oben erwähnten Bromid 6 per SonogashiraReaktion mit dem speziellen Katalysator, der sich in situ aus dem Palladiumsalz und Tritert-butylphosphoniumtetrafluoroborat bildet, und Trimethylsilylethin in das entsprechende Ethinderivat 16 überführt (Abb. 5.10). Anschließend wurde 16 mit Tetra- $n$-Butylammoniumfluorid in Acetonitril entschützt.

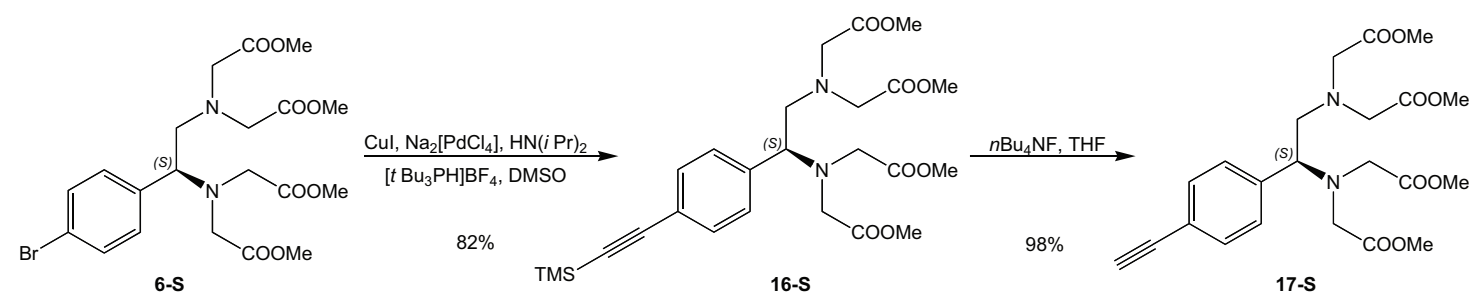

Abb. 5.10: Synthese der chelatisierenden Bausteine mit Ethinfunktion.

Die Sonogashira-Kreuzkupplung wurde unter verschiedenen Bedingungen durchgeführt. Dazu wurden verschiedene Palladiumkatalysatoren gewählt, unterschiedliche Lösungsmittel, Reaktionstemperaturen und Reaktionszeiten getestet, auch mit Mehrfachkupplungen wurde gearbeitet, aber die Reaktion lieferte keinen Umsatz. Sowohl die Reaktion an dem iodierten Dodecamer als auch an dem ethinylierten Dodecamer waren wohl sterisch zu anspruchsvoll. In der Literatur werden meist flexiblere Modifizierungen durch Sonogashira-Reaktionen an Oligonukleotide geknüpft [106,109]. Das Phosphoramidit des 5-Iod-2'-desoxyuridins und des 5-Ethin-2'-desoxyuridins wurde analog zu den anderen Phosphoramiditen hergestellt. 


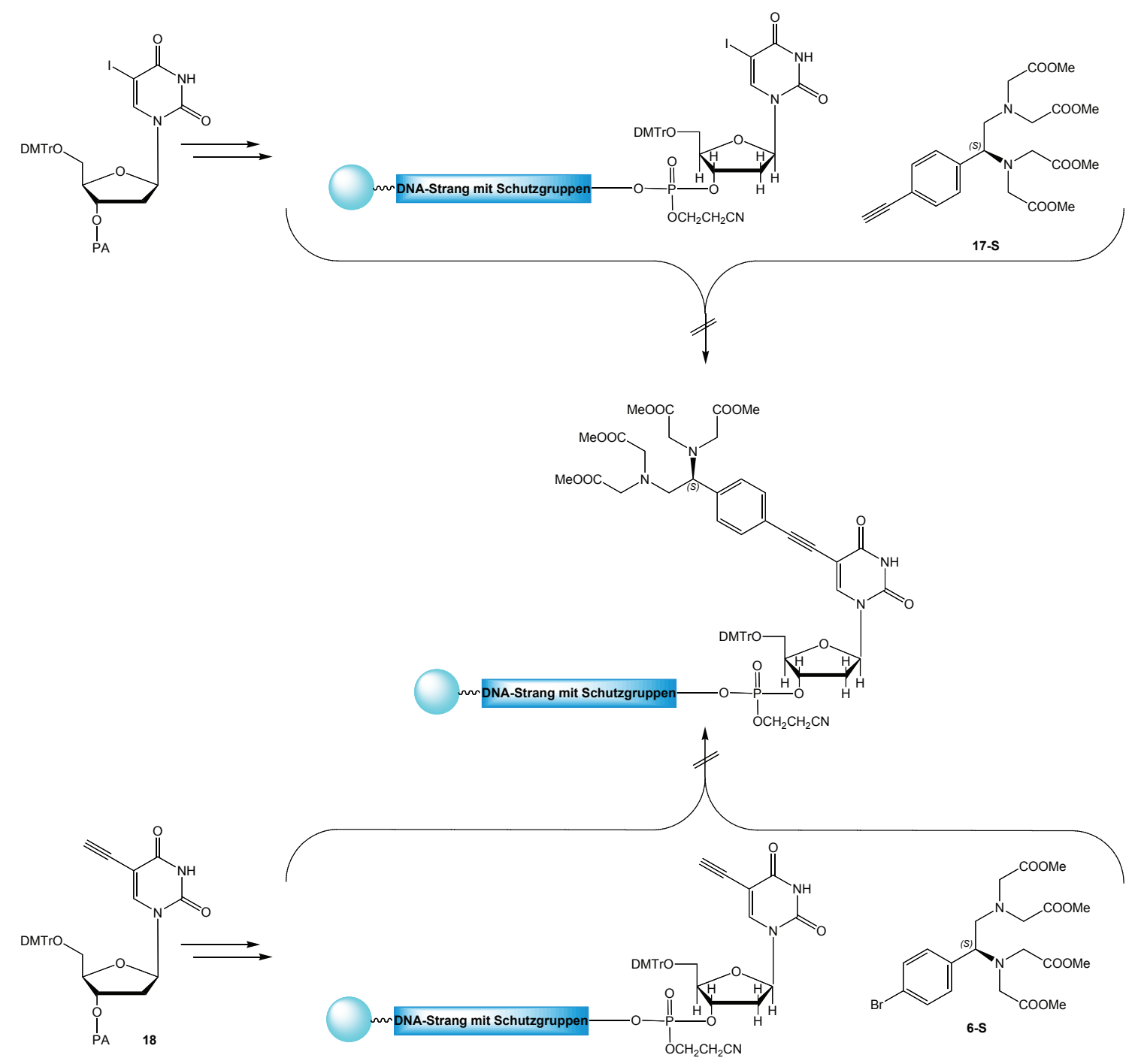

Abb. 5.11: Sonogashira-Reaktionen an festphasengebundener DNA.

\subsection{Clickchemie}

\subsubsection{Allgemeines}

Die Clickreaktionen sind nahezu perfekt ablaufende chemische Reaktionen. Entwickelt wurden sie von Sharpless, um eine große Vielfalt an chemischen Verbindungen möglichst einfach zugänglich zu machen [15]. In Abb. 5.12 sind einige dieser in wässriger Lösung ablaufenden exothermen Reaktionen dargestellt. Ungesättigte Kohlenstoffverbindungen stellen dabei 

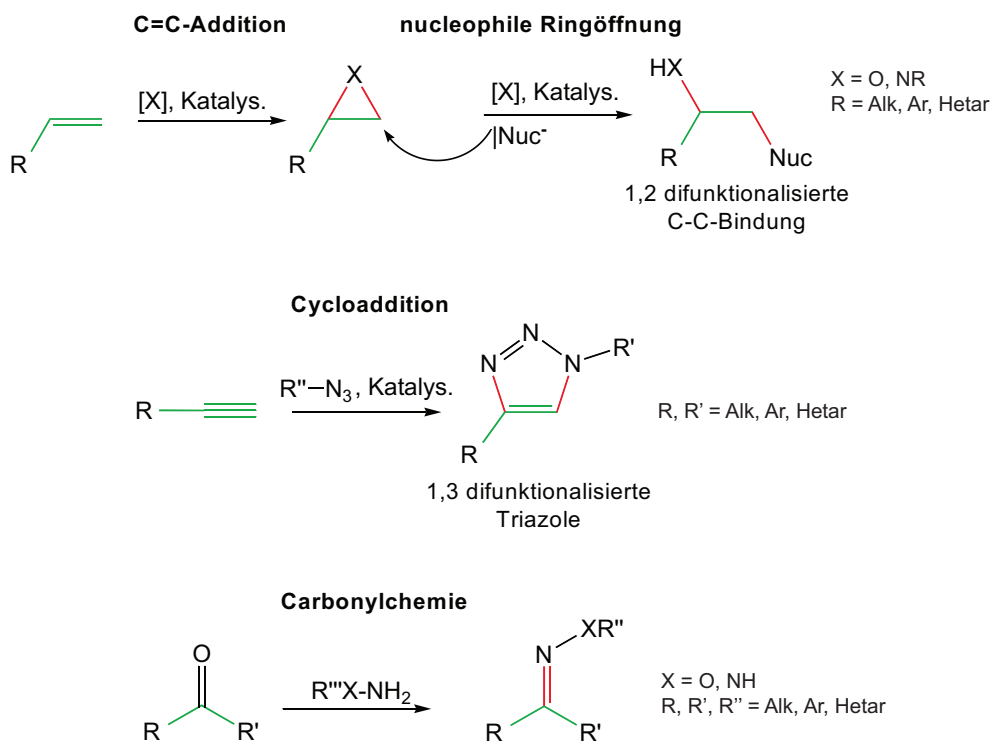

z.B. Hydrazon, Oxim

Abb. 5.12: Übersicht zu verschiedenen Clickreaktionen nach Sharpless. rot: neu geknüpfte Bindungen, grün: Kohlenstoffgrundgerüst.

das Kohlenstoffgrundgerüst dar, das durch neu geknüpfte Kohlenstoff-Heteroatombindungen verändert wird.

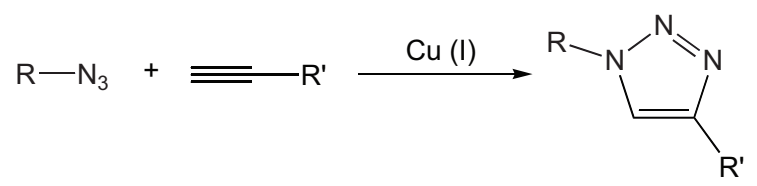

Abb. 5.13: Huisgen 1,3-dipolare Cycloaddition.

Die gängigste Clickreaktion ist eine Huisgen 1,3-dipolare Cycloaddition, die von Kupfer (I) katalysiert wird. Dabei reagiert ein organisches Azid mit einem Ethin zu einem Triazol (Abb. 5.13). Dies ist die zurzeit effektivste Clickreaktion $[15,16]$. Diese Cycloaddition hat in den letzten Jahren eine weite Verbreitung erreicht, da sie kaum Nebenreaktionen aufweist und damit hohe Ausbeuten liefert. Zudem ist sie mit vielen funktionellen Gruppen kompatibel und verläuft unter sehr milden Bedingungen. Des Weiteren ist sie in wässrigen Lösungen durchführbar, die auch besonders gut die große freiwerdende Reaktionswärme dieser stark exothermen Reaktion aufnehmen können. Diese verschiedenen Aspekte haben sie besonders für die Biochemie interessant gemacht. Es sind bereits viele Clickreaktionen an Peptiden und an Oligonukleotiden bekannt. Darüber hinaus findet die Clickchemie Verwendung in der 
Organometallchemie, so lassen sich Ethin-Rutheniumkomplexe beispielsweise mit Benzylazid modifizieren, ohne dass der Komplex zerstört wird [110].

Der von Fokin et al. vorgeschlagene Katalysezyklus der Clickreaktion ist in Abb. 5.14 dargestellt [111]. Die Aktivierung des Ethins erfolgt durch Angriff des Kupfer(I)ions am endständi-

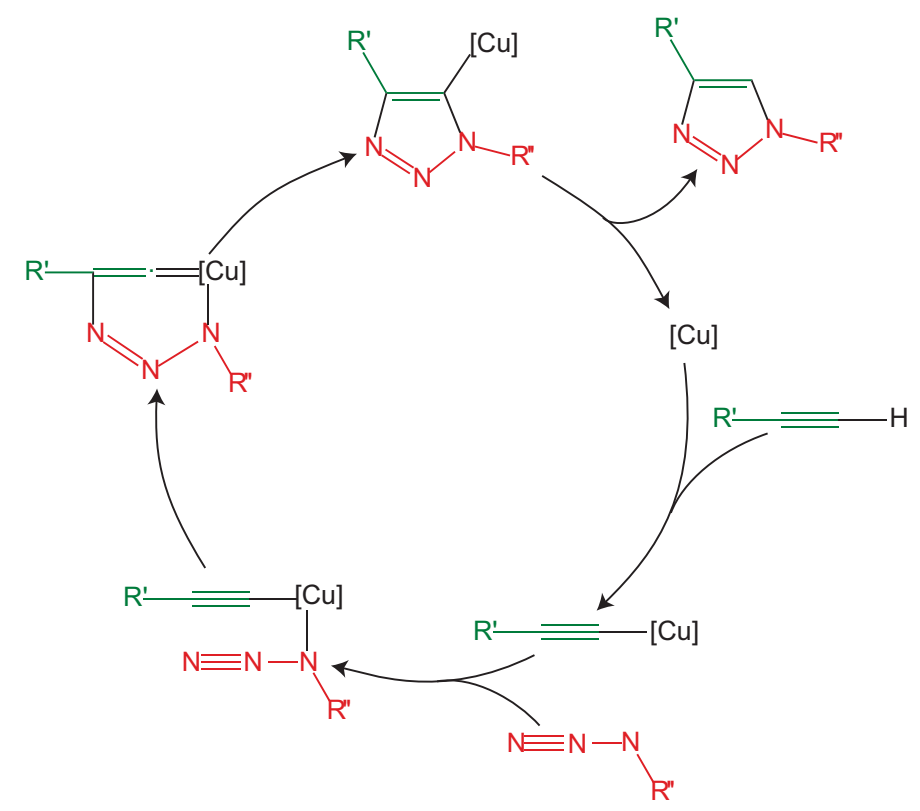

Abb. 5.14: Katalysezyklus der Huisgen 1,3- dipolaren Cycloaddition.

$[\mathrm{Cu}]=$ mono oder dinukleare Kupfer(I)komplexfragmente.

gen Ethin, das durch Basenzugabe deprotoniert ist. Der zweite Schritt des Katalysezyklus ist dabei der Ligandenaustausch des Kupfer(I)-Komplexes zu einem Kupferazidkomplex. Theoretisch ist dies ein schwach exothermer Vorgang, falls der Ligand Wasser oder Acetonitril ist. Im nächsten Schritt wird ein Kupfer(III)-Metallzyklus gebildet. Diese endotherme Reaktion besitzt eine sehr viel geringere Übergangsbarriere als die unkatalysierte HuisgenCycloaddition (ca. $15 \mathrm{kcal} / \mathrm{mol}$ statt $25 \mathrm{kcal} / \mathrm{mol}$ ) und bildet die Basis der Reaktionsbeschleunigung durch $\mathrm{Cu}(\mathrm{I})$-Zugabe. Im vierten Schritt wird der Ring zu einem TriazoloylKupferderivat kontrahiert, das im letzten Schritt durch Protolyse und Freisetzung des Katalysators zum gewünschten Triazol wird. In der Literatur wird diskutiert, ob die katalytisch aktive Spezies ein mononuklearer oder Dinuklearer-Kupfer(I)-Komplex ist [112]. Der neueste Artikel von Straub et al. 2007 liefert jedoch Indizien für einen mononuklearen Kupferkomplex. 


\subsubsection{Clickreaktionen an DNA}

In den letzten Jahren wurden verschiedene Azide an ethinylmodifizierte DNA gekuppelt [113116]. Beispielsweise erfolgte die Reaktion eines azidmodfizierten Farbstoffes an den Cowpea Mosaicvirus [116]. Dabei wurde Tristriazolylamin als Katalysatorzusatz eingesetzt, der die Reaktion beschleunigt und die Nebenreaktionen einschränkt. Von Carell et al. [114] wird die Reaktion von verschiedenen Aziden mit 5-Ethinyl-2'-desoxyuridin und 5-Octyldi-1",7"'-in-2'desoxyuridin beschrieben.

In der Literatur werden auch Clickreaktionen an Peptiden beschrieben. Besonders hervorzuheben sind dabei Clickreaktionen an Aminosäuren, die am Harz der Peptidfestphasensynthese gebunden sind $[117,118]$ und somit einen geringeren Aufwand bei der Aufarbeitung erfordern. Auch Clickreaktionen an der festphasengebundenen DNA sind wegen der leichteren Aufarbeitung wünschenswert. In dieser Arbeit bietet dies zudem den Vorteil, dass das freie EDTA-Derivat (ohne Methylesterschutzgruppen) als Clickedukt verwendet werden kann und die gebundenen Kupferionen anschließend mit wässriger EDTA-Lösung aus dem festphasengebundenen Komplex gewaschen werden können. Dadurch wird die spezielle Aufarbeitung mit Natronlauge anstelle von Ammoniak überflüssig und auch die Trennung von überschüssigem Azid und DNA kann durch Waschen der festphasengebunden DNA mit Acetonitril eingespart werden.

\subsubsection{Darstellung von DNA mit einem spin label}

Nachdem die Clickreaktionen an Monomeren 5-Ethinyl-2'-desoxyuridin mit verschiedenen Aziden gut verliefen, wurde als erstes DNA mit einem spin label als Modifizierung synthetisiert (Abb. 5.15). Spin label sind stabile radikalische Verbindungen, meist basierend auf dem Radikal TEMPO (2,2,6,6-Tetramethylpiperidinyloxyl), die an Biomoleküle gebunden werden. Ihr ungepaartes Elektron sorgt für die paramagnetische Relaxationsbeschleunigung (PRE). Die Einführung eines spin label stellte eine gute Testreaktion dar, da das zugehörige 
Azid relativ klein und flexibel ist und somit den bereits bekannten DNA-Clickreagenzien ähnelt.

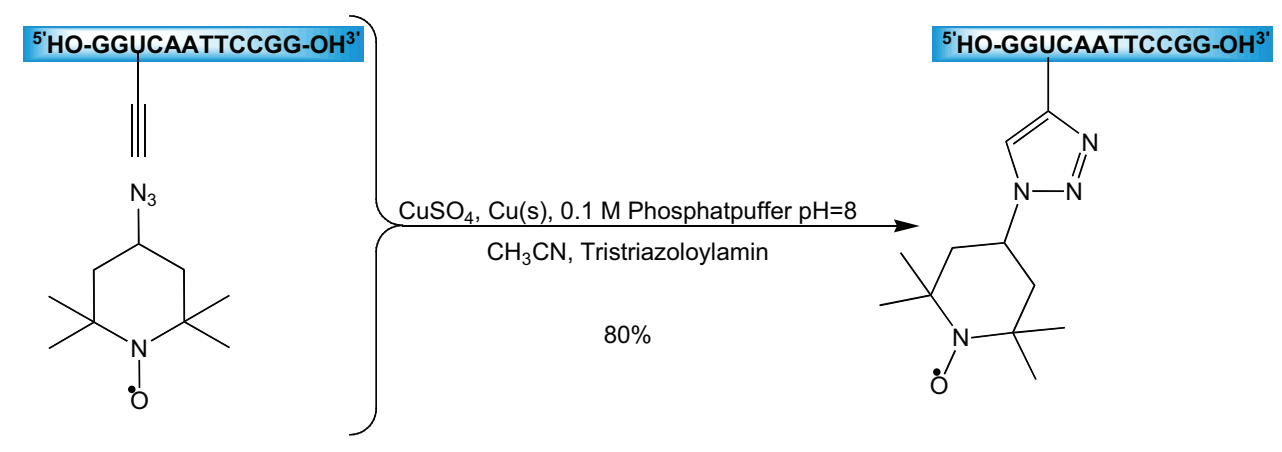

Abb. 5.15: Spin label-Einführung in DNA mittels Clickchemie.

Die Synthese dieser spin labeled DNA ist sehr effektiv und einfach. Bereits bekannte spin labeled DNAs wurden meist durch Festphasensynthese mit dem korrespondierenden Phosphoramidit synthetisiert. NMR-spektroskopisch werden derartige Oligonukleotide meist zur Untersuchung von Protein-DNA-Komplexen genutzt, insbesondere zur Lokalisierung von Bindungsstellen. Die Synthese des radikalischen Azides ist in Bushmakina et al. [119] beschrieben. In dieser Arbeit wurde ein spin label derart an die DNA gebunden, dass die Struktur der dsDNA kaum beeinflusst war. Damit ist es hervorragend für PRE-Messungen oder auch ESR-Messungen geeignet.

\subsubsection{Darstellung von DNA mit einem TE-Tag}

Eigentliches Ziel der Arbeit ist die Synthese von chelatisierenden Oligonukleotiden. Um die in Abschnitt 6.3 bereits hergestellten Verbindungen weiter nutzen zu können, wurde die Synthese von 5-Azidomethyl-2'-desoxyuridin geplant, allerdings stellte sich diese als nicht durchführbar heraus, da die Azidfunktion durch das Phosphoramidit reduziert wurde und somit diese beiden Gruppen nicht miteinander kompatibel sind. 


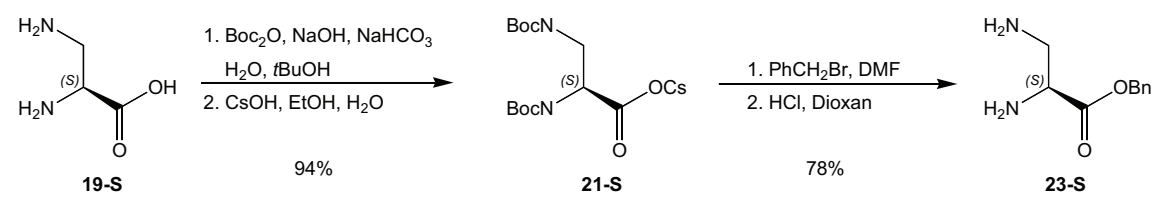

Abb. 5.16: Schema zur Synthese von Diaminopropionsäurebenzylester.

Im weiteren Verlauf dieses Projektes wurde deshalb ein EDTA-modifiziertes enantiomerenreines Azid synthetisiert, das eine Clickreaktion mit einer ethinfunktionalisierten DNA eingehen soll. Die Synthese wurde auf Basis von [120] entwickelt. Ausgegangen wurde dabei von Doder L-Diaminopropionsäure 19. Die Synthese der beiden Enantiomere erfolgte dabei analog. Nach einer Boc(tert-Butyloxycarbonyl)-Schützung der Aminogruppen wurde anschließend die Hydroxylfunktion über ein Cäsiumcarboxylat zum Benzylester geschützt. Dann wurden die Boc-Gruppen sauer abgespalten (Abb. 5.16).
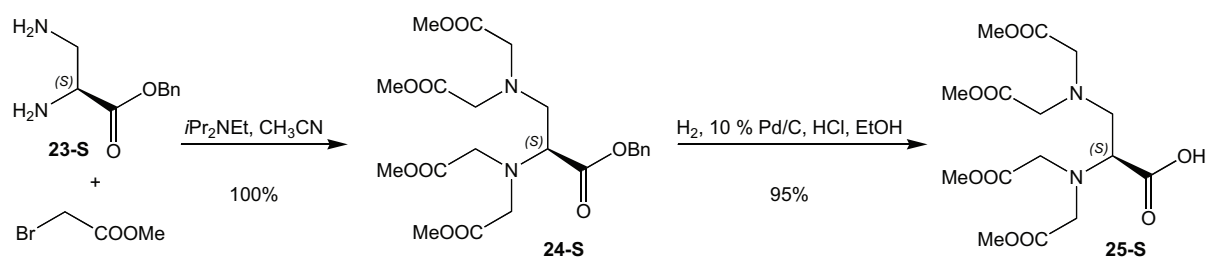

Abb. 5.17: Synthese des (S)-1- Carboxylethylendiamintetraessigsäuretetramethylesters

Danach wurde die Aminofunktion mit Bromessigsäuremethylester alkyliert (Abb. 5.17). Um 25-S zu erhalten wurde dann der Benzylester durch eine Hydrogenolyse unter PalladiumKatalyse entfernt. Die freie Carboxylgruppe wurde nun mit HATU (O-(7-Azabenzotriazol1-yl)- $N, N, N^{\prime}, N^{\prime}$-tetramethyluronium-Hexafluorophosphat) aktiviert und mit 4-Azidoanillin zum Amid 26-S umgesetzt (Abb. 5.18). So erhielt man ein EDTA-modifiziertes Azid, das in Clickreaktionen eingesetzt werden kann.
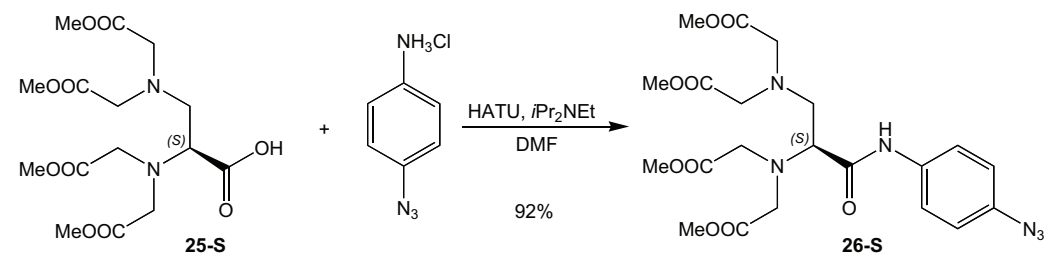

Abb. 5.18: Synthese des EDTA-modifizierten Azids. 
Die Reaktion von 26-S mit diacetyliertem 5-Ethinyl-2'-desoxyuridin verlief quantitativ zum gewünschten Clickprodukt, einem Thyminderivat mit TE-Tag. Aber die Reaktion an ethinmodifizierter DNA lieferte trotz mehrfacher Umsetzung und längeren Reaktionszeiten nur bis zu 10\% Ausbeute. Dabei waren die Retentionszeiten an HPLC-C18 Säulen identisch und Edukt- und Produkt-DNA konnten nur analytisch über eine Anionenaustauschersäule getrennt werden. Neben den in Abbildung 5.19 genannten Reaktionsbedingungen wurden noch viele weitere getestet, z. B. Temperaturen von 0 bis $50{ }^{\circ} \mathrm{C}$, die Nutzung von anderen Lösungsmitteln wie DMSO und tert-Butanol anstelle von Acetonitril, die Nutzung von Triethylammoniumacetatpuffer $(0.1 \mathrm{M}, \mathrm{pH}=7)$ anstatt des Phosphatpuffers und verschiedene Kupfer(I)katalysatorsysteme wie $\mathrm{Cu}(\mathrm{I}) \mathrm{Br}, \mathrm{CuSO}_{4} / \mathrm{Cu}$ (nanosize).

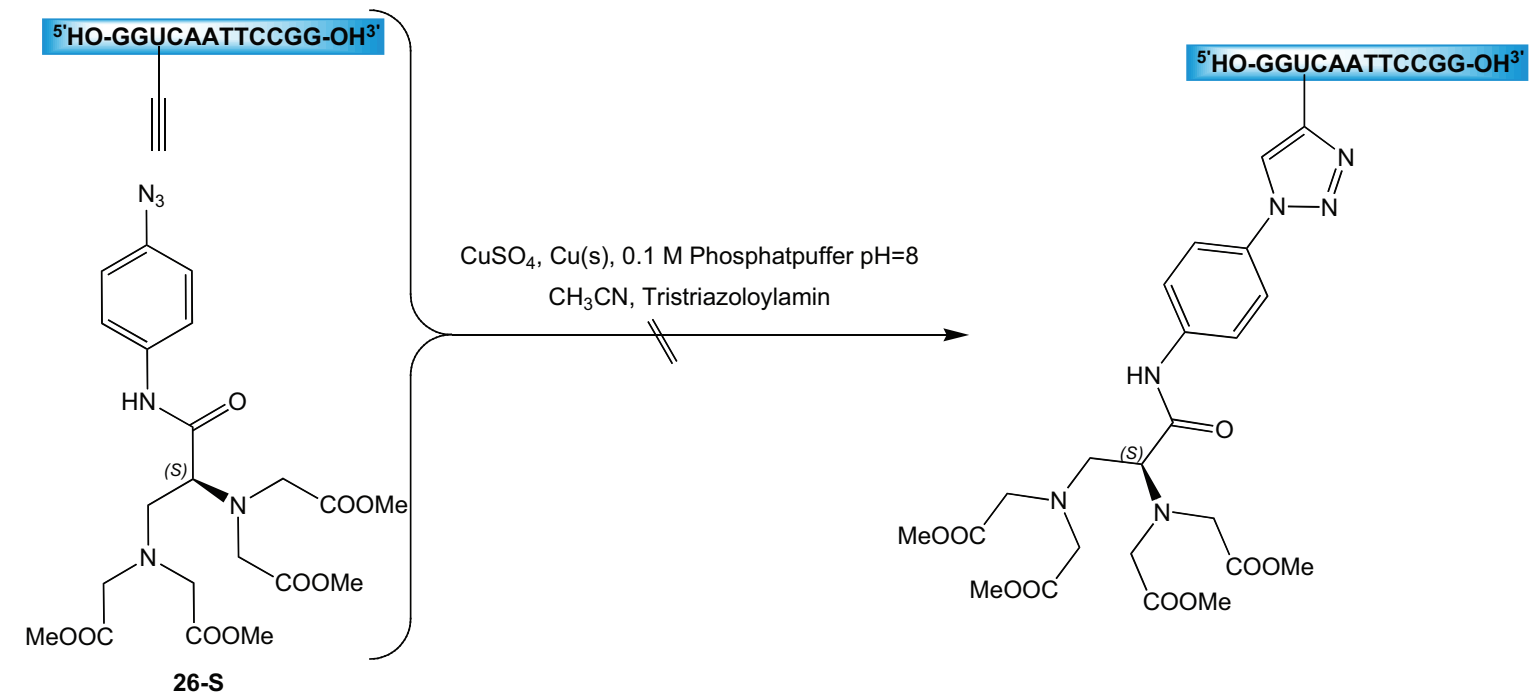

Abb. 5.19: Synthese einer DNA mit TE-Tag.

\subsubsection{Darstellung von EDTA-modifizierten DNA mit einem zykli- schen Alkylazid}

Azide, die an ein aromatisches System gebunden sind, werden mesomeriestabilisiert und sind demzufolge weniger reaktiv als Alkylazide. Aus diesem Grund wurde ein EDTA-modifiziertes Azid synthetisiert, das anstelle des Phenylringes einen trans-substituierten Cyclohexanring aufweist. Die trans-Substitution ist wichtig für die Rigidität der Ausgangsverbindung. Trans1,4-substituierte Cyclohexanringe bilden stets eine stabile Sesselkonformation aus, mit beiden 
Substituenten in äquatorialer Stellung. Bei cis-substituierten Cyclohexanen muss ein Substituent in äquatorialer und der andere in axialer Position liegen. Dies führt energetisch zu einer nicht so stabilen Konformation.

cis-4-Aminocyclohexanol wurde in einem ersten Schritt Boc geschützt und dann als Mesylat aktiviert. Durch Umsetzung mit Natriumazid erfolgte eine $\mathrm{S}_{N}$ 2-Reaktion, deren Stereospezifität chromatographisch kontrolliert wurde. Dazu wurde analog zur trans-Verbindung die cis-Verbindung aus trans-4-Aminocyclohexanol hergestellt (Abb. 5.20).

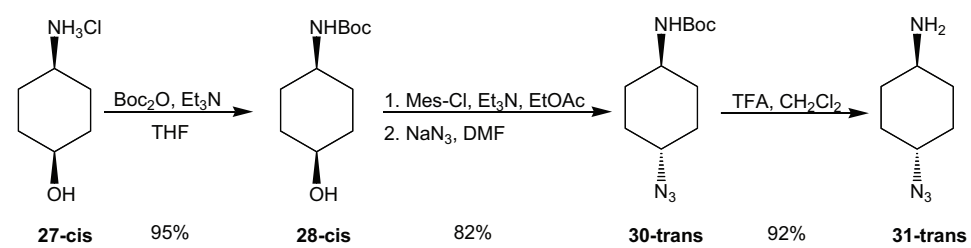

Abb. 5.20: Synthese des trans-4-Aminocyclohexylazid.

31-trans und 31-cis haben als Diastereomere verschiedene Retentionszeiten an HPLC-C18Säulen. In Abb. 5.21 sind die LC-MS-Chromatogramme der cis- und trans-Verbindung und eines Gemisches der beiden abgebildet. Analog zum Azidoanilin, kann 31-trans an die Carboxylfunktion von 25-S gekuppelt werden (Abb. 5.22).

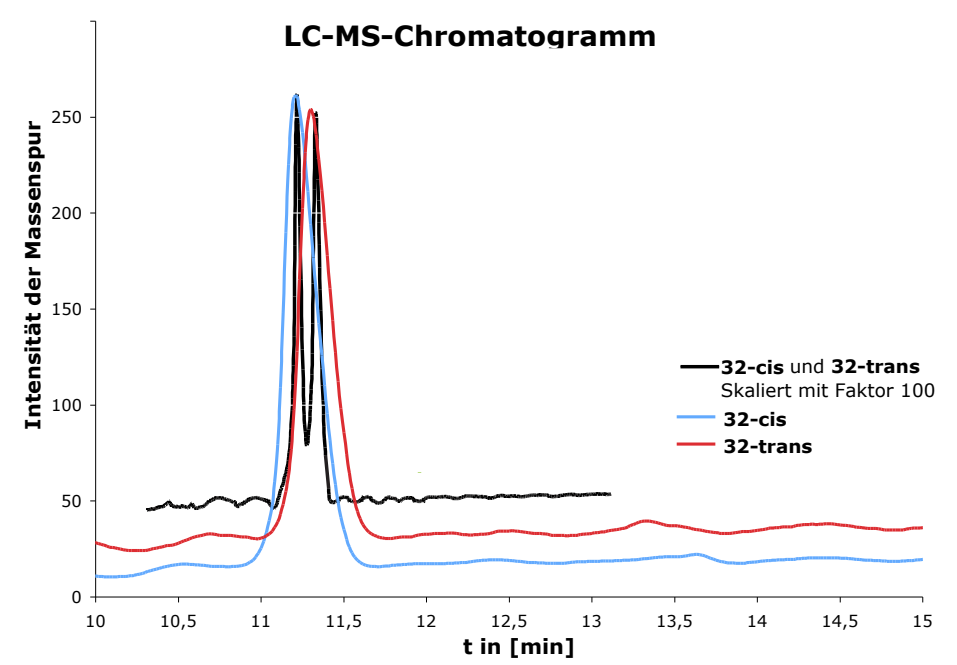

Abb. 5.21: LC-MS-Chromatogramm zur Untersuchung der Stereoselektivität der $\mathrm{S}_{N} 2$-Reaktion (Gradient: 0-25\% in 25 min mit $0.1 \mathrm{M}$ Triethylammoniumacetatpuffer $\mathrm{pH}=7$ gegen Acetonitril). 


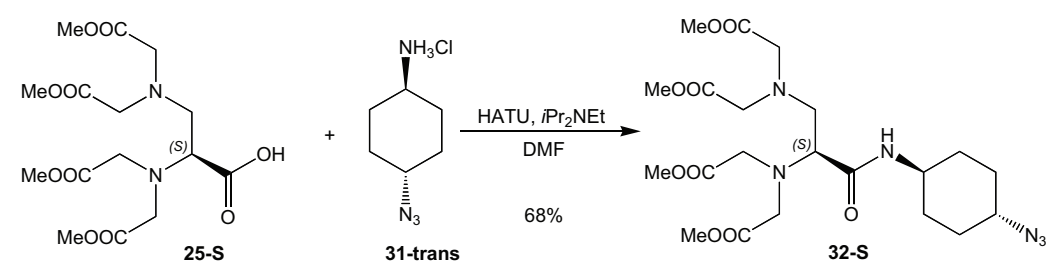

Abb. 5.22: Synthese des EDTA-modifizierten Alkylazides.

Clickreaktionen an ein DNA-Dodecamer mit einem eingebauten Ethindesoxyuridin an drittletzter Position wurde mit bis zu 60\% Ausbeute durchgeführt. Die anschließende HPLCAufreinigung an einer reversed phase-C18-Säule stellte sich aber erneut als unmöglich heraus, da oligomeres Edukt und Produkt identische Retentionszeiten aufwiesen. Im ESI-Massenspektrum des aufgefangenen Peaks wurde sowohl Edukt als auch Produkt detektiert.

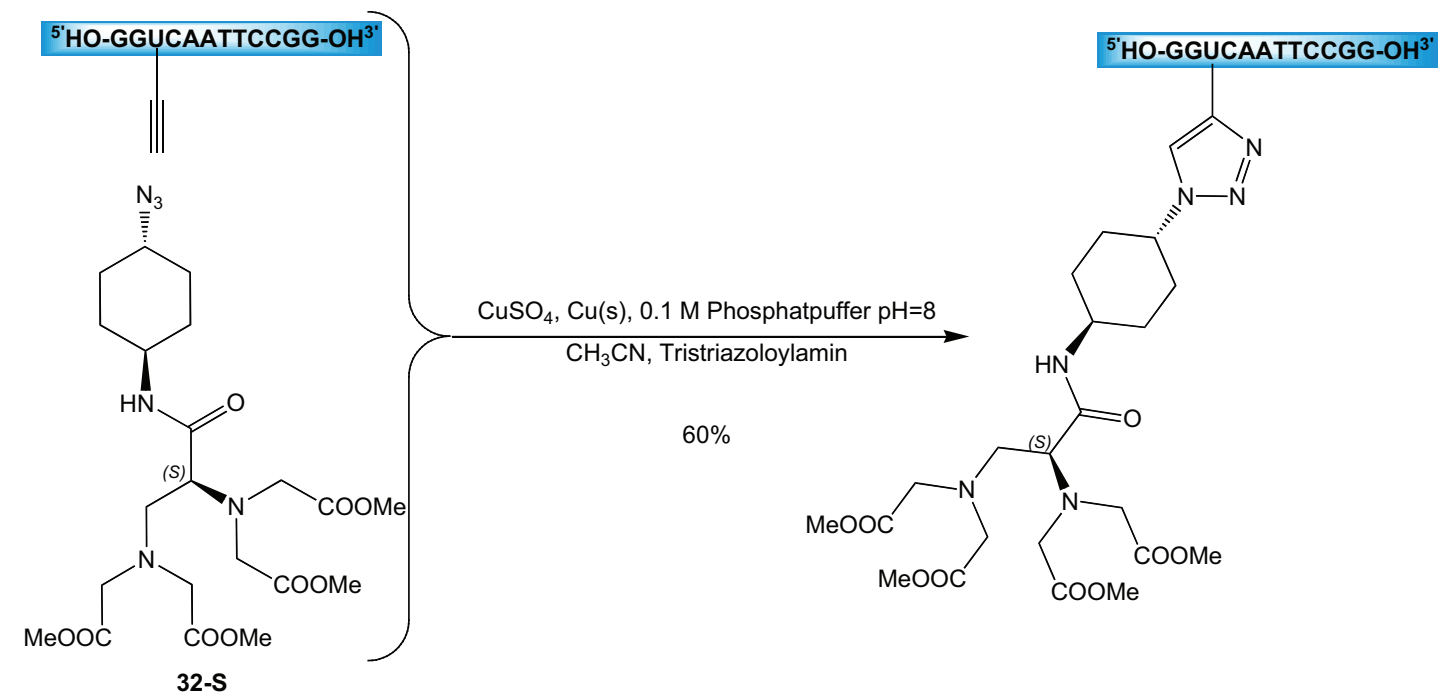

Abb. 5.23: Clickreaktion mit eines zyklischen Alkylazid.

\subsubsection{Darstellung von DNA mit EPTE-Tag}

Prinzipiell ist die Clickreaktion eine so populäre Reaktion aufgrund ihres vollständigen Ablaufs. Vermutlich wurde dies im obigem Fall aufgrund sterischer Einschränkungen nicht erreicht. Sehr rigide aber sterisch wesentlich leichter zugänglich sollte die endständige Dreifachbindung eines 5-(4-Ethinylphenylethinyl)-2'-desoxyuridin sein. Ein ähnliches Prinzip ver- 
wenden auch Chittepu et al., die eine Octa-1,7-diinylgruppe als Modifizierung an 5-Position verwenden [99]. Mit Hilfe einer zusätzlichen Sonogashira-Kupplung konnte das gewünschte Phosphoramidit leicht aus 11 gewonnen werden (Abb. 5.24). Bei der anschließenden Entschützung in Tetra- $n$-butylammoniumfluoridlösung wurde mit Triethylamin als zusätzlichem basischen Reagenz gearbeitet, um die DMTr-Schutzgruppe zu stabilisieren.
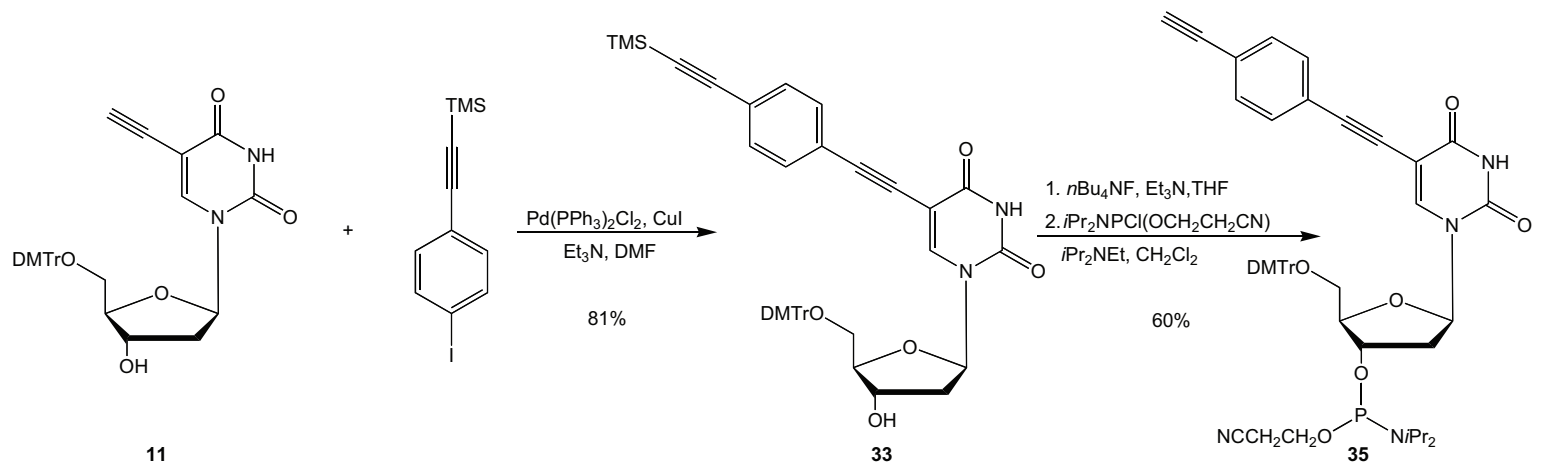

Abb. 5.24: Synthese des verlängerten ethinylfunktionalisierten Desoxyuridins und dessen Phosphoramidits.

Sterische Hinderung der Alkinfunktion des Desoxyuridins konnte durch Verwendung eines 5[(4-Ethinyl)phenylethinyl]-2'-desoxyuridins vermindert werden. Die Clickreaktion an derart modifizierter DNA mit dem zyklischen Alkylazid verlief quantitativ (Abb. 5.25). Danach wurde die DNA noch alkalisch aufgearbeitet, um die Methylesterfunktion zu entschützen. Würde man mit der freien EDTA-Funktion eine Clickreaktion vornehmen, so befänden sich Kupferionen in der EDTA-Tasche, die sowohl das NMR-Spektrum stark verbreitern, als auch eine Beladung mit Lanthanoidionen behindern würden.

Um die Aufarbeitung der getaggten DNA zu verkürzen wurde die Clickreaktion an den festphasengebundenen Oligonukleotiden entwickelt. Vorteil hierbei ist, dass ungeschützte EDTAAzide 26b verwendet werden können (Abb. 5.26). Während der Clickreaktion sind auch geringe Konzentrationen von Kupfer(II)-Ionen in Lösung, die einen Komplex mit der EDTAFunktion bilden. Diese Kupferionen konnten bei einer Reaktion an der Festphase einfach durch Waschen mit einer 0.1 M EDTA-Lösung bei pH 7 entfernt werden. Das überschüssige Azid und das Tristriazolylamin wurden durch mehrfaches Waschen mit einem $0.1 \mathrm{M}$ Triethylammoniumacetatpuffer-Acetonitrilgemisch (1:1) entfernt. Anschließend konnten die 


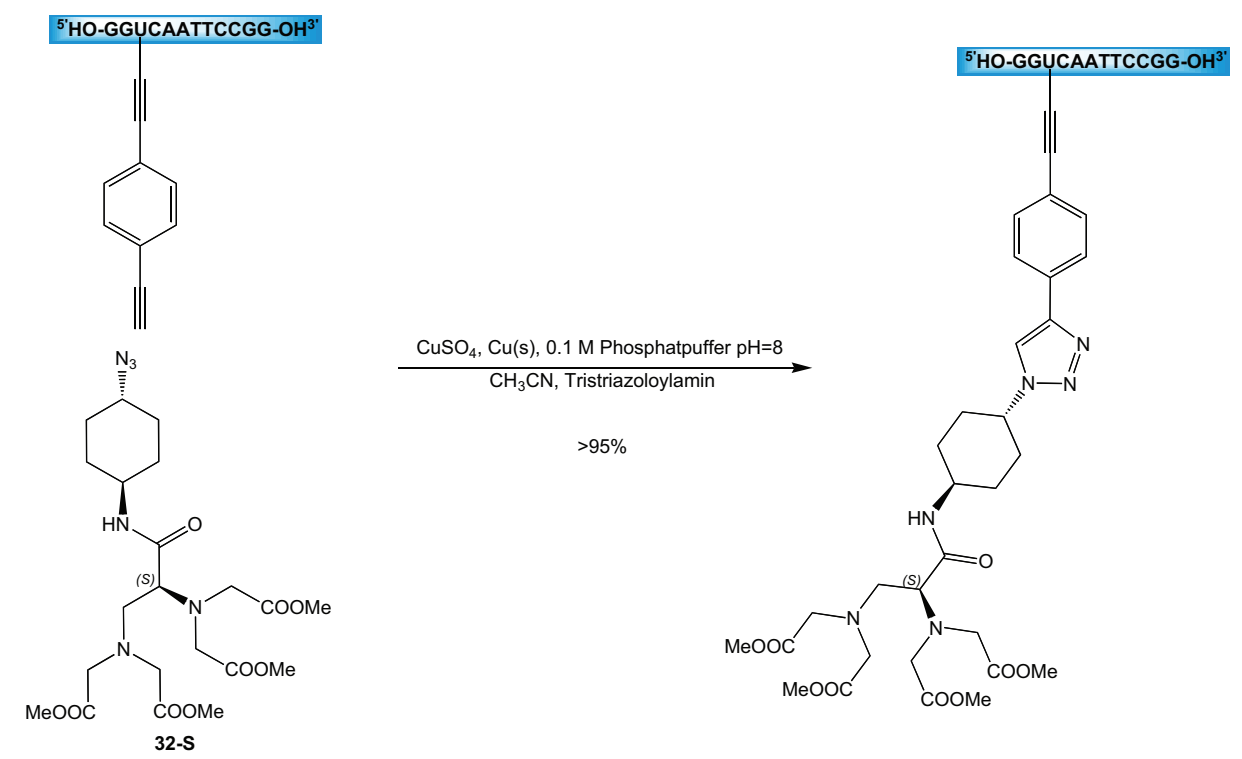

Abb. 5.25: Clickreaktion des verlängerten ethinfunktionalisierten Desoxyuridins mit dem Alkylazid 32-S.

Oligonukleotide unter Standardbedingungen (konz. Ammoniak, $55^{\circ} \mathrm{C}$ ) abgespalten werden. Die erhaltene DNA musste nur einmal über HPLC-gereinigt werden, da nur die Trennung von gewünschter DNA und ihren Abbruchsegmenten nötig war (Abb. 5.27). Hierbei gelang auch die Clickreaktion mit dem aromatischen Azid 26b-S.

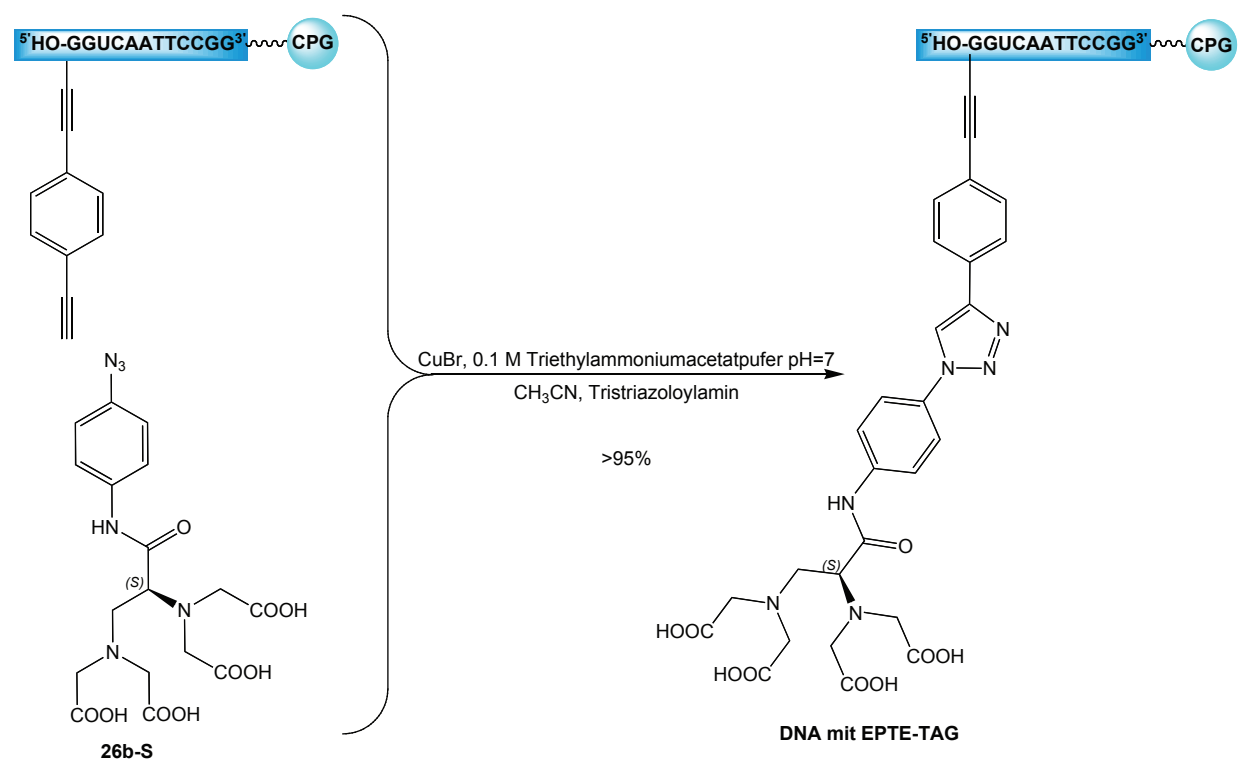

Abb. 5.26: Clickreaktion des verlängerten ethinfunktionalisierten Desoxyuridins mit dem aromatischen Azid 26b-S an der Festphase. 


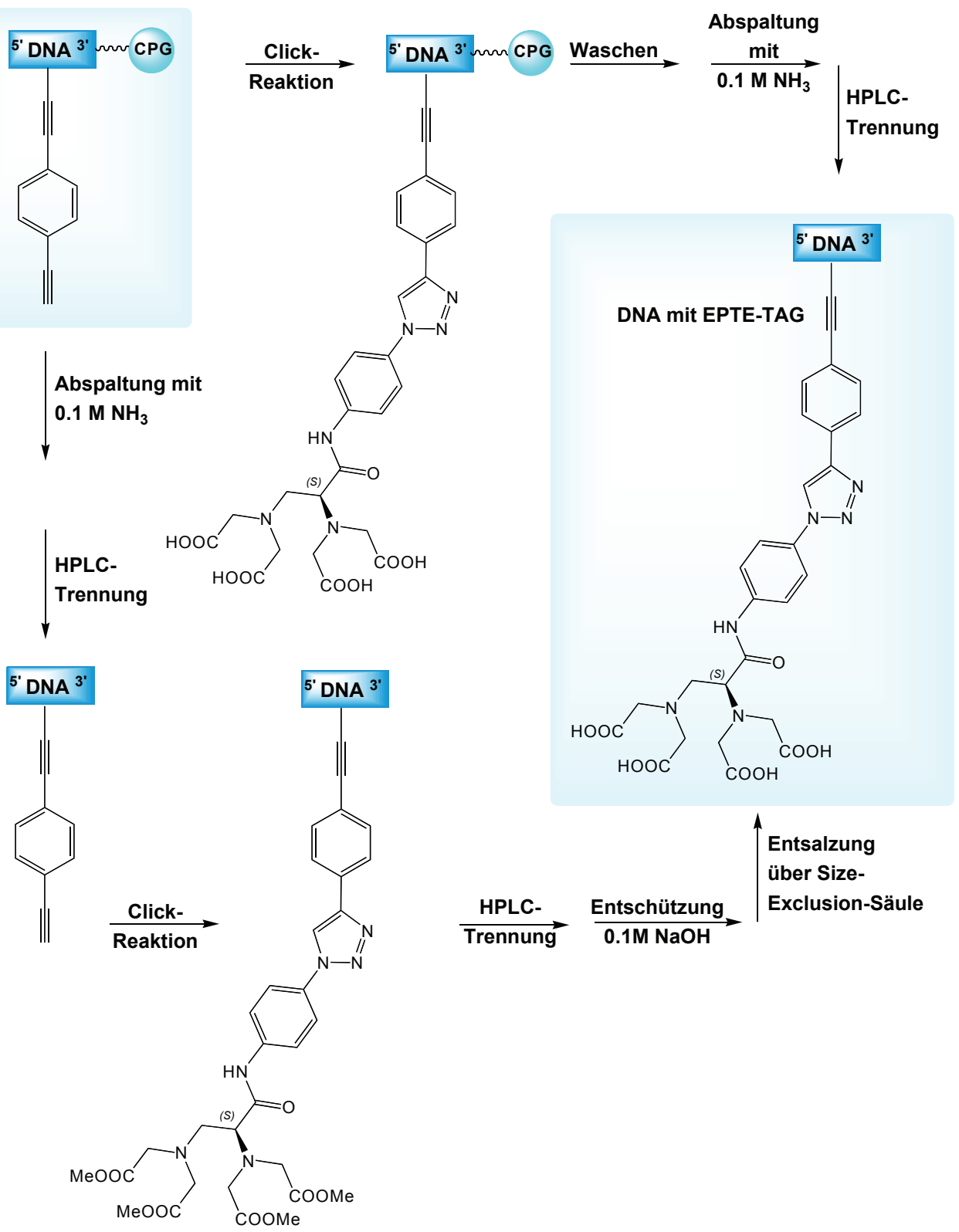

Abb. 5.27: Überblick der Aufarbeitung der EPTE-getaggten DNA. 


\subsection{Tagging über eine Disulfidbrücke}

Bereits seit 1975 setzt man Thiosulfonate zur Modifizierung von Cysteinresten ein, um asymmetrische Disulfide zu erhalten. Methylmethanthiosulfonat (MMTS) ist dabei ein gängiges Sulfonierungsmittel $[121,122]$. Diese Derivatisierungsmethode wird zunehmend auch für Proteine eingesetzt, wobei zu beachten ist, dass nur solche Cysteine modifiziert werden, die gut für Lösungsmittel zugänglich sind. Cysteine, die im Inneren der Proteine liegen, sind inert. Ein Vorteil dieser Modifizierungsmethode ist die Unempfindlichkeit gegenüber funktionellen Gruppen wie Säuren, Radikalen etc.. Durch die spezifische Reaktion ist die Einführung von Schutzgruppen nicht nötig. Beispiele für NMR-technisch interessante Modifizierungen sind in Abb. 5.28 dargestellt. Die ersten beiden Modifizierungen [12,123,124] stellen Derivate von chelatisierenden Verbindungen dar, nämlich EDTA und DTPA. Sie werden in das Protein eingebracht, um eine stark metallionenaffine Stelle im Protein zu schaffen.
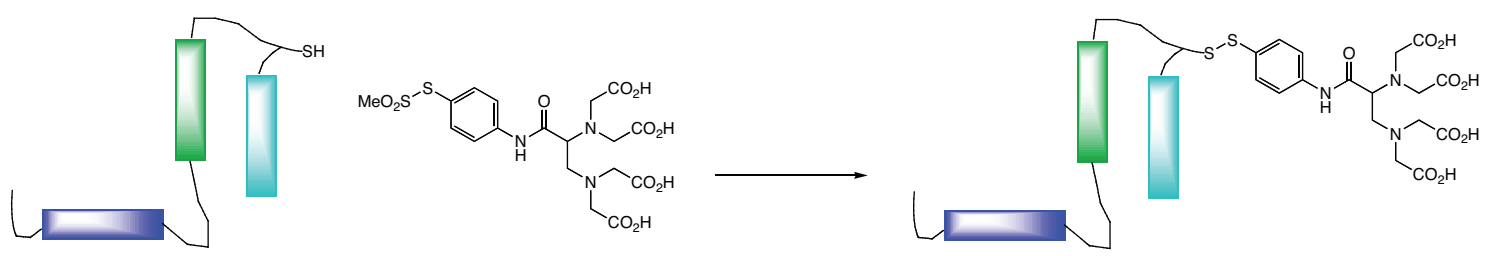

Protein (gegebenenfalls Cysteinmutante) Thiosulfonatderivat
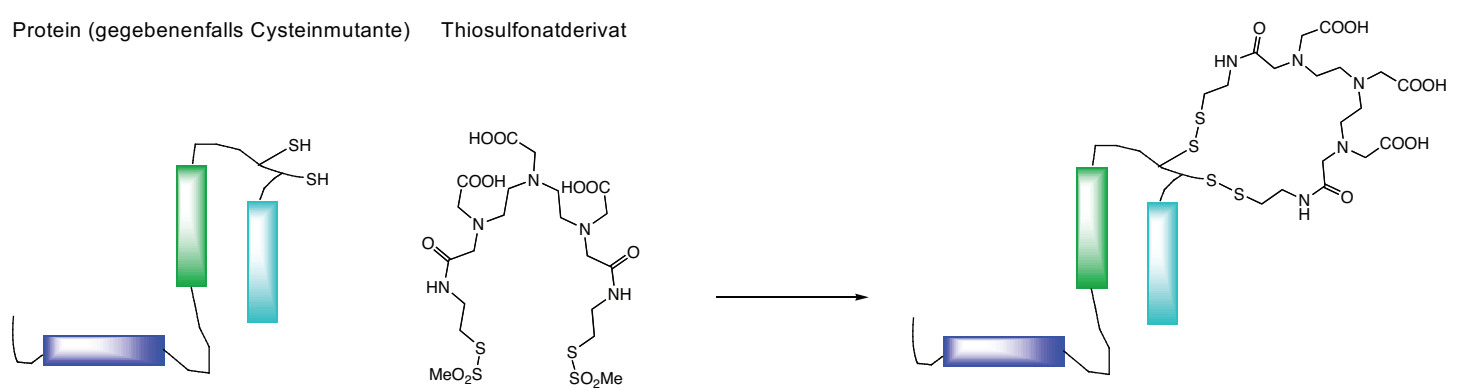

Protein (gegebenenfalls Dicysteinmutante) Thiosulfonatderivat
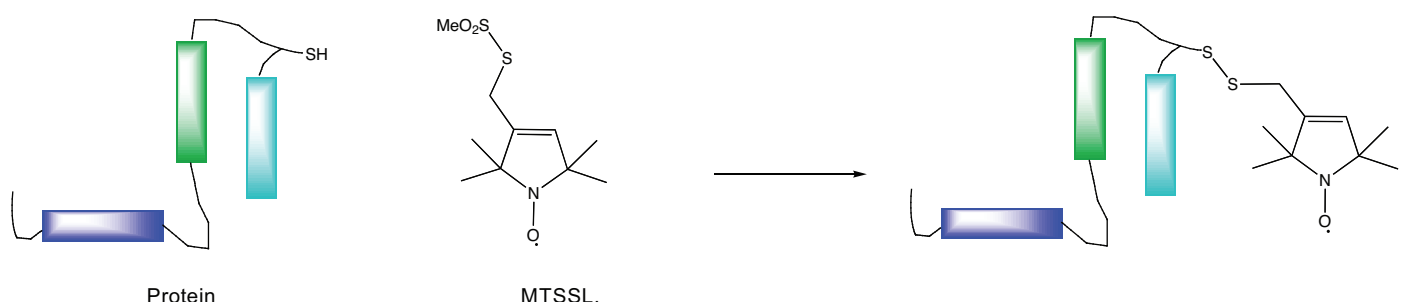

(gegebenenfalls Dicysteinmutante)

ein Spin-label-thiosulfonatderivat

Abb. 5.28: Beispiele zur Modifizierung von Cysteinen $[12,123,124]$. 
Disulfidbrücken werden aber auch genutzt, um andere Biomoleküle zu modifizieren [125,126]. So werden beispielsweise Zucker mit Hilfe von Disulfidbrücken modifiziert, aber auch an DNA-Bausteinen wurden derartige Modifizierungen schon vorgenommen. Ein Beispiel ist die Bildung des TT-Pyridin(6-4)-pyrimidon-Photoaddukts aus dem 4-Thiotymidinanaloga (Abb. 5.29) [127].
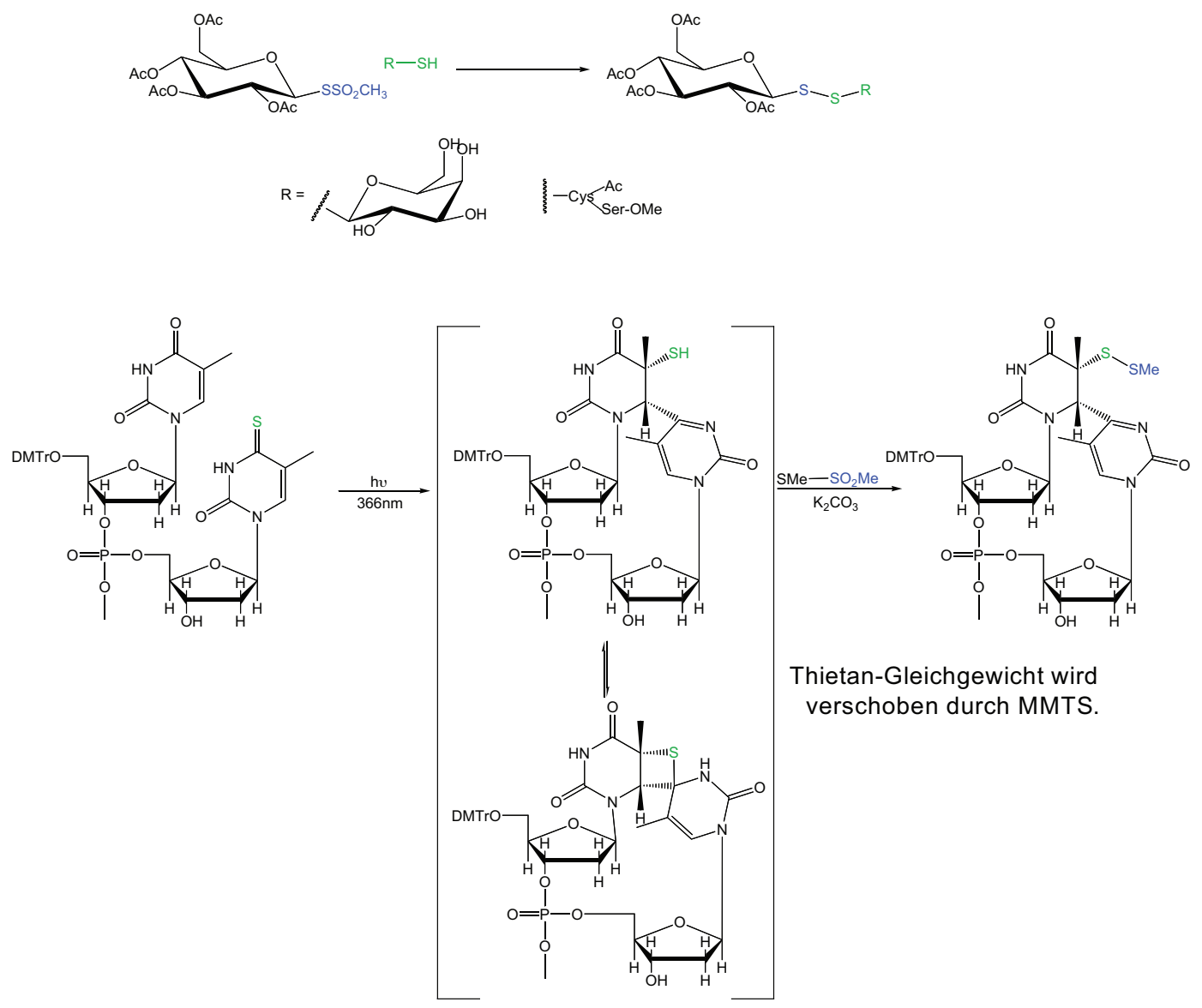

Abb. 5.29: Reaktionsbeispiele an Zuckern und Nukleosiden.

Das 4-Thio-2'-desoxythymidinphosphoramidit ist kommerziell erhältlich und durch die Thioketo-thioenol-Tautomerie sollte es für Reaktionen mit Methanthiosulfonaten zugänglich sein. Ein Beispiel für die Reaktion findet sich in [128]. Abb 5.30 zeigt, dass die Sulfonierung am Mononucleotid ThiodT bei $50^{\circ} \mathrm{C}$ mit zufriedenstellender Ausbeute abläuft. Bei Modifizierungsversuchen an Dodecameren mit eingebautem ThiodT stellte sich aber heraus, dass die Reaktion an Oligonukleotiden sehr schleppend verläuft und nur Ausbeuten von etwa 30\% ergibt. 

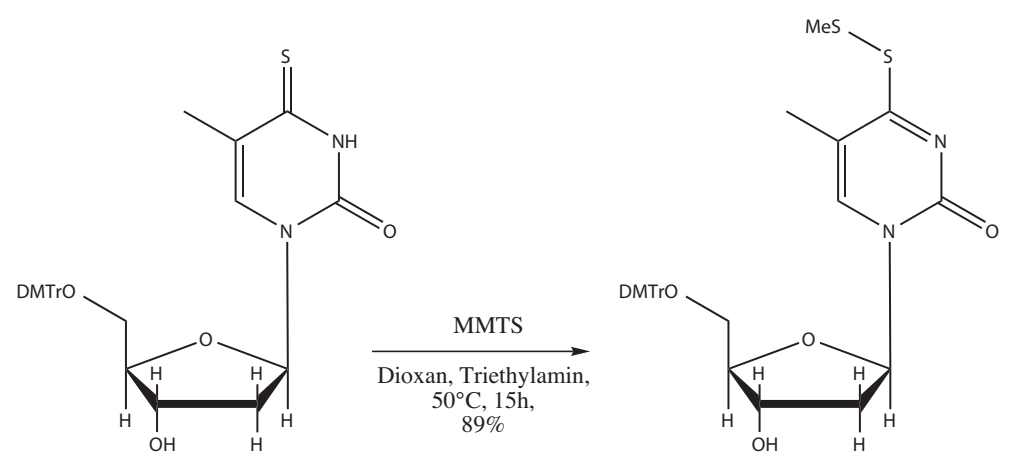

Abb. 5.30: Taggingreaktion an 4-Thio-2'-desoxythymidin.

Zudem beeinflusst eine derartige Modifizierung die Ausbildung von Watson-Crick-Basenpaaren. In Abb. 5.31 ist dargestellt, zu welcher Struktur eine einfache Konformationssimulation mit Macromodel führt. Die Basen-Paarung zwischen den Nukleotiden ist dabei geschwächt, einerseits durch die fehlende Wasserstoffbrückenbindung, andererseits durch die erhöhte sterische Hinderung gegenüber Modifizierungen an der 5-Position des Thymidins. Um diese Destabilisierung des DNA-Doppelstranges zu verhindern, kann man ein Thyminderivat mit einer Thiolfunktion an der 5-Position der Pyrimidin verwenden. Eine Struktursimulation der mit Macromodel energieminimierten Strukturen ist ebenfalls in Abbildung 5.31 dargestellt.

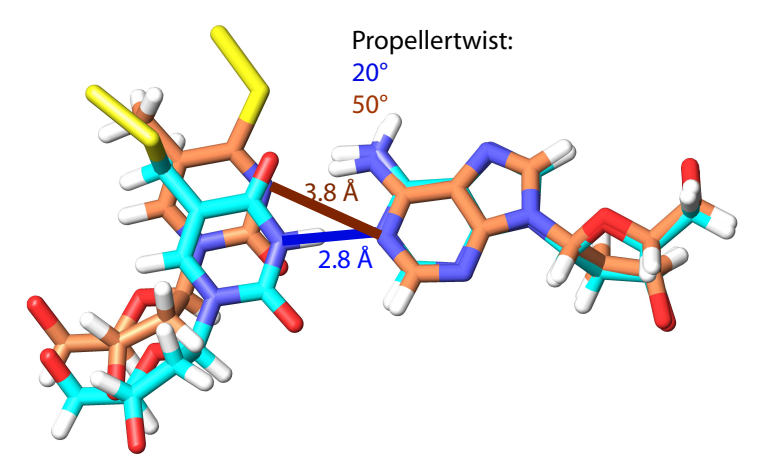

Abb. 5.31: Macromodelsimulation der an 4(orange)- und 5(blau)-Position getaggten DNA. Die Modifizierung befand sich dabei flankiert von je drei unmodifizierten Basenpaaren in 3'- und in 5'-Richtung der DNA. Nur der für die Basenpaarung relevante Bildausschnitt ist dargestellt. 


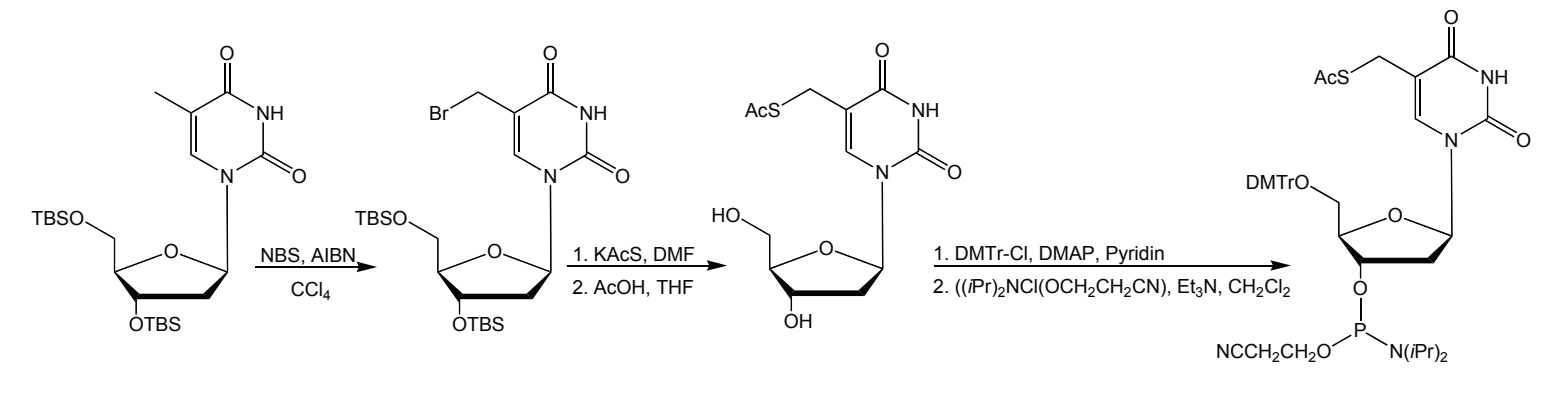

Abb. 5.32: Synthese von $S$-Acetyl-5-mercaptomethyl-2'-desoxyuridin.

Das entsprechende $S$-Acetyl-5-mercaptomethyl-2'-desoxyuridin wurde bereits von Bornemann et al. synthetisiert [129]. In Abb. 5.32 ist die Syntheseroute dargestellt. Um S-Acetyl5-mercaptomethyl-2'-desoxyuridin schneller und effizienter zu synthetisieren, wurde die Reaktionsroute verändert. Die alternative Syntheseroute ist in Abb. 5.33 dargestellt [130]. Ausgehend vom 2'-Desoxyuridin wurde 5-Hydroxymethyl-2'-desoxyuridin in einer PrinsReaktion synthetisiert. Anschließend erfolgte eine nukleophile Substitution zum S-Acetyl-5mercaptomethyl-2'-desoxyuridin, das analog zu Bornemann et al. mit den benötigten Schutzgruppen zum korrespondierenden Phosphoramidit umgewandelt werden konnte. Zu beachten ist dabei, dass eine komplette Aufreinigung von $\mathbf{3 6}$ und $\mathbf{3 7}$ nicht stattfand und erst das DMTr-Derivat 38 chromatographisch gereinigt wurde. Die Ausbeute über drei Stufen betrug dabei nur $6 \%$.

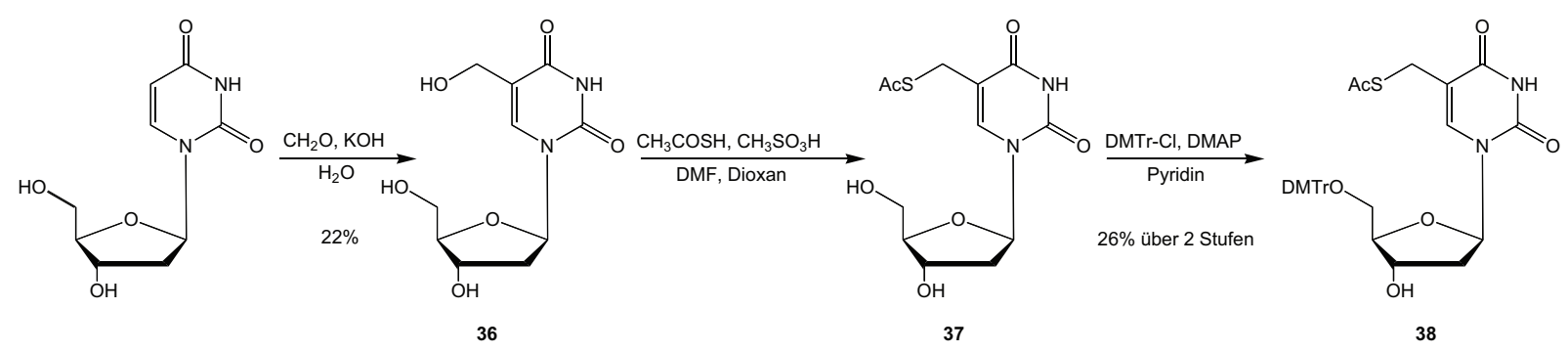

Abb. 5.33: Dreistufige Synthese von $S$-Acetyl-5-mercaptomethyl-2'-desoxyuridin.

Das S-Acetyl-5-mercaptomethyl-dU-Phosphoramidit ließ sich per Festphasensynthese mit guten Ausbeuten einbauen und besaß eine ähnliche Kupplungseffizienz wie unmodifizierte Basen. Die Abspaltung verlief unter speziellen Bedingungen. In einem ersten Schritt wurde die DNA mit 0.1 M DBU (1,8-Diazabicyclo[5.4.0]undec-7-en)-Lösung in Acetonitril für 30 min bei Raumtemperatur behandelt, um die Thiolgruppe zu deacetylieren. Anschließend 
erfolgte die Abspaltung von der Festphase unter reduktiven Bedingungen mit 1 M Dithiothreitol (DTT)-Lösung in konzentriertem Ammoniak (Abb. 5.34). Nach chromatographischer Aufreinigung erfolgte die Modifizierung der 5-Thiolgruppe an der drittletzten Position des Oligomers mit 36 in neutraler wässriger Lösung innerhalb von 3 Stunden bei Raumtemperatur. Die Umsetzung erfolgte quantitativ. 36 ist bereits durch das Tagging von Proteinen bekannt [13].

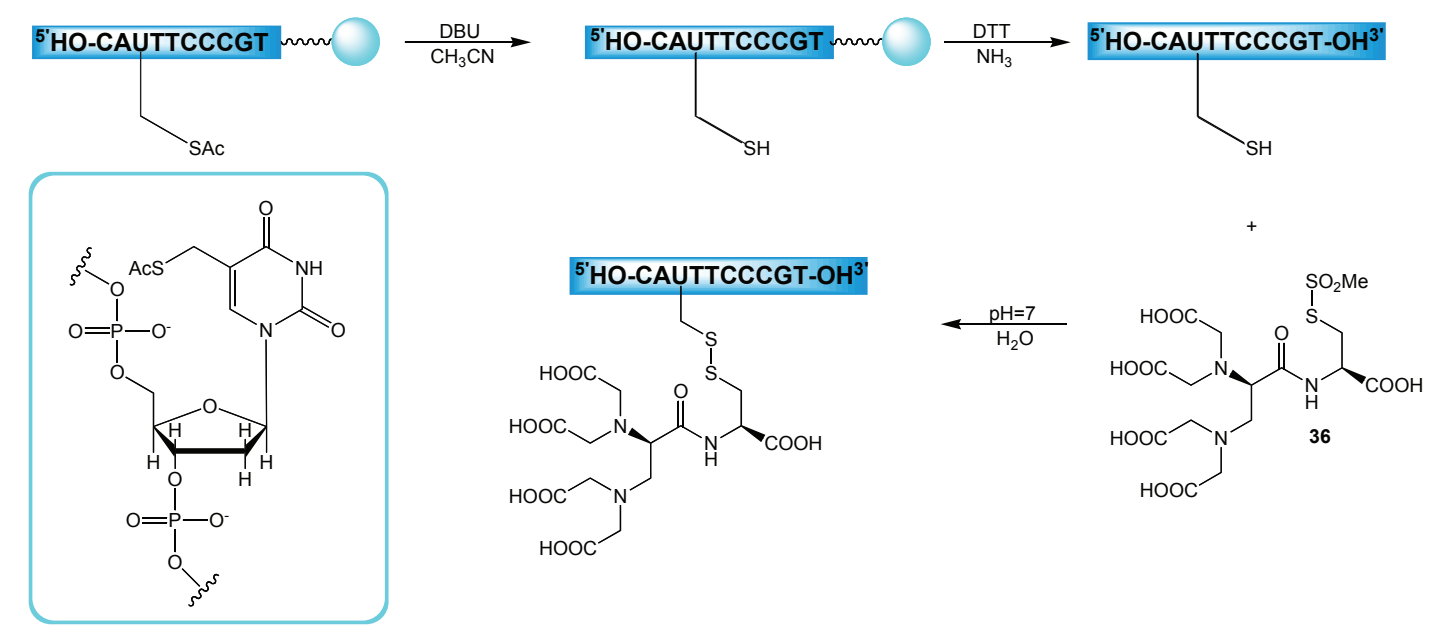

Abb. 5.34: Schematische Darstellung der Synthese von DNA mit einem DSE-Tag.

Zusammenfassend lässt sich feststellen, dass die Einführung einer EDTA-Funktion in Oligonukleotide über eine Disulfidbrücke in Lösung sehr gut funktioniert. Prinzipiell sollte es auch möglich sein 36 mit Lanthanoidionen zu beladen und anschließend mit der DNA zu verbinden. So kann die Titration von Lanthanoidionen zu DNA umgangen werden. Auch andere Modifizierungen sollten so einfach an Oligonukleotide gebunden werden können. Diese Taggingreaktion ist aufgrund der milden Reaktionsbedingungen auch zur Modifizierung von labilerer RNA geeignet.

Die korrespondierende Tagging-Reaktion an der festphasengebundenen DNA verlief erfolglos. Dabei wurde nach der Behandlung mit DBU das Thiosulfonat zugegeben. Anschließend wurde sowohl in Anwesenheit, als auch in Abwesenheit von DTT die Abspaltung mit konz. Ammoniak durchgeführt. Das gewünschte Produkt konnte nicht nachgewiesen werden. 


\section{Kapitel 6}

\section{Analyse der Oligonukleotide}

\subsubsection{Massenspektroskopie getaggter Oligonukleotide}

Mit Hilfe von Massenspektrometern lässt sich das Verhältnis von Masse zu Ladung messen. Dazu wird im ersten Schritt eine elektrische Ladung auf das zu untersuchende Molekül übertragen (Ionisation), anschließend wird dieses geladene Teilchen im Detektor analysiert. Bei Makromolekülen ist eine besonders schonende Ionisation von Nöten, damit das Biomolekül nicht zu großen, zerstörerischen Kräften ausgesetzt ist. Die Elektronensprayionisation ist eine milde Ionisationsmethode, die für Makromoleküle gut geeignet ist.

Bei der Massenspektroskopie von Oligonukleotiden mit ihrem Phosphatrückgrat ist die Ionisierung mit Hilfe negativer Ladung gegenüber der mit positiver Ladung von Vorteil. Bei Messung im Positiv-Modus bilden sich verschiedene Natriumaddukte, die zu einem schwer analysierbaren Massenspektrum mit diversen Signalen führen. Im Negativ-Modus dagegen wurden meist die Oligonukleotidmassen ohne oder mit nur ein bis zwei koordinierten Natriumionen detektiert. Dabei waren sie meist mehrfach negativ geladen (Abb. 6.1). 


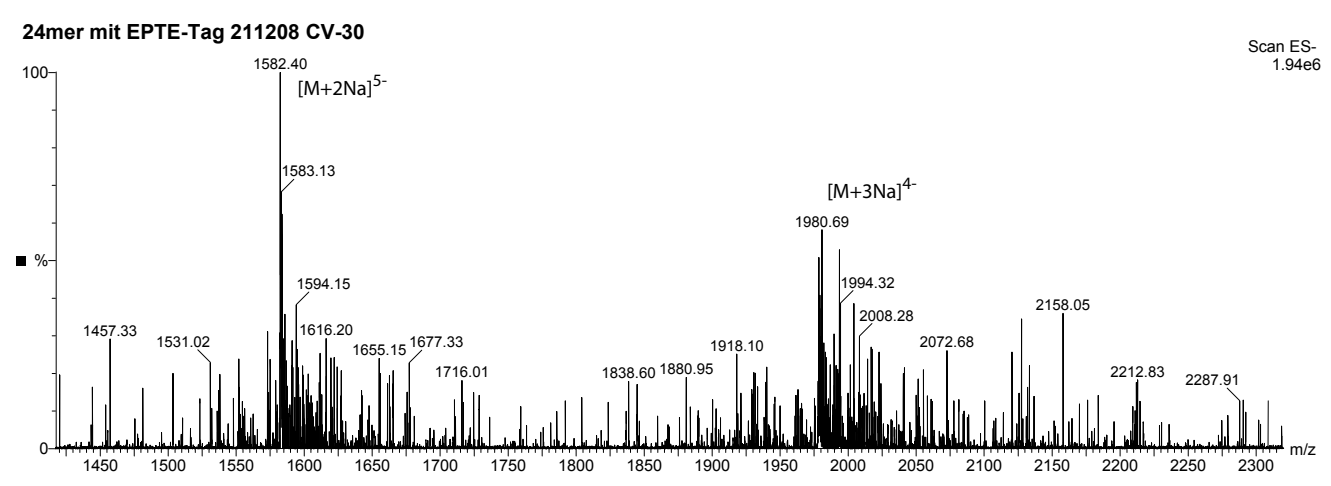

Abb. 6.1: ESI-Massenspektrum der 24meren DNA mit EPTE-Tag im Negativ-Modus. Die Lösung lag in $100 \mathrm{mM}$ Triethylammoniumacetatpuffer vor $(\mathrm{pH}=7)$.

Komplexiert man die getaggte DNA mit Lanthanoidionen, so lässt sich die Masse des Komplexes im Negativ-Modus detektieren (Abb. 6.2).

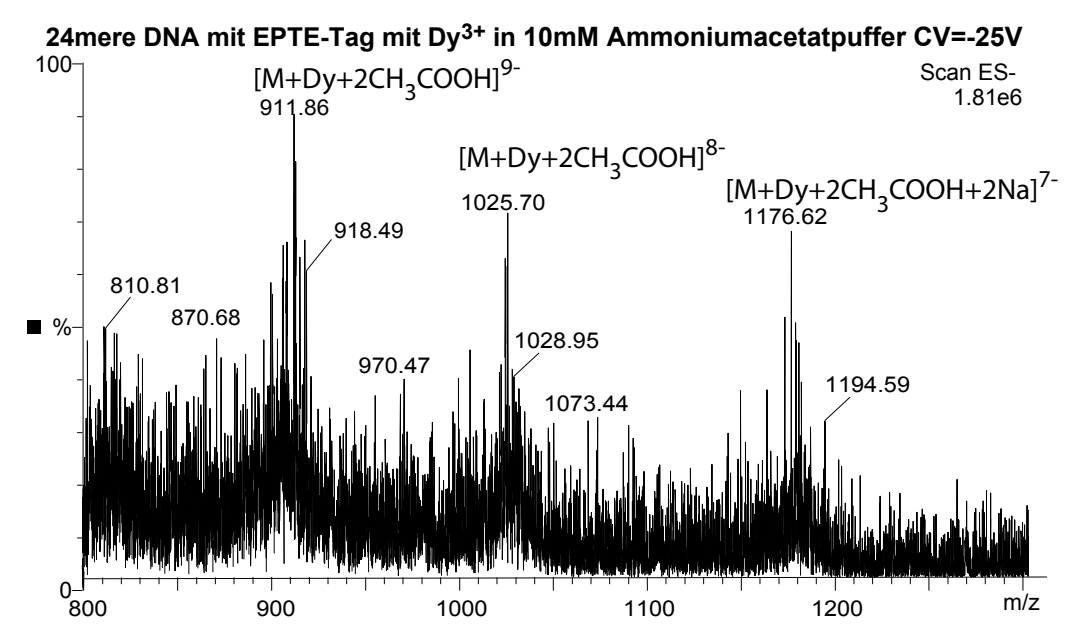

Abb. 6.2: ESI-Massenspektrum der 24 meren DNA mit EPTE-Tag mit $\mathrm{Dy}^{3+}$ im Negativ-Modus.

Die Lösung lag in $10 \mathrm{mM}$ Ammoniumacetatpuffer vor $(\mathrm{pH}=7)$.

\subsection{Zur Auswahl der Sequenzen}

In den ersten Experimenten zur Modifizierung von Oligonukleotiden wurde eine dodecamere DNA-Sequenz verwendet, die eine ähnliche Basenabfolge wie die Dickerson-DNA besitzt [131]. Im Gegensatz zu dieser ist sie jedoch nicht palindronisch, damit nur eine Modifi- 
zierung pro Duplex vorhanden ist (Abb. 6.3 links). Im Verlauf der Arbeit wurde später ein kürzeres Decamer verwendet (Abb. 6.3 rechts), welches einen Ausschnitt aus einer STATbindenden Sequenz darstellt (siehe Kapitel 3) [20-22]. Dabei wird ein Strang des Oligonukleotids modifiziert und anschließend mit dem Gegenstrang versetzt und hybridisiert.

\title{
5' GGTCAATTCCGG 3' 5' CATTTCCCGT 3' \\ 3' CCAGTTAAGGCC 5' 3' GTAAAGGGCA5'
}

\begin{abstract}
Abb. 6.3: Dodecamere DNA und die decamere DNA. Mit einem Sternchen markiert ist das Thy-
\end{abstract} min, das durch die getaggte Base ersetzt wurde.

Die Schwierigkeit dabei stellt die genaue Konzentrationsbestimmung der beiden Stränge dar, um ein genau äquimolares Verhältnis und damit das Vorliegen eines reinen Doppelstranges zu gewährleisten. Normalerweise verwendet man zur Konzentrationsbestimmung die UVAbsorption bei $260 \mathrm{~nm}$, um die Menge an Oligonukleotid in Lösung zu bestimmen. Das Verhältnis der Absorption bei $260 \mathrm{~nm}$ zu 280 nm gibt Auskunft über die Reinheit der Probe [132].

Durch den Tag kann es zu einer veränderten UV-Absorption kommen, die die gängige Konzentrationsbestimmung verfälscht. Besonders deutlich zu erkennen ist diese Veränderung bei dem Vergleich des Absorptionsspektrums von DNA ohne Modifizierung und DNA mit EPTE-Tag. Durch das große aromatische System des Tags bildet sich ein zweites lokales Absorptionsmaximum bei $320 \mathrm{~nm}$ (Abb. 6.4).

Um einen reinen Doppelstrang zu erhalten, wurde deshalb eine HPLC-Methode entwickelt, mit Hilfe derer man gepaarte und ungepaarte DNA trennen kann. Dabei konnte auch das Verhältnis von dsDNA zu ssDNA ermittelt werden, sowie welcher Strang im Überschuss vorlag (siehe Abschnitt 6.2.2).

Um die Titration von Strang zu Gegenstrang zu vermeiden wurde an die STAT-Sequenz ein Tetraloop angebracht (Abb. 6.5). Dieser hat den weiteren Vorteil, dass er die Stabilität 


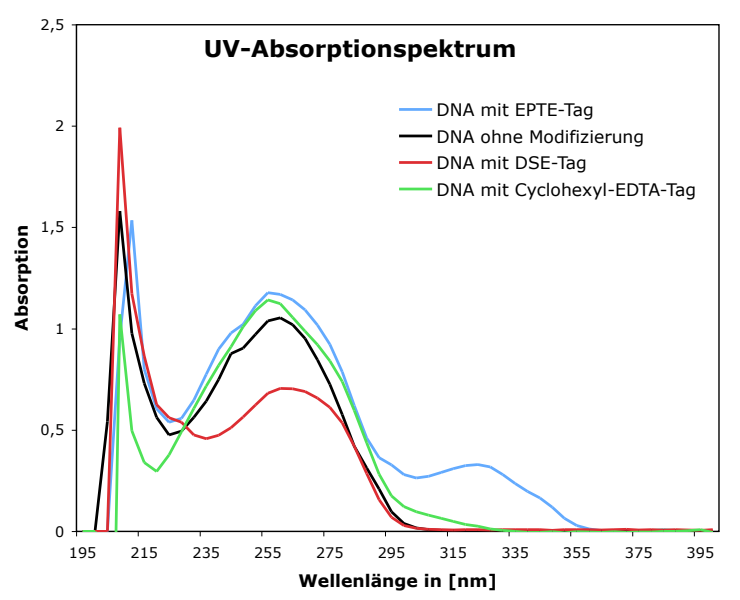

Abb. 6.4: Veränderte UV-Absorption durch den EPTE-Tag.

des Doppelstranges erhöht. Von zusätzlichen Interesse ist, dass die Clickreaktion auch an dieser potentiell als Duplex vorliegenden DNA stattfindet, was die Robustheit der Methode untermauert. In Abschnitt 3.4 und 3.5 ist die Strukturaufklärung dieser Sequenz beschrieben.

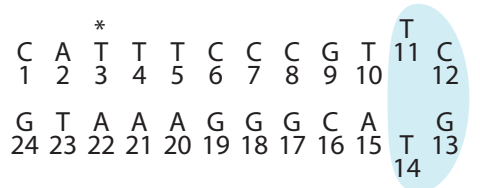

Abb. 6.5: 24mer Hairpin-DNA basierend auf einer STAT-bindenden Sequenz.

\subsection{HPLC von Oligonukleotiden}

Hochleistungsflüssigkeitschromatographie (HPLC) ist ein chromatographisches Trennverfahren, bei dem ein Laufmittelgemisch durch eine stationäre Phase mit erhöhtem Druck gepumpt wird. Das Trennvermögen der HPLC-Chromatographie ist circa 100 mal größer als das der Säulenchromatographie. Zur Analyse der Oligonukleotide wurden in dieser Arbeit zwei verschiedene HPLC-Methoden verwendet, einerseits die reversed phase-HPLC (RP-HPLC) und andererseits die Anionenaustauscher-HPLC. Letztere liefert ähnliche Trenneigenschaften wie die Gelelektrophorese. 


\subsubsection{Reversed phase-HPLC}

Bei der RP-Chromatographie wird eine unpolare stationäre Phase und ein polares Laufmittel verwendet. Die unpolare Phase besteht dabei aus Silicagel, das mit langkettigen Alkanen (z. B. Octadecyl) modifiziert ist. Als polare Phase werden Wasser, Acetonitril oder Methanol verwendet. Diese Methode ist besonders gut geeignet zur Trennung polarer Stoffgemische. Je nach Anwendungszweck wird bei verschiedenen pH-Werten und Temperaturen gearbeitet. Zur Analyse von Oligonukleotiden arbeitet man bei neutralem pH-Wert. Als Puffersystem wird häufig Triethylammoniumacetat verwendet. Dieses hat zum einen den Vorteil, dass es ein flüchtiger Puffer ist, der durch mehrfache Lyophilisation entfernt werden kann und eine anschließende Elektronenspray-Massenspektroskopie somit nicht beeinflusst, und zum anderen lagert sich das Triethylammoniumion an das negative Rückgrat des Oligonukleotides, erniedrigt damit seine Polarität und verbessert so die Trenneigenschaften [133]. Als Trenntemperatur wurde in der Regel $40{ }^{\circ} \mathrm{C}$ gewählt, da bei dieser Temperatur noch keine thermische Zersetzung von Oligonukleotiden stattfindet.

\subsubsection{Anionenaustauscher-HPLC}

Anionenaustauschersäulen trennen DNA verschiedener Längen basierend auf der unterschiedlichen Anzahl negativ geladener Phosphatgruppen am Oligonukleotidrückgrat. Das verwendete Laufmittelgemisch ist dabei auf rein wässriger Basis. Genutzt wird ein Gemisch aus drei Komponenten: Wasser, Salzlösung $(1 \mathrm{M} \mathrm{NaCl})$ und ein Puffersystem (0.25 mM Tris$\mathrm{HCl}, \mathrm{pH}=8$ ). Diese milden Bedingungen erlauben es Oligonukleotide in ihrer nativen Form aufzureinigen.

Folgende Konstrukte wurden zur Entwicklung einer Trennmethode sehr kurzer ssDNA von dsDNA verwendet :

\begin{tabular}{|llll}
\hline $5^{\prime}$ GGTCAACCGG 3' & 10a & 5' GGTCAATTCCGG 3' & 12a \\
\hline 3' $^{\prime}$ CCAGTTGGCC 5' & 10b & 3' CCAGTTAAGGCC 5' & $12 \mathrm{~b}$
\end{tabular}


Die Anionenaustauschersäule kann auf Temperaturen von bis zu $85{ }^{\circ} \mathrm{C}$ temperiert werden. Durch die Einstellung der Temperatur lassen sich die Signalformen von Einzelstrang und Doppelstrang beeinflussen, aber auch die Retentionszeit ändert sich. Bei ansteigender Temperatur verlängert sich die Retentionszeit. Je höher die Temperatur gewählt wird, desto breiter wird der Peak des Doppelstranges (Abb. 6.6), anschaulich lässt sich dies durch das partielle Aufschmelzen erklären, das zu inhomogenen Wechselwirkungen des Konstrukts mit der stationären Phase führt. Bei den Einzelsträngen ist die Situation genau umgekehrt, je höher die Temperatur, desto schärfer ist der Peak (Abb. 6.7). Ein mögliche Erklärung ist, dass bei sehr niedrigen Temperaturen Wechselwirkungen zwischen kurzen komplementären Sequenzabschnitten existieren. Der decamere Einzelstrang bildet bei $15{ }^{\circ} \mathrm{C}$ sogar einen stabilen Duplex.

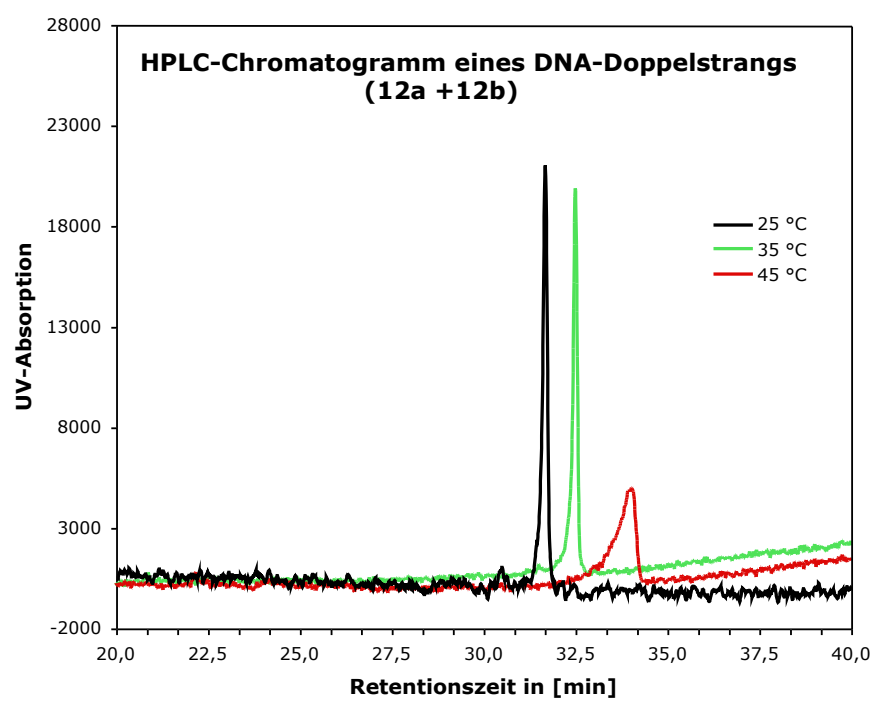

Abb. 6.6: Temperaturabhängige HPLC-Chromatogramme der dodecamerer DNA-Doppelstränge an einer Anionenaustauschersäule.

Um ein Gemisch aus doppelsträngiger und einzelsträngiger DNA zu analysieren, muss die Temperatur so gewählt werden, dass der Peak des überschüssigen Einzelstranges gut definiert ist. Nur in diesem Fall kann man bestimmen, welcher DNA-Strang im Überschuss vorliegt. Dabei darf die Temperatur nicht zu hoch gewählt sein, um die nativen Bedingungen nicht zu gefährden. In Abb. 6.8 ist die Trennung von ds- und ssDNA bei $35{ }^{\circ} \mathrm{C}$ abgebildet. Dabei ist klar erkennbar, welcher Strang im Überschuss vorliegt. 

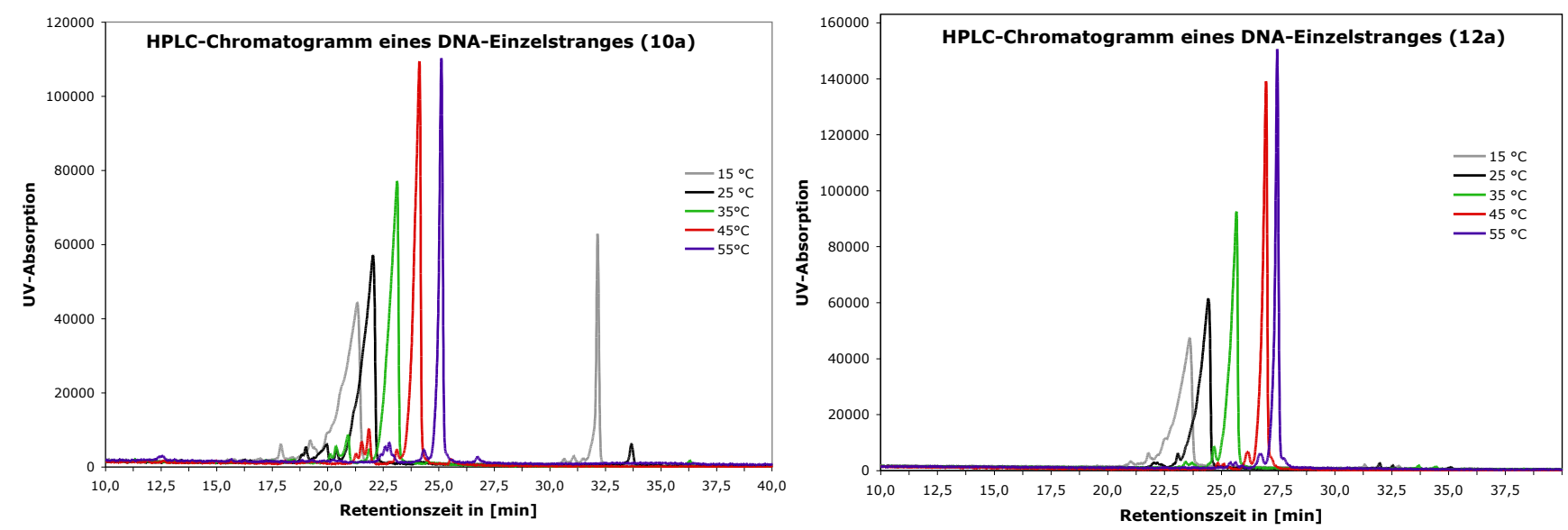

Abb. 6.7: Temperaturabhängige HPLC-Chromatogramme der DNA-Einzelstränge an einer Anionenaustauschersäule.
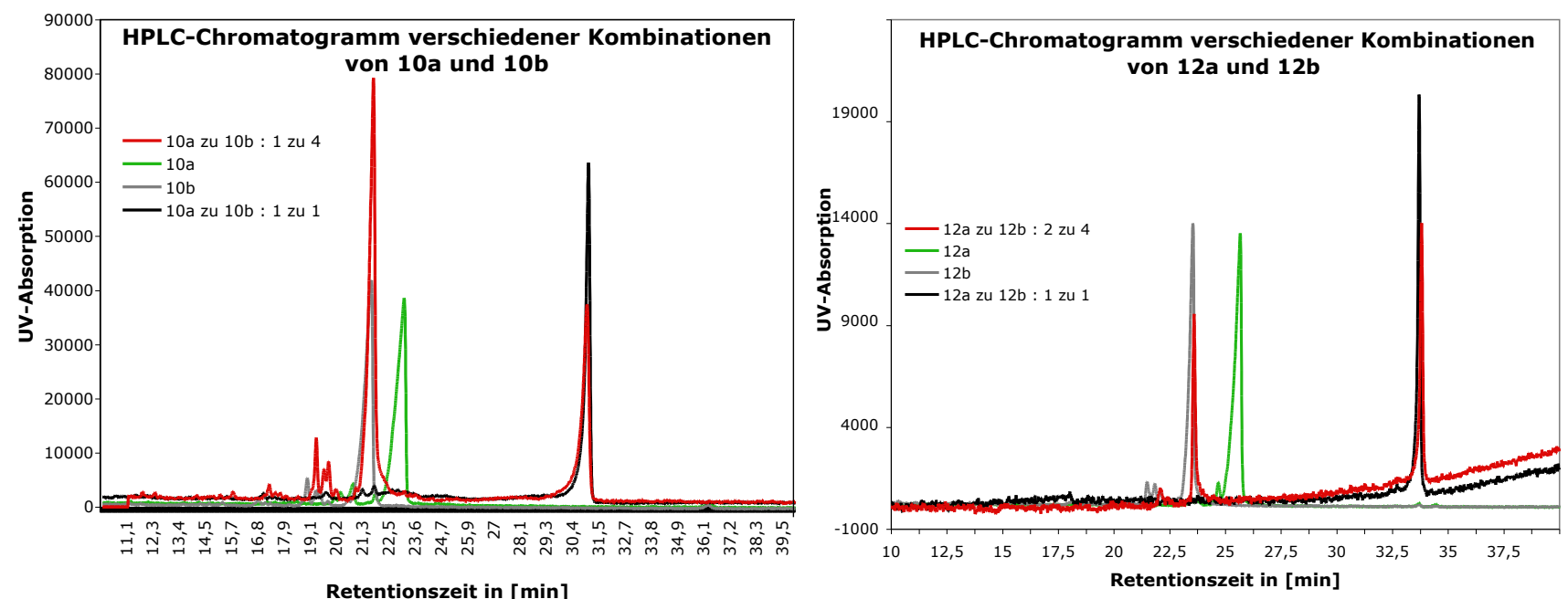

Abb. 6.8: HPLC-Chromatogramme der dsDNA- und ssDNA-Mischungen bei $35^{\circ} \mathrm{C}$.

Durch die Kapillargelelektrophorese (CGE) mit UV-Detektor lassen sich unter nativen Bedingungen auch ssDNA und dsDNA voneinander trennen. Die Identifizierung des überschüssigen Einzelstranges gelingt bei der CGE jedoch nicht [134,135]. Es existieren noch weitere Methoden, um das Verhältnis von dsDNA und ssDNA zu analysieren, z. B. durch Fluoreszenzmessung mit interkalierenden Farbstoffen [136].

Bei der hier entwickelten Methode lässt sich durch Integration über das Doppel- und das Einzelstrangsignal der unmodifizierten Oligonukeotide das Verhältnis von Einzelstrang zu 
Doppelstrang bestimmen. Wenn die Konzentration des Einzelstranges a $\left(\mathrm{c}_{a}\right)$ größer als die Konzentration des Stranges b $\left(\mathrm{c}_{b}\right)$ ist, gilt für das Verhältnis der Integrale $I_{a} / I_{d s}$ :

$$
\frac{I_{a}}{I_{d s}}=0.6 \frac{\left(c_{a}-c_{b}\right)}{2 c_{b}}
$$

Der Faktor 0.6 resultiert aus der erniedrigten Absorption der dsDNA im Vergleich zu ssDNA bei $260 \mathrm{~nm}[137]$.

Für NMR-Messungen und zur Kristallisation benötigt man sehr reine Oligonukleotidproben. Dazu wurden die Konzentrationen zweier komplementärer DNAs durch UV-Absorptionsmessungen ermittelt und anschließend im erwarteten Verhältnis 1 zu 1 vermischt. Die Lösung wurde hybridisiert und danach wurde eine Probe für die HPLC-Analyse entnommen. Anhand des ermittelten Verhältnisses dsDNA zu ssDNA konnte nun exakt die noch fehlende Menge des benötigten Stranges zugegeben werden. Bei der Analyse von getaggter DNA kann es bei der Konzentrationsverhältnisbestimmung zu geringen Fehlern kommen. Mit einem weiteren HPLC-Lauf der verbesserten Probe kann nachfolgend kontrolliert werden, ob ausschließlich gepaarte DNA vorliegt.

Prinzipiell ist es auch möglich eine präparative HPLC-Trennung von gepaarten und ungepaarten Oligonukleotiden durchzuführen. Nachteil dieser Methode ist, dass die gewonnene Probe stark salzhaltig ist und somit nicht direkt weiter verarbeitet werden kann. Eine anschließenden Dialyse, Entsalzung durch size exclusion-Chromatographie oder Ausfällung mit Isopropanol ist notwendig. Insgesamt betrachtet sind deshalb durch eine präparative HPLC-Trennung höhere Verluste zu erwarten als bei der Entnahme einer Probemenge zur Analyse. Dies ist natürlich abhängig von den verwendeten Mengen. Es gilt für OligonukleotidMaßstäbe von etwa $200 \mathrm{nmol}$ und HPLC-Testläufe von $2 \mathrm{nmol}$. 


\subsection{Die Beladung der getaggten DNA mit Lanthanoi- dionen}

\subsubsection{EDTA-Komplexe mit Lanthoidionen}

Die chemischen Eigenschaften der Lanthanoid(III)ionen sind untereinander sehr ähnlich. Die unterschiedlich besetzte f-Schale hat nur einen sehr schwachen Einfluss auf die physikalischen und chemischen Eigenschaften der Lanthanoide. Diese haben mit zunehmender Ordnungszahl einen abnehmenden Ionenradius (Lanthoidkontraktion) und sind dabei reduktions- und oxidationsstabil. Einzige Ausnahmen stellen Europium und Cer dar, ersteres kann in wässriger Lösung auch in Oxidationsstufe +2 vorliegen, letzteres auch in Oxidationsstufe +4 [39].

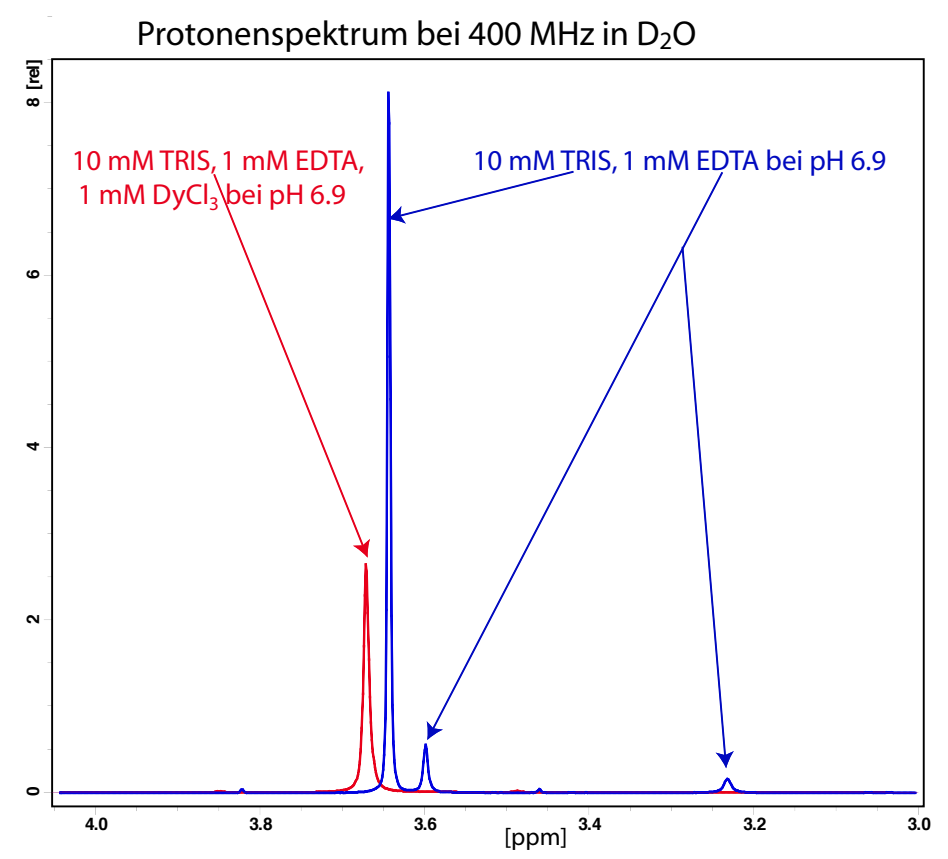

Abb. 6.9: Abgebildet sind die NMR-Spektren von $1 \mathrm{mM}$ EDTA und $10 \mathrm{mM}$ TRIS in $\mathrm{D}_{2} \mathrm{O}$ mit (rot) und ohne (blau) $1 \mathrm{mM} \mathrm{DyCl}_{3}$. 
Die Komplexbindungskonstanten der Lanthanoid(III)ionen zu EDTA sind sehr ähnlich. Da Lanthanoidionen bis zu 9 Koordinationsstellen in Komplexen besitzen, bilden sich in Wasser $\left[\mathrm{Ln}^{3+} \mathrm{EDTA}^{4-}\left(\mathrm{H}_{2} \mathrm{O}\right)_{n}\right]^{-}$-Komplexe aus. Wird jedoch in Puffersystemen gearbeitet, agiert das Anion oft als zusätzlicher Ligand neben EDTA. So fungiert der in biologischen Systemen häufig verwendete TRIS (Tris(hydroxymethyl)-aminomethan)-Puffer, aber auch AcetatPuffer als zusätzlicher Ligand von Lanthanoidkomplexen. Aus den NMR-Spektren von 1 mM EDTA und $10 \mathrm{mM}$ TRIS in $\mathrm{D}_{2} \mathrm{O}$ mit (rot) und ohne (blau) $1 \mathrm{mM} \mathrm{DyCl} \mathrm{m}_{3}$ ist ersichtlich, dass durch Zugabe von Dysprosiumionen nicht nur die Signale des EDTAs durch die PRE so stark verbreitert werden, dass sie nicht mehr im Spektrum zu erkennen sind, sondern auch der TRIS-Peak in Form von Signalverminderung und Signalverschiebung beeinflusst wird (Abb. 6.9).

EDTA weist bei neutralem pH Wert eine sehr hohe Komplexbindungskonstante zu Lanthanoiden auf. Dies ermöglichte eine HPLC-Trennung des Lanthanoidsalzes vom Natriumsalz des EDTAs. Die Chromatographie erfolgte mit Hilfe eines Triethylammoniumacetatpuffers bei pH 7 an einer C18-Kieselgelsäule. EDTA als Chelatmolekül erwies sich als ungeeignet, da es nur sehr schwach UV-aktiv ist. Um eine hinreichende UV-Detektionssensitivität zu erlangen, werden große Mengen EDTA benötigt, die zu einer Überladung der Säule führen und somit die Peakform verbreitern (Abb. 6.10).

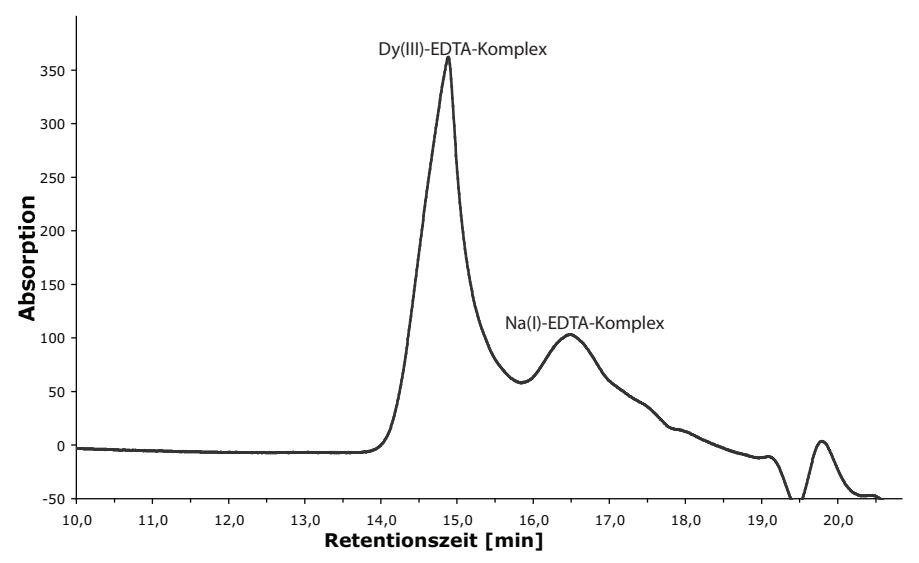

Abb. 6.10: HPLC-Chromatogramm einer Mischung aus EDTA und $\mathrm{DyCl}_{3}(3: 2)$. 
Deshalb wurde ein racemisches EDTA-Derivat eingesetzt (Abb.6.11), das wesentlich stärker UV-aktiv ist [138]. Die lanthanoidfreie Form wurde mit einem Überschuss Natriumchlorid an der HPLC injiziert. Der Überschuss an Natriumchlorid bewirkt aufgrund des einheitlichen Gegenions der Carboxylgruppen der EDTA-Derivats eine eindeutige Retentionszeit. Ohne Überschuss an Natriumchlorid traten mehrere Peaks auf, resultierend aus den unterschiedlichen Gegenionen (Abb. 6.12).<smiles>CC(=O)CN(CC(C)=O)C[C@H](C(=O)Nc1ccc2c(C)cc(=O)[nH]c2c1)N(CC(C)=O)CC(C)=O</smiles>

Abb. 6.11: UV-aktives EDTA-Derivat.

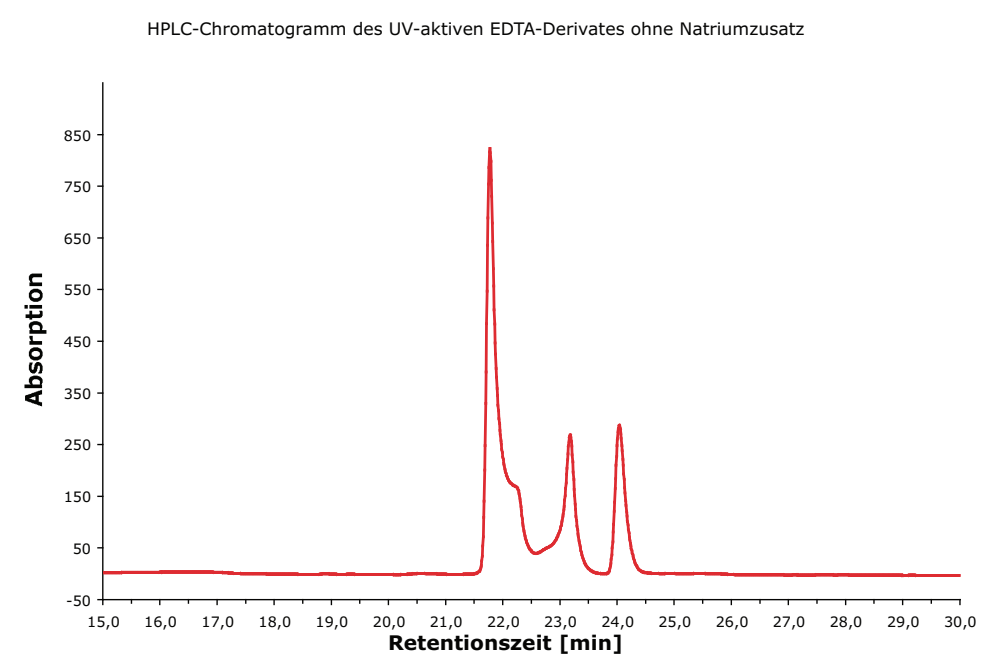

Abb. 6.12: HPLC-Chromatogramm des UV-aktiven EDTA-Derivates ohne Natriumchloridzusatz.

Die Retentionszeit des Natriumsalzes war etwa 1 min kürzer als die des mit Dysprosium(III) beladenen EDTA-Derivates, das ein scharfes Signal aufwies (Abb. 6.13). Mit der in dieser Arbeit implementierten Methode ist es möglich, lanthanoidionenkomplexierte und freie Form voneinander zu trennen. Dies kann auch zur Aufreinigung der mit EDTA getaggten DNA genutzt werden, um die mit Lanthanoidionen beladene DNA zu isolieren. 


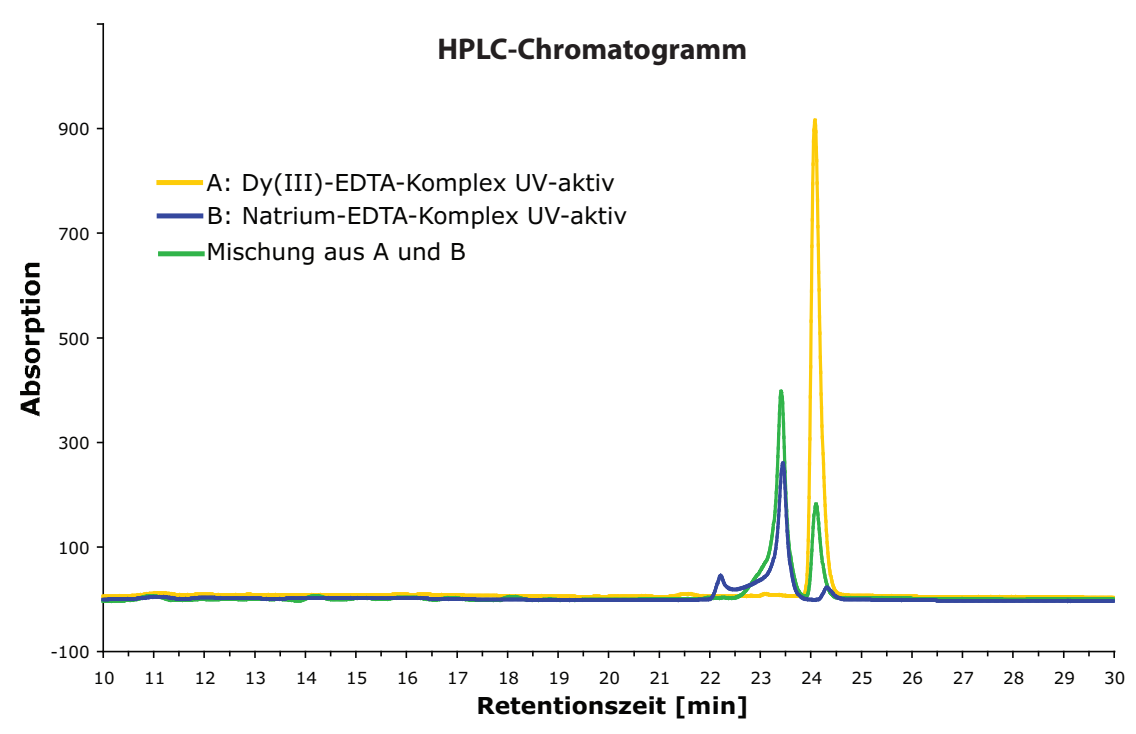

Abb. 6.13: HPLC-Chromatogramm des UV-aktiven EDTA-Derivates mit Natriumüberschuss, mit Dysprosium und deren Mischform.

\subsection{NMR-Messungen der Hairpin-DNA mit EPTE-Tag}

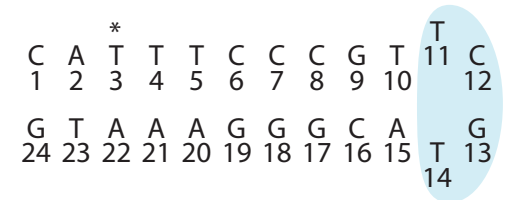

Abb. 6.14: 24mer Hairpin-DNA mit EPTE-Tag an der Position T*.

Die STAT-bindende Hairpin-Sequenz, deren Struktur wie in Kapitel 3 beschrieben gelöst wurde, kann durch eine Clickreaktion mit einem EPTE-Tag versehen werden (Abb. 6.14). Dazu wurde eine modifizierte Uridinbase an der dritten Position der Sequenz eingebaut und anschließend eine Clickreaktion an der festphasengebundenen DNA durchgeführt. Das in Kapitel 4 gemachte Postulat, dass die Struktur der DNA durch die Bindung eine Tags nicht verändert wird, wurde als erstes überprüft. Dazu wurden ein NOESY, COSY und TOCSYSpektrum aufgenommen. Das NMR-Spektrum der DNA ist dem der unmodifizierten Sequenz sehr ähnlich. Nur die chemischen Verschiebungen der tagbenachbarten Nukleotide A2 und T4 unterscheiden sich, sowie die Signale des modifizierten Nukleotids (Abb. 6.15 und 6.17). 
DNA-Hairpin mit EPTE-Tag

\begin{tabular}{|c|c|c|c|c|c|}
\hline & H1' & H2' & H2' & H6/H8 & H5/7* \\
\hline $\mathbf{c 1}$ & 5,63 & 1,62 & 2,20 & 7,46 & 5,77 \\
\hline $\mathbf{a 2}$ & 6,26 & 2,69 & 3,16 & 8,07 & \\
\hline $\mathbf{x 3}$ & 6,15 & 2,26 & 2,67 & 7,92 & \\
\hline $\mathbf{t 4}$ & 6,17 & 2,21 & 2,61 & 7,50 & 1,61 \\
\hline $\mathbf{t 5}$ & 6,02 & 2,13 & 2,49 & 7,38 & 1,60 \\
\hline $\mathbf{c 6}$ & 5,85 & 2,15 & 2,38 & 7,51 & 5,60 \\
\hline $\mathbf{c 7}$ & 5,83 & 2,09 & 2,37 & 7,45 & 5,52 \\
\hline $\mathbf{c 8}$ & 5,51 & 1,99 & 2,30 & 7,38 & 5,56 \\
\hline $\mathbf{g 9}$ & 5,92 & 2,56 & 2,65 & 7,87 & \\
\hline $\mathbf{t 1 0}$ & 6,11 & 2,18 & 2,39 & 7,25 & 1,49 \\
\hline $\mathbf{t 1 1}$ & 6,10 & 2,09 & 2,35 & 7,52 & 1,78 \\
\hline $\mathbf{c 1 2}$ & 6,11 & 1,98 & 2,20 & 7,63 & 5,99 \\
\hline $\mathbf{c 1 3}$ & 5,74 & 1,80 & 2,31 & 7,31 & 5,73 \\
\hline $\mathbf{t 1 4}$ & 5,87 & 2,05 & 2,26 & 7,38 & 1,69 \\
\hline $\mathbf{a 1 5}$ & 6,09 & 2,68 & 2,79 & 8,31 & \\
\hline $\mathbf{c 1 6}$ & 5,45 & 1,82 & 2,20 & 7,22 & 5,21 \\
\hline $\mathbf{g 1 7}$ & 5,47 & 2,52 & 2,63 & 7,73 & \\
\hline $\mathbf{g 1 8}$ & 5,53 & - & - & 7,56 & \\
\hline $\mathbf{g 1 9}$ & 5,24 & 2,38 & 2,51 & 7,56 & \\
\hline $\mathbf{a 2 0}$ & 5,74 & 2,55 & 2,77 & 8,00 & \\
\hline $\mathbf{a 2 1}$ & 5,85 & 2,55 & 2,82 & 8,01 & \\
\hline $\mathbf{a 2 2}$ & 6,06 & 2,42 & 2,80 & 8,02 & \\
\hline $\mathbf{t 2 3}$ & 5,70 & 1,72 & 2,20 & 6,90 & 1,32 \\
\hline $\mathbf{g 2 4}$ & 6,03 & 2,50 & 2,28 & 7,75 & \\
\hline
\end{tabular}

DNA-Hairpin ohne EPTE-Tag

\begin{tabular}{|c|c|c|c|c|c|}
\hline & H1' & $\mathrm{H}^{\prime}$ & H2" & H6/H8 & H5/7* \\
\hline c1 & 5,63 & 1,91 & 2,38 & 7,64 & 5,89 \\
\hline a2 & 6,30 & 2,73 & 2,95 & 8,37 & \\
\hline t3 & 5,93 & 2,03 & 2,55 & 7,18 & 1,35 \\
\hline t4 & 6,08 & 2,12 & 2,57 & 7,39 & 1,51 \\
\hline t5 & 6,02 & 2,10 & 2,52 & 7,33 & 1,55 \\
\hline c6 & 5,84 & 2,10 & 2,37 & 7,47 & 5,56 \\
\hline c7 & 5,82 & 2,05 & 2,35 & 7,42 & 5,49 \\
\hline c8 & 5,49 & 1,99 & 2,30 & 7,36 & 5,55 \\
\hline g9 & 5,90 & 2,55 & 2,64 & 7,84 & \\
\hline t10 & 6,09 & 2,18 & 2,39 & 7,23 & 1,48 \\
\hline t11 & 6,11 & 2,08 & 2,35 & 7,50 & 1,76 \\
\hline c12 & 6,09 & 1,97 & 2,20 & 7,64 & 5,97 \\
\hline c13 & 5,74 & 1,80 & 2,30 & 7,35 & 5,72 \\
\hline t14 & 5,79 & 2,01 & 2,23 & 7,32 & 1,65 \\
\hline a15 & 6,08 & 2,67 & 2,78 & 8,29 & \\
\hline c16 & 5,47 & 1,77 & 2,18 & 7,19 & 5,21 \\
\hline g17 & 5,42 & 2,51 & 2,61 & 7,70 & \\
\hline g18 & 5,54 & 2,41 & 2,59 & 7,54 & \\
\hline g19 & 5,30 & 2,42 & 2,55 & 7,57 & \\
\hline a20 & 5,82 & - & 2,80 & 7,98 & \\
\hline a21 & 5,84 & 2,53 & 2,80 & 7,97 & \\
\hline a22 & 6,05 & 2,41 & 2,79 & 7,99 & \\
\hline$t 23$ & 5,74 & 1,76 & 2,25 & 6,94 & 1,25 \\
\hline 924 & 6,07 & 2,38 & 2,38 & 7,77 & \\
\hline
\end{tabular}

Abb. 6.15: Tabelle der chemischen Verschiebungen der DNA mit und ohne EPTE-Tag in ppm.

Zusätzlich finden sich einige gut aufgelöste Signale des Tags: Das Triazol-Proton bei 8.91 ppm, sowie die Signale der benachbarten Phenylprotonen bei 7.94 (Ph1a), 7.67 (Ph1b) und 7.81 (Ph2a) ppm. Die Zuordnung der Signale erfolgte dabei durch ein ${ }^{1}$ H-NOESY-Spektrum unter Zuhilfenahme eines COSY- und eines TOCSY-Spektrums. Der „NOESY-Walk“ ist in Abb. 6.17 oben abgebildet, die Region der H2"/H2'-H6/H8-NOE-Kreuzpeaks ist in Abb. 6.17 unten abgebildet. Eine Tabelle der gemessenen Resonanzfrequenzen befindet sich in Abb. 6.15.

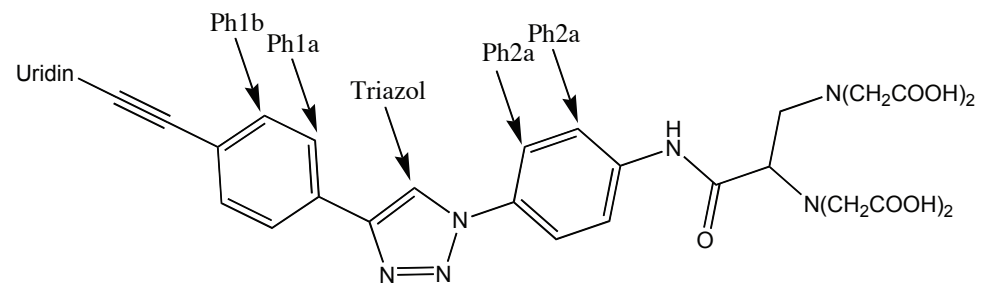

Abb. 6.16: EPTE-Tag, der durch eine Clickreaktion an der festen Phase die DNA modifiziert. 

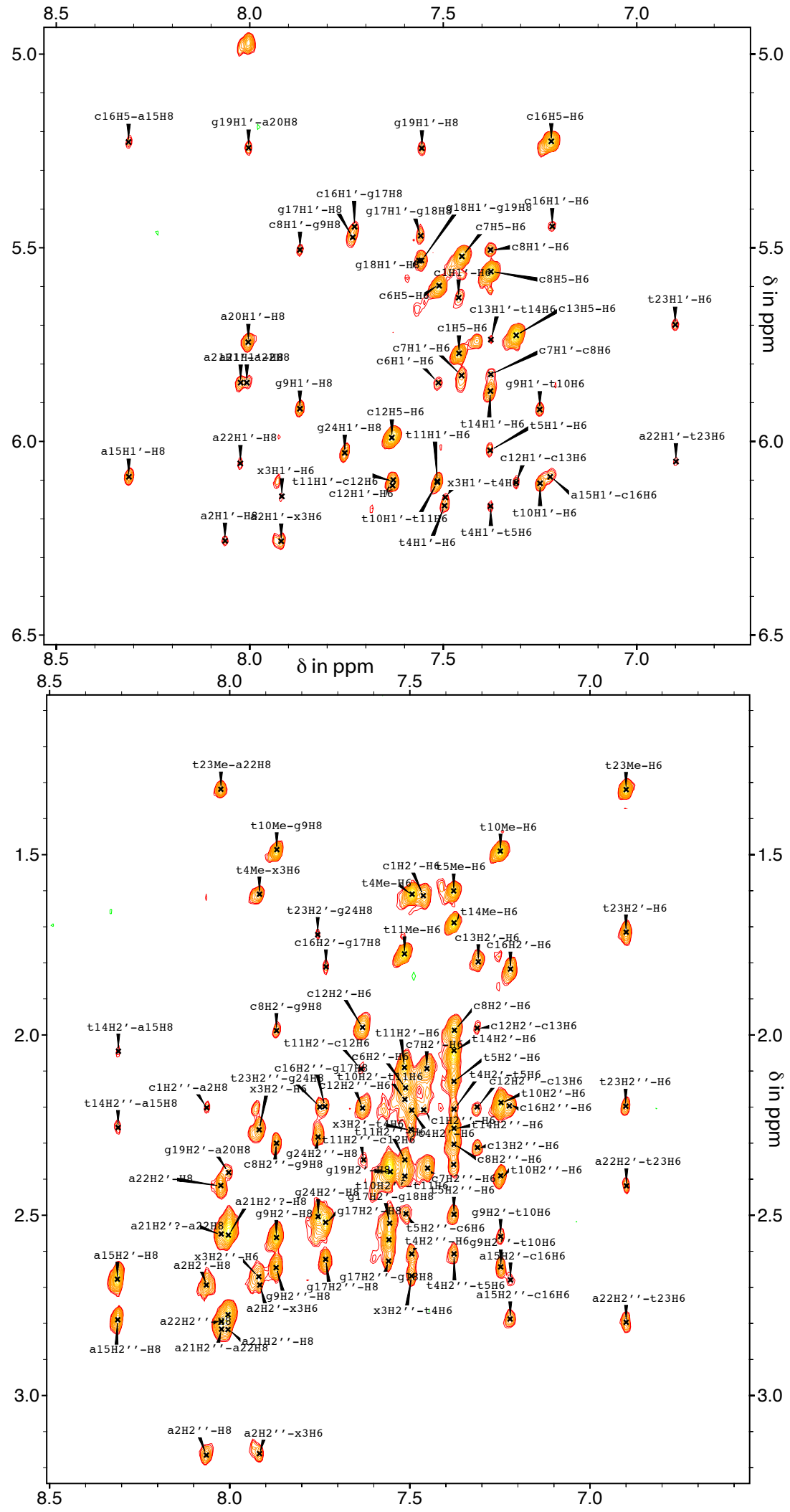

Abb. 6.17: Ausschnitte aus dem ${ }^{1} \mathrm{H}-\mathrm{NOESY}-S p e k t r u m, 1 \mathrm{mM}$ DNA mit EPTE-Tag in $\mathrm{D}_{2} \mathrm{O}$ bei $25{ }^{\circ} \mathrm{C}, 10 \mathrm{mM}$ Natriumphosphatpuffer ( $\left.\mathrm{pH}=7\right), 250 \mathrm{~ms}$ Mischzeit, $600 \mathrm{MHz}$. 
Aus der geringen Veränderung der NMR-Spektren (Abb. 6.15) lässt sich der Schluss ziehen, dass sich die Struktur des Hairpins durch die EPTE-Markierung kaum veränderte. Dies ist essentiell für die Funktionalität der Taggingmethode, damit die native Struktur des Biomoleküls erhalten bleibt. Die EPTE-modifizierte DNA wurde anschließend mit einer Dysprosiumchloridlösung (17 mM, pH =6.8) versetzt. NMR-Spektren von unmarkierten Oligonukleotiden werden meist in Natriumphosphatpuffersystemen gemessen, da dadurch keine zusätzlichen ${ }^{1} \mathrm{H}$ - und ${ }^{13} \mathrm{C}$-Signale auftreten. Dieses Puffersystem ist jedoch nicht für $\mathrm{Ln}^{3+}$-haltige Systeme geeignet, da diese in Anwesenheit von Phosphationen ausfallen. Auch die Nutzung anderer Puffersysteme, wie beispielsweise TRIS-HCl birgt die Gefahr, dass der $\mathrm{Ln}^{3+}$-EDTA-Komplex durch die konkurrienden TRIS-Liganden geschwächt wird. Bei einer Titration von Dysprosiumchlorid zu einer $1 \mathrm{mM}$ Oligonukleotidlösung in $10 \mathrm{mM}$ Tris- $\mathrm{HCl}$ $(\mathrm{pH}=7)$ zeigte das NOESY-Spektrums keine Pseudokontaktshifts.

In Anwesenheit von 10 mM Ammoniumacetat $(\mathrm{pH}=7)$ bildete sich durch Titration mit Dysprosiumchlorid ein zweiter Satz von Signalen aus. Die Zuordnung der Signale erfolgte durch die NOE-Kreuzpeaks, wie auch in Kapitel 3 beschrieben. Durch die Komplexität des teilweise verdoppelten Signalsatzes wurden zudem die bekannten chemischen Verschiebungen des unbeladenen Hairpins mit EPTE-Tag zu Hilfe genommen. Dabei müssen das diamagnetische und paramagnetische Signal, wie in Kapitel 3.8 beschrieben, in etwa diagonal (45 ${ }^{\circ}$ Winkel) zueinander verschoben sein, da der Vektor zwischen Kern und paramagnetischem Zentrum für zwei benachbarte Kerne in etwa die gleiche Orientierung und die gleiche Länge besitzt (Abb. 6.19). Ausschnitte des paramagnetischen Spektrums finden sich in Abb. 6.18. 

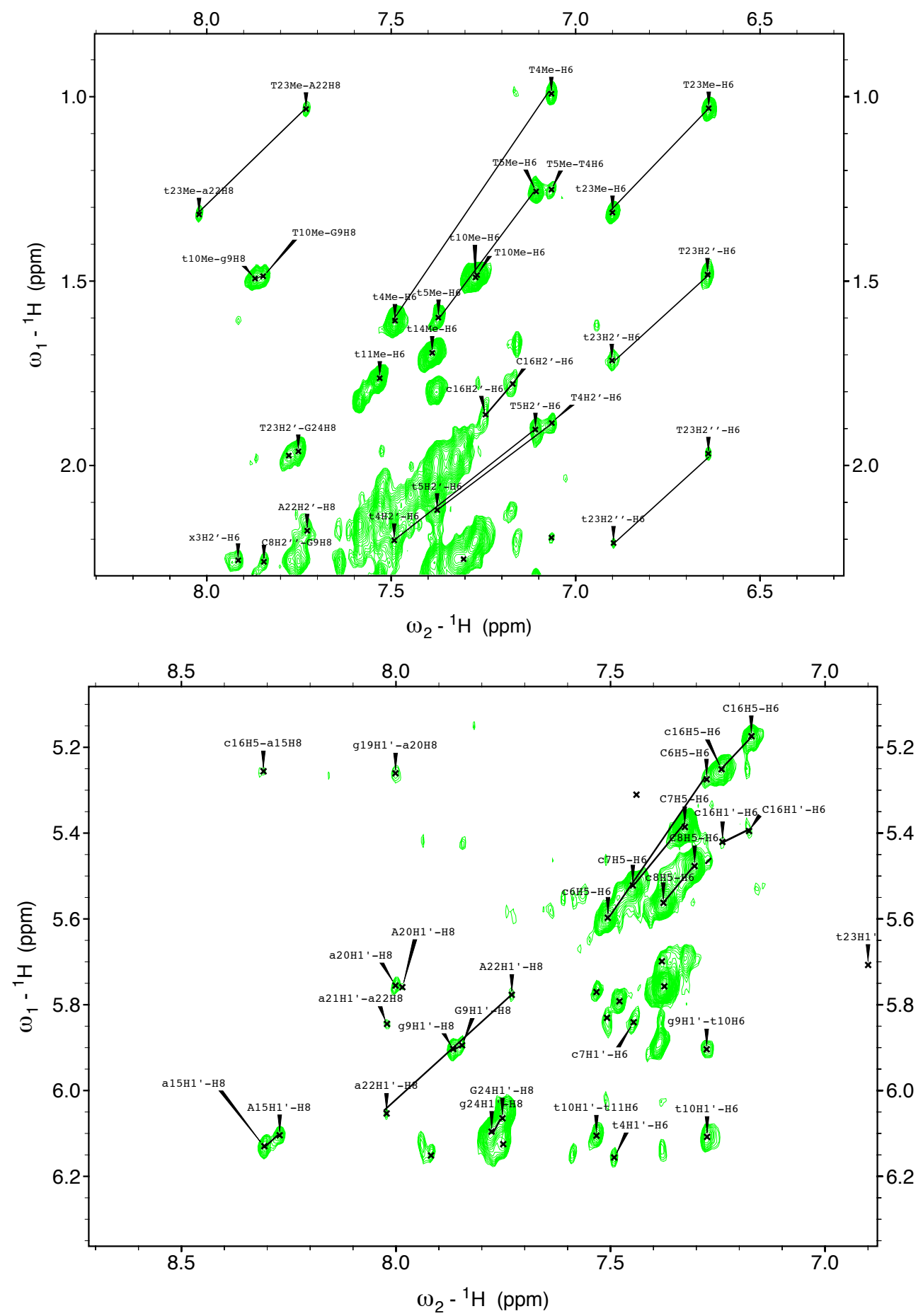

Abb. 6.18: Ausschnitte des NOESY-Spektrums des DNA-Hairpins mit EPTE-Tag und Dy ${ }^{3+}$ in $\mathrm{D}_{2} \mathrm{O}$ bei $25^{\circ} \mathrm{C}$ und $700 \mathrm{MHz}, 10 \mathrm{mM}$ Ammoniumacetatpuffer $(\mathrm{pH}=7), 250 \mathrm{~ms}$ Mischzeit. Großbuchstaben bezeichnen die paramagnetischen Signale, Kleinbuchstaben die diamagnetischen Signale. 
Einige Signale verschwanden dabei vollständig durch die PRE. Neben allen Signalen des modifizierten Nukleotids verschwanden auch die Signale von A2, G19 und G18. Im Gegensatz dazu veränderten sich die Signale der Thyminbasen im Loop kaum. Die Signale von C12 und C13 im Loop waren generell an einer anderen Position als im Spektrum der getaggten DNA in Phosphatpuffer, besitzen jedoch nur einen Satz an Signalen. Die flexible Loopregion ist in ihrer Struktur also eventuell durch den Wechsel des Puffersystems von Natriumphosphat zu Ammoniumacetat verändert. Wie zu erwarten treten die größten PCS im Bereich von T4 und T5 auf (Abb. 6.19). Diese Nukleotide befinden sich in unmittelbarer Nähe des Metallzentrums.

a)

\begin{tabular}{|c|c|c|}
\hline Nukleotid & Kern & PCS in ppm \\
\hline T4 & $\mathrm{H} 7 *$ & $-0,616$ \\
\hline T4 & $\mathrm{H} 6$ & $-0,424$ \\
\hline T5 & $\mathrm{H} 7 *$ & $-0,342$ \\
\hline T5 & $\mathrm{H} 6$ & $-0,266$ \\
\hline T5 & $\mathrm{H}^{\prime}$ & $-0,218$ \\
\hline C6 & $\mathrm{H} 5$ & $-0,322$ \\
\hline C6 & $\mathrm{H} 6$ & $-0,229$ \\
\hline C7 & $\mathrm{H} 5$ & $-0,136$ \\
\hline C7 & $\mathrm{H} 6$ & $-0,120$ \\
\hline C7 & $\mathrm{H}^{\prime}$ & $-0,101$ \\
\hline $\mathrm{C} 8$ & H2" & $-0,043$ \\
\hline C8 & H5 & $-0,086$ \\
\hline C8 & $\mathrm{H} 6$ & $-0,073$ \\
\hline G9 & $\mathrm{H} 1^{\prime}$ & $-0,009$ \\
\hline G9 & $\mathrm{H} 8$ & $-0,023$ \\
\hline T10 & $\mathrm{H} 7 *$ & $-0,003$ \\
\hline T10 & H2" & $-0,006$ \\
\hline T10 & $\mathrm{H} 6$ & $-0,003$ \\
\hline A15 & $\mathrm{H} 1^{\prime}$ & $-0,026$ \\
\hline A15 & $\mathrm{H} 2^{\prime}$ & $-0,037$ \\
\hline A15 & H2" & $-0,035$ \\
\hline A15 & $\mathrm{H} 8$ & $-0,116$ \\
\hline C16 & H5 & $-0,080$ \\
\hline $\mathrm{C} 16$ & $\mathrm{H} 6$ & $-0,068$ \\
\hline $\mathrm{C} 16$ & $\mathrm{H} 2^{\prime}$ & $-0,083$ \\
\hline A22 & $\mathrm{H} 1^{\prime}$ & $-0,277$ \\
\hline A22 & $\mathrm{H}^{\prime}$ & $-0,242$ \\
\hline A22 & $\mathrm{H} 2^{\prime \prime}$ & $-0,237$ \\
\hline A22 & $\mathrm{H} 8$ & $-0,292$ \\
\hline T23 & $\mathrm{H} 7 *$ & $-0,284$ \\
\hline T23 & H6 & $-0,259$ \\
\hline $\mathrm{T} 23$ & $\mathrm{H} 2^{\prime \prime}$ & $-0,245$ \\
\hline $\mathrm{T} 23$ & $\mathrm{H} 1^{\prime}$ & $-0,295$ \\
\hline
\end{tabular}

b)

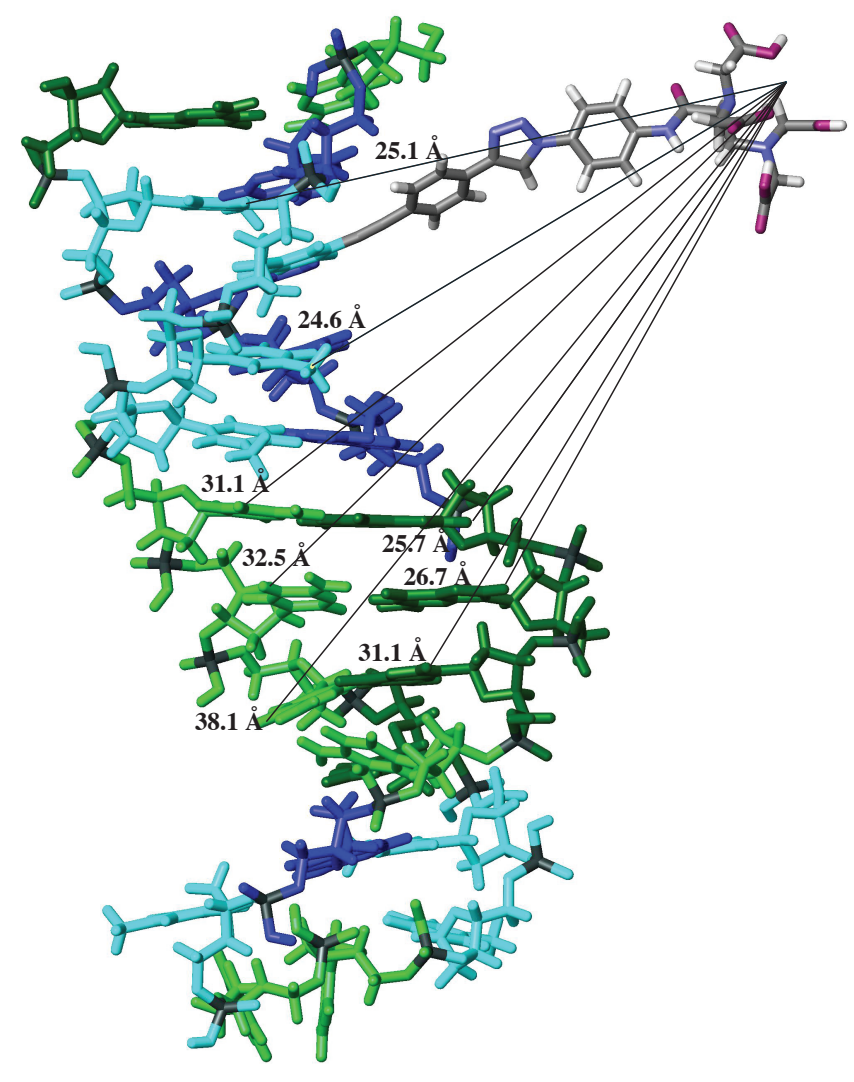

Abb. 6.19: a) Tabelle der Pseudokontaktshifts des EPTE-DNA-Hairpins mit $\mathrm{Dy}^{3+}$.

b) Abstandsinformationen des DNA-Hairpin mit EPTE-Tag (hellblau: Thymindin, dunkelblau: Adenosin, hellgrün: Cytidin, dunkelgrün: Guanosin). 
Aus der NMR-Struktur des unmodifizierten Hairpins (Abschnitt 3.5) wurde mit dem Programm Macromodel eine Struktur des Oligonukleotids mit EPTE-Tag simuliert. Dazu wurde der Tag an die Grundstruktur gebunden, eine Konformationssuche für den Tag durchgeführt und die am häufigsten vorhandene Struktur anschließend energieminimiert. Die resultierende Struktur inklusive einiger repräsentativer Abstandsinformationen ist in Abbildung 6.19 dargestellt. Dabei wird deutlich, dass die Nukleotide G18 und G19 aufgrund der helikalen Struktur näher am Metallzentrum liegen als A21. Dies erklärt die Beobachtung, dass neben A2 auch die Signale von G18 und G19 so stark verbreitert waren, dass sie nicht mehr gut zu erkennen waren.

Aus den Pseudokontaktverschiebungen wurde mit Hilfe des Programms RELAX der Alignmenttensor berechnet. Dazu wurden die mit Macromodel generierten DNA-Strukturen mit den unterschiedlichen Tag-Konformationen (77 Stück) in pdb-Dateien umgewandelt. In jede Struktur wurde ein Lanthanoidion als Pseudoatom eingefügt, das durch einen linearen Mittelwert aller Sauerstoffatome der EDTA-Funktion berechnet wurde. Zudem wurden alle Methylgruppen der Thyminbasen mittels linearer Mittelung durch ein Pseudoatom H7* ersetzt. Nun wurde der Anisotropietensor durch Iteration ermittelt. Dabei wurden für verschiedene Tensoren die theoretischen PCS berechnet und jeweils mit den gemessenen PCS verglichen. Die beste Übereinstimmung liefert das Ergebnis für den Alignmenttensor. Dabei ergab sich bei $298 \mathrm{~K}$ und $700 \mathrm{MHz}$ ein Tensor von:

$$
A=\left(\begin{array}{ccc}
A_{x x} & A_{x y} & A_{x z} \\
A_{x y} & A_{y y} & A_{y z} \\
A_{x z} & A_{y z} & A_{z z}
\end{array}\right)=\left(\begin{array}{ccc}
0,4504 & 1,7050 & 1,5210 \\
1,7050 & -0,7248 & -1,2655 \\
1,5210 & -1,2655 & 0,2744
\end{array}\right) * 10^{-4}
$$

Der q-Faktor betrug 0.086. Der diagonalisierte Alignmenttensor entspricht (Abb. 6.20):

$$
A=\left(\begin{array}{ccc}
1.0677 & 0 & 00 \\
0 & 1.9898 & 0 \\
0 & 0 & -3.0575
\end{array}\right) * 10^{-4}
$$




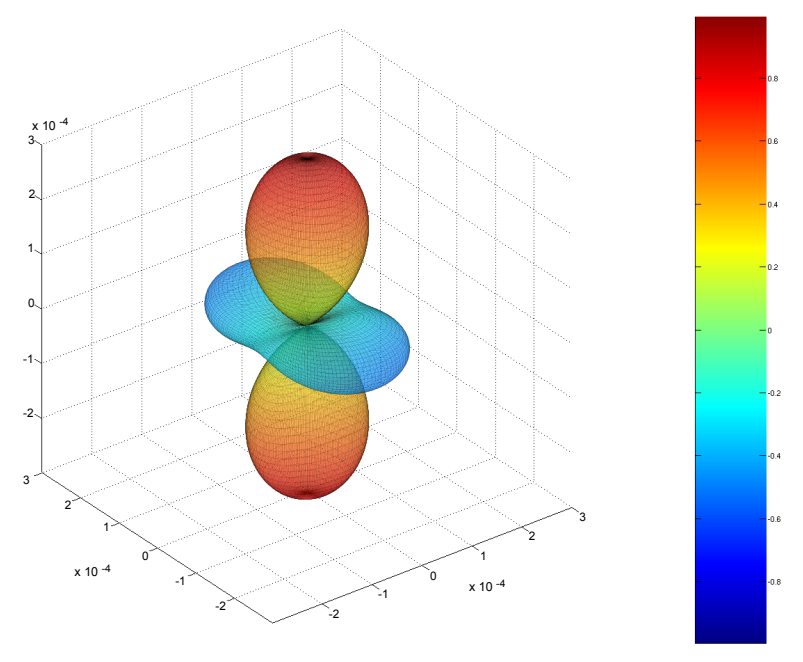

Abb. 6.20: Der diagonalisierte Alignmenttensor.

Der Alignmenttensor wird in der Regel in seiner diagonalisierten Form angegeben. Die Diagonalisierung entspricht dabei der Transformation des Koordinatensystem vom Molekül- zum Alignmentkoordinatensystem. Vorteilhaft ist dabei, dass die Größen verschiedener Tensoren einfacherer miteinander verglichen werden können. Zudem werden auch die Winkelinformationen der rdcs in diesem Koordinatensystem bestimmt. Die aus dem Alignmenttensor berechneten PCS korrelieren gut mit den gemessenen PCS, wie in Abbildung 6.21 ersichtlich. Auffällig ist vor allem die Abweichung von A15 H8, einer loopbenachbarten Base. Ursache dafür könnte eine veränderte Loopstruktur sein, die aus der Messung in einem anderen Puffersystem resultiert. Der maximal zu erwartende rdc bei $700 \mathrm{MHz}$ mit $\cos \Theta=1$ entspricht $A_{z z} * D_{\max , C-H}$ und ist damit $13.8 \mathrm{~Hz}$ groß.

Bildet man DNA-Struktur und Tensor im selben Koordinatensystem ab, so ist erkennbar, dass der Tensor in Richtung der DNA die maximale Ausdehnung erreicht (Abb. 6.22). Dadurch lassen sich die relativ hohen gemessenen PCS-Werte erklären. Außerdem zeigt sich, dass der Anisotropietensor des paramagnetischen Zentrums im Vergleich zur Oligonukleotidachse gedreht vorliegt. Die Achsen unmodifizierter DNAs richten sich in einem externen Magnetfeld durch Ringströme in den Basen aus. Dies führt zu der self alignment-Fähigkeit von Nukleinsäuren $[139,140]$. Dieses diamagnetische self alignment ist jedoch viel schwächer als paramagnetisches Alignment. Die Größe des Tensors und damit auch der erwarteten rdcs 


\section{Vergleich der berechneten PCS mit den gemessenen PCS}

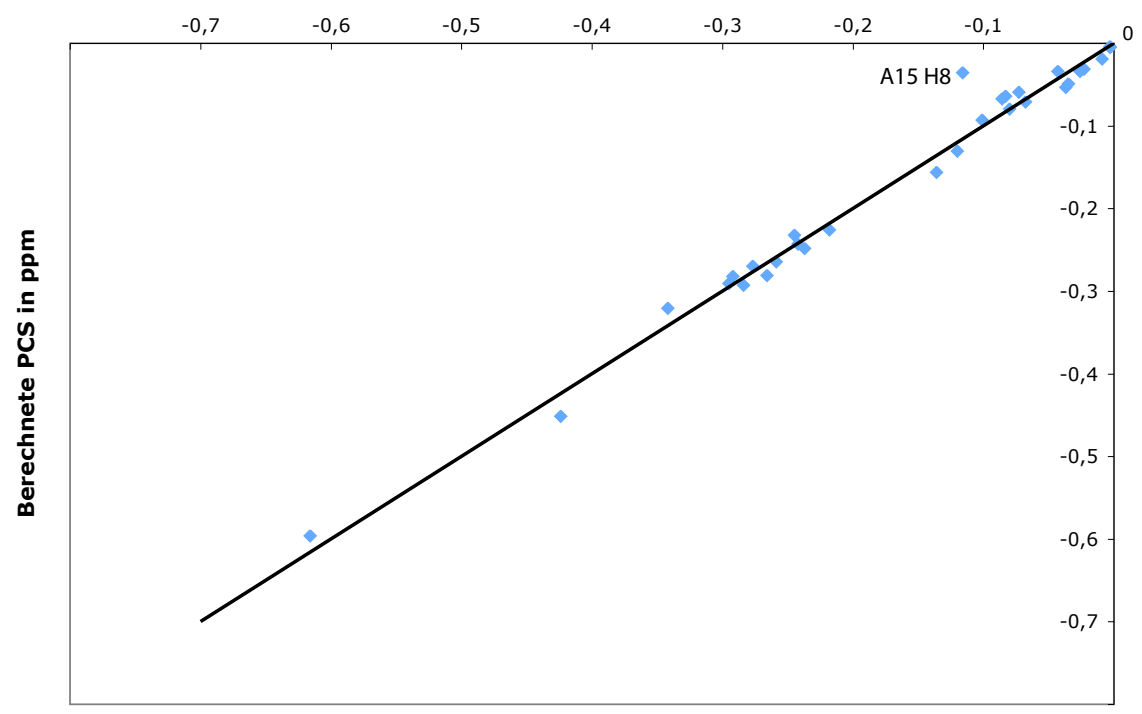

Gemessene PCS in ppm

Abb. 6.21: Auftragung der gemessenen PCS gegen die berechneten PCS. Die gute Korrelation besitzt einen q-Faktor von 0.086 .

entspricht in etwa den Werten der mit EDTA-Tag modifizierten Proteinen [12,14]. Dies war zu erwarten, da die Größe des Alignments sowohl von der Koordinationssphäre des Lanthanoids, dem Element und der Flexibilität des Tags in Bezug auf das Biomolekül abhängt. Bei den Proteinmessungen findet nun im Wesentlichen die gleiche Koordinationssphere aufgrund der Verwendung von EDTA. Zudem wurden Terbiumionen komplexiert, die eine ähnlich große magnetische Anisotropie wie Dysprosiumionen besitzen. Auch die Flexibilität der Tags sollte vergleichbar sein. 


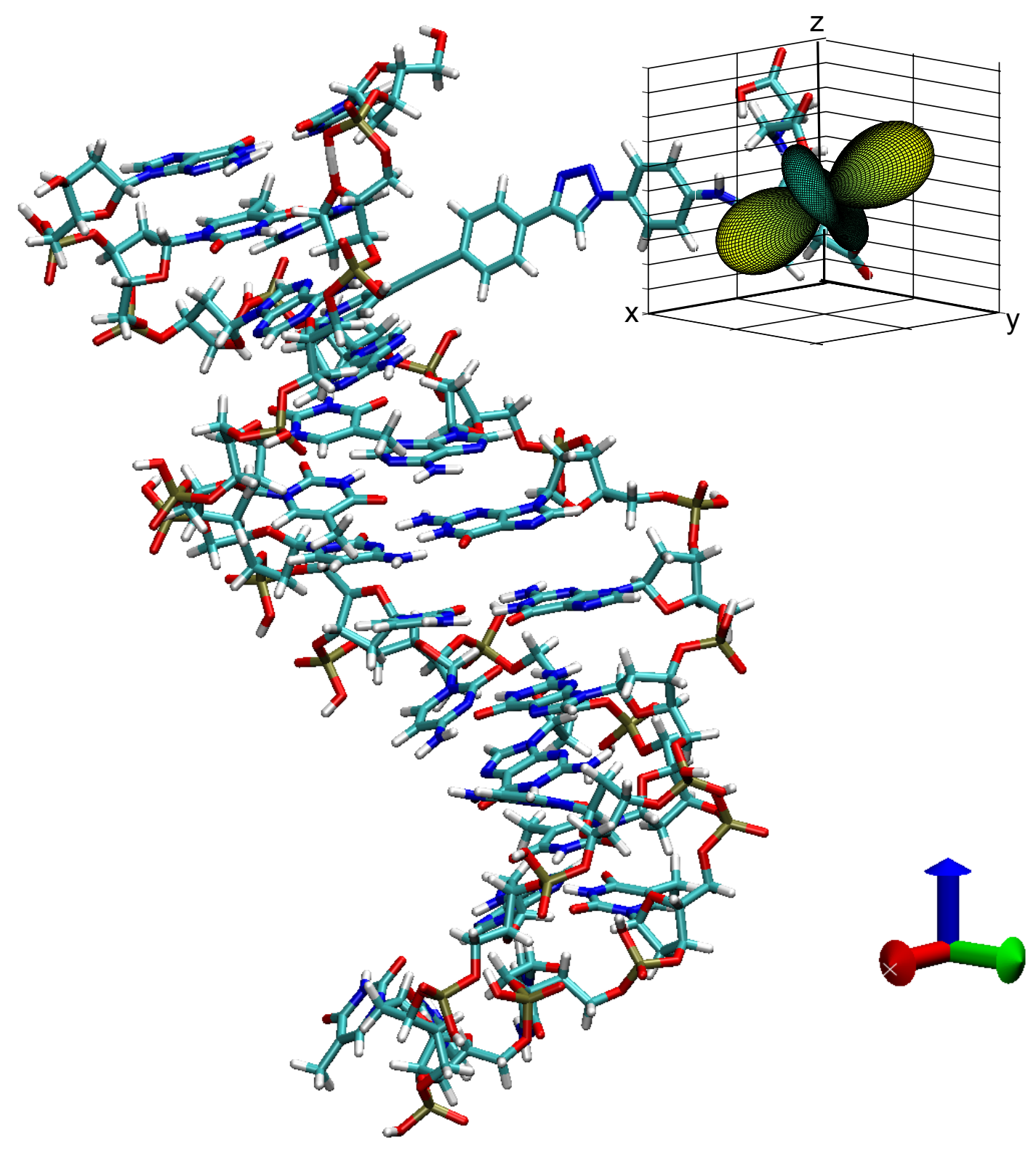

Abb. 6.22: DNA-Struktur und Tensor im Molkülkoordinatensystem.

\subsection{Chimäre TAR-RNA}

Die biologische Bedeutung der TAR-RNA ist bereits in Kapitel 2.4 dargestellt. In dieser Arbeit wurde ein TAR-RNA-Konstrukt entwickelt, das ein Alignment der RNA ermöglicht. Die TAR-RNA aus HIV-2 ist eine strukturell in Lösung, insbesondere mit Liganden, sehr 
gut charakterisierte RNA $[35,36]$. Die Zuordnung der chemischen Verschiebungen der RNA ist bekannt (personal communciation: Teresa Carlomagno).

Um RNA mit Hilfe eines EPTE-Tags in einem externen Magnetfeld auszurichten, muss eine ethinylmodifizierte Base in den Strang eingebaut werden. Dies ist bisher nicht durch den Einbau des entsprechenden Monomers möglich, da zur chemischen RNA-Synthese eine andere Schutzgruppenchemie verwendet wird als bei der DNA-Synthese. Außerdem soll die RNA durch Transkription synthetisiert werden, damit es möglich ist ${ }^{13} \mathrm{C}$ und ${ }^{15} \mathrm{~N}$ gelabelte Nukleotide zu verwenden. Um trotzdem einen EPTE-Tag nutzen zu können, wird ein chimäres Konstrukt verwendet, bestehend aus der gewünschten RNA-Sequenz, verlängert durch zusätzliche Nukleotide am 3'-Ende. Durch Zugabe des komplementären DNA-Stranges mit EPTE-Tag kann der gesamte Komplex im Magnetfeld ausgerichtet werden.

Eine TAR-RNA-Sequenz wurde zunächst am 3' Ende um acht Basen verlängert und anschließend ein komplementärer DNA-Gegenstrang zur RNA titriert. Dabei stellte sich heraus, dass sich kein stabiler chimärer Duplex ausbildete. Ein Überhang von elf Basen mit einem komplementären DNA-Decamer mit einem Uridincap bildete dagegen einen stabilen Doppelstrang bei $25^{\circ} \mathrm{C}$. (Abb. 6.23). Die Sequenzabfolge der zusätzlichen Basen wurde dabei so gewählt, dass keine fünf aufeinanderfolgenden Basen komplementär zu einem Abschnitt der TAR-RNA sind, um eine Veränderung der nativen TAR-RNA-Struktur zu vermeiden. Des Weiteren wurden der DNA-Strang so entworfen, dass er möglichst viele Thymidine enthält und somit die Möglichkeit mehrerer Modifikationsstellen bietet. Das Uridincap U57 wurde als zusätzlicher Stabilisator des chimären Doppelstranges gewählt [141].

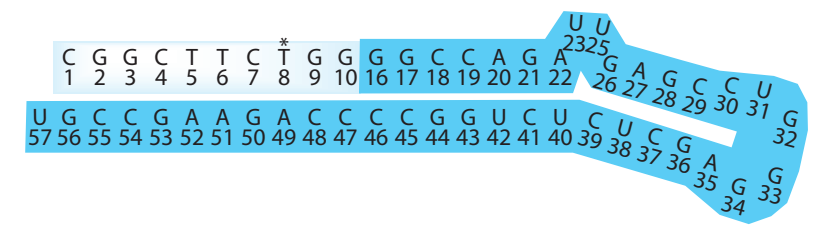

Abb. 6.23: Verlängerte TAR-Sequenz des HIV2. In dunkelblau ist die TAR-RNA mit elf zusätzlichen Basen, in hellblau der decamere DNA-Gegenstrang dargestellt. Das Sternchen kennzeichnet die Position der getaggten Base. 
Die Duplexbildung wurde durch ${ }^{13} \mathrm{C}$-HSQC-Spektren der verlängerten TAR-RNA mit ${ }^{13} \mathrm{C}$ markierten Adenosinen verifiziert. Dazu wurden die HSQC-Spektren ohne und mit DNAGegenstrang verglichen. Bei $25{ }^{\circ} \mathrm{C}$ bildet sich ein stabiler chimärer Duplex (Abb. 6.24, Abb. 6.25 und Abb. 6.26).
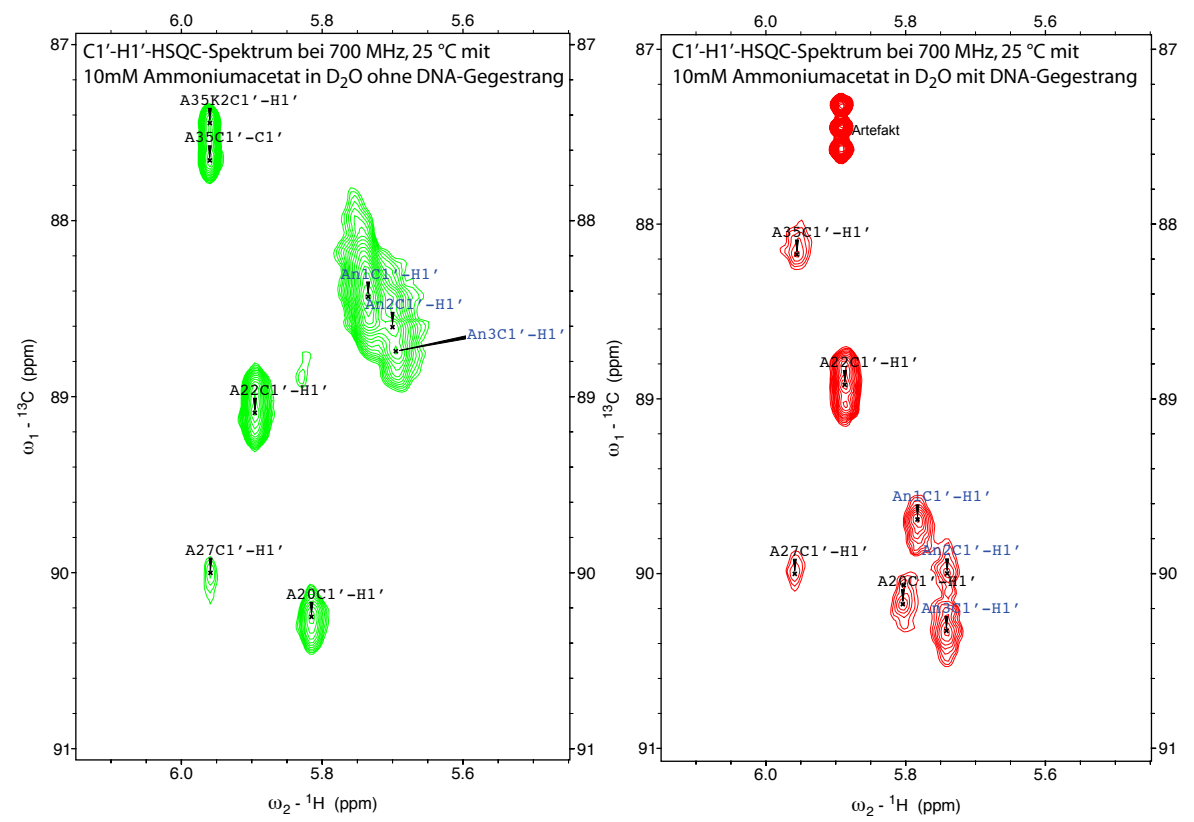

Abb. 6.24: C1'-H1'-HSQC-Spektrum der verlängerten TAR-RNA ohne (grün) und mit DNADecamer (rot). A49, A51 und A52 sind nicht zugeordnet und willkürlich mit An1, An2 und An3 bezeichnet. Sie verändern ihre Position im Spektrum stark. Es finden sich die erwarteten sieben Signale.

Durch die Modifikation der RNA darf die Struktur und Dynamik der TAR-RNA nur gering beeinflusst werden. Das dies der Fall ist, zeigte sich an der geringen Modulation der Signale der verlängerten und Wildtyp-RNA (Abb. 6.24, 6.25 und 6.26). Die Signale der Adenosine A20, A22, A27 und A35 werden durch die Zugabe der DNA nur schwach verschoben. A35 nimmt unter den Adenosinen eine besondere Stellung ein, es kann im Loop in zwei Konformationen (A35 und A35K2) vorliegen. Diese Dynamik wurde in der unverlängerten wie in der verlängerten RNA beobachtet. Auch A22 hat keine starre Konformation, da nur eine schwache Wasserstoffbrückenbindung zu U40 existiert. Das Basenpaar A22-U40 liegt benachbart zum bulge. Die Adenosine A49, A51 und A52 liefern in der ungepaarten RNA relativ breite diffuse Signale, da der Einzelstrang eine hohe Flexibilität aufweist. Die chemischen Verschiebungen liegen eher im Bereich des Loop-Adenosins A35. Durch Zugabe der DNA 


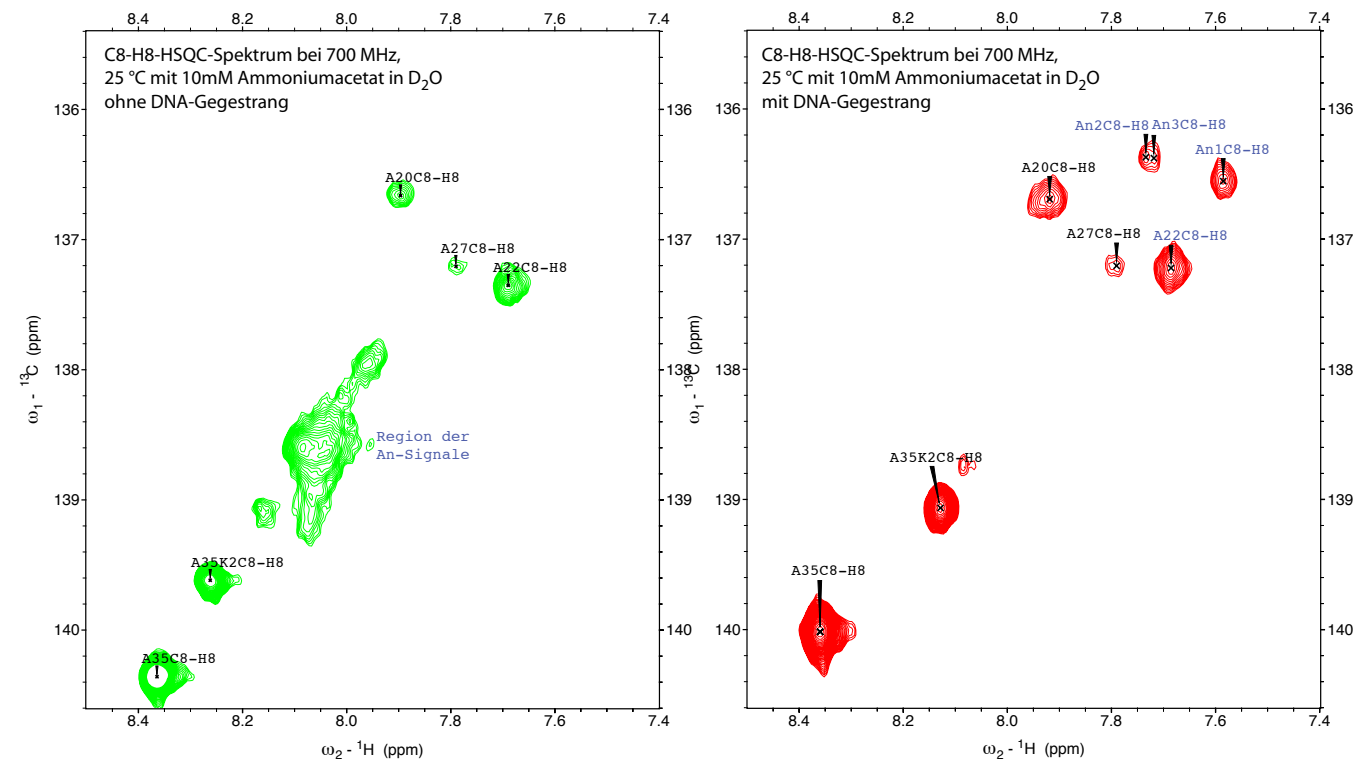

Abb. 6.25: C8-H8-HSQC-Spektrum der verlängerten TAR-RNA ohne (grün) und mit DNADecamer (rot). A49, A51 und A52 sind nicht zugeordnet und willkürlich mit An1, An2 und An3 bezeichnet. Die Position ihrer Signale wandert von einer loopartigen zu einer duplexartigen Region. Es finden sich die erwarteten sieben Signale und das Signal der zweiten A35-Konformation.
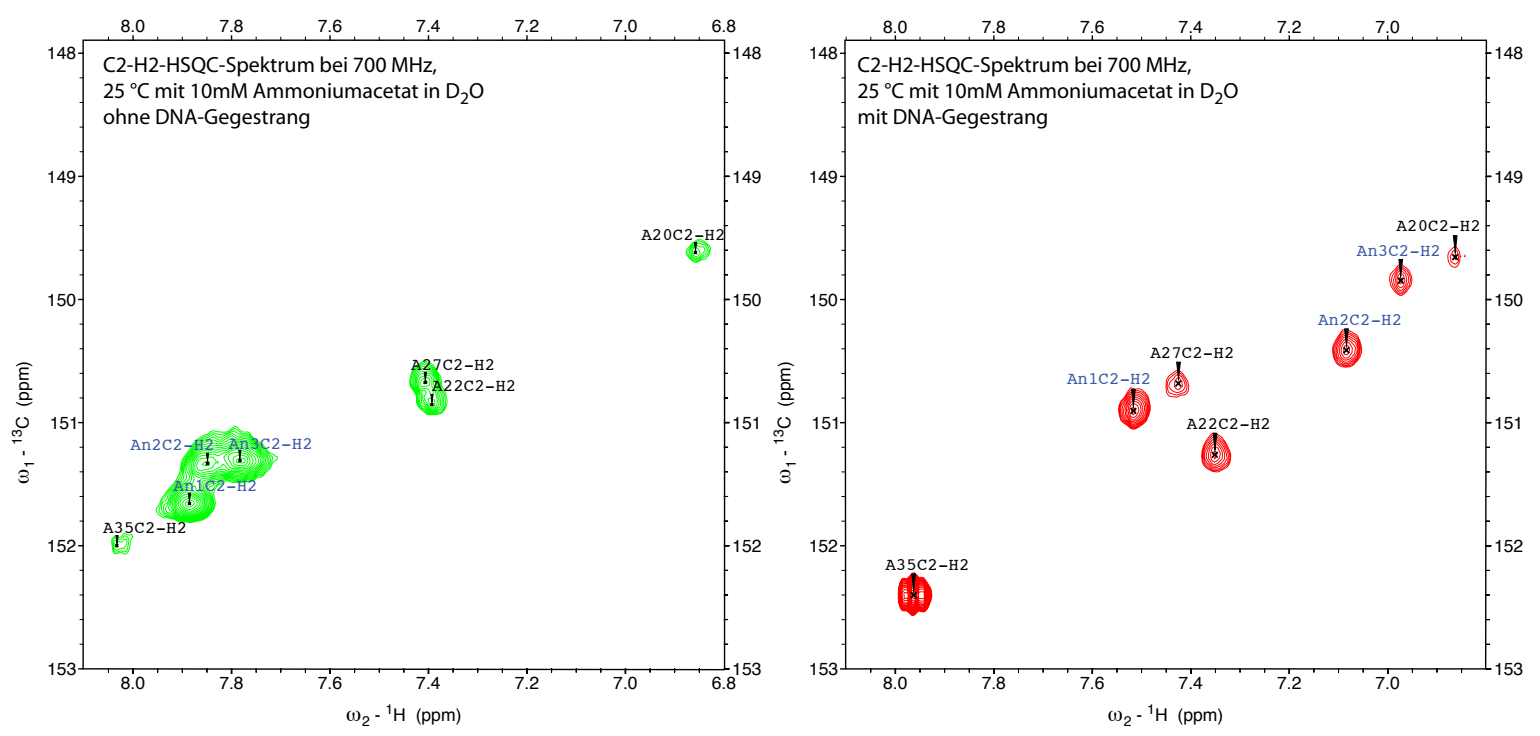

Abb. 6.26: C2-H2-HSQC-Spektrum der verlängerten TAR-RNA ohne (grün) und mit DNADecamer (rot). Es finden sich die erwarteten sieben Signale, von denen die drei Adenosine des Überhangs stark verschoben werden, während die anderen vier Signale in etwa an der gleichen Stelle liegen. 
bildet sich eine Doppelhelix, die zu schärferen Signalen der Basen im Überhang führt, deren chemische Verschiebungen nun im Bereich der mit Uridin gepaarten Adenosine A20, A22 und A27 liegen. Die Spektren wurden bei 700 MHz und 298 K aufgenommen. Details zu den verwendeten Parametern und Pulsprogrammen finden sich im Anhang.

\subsection{Chimäre TAR-RNA mit einem EPTE-Tag}

Lanthanoide besitzen eine geringe Hydrolyseaktivität, die ebenfalls beim Design von künstlichen Nukleasen [142-144] genutzt wird. Da RNA stärker hydrolyseempfindlich ist als DNA, wurde die DNA mit EPTE-Tag zuerst mit Dysprosiumionen beladen und anschließend zur TAR-RNA titriert. So kommt die RNA nicht mit den freien Lanthanoidionen in Kontakt. Als Puffersystem wurde $10 \mathrm{mM}$ Ammoniumacetat verwendet $(\mathrm{pH}=6.8)$. Die Beladung der DNA mit $\mathrm{Dy}^{3+}$ wurde NMR-spektroskopisch visualisiert, dabei wurden nach jedem Titrationsschritt ein 1D-Protonenspektren und ein NOESY-Spektrum aufgenommen. Es wurde bei einer Temperatur von $35{ }^{\circ} \mathrm{C}$ gearbeitet. Bei der sonst verwendeten Temperatur von $25^{\circ} \mathrm{C}$ waren die Signale zu breit, da der Einzelstrang keine eindeutige Konformation hat. Das NOESY-Spektrum wurde partiell zugeordnet. Die internukleosidischen Kreuzsignale sind dabei im Einzelstrang viel schwächer als in Duplexen, da der ungepaarte Strang eine viel höherer Flexibilität besitzt. Die Veränderung der Signalintensität durch Zugabe von Dysprosiumchloridlösung ist Abb. 6.27 dargestellt.

Der NOESY-Kreuzpeak zwischen dem H1' und dem H6 des getaggten Nukleotids weist nur noch eine sehr geringe Signalintensität auf (Abb. 6.28). Bemerkenswert ist auch, dass das Kreuzsignal des EDTA-benachbarten Phenylrings mit dem Triazol-Proton fast vollständig verschwindet, während das Kreuzsignal des ethinylbenachbarten Phenylrings Ph1 mit dem Triazol-Proton wesentlich weniger beeinflusst wird. Dysprosium besitzt einen Signalauslöschungsradius von etwa $17 \AA$, Ph2 ist nur etwa $15 \AA$ von Metallzentrum entfernt, während Ph1 in etwa $20 \AA$ Distanz liegt. C4, T6, und T7 sind stärker beeinflusst als Ph1. Eine mögliche Ursache dafür ist, dass die ssDNA sehr flexibel ist und und zwischen dem Metall-EDTA- 
Tag und dem DNA-Rückgrat Wechselwirkungen vorliegen. Deutlich zu erkennen ist jedoch, dass das Metallion mit dem Tag einen stabilen Komplex bildet und die benachbarten Basen stärker beeinflusst als die weiter entfernten Basen.

\section{a) 5'HO-CGGCXCTTGG-OH}

b)

\section{NOESY-Spektren der Titration}

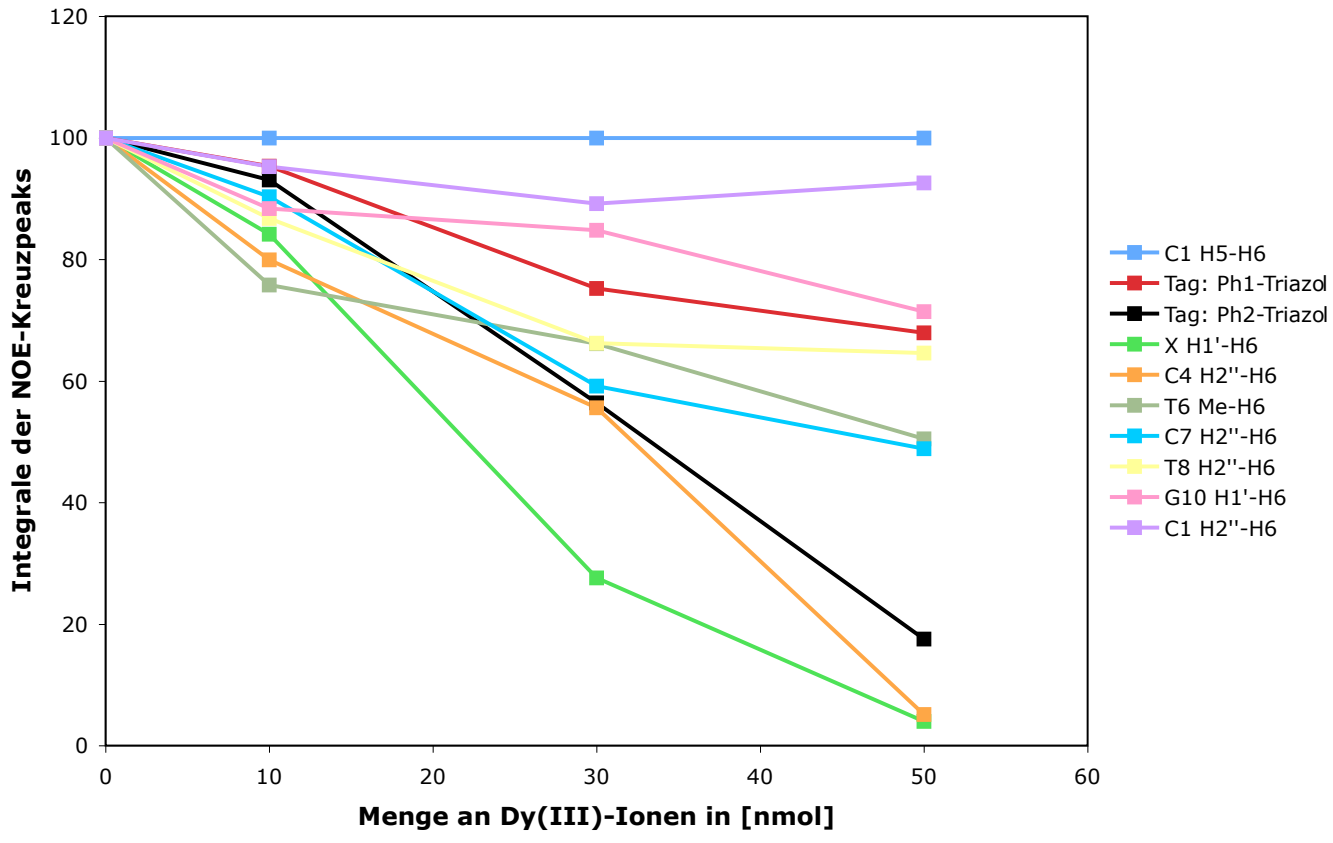

C)

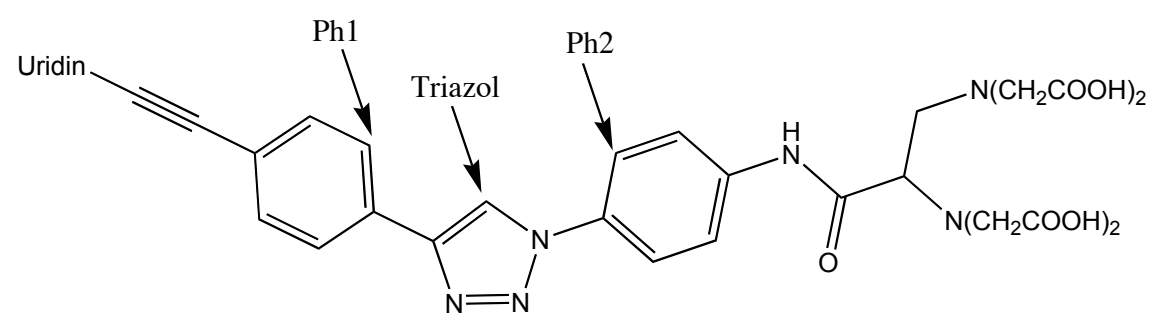

Abb. 6.27: a) Eine Abbildung der DNA-Sequenz mit EPTE-TAG X.

b) Die Veränderung der NOESY-Kreuzsignalintensität durch Zugabe von Dysprosiumchlorid. Die Spektren wurden auf die Signalintensität der C1 H5-H6-Kreuzsignale geeicht und die maximale Integral stets auf 100 gesetzt.

c) Die zugehörigen Protonen des EPTE-Tags. 

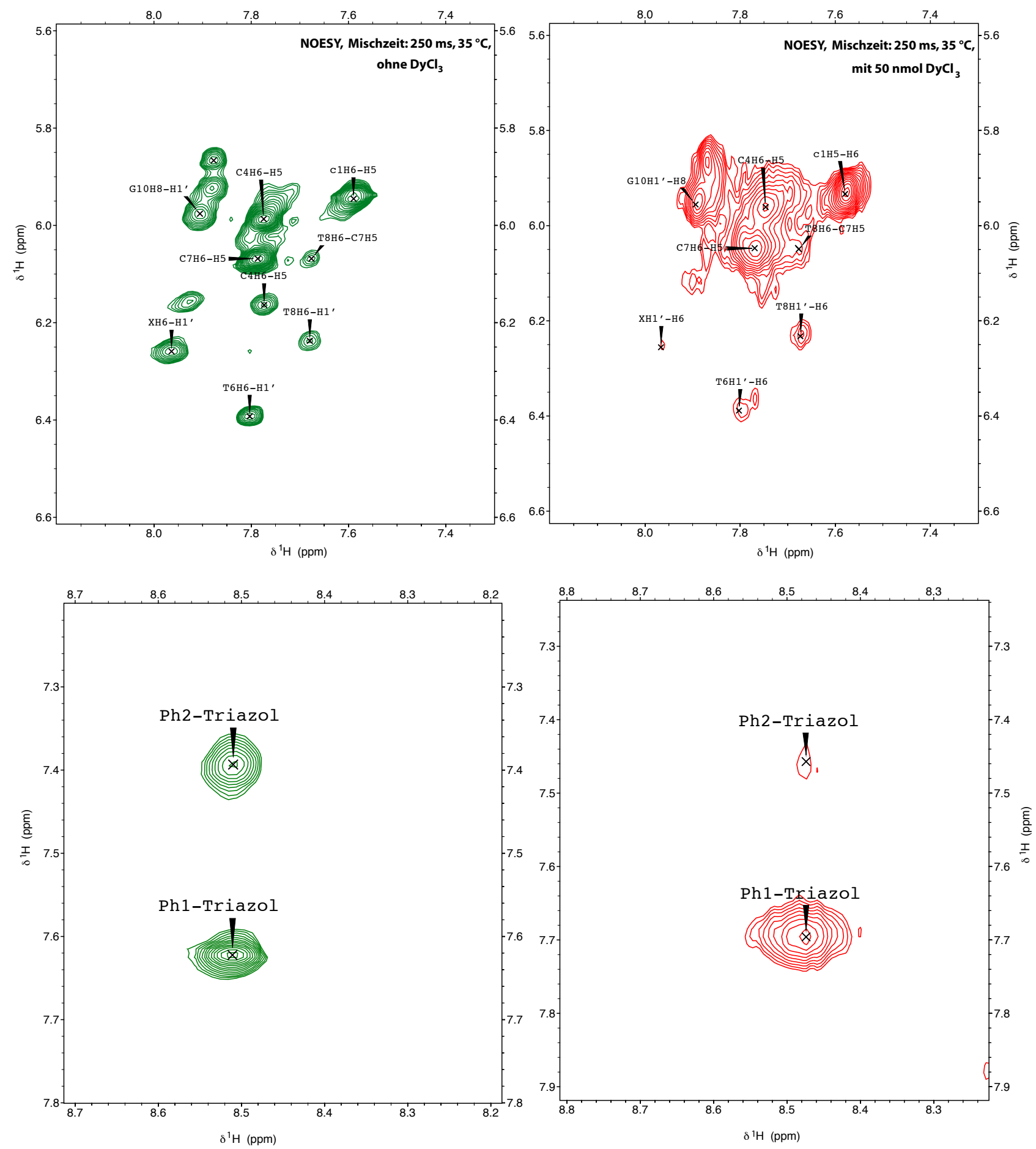

Abb. 6.28: NOESY-Spektrenausschnitte des DNA-Gegenstranges ohne (grün) und mit $\mathrm{DyCl}_{3}$ (rot) bei $35{ }^{\circ} \mathrm{C}$ und $600 \mathrm{MHz}$ mit einer Mischzeit von $250 \mathrm{~ms}$. 
Der mit Dysprosium versetzte modifizierte decamere DNA-Einzelstrang wurde zur verlängerten TAR-RNA mit ${ }^{13} \mathrm{C}$-markierten Adenosinen titriert, bis die C8-H8 und C2-H2-Kreuzpeaks der ungepaarten Adenosine im HSQC nicht mehr sichtbar waren (Abb. 6.29). Aus den Spektren ist ersichtlich, dass die Basenpaarung zwischen getaggter DNA und komplementärer RNA stabil ist. Die Signale der ungepaarten Adenosine verschwinden, stattdessen bilden sich drei neue Kreuzpeaks, die den chimär gepaarten Adenosinen entsprechen. Es finden sich die erwarteten acht Signale, davon zwei Kreuzsignale der zwei A35 Konformationen. Die Intensität der Kreuzsignale ist mit Ausnahme von A35 gesunken. PRE-Effekte wirken sich vor allem auf die chimär gepaarten Adenosine aus.

Um zu überprüfen, ob EPTE-markierte DNA die TAR-RNA im Magnetfeld ausrichten kann, wurden Spektren ohne und mit $\mathrm{Dy}^{3+}$-beladenem EPTE-Tag aufgenommen. In gekoppelten HSQC-Spektren ist ohne Dysprosium nur die skalare CH-Kopplung sichtbar, während in Spektren mit Dysprosium die residuale dipolare Kopplung mit auftritt. Die Kopplung wurde in den Spektren in der direkten $t_{2}$-Dimension visualisiert, indem während der Detektion die HC-Kopplung evolvierte. Dazu wurde statt der Breitbandentkopplung in $t_{2}$ nur ein $90^{\circ}$ Puls auf den Protonenkanal eingestrahlt, bevor das Signal detektiert wurde. Zur Auswertung der rdes wurden nur C8-H8 und C2-H2-Kreuzpeaks herangezogen (Abb. 6.31), da die C1'-H1' -Kreuzpeaks aufgrund der zusätzlichen ${ }^{1} \mathrm{H}-{ }^{1} \mathrm{H}-$ Kopplungen komplexere Signalformen aufwiesen. Da rdcs proportional zum Quadrat des Magnetfeldes sind, wurden die gekoppelten Spektren an einem $900 \mathrm{MHz}$ Spektrometer aufgenommen. 

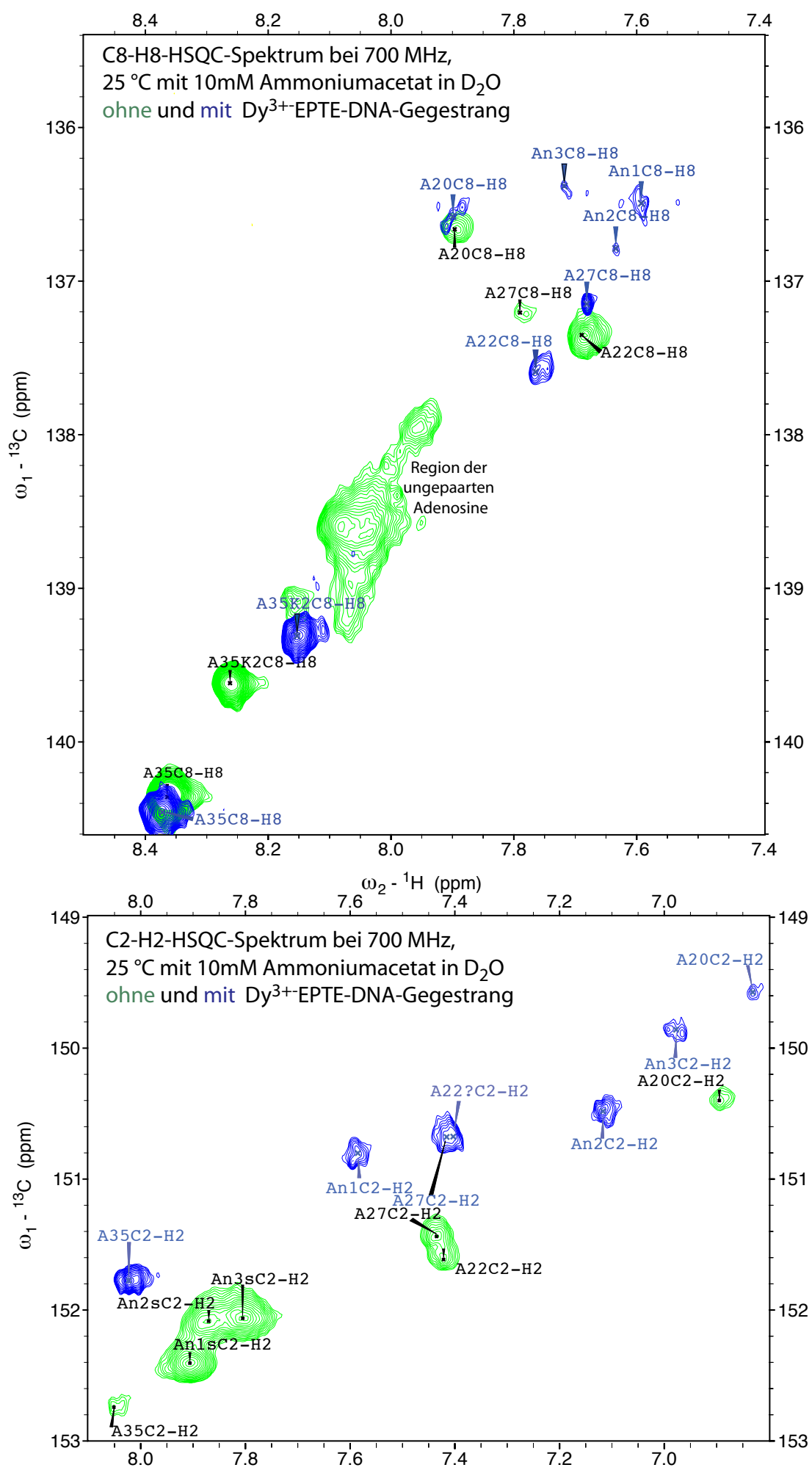

Abb. 6.29: HSQC-Spektren der A-gelabelten verlängerten TAR-RNA ohne (grün) und mit DyEPTE-DNA (blau) bei $700 \mathrm{MHz}$ und $25^{\circ} \mathrm{C}$. Die Signale der ungepaarten Adenosine sind nicht mehr sichtbar. Es findet sich die erwartete Anzahl an Signalen, deren Intensität mit Ausnahme von A35 geringer ist. 


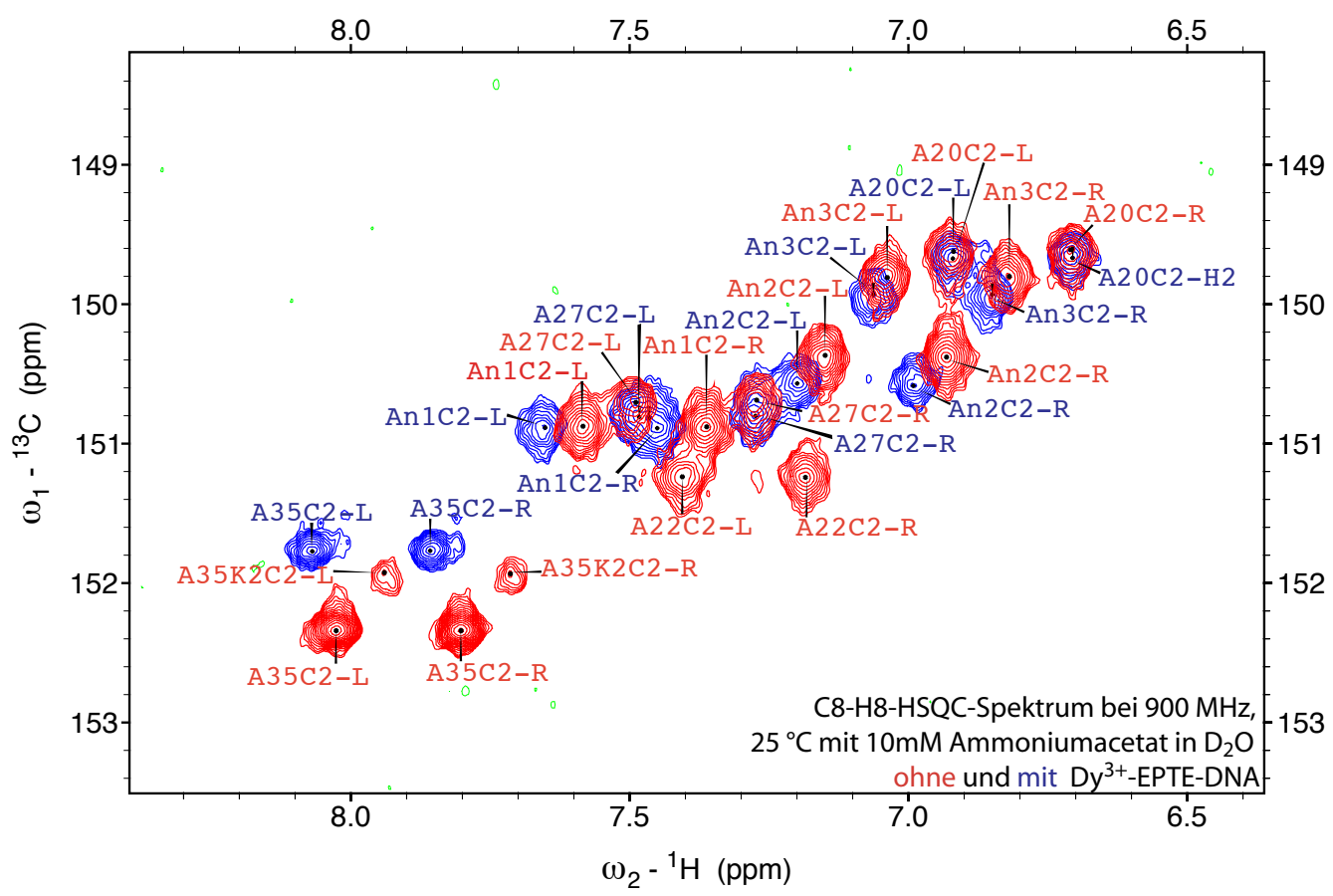

Abb. 6.30: Gekoppeltes C2-H2-HSQC-Spektrum der paramagnetischen Probe (blau) und der diamagnetischen Probe (rot) bei $25^{\circ} \mathrm{C}$ und $900 \mathrm{MHz}$.

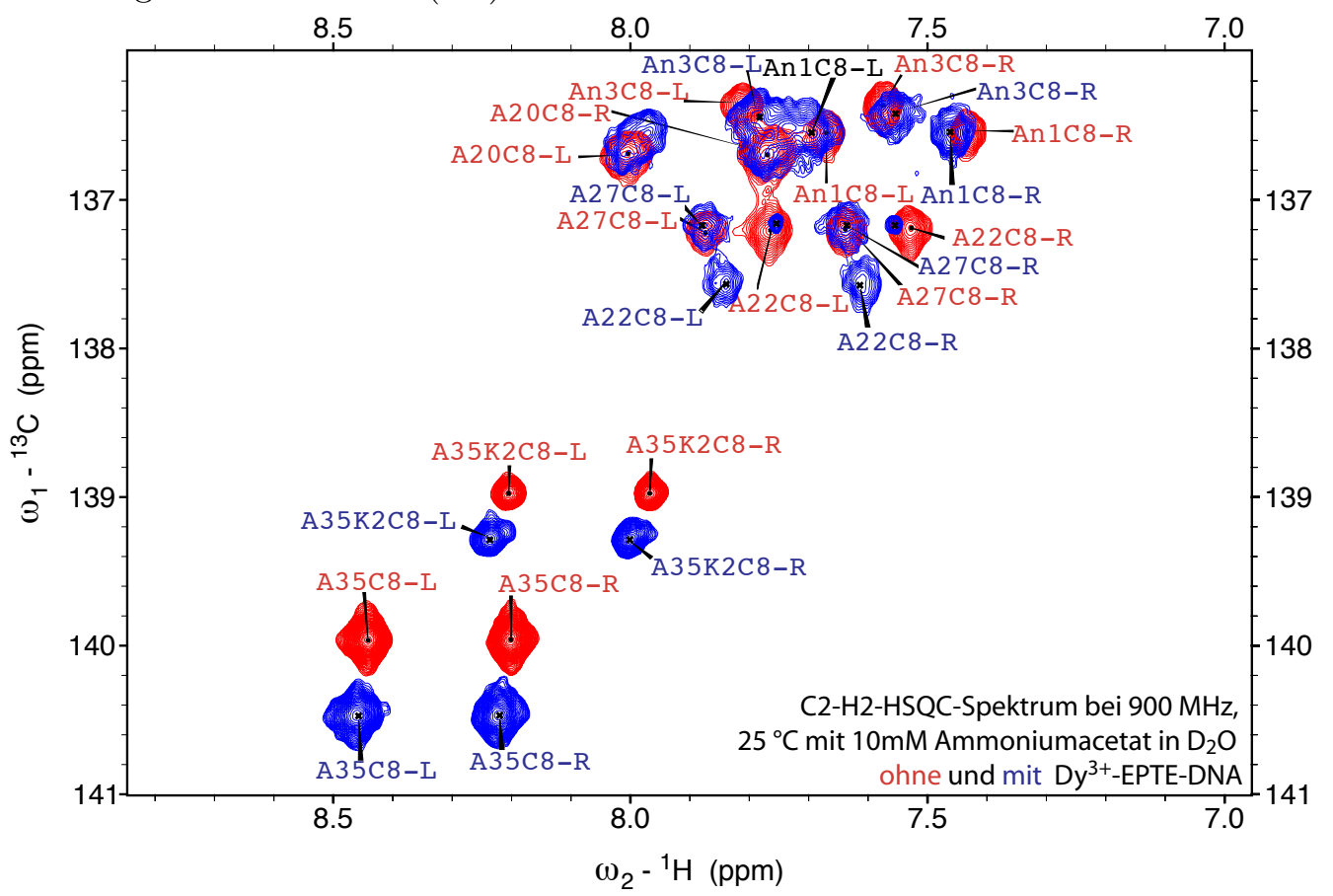

Abb. 6.31: Gekoppeltes C8-H8-HSQC-Spektrum der paramagnetischen Probe (blau) und der diamagnetischen Probe (rot) bei $25^{\circ} \mathrm{C}$ und $900 \mathrm{MHz}$ 
Die rdcs sind in Tabelle 6.32 aufgelistet. Sie betragen zwischen -7 und $11 \mathrm{~Hz}$. Die Signale des A35 sind im paramagnetischen und im diamagnetischen Spektrum sehr gut aufgelöst und diese rdcs konnten sehr gut extrahiert werden (Fehlergrenze etwa $0.5 \mathrm{~Hz}$ ). Die übrigen Signale sind bereits stärker überlagert. Im paramagnetischen Spektrum tritt zusätzlich eine Verbreiterung der Linien auf. Dies liegt an PRE-Effekten des Dysprosiums. Diese rdcs besitzen Fehlergrenzen von mindestens $2 \mathrm{~Hz}$.

\begin{tabular}{|c|c|c|c|}
\hline Assignment & $\begin{array}{c}\text { Diamagne- } \\
\text { tische } \\
\text { Kopplung in } \\
\mathrm{Hz}\end{array}$ & $\begin{array}{c}\text { Paramagne- } \\
\text { tische } \\
\text { Kopplung in } \\
\mathrm{Hz}\end{array}$ & $\begin{array}{c}\text { Dipolare } \\
\text { Kopplung in } \\
\mathrm{Hz}\end{array}$ \\
\hline An1 C2-H2 & 199,6 & 192,50 & 7,1 \\
An2 C2-H2 & 195,6 & 194,3 & 1,3 \\
An3 C2-H2 & 197,2 & 198,9 & $-1,7$ \\
A20 C2-H2 & 195,1 & 193,0 & 2,1 \\
A22 C2-H2 & 199,1 & & \\
A27 C2-H2 & 195,4 & 194,1 & 1,3 \\
A35 C2-H2 & 201,6 & 199,6 & 2,0 \\
\hline
\end{tabular}

\begin{tabular}{|l|c|c|c|}
\hline Assignment & $\begin{array}{c}\text { Diamagne- } \\
\text { tische } \\
\text { Kopplung in } \\
\mathrm{Hz}\end{array}$ & $\begin{array}{c}\text { Paramagne- } \\
\text { tische } \\
\text { Kopplung in } \\
\mathrm{Hz}\end{array}$ & $\begin{array}{c}\text { Dipolare } \\
\text { Kopplung in } \\
\mathrm{Hz}\end{array}$ \\
\hline An1 C8-H8 & 214,1 & 209,8 & 4,3 \\
An3 C8-H8 & 212,7 & 205,7 & 7,0 \\
A20 C8-H8 & 211,7 & & \\
A22 C8-H8 & 213,3 & 201,9 & 11,4 \\
A27 C8-H8 & 212,0 & 218,7 & $-6,7$ \\
A35 C8-H8 & 216,4 & 213,8 & 2,6 \\
\hline
\end{tabular}

Abb. 6.32: Tabelle der extrahierten rdcs bei $900 \mathrm{MHz}$ und $25^{\circ} \mathrm{C}$.

Die erhaltenen rdcs stimmen mit den erwarteten rdcs aus dem Alignmenttensor des DNAHairpins überein. Der Tensor sollte für RNA und DNA in etwa gleich groß sein, da dessen Größe vom Metallion und der Ligandengeometrie abhängt, die bei der Hairpin-DNA und dem TAR-RNA-Konstrukt gleich geblieben ist. Differenzen ergeben sich durch das unterschiedliche zusätzliche diamagnetischen Alignment der $\mathrm{Nu}$ kleinsäure, das aus den Ringströmen der gestapelten Basenpaaren resultiert. Dieses sollte jedoch vernachlässigbar klein gegenüber dem paramagnetischen Alignment sein.

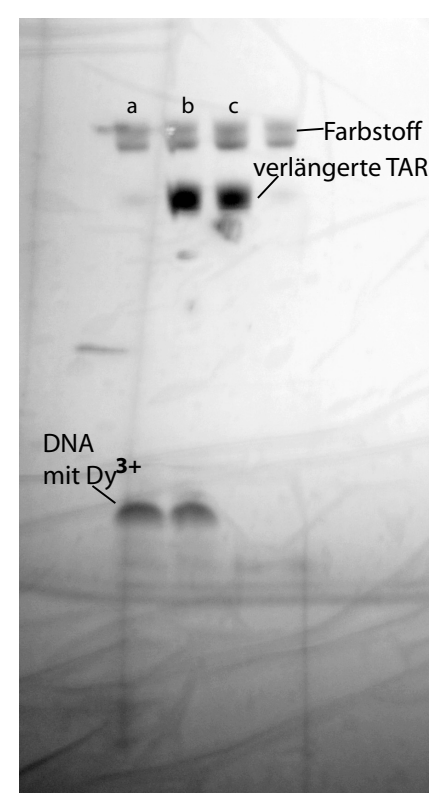

Abb. 6.33: Gelelektrophorese zur Untersuchung auf Abbauprodukte. 
Die RNA wurde zudem in Gegenwart der lanthanoidhaltigen DNA nicht hydrolysiert, was mit einer Gelelektrophorese nach einer Woche Lagerung überprüft wurde (Abb. 6.33). Diese Taggingmethode ist also auf chimäre DNA-RNA-Konstrukte anwendbar.

\subsection{Vergleich des paramagnetischen Alignments mit an- deren Verfahren für Nukleinsäuren}

\subsubsection{Der GAAA-Loop}

Zweiwertige Ionen sind für RNA-Strukturen essentiell, sowohl durch spezifische Bindungen, als auch durch unspezifische Bindungen. Anstelle von Magnesiumionen können RNAs im Falle des GAAA-RNA-Tetraloops auch dreiwertige Europiumionen binden [145, 146] mit einem $\mathrm{K}_{d}$ von $12 \mu \mathrm{mol}$. Diese Affinität wird von Schwalbe et al. genutzt um rdcs von RNAs zu messen. Dazu wird die zu untersuchende RNA- Sequenz um einen Hairpin mit GAAALoop verlängert und mit Europiumionen versetzt. Dabei treten rdcs bis zu $8 \mathrm{~Hz}\left({ }^{13} \mathrm{C}-{ }^{1} \mathrm{H}\right.$ bei $950 \mathrm{MHz}$ ) auf (personal communication D. Mathieu und H. Schwalbe).

Eine Schwierigkeit dieser Methode ist, dass die RNA ab einer Temperatur von $25^{\circ} \mathrm{C}$ hydrolysiert wird, da die Europiumionen nicht stabil genug an den Loop gebunden sind. Bei der Messung von RNA-Protein-Komplexen ist es bei dieser Methode sehr wichtig, dass das Protein keine Affinität gegenüber Europium besitzt, da sonst der $\mathrm{Eu}^{3+}$-Loop-Komplex zerstört werden könnte.

Der korrespondierende GAAA-DNA-Loop ist strukturell wesentlich flexibler und bindet aufgrund der fehlenden 2'-Hydroxylgruppen keine Europiumionen. Die Methode ist also nur auf RNAs beschränkt. 


\subsubsection{Externes Alignment}

Es existieren verschiedene Alignmentmedien um Nukleinsäuren in einem Magnetfeld auszurichten. Häufig genutzt werden beispielsweise DMPC:DHPC-Bicellen, Pf1-Phagen und TMV [4]. Das externe Alignment der genannten Beispiele beruht auf der Tatsache, dass sich die Medien im Magnetfeld ausrichten und somit eine anisotrope Umgebung für die darin gelöste Nukleinsäure schaffen. Diese kann nicht mehr frei rotieren und bekommt somit eine Vorzugsausrichtung. Die gemessenen rdcs werden in der Regel zur Strukturverfeinerung der Nukleinsäuren verwendet.

Al-Hashimi et al. entwickelte 2006 eine Methode, um Rückschlüsse auf die Dynamik der untersuchten RNA-Strukturen zu gewinnen [147, 148]. Eine HIV1-TAR-RNA, die wie die HIV2-TAR-RNA aus zwei doppelhelikalen Bereichen verbunden über einen bulge besteht, wird dabei modifiziert. Dabei werden nacheinander die beiden Doppelstränge um je 20 Basenpaare verlängert. Der verlängerte Strang bildet dann jeweils die Hauptachse der RNA, die durch die anisotrope Umgebung des Alignmentmediums parallel im Magnetfeld ausgerichtet wird. Ein Vergleich, der so gewonnenen rdes, liefert Informationen zur Dynamik der beiden Helices. Inwieweit die Verlängerung der einzelnen Bereiche die Dynamik der RNA verändert, ist noch nicht eindeutig geklärt.

\subsubsection{Dynamikuntersuchungen mit paramagnetischen Tags}

Paramagnetisches Alignment ist außerordentlich gut geeignet, um die Domänenorientierung und die Domänendynamik von Proteinen zu untersuchen. Bertini et al. untersuchten die Domänendynamik von Calmodulin, indem sie eine mutierte Calciumbindungstelle mit Terbium- und Thuliumionen komplexierten [5]. Der Alignmenttensor, erzeugt durch den Tag, wird dabei skaliert mit der Beweglichkeit des Tags gegenüber der jeweiligen Proteindömäne. Analog kann die Dynamik von Nukleinsäuren ermittelt werden. Für detaillierte Dynamikuntersuchungen ist es jedoch notwendig das Biomolekül durch mindestens fünf verschiedene 
Alignmenttensoren im Magnetfeld partiell auszurichten. Dies wird möglich durch die Verwendung verschiedener Lanthanoidionen und der $R$ - und $S$-Enantiomere der EDTA-Tags [149]. 


\section{Kapitel 7}

\section{Ausblick}

Durch die Entwicklung dieser neuen Methode zur paramagnetischen Markierung von DNA, ist es nun möglich rdcs und PCS für diverse DNA-Sequenzen zu messen und dadurch ihre Struktur und Dynamik genauer zu studieren. Einen interessanten Anwendungsbereich stellen zudem DNA-Komplexe mit Proteinen dar. Dabei kann das Protein bei genügend fester Bindung durch den Tag im Magnetfeld ausgerichtet werden. Ein möglicher Komplex wäre beispielweise ein DNA-STAT-Komplex. Die erhaltenen rdes geben Aufschluss über die Bindungsstärke zwischen DNA und Protein, sowie über die Struktur des Komplexes. Dabei ist die Synthese ${ }^{13} \mathrm{C}$ oder ${ }^{15} \mathrm{~N}$ gelabelter Proteine von Vorteil. Die getaggte DNA muss dabei nicht gelabelt vorliegen. Will man ${ }^{1} \mathrm{H}_{-}{ }^{13} \mathrm{C}$-rdes direkt aus den ungelabelten DNA-Spektren ermitteln, sind hohe Konzentration von mindestens 1 mmolar nötig.

Die entwickelten Verfahren basierend auf Click- und Disulfidchemie können auf verschiedene biologische Systeme angewendet werden. Dabei liegt ein Fokus zunächst auf der TAR-RNA, die komplexiert mit unterschiedlichen Metallionen tiefergehend untersucht werden soll. Außerdem kann Zuordnung der verlängerten TAR vervollständigt werden. Untersuchungen der Dynamik von RNA sind mit Hilfe dieser neuartigen paramagnetischen Tags geplant. 
Um die Clickreaktion an Oligonukleotiden zur paramagnetischen Markierung noch weiter $\mathrm{zu}$ verbessern, ist es geplant sie an gelöster, verlängerter, ethinylmodifizierter DNA und mit Lanthanoidionen beladenen EDTA-Aziden durchzuführen. Die Beladung mit Lanthanoidionen ist dadurch erleichert, da das Azid mit einem Überschuss an Lanthanoidionen versetzt werden kann, ohne dass die überzähligen Lanthanoidionen von Phosphatresten abgefangen werden. Anschließend kann das Gemisch bei neutralem pH-Wert HPLC-chromatografisch gereinigt werden (Kapitel 6.3).

Die korrespondierenden RNA-Phosphoramidite können ebenfalls mit Thiol- bzw. Ethinylgruppe synthetisiert und per Festphasensynthese in kürzere RNA-Sequenzen inkooperiert werden. Die Verwendung chimärer DNA-RNA-Konstrukte zur Strukturanalyse kann so vermieden werden (Abb. 7.1). Konstrukte, die nur aus RNA bestehen, haben gegenüber chimären den Vorteil, dass ihre native Struktur weniger stark beeinflusst wird. Zudem liegt die Schmelztemperatur von RNA-RNA- höher als die der korrespondierenden DNA-RNA-Doppelstränge [150], dadurch kann die Verlängerung der zu untersuchenden RNA minimal gehalten werden.

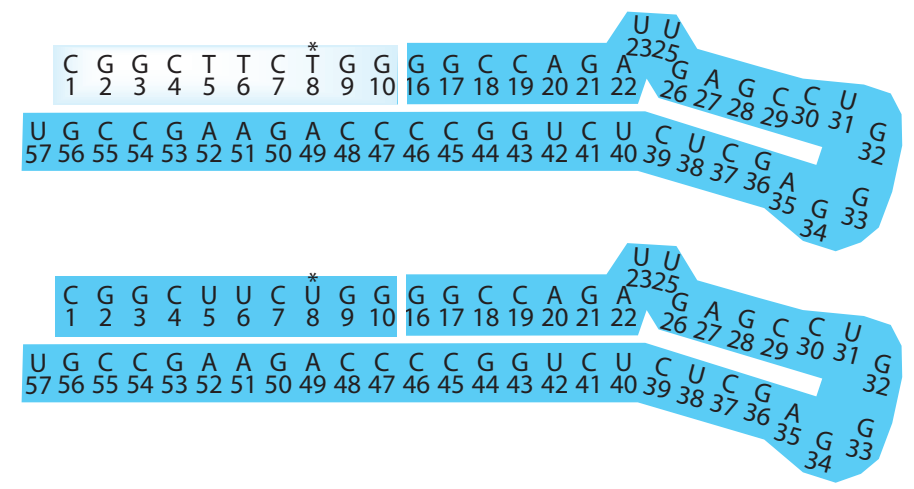

Abb. 7.1: Verlängerte TAR-RNA oben mit getaggtem DNA-Gegenstrang (hellblau) und unten mit getaggtem RNA-Gegenstrang.

Da EDTA nur sechs der neun Koordinationsstellen der Lanthanoidionen komplexiert, ist es wünschenswert, Tags basierend auf neunfach chelatisierenden Liganden zu entwickeln. Dazu können Proteintaggingmethoden für die Clickchemie an Oligonukleotiden angepasst werden $[123,151]$. 


\section{Kapitel 8}

\section{Experimenteller Teil}

\subsection{Material und Methoden}

\section{NMR-Spektren:}

Alle NMR-Spektren wurden, soweit nicht anders beschrieben, an einem Bruker 400 MHzUltrashield-Spektrometer bei einer Temperatur von $298 \mathrm{~K}$ aufgenommen. Informationen zum Probenkopf und den verwendeten Pulsprogrammen finden sich im Anhang. Die ${ }^{1} \mathrm{H}$ chemischen Verschiebungen $\delta$ wurden in parts per million (ppm) relativ zu $\mathrm{CDCl}_{3}(\delta=7.26$ ppm), $\left[\mathrm{D}_{6}\right] \mathrm{DMSO}(\delta=2.49 \mathrm{ppm})$ und dem Natriumsalz der 4,4-Dimethyl-4-silapentan-1sulfonsäure $\left(\delta=0.00 \mathrm{ppm}\right.$ in $\left.\mathrm{D}_{2} \mathrm{O}\right)$ als interne Standards angegeben. Die ${ }^{13} \mathrm{C}$ chemischen Verschiebungen wurden ebenfalls in ppm angegeben und auf $\mathrm{CDCl}_{3}(\delta=77.0 \mathrm{ppm}),\left[\mathrm{D}_{6}\right] \mathrm{DMSO}$ $(\delta=39.7 \mathrm{ppm})$ referenziert. Die Daten wurden wie folgt angegeben: Chemische Verschiebung, Multiplizität $(\mathrm{s}=$ Singulett, $\mathrm{d}=$ Dublett, $\mathrm{t}=$ Triplett, $\mathrm{q}=$ Quartett, $\mathrm{m}=$ Multiplett, $\mathrm{br}=$ verbreitert), Kopplungskonstanten $J$ in Hertz und Integral. Die Zuordnung der Signale erfolgte mit Hilfe von 2D- $\left[{ }^{13} \mathrm{C},{ }^{1} \mathrm{H}\right]-\mathrm{HSQC}$ (Heteronuclear Single Quantum Coherence)-Spektren und 2D- $\left[{ }^{13} \mathrm{C},{ }^{1} \mathrm{H}\right]-\mathrm{HMBC}$ (Heteronuclear Multiple Bond Correlation)-Spektren. 


\section{Reagenzien:}

Alle Lösungsmittel wurden bei Merck und Fluka in p.a. Qualität gekauft, gegebenenfalls auch getrocknete Lösungsmittel, die über Molsieb lagerten. Die benötigten Chemikalien wurden bei Merck, Fluka, Aldrich, Acros und Lancaster bestellt. Für Reaktionen unter Feuchtigkeitsoder Sauerstoffauschluss diente Argon als Inertgas. Das Gas wurde mittels eines Trockenturms aus $\mathrm{P}_{2} \mathrm{O}_{5} /$ Bimsstein getrocknet.

\section{Oligonukleotide:}

Oligonukleotide wurden bei der IBA GmbH in Göttingen bestellt. Um ethinyl- und thiolmodifizierte Oligonukleotide zu erhalten wurden die entsprechenden Phosphoramidite zu IBA gesandt, die diese dann mit normaler Phosphoramiditchemie und normalen Kopplungszeiten in die entsprechende Zielsequenz einbaute.

\section{Massenspektren:}

Für die Messungen wurde das ESI-Massenspektrometer Micromass ZQ von Waters mit Quadrupoldetektor verwendet. Diese Proben wurden soweit nicht anders angegeben in Acetonitril/Wasser/Trifluoressigsäure: 50/50/0.1 gemessen. Die Angaben erfolgen in $\mathrm{m} / z$.

\section{HPLC-Trennungen:}

Die genutzten HPLC-Anlagen von JASCO mit DAD-Detektor besaßen reversed phase Säulen (Eurospher C18), deren Größe abhängig von der zu trennenden Substanzmenge gewählt wurde. Bei analytischen Trennungen wurde eine Säule mit den Maßen 4.6 x $250 \mathrm{~mm}$ gewählt. Als Eluent wurde Wasser und Acetonitril mit 0.1\% TFA genutzt. Starteluent war stets 100\% Wasser, das zunehmend mit Acetonitril versetzt wurde. Der jeweilige Gradient findet sich bei den Versuchsbeschreibungen. Neben den Trennungen bei saurem pH-Wert wurden auch 
Trennungen bei $\mathrm{pH}=7$ durchgeführt. Dazu wurde ein System aus 0.1 M Triethylammoniumacetatpuffer und Acetonitril verwendet, das den Vorteil besitzt, dass der flüchtige Puffer durch mehrfache Lyophilisation entfernt werden kann und bei anschließenden massenspektroskopischen Analysen nicht stört. Die 2 M Triethylammoniumacetatstammlösung wurde in p.a. Qualität von Fluka erworben.

Die Anionenaustauschersäule DNAPac PA-100 (4 x 250 mm) der Firma Dionex mit einer 4 x 50 mm Vorsäule. Als Gradientengemisch wurde Wasser, 1 M Natriumchloridlösung und $0.25 \mathrm{mM}$ Tris-HCl-Puffer $(\mathrm{pH}=8)$ verwendet. Von der Startbedingung mit 80\% Wasser, 10\% Natriumchloridlösung und 10\% Pufferlösung wurde in 45 min der Salzanteil auf 45\% zu $45 \%$ zu 10\% erhöht. Soweit nicht anders angegeben betrug die Temperatur $40{ }^{\circ} \mathrm{C}$.

Die wässrigen Lösungen wurden mit flüssigen Stickstoff eingefroren und an einem Christ alpha 1-4 Lyophilisator gefriergetrocknet.

\subsubsection{NMR-Probenvorbereitung}

Die Oligonukleotidlösungen der HPLC-Trennungen wurden lyophilisiert und anschließend mit 10 mM Phosphatpuffer $(\mathrm{pH}=7)$ aufgenommen und über eine PD-10 Säule entsalzt. Die rein wässrigen Lösungen wurden mit dem jeweiligen für die NMR-Messung benötigten Puffer versetzt und erneut lyophilisiert. Danach wurden die Lösungen in $250 \mu$ l deuteriertem Wasser gelöst und für 5 min auf $70{ }^{\circ} \mathrm{C}$ erhitzt und dann langsam abgekühlt. Die NMR-Messungen erfolgten in Shigemi-NMR-Röhrchen. 


\subsection{Versuchsvorschriften}

\subsubsection{5-Iod-2'-desoxyuridin-3',5'-di- $O$-acetat [152]}

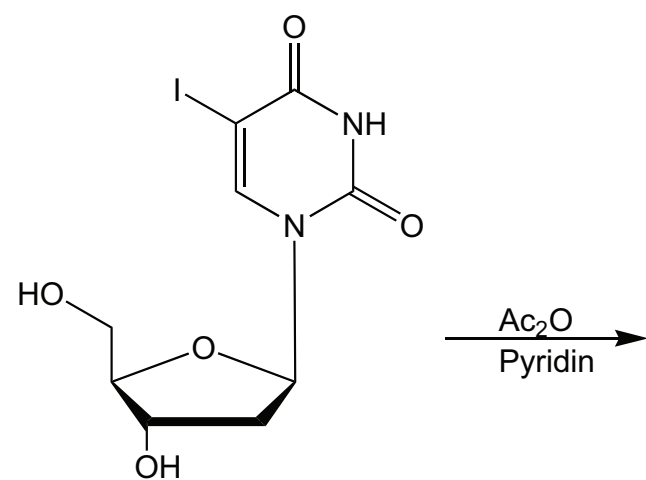

354.1

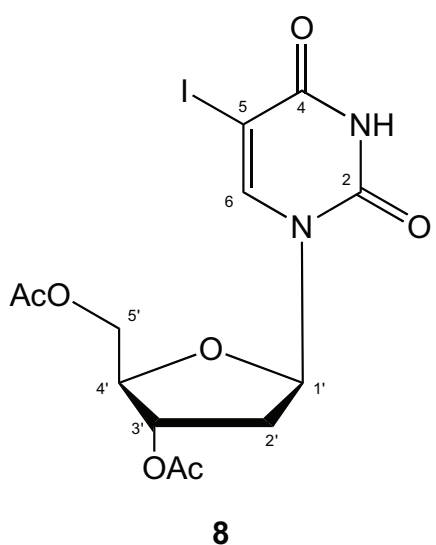

438.17

$\mathrm{Zu} 1.00 \mathrm{~g}$ 5-Iod-2'-desoxyuridin $(2.82 \mathrm{mmol})$ in $8 \mathrm{~mL}$ Pyridin wurden langsam $2.67 \mathrm{~mL}$ Essigsäureanhydrid (2.89 g, 28.2 mmol, 10 Äq.) getropft und 4 h gerührt. Die Lösung wurde im Vakuum aufkonzentriert, zweimal mit Ethanol $(10 \mathrm{~mL})$ versetzt und eingeengt. 8 wurde in quantitativer Ausbeute erhalten und direkt weiter verarbeitet.

${ }^{1} \mathbf{H}-\mathrm{NMR}\left(\mathrm{CDCl}_{3}, 400 \mathrm{MHz}\right): \delta=9.23(\mathrm{~s}, \mathrm{br}, 1 \mathrm{H}, \mathrm{NH}), 7.96(\mathrm{~s}, 1 \mathrm{H}, \mathrm{H} 6), 6.28(\mathrm{dd}, J=$ 8.4, 5.7 Hz, 1H, H1'), 5.23 (m, 1H, H3'), 4.38 (m, 1H, H5'), 4.30 (m, 1H, H5”), 4.29 (m, 1H, H4'), 2.54 (ddd, $J=14.2,5.6,2.0$ Hz, 1H, H2'a), 2.20 (s, 3H, Ac), 2.17 (m, 1H, H2'b), 2.11 (s, 3H, Ac) ppm.

${ }^{13}$ C-NMR $\left(\mathrm{CDCl}_{3}, 100.6 \mathrm{MHz}\right): \delta=170.32$ (1C, 3’CO), 170.12 (1C, 5'CO), $159.65(1 \mathrm{C}$, C4), 149.89 (1C, C2), 143.79 (1C, C6), 85.52 (1C, C1'), 82.67 (1C, C4'), 73.74 (1C, C3'), 68.91 (1C, C5), 63.48 (1C, C5'), 38.29 (1C, C2'), 21.10 (1C, 5’ $\mathrm{CH}_{3}$ ), 20.84 (1C, 3’ $\left.\mathrm{CH}_{3}\right)$ ppm.

ESI-MS $m / z$ (Acetonitril, positive mode): ber. für $\mathrm{C}_{13} \mathrm{H}_{16} \mathrm{IN}_{2} \mathrm{O}_{7}[\mathrm{M}+\mathrm{H}]^{+}:$439.18, gef.: 439.07. 


\subsubsection{5-Trimethylsilylethinyl-2'-desoxyuridin-3',5'-di- $O$-acetat [153]}

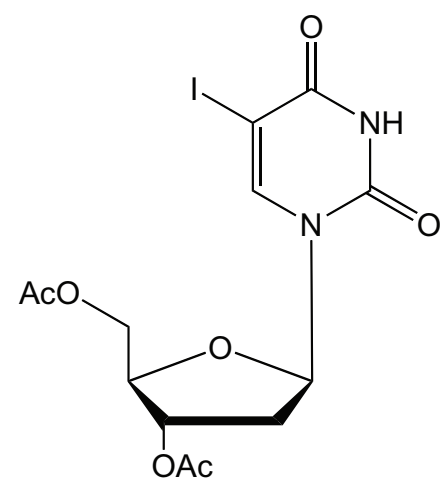

8

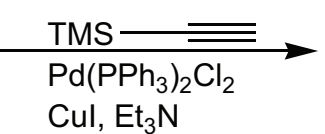

438.17

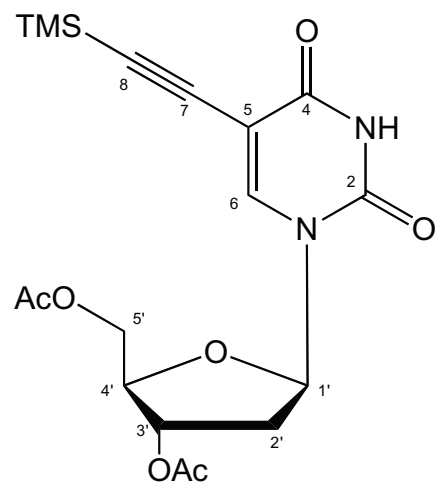

9

408.48

1.00 g 5-Iod-2'-desoxyuridin-3',5'-di-O-acetat 8 (2.28 mmol), $34.8 \mathrm{mg}$ Kupfer(I)iodid (0.18 mmol, 0.08 Äq.) und 48 mg Bis-(triphenylphosphin)-palladium(II)chlorid (68.5 $\mu \mathrm{mol}$, 0.03 Äq.) wurden in $30 \mathrm{~mL}$ Triethylamin suspendiert und $949 \mu \mathrm{L}$ Trimethylsilylethin (0.67 g, $6.85 \mathrm{mmol}, \rho=0.709,3.0$ Äq.) langsam zugetropft. Nach 3 h Rühren bei $50{ }^{\circ} \mathrm{C}$ wurde das Gemisch im Vakuum eingeengt, in Chloroform $(250 \mathrm{~mL})$ aufgenommen und mit 5\%iger EDTA-Lösung (100 mL) gewaschen. Der Rückstand wurde mittels Säulenchromatographie an Kieselgel mit den Eluenten Chloroform/Methanol: 100/1 gereinigt. Man erhielt $869 \mathrm{mg} 9$ (2.13 mmol, 93\%).

${ }^{1} \mathbf{H}-\mathbf{N M R}\left(\mathrm{CDCl}_{3}, 400 \mathrm{MHz}\right): \delta=7.82(\mathrm{~s}, 1 \mathrm{H}, \mathrm{H} 6), 6.31\left(\mathrm{~m}, 1 \mathrm{H}, \mathrm{H} 1^{\prime}\right), 5.24(\mathrm{~m}, 1 \mathrm{H}, \mathrm{H} 3$ '), 4.36 (m, 2 H, H5'), 4.28 (m, 2H, H4'), 2.53 (m, 1H, H2'a), 2.21 (m, 1H, H2'b), 2.18 (s, 3H, 5’Ac), 2.11 (s, 3H, 3’Ac), 0.21 (s, 9H, TMS) ppm.

${ }^{13} \mathbf{C}-\mathrm{NMR}\left(\mathrm{CDCl}_{3}, 100.6 \mathrm{MHz}\right): \delta=170.41$ (1C, 3'CO), 170.03 (1C, 5'CO), $160.75(1 \mathrm{C}$, C4), 149.11 (1C, C2), 142.11 (1C, C6), 100.99 (1C, C5), 95.48 (1C, C7), 99.92 (1C, C8), 85.32 (1C, C1'), 82.62 (1C, C4'), 73.97 (1C, C3'), 63.82 (1C, C5'), 38.24 (1C, C2'), 20.88 $\left(1 \mathrm{C}, 3^{\prime} \mathrm{CH}_{3}\right), 20.83\left(1 \mathrm{C}, 5^{\prime} \mathrm{CH}_{3}\right),-0.37$ (3C, TMS) ppm.

ESI-MS $m / z$ (Acetonitril, positive mode): ber. für $\mathrm{C}_{18} \mathrm{H}_{25} \mathrm{~N}_{2} \mathrm{O}_{7} \mathrm{Si}[\mathrm{M}+\mathrm{H}]^{+}:$409.49, gef.: 409.27. 


\subsubsection{5-Ethinyl-2'-desoxyuridin-3',5'-di- $O$-acetat [152]}

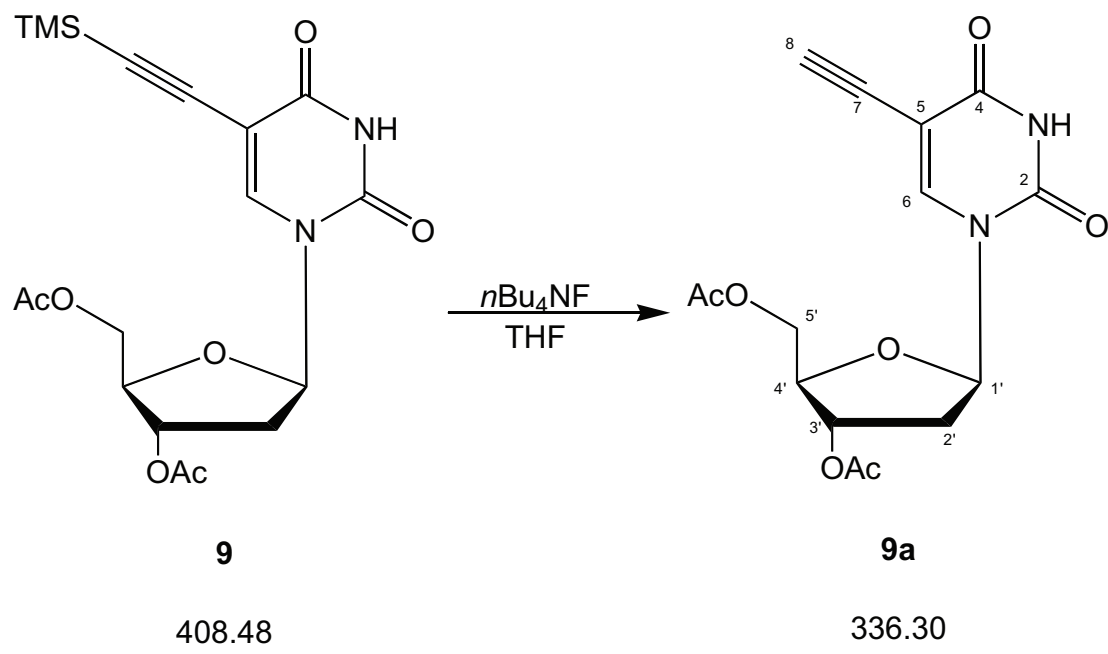

$800 \mathrm{mg}$ 5-Trimethylsilylethinyl-2'-desoxyuridin-3',5'-di- $O$-acetat 9 (1.96 mmol) wurden in $10 \mathrm{~mL}$ Tetrahydrofuran gelöst und mit $4.11 \mathrm{~mL}$ Tetra- $n$-butylammoniumfluorid-Lösung (1 M in Tetrahydrofuran, $4.11 \mathrm{mmol}, 2.1$ Äq.) versetzt. Die Lösung wurde $2 \mathrm{~h}$ bei Raumtemperatur gerührt und anschließend das Lösungsmittel im Vakuum entfernt. Das Öl wurde säulenchromatographisch an Kieselgel mit dem Eluenten Chloroform/Methanol: 100/1 aufgereinigt. Man erhielt $561 \mathrm{mg}$ eines weißes Pulvers 9a (1.67 mmol, 85\%).

${ }^{1} \mathbf{H}-\mathbf{N M R}\left(\mathrm{CDCl}_{3}, 400 \mathrm{MHz}\right): \delta=7.94$ (s, 1H, H6), $6.32(\mathrm{~m}, 1 \mathrm{H}, \mathrm{H} 1$ '), 5.24 (m, 1H, H3'), 4.37 (m, 2H, H5'), 4.32 (m, 2H, H4'), 3.21 (s, 1H, H8), 2.23 (m, 1H, H2'a), 2.58 (m, 1H, H2’b), 2.17 (s, 3H, 5’Ac), 2.12 (s, 3H, 3’Ac) ppm.

${ }^{13} \mathrm{C}-\mathrm{NMR}\left(\mathrm{CDCl}_{3}, 100.6 \mathrm{MHz}\right): \delta=170.14$ (1C, 5'CO), 170.11 (1C, 3'CO), 161.81 (1C, C4), 148.95 (1C, C2), 142.71 (1C, C6), 99.65 (1C, C5), 85.94 (1C, C1'), 82.81 (1C, C4'), 82.21 (1C, C7), 74.46 (1C, C8), 73.88 (1C, C3'), 63.72 (1C, C5'), 38.34 (1C, C2'), 20.85 (2C, $\left.2 \times \mathrm{CH}_{3}\right)$ ppm.

ESI-MS $m / z$ (Acetonitril, positive mode): ber. für $\mathrm{C}_{15} \mathrm{H}_{17} \mathrm{~N}_{2} \mathrm{O}_{7}[\mathrm{M}+\mathrm{H}]^{+}:$337.10, gef.: 337.08 . 


\subsubsection{5-Ethinyl-2'-desoxyuridin [152]}

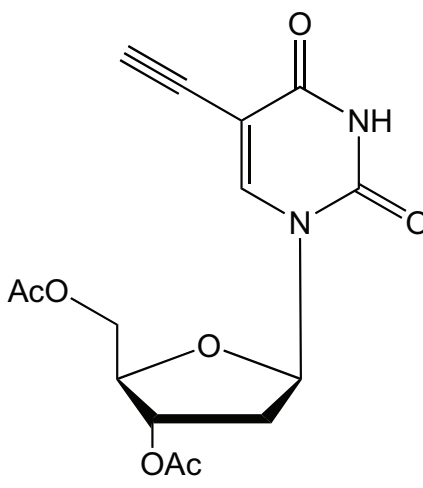

9a

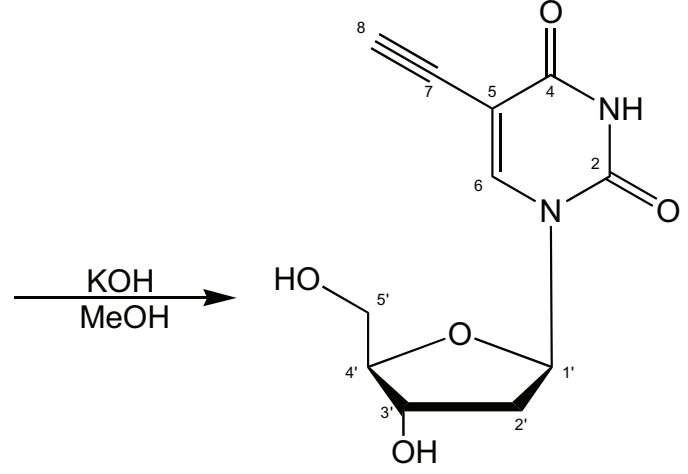

10

336.30

252.22

$428 \mathrm{mg}$ Kaliumhydroxid (7.62 mol, 4 Äq) wurden in $40 \mathrm{~mL}$ Methanol gelöst und mit $641 \mathrm{mg}$ 5-Ethinyl-2'-desoxyuridin-3',5'-di-O-acetat 9a (1.91 mmol) versetzt. Die Lösung wurde zuerst $2 \mathrm{~h}$ bei Raumtemperatur gerührt und danach mit $30 \mathrm{~mL}$ Wasser verdünnt. Durch Zugabe von Kationenaustauscher Amberlite IR-120 H+-Form wurde ein pH-Wert von 6.5 eingestellt und anschließend der Kationenaustauscher abfiltriert. Das Methanol wurde im Vakuum dem Filtrat entzogen und die wässrige Lösung anschließend lyophilisiert. Quantitativ wurde das Produkt 10 als gelblicher Feststoff erhalten.

${ }^{1} \mathbf{H}-\mathbf{N M R}\left(\mathrm{CDCl}_{3}, 400 \mathrm{MHz}\right): \delta=8.23(\mathrm{~s}, 1 \mathrm{H}, \mathrm{H} 6), 6.11\left(\mathrm{~m}, 1 \mathrm{H}, \mathrm{H} 1^{\prime}\right), 4.25$ (m, 1H, H3'), 3.97 (s, 1H, H8), 3.78 (m, 2H, H4'), 3.58 (m, 2H, H5'), 2.50-2.53 (m, 2H, H2') ppm.

${ }^{13}$ C-NMR $\left(\mathrm{CDCl}_{3}, 100.6 \mathrm{MHz}\right): \delta=162.59$ (1C, C4), 150.29 (1C, C2), 144.64 (1C, C6), 97.66 (1C, C5), 87.96 (1C, C4'), 85.08 (1C, C1'), 83.33 (1C, C7), 77.44 (1C, C8), 70.37 (1C, C3'), 61.15 (1C, C5'), 40.57 (1C, C2') ppm.

ESI-MS $m / z$ (Acetonitril, positive mode): ber. für $\mathrm{C}_{11} \mathrm{H}_{12} \mathrm{NaN}_{2} \mathrm{O}_{5}[\mathrm{M}+\mathrm{Na}]^{+}: 275.21$, gef.: 275.11 . 


\subsubsection{5'-O-Dimethoxytrityl-5-ethinyl-2'-desoxyuridin [152]}

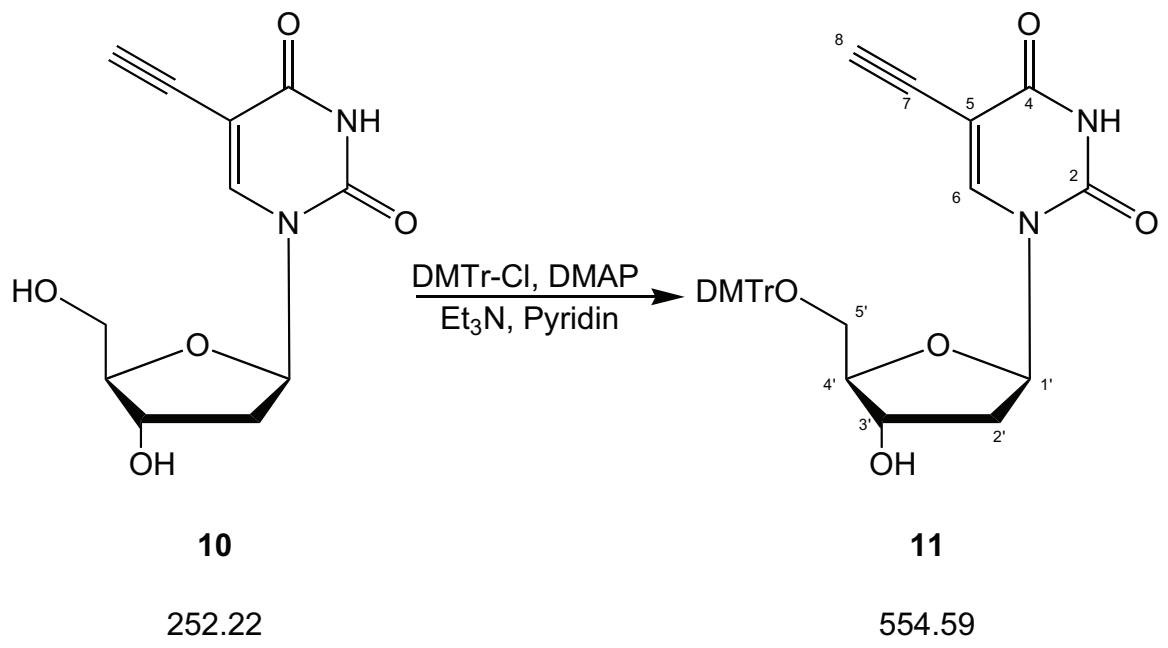

In $8.5 \mathrm{~mL}$ Pyridin wurden $481 \mathrm{mg}$ 5-Ethinyl-2'-desoxyuridin 10 (1.91 mmol) gelöst und mit 18.6 mg DMAP (0.15 mmol, 0.08 Äq.), $237 \mu \mathrm{L}$ Triethylamin (174 mg, 1.72 mmol, $\rho$ $=0.709,0.9$ Äq.) und $775 \mathrm{mg}$ Dimethoxytritylchlorid (2.29 mmol, 1.2 Äq) versetzt. Die Lösung wurde $4 \mathrm{~h}$ bei Raumtemperatur gerührt und anschließend das Lösungsmittel im Vakuum entfernt. Das gelbe Öl wurde säulenchromatographisch an Kieselgel mit den Eluenten Chloroform/Methanol/Triethylamin: 100/1/1 bis 100/10/1 aufgereinigt. Man erhielt 11 als einen weißen Schaum (1.04 g, $1.87 \mathrm{mmol}, 98 \%)$.

${ }^{1} \mathbf{H}-\mathbf{N M R}\left(\mathrm{CDCl}_{3}, 400 \mathrm{MHz}\right): \delta=8.06$ (s, 1H, H6), 7.18-7.43 (m, 9H, DMTr), 6.90-7.08 (m, 4H, DMTr), 6.85 (dd, J=8.8, 1.1 Hz, 1H, H1'), 4.50-4.57 (m, 1H, H3'), 4.05-4.09 (m, 2H, H4'), 3.79 (s, 6H, 2 x OMe), 3.35-3.43 (m, 2H, H5'), 2.91 (s, 1H, H8), 2.45-2.53 (m, 2H, H2') ppm.

${ }^{13}$ C-NMR $\left(\mathrm{CDCl}_{3}, 100.6 \mathrm{MHz}\right): \delta=160.92$ (1C, C4), 149.19 (1C, C2), 142.92 (1C, C6), 135-113 (18C, DMTr), 97.13 (1C, C5), 86.71 (1C, DMTr), 86.68 (1C, C4'), 86.00 (1C, C1'), 82.87 (1C, C7), 77.12 (1C, C8), 71.25 (1C, C3’), 63.14 (1C, C5'), 54.99 (2C, 2 x OMe), 41.82 (1C, C2') ppm.

ESI-MS $m / z$ (Acetonitril, positive mode): ber. für $\mathrm{C}_{32} \mathrm{H}_{30} \mathrm{~N}_{2} \mathrm{NaO}_{7}[\mathrm{M}+\mathrm{Na}]^{+}$: 577.58 , gef.: 577.26 . 


\subsubsection{5'-O-Dimethoxytrityl-5-iod-2'-desoxyuridin [154]}

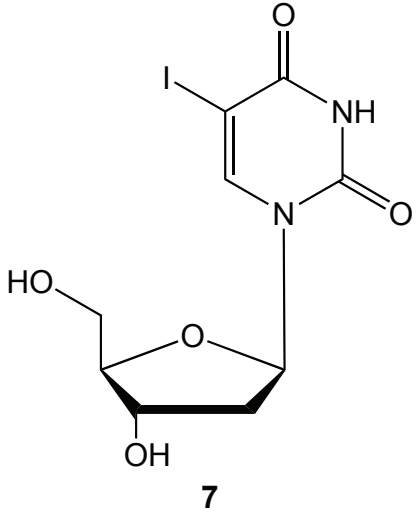

354.10

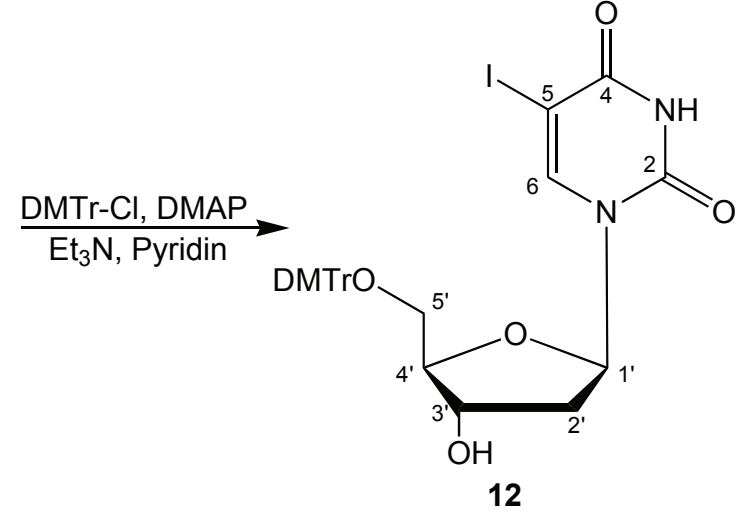

656.46

$\mathrm{Zu} 1.00$ g 5-Iod-2'-desoxyuridin (2.82 mmol) in $10 \mathrm{~mL}$ Pyridin wurden $401 \mu \mathrm{L}$ Triethylamin (285 mg, $\rho=0.709,1.0$ Äq.), 34.5 mg DMAP (0.28 $\mu \mathrm{mol}, 0.1$ Äq.) und 1.15 g 4,4'-Dimethoxytritylchlorid (3.41 mmol, 1.2 Äq.) gegeben und und $16 \mathrm{~h}$ bei Raumtemperatur gerührt. Die Lösung wurde mit $2 \mathrm{~mL}$ Methanol versetzt und das Lösungsmittel im Vakuum entfernt. Der gelbe Rückstand wurde in Dichlormethan aufgenommen und mit gesättigter Natriumhydrogencarbonat- und gesättigter Natriumchloridlösung gewaschen. Nach dem Trocknen der organischen Phase über Natriumsulfat wurde das Lösungsmittel im Vakuum entfernt. 2.41 g Rohprodukt wurden durch Kieselgelsäulenchromatographie mit den Eluenten Chloroform/Methanol/Triethylamin: 100/1/1 dann 100/2/1 gereinigt. Man erhielt 1.68 g weißen Schaums 12 (2.56 mmol, 91\%).

${ }^{1} \mathbf{H}-\mathbf{N M R}\left(\mathrm{CDCl}_{3}, 400 \mathrm{MHz}\right): \delta=8.13$ (s, 1H, H6), 7.17-7.47 (m, 9H, DMTr), 6.88-7.10 (m, 4H, DMTr), 6.35 (t, J =6.1 Hz, 1H, H1'), 4.55 (m, 1H, H3'), 4.10 (m, 1H, H4'), 3.80 (s, 6H, 2 x OMe), 3.39 (m, 2H, H5'), 2.50 (m, 1H, H2'a), 2.30 (m, 1H, H2’b) ppm.

${ }^{13}$ C-NMR $\left(\mathrm{CDCl}_{3}, 100.6 \mathrm{MHz}\right): \delta=160.57$ (1C, C4), 150.28 (1C, C6), 135-113 (18C, DMTr), 86.41 (1C, C4'), 85.45 (1C, C1'), 72.31 (1C, C3’), 68.66 (1C, C5), 63.95 (1C, C5'), 55.11 (2C, 2 x OMe), 41.46 (1C, C2') ppm.

ESI-MS m/z (Acetonitril, positive mode): ber. für $\mathrm{C}_{36} \mathrm{H}_{45} \mathrm{IN}_{3} \mathrm{O}_{7}\left[\mathrm{M}+\mathrm{Et}_{3} \mathrm{~N}+\mathrm{H}\right]^{+}: 758.23$, gef.: 758.22 . 


\subsubsection{5'-O-Dimethoxytrityl-5-trimethylsilylethinyl-2'-desoxyuridin}

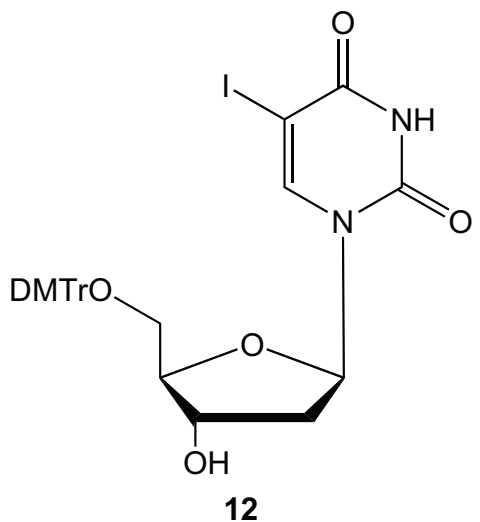

656.46
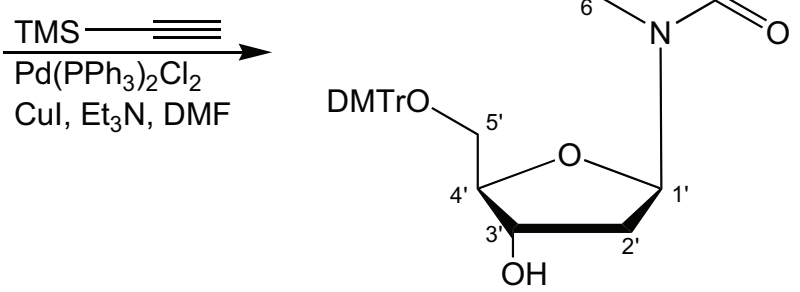

13

626.77

1.5 g 5'-O-Dimethoxytrityl-5-iod-2'-desoxyuridin 12 (2.28 mmol) wurden in $20 \mathrm{~mL}$ Triethylamin suspendiert und mit Argon belüftet. $34 \mathrm{mg}$ Kupfer(I)iodid (183 $\mu$ mol, 0.08 Äq.), $48 \mathrm{mg}$ Bis-(triphenylphosphin)-palladium(II)chlorid (68.5 $\mu \mathrm{mol}, 0.03$ Äq) und $949 \mu \mathrm{L}$ Trimethylsilylethin (0.67 g, $6.85 \mathrm{mmol}, \rho=0.709,3$ Äq.) wurden hinzugegeben und $2 \mathrm{~h}$ bei 50 ${ }^{\circ} \mathrm{C}$ gerührt. Nach Zugabe von $5 \mathrm{~mL}$ Dimethylformamid wurde die schwarze Lösung weitere 2 h bei $50{ }^{\circ} \mathrm{C}$ gerührt. Das Lösungsmittel wurde im Vakuum entfernt und das Rohprodukt mit Dichlormethan koevaporiert. Das Rohprodukt wurde mittels Säulenchromatographie an Kieselgel mit den Eluenten Chloroform/Methanol/Triethylamin: 100/1/1 gereinigt. Man erhielt 1.28 g eines gelblichen Schaums 13 (2.04 mmol, 90\%).

${ }^{1} \mathbf{H}-\mathbf{N M R}\left(\mathrm{CDCl}_{3}, 400 \mathrm{MHz}\right): \delta=7.98$ (s, 1H, H6), 7.46- 7.18 (m, 9H, DMTr), 7.10-6.88 (m, 4H, DMTr), $6.26\left(\mathrm{dd}, J=7.6,6.0 \mathrm{~Hz}, 1 \mathrm{H}, \mathrm{H} 1^{\prime}\right), 4.43(\mathrm{ddd}, J=5.9,3.0,2.9 \mathrm{~Hz}, 1 \mathrm{H}$, H3'), 4.05 (dt, $J=3.7,3.0 \mathrm{~Hz}, 1 \mathrm{H}, \mathrm{H} 4^{\prime}$ ), 3.78 (s, $6 \mathrm{H}, 2$ x OMe), 3.42 (dd, $J=10.6,3.7 \mathrm{~Hz}$, 1H, H5”), 3.31 (dd, $J=10.6,3.7 \mathrm{~Hz}, 1 \mathrm{H}, \mathrm{H} 5$ '), 2.45 (ddd, $J=13.7,6.0,2.9 \mathrm{~Hz}, 1 \mathrm{H}, \mathrm{H} 2 ”)$, 2.21 (ddd, $J=13.7,7.6,5.9 \mathrm{~Hz}, 1 \mathrm{H}, \mathrm{H} 2^{\prime}$ ), 0.00 (s, 9H, TMS) ppm.

${ }^{13} \mathrm{C}-\mathrm{NMR}\left(\mathrm{CDCl}_{3}, 100.6 \mathrm{MHz}\right): \delta=158.64$ (1C, C4), 149.14 (1C, C2), 142.99 (1C, C6), 135-113 (18C, DMTr), 99.37 (1C, C8), 94.54 (1C, C5), 86.69 (1C, DMTr), 86.36 (1C, C4'), 85.72 (1C, C1'), 75.23 (1C, C7), 72.31 (1C, C3'), 63.45 (1C, C5'), 55.31 (2C, 2 x OMe), 41.30 (1C, C2'), -0.37 (3C, TMS) ppm.

ESI-MS $m / z$ (Acetonitril $+1 \%$ Triethylamin, positive mode): ber. für $\mathrm{C}_{41} \mathrm{H}_{54} \mathrm{~N}_{3} \mathrm{O}_{7} \mathrm{Si}$ $\left[\mathrm{M}+\mathrm{Et}_{3} \mathrm{~N}+\mathrm{H}\right]^{+}:$728.37, gef.: 728.40 . 


\subsubsection{5'-O-Dimethoxytrityl-5-ethinyl-2'-desoxyuridin}

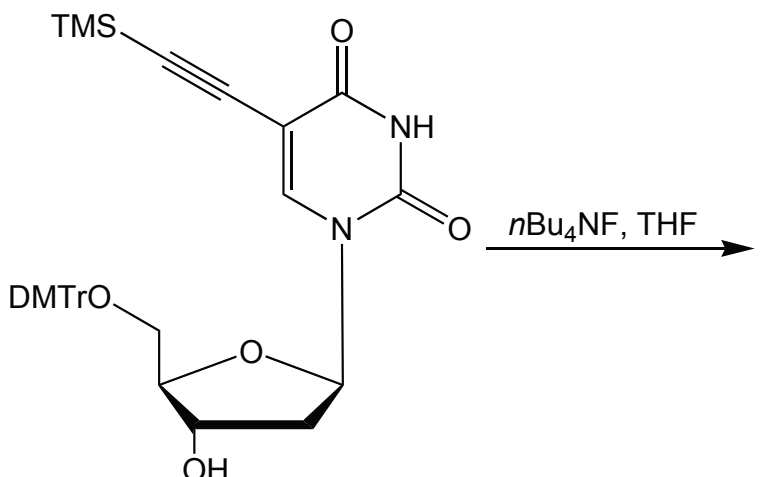

13

626.77

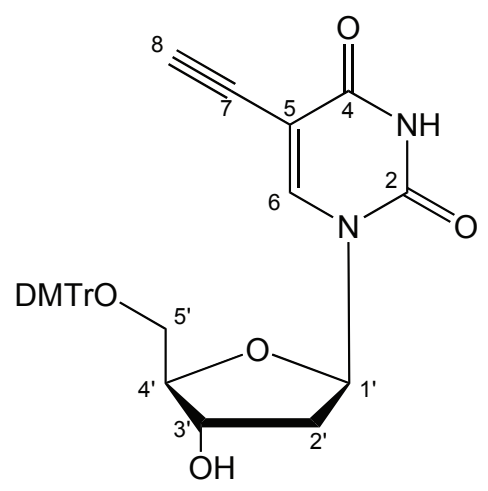

11

554.59

1.09 g 5'-O-Dimethoxytrityl-5-trimethylsilyl-2'-desoxyuridin 13 (1.74 mmol) wurden in 30 $\mathrm{mL}$ Tetrahydrofuran und $247 \mu \mathrm{L}$ Triethylamin $(175 \mathrm{~g}, 1.74 \mathrm{mmol}, \rho=0.709,1.0$ Äq.) gelöst. Zum Reaktionsgemisch wurden $3.48 \mathrm{~mL} 1 \mathrm{M}$ Tetra- $n$-butylammoniumfluoridlösung in Tetrahydrofuran (3.48 mmol, 2.0 Äq.) gegeben und 6 h bei Raumtemperatur gerührt. Anschließend wurde das Lösungsmittel im Vakuum entfernt und das Rohprodukt mittels Säulenchromatographie mit dem Laufmittel Chloroform/Triethylamin/Methanol: 100/1/0 dann 100/1/10 gereingt. Man erhielt 797 mg eines gräulichen Schaums 11 (1.44 mmol, 82\%).

Analysen siehe Abschnitt 8.2.5. 


\subsubsection{5'-O-Dimethoxytrityl-5-ethinyl-2'-desoxyuridin-phosphoramidit}

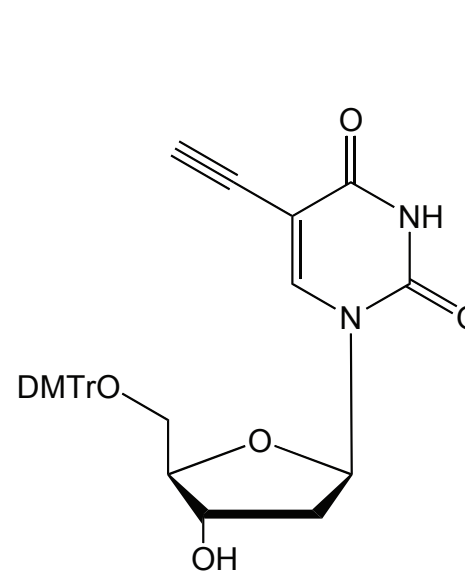

11

554.59

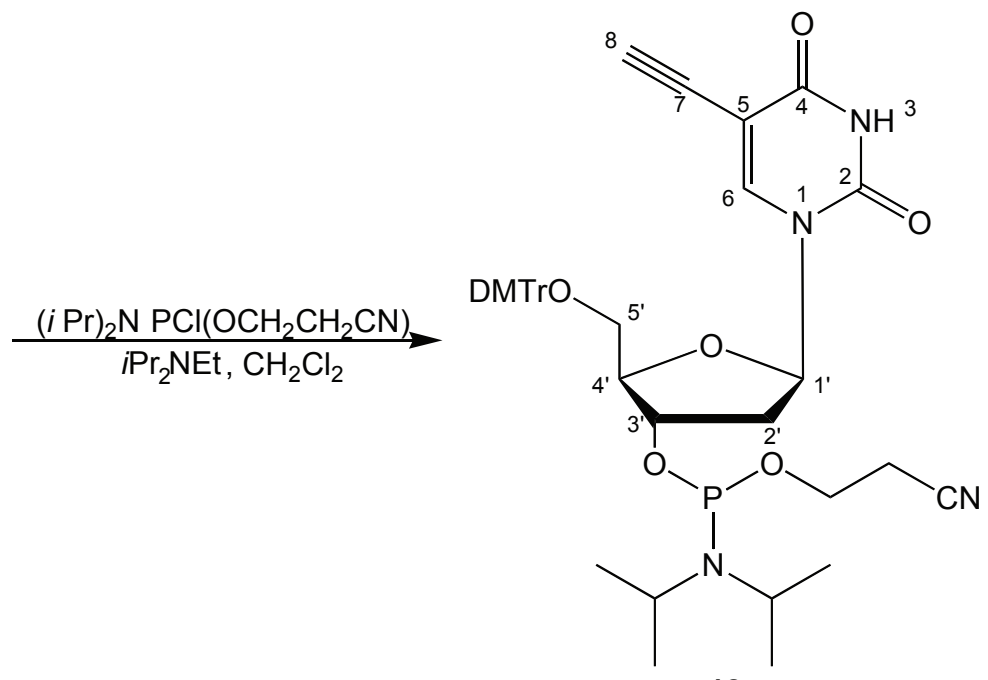

18

754.81

$200 \mathrm{mg} 11$ (0.36 mmol) wurden in $2 \mathrm{~mL}$ Dichlormethan gelöst und mit $92 \mu \mathrm{L} N$-Ethyldiisopropylamin (69 mg, $0.54 \mathrm{mmol}, \rho=0.755,1.5$ Äq.) und $96.5 \mu \mathrm{L}$ 2-Cyanoethyl- $N, N$-diisopropylchloro-phosphoramidit (102 mg, $0.43 \mathrm{mmol}, \rho=1.061,1.2$ Äq.) versetzt. Nach 1 h Rühren bei Raumtemperatur wurde die Lösung mit Dichlormethan verdünnt und mit gesättigter Natriumhydrogencarbonat- und gesättigter Natriumchloridlösung gewaschen. Die organische Phase wurde über Natriumsulfat getrocknet und das Lösungsmittel im Vakuum entfernt. Der Rückstand wurde säulenchromatographisch an Kieselgel mit den Eluenten Chloroform/Methanol/Triethylamin: 100/1/1 gereinigt. Man erhielt 244 mg eines weißen Schaums 18 (0.32 mmol, 90\%).

${ }^{31}$ P-NMR (243 MHz, $\mathrm{CDCl}_{3}$ mit 0.5\% Triethylamin) $: \delta=149.56(\mathrm{~d}, J=50 \mathrm{~Hz})$.

ESI-MS $m / z$ (Acetonitril mit $1 \%$ Triethylamin, positive mode): ber. für $\mathrm{C}_{47} \mathrm{H}_{63} \mathrm{~N}_{5} \mathrm{O}_{8} \mathrm{P}$ $\left[\mathrm{M}+\mathrm{Et}_{3} \mathrm{~N}+\mathrm{H}\right]^{+}:$856.44, gef.: 856.53. 


\subsubsection{0 (S)-N, N'-Di-tert-butyloxycarbonyl-2,3-diaminopropionsäure}<smiles>NC[C@@H](N)C(=O)O</smiles>

19-S

140.57

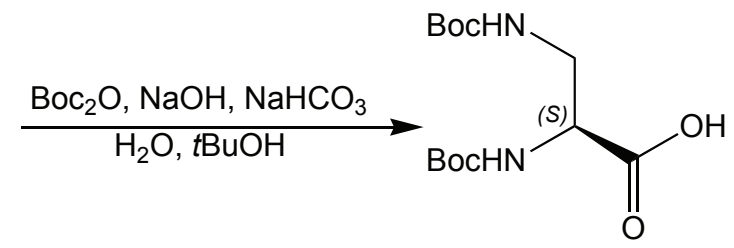

20-S

304.34

5.14 g (S)-2,3-Diaminopropionsäure-monohydrochlorid 19-S (36.5 mmol) wurde in $36.6 \mathrm{~mL}$ Wasser und $36.6 \mathrm{~mL} 1 \mathrm{M}$ Natronlauge gelöst. $35 \mathrm{~mL}$ tert-Butanol, $9.22 \mathrm{~g}$ Natriumhydrogencarbonat (110 mmol, 3.0 Äq.) und 16.0 g Di-tert-butyldicarbonat (73 mmol, 2.0 Äq.) wurden zugegeben und bei Raumtemperatur 24 h gerührt. Das tert-Butanol wurde im Vakuum entfernt und der Rückstand mit Chloroform (3 x $50 \mathrm{~mL})$ extrahiert. Die wässrige Phase wurde bei $4{ }^{\circ} \mathrm{C}$ mit $1 \mathrm{M}$ Salzsäure auf $\mathrm{pH}=2$ eingestellt und erneut mit Chloroform extrahiert. Die organische Phase wurde über Natriumsulfat getrocknet und im Vakuum eingeengt. Man erhielt 10.5 g eines weißen Schaums 20-S (34.5 mmol, 95\%).

${ }^{1} \mathbf{H}-\mathbf{N M R}\left(\mathrm{CDCl}_{3}, 400 \mathrm{MHz}\right): \delta=4.26(\mathrm{~m}, 1 \mathrm{H}, \mathrm{CH}), 3.60\left(\mathrm{~m}, 1 \mathrm{H}, \mathrm{CH}_{2} \mathrm{a}\right), 3.53(\mathrm{~m}, 1 \mathrm{H}$, $\mathrm{CH}_{2} \mathrm{~b}$ ), 1.45 (s, 18H, 2 x Boc) ppm.

ESI-MS $m / z$ (Acetonitril, positive mode): ber. für $\mathrm{C}_{13} \mathrm{H}_{24} \mathrm{~N}_{2} \mathrm{NaO}_{6}[\mathrm{M}+\mathrm{Na}]^{+}: 327.15$, gef.: 327.19 . 


\subsubsection{1 (S)- $N, N^{\prime}$-Di-tert-Butyloxycarbonyl-2,3-Diaminopropionsäure- benzylester}

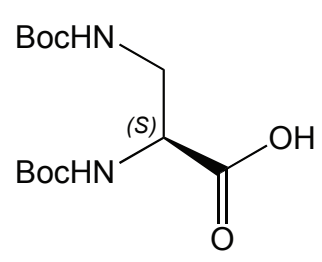

20-S

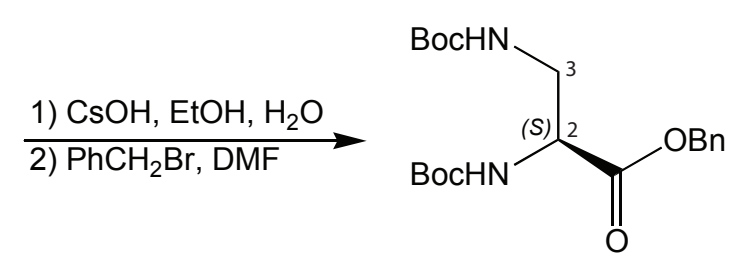

22-S

304.34

9.95 g (S)-N,N'-Di-tert-butyloxycarbonyl-2,3-diaminopropionsäure 20-S (32.7 mmol) wurde in $70 \mathrm{~mL}$ Ethanol und $35 \mathrm{~mL}$ Wasser gelöst. Danach wurde ein 10\%ige CäsiumhydroxidhydratLösung (etwa $40 \mathrm{~mL}$ ) zugetropft bis pH 7 erreicht war. Das Gemisch wurde im Vakuum (0.1 mbar) getrocknet und man erhielt 12.9 g des entsprechenden Cäsiumsalzes 21-S. Dieses wurde in Dimethylformamid gelöst und mit 9.66 mL Benzylbromid (6.71 g, 39 mmol, 1.2 Äq.) versetzt. Nach 15 h Rühren bei Raumtemperatur wurde das Lösungsmittel im Vakuum entfernt und der Rückstand in Essigester aufgenommen, mit Wasser und gesättigter Natriumchloridlösung gewaschen und die organische Phase über Natriumsulfat getrocknet, im Vakuum eingeengt und in Cyclohexan umkristallisiert. Man erhielt $10.5 \mathrm{~g}$ einer weißen Substanz 22-S (26.5 mmol, 81\%).

${ }^{1} \mathbf{H}-\mathbf{N M R}\left(\mathrm{CDCl}_{3}, 400 \mathrm{MHz}\right): \delta=7.39-7.29(\mathrm{~m}, 5 \mathrm{H}, \mathrm{Ph}), 5.18\left(\mathrm{~s}, 2 \mathrm{H}, \mathrm{CH}_{2} \mathrm{Ph}\right), 4.38(\mathrm{~m}$, 1H, H2), 3.51 (m, 2H, H3), 1.43 (s, 18H, 2 x Boc) ppm.

ESI-MS $m / z$ (Acetonitril, positive mode): ber. für $\mathrm{C}_{20} \mathrm{H}_{31} \mathrm{~N}_{2} \mathrm{O}_{6}[\mathrm{M}+\mathrm{H}]^{+}:$395.22, gef.: 395.29. 


\subsubsection{2,3-Diaminopropionsäurebenzylester Dihydrochlorid}<smiles>CC(C)(C)OC(=O)NCC(C(=O)OCc1ccccc1)C(=O)OCc1ccccc1</smiles>

22-S<smiles>COC(C)C(C)C(C)C(C)(Cl)OCc1ccccc1</smiles>

23-S

394.46

9.86 g 22-S (25.0 mmol) wurden in $70 \mathrm{~mL}$ Chloroform gelöst und mit $35 \mathrm{~mL}$ Methanol und $35 \mathrm{~mL} 4 \mathrm{M}$ HCl-Lösung in Dioxan (5.6 Äq.) versetzt. Das Gemisch wurde $4 \mathrm{~h}$ bei Raumtemperatur gerührt bis keine Gasentwicklung mehr zu beobachten war. Das Gemisch wurde im Vakuum eingeengt und der Rückstand mit Aceton (30 mL) und Ether (30 mL) gewaschen. Man erhielt 6.52 g eines weißen Schaums 23-S (24.4 mmol, 97\%).

${ }^{1} \mathbf{H}-\mathbf{N M R}\left(\mathrm{CDCl}_{3}, 400 \mathrm{MHz}\right): \delta=7.51-7.34(\mathrm{~m}, 5 \mathrm{H}, \mathrm{Ph}), 5.28\left(\mathrm{AB}, J=15 \mathrm{~Hz}, 2 \mathrm{H}, \mathrm{CH}_{2} \mathrm{Ph}\right)$, $4.48(\mathrm{t}, J=7 \mathrm{~Hz}, 1 \mathrm{H}, \mathrm{H} 2), 3.38(\mathrm{~m}, 2 \mathrm{H}, \mathrm{H} 3) \mathrm{ppm}$.

ESI-MS $m / z$ (Acetonitril, positive mode): ber. für $\mathrm{C}_{10} \mathrm{H}_{15} \mathrm{~N}_{2} \mathrm{O}_{2}[\mathrm{M}+\mathrm{H}]^{+}:$195.11, gef.: 195.22. 


\subsubsection{3 (S)-(1-Benzyloxycarbonyl)-ethylendiamintetraessigsäurete- tramethylester}

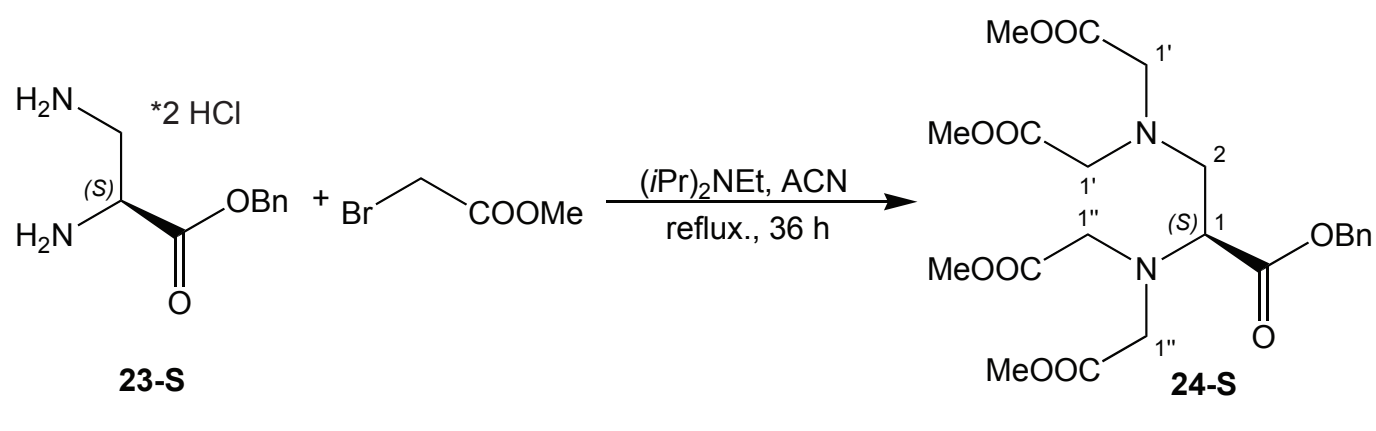

267.15

152.97

482.48

6.38 g (S)-2,3-Diaminopropionsäurebenzylester Dihydrochlorid 23-S (23.9 mmol) wurde in $300 \mathrm{~mL}$ Acetonitril gelöst und mit $32.7 \mathrm{~mL} N$-Ethyldiisopropylamin $(24.7 \mathrm{~g}, 191 \mathrm{mmol}, 8.0$ Äq.) versetzt. Anschließend wurden $21.9 \mathrm{~mL}$ Bromessigsäuremethylester (36.4 g, $238 \mathrm{mmol}, \rho=1.664,10.0$ Äq) zugetropft und die Lösung 36 h refluxiert. Das Lösungsmittel wurde im Vakuum entfernt und man erhielt ein orangenes Pulver, das in Dichlormethan aufgenommen und mit Phosphatpuffer $(\mathrm{pH}=2,0.1 \mathrm{M})$ gewaschen wurde. Die organische Phase wurde über Magnesiumsulfat getrocknet und das Lösungsmittel im Vakuum entfernt. Das erhaltene braune Öl wurde säulenchromatographisch an Kieselgel aufgereinigt (Eluent: Heptan/Essigester: 2/1). Man erhielt 12.6 g eines gelbes Öls 24-S (>100\%).

${ }^{1} \mathbf{H}-\mathbf{N M R}\left(\mathrm{CDCl}_{3}, 400 \mathrm{MHz}\right): \delta=7.39-7.28(\mathrm{~m}, 5 \mathrm{H}, \mathrm{Ph}), 5.12\left(\mathrm{~s}, 2 \mathrm{H}, \mathrm{CH}_{2} \mathrm{Ph}\right), 3.71(\mathrm{~m}$, 1H, H1), 3.67 (m, 4H, H1”), 3.65 (s, 6H, Me'), 3.64 (s, 6H, Me”), 3.61 (s, 4H, H1'), 3.18 (dd, $J=13.8 \mathrm{~Hz}, 6.4 \mathrm{~Hz}, 1 \mathrm{H}, \mathrm{H} 2 \mathrm{a}), 3.08$ (dd, $J=13.8 \mathrm{~Hz}, 8.4 \mathrm{~Hz}, 1 \mathrm{H}, \mathrm{H} 2 \mathrm{~b}) \mathrm{ppm}$.

${ }^{13}$ C-NMR $\left(\mathrm{CDCl}_{3}, 100.6 \mathrm{MHz}\right): \delta=171.43$ (2C, 2 x COOMe'), 171.34 (2C, 2 x COOMe"), 171.22 (1C, COOBn), 135.50 (1C, $\left.\mathrm{Ph}_{\text {quart. }}\right), 128.22$ (2C, $\left.2 \times \mathrm{Ph}_{\text {meta }}\right), 127.99$ (2C, $\left.2 \times \mathrm{Ph}_{\text {ortho }}\right)$, 127.90 (1C, $\mathrm{Ph}_{\text {para }}$ ), 66.24 (1C, $\left.\mathrm{CH}_{2} \mathrm{Ph}\right), 63.88$ (1C, C1), 54.83 (2C, 2 x C1"), 54.53 (1C, C2), 52.30 (2C, 2 x C1'), 51.29 (2C, 2 x Me'), 51.14 (2C, 2 x Me") ppm.

ESI-MS $m / z$ (Acetonitril, positive mode): ber. für $\mathrm{C}_{22} \mathrm{H}_{30} \mathrm{NaN}_{2} \mathrm{O}_{10}[\mathrm{M}+\mathrm{Na}]^{+}: 505.18$, gef.: 505.23 . 


\subsubsection{4 (S)-1-Carboxyethylendiamintetraessigsäuretetramethylester}<smiles>CC(=O)COC(=O)[C@H](CN(CC(C)=O)CC(C)=O)N(CC(C)=O)CC(C)=O</smiles>

24-S

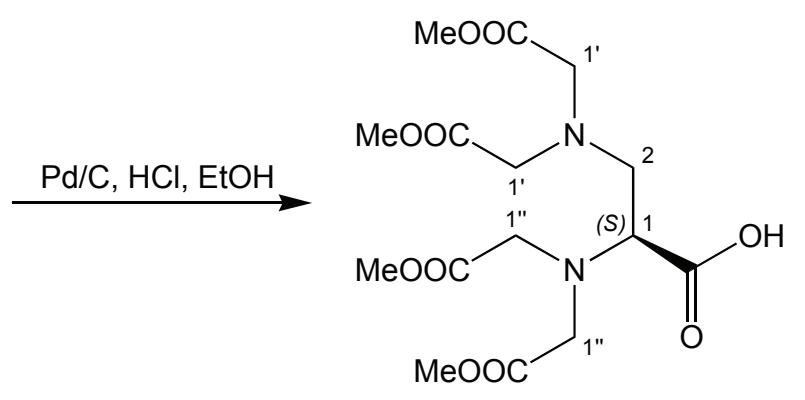

25-S

392.36

490 mg (S)-(1-Benzyloxycarbonyl)-ethylendiamintetraessigsäuretetramethylester 24-S (1.02 mmol) und $80 \mu \mathrm{L}$ konzentrierte Salzsäure (1.0 Äq.) wurden in $3 \mathrm{~mL}$ Ethanol gelöst und unter Argonatmosphäre gebracht. 10\%wt Pd/C-Katalysator (34.5 mg) wurde abwechselnd mit Argon belüftet und evakuiert (dreimal). Danach wurden $3 \mathrm{~mL}$ Ethanol zugegeben. Die Suspension wurde erneut dreimal mit Argon belüftet und evakuiert und dann unter Wasserstoffatmosphäre gebracht. Die Suspension wurde 2 min gerührt und anschließend die Lösung von 24-S zugegeben. Nach fünfstündigem Rühren bei Raumtemperatur wurde der Katalysator durch eine Natriumsulfatschicht $(1 \mathrm{~cm})$ abfiltriert und der Rückstand mit Ethanol gewaschen. Die Lösung wurde im Vakuum eingeengt und zweimal mit Toluol koevaporiert. Man erhielt $380 \mathrm{mg}$ gilbliches Glas 25-S (0.91 mmol, 95\%).

${ }^{1} \mathbf{H}-\mathbf{N M R}\left(\mathrm{D}_{2} \mathrm{O}, 400 \mathrm{MHz}\right): \delta=3.74(\mathrm{~m}, 1 \mathrm{H}, \mathrm{H} 1), 3.71$ (m, 4H, H1" ), 3.67 (s, 6H, 2 x Me), 3.65 (m, 4H, H1'), 3.59 (s, 6H, 2 x Me), 3.23 (dd, J=13.8 Hz, $6.4 \mathrm{~Hz}, 1 \mathrm{H}, \mathrm{H} 2 \mathrm{a}$ ), 3.12 (dd, $J=13.8 \mathrm{~Hz}, 8.0 \mathrm{~Hz}, 1 \mathrm{H}, \mathrm{H} 2 \mathrm{~b}) \mathrm{ppm}$.

${ }^{13}$ C-NMR $\left(\mathrm{D}_{2} \mathrm{O}, 100.6 \mathrm{MHz}\right): \delta=173.81$ (1C, COOH), 168.45 (2C, 2 x COOMe), 167.18 (2C, 2 x COOMe), 63.94 (1C, C1), 55.21 (2C, 2 x C1'), 54.23 (1C, C2), 52.12 (2C, 2 x C1"), 51.77 (4C, 4 x Me) ppm.

ESI-MS $m / z$ (Wasser $+10 \%$ Acetonitril, positive mode): ber. für $\mathrm{C}_{15} \mathrm{H}_{25} \mathrm{~N}_{2} \mathrm{O}_{10}[\mathrm{M}+\mathrm{H}]^{+}$: 393.15, gef.: 393.22. 


\subsubsection{5 (S)-1-(4-Azidophenylcarbamoyl)-ethylendiamintetraessig-}

säuretetramethylester

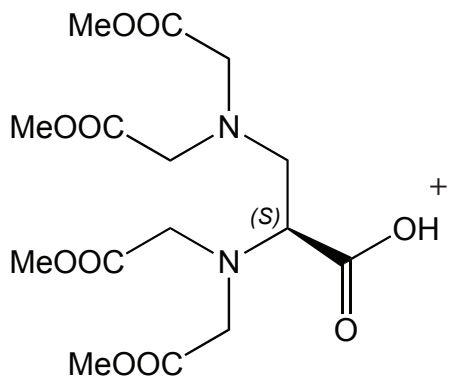

25-S<smiles>Nc1ccc(N)cc1</smiles>

170.60

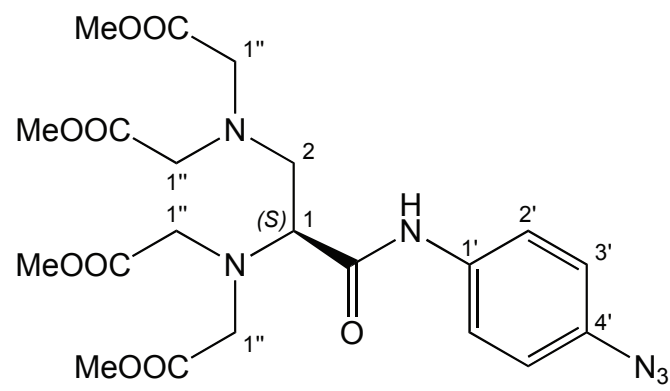

26-S

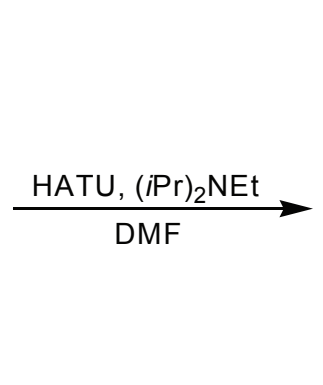

392.36

$100 \mathrm{mg}$ 25-S $(255 \mu \mathrm{mol})$ und $174 \mathrm{mg}$ HATU $(459 \mu \mathrm{mol}, 3.0$ Äq.) wurden in $131 \mu \mathrm{L}$ $N$-Ethyldiisopropylamin (99 mg, $\rho=0.755,765 \mu \mathrm{mol}, 3.0$ Äq.) und $5 \mathrm{~mL}$ Dimethylformamid gelöst und $2 \mathrm{~h}$ unter Argon gerührt. Dann gab man eine Lösung aus $52 \mathrm{mg}$ Azidoanilinhydrochlorid (306 $\mu \mathrm{mol}, 1.2$ Äq.) und $52 \mu \mathrm{L} N$-Ethyldiisopropylamin (40 mg, $\rho=0.755,306$ $\mu \mathrm{mol}, 1.2$ Äq.) in $5 \mathrm{~mL}$ Dimethylformamid hinzu und rührte $16 \mathrm{~h}$ bei Raumtemperatur. Das Lösungsmittel wurde im Vakuum entfernt und der Rückstand in Dichlormethan aufgenommen. Die organische Phase wurde mit Phosphatpuffer $(0.1 \mathrm{M}, \mathrm{pH}=2)$ und gesättigter Natriumchloridlösung gewaschen, über Natriumsulfat getrocknet und im Vakuum eingeengt. Das Öl wurde säulenchromatographisch an Kieselgel mit dem Eluenten Chloroform/Methanol: 100/1 gereinigt. Man erhielt 119 mg eines gelben Öls 26-S (234 $\mu \mathrm{mol}, 92 \%)$.

${ }^{1}$ H-NMR (DMSO, $\left.400 \mathrm{MHz}\right): \delta=10.36(\mathrm{br}, 1 \mathrm{H}, \mathrm{NH}), 7.68$ (d, $J=8.3 \mathrm{~Hz}, 2 \mathrm{H}, 2 \mathrm{x} \mathrm{H} 2$ '), 6.97 (d, $J=8.3 \mathrm{~Hz}, 2 \mathrm{H}, 2$ x H3'), 3.77 (AB, 4H, 4 x H1”), 3.73 (s, 6H, 2 x Me), 3.70 (m, 1H, H1), 3.69 (s, 6H, 2 x Me), 3.62 (AB, 4H, 4 x H1"), 3.35 (dd, J=13.9 Hz, $6.9 \mathrm{~Hz}, 1 \mathrm{H}$, H2a), 3.09 (dd, $J=13.9 \mathrm{~Hz}, 7.1 \mathrm{~Hz}, 1 \mathrm{H}, \mathrm{H} 2 \mathrm{~b}$ ) ppm.

${ }^{13}$ C-NMR (DMSO, 100.6 MHz): $\delta=173.14$ (2C, $2 \times$ COOMe), 171.99 (2C, 2 x COOMe), 170.86 (1C, CONH), 136.01 (1C, C4'), 135.39 (1C, C1'), 120.86 (2C, 2 x C2'), 119.67 (2C, 2 x C3'), 65.28 (1C, C1), 55.67 (2C, 2 x C1”), 55.15 (1C, C2), 53.85 (2C, 2 x C1”), 52.47 (2C, $2 \times \mathrm{Me}), 51.95(2 \mathrm{C}, 2 \times \mathrm{Me}) \mathrm{ppm}$.

ESI-MS $m / z$ (Acetonitril, positive mode): ber. für $\mathrm{C}_{21} \mathrm{H}_{29} \mathrm{~N}_{6} \mathrm{O}_{9}[\mathrm{M}+\mathrm{H}]^{+}$: 509.20, gef.: 509.20. 


\subsubsection{6 trans-4-tert-Butoxycarbonylaminocyclohexanol}

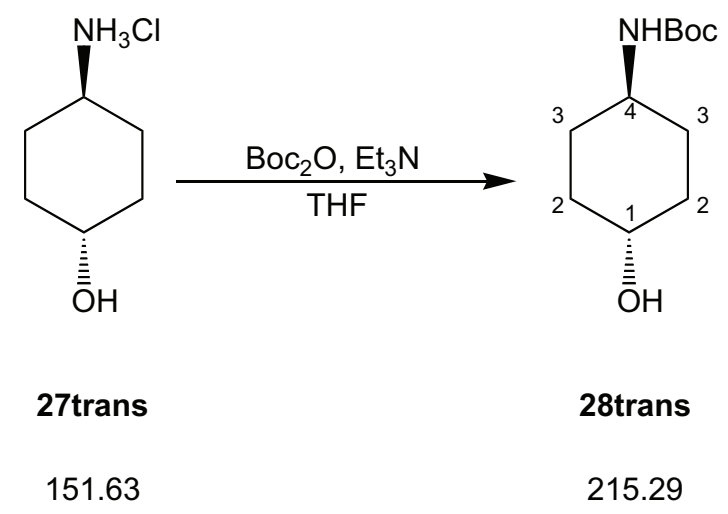

Zu 1.00 g trans-4-Aminocyclohexanol Hydrochlorid 27trans (6.60 mmol) in $1.84 \mathrm{~mL}$ Triethylamin (1.34 g, $13.2 \mathrm{mmol}, 2.0$ Äq.) und $10 \mathrm{~mL}$ Tetrahydrofuran wurden $2.88 \mathrm{~g}$ Ditert-butyldicarbonat (13.2 mmol, 2.0 Äq.) in $5 \mathrm{~mL}$ Tetrahydrofuran bei $0{ }^{\circ} \mathrm{C}$ langsam zugetropft. Anschließend wurde $5 \mathrm{~min}$ bei $0{ }^{\circ} \mathrm{C}$ und nochmals $15 \mathrm{~min}$ bei Raumtemperatur gerührt. Die Lösung wurde mit Diethylether verdünnt und mit gesättigter Natriumhydrogencarbonatlösung, Wasser und gesättigter Natriumchloridlösung gewaschen. Die etherische Phase wurde über Natriumsulfat getrocknet und das Lösungsmittel im Vakuum entfernt. Das Produkt wurde aus Essigester/Heptan umkristallisiert. Im Vakuum (0.1 mbar) wurden die tert-Butanolreste entfernt. Die Ausbeute betrug 1.35 g (6.27 mmol, 95\%).

${ }^{1} \mathbf{H}-\mathbf{N M R}\left(\mathrm{CDCl}_{3}, 400 \mathrm{MHz}\right): \delta=4.35(\mathrm{~s}, \mathrm{br}, 1 \mathrm{H}, \mathrm{NH}), 3.59(\mathrm{~m}, 1 \mathrm{H}, \mathrm{H} 1), 3.42(\mathrm{~s}, \mathrm{br}, 1 \mathrm{H}$, H4), 2.04 (m, 2H, $2 \times \mathrm{H} 2_{e q}$ ), 1.95 ( $\mathrm{m}, 2 \mathrm{H}, 2 \times \mathrm{H} 3_{\text {eq }}$ ), 1.43 (s, 9H, Boc), 1.38 (m, 2H, $2 \times$ $\left.\mathrm{H} 2_{a x}\right), 1.17$ (m, 2H, $2 \times \mathrm{H} 3_{a x}$ ) ppm (Zuordnung der axialen und äquatorialen Protonen aus E.COSY).

${ }^{13}$ C-NMR $\left(\mathrm{CDCl}_{3}, 100.6 \mathrm{MHz}\right): \delta=155.30(1 \mathrm{C}, \mathrm{CO}), 79.20\left(1 \mathrm{C}, \mathrm{C}\left(\mathrm{CH}_{3}\right)_{3}\right), 69.78(1 \mathrm{C}, \mathrm{C} 1)$, 48.73 (1C, C4), 33.91 (2C, 2 x C2), 31.09 (2C, $2 \times$ C3), 28.48 (3C, 3 x $\mathrm{CH}_{3}$ ) ppm.

ESI-MS $m / z$ (Acetonitril, positive mode): ber. für $\mathrm{C}_{11} \mathrm{H}_{22} \mathrm{NO}_{3}[\mathrm{M}+\mathrm{H}]^{+}:$216.16, gef.: 216.08. 


\subsubsection{7 cis-4-tert-Butoxycarbonylaminocyclohexanol}

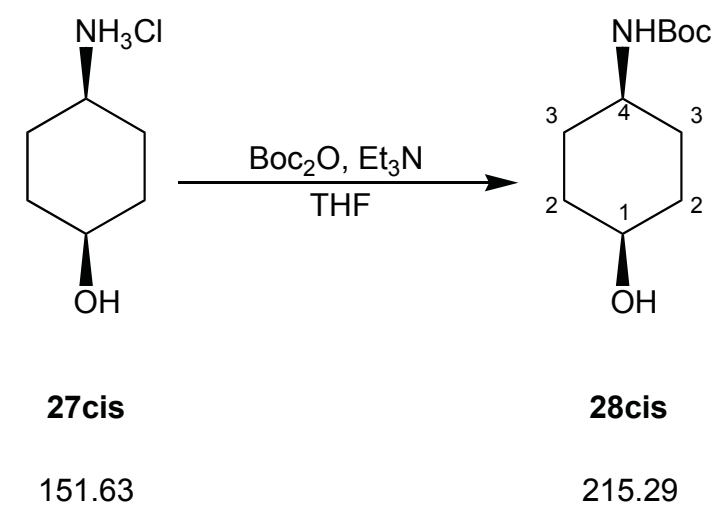

Die Synthese der cis-Verbindung erfolgt analog zur trans-Verbindung.

${ }^{1} \mathbf{H}-\mathrm{NMR}\left(\mathrm{CDCl}_{3}, 400 \mathrm{MHz}\right): \delta=4.53(\mathrm{~s}, \mathrm{br}, 1 \mathrm{H}, \mathrm{NH}), 3.89(\mathrm{~m}, 1 \mathrm{H}, \mathrm{H} 1), 3.53$ (s, br, 1H, H4), 1.72 (m, 2H, 2 x H3), 1.67-1.64 (m, 4H, 4 x H2), 1.60 (m, 2H, 2 x H3), 1.45 (s, 9H, Boc) ppm.

${ }^{13} \mathrm{C}-\mathrm{NMR}\left(\mathrm{CDCl}_{3}, 100.6 \mathrm{MHz}\right): \delta=155.30(1 \mathrm{C}, \mathrm{CO}), 79.20\left(1 \mathrm{C}, \mathrm{C}\left(\mathrm{CH}_{3}\right)_{3}\right), 66.23(1 \mathrm{C}, \mathrm{C} 1)$, 47.42 (1C, C4), 30.38 (2C, 2 x C2), 28.16 (3C, 3 x $\left.\mathrm{CH}_{3}\right), 27.52$ (2C, $\left.2 \times \mathrm{C} 3\right)$ ppm. 


\subsubsection{8 trans-4-tert-Butoxycarbonylaminocyclohexylmesylat}

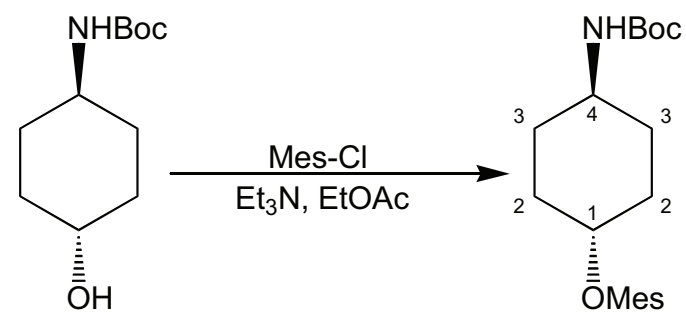

28trans

29trans

215.29

293.38

0.90 g trans-4-tert-Butoxycarbonylaminocyclohexanol 28trans $(4.18 \mathrm{mmol})$ wurden in $20 \mathrm{~mL}$ Essigester und $2.33 \mathrm{~mL}$ Triethylamin (1.69 g, $16.7 \mathrm{mmol}, 2$ Äq.) gelöst und auf $-10{ }^{\circ} \mathrm{C}$ gekühlt. Anschließend wurde eine $-10{ }^{\circ} \mathrm{C}$ kalte Lösung aus $0.46 \mathrm{~mL}$ Mesylchlorid (0.67 g, $5.85 \mathrm{mmol}, 1.4$ Äq.) in $5 \mathrm{~mL}$ Essigester langsam zugetropft und $1 \mathrm{~h}$ bei $-10^{\circ} \mathrm{C}$ gerührt. Die Reaktionslösung wurde mit Essigester verdünnt und mit $0{ }^{\circ} \mathrm{C}$ kalter $0.1 \mathrm{M}$ Salzsäure, gesättigter Natriumhydrogencarbonatlösung und gesättigter Natriumchloridlösung gewaschen. Die organische Phase wurde über Magnesiumsulfat getrocknet und das Lösungsmittel wurde im Vakuum entfernt. Man erhielt 29trans als weißes Pulver in quantitativer Ausbeute.

${ }^{1} \mathbf{H}-\mathrm{NMR}\left(\mathrm{CDCl}_{3}, 400 \mathrm{MHz}\right): \delta=4.62(\mathrm{~m}, 1 \mathrm{H}, \mathrm{H} 1), 4.38$ (s, br, 1H, NH), 3.47 (sbr, 1H, H4), 3.02 (s, 3H, Mes), 2.12 (m, 2H, 2 x H3), 2.06 (m, 2H, 2 x H2), 1.68 (m, 2H, 2 x H3), 1.45 (s, 9H, Boc), 1.25 (m, 2H, 2 x H2) ppm.

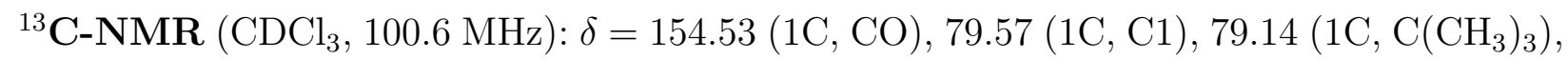
47.83 (1C, C4), 38.78 (1C, Mes), 30.91 (2C, 2 x C3), 30.44 (2C, $2 \times$ C2), 28.44 (3C, 3 x $\mathrm{CH}_{3}$ ) ppm.

ESI-MS $m / z$ (Acetonitril $+1 \%$ Ameisensäure, positive mode): ber. für $\mathrm{C}_{12} \mathrm{H}_{23} \mathrm{NNaO}_{3} \mathrm{~S}$ $[\mathrm{M}+\mathrm{Na}]^{+}: 316.12$, gef.: 316.07 . 


\subsubsection{9 cis-4-tert-Butoxycarbonylaminocyclohexylmesylat}

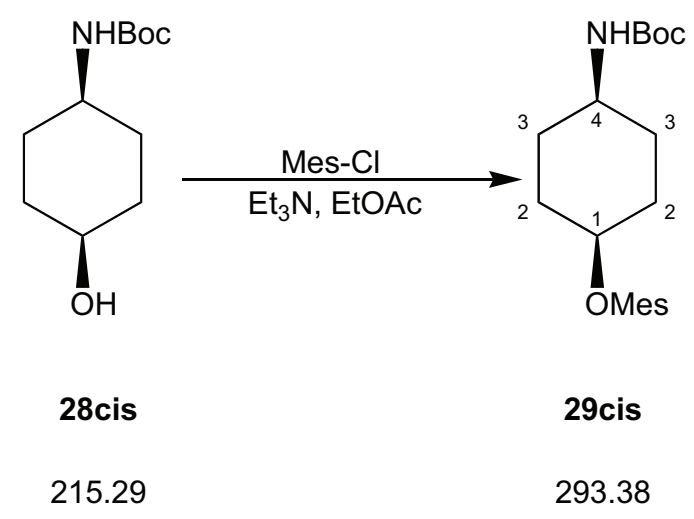

Die Synthese der cis-Verbindung erfolgt analog zur trans-Verbindung.

${ }^{1} \mathbf{H}-\mathrm{NMR}\left(\mathrm{CDCl}_{3}, 400 \mathrm{MHz}\right): \delta=4.88$ (m, 1H, H1), 4.46 (sbr, 1H, NH), 3.52 (sbr, 1H, H4), 3.01 (s, 3H, Mes), 2.06 (m, 2H, 2 x H3), 1.84 (m, 2H, $2 \times$ H2), 1.74 (m, 2H, 2 x H3), 1.58 (m, 2H, 2 x H2), 1.44 (s, 9H, Boc) ppm.

${ }^{13}$ C-NMR $\left(\mathrm{CDCl}_{3}, 100.6 \mathrm{MHz}\right): \delta=154.53(1 \mathrm{C}, \mathrm{CO}), 79.14\left(1 \mathrm{C}, \mathrm{C}\left(\mathrm{CH}_{3}\right)_{3}\right), 77.63(1 \mathrm{C}, \mathrm{C} 1)$, 47.38 (1C, C4), 38.43 (1C, Mes), 29.78 (2C, $2 \times$ C3), $28.44\left(3 \mathrm{C}, 3 \times \mathrm{CH}_{3}\right), 27.44(2 \mathrm{C}, 2 \mathrm{x}$ C2) ppm. 


\subsubsection{0 cis-4-tert-Butoxycarbonylaminocyclohexylazid}

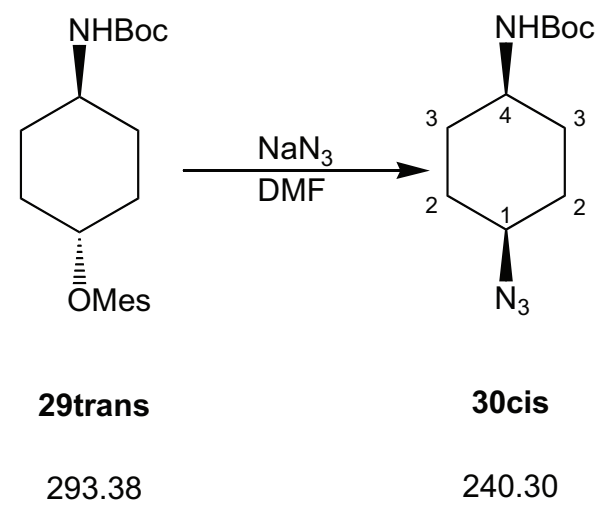

$1.00 \mathrm{~g}$ trans-4-tert-Butoxycarbonylaminocyclohexylmesylat 29trans (3.41 mmol) und $2.22 \mathrm{~g}$ Natriumazid (34.08 mmol, 10 Äq.) in $50 \mathrm{~mL}$ Dimethylformamid wurden $4 \mathrm{~d}$ bei $50{ }^{\circ} \mathrm{C}$ gerührt. Die Suspension wurde mit Dichlormethan versetzt und mit gesättigter Natriumhydrogencarbonatlösung und gesättigter Natriumchloridlösung gewaschen. Die organische Phase wurde über Natriumsulfat getrocknet und im Vakuum eingeengt. Das gelbliche Öl wurde säulenchromatographisch aufgereinigt mit Hexan/Essigester: 4 /1 dann 1/1. Die Ausbeute betrug $82 \%$ (2.79 mmol, $0.67 \mathrm{~g})$.

${ }^{1} \mathbf{H}-\mathrm{NMR}\left(\mathrm{CDCl}_{3}, 400 \mathrm{MHz}\right): \delta=4.46$ (sbr, 1H, NH), 3.69 (m, 1H, H1), 3.51 (sbr, 1H, H4), 1.88 (m, 2H, 2 x H3), 1.75 (m, 2H, 2 x H2), 1.65 (m, 2H, $2 \times \mathrm{H} 2), 1.46$ (s, 9H, Boc), 1.42 (m, 2H, 2 x H3) ppm.

${ }^{13}$ C-NMR $\left(\mathrm{CDCl}_{3}, 100.6 \mathrm{MHz}\right): \delta=154.51(1 \mathrm{C}, \mathrm{CO}), 79.02\left(1 \mathrm{C}, \mathrm{C}\left(\mathrm{CH}_{3}\right)_{3}\right), 57.01(1 \mathrm{C}, \mathrm{C} 1)$, 47.67 (1C, C4), 28.67 (2C, 2 x C3), 28.39 (3C, 3 x $\left.\mathrm{CH}_{3}\right), 28.04$ (2C, $\left.2 \times \mathrm{C} 2\right)$ ppm.

ESI-MS $m / z$ (Acetonitril+ $1 \%$ Triethylamin, positive mode): ber. für $\mathrm{C}_{11} \mathrm{H}_{21} \mathrm{~N}_{4} \mathrm{O}_{2}[\mathrm{M}+\mathrm{H}]^{+}$: 241.17, gef.: 241.11 . 


\subsubsection{1 trans-4-tert-Butoxycarbonylaminocyclohexylazid}

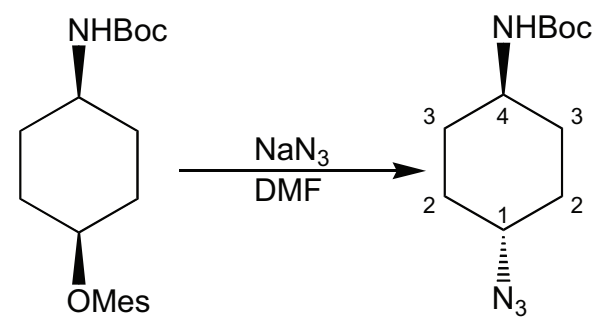

29cis

30 trans

293.38

240.30

Die Synthese der trans-Verbindung erfolgt analog zur cis-Verbindung in nur 24 h Reaktionszeit.

${ }^{1} \mathbf{H}-\mathrm{NMR}\left(\mathrm{CDCl}_{3}, 400 \mathrm{MHz}\right): \delta=4.34(\mathrm{sbr}, 1 \mathrm{H}, \mathrm{NH}), 3.43(\mathrm{sbr}, 1 \mathrm{H}, \mathrm{H} 4), 3.26(\mathrm{~m}, 1 \mathrm{H}, \mathrm{H} 1)$, 2.05 (m, 2H, 2 x H3), 1.99 (m, 2H, 2 x H2), 1.46 (s, 9H, Boc), 1.43 (m, 2H, 2 x H2), 1.19 (m, 2H, $2 \times \mathrm{x} 3)$ ppm.

${ }^{13} \mathrm{C}-\mathrm{NMR}\left(\mathrm{CDCl}_{3}, 100.6 \mathrm{MHz}\right): \delta=154.52(1 \mathrm{C}, \mathrm{CO}), 79.02\left(1 \mathrm{C}, \mathrm{C}\left(\mathrm{CH}_{3}\right)_{3}\right), 59.12(1 \mathrm{C}, \mathrm{C} 1)$, 48.63 (1C, C4), 31.30 (2C, 2 x C3), 30.08 (2C, 2 x C2), $28.41\left(3 \mathrm{C}, 3 \times \mathrm{CH}_{3}\right) \mathrm{ppm}$. 


\subsubsection{2 trans-4-Aminocyclohexylazid}<smiles>CC(C)(C)O[Mg]N1CCC(N)CC1</smiles>

30 trans

240.30

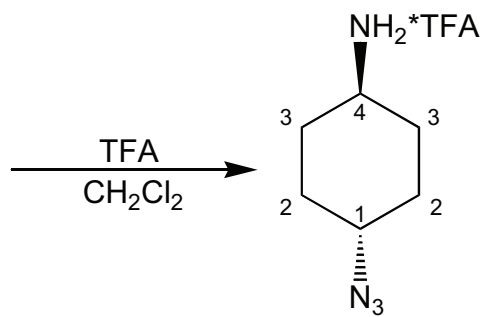

31 trans

254.21

$100 \mathrm{mg}$ 4-tert-Butoxycarbonylaminocyclohexylazid 30trans (0.42 mmol) wurde in $2 \mathrm{~mL}$ Dichlormethan und $2 \mathrm{~mL}$ Trifluoressigsäure gelöst und 30 min bei Raumtemperatur gerührt. Das Lösungsmittel wurde im Vakuum entfernt und der ölige Rückstand wurde aus Essigester/Hexan umkristallisiert. Das Produkt fiel als Trifluoracetat 31trans (97 mg, 0.38 mmol, $92 \%)$ aus.

${ }^{1} \mathbf{H}-\mathbf{N M R}\left(\mathrm{CD}_{3} \mathrm{CN}, 400 \mathrm{MHz}\right): \delta=3.38(\mathrm{~m}, 1 \mathrm{H}, \mathrm{H} 1), 3.13(\mathrm{~m}, 1 \mathrm{H}, \mathrm{H} 4), 2.06(\mathrm{~m}, 2 \mathrm{H}, 2 \mathrm{x}$ H2), 2.02 (m, 2H, 2 x H3), 1.50 (m, 2H, 2 x H2), 1.37 (m, 2H, 2 x H3) ppm.

${ }^{13}$ C-NMR (CD 3 CN, $\left.100.6 \mathrm{MHz}\right): \delta=59.01$ (1C, C1), 50.44 (1C, C4), 30.06 (2C, 2 x C3), $29.22(2 \mathrm{C}, 2 \times \mathrm{C} 2) \mathrm{ppm}$.

ESI-MS $m / z$ (Acetonitril, positive mode): ber. für $\mathrm{C}_{6} \mathrm{H}_{13} \mathrm{~N}_{4}[\mathrm{M}+\mathrm{H}]^{+}$: 141.11, gef.: 140.90 . 


\subsubsection{3 cis-4-Aminocyclohexylazid}

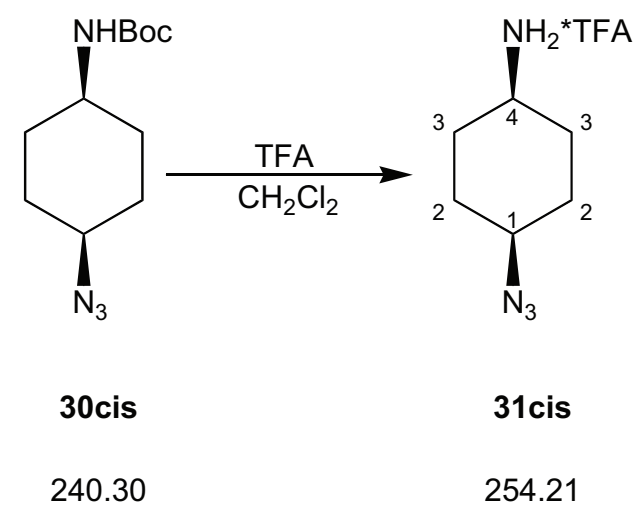

Die Synthese der cis-Verbindung erfolgt analog zur trans-Verbindung.

${ }^{1} \mathbf{H}-\mathrm{NMR}\left(\mathrm{CD}_{3} \mathrm{CN}, 400 \mathrm{MHz}\right): \delta=7.44(\mathrm{sbr}, 2 \mathrm{H}, \mathrm{NH} 2), 3.88(\mathrm{~m}, 1 \mathrm{H}, \mathrm{H} 1), 3.21(\mathrm{~m}, 1 \mathrm{H}$, H4), 1.87 (m, 2H, 2 x H3), 1.85 (m, 2H, 2 x H2), 1.68 (m, 2H, 2 x H3), 1.66 (m, 2H, 2 x H2) ppm.

${ }^{13}$ C-NMR ( $\left.\mathrm{CD}_{3} \mathrm{CN}, 100.6 \mathrm{MHz}\right): \delta=55.77$ (1C, C1), 49.13 (1C, C4), 24.71 (2C, 2 x C3), 26.95 (2C, 2 x C2) ppm. 


\subsubsection{4 (S)-1-(trans-4-Azidocyclohexylcarbamoyl)ethylendiamin-}

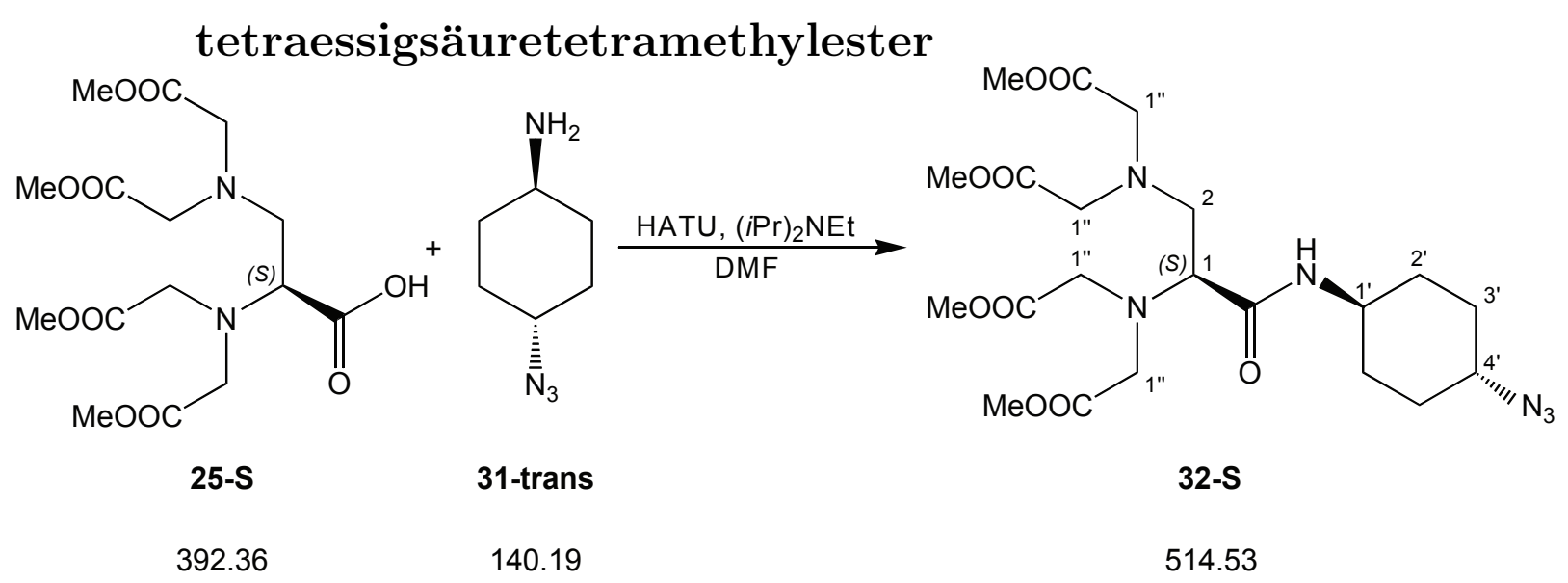

$200 \mathrm{mg}$ 25-S $(510 \mu \mathrm{mol})$ und $349 \mathrm{mg} \operatorname{HATU}(918 \mu \mathrm{mol}, 3.0$ Äq.) wurde mit $262 \mu \mathrm{L} N$ Ethyldiisopropylamin (198 mg, $\rho=0.755,1.53 \mathrm{mmol}, 3.0$ Äq.) in $8 \mathrm{~mL}$ Dimethylformamid gelöst und 2 Stunden unter Argon gerührt. Anschließend gab man eine Lösung aus $108 \mathrm{mg}$ trans-4-Aminocyclohexylazid 31trans (612 $\mu \mathrm{mol}, 1.2$ Äq.) und $105 \mu \mathrm{L} N$-Ethyldiisopropylamin (79 mg, $\rho=0.755,612 \mu \mathrm{mol}, 1.2$ Äq.) in $8 \mathrm{~mL}$ Dimethylformamid hinzu und rührte $24 \mathrm{~h}$ bei Raumtemperatur. Das Lösungsmittel wurde im Vakuum entfernt und der Rückstand in Dichlormethan aufgenommen. Die organische Phase wurde mit Phosphatpuffer (0.1 M, pH = 2) und gesättigter Natriumchloridlösung ausgeschüttelt und über Natriumsulfat getrocknet. Das braune Öl wurde säulenchromatographisch an Kieselgel mit den Eluenten Chloroform/Methanol: 100/1 gereinigt. Man erhielt 180 mg eines gelben Öls 32-S (350 $\mu \mathrm{mol}, 68 \%)$.

${ }^{1} \mathbf{H}-\mathbf{N M R}\left(\mathrm{D}_{2} \mathrm{O}, 400 \mathrm{MHz}\right): \delta=8.84(\mathrm{sbr}, 1 \mathrm{H}, \mathrm{NH}), 4.06(\mathrm{~m}, 1 \mathrm{H}, \mathrm{H} 4$ '), 3.91 (m, 1H, H1'), 3.76 (m, 1H, H1), 3.72 (s, 12H, 4 x Me), 3.7-3.6 (m, 8H, 8 x H1”), 3.47 (m, 1H, H2a), 3.28 (m, 1H, H2b), 2.04 (m, 2H, 2 x H2'a), 1.91 (m, 2H, 2 x H3'a), 1.72 (m, 2H, 2 x H3'b), 1.45 (m, 2H, 2 x H2'b) ppm.

${ }^{13}$ C-NMR $\left(\mathrm{D}_{2} \mathrm{O}, 100.6 \mathrm{MHz}\right): \delta=172.16$ (4C, 4 x COOMe), 170.14 (1C, CONH), 63.61 (1C, C1), 55.08 (1C, C2), 53.13 (4C, 4 x C1"), 51.78 (4C, 4 x Me), 50.65 (1C, C1'), 48.69 (1C, C4'), 30.52 (2C, $2 \times \mathrm{C}^{\prime}$ '), 25.98 (2C, $\left.2 \times \mathrm{C}^{\prime}\right)$ ppm.

ESI-MS $m / z$ (Acetonitril, positive mode): ber. für $\mathrm{C}_{21} \mathrm{H}_{34} \mathrm{~N}_{6} \mathrm{NaO}_{9}[\mathrm{M}+\mathrm{Na}]^{+}: 537.23$, gef.: 537.44 . 


\subsubsection{5'-O-Dimethoxytrityl-5-[[[4-(trimethylsilyl)ethinyl]- phenyl]-ethinyl]-2'-desoxyuridin}

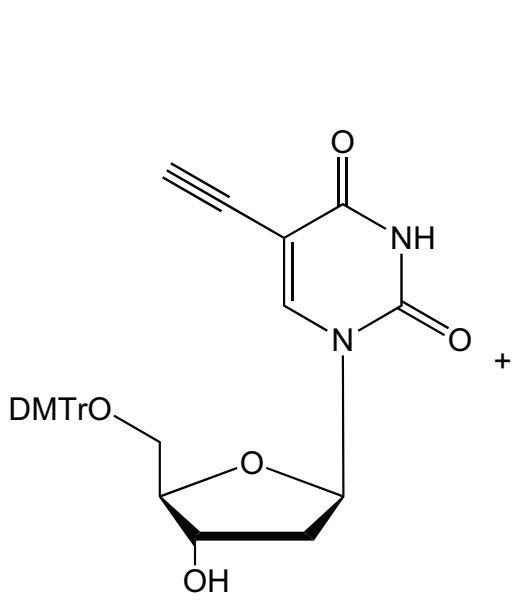

11

554.59

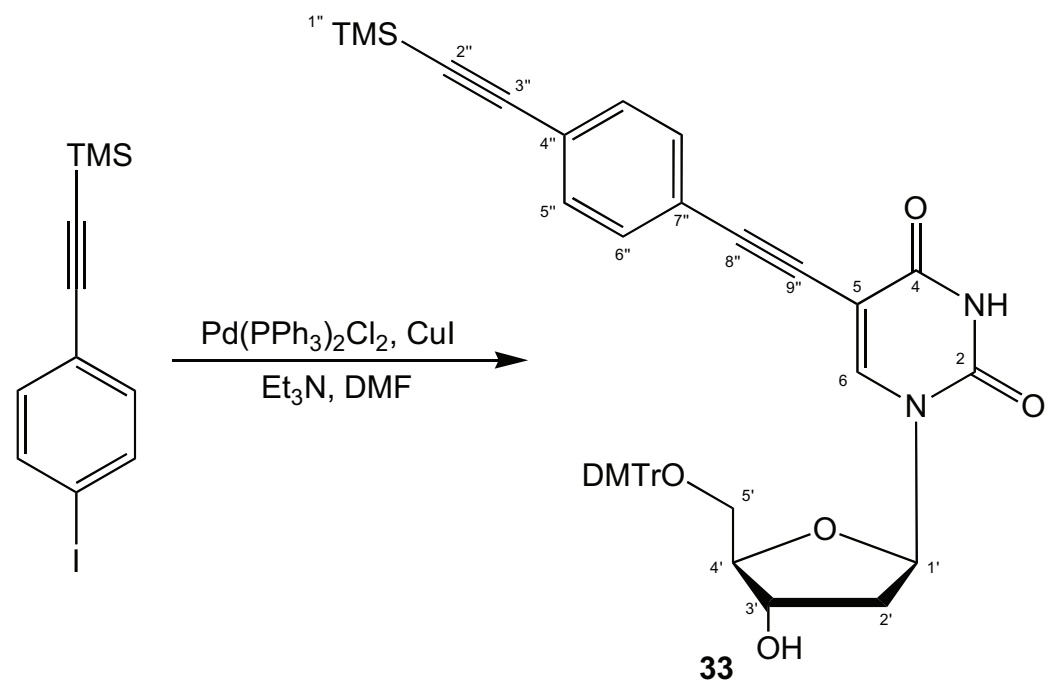

300.21

726.89

$400 \mathrm{mg}$ 5'-O-Dimethoxytrityl-5-ethinyl-2'-desoxyuridin 11 (0.72 mmol), $11.0 \mathrm{mg}$ Kupfer(I)io$\operatorname{did}(57.7 \mu \mathrm{mol}, 0.08$ Äq.), $282 \mathrm{mg}$ [(4-Iodphenyl)ethinyl] trimethylsilan (0.94 mmol, 1.3 Äq.) und $15.2 \mathrm{mg}$ Bis-(triphenylphosphin)-palladium(II)chlorid (21.6 $\mu \mathrm{mol}, 0.03$ Äq.) wurden in $4 \mathrm{~mL}$ sauerstofffreiem, trockenem Triethylamin und $4 \mathrm{~mL}$ sauerstofffreiem, trockenem Dimethylformamid gelöst und $3 \mathrm{~h}$ bei $40{ }^{\circ} \mathrm{C}$ gerührt. Die Lösungsmittel wurden im Vakuum entfernt und das Rohprodukt wurde mittels Säulenchromatographie an Kieselgel mit den Eluenten Chloroform/Methanol/Triethylamin: 100/0/1 bis 100/4/1 gereinigt. Man erhielt $423 \mathrm{mg}$ eines gelblichen Schaums (0.58 mmol, 81\%).

${ }^{1} \mathbf{H}-\mathrm{NMR}\left(\mathrm{CDCl}_{3}, 400 \mathrm{MHz}\right): \delta=8.18$ (s, 1H, H6), 7.46-7.17 (m, 9H, DMTr), 7.05-6.75 (m, 4H, DMTr), 7.22 (d, J=8.19 Hz, 2H, 2 x H5"), 6.90 (d, J=8.19 Hz, 2H, 2 x H6"), 6.37 (t, $\left.J=6.7 \mathrm{~Hz}, 1 \mathrm{H}, \mathrm{H} 1^{\prime}\right), 4.58$ (m, 1H, H3'), 4.11 (m, 1H, H4'), 3.70 (s, 6H, OMe), 3.52-3.29 (m, 2H, 2 x H5'), 2.56-2.48 (m, 2H, 2 x H2'), 0.23 (s, 9H, TMS) ppm. 
${ }^{13}$ C-NMR $\left(\mathrm{CDCl}_{3}, 100.6 \mathrm{MHz}\right): \delta=159.92(1 \mathrm{C}, \mathrm{C} 4), 148.99$ (1C, C2), 142.13 (1C, C6), 135-113 (18C, DMTr), 131.13 (2C, 2 x C6"), 131.31 (2C, 2 x C5"), 120.88 (1C, C4"), 120.46 (1C, C7”), 106.46 (1C, C3"), 99.72 (1C, C5), 96.11 (1C, C2"), 93.48 (1C, C8”), 86.17 (1C, C4'), 86.12 (1C, C1'), 82.88 (1C, C9”), 72.15 (1C, C3'), 63.14 (1C, C5'), 54.92 (2C, 2 x OMe), 41.89 (1C, C2'), -0.12 (3C, TMS) ppm.

ESI-MS $m / z$ (Acetonitril mit $1 \%$ Triethylamin, positive mode): ber. für $\mathrm{C}_{49} \mathrm{H}_{58} \mathrm{~N}_{3} \mathrm{O}_{7} \mathrm{Si}$ $\left[\mathrm{M}+\mathrm{NEt}_{3}+\mathrm{H}\right]^{+}:$828.40, gef.: 828.31 . 


\subsubsection{5'-O-Dimethoxytrityl-5-[[(4-ethinyl)phenyl]ethinyl]-2'-desoxyuridin} TMS

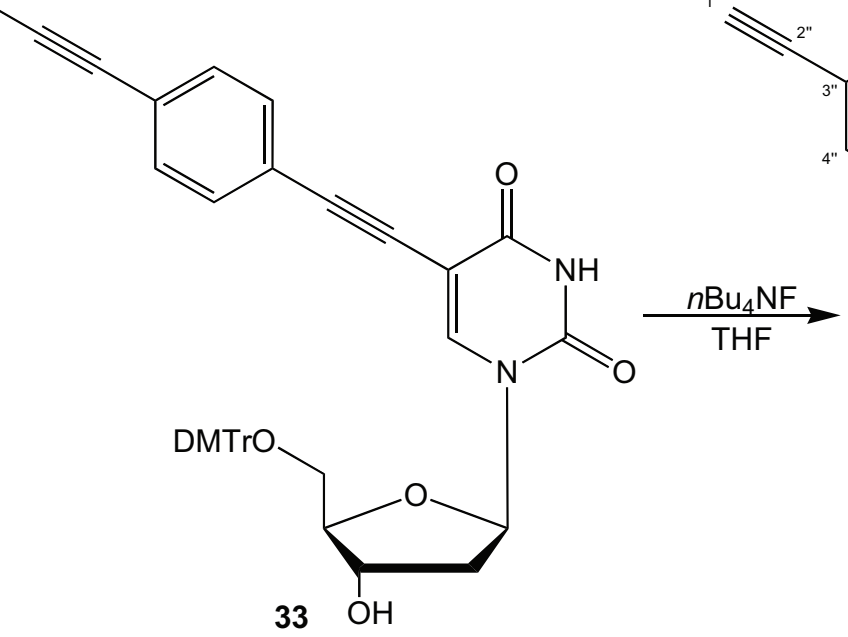

726.89

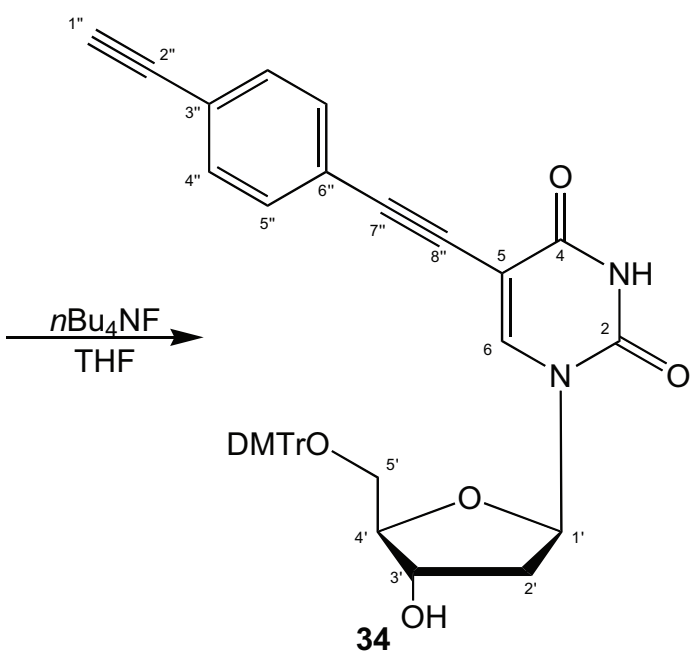

654.71

$100 \mathrm{mg}$ 5'-O-Dimethoxytrityl-5-[[[4-(trimethylsilyl)ethinyl]phenyl]-ethinyl]-2'-desoxyuridin 33 $(138 \mu \mathrm{mol})$ wurden in $3.6 \mathrm{~mL}$ Tetrahydrofuran und $400 \mu \mathrm{L}$ Triethylamin gelöst und mit 360 $\mu \mathrm{l}$ Tetra-n-butylammoniumfluorid-Lösung (1M in Tetrahydrofuran, $360.0 \mu$ mol, 2.6 Äq.) versetzt. Die Lösung wurde 2.5 h bei Raumtemperatur gerührt und das Lösungsmittel im Vakuum entfernt. Das Rohprodukt wurde mittels Säulenchromatographie an Kieselgel mit dem Eluenten Chloroform/Methanol/Triethylamin: 100/1/1 gereinigt. Man erhielt 63 mg 34 (96 $\mu \mathrm{mol}, 70 \%)$.

${ }^{1} \mathbf{H}-\mathbf{N M R}\left(\mathrm{CDCl}_{3}, 400 \mathrm{MHz}\right): \delta=8.23$ (s, 1H, H6), 7.46-6.75 (m, 13H, DMTr), 7.24 (d, J $=8.19 \mathrm{~Hz}, 2 \mathrm{H}, 2 \times \mathrm{H} 5 "), 6.91$ (d, $J=8.19 \mathrm{~Hz}, 2 \mathrm{H}, 2 \times \mathrm{H6}$ '), 6.35 (t, J=6.7 Hz, 1H, H1'), 4.57 (m, 1H, H3'), 4.10 (m, 1H, H4'), 3.69 (s, 6H, 2 x OMe), 3.55-3.29 (m, 2H, 2 x H5'), 3.13 (s, 1H, H1"), 2.53-2.33 (m, 2H, 2 x H2') ppm.

${ }^{13}$ C-NMR $\left(\mathrm{CDCl}_{3}, 100.6 \mathrm{MHz}\right): \delta=158.54$ (1C, C4), 148.58 (1C, C2), 142.84 (1C, C6), 135-113 (18C, DMTr), 131.42 (2C, 2 x C5”), 131.52 (2C, 2 x C4”), 122.75 (1C, C3"), 121.28 (1C, C6”), 99.98 (1C, C5), 92.76 (1C, C7”), 86.91 (1C, C4'), 86.62 (1C, DMTr), 85.46 (1C, C1'), 83.24 (1C, C2"), 81.56 (1C, C8”), 78.7 (1C, C1"), 72.00 (1C, C3'), 63.20 (1C, C5'), 55.12 (2C, 2 x OMe), 41.83 (1C, C2') ppm.

ESI-MS $m / z$ (Acetonitril mit 1\% Triethylamin, positive mode): ber. für $\mathrm{C}_{46} \mathrm{H}_{50} \mathrm{~N}_{3} \mathrm{O}_{7}$ $\left[\mathrm{M}+\mathrm{NEt}_{3}+\mathrm{H}\right]^{+}:$756.36, gef.: 756.37 . 


\subsubsection{5'-O-Dimethoxytrityl-5-[[(4-ethinyl)phenyl]-ethinyl]-2'-desoxy- uridin-3'-[2-cyanoethyl- $N, N$-bis(diisopropyl)])phosphoramidit}

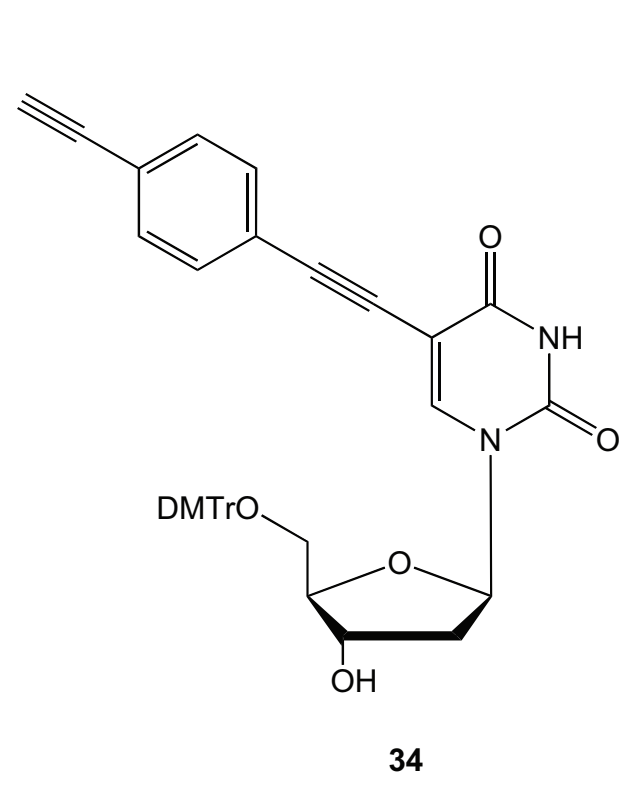

654.71

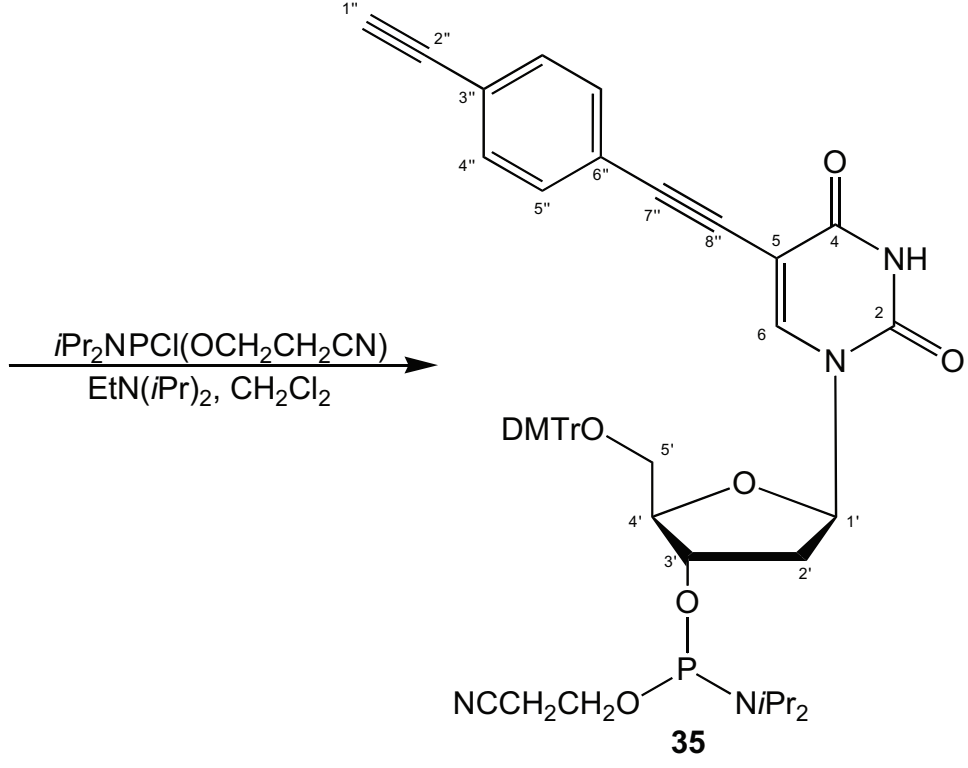

854.93

$63 \mathrm{mg}$ 5'-O-Dimethoxytrityl-5-[[(4-ethinyl)phenyl]ethinyl]-2'-desoxyuridin 34 (96 $\mu \mathrm{mol})$ wurden in $24.7 \mu \mathrm{L} N$-Ethyldiisopropylamin (18.6 mg, $144 \mu \mathrm{mol}, \rho=0.755,1.5$ Äq.) und $1 \mathrm{~mL}$ Dichlormethan gelöst. Danach wurden $25.8 \mu \mathrm{L}$ 2-Cyanoethyl- $N, N$-diisopropylchlorophosphoramidit (27.3 mg, $115 \mu \mathrm{mol}, \rho=1.061,1.2$ Äq.) langsam zugetropft und die Lösung $2 \mathrm{~h}$ bei Raumtemperatur gerührt. Die Lösung wurde mit Dichlormethan verdünnt, mit gesättigter Natriumhydrogencarbonat- und gesättigter Natriumchloridlösung gewaschen und über Magnesiumsulfat getrocknet. Das Rohprodukt wurde mittels Säulenchromatographie an Kieselgel mit den Eluentem Chloroform/Methanol/Triethylamin: 100/1/1 gereinigt. Man erhielt 70 mg eines gelblichen Schaums 35 (81.8 $\mu \mathrm{mol}, 85 \%)$.

${ }^{31}$ P-NMR (243 MHz, $\mathrm{CDCl}_{3}$ mit 0.5\% Triethylamin) $: \delta=152.05(\mathrm{~d}, J=50 \mathrm{~Hz}) \mathrm{ppm}$.

ESI-MS $m / z$ (Acetonitril mit 1\% TEA, positive mode): ber. für $\mathrm{C}_{55} \mathrm{H}_{67} \mathrm{~N}_{5} \mathrm{O}_{8} \mathrm{P}\left[\mathrm{M}+\mathrm{NEt}_{3}+\mathrm{H}\right]^{+}$: 956.47, gef.: 956.41 . 


\subsubsection{5-Hydroxymethyl-2'-desoxyuridin [130]}

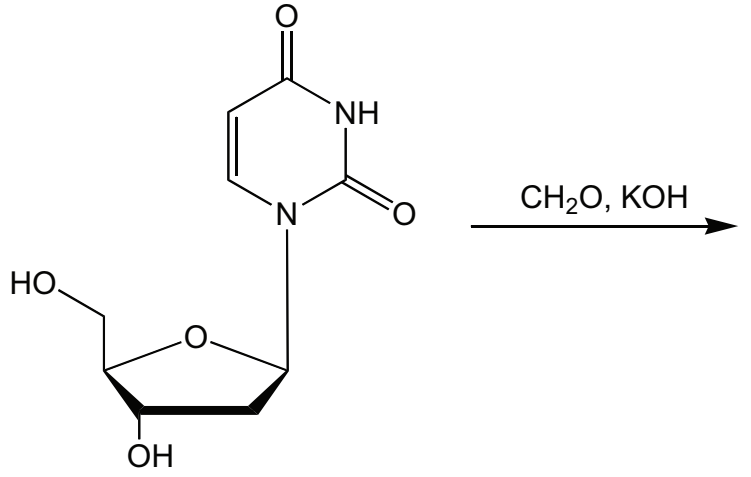

228.20<smiles>O=c1[nH]c(=O)n([C@@H]2C[C@@H]3O[C@@H]([C@H]2O)[C@@H](CO)O3)cc1CO</smiles>

36

258.23

Zu 5.0 g 2'-Desoxyuridin (21.9 mmol) wurden 16 mL 37\% wässriges Formaldehyd (212 mmol) und $16 \mathrm{~mL} 1 \mathrm{M}$ Kalilauge $(16 \mathrm{mmol})$ gegeben und $18 \mathrm{~h}$ bei $65^{\circ} \mathrm{C}$ unter Argon gerührt. Nach Abkühlen der Reaktionsmischung wurden $6 \mathrm{~mL}$ Kalilauge $(6 \mathrm{mmol})$ zugegeben, so dass der pH-Wert von 9.5 auf 10.5 anstieg und anschließend wurde bei $65{ }^{\circ} \mathrm{C}$ für weitere 34 h gerührt. Das Reaktionsgemisch wurde nach Abkühlung auf Raumtemperatur erneut mit $6 \mathrm{~mL}$ Kalilauge $(6 \mathrm{mmol})$ versetzt, so dass der $\mathrm{pH}$-Wert wieder auf 10.5 anstieg, anschließend wurde die Temperatur wieder auf $65{ }^{\circ} \mathrm{C}$ erhöht. Genauso wurde nach weiteren $66 \mathrm{~h}$ und $45 \mathrm{~h}$ verfahren. Nach insgesamt $210 \mathrm{~h}$ wurde das abgekühlte Gemisch mit $60 \mathrm{~mL}$ Wasser und 15 g Kationenaustauscher 1 h im Eisbad gerührt. Das Harz wurde abfiltriert und mit $140 \mathrm{~mL}$ Wasser gespült. Das Wasser wurde bei Raumtemperatur im Vakuum entfernt und der Rückstand mit 100 mL Acetonitril koevaporiert. Der entstandene Schaum wurde in $10 \mathrm{~mL}$ Methanol gelöst und mit $160 \mathrm{~mL}$ Essigester versetzt. Der ausgefallen Feststoff wurde dekantiert und unter Vakuum getrocknet. Der Rückstand wurde erneut in $10 \mathrm{~mL}$ Methanol gelöst und unter schnellem Rühren mit $300 \mathrm{~mL}$ Essigester versetzt. Nach $15 \mathrm{~h}$ bei $-26{ }^{\circ} \mathrm{C}$ wurde die Suspension auf Raumtemperatur gebracht und dekantiert. Der Rückstand wurde mit Methanol koevaporiert und im Vakuum getrocknet. Nach einer säulenchromatographischen Reinigung an Kieselgel mit dem Eluenten Chloroform/Methanol: 3/1 erhielt man $1.3 \mathrm{~g}$ weiße Kristalle 36 (5.0 mmol, $22 \%)$. 


\subsubsection{S-Acetyl-5-(mercaptomethyl)-2'-desoxyuridin [130]}

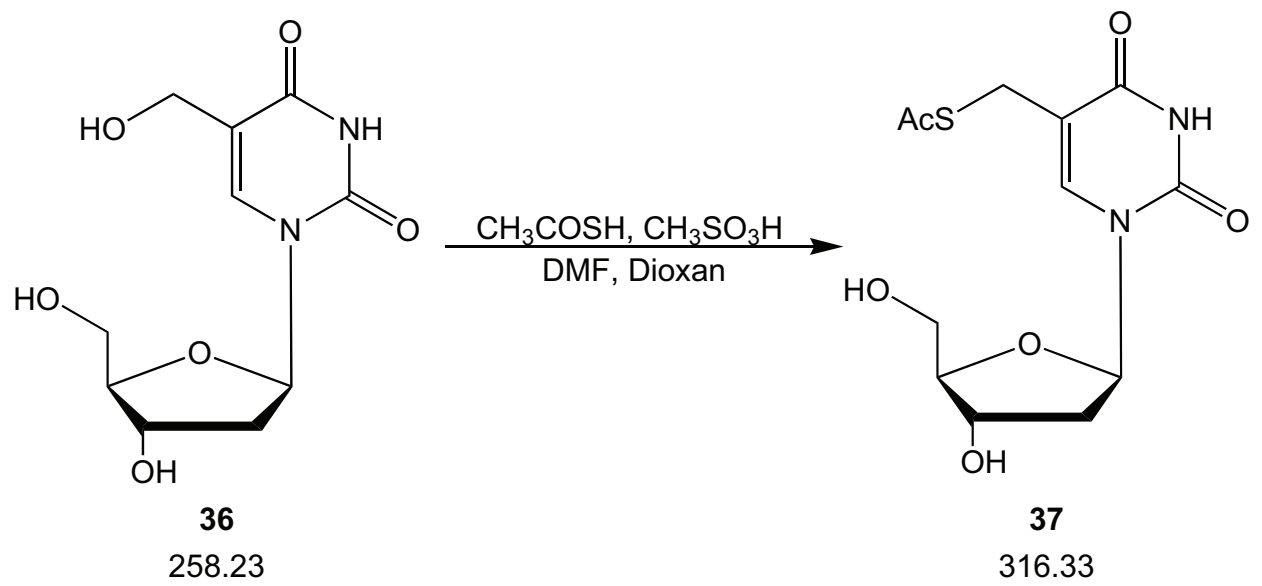

1.10 g 5-Hydroxymethyl-2'-desoxyuridin 36 (4.26 mmol) wurde in $3 \mathrm{~mL}$ Dimethylformamid gelöst, anschließend wurden $15 \mathrm{~mL}$ Dioxan, $1.52 \mathrm{~mL}$ Thioesssigsäure $(21.3 \mathrm{mmol}, 1.62 \mathrm{~g}, \rho=$ 1.065, 5.0 Äq) und $69.1 \mathrm{uL}$ Methansulfonsäure (1.06 mmol, $0.10 \mathrm{~g}, \rho=1.481,0.25 \mathrm{Äq})$ zugegeben. Nach Lösung aller Reaktanden im Ultraschallbad wurde die Reaktion $4 \mathrm{~h}$ bei $82{ }^{\circ} \mathrm{C}$ unter Argon gerührt. Das Reaktionsgemisch wurde mit $1.08 \mathrm{~g}$ Anionenaustauscher versetzt und 1 h gerührt. Das Harz wurde abfiltriert und mit Methanol gewaschen. Die Lösungsmittel wurden im Vakuum entfernt und der Rückstand dreimal mit $5 \mathrm{~mL}$ Diethylether zerrieben und der Überstand jeweils abdekantiert. Der Rückstand wurde in $25 \mathrm{~mL}$ Tetrahydrofuran aufgenommen, die unlöslichen Reste abfiltriert und mit $25 \mathrm{~mL}$ Tetrahydrofuran gewaschen. Das Filtrat wurde im Vakuum eingeengt und in $2 \mathrm{~mL}$ Tetrahydrofuran aufgenommen. Nacheinander wurden $16 \mathrm{~mL}$ Diethylether, $16 \mathrm{~mL}$ Hexan und nach 15 min erneut $15 \mathrm{~mL}$ Hexan zugegeben und $16 \mathrm{~h}$ bei $-20{ }^{\circ} \mathrm{C}$ gelagert. Die Lösungsmittel wurden abdekantiert und der Rückstand im Vakuum getrocknet. Man erhielt 0.63 g eines zähen Öls 37 (2.0 mmol, 47\%). Das Rohprodukt wurde direkt weiterverarbeitet zu 38.

ESI-MS $m / z$ (Acetonitril, postive mode): ber. für $\mathrm{C}_{12} \mathrm{H}_{16} \mathrm{~N}_{2} \mathrm{O}_{6} \mathrm{SNa}[\mathrm{M}+\mathrm{Na}]^{+}: 339.06$, gef.: 339.07. 


\subsubsection{S-Acetyl-5'-O-dimethoxytrityl-5-(mercaptomethyl)- 2'-desoxyuridin [129]}

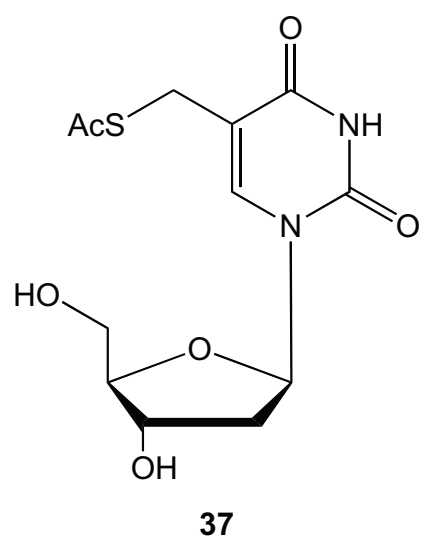

316.33

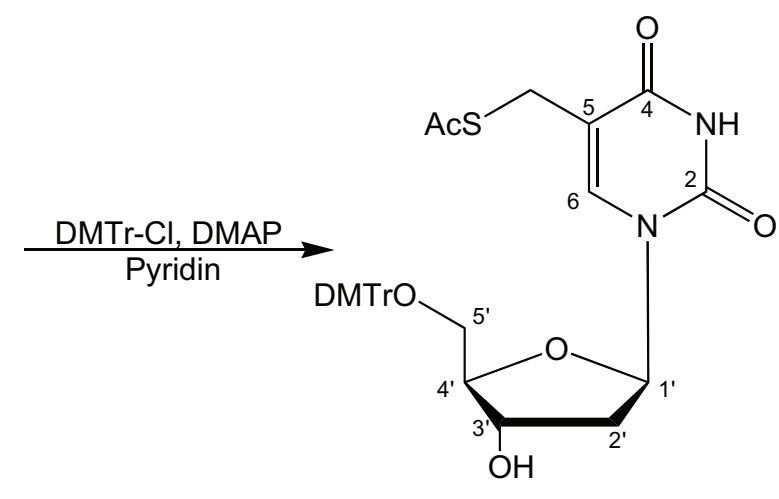

38

618.70

$520 \mathrm{mg} S$-Acetyl-5-(mercaptomethyl)-2'-desoxyuridin 37 (1.64 mmol) wurden bei $0{ }^{\circ} \mathrm{C}$ unter Argon in 40 mL Pyridin gelöst und mit 668 mg Dimethoxytritylchlorid (1.97 mmol, 1.2 Äq.) und $20 \mathrm{mg}$ DMAP (0.16 mmol, 0.1 Äq) versetzt. Nach $21 \mathrm{~h}$ im Kühlschrank $\left(4^{\circ} \mathrm{C}\right)$ gab man $5 \mathrm{~mL}$ Methanol zu und entfernte die Lösungsmittel im Vakuum. Der Rückstand wurde in Essigester aufgenommen, mit gesättigter Natriumhygrogencarbonatlösung gewaschen, über Natriumsulfat getrocknet und im Vakuum eingeengt. Das Rohprodukt wurden säulenchromatographisch an Kieselgel gereinigt (Essigester/Hexan/Triethylamin: 200/100/1, dann Essigester/Triethylamin: 200/1). Man erhielt $550 \mathrm{mg}$ Produkt 38 (0.89 mmol, 54\%).

${ }^{1} \mathbf{H}-\mathbf{N M R}\left(400 \mathrm{MHz}, \mathrm{CDCl}_{3}\right): \delta=7.73$ (s, 1H, H6), 7.44-7.16 (m, 9H, DMTr), 7.08-7.80 (m, 4H, DMTr), 6.29 (t, J=6.5 Hz, 1H, H1'), 4.52 (m, 1H, H3'), 4.00 (m, 1H, H4'), 3.79 (s, 6H, $2 \times \mathrm{OMe}$ ), 3.55-3.40 (m, 4H, 2 x H5' und $\left.\mathrm{CH}_{2} \mathrm{~S}\right), 2.20-2.44$ (m, 2H, $2 \times \mathrm{H} 2$ ' ), 2.21 (s, $\left.3 \mathrm{H},(\mathrm{CO}) \mathrm{CH}_{3}\right) \mathrm{ppm}$.

${ }^{13}$ C-NMR (100.6 MHz, $\left.\mathrm{CDCl}_{3}\right): \delta=195.03$ (1C, S(CO)), 161.75 (1C, C4), 149.26 (1C, C2), 138.31 (1C, C6), 135-113 (18C, DMTr), 110.32 (1C, C5), 86.59 (1C, DMTr), 85.54 (1C, C4'), 84.87 (1C, C1'), 72.03 (1C, C3'), 63.49 (1C, C5'), 40.27 (1C, C2'), 30.30 (1C, $\left.(\mathrm{CO}) \mathrm{CH}_{3}\right), 25.58\left(1 \mathrm{C}, \mathrm{CH}_{2} \mathrm{~S}\right) \mathrm{ppm}$.

ESI-MS (Acetonitril, postive mode): ber. für $\mathrm{C}_{39} \mathrm{H}_{50} \mathrm{~N}_{3} \mathrm{O}_{8} \mathrm{~S}$ : $\left[\mathrm{M}+\mathrm{Et}{ }_{3} \mathrm{~N}+\mathrm{H}\right]^{+}: 720.33$, gef. 720.32 . 


\subsubsection{S-Acetyl-5'-O-dimethoxytrityl-5-(mercaptomethyl)-2'-desoxy-} uridin-3'-[2-cyanoethyl- $N, N$-bis(diisopropyl)]-phosphoramidit

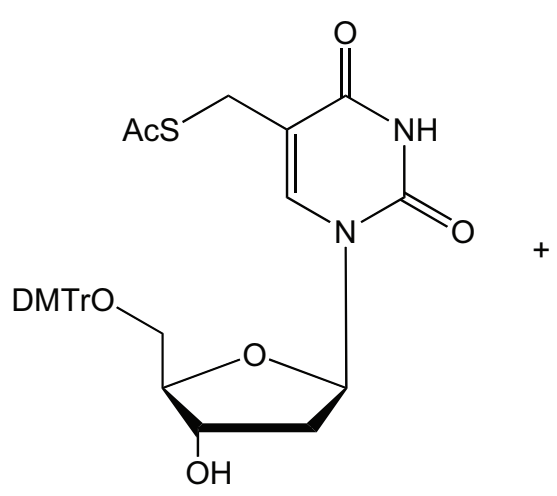

38

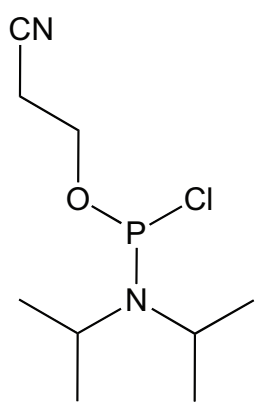

236.68

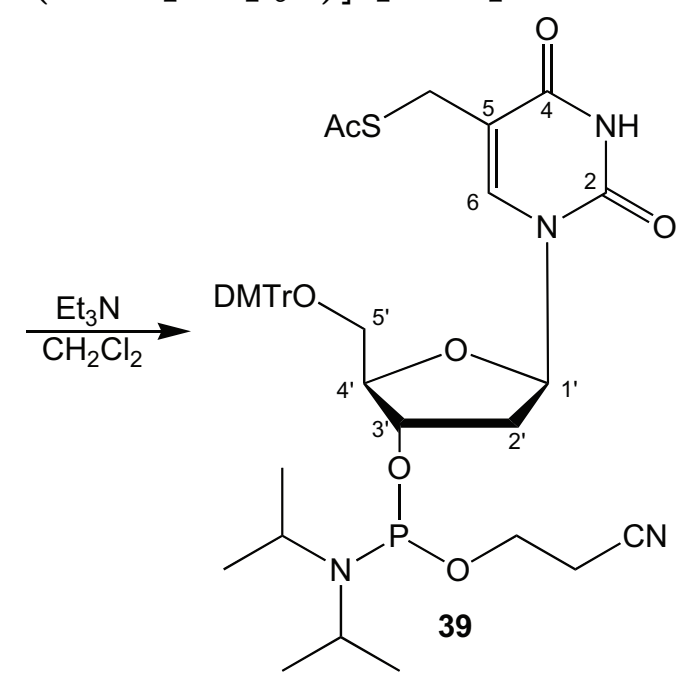

818.91

Zu einer Lösung aus $50 \mathrm{mg} S$-Acetyl-5'-O-dimethoxytrityl-5-(mercaptomethyl)-2'-desoxyuridin $38(81 \mu \mathrm{mol})$ in $1 \mathrm{~mL}$ Dichlormethan gab man unter Argon $21 \mu \mathrm{L} N$-Ethyldiisopropylamin (16 mg, $121 \mu \mathrm{mol}, \rho=0.755,1.5$ Äq. ) und $23 \mu \mathrm{L}$ Cyanoethyl- $N, N$-diisopropylchlorophosphoramidit (25 mg, $105 \mathrm{mmol}, \rho=1.100,1.3$ Äq.) . Die Lösung wurde 1.5 h bei Raumtemperatur gerührt und anschließend mit $10 \mathrm{~mL}$ Dichlormethan verdünnt. Die organische Phase wurde mit gesättigter Natriumhydrogencarbonatlösung gewaschen und über Natriumsulfat getrocknet. Die Lösungsmittel wurden im Vakuum entfernt. Nach einer Säulenchromatographie an Kieselgel (Eluent: Chlorform/Methanol/Triethylamin: 100/1/1) erhielt man $48 \mathrm{mg}$ eines gilbliches Produkt 39 (59 $\mu \mathrm{mol}, 73 \%)$.

${ }^{1} \mathbf{H}-\mathbf{N M R}\left(400 \mathrm{MHz}, \mathrm{CDCl}_{3}\right.$ mit 0.5\% Triethylamin): $\delta=7.73$ (s, 1H, H6), 7.44-7.16 (m, 9H, DMTr), 7.06-6.86 (m, 4H, DMTr), 6.29 (t, J=6.5 Hz, 1H, H1'), 4.69 (m, 1H, H3'), 4.19 (m, 1H, H4') 3.95 (t, $\left.J=6.1 \mathrm{~Hz}, 2 \mathrm{H}, \mathrm{CH}_{2} \mathrm{O}\right), 3.79$ (s, 6H, 2 x OMe), 3.70-3.76 (m, 2H, 2 x $\mathrm{N}(\mathrm{CH})$ ), 3.58-3.40 (m, 4H, $2 \times \mathrm{H} 5$ ' und $\left.\mathrm{CH}_{2} \mathrm{~S}\right), 2.63\left(\mathrm{t}, J=6.1 \mathrm{~Hz}, 2 \mathrm{H}, \mathrm{CH}_{2} \mathrm{CN}\right), 2.36-2.44$ (m, 2H, 2 x H2'), $2.23\left(\mathrm{~s}, 3 \mathrm{H},(\mathrm{CO}) \mathrm{CH}_{3}\right), 1.23$ (d, $\left.J=7.5 \mathrm{~Hz}, 12 \mathrm{H}, 2 \times \mathrm{NCH}\left(\mathrm{CH}_{3}\right)_{2}\right)$ ppm.

${ }^{31}$ P-NMR (243 MHz, $\mathrm{CDCl}_{3}$ mit $0.5 \%$ Triethylamin) $: \delta=149.21(\mathrm{~d}, J=50 \mathrm{~Hz}) \mathrm{ppm}$.

ESI-MS (Acetonitril, 1\% Triethylamin, positive mode): ber. für $\mathrm{C}_{48} \mathrm{H}_{67} \mathrm{~N}_{5} \mathrm{O}_{9} \mathrm{PS}\left[\mathrm{M}+\mathrm{Et}_{3} \mathrm{NH}\right]^{+}$: 920.44 gef. 920.46 . 


\subsubsection{5-[1-(2,2,6,6- Tetramethylpiperidin-1-oxyl-4yl)-1 $H-1,2,3$-tria- zol-4-yl]-3',5'-diacetyl-2'-desoxyuridin}

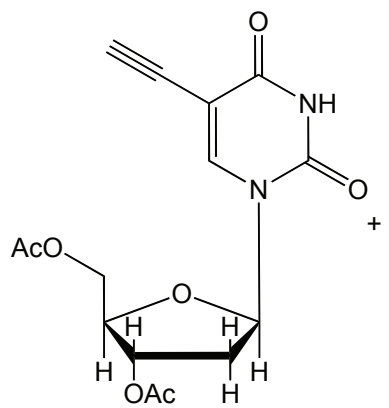

10 336.30<smiles>CC1(C)CC(N)CC(C)(C)N1O</smiles>

40 197.26

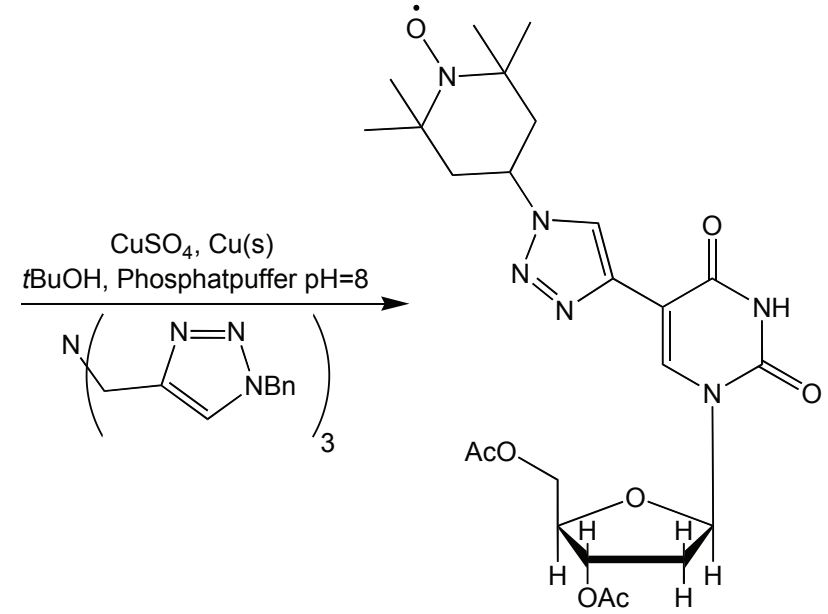

533.55

$50 \mathrm{mg}$ 5-Ethinyl-2'-desoxyuridin-3',5'-diacetat 10 (149 $\mu \mathrm{mol}), 58 \mathrm{mg}$ radikalisches Azid 40 (298 $\mu \mathrm{mol}, 2$ Äq.) und 2 mg $N, N, N$-Tris[(1-benzyl-1 $H$-1,2,3-triazol-4-yl)methylamin (4 $\mu$ mol, 2.5\% Äq.) wurden in $1 \mathrm{~mL}$ tert-Butanol und $1 \mathrm{~mL}$ Natriumphosphatpuffer $(\mathrm{pH}=8,0.1 \mathrm{M})$ gelöst. $0.3 \mathrm{mg}$ Kupfer(II)sulfat (2 $\mu \mathrm{mol}, 1.2 \%$ Äq.) und $10 \mathrm{mg}$ Kupfer (Drahtstücke) wurden zugegeben und die Lösung anschließend für $20 \mathrm{~h}$ bei Raumtemperatur geschüttelt. Nach Zugabe von $6 \mathrm{~mL}$ Wasser fällt eine weißer Niederschlag aus, der abzentrifugiert wird. Im HPLC-Chromatogramm (0-100\% in 50 min, 0.1 M Triethylammoniumacetatpuffer $(\mathrm{pH}=7)$ gegen Acetonitril) findet sich nur ein Peak bei einer Retentionszeit von $23.2 \mathrm{~min}$, in dessen Massenspektrum sich nur die Produktmasse findet.

Das NMR-Spektrum des Produkts war nicht analysierbar, da das Radikal zu einer starken Signalverbreiterung führt.

ESI-MS (Wasser/Acetonitril, negativ mode): ber. für $\mathrm{C}_{24} \mathrm{H}_{33} \mathrm{~N}_{6} \mathrm{NaO}_{8}[\mathrm{M}+\mathrm{Na}]^{+}: 556.23$, gef.: 556.27 . 


\subsubsection{Synthese von einem DNA-Trimer mit 5-[1-(2,2,6,6-Tetramethyl- piperidin-1-oxyl-4-yl)-1 H-1,2,3-triazol-4-yl]-2'-desoxyuridin}

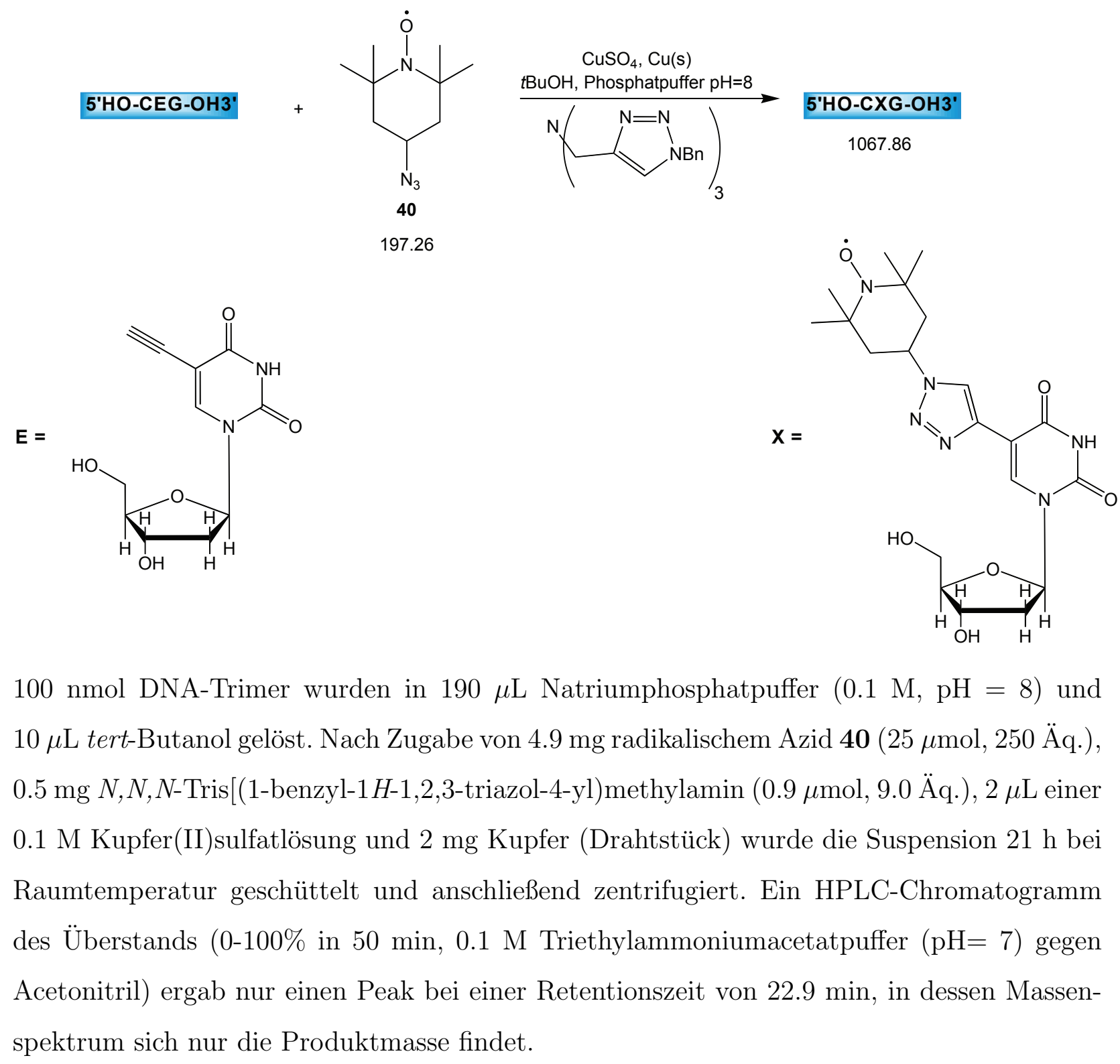

ESI-MS (Wasser/Acetonitril, negativmode): ber. [M-H] ${ }^{-}$: 1066.86, gef.: 1067.63. 


\subsubsection{Synthese eines DNA-Dodecamers mit 5-[1-(2,2,6,6-Tetramethyl-} piperidin-1-oxyl-4-yl)-1 H-1,2,3-triazol-4-yl]-2'-desoxyuridin

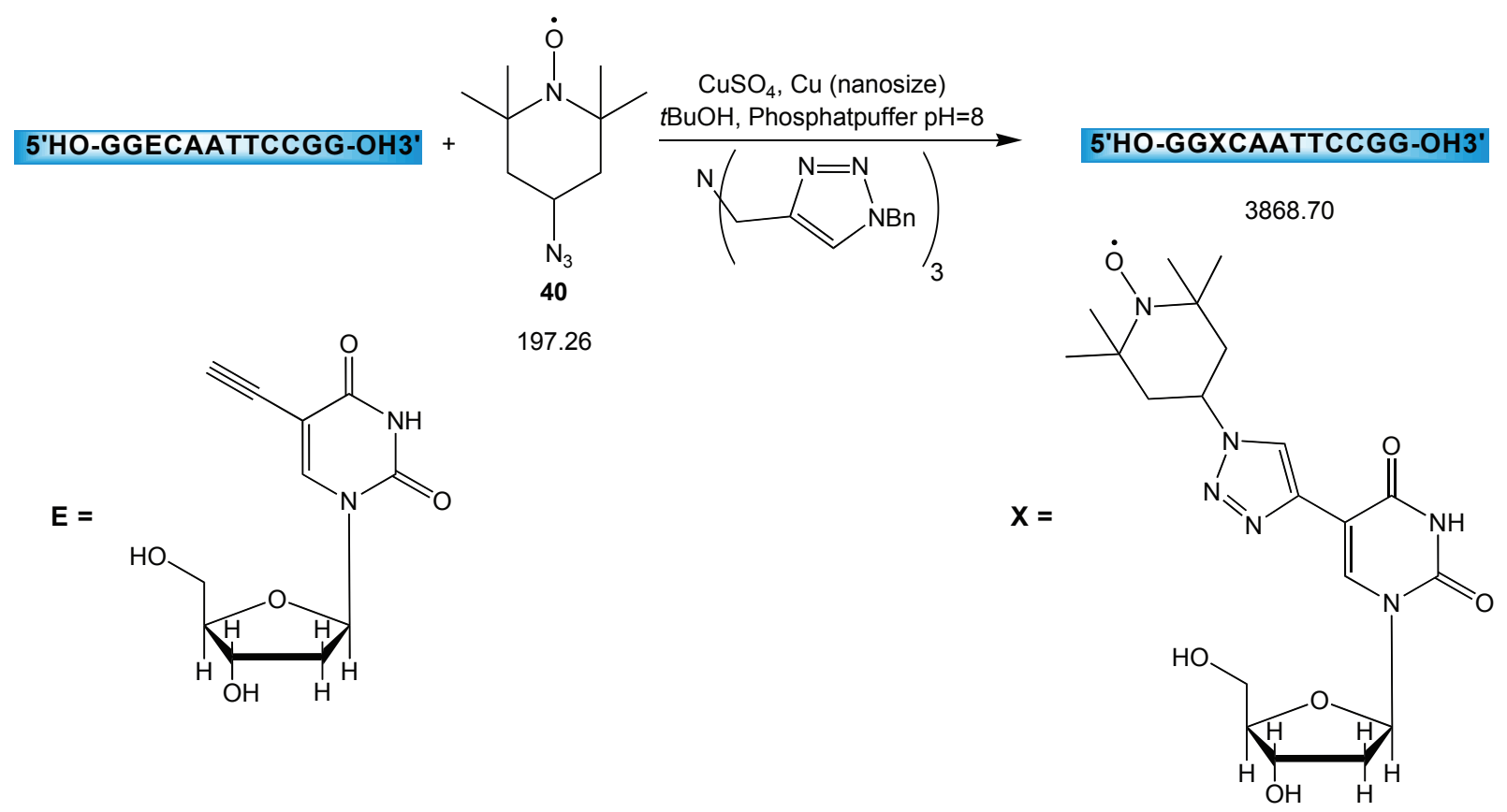

140 nmol DNA-Trimer wurden in $95 \mu \mathrm{L}$ Natriumphosphatpuffer $(0.1 \mathrm{M}, \mathrm{pH}=8)$ und $5 \mu \mathrm{L}$ tert-Butanol gelöst. Nach Zugabe von $0.7 \mathrm{mg}$ radikalischem Azid 40 (3.5 $\mu \mathrm{mol}, 25$ Äq.), $2 \mu \mathrm{L} N, N, N$-Tris[(1-benzyl-1H-1,2,3-triazol-4-yl)methylamin-Lösung (50 mmolar, 100 nmol, 0.7 Äq.), $1 \mu \mathrm{L}$ einer 0.1 M Kupfer(II)sulfatlösung und 2 mg Kupfer (nanosize) wurde die grüne Reaktionslösung $15 \mathrm{~h}$ bei Raumtemperatur geschüttelt. Anschließend wurde das Gemisch an der HPLC gereinigt. Im HPLC-Chromatogramm (0-25\% in 30 min, 0.1 M Triethylammoniumacetatpuffer $\mathrm{pH}=7$ gegen Acetonitril) findet sich ein DNA-Peak bei einer Retentionszeit von 25.2 min, in dessen Massenspektrum sich nur die Produktmasse findet. .

ESI-MS (Wasser/Acetonitril, negativ mode): ber. [M-2H $]^{2-}$ : 1284.53 , gef.: 1284.51.

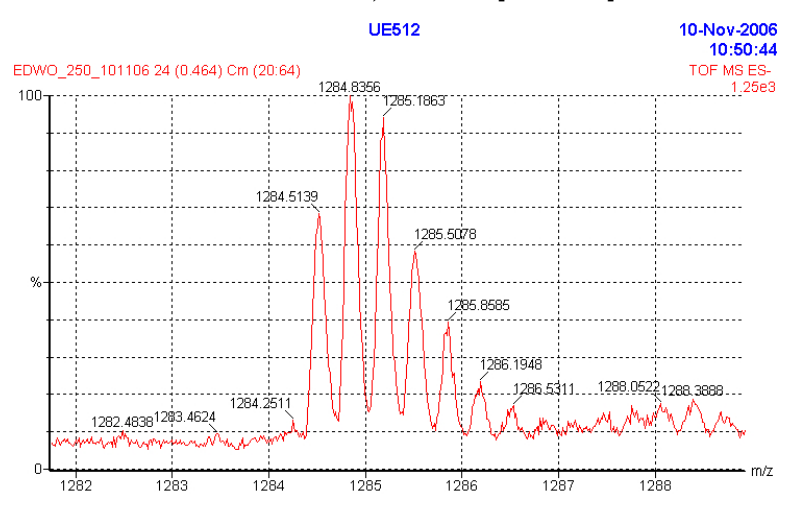

Abb. 8.1: ESI-Massenspektrum mit TOF-Detektion 


\subsubsection{Clickreaktion an einem 5-Ethinyl-2'-desoxyuridinmonomer}

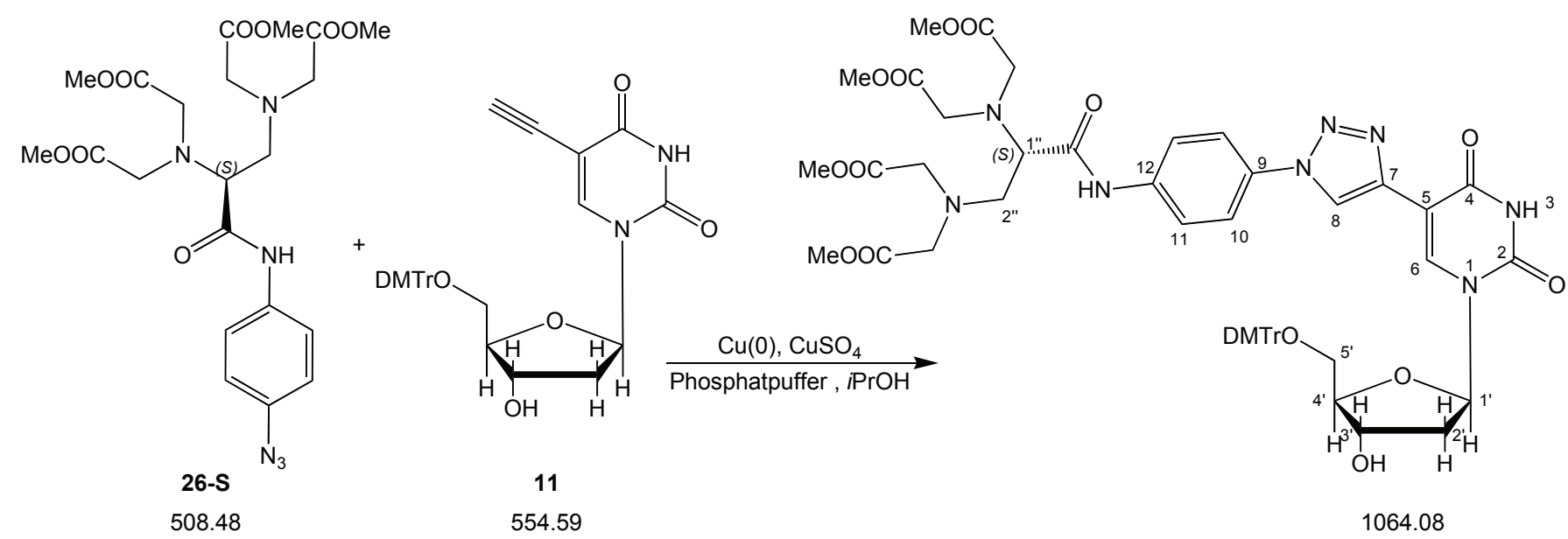

$44 \mathrm{mg} 11$ (79 $\mu \mathrm{mol})$ und $40 \mathrm{mg}$ 26-S (79 $\mu \mathrm{mol}, 1.0$ Äq.) wurden in $1 \mathrm{~mL}$ Natriumphosphatpuffer $(0.1 \mathrm{M}, \mathrm{pH}=8)$ und $2 \mathrm{~mL}$ Isopropanol gelöst und mit $0.2 \mathrm{mg}$ Kupfer (nanosize), $10 \mu \mathrm{L}$ Kupfer(II)sulfatlösung (0.1 M) und $1.4 \mathrm{mg} N, N, N$-Tris[(1-benzyl-1H-1,2,3-triazol-4yl)methylamin (2.4 $\mu \mathrm{mol}, 3.0 \%$ Äq.) versetzt. Das Reaktionsgemisch wurde $18 \mathrm{~h}$ bei Raumtemperatur geschüttelt und anschließend mit $4 \mathrm{~mL}$ Wasser verdünnt. Das Produkt wurde mit Diethylether extrahiert und die organische Phase über Natriumsulfat getrocknet. Nachdem das Lösungsmittel im Vakuum entfernt wurde, erhielt man 80 mg Produkt (75 mmol, 95\%). Im HPLC-Chromatogramm (0-100\% in 30 min, $0.1 \mathrm{M}$ Triethylammoniumacetatpuffer $\mathrm{pH}=$ 7 gegen Acetonitril) findet sich ein Peak bei einer Retentionszeit von 32 min.

${ }^{1} \mathbf{H}-\mathrm{NMR}\left(400 \mathrm{MHz}, \mathrm{CDCl}_{3}\right): \delta=8.66(\mathrm{~s}, 1 \mathrm{H}, \mathrm{H} 8), 8.57$ (s, 1H, H6), 7.44-7.16 (m, 9H, DMTr), 6.95-6.75 (m, 4H, DMTr), 6.35 (t, $J=6.8$ Hz, 1H, H1'), 4.50 (m, 1H, H3'), 4.15 (m, 1H, H4'), 3.82 (m, 1H, H1"), 3.79 (s, 6H, 2 x COOMe), 3.73 (s, 6H, 2 x OMe), 3.69 (s, 6H, 2 x COOMe), 3.47 (m, 4H, $\mathrm{CH}_{2}$ ), 3.43-3.07 (m, 2H, H5'), 3.15 (m, 4H, 2 x $\mathrm{CH}_{2}$ ), 3.00 (m, 2H, 2 x H2”), 2.52 (m, 1H, H2'a), 2.35 (m, 1H, H2’b) ppm. 
${ }^{13}$ C-NMR (100.6 MHz, $\mathrm{CDCl}_{3}$ ): $\delta=172.90$ (2C, 2 x COOMe), 172.84 (1C, CONH), 171.14 (2C, 2 x COOMe), 150.81 (1C, C4), 149.23 (1C, C2), 139.06 (1C, C12), 138.89 (1C, C7), 135.48 (1C, C6), 135-113 (18C, DMTr), 132.44 (1C, C9), 121.99 (2C, 2 x C11), 120.31 (1C, C8), 119.55 (2C, 2 x C10), 119.06 (1C, C5), 88.31 (1C, C4'), 87.37 (1C, DMTr), 85.88 (1C, C1'), 72.31 (1C, C3'), 65.68 (1C, C1), 63.49 (1C, C5'), 55.00 (1C, C2”), 54.95 (2C, 2 x $\mathrm{CH}_{2}$ ), $53.85\left(2 \mathrm{C}, 2 \times \mathrm{CH}_{2}\right), 52.45$ (2C, $\left.2 \times \mathrm{Me}\right), 51.92$ (2C, $\left.2 \times \mathrm{Me}\right), 40.99$ (1C, C2') ppm.

ESI-MS (Wasser/Acetonitril, positive mode): ber. für $\mathrm{C}_{53} \mathrm{H}_{69} \mathrm{~N}_{8} \mathrm{O}_{16}[\mathrm{M}+\mathrm{H}]^{+}:$: 1064.41, gef.: 1064.44 . 


\subsubsection{Clickreaktion an einer ethinyl-modifizierten DNA in Lösung}

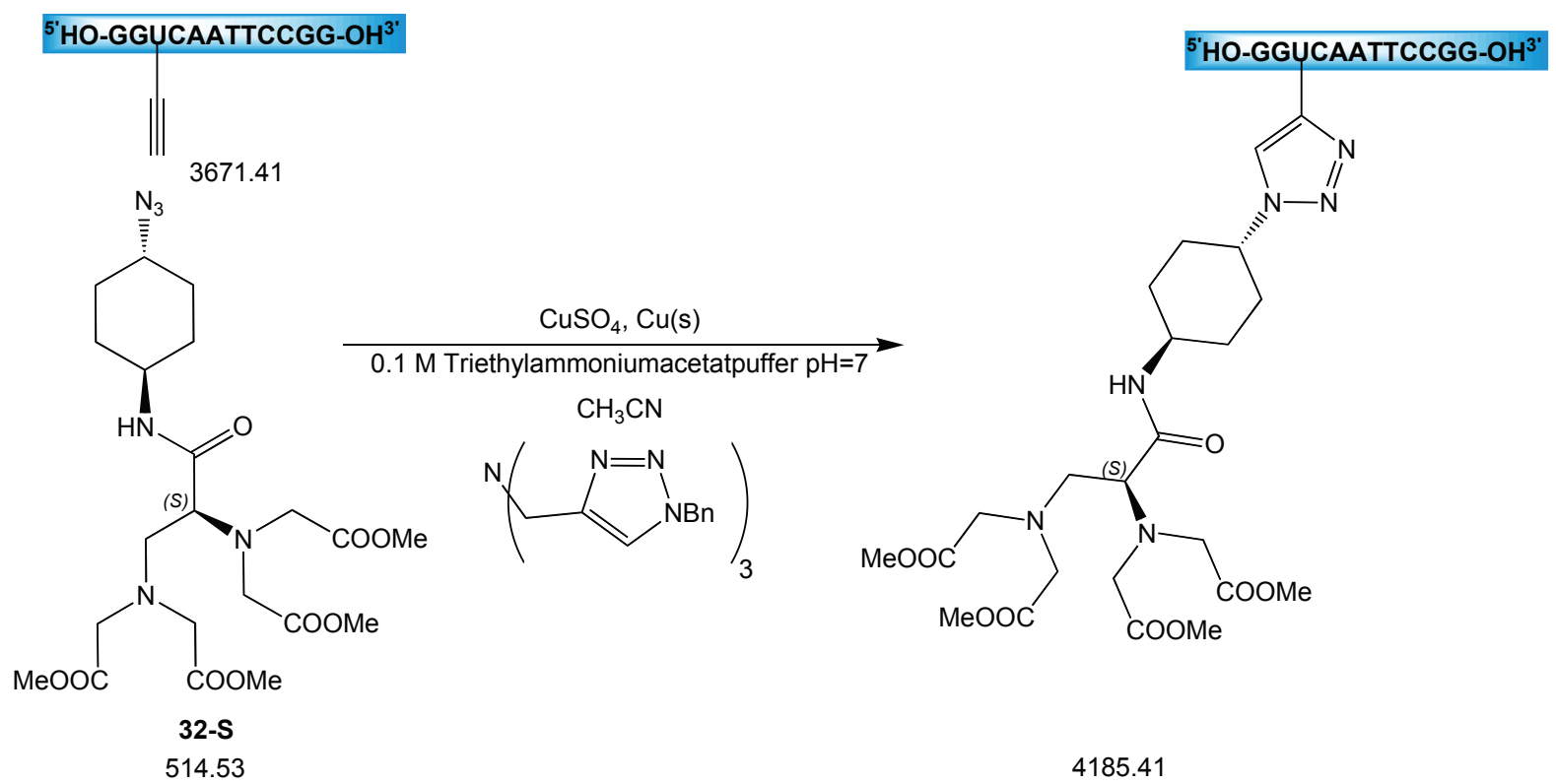

140 nmol DNA-Dodecamer wurden in $95 \mu \mathrm{L}$ Triethylammoniumacetatpuffer $(0.1 \mathrm{M}, \mathrm{pH}$ $=7$ ) und $5 \mu \mathrm{L}$ Acetonitril gelöst. Nach Zugabe von $0.7 \mathrm{mg}$ EDTA-Azid 32-S (3.5 $\mu \mathrm{mol}$, 25 Äq.), $2 \mu \mathrm{L} N, N, N$-Tris[(1-benzyl-1H-1,2,3-triazol-4-yl)methylamin-Lösung (50 mmolar, 100 nmol, 0.7 Äq.), $1 \mu \mathrm{L}$ einer 0.1 M Kupfer(II)sulfatlösung und 2 mg Kupfer (nanosize) wurde die grüne Reaktionslösung $24 \mathrm{~h}$ bei $50^{\circ} \mathrm{C}$ geschüttelt. Anschließend wurde das Gemisch an der HPLC gereinigt. Im HPLC-Chromatogramm (0.1 M Triethylammoniumacetatpuffer $\mathrm{pH}=7$ gegen Acetonitril, in 0-5 min 100\% Puffer, 0-25\% in 5-30 min) findet sich ein DNAPeak (enthält Edukt- und Produkt-DNA) bei einer Retentionszeit von 24.0 min und weitere Peaks von Abbauprodukten.

ESI-MS (Wasser/Acetonitril, negativ mode): ber. für [M-3H $\left.\mathrm{H}^{+}\right]^{3-} 1393.53$ gef. 1393.64 und ber. für $[\mathrm{M}-5 \mathrm{H}+\mathrm{Na}]^{4-}: 1050.39$, gef. 1051.01. 

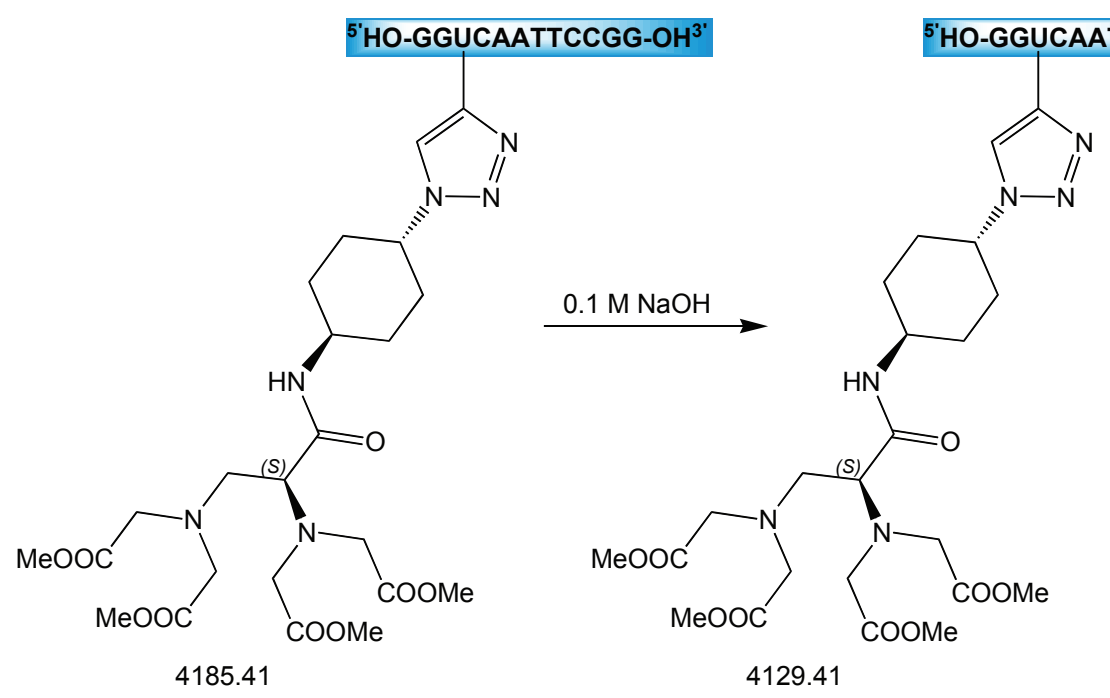

Die HPLC-Fraktion wurde lyophilisiert und in $1 \mathrm{~mL} 0.1 \mathrm{M}$ Natronlauge gelöst und $10 \mathrm{~h}$ bei Raumtemperatur gerührt. Nach einer Zugabe von $1.5 \mathrm{~mL} 1 \mathrm{M}$ Triethylammoniumacetatpuffer $(\mathrm{pH}=7)$ wurde die Lösung manuell an einer PD-10-Säule entsalzt.

ESI-MS (Wasser/Acetonitril, negativ mode): ber. für $\left[\mathrm{M}-3 \mathrm{H}^{+}\right]^{3-}: 1374.87$, gef. 1374.97 und ber. für $[\mathrm{M}-2 \mathrm{H}]^{2-}$ : 2062.81, gef. 2062.87. 


\subsubsection{Clickreaktion einer [(4-ethinyl)phenyl] ethinyl-modifizierten DNA in Lösung}

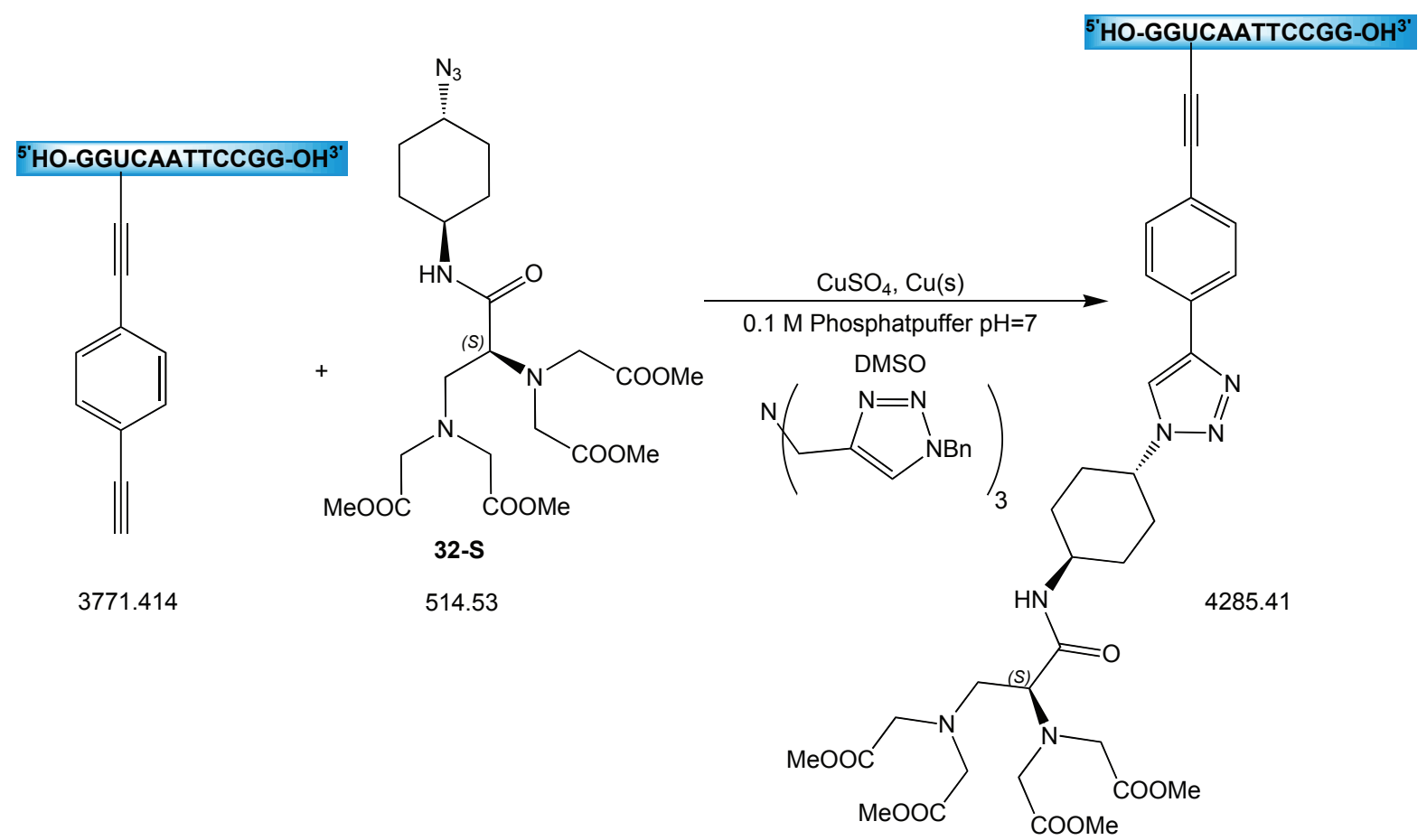

140 nmol DNA-Dodecamer wurden in $200 \mu \mathrm{L}$ Phosphatpuffer $(0.1 \mathrm{M}, \mathrm{pH}=7)$ und $200 \mu \mathrm{L}$ DMSO gelöst. Nach Zugabe von 2 mg EDTA-Azid 32-S(3.89 $\mu \mathrm{mol}, 25$ Äq.), $2 \mu \mathrm{L} N, N, N$ Tris[(1-benzyl-1H-1,2,3-triazol-4-yl)methylamin-Lösung (50 mM, 100 nmol, 0.7 Äq.), $1 \mu \mathrm{L}$ einer 0.1 M Kupfer(II)sulfatlösung und $2 \mathrm{mg}$ Kupfer (nanosize) wurde die grüne Reaktionslösung $24 \mathrm{~h}$ bei Raumtemperatur geschüttelt . Anschließend wurde das Gemisch an der HPLC gereinigt. Im HPLC-Chromatogramm (0.1 M Triethylammoniumacetatpuffer (pH = 7) gegen Acetonitril, in 0-5 min 100\% Puffer, 0-25\% in 5-30 min) findet sich ein DNA-Peak (enthält nur Produkt-DNA) bei einer Retentionszeit von 31.1 min.

ESI-MS (Wasser/Acetonitril, negativ mode): ber. für $\left[\mathrm{M}-3 \mathrm{H}^{+}\right]^{3-}$ : 1426.87 , gef. 1426.98 und ber. für $[\mathrm{M}-2 \mathrm{H}]^{2-}: 2140.81$, gef. 2140.49 . 


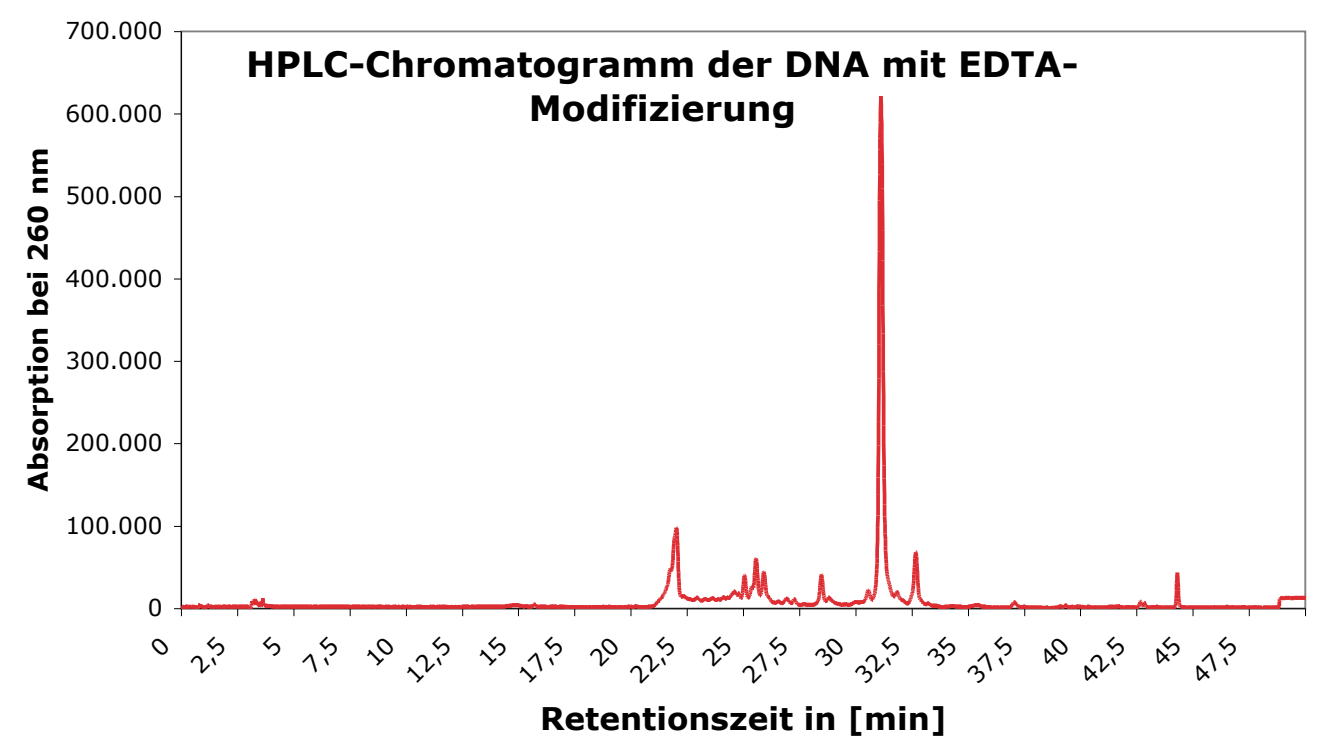

Abb. 8.2: HPLC-Chromatogramm der DNA mit EPTE-Tag (Abschnitt 8.2.37)

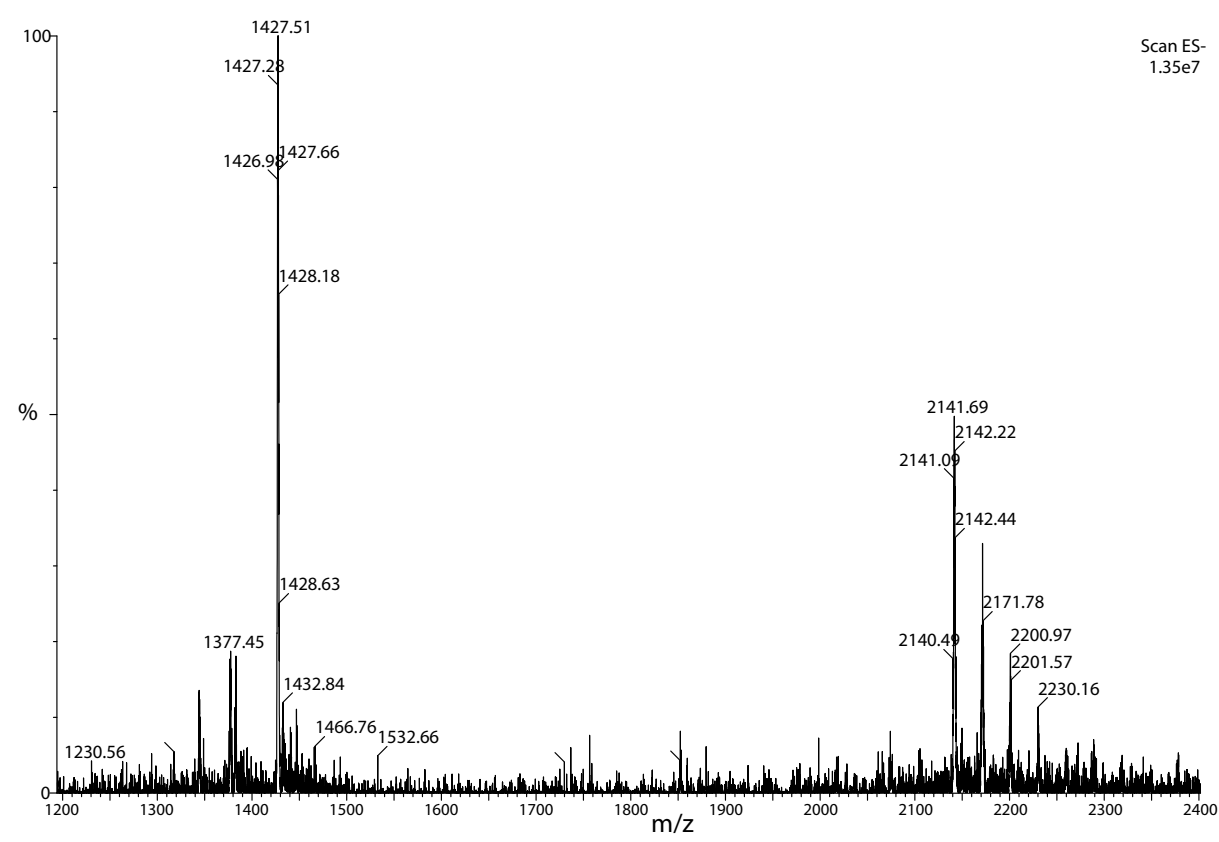

Abb. 8.3: ESI-Massenspektrum der DNA mit EPTE-Tag (Abschnitt 8.2.37) 


\subsubsection{Clickreaktion einer [(4-ethinyl)phenyl] ethinyl-modifizierten DNA an der Festphase}

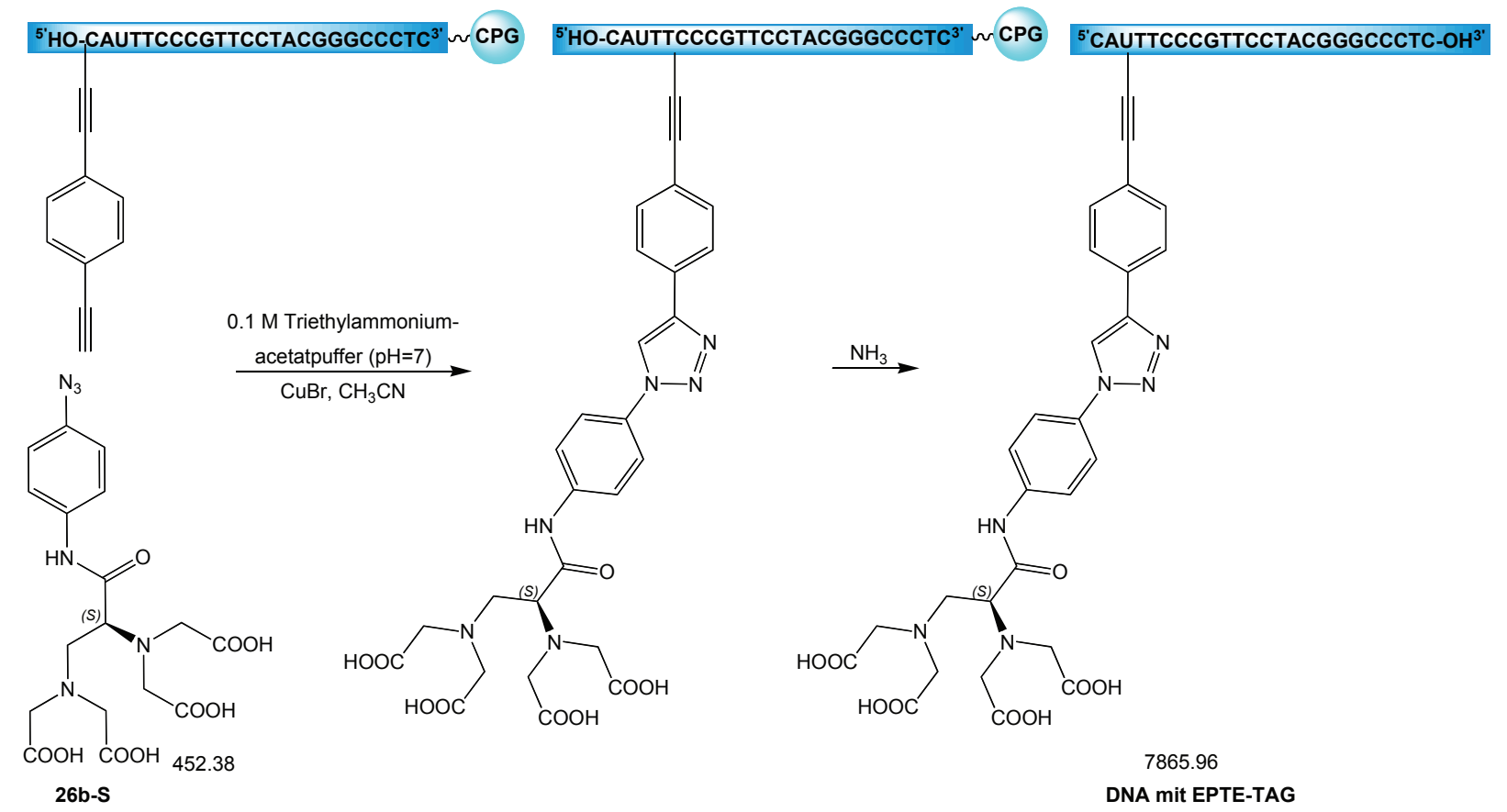

An der Festphase gebundenes DNA-24mer (Syntheseansatz $1 \mu$ mol) wurde in $100 \mu \mathrm{L}$ Triethylammoniumacetatpuffer $(0.1 \mathrm{M}, \mathrm{pH}=7)$ und $400 \mu \mathrm{L}$ DMSO gelöst. Nach Zugabe von 5 mg EDTA-Azid 26b-S (3.89 $\mu \mathrm{mol}, 25$ Äq.), 3 mg $N, N, N$-Tris[(1-benzyl-1H-1,2,3-triazol4-yl)methylamin-Lösung (50 mmol, 0.7 Äq.), $1 \mu \mathrm{L}$ einer $2.5 \mathrm{mg}$ Kupfer(I)bromid wurde die grüne Suspension 20 h bei Raumtemperatur geschüttelt. Danach wurde die festphasengebundene DNA mit $1 \mathrm{ml}$ Triethylammoniumacetatpuffer (0.1 M, pH =7), $1 \mathrm{ml}$ Acetonitril, $5 \mathrm{ml}$ EDTA-Lösung (0.1 M, pH=7) und nochmals $5 \mathrm{ml}$ Acetonitril gewaschen und anschließend mit $5 \mathrm{ml} \mathrm{konz.} \mathrm{Ammoniak} \mathrm{bei} 55^{\circ} \mathrm{C}$ für $16 \mathrm{~h}$ geschüttelt. Die Lösung wurde abfiltriert und lyophilisiert. Anschließend wurde der Rückstand in $1 \mathrm{ml}$ Wasser aufgenommen und präparativ an der reversed phase HPLC aufgereinigt. Im HPLC-Chromatogramm (0.1 M Triethylammoniumacetatpuffer ( $\mathrm{pH}=7$ ) gegen Acetonitril, in 0-5 min 100\% Puffer, 0-25\% in 5-30 min) findet sich ein DNA-Peak (enthält nur Produkt-DNA) bei einer Retentionszeit von 23.5 min und mehrere Abbauprodukte.

ESI-MS (Wasser/Acetonitril, negativ mode): ber. für $[\mathrm{M}+2 \mathrm{Na}-6 \mathrm{H}]^{4-}$ : 1975.54, gef. 1975.14 und ber. für $[\mathrm{M}+3 \mathrm{Na}-8 \mathrm{H}]^{5-}: 1584.63$, gef. 1583.93 . 


\subsubsection{Modifizierung von einem DNA-Dodecamer mit einer Di- sulfidbrücke}

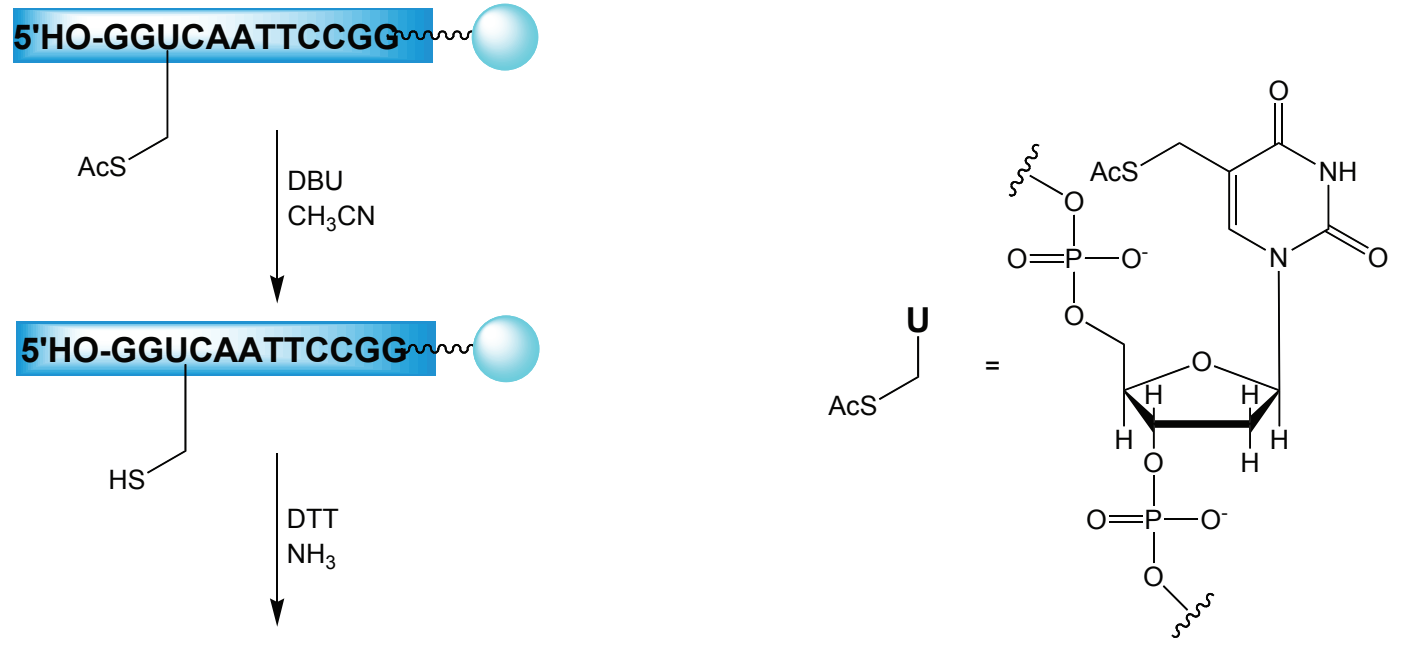

\section{5'HO-GGUCAATTCCGG-OH3'}

$\mathrm{HS}^{\top}$

$1 \mu \mathrm{mol}$ festphasengebundener DNA mit einem $S$-Acetyl-5-(mercaptomethyl)-2'-desoxyuridin wurde bei Raumtemperatur 30 min mit 5 mL 10\%iger DBU-Lösung in Acetonitril geschüttelt. Nach Waschen der Festphase mit $25 \mathrm{~mL}$ Acetonitril wurden $5 \mathrm{~mL}$ konz. Ammoniak mit $0.2 \mathrm{M}$ DTT zugegeben und die Suspension für $16 \mathrm{~h}$ auf $55^{\circ} \mathrm{C}$ erhitzt. Die Lösung wurde dekantiert und der Rückstand mit Wasser gewaschen. Die vereinigte Lösungen wurden anschließend lyophilisiert und an einer reversed phase HPLC-Säule präparativ getrennt (Triethylammoniumacetat (0.1 M, pH = 7) gegen Acetonitril, in 0-5 min 100\% Puffer, in 5-30 min von 0 auf $25 \%$ Acetonitril, $40{ }^{\circ} \mathrm{C}, \mathrm{Rt}=22.9 \mathrm{~min}$ ).

ESI-MS (Triethylammoniumacetat/Acetonitril: 80/20, negative mode): ber. für $[\mathrm{M}-3 \mathrm{H}]^{3-}$ : 1230.14, gef.: 1230.09 . 


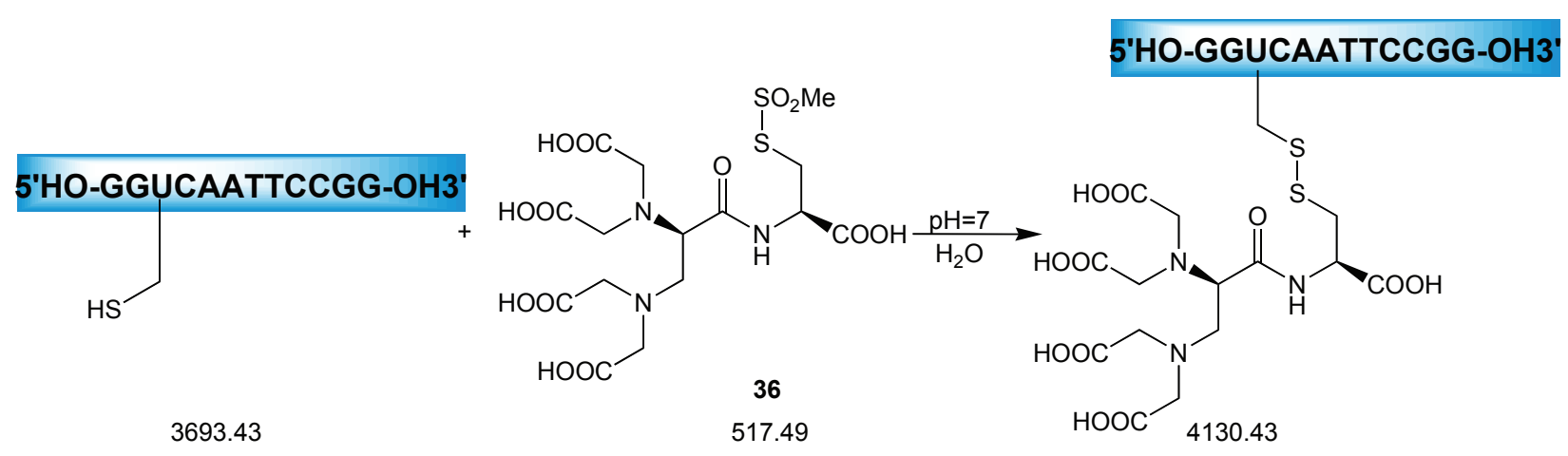

Die gesammelten Produktfraktionen wurden sofort vereinigt und $2 \mathrm{mg} \mathbf{3 6}(3.8 \mu \mathrm{mol})$ zugegeben. Die Lösung wurde für $16 \mathrm{~h}$ bei $5{ }^{\circ} \mathrm{C}$ gerührt und anschließend erneut per HPLC untersucht (gleiche Methode wie oben, Rt $=22.5 \mathrm{~min}$ ).

ESI-MS (Triethylammoniumacetat/ Acetonitril : 80/20, negative mode): ber. für [M-3H $]^{3-}$ : 1375.80, gef. 1375.65 . 


\subsubsection{Präparation der verlängerten TAR-RNA}

$4.55 \mathrm{~mL}$ ATP-Lösung (22 mM, ${ }^{13} \mathrm{C}$ und ${ }^{15} \mathrm{~N}$ gelabelt), $291 \mu \mathrm{L}$ CTP-Lösung (344 mM), $201 \mu \mathrm{L}$ GTP-Lösung (498 mM), $331 \mu \mathrm{L}$ UTP-Lösung (302 mM), $32 \mu \mathrm{L}$ PEG8000, $80 \mu \mathrm{L}$ IPP (inorganic pyrophosphate), $7.20 \mathrm{ml}$ T7-Polymerase-Lösung, $400 \mu \mathrm{L}$ MagnesiumdichloridLösung (1 M), $100 \mu \mathrm{L}$ DTT-Lösung (1 M), $2000 \mu \mathrm{L}$ Transkriptionspuffer (400mM Tris-HCl, 10 mM Spermidine, 50 mM DTT, 0.1\% Triton X-100, pH = 8) und 1.6 mL DNA-DuplexLösung (je 100 mM 5' TAA TAC GAC TCA CTA TA GGC CAG ATT GAG CCT GGG AGC TCT CTG GCC CCA GAA GCC GT 3' und 5' AC GGC TTC TGGGGC CAG AGA GCT CCC AGG CTC AAT CTG GCC TAT AGT GAG TCG TAT TA 3' ) und 3.22 $\mathrm{mL}$ Wasser wurden $6 \mathrm{~h}$ bei $37^{\circ} \mathrm{C}$ inkubiert. Die Transkription wurde dann durch Zugabe von $2 \mathrm{ml}$ EDTA-Lösung (0.5 M, pH =8) gestoppt. Die Rohtranskription wurde über einen DEAE-Anionenaustauscher mit Natriumacetatlösung (0.6 bis $2 \mathrm{M}, \mathrm{pH}=5.5)$ aufgereinigt.

Die erhaltenen RNA-Lösung wurde mit Isopropanol $\left(1: 1,16 \mathrm{~h}\right.$ bei $\left.-20{ }^{\circ} \mathrm{C}\right)$ ausgefällt und zur

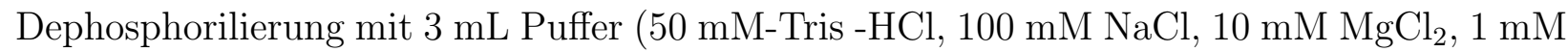
DTT, $\mathrm{pH}=7.9)$ und $100 \mu \mathrm{L}$ alkalische Phosphatase-Stammlösung (10000 Einheiten/mL) von der Firma Biolab versetzt. Nach 4.5 h bei $37^{\circ} \mathrm{C}$ wurde zur die Lösung das gleichen Volumen Harnstofflösung (8 M) gegeben und die erhaltene Lösung über eine Gelelektrophoese (15\% PAGE in 1 M TBE-Pufffer und 4 M Harnstofflösung, 55 W, 16 h) aufgereinigt. Man erhielt $3.7 \mathrm{mg}$ der gewünschten RNA.

Die RNA wurde dialysiert in einem Tube-o-dialyzer (1 kDa Cut-off von Chemicon, 3 x $2 \mathrm{~h}$ bei $6{ }^{\circ} \mathrm{C}$ ) gegen $5 \mathrm{mM}$ Ammoniumacetatpuffer $(\mathrm{pH}=6.9)$. Die Lösung wurde lyophilisiert und in $250 \mu \mathrm{L}$ deuterierter Ammoniumacetat-Lösung $(10 \mathrm{mM}, \mathrm{pH}=6.9)$ aufgenommen und NMR-spektroskopisch untersucht.

Anschließend erfolgte die Zugabe von 1. 5 Äq. der mit Dyprosium(III)ionen beladenen DNA und die Lösung wurde 5 min auf $50{ }^{\circ} \mathrm{C}$ erhitzt und langsam abgekühlt, bevor die NMRspektroskopisch untersucht wurde. Nach 1 d war kein Abbau der RNA sichtbar. 


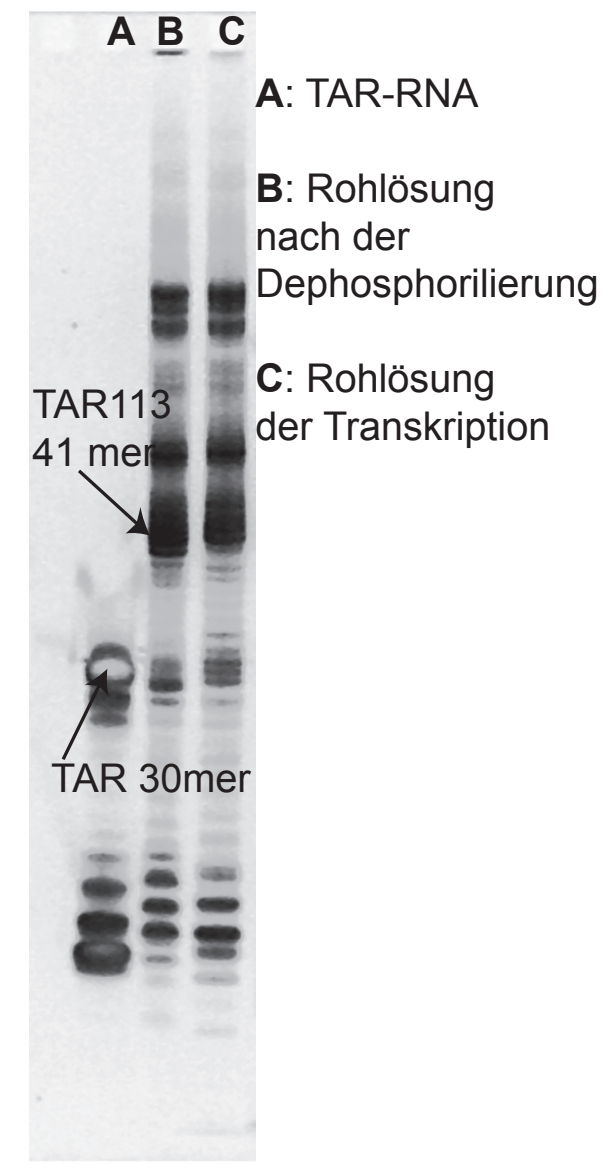

A B C Farbstoff

TAR113

- $=1$

A: DNA-Gegenstrang

B: TAR113-RNA +

1.5 Äq. DNA-

Gegenstrang

DNA

mit Dy

C: TAR113-RNA 


\section{Literaturverzeichnis}

[1] M. Latham, D. Brown, S. McCallum, A. Pardi, ChemBiochem. 2005, 6, 1492-1505.

[2] J. Tolman, J. Flanagan, M. Kennedy, J. Prestegard, Proc. Natl. Acad. Sci. USA 1995, 92, 9279-9283.

[3] N. Tjandra, A. Bax, Science 1997, 278, 1111-1113.

[4] M. Bailor, C. Musselmann, A. Hansen, K. Gulati, D. Patel, H. Al-Hashimi, Nature Protocols 2007, 2, 1563-1546.

[5] I. Bertini, C. D. Bianco, I. Gelis, N. Katsaros, C. Luchinat, G. Parigi, M. Peana, A. Provenzani, M. Zoroddu, Proc. Natl. Acad. Sci. USA 2004, 101, 6841-6848.

[6] J. Hines, G. Ammar, J. Buss, P. Schmalbrock, Bioconj. Chem. 1999, 10, 155-158.

[7] S. Joseph, H. Noller, Methods in Enzymology 2000, 318, 175-190.

[8] B. Rhode, K. Hartmuth, E. Westhof, R. Lührmann, The EMBO Journal 2006, 25, $2475-2486$.

[9] C. Wirges, J. Timper, M. Fischler, A. Sologubenko, J. Mayer, U. Simon, T. Carell, Angew. Chem., Int. Ed. 2009, 48, 219-223.

[10] K. Tanaka, A. Tengeiji, T. Kato, N. Toyama, M. Shionoya, Science 2003, 21, 12121213.

[11] A. Sigl, H. Sigl, Metal Ions in Biological Systems, 40, Marcel Dekker, Inc, Basel, 1. Auflage, 2003. 
[12] P. Haberz, F. Rodriguez-Castaneda, J. Junker, S. Becker, A. Leonov, C. Griesinger, Org. Lett. 2006, 8, 1275-1278.

[13] A. Leonov, B. Voigt, F. Rodriguez-Castaneda, P. Sakhaii, C. Griesinger, Chem. Eur. J. 2005, 11, 3342-3348.

[14] A. L. F. Rodriguez-Castaneda, P. Haberz, C. Griesinger, Magn. Reson. Chem. 2006, $44,10-16$.

[15] H. Kolb, K. Sharpless, Drug Discovery Today 2003, 8, 1128-1137.

[16] H. Kolb, M. Finn, K. Sharpless, Angew. Chem., Int. Ed. 2001, 40, 2004-2008.

[17] J. Prestegard, H. Al-Hashimi, J. Tolman, Q. Rev. Biophys. 2000, 33, 371-424.

[18] A. Brunger, P. Adams, G. Clore, P. Gros, R. Grosse-Kunstleve, J.-S. Jiang, J. Kuszewski, N. Nilges, N. Pannu, R. Read, L. Rice, T. Simonson, G. Warren, Acta Cryst. 1998, D54, 905-921.

[19] A. Brunger, Nature Protocols 2 2007, 372, 2728-2733.

[20] D. Neculai, A. Neculai, S. Verrier, K. Straub, K. Klumpp, E. Pfitzner, S. Becker, J. Biol. Chem. 2005, 280, 40782-40787.

[21] X. Mao, Z. Ren, G. Parker, H. Sondermann, M. Pastorello, W. Wang, J. McMurray, B. Demeler, J. Darnell, X. Chen, Molecular Cell 2005, 17, 761-771.

[22] X. Chen, U. Vinkemeier, Y. Zhao, D. Jeruzalmi, J. Darnell, J. Kuriyan, Cell 1998, 93, 827-839.

[23] C. Guimaraes, M. Cardozo, J. Chem. Inf. Model. 2008, 48, 958-970.

[24] E. d'Auvergne, P.Gooley, J. Biomol. NMR 2008, 40, 107-119.

[25] E. d'Auvergne, P. Gooley, J. Biomol. NMR 2008, 40, 121-133.

[26] R. Lee, R. Feinbaum, V. Ambros, Cell 1993, 75, 843-854.

[27] M. Jinek, J. Doudna, Nature 2009, 457, 405-412.

[28] R. Carthew, E. Sontheimer, Cell 2009, 136, 642-655. 
[29] S. Elbashir, J. Harborth, W. Lendeckel, A. Yalcin, K. Weber, T. Tuschl, Nature 2001, 411, 494-498.

[30] J. Watson, F. Crick, Nature 1953, 171, 737-738.

[31] F. Peters, Synthese eines EDTA-basierten Thyminderivats, dessen Einbau in DNA und spektroskopische Charakterisierung, Diplomarbeit, Göttingen, 2006.

[32] M. Scalley-Kim, A. McConnell-Smith, B. Stoddard, J. Mol. Biol. 2007, 372, 13051319.

[33] R. D. Guzman, Z. Wu, C. Stalling, L. Pappalardo, P. Borer, M. Summers, Science 1998, 279, 384-388.

[34] M. Yang, Current Drug Targets - Infectious Disorders. 2005, 5, 433-444.

[35] A. Brodsky, J. Williamson, J. Mol. Biol. 1997, 267, 624-639.

[36] D. Raghunathan, V. Sánchez-Pedregal, C. S. J. Junker, M. Kalesse, A. Kirschning, T. Carlomagno, Nucl. Acids Res. 2006, 34, 3599-3608.

[37] M. Stevens, E. D. Clercq, J. Balzarini, Medicinal Research Rev. 2006, 26, 595-625.

[38] K. Pachulska-Wieczorek, K. Purzycka, R. Adamiak, Nucl. Acids Res. 2006, 34, 29842997.

[39] A. Holleman, E. Wiberg, N. Wiberg, Lehrbuch der Anorganischen Chemie, Walter de Gruyter, Berlin, 101. Auflage, 1995.

[40] E. Carpenter, K. Beis, A. Cameron, S. Iwata, Curr. Opin. Struct. Biol. 2008, 18, 581-586.

[41] R. Henderson, Q. Rev. Biophys. 2004, 37, 3-13.

[42] B. Fürtig, C. Richter, J. Wöhnert, H. Schwalbe, ChemBioChem 2003, 4, 936-962.

[43] A. Kumar, G. Wagner, R. Ernst, K. Wüthrich, Biochem. Biophys. Res. Commun. 1980, $96,1156-1163$.

[44] H. Kessler, M. Gehrke, C. Griesinger, Angew. Chem. 1988, 100, 507-554. 
[45] K. Wüthrich, G. Wider, G. Wagner, W. Braun, J. Mol. Biol. 1982, 155, 311-319.

[46] G. Clore, A. Gronenborn, Crit. Rev. Biochem. Mol. Biol. 1989, 24, 479-564.

[47] A. Overhauser, Phys. Rev. 1953, 89, 689-700.

[48] A. Overhauser, Phys. Rev. 1953, 93, 411-415.

[49] H. Al-Hashimi, A. Gorin, A. Majumdar, D. Patel, J. Am. Chem. Soc. 2001, 123, $3179-3180$.

[50] W. Aue, E. Bartholdi, R. Ernst, J. Chem. Phys. 1976, 64, 2229-2246.

[51] L. Braunschweiler, R. Ernst, J. Magn. Reson. 1983, 53, 521-528.

[52] D. Reid, S. Salisbury, S. Bellard, Z. Shakked, D. Williams, Biochemistry 1983, 22, 2019 .

[53] J. Feigon, J. Wright, W. Leupin, W. Denny, D. Kearns, J. Am. Chem. Soc. 1982, 104, 5540 .

[54] J. Feigon, W. Leupin, W. Denny, D. Kearns, Biochemistry 1983, 22, 5943.

[55] S. Wijmenga, B. van Buuren, Prog. Nucl. Magn. Res. Sp. 1983, 53, 521-528.

[56] C. Roberts, NMR of Marcromolecules, Oxford University Press, Oxford, 1. Auflage, 1993.

[57] M. Piotto, V. Saudek, V. Sklenar, J. Biomol. NMR 1992, 2, 661-666.

[58] C. Altona, D. Fabery, A. W. Hoekzem, Magn. Reson. Chem. 2000, 38, 95-107.

[59] M. Hansen, L. Mueller, A. Pardi, Nat. Struct. Biol. 1998, 5, 1065-1074.

[60] C. Sanders, B. Hare, K. Howard, J. Prestegard, Prog. Nucl. Mag. Res. Sp. 1994, 26, $421-444$.

[61] Y. Dong, Nuclear Magnetic Resonance of Liquid Crystals, Springer-Verlag, New York, 2. Auflage, 1997. 
[62] I. Bertini, C. Luchinat, NMR of Paramagnetic Molecules in Biological Systems, The Benjamin/Cummings Publishing Company, Menlo Park, 1. Auflage, 1986.

[63] I. Bertini, C. Luchinat, S. Aime, Coord. Chem. Rev. 1996, 150, 1-28.

[64] I. Bertini, C. Luchinat, G. Parigi, R. Pieratelli, Dalton Trans. 2008, 29, 3782-3790.

[65] I. Bertini, C. Luchinat, S. Aime, Coord. Chem. Rev. 1996, 150, 29-75.

[66] G. Otting, J. Biomol. NMR 2008, 42, 1-9.

[67] B. Bleaney, J. Magn. Res. 1972, 8, 91-100.

[68] I. Bertini, C. Luchinat, G. Parigi, Progr. Nuc. Magn. Res. 2002, 40, 249-273.

[69] I. Bertini, J. Kowalewski, C. Luchinat, G. Parigi, J. Mag. Res. 2001, 152, 103-108.

[70] V. Mironov, Y. Galyametdinov, A. Ceulemans, C. Görller-Walrand, K. Binnemans, J. Chem. Phys. 2002, 116, 4673-4685.

[71] R. Golding, P. Pyykkö, Molecular Physics 1973, 26, 1389-1396.

[72] B. McGarvey, J. Mag. Reson. 1979, 33, 445-455.

[73] N. Sakagami, Y. Yamada, T. Konno, K. Okamoto, Inorganica Chimica Acta 1999, $288,7-16$.

[74] I. Bertini, M. Janik, Y. Lee, C. Luchinat, A. Rosato, J. Am. Chem. Soc. 2001, 123, $4181-4188$.

[75] R. Golding, P. Pyykkö, Molecular Physics 1973, 26, 1389-1396.

[76] B. Bleaney, C. M. Dobson, B. A. Levine, R. B. Martin, R. J. Williams, A. V. Xavier, J. Chem. Soc., Chem. Comm. 1972, 791-793.

[77] F. Kramer, M. Deshmukh, H. Kessler, S. Glaser, Concepts in Mag. Reson. 2004, 21A, $10-21$.

[78] I. Bertini, C. Luchinat, S. Aime, Coord. Chem. Rev. 1996, 150, 77-110. 
[79] I. Bertini, C. Luchinat, G. Parigi, Solution NMR of Paramagnetic Molecules, Elsevier, Amsterdam, 1. Auflage, 2001.

[80] A. Hudson, J. Lewis, Trans. Faraday Soc. 1970, 66, 1297-1301.

[81] I. Bertini, C. Luchinat, S. Aime, Coord. Chem. Rev. 1996, 150, 77-110.

[82] R. Tsien, Ann. Rev. Biochem. 1998, 67, 509-544.

[83] A. Leitner, W. Lindner, Proteomics 2006, 6, 5418-5434.

[84] J. Schmitt, H. Hess, H. Stunnenberg, Mol. Biol. Rep. 1993, 18, 223-230.

[85] O. Schiemann, T. Prisner, Quart. Rev. Biophys. 2007, 40, 1-53.

[86] B. Liang, J. Bushweller, L. Tamm, J. Am. Chem. Soc. 2006, 128, 4389-4397.

[87] J. Iwahara, D. Anderson, E. Murphy, G. Clore, J. Am. Chem. Soc. 2003, 125, 66346635 .

[88] J. Iwahara, G. Clore, Nature 2006, 440, 1227-1230.

[89] G. Clore, Mol. BioSyst. 2008, 4, 1058-1069.

[90] H. Hakala, P. Ollikka, J. Degerholm, J. Hovinen, Tetrahedron 2002, 58, 8771-8777.

[91] M. Bidot-Forget, M. Chassignol, M. Takasugi, N. Thuong, C. Helen, Gene 1988, 72, $361-371$.

[92] Y. Kitamura, T. Ihara, Y. Tsujimura, M. Tazaki, A. Jyo, Chem. Lett. 2005, 34, 16061607.

[93] G. Dreyer, P. Dervan, Proc. Natl. Acad. Sci. USA 1985, 82, 968-972.

[94] T. Ikegami, L. Verdier, P. Sakhaii, S. Grimme, B. Pescatore, K. Saxena, M. Vogtherr, K. M. Fiebig, C. Griesinger, J. Biomol. NMR 2004, 29, 339-349

[95] F. Westheimer, Science 1987, 235, 1173-1178.

[96] M. Septak, Nucl. Acids Res. 1996, 24, 3053-3058. 
[97] M. Mato-Iglesias, E. Balogh, C. Platas-Iglesias, E. Toth, A. de Blas, T. Rodriguez-Blas, Dalton Trans. 2006, 45, 5404-5415.

[98] L. Burai, V. Hietapelto, R. Kiraly, E. Toth, E. Brucher, Magn. Res. Med. 1997, 38, 146-150.

[99] F. Seela, V. Sirivolu, P. Chittepu, Bioconj. Chem 2007, 19, 211-224.

[100] J. Milligan, O. Uhlenbeck, Methods Enzymol. 1989, 180, 51-62.

[101] J. Milligan, D. Groebe, G. Witherell, O. Uhlenbeck, Nucl. Acids Res. 1987, 15, $8783-8798$.

[102] P. Capek, H. Cahova, R. Pohl, M. Hocek, C. Gloeckner, A. Marx, Chem. Eur. J. 2007, 13,6196 .

[103] L. Scott, M. Hennig, Methods Mol. Biol. 2008, 452, 29-61.

[104] E. Wöltjen, Synthese eines paramagnetischen Tags zur NMR-spektroskopischen Untersuchung von Oligonukleotiden, Diplomarbeit, Göttingen, 2005.

[105] S. Khan, M. Grinstaff, J. Am. Chem. Soc. 1999, 121, 4704-4705.

[106] W. Flasche, C. Cismas, A. Herrmann, J. Liebscher, Synthesis 2004, 2335 - 2341.

[107] M. Rist, N. Amann, H. Wagenknecht, Eur. J. Org. Chem. 2003, 13, 2498-2504.

[108] N. Minakawa, Y. Ono, A. Matsuda, J. Am. Chem. Soc. 2003, 125, 11545-11552.

[109] T. Kottysch, C. Ahlborn, F. Brotzel, C. Richert, Chem. Eur. J. 2004, 10, 4017-4028.

[110] L. Pachòn, J. van Maarseveen, G. Rothenberg, Add. Synth. Catal. 2005, 347, 811-815.

[111] V. Bock, H. Hiemstra, J. van Maarseveen, Eur. J. Org. Chem. 2006, 1, 51-68.

[112] C. Nolte, P. Mayer, B. Straub, Angew. Chem., Int. Ed. 2007, 46, 2101-2103.

[113] G. Burley, J. Gierlich, M. Mofid, H. Nir, S. Tal, Y. E. und T. Carell, J. Am. Chem. Soc. 2006, 128, 1398-1399. 
[114] J. Gierlich, G. Burley, P. Gramlich, D. Hammond, T. Carell, Org. Lett. 2006, 8, 36393642 .

[115] T. Seo, Z. Li, H. Ruparel, J. Ju, J. Org. Chem. 2003, 68, 609-612.

[116] Q. Wang, T. R. Chan, R. Hilgraf, V. Fokin, K. Sharpless, M. Finn, J. Am. Chem. Soc. 2003, 125, 3192-3193.

[117] R. Franke, C. Doll, J. Eichler, Tetrahedron Letters 2005, 46, 4479-4482.

[118] C. Tornoe, C. Christensen, M. Meldal, J. Org. Chem. 2002, 67, 3057-3064.

[119] N. Bushmakina, A. Misharin, Synthesis 1986, 11, 966-967.

[120] F. Chiu, R. Brownlee, K. Mitchell, D. Phillips, Chem. Eur. J. 2002, 8, 2891-2899.

[121] T. Kirley, Anal. Biochem. 1989, 180, 231-236.

[122] D. Smith, E. Maggio, G. Kenyon, Biochemistry 1975, 14, 766-771.

[123] M. Prudencio, J. Rohovec, J. Peters, E. Tocheva, M. Boulanger, M. Murphy, H.Hupkes, W. Kosters, A. Impagliazzo, M. Ubbink, Chem. Eur. J. 2004, 10, 3252-3260.

[124] B. Liang, J. Bushweller, L. Tamm, J. Am. Chem. Soc. 2006, 128, 4389-4397.

[125] B. Davis, S. Ward, P. Rendle, Chem. Commun. 2001, 2, 189-190.

[126] S. Matus, J. Fourrey, P. Clivio, Org. Biomol. Chem. 2003, 1, 3316-3320.

[127] V. Guerineau, S. Matus, F. Halgand, O. Laprevote, P. Clivio, Org. Biomol. Chem. 2004, 2, 899-907.

[128] B. Connolly, P. Newman, Nuc. Acids Res. 1989, 17, 4957-4974.

[129] B. Bornemann, A. Marx, Bioorg. Med. Chem 2006, 14, 6235-6238.

[130] N. Bischofberger, C. Buhr, J. Dougherty, B. Froehler, A. Gutierrez, H. Gong-Xin, R. Shea, S. Swaminathan, M. Williams, WO9910365, Gilead Sciences Inc., USA 1999

[131] H. Drew, R. Wing, T. Takano, C. Broka, S.Tanaka, K. Itakura, R. Dickerson, Proc. Natl. Acad. Sci. USA 1981, 78, 2179-2183. 
[132] J. Heptinstall, R. Rapley, The Nucleic Acid Protocols Handbook, Humana Press, Totowa, 1. Auflage, 2000.

[133] S. Eriksson, G. Glad, P. Pernemalm, E. Westman, J. Chromatogr. 1986, 359, 265-274.

[134] P. Oefner, G. Bonn, C. Huber, S. Nathakarnkitkool, J. Chromatogr. 1992, 625, 331340.

[135] A. von Brocke, T. Freudemann, E. Bayer, J. Chromatogr. A 2003, 991, 129-141.

[136] L. Beach, C. Schweitzer, J. Scaiano, Org. Biomol. Chem. 2003, 1, 450-451.

[137] V. Bloomfield, D. Crothers, I. Tinoco, Nucleic Acids, University Sciende Books, Sausalito, 10. Auflage, 2000.

[138] A. Leonov, F. Rodriguez-Castaneda, P. Sakhaii, L. Verdier, C. Griesinger, Chem. Eur. J. 2005, 3342-3348.

[139] J. Ying, A. Grishaev, M. Latham, A. Pardi, A. Bax, J. Biomol. NMR 2007, 39, 91-96.

[140] D. Bryce, J. Boisbouvier, A. Bax, J. Am. Chem. Soc. 2004, 126, 10820-10821.

[141] A. O’Toole, S. Miller, N. Haines, C. Zink, M. Serra, Nucl. Acids Res. 2006, 34, 33383344.

[142] S. Franklin, Curr. Opin. Chem. Biol. 2001, 5, 201-208.

[143] M. Komiyama, H. Arishima, M. Yokoyama, Y. Kitamura, Y. Yamamoto, ChemBioChem 2005, 6, 192-196.

[144] J. Rammo, R. Hettich, A. Roigk, H. Schneider, Chem. Commun. 1996, 1, 105-107.

[145] C. Mundoma, N. Greenbaum, J. Am. Chem. Soc. 2002, 124, 3525-3532.

[146] C. Mundoma, N. Greenbaum, Biopolymers 2003, 69, 100-109.

[147] Q. Zhang, X. Sun, E. Watt, H. Al-Hashimi, Science 2006, 311, 653-656.

[148] Q. Zhang, A. Stelzer, C. Fisher, H. Al-Hashimi, Nature 2007, 450, 1263-1267. 
[149] P. Haberz, F. Rodriguez-Castaneda, J. Junker, S. Becker, A. Leonov, C. Griesinger, Org. Lett. 2006, 8, 1275-1278.

[150] E. Lesnik, S. Freier, Biochemistry 1995, 34, 10807-10815.

[151] P. Keizers, M. O. A. Saragliadis, Y. Hiruma, M. Ubbink, J. Am. Chem. Soc. 2008, $130,14802-14812$.

[152] M. Robins, P. Barr, J. Org. Chem. 1983, 48, 1854-1862.

[153] Y. Shealy, C. O’Dell, G. Arnett, W. Shannon, J. Med. Chem. 1986, 29, 79-84.

[154] A. Pike, L. Ryder, B. Horrocks, W. Clegg, M. Elsegood, B. Connolly, A. Houlton, Bioorg. Medicinal. Chem. Letters 1995, 5, 1689-1694. 


\section{Kapitel 9}

\section{Anhang}

\subsection{Abkürzungsverzeichnis}

\begin{tabular}{l|l} 
A & Adenin \\
Ac & Acetat \\
ACN & Acetonitril \\
äq. & äquivalente \\
ADP & Adenosindiphosphat \\
AIDS & Acquired immunodeficiency syndrome \\
AMP & Adenosinmonophosphat \\
APS & Ammoniumperoxodisulfat \\
ATP & tert-Butyloxycarbonyl \\
Boc & Benzyl \\
Bn & Cytosin \\
C & capillary electrophoresis \\
CE & Correlation Spectroscopy \\
COSY & controlled pore glas \\
CPG & Dioden-Array-Detektor \\
DAD &
\end{tabular}




\begin{tabular}{|c|c|}
\hline $\mathrm{DC}$ & Dünnschichtchromatographie \\
\hline DMAP & 4-(Dimethylamino)-pyridin \\
\hline $\mathrm{DMF}$ & Dimethylformamid \\
\hline DMSO & Dimethylsulfoxid \\
\hline $\mathrm{DMTr}$ & Dimethoxytrityl \\
\hline DNA & Desoxyribonukleinsäure \\
\hline dNTP & Desoxyribonukleosidtriphosphat \\
\hline DQF-COSY & Double Quantum Filtered-COSY \\
\hline dsDNA & double-stranded DNA \\
\hline EDTA & Ethylendiamintetraacetat \\
\hline EdU & 5-Ethinyl-2'-desoxyuridine \\
\hline ee & enantiomeric excess \\
\hline ESI & Elektronensprayionisation \\
\hline ESR & Elektronenspinresonanz \\
\hline G & Guanin \\
\hline HATU & ( $O$-(7-Azabenzotriazol-1-yl)- $N, N, N^{\prime}, N$-tetramethyluronium-hexafluorophosphat \\
\hline HIV & Human immunodeficiency virus \\
\hline HMBC & Heteronuclear Multiple Bond Correlation Experiment \\
\hline HPLC & High Performance Liquid Chromatography \\
\hline HSQC & Heteronuclear Single Quantum Correlation Experiment \\
\hline $\mathrm{Hz}$ & Hertz \\
\hline IR & Infrarot \\
\hline LC-MS & Liquid chromatography-mass spectroscopy \\
\hline MALDI-TOF & matrix assisted laser desorption/ionisation time-of-flight \\
\hline Mes & Mesylat \\
\hline MMTS & Methylmethanthiosulfonat \\
\hline MOPS & 3-Morpholinopropansulfonsäure \\
\hline MS & Massenspektroskopie \\
\hline MTPA & $\alpha$-Methoxy- $\alpha$-trifluoromethylphenylacetylchlorid \\
\hline NMR & Nuclear Magnetic Resonance \\
\hline NOESY & Nuclear Overhauser Enhancement Spectroscopy \\
\hline
\end{tabular}




\begin{tabular}{|c|c|}
\hline NTA & Nitrilotriessigsäure \\
\hline NTP & Nukleosidtriphosphat \\
\hline ODN & Oligodesoxynukleotid \\
\hline ON & Oligonukleotid \\
\hline p.a. & pro analysis \\
\hline PA & Phosphoramidit \\
\hline PAGE & polyacrylamide gel electrophoresis \\
\hline PCS & Pseudocontact shifts \\
\hline PRE & Paramagnetic relaxation enhancement \\
\hline ppm & parts per million \\
\hline $\mathrm{RDC}$ & residual dipolar couplings \\
\hline RNA & Ribonukleinsäure \\
\hline ssDNA & single-stranded DNA \\
\hline $\mathrm{T}$ & Thymin \\
\hline TAR & Trans-activating response region \\
\hline TAT & Transactivator of transcription \\
\hline TBE & 1,1,2,2-Tetrabromethan \\
\hline TEAA & Triethylammoniumacetat \\
\hline TEMED & $N, N, N^{\prime}, N^{\prime}$-Tetramethylethylendiamine \\
\hline TEMPO & 2,2,6,6-Tetramethylpiperidinyloxyl \\
\hline TFA & Trifluoressigsäure \\
\hline $\mathrm{THF}$ & Tetrahydrofuran \\
\hline TMS & Trimethylsilyl \\
\hline TOCSY & Total Correlation Spectroscopy \\
\hline $\mathrm{U}$ & Uracil \\
\hline UV & Ultraviolett \\
\hline
\end{tabular}




\subsection{Abbildungsverzeichnis}

1.1 Tagging über eine Disulfidbrücke. . . . . . . . . . . . . . . . . . . 2

1.2 Methodenübersicht: Clickreaktionen an ethinylmodifizierter DNA. . . . . . . 3

1.3 Methodenübersicht: Clickreaktionen an verlängerter ethinylmodifizierter DNA. 4

1.4 DNA-Hairpinsequenz. Das Sternchen markiert die Position des Tags. . . . . 5

1.5 Verlängerte TAR-Sequenz des HIV2. . . . . . . . . . . . . . . . . 6

2.1 Entwicklung der Nukleinsäurestrukturaufklärungen anhand der PDB-Daten. 10

2.2 Abbildung der Nukleobasen. . . . . . . . . . . . . . . . . . . . . 11

2.3 Die beiden Zuckerkonformationen von DNA (links) und RNA (rechts). . . . 11

2.4 Die verschiedenen Nukleinsäurehelices: A-Form (links), B-Form (rechts) [31]. 12

2.5 Eine Endonuclease gebunden an die DNA-Zielsequenz [32] . . . . . . . . . 13

2.6 Schematische Darstellung des HI-Virus. . . . . . . . . . . . . . . . 14

2.7 Untersuchte TAR-Sequenz des HIV2 . . . . . . . . . . . . . . . . . . . . 15

2.8 Verlängerte TAR-Sequenz . . . . . . . . . . . . . . . . 15

3.1 Schematische Darstellung eines zweidimensionalen NMR-Spektrums. . . . . . 19

3.2 Schema zum Aufbau zweidimensionaler NMR-Pulsprogramme. . . . . . . . . 19

3.3 Schema zum Ablauf einer NMR-Strukturaufklärung mit NOE-Daten. . . . . 20

3.4 STAT1 mit DNA-Doppelstrang . . . . . . . . . . . . . . . 21

3.5 „NOESY-Walk“der ersten zehn Basen vom 5'- in Richtung 3'-Ende. . . . . . 22

3.6 Abbildung der Nukleobasen und der 2'Desoxyribose inklusive ihrer Nomen-

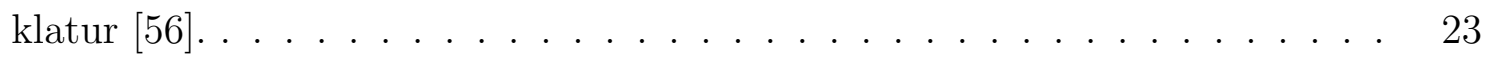

3.7 Chemische Verschiebungen der 2'-Desoxyriboseprotonen in ppm . . . . . . . 24

3.8 Chemische Verschiebungen der Basenprotonen in ppm. . . . . . . . . . . . 25

3.9 Abbildung der Internukleotid-NOE-Restraints. . . . . . . . . . . . . . . . 26

3.10 Die energieniedrigsten Strukturen nach der ersten und der zweiten Rechnung 28 
3.11 Die energieniedrigsten Strukturen aus der verfeinerten Moleküldynamikrechnung 29

3.12 Tabelle der paramagnetischen Effekte. . . . . . . . . . . . . . . . 31

3.13 Übersicht der NMR-Eigenschaften der Lanthanoide. . . . . . . . . . . . . . . 32

3.14 Abbildung des Koordinatensystems des Anisotropietensor. . . . . . . . . . . 33

3.15 Die axialen Suszeptibilitätsanisotropiewerte der Lanthanoide. . . . . . . . . . 36

3.16 Der Winkel $\Theta$ zwischen dem externen Magnetfeld und dem Kernverbindungs-

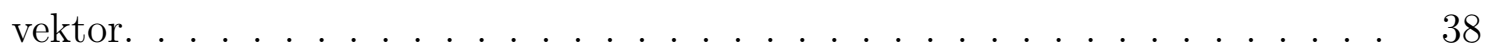

3.17 Abbildung des für Winkel $\Theta$ im Molekülkoordinatensystem. . . . . . . . . . . 40

3.18 Zusammenhang zwischen Alignmenttensor und Suszeptibilitätstensor . . . . . 43

3.19 Beispiele für Elektronenrelaxationszeiten. . . . . . . . . . . . . . . . . . 45

4.1 Die schematische Darstellung der His-Tag-Affinitätschromatographie. . . . . 48

4.2 Einführung eines MTSSL-Tags in ein Protein . . . . . . . . . . . . . . . . . 49

4.3 Die Einführung eines endständigen Fe-BABE-Tags in RNA . . . . . . . . . 50

4.4 Alternative nichtendständige BABE-Modifizierung von RNA. . . . . . . . . . 51

4.5 5'-EDTA-Fluoreszenztag. . . . . . . . . . . . . . . . . . . 51

4.6 Einbau des Hovinen-Tags. . . . . . . . . . . . . . . . . . . . 52

4.7 Kommerziell erhältlicher EDTA-Tag für DNA (dT-EDTA) . . . . . . . . . . 52

4.8 DTPA-Derivatisierung eines Oligonukleotids für MRI-Studien. . . . . . . . . 53

4.9 Strukturformeln und Abkürzungen der drei verschiedenen Tags. . . . . . . . 56

4.10 Vergleich der Struktur der EPTE-modifizierten und der nativen DNA . . . . 57

4.11 Vergleich der Struktur der DSE-modifizierten und der nativen DNA . . . . . 57

5.1 Der Synthesezyklus der Phosphoramiditmethode. . . . . . . . . . . . 61

5.2 Basenlabile Aminoschutzgruppen. . . . . . . . . . . . . . . . . . . . . 62

5.3 Enantiomeren selektive Synthese von $(R / S)$-(4-Bromphenyl)-glycin. . . . . . 63

5.4 Aufbau der EDTA-Funktion. . . . . . . . . . . . . . . . 64

5.5 Aufbau des 5-Ethinyl-2'-desoxyuridins. . . . . . . . . . . . . . 64

5.6 Verkürzte Synthese des 5-Ethinyl-2'-desoxyuridins. . . . . . . . . . . . . . . 65

5.7 Synthese des Phosphoramidits. . . . . . . . . . . . . . . 66

5.8 Übersicht zur Pd(0)-katalysierten Reaktion nach Grinstaff. . . . . . . . . . . 67

5.9 Übersicht zur Glaser-Kupplung. . . . . . . . . . . . . . . . . . . . . 68

5.10 Synthese der chelatisierenden Bausteine mit Ethinfunktion. . . . . . . . . . . 68 
5.11 Sonogashira-Reaktionen an festphasengebundener DNA. . . . . . . . . . . 69

5.12 Übersicht zu verschiedenen Clickreaktionen nach Sharpless. . . . . . . . . . . 70

5.13 Huisgen 1,3-dipolare Cycloaddition. . . . . . . . . . . . . . . . 70

5.14 Katalysezyklus der Huisgen 1,3- dipolaren Cycloaddition. . . . . . . . . . . 71

5.15 Spin label-Einführung in DNA mittels Clickchemie. . . . . . . . . . . . 73

5.16 Schema zur Synthese von Diaminopropionsäurebenzylester. . . . . . . . . . 74

5.17 Synthese des (S)-1- Carboxylethylendiamintetraessigsäuretetramethylesters . 74

5.18 Synthese des EDTA-modifizierten Azids. . . . . . . . . . . . . . . . 74

5.19 Synthese einer DNA mit TE-Tag. . . . . . . . . . . . . . . . . 75

5.20 Synthese des trans-4-Aminocyclohexylazid. . . . . . . . . . . . . 76

5.21 LC-MS-Chromatogramm zur Stereoselektivität der $\mathrm{S}_{N} 2$-Reaktion. . . . . . . 76

5.22 Synthese des EDTA-modifizierten Alkylazides. . . . . . . . . . . . . 77

5.23 Clickreaktion mit eines zyklischen Alkylazid. . . . . . . . . . . . . . 77

5.24 Synthese des verlängerten ethinylfunktionalisierten Desoxyuridins . . . . . 78

5.25 Clickreaktion des verlängerten Ethindesoxyuridins mit 32-S. . . . . . . . . 79

5.26 Clickreaktion des verlängerten Ethindesoxyuridins mit 26b-S an der Festphase. 79

5.27 Überblick der Aufarbeitung der EPTE-getaggten DNA. . . . . . . . . . . . . 80

5.28 Beispiele zur Modifizierung von Cysteinen $[12,123,124] \ldots$. . . . . . . . . . 81

5.29 Reaktionsbeispiele an Zuckern und Nukleosiden. . . . . . . . . . . . . . 82

5.30 Taggingreaktion an 4-Thio-2'-desoxythymidin. . . . . . . . . . . . . . 83

5.31 Macromodelsimulation der an 4(orange)- und 5(blau)-Position getaggten DNA. 83

5.32 Synthese von $S$-Acetyl-5-mercaptomethyl-2'-desoxyuridin. . . . . . . . . . 84

5.33 Dreistufige Synthese von $S$-Acetyl-5-mercaptomethyl-2'-desoxyuridin. . . . . 84

5.34 Schematische Darstellung der Synthese von DNA mit einem DSE-Tag. . . . . 85

6.1 ESI-Massenspektrum der 24meren DNA mit EPTE-Tag. . . . . . . . . . . 88

6.2 ESI-Massenspektrum der 24meren DNA mit EPTE-Tag mit $\mathrm{Dy}^{3+} \ldots \ldots$. . . 88

6.3 Verwendete DNA-Sewuenzen. . . . . . . . . . . . . . . . . . . . 89

6.4 Veränderte UV-Absorption durch den EPTE-Tag. . . . . . . . . . . . . . 90

6.5 24mer Hairpin-DNA basierend auf einer STAT-bindenden Sequenz. . . . . . 90

6.6 HPLC-Chromatogramme der dodecamerer DNA-Doppelstränge. . . . . . . . 92

6.7 HPLC-Chromatogramme der DNA-Einzelstränge. . . . . . . . . . . . . . . 93 
6.8 HPLC-Chromatogramme der dsDNA- und ssDNA-Mischungen bei $35^{\circ} \mathrm{C} . .93$

6.9 NMR-Spektren von EDTA und TRIS mit und ohne $\mathrm{DyCl}_{3} \ldots \ldots$. . . . . . . 95

6.10 HPLC-Chromatogramm einer Mischung aus EDTA und $\mathrm{DyCl}_{3}(3: 2)$. . . . 96

6.11 UV-aktives EDTA-Derivat. . . . . . . . . . . . . . . . . 97

6.12 HPLC-Chromatogramm des UV-aktiven EDTA-Derivates ohne NaCl. . . . . 97

6.13 HPLC-Chromatogramm des UV-aktiven EDTA-Derivates mit $\mathrm{DyCl}_{3}$. . . . 98

6.14 24mer Hairpin-DNA mit EPTE-Tag an der Position T* . . . . . . . . . . . 98

6.15 Tabelle der chemischen Verschiebungen der DNA mit und ohne EPTE-Tag. . 99

6.16 EPTE-Tag . . . . . . . . . . . . . . . . . . . . 99

$6.17{ }^{1} \mathrm{H}-\mathrm{NOESY}-S p e k t r u m, 1 \mathrm{mM}$ DNA mit EPTE-Tag (ohne Dysprosiumionen). 100

$6.18{ }^{1} \mathrm{H}-\mathrm{NOESY}-$ Spektrum 1mM DNA mit EPTE-Tag und Dy ${ }^{3+} \ldots \ldots$. . . . . . . 102

6.19 Tabelle der Pseudokontaktshifts. . . . . . . . . . . . . . . 103

6.20 Der diagonalisierte Alignmenttensor. . . . . . . . . . . . . . . . 105

6.21 Auftragung der gemessenen PCS gegen die berechneten PCS. Die gute Korrelation besitzt einen q-Faktor von $0.086 \ldots \ldots \ldots$. . . . . . . . 106

6.22 DNA-Struktur und Tensor im Molkülkoordinatensystem. . . . . . . . . . . 107

6.23 Verlängerte TAR-Sequenz des HIV2. . . . . . . . . . . . . . . . . . 108

6.24 C1'-H1'-HSQC-Spektrum der verlängerten TAR-RNA ohne und mit DNADecamer. . . . . . . . . . . . . . . . . . . . 109

6.25 C8-H8-HSQC-Spektrum der verlängerten TAR-RNA ohne und mit DNA-

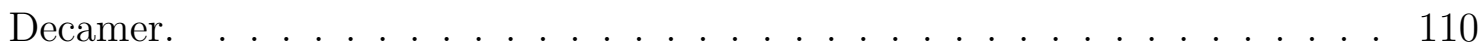

6.26 C2-H2-HSQC-Spektrum der verlängerten TAR-RNA ohne und mit DNADecamer. . . . . . . . . . . . . . . . . . . 110

6.27 Veränderung der NOESY-Kreuzsignalintensität durch Zugabe von Dysprosi-

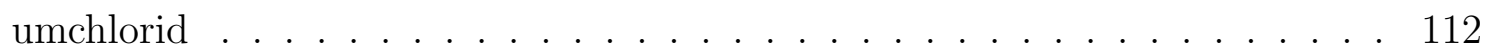

6.28 NOESY-Spektrum des DNA-Gegenstranges ohne und mit $\mathrm{DyCl}_{3}$. . . . . . 113

6.29 HSQC-Spektren der verlängerten TAR-RNA ohne und mit Dy-EPTE-DNA . 115

6.30 Gekoppeltes C2-H2-HSQC-Spektrum der paramagnetischen Probe (blau) und der diamagnetischen Probe (rot) bei $25{ }^{\circ} \mathrm{C}$ und $900 \mathrm{MHz}$. . . . . . . . . . 116

6.31 Gekoppeltes C8-H8-HSQC-Spektrum der paramagnetischen Probe (blau) und der diamagnetischen Probe (rot) bei $25{ }^{\circ} \mathrm{C}$ und $900 \mathrm{MHz}$. . . . . . . . . . 116

6.32 Tabelle der extrahierten rdcs bei $900 \mathrm{MHz}$ und $25{ }^{\circ} \mathrm{C} \ldots \ldots$. . . . . . . . . 117 
6.33 Gelelektrophorese zur Untersuchung auf Abbauprodukte. . . . . . . . . . . . 117

7.1 Verlängerte TAR-RNA mit DNA-Gegenstrang und mit RNA-Gegenstrang. 122

8.1 ESI-Massenspektrum mit TOF-Detektion . . . . . . . . . . . . . . . . 160

8.2 HPLC-Chromatogramm der DNA mit EPTE-Tag (Abschnitt 8.2.37) . . . . . 166

8.3 ESI-Massenspektrum der DNA mit EPTE-Tag (Abschnitt 8.2.37) . . . . . 166

\subsection{Macromodelparameter}

Force field: OPLS_2005

Solvent: Water

Constant dielectric with dielectric constant 1.0

Extended cutoff

Optimisation of the whole structure with no constraints

Energy minimazation via the PRCG-Method until convergence threshold is less then 0.05 (Energy).

\subsection{Weitere Versuchsvorschriften}

Im Folgenden sind einige ausgewählte Reaktionsvorschriften, die nicht zur erfolgreichen Synthese von paramagnetisch markierter DNA verwendet wurden, aufgeführt. Darunter je eine repräsentatives Beispiel für Sonogashira-Kupplungen an der Festphase. Andere getestete DNA-Sequezen waren beispielsweise CXG und XCAATTCCGG (X entspricht dem modifizierten Uridinbausteinen). 


\subsubsection{Beispiel einer Sonogashira-Reaktion an der festphasenge- bundenen DNA mit 5-Iod-2'-desoxyuridin}

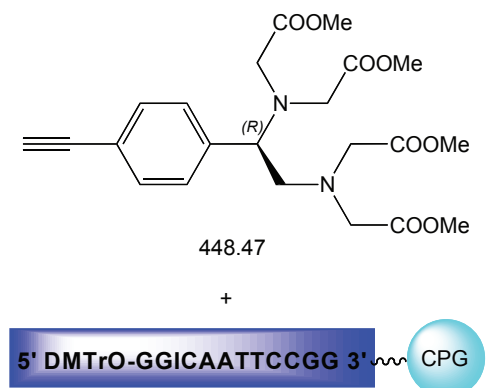

4075.68

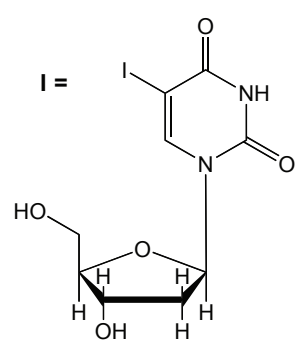

1.) Cul, $\mathrm{Na}_{2}\left[\mathrm{PdCl}_{4}\right],\left[t \mathrm{Bu}_{3} \mathrm{PH}\right]\left[\mathrm{BF} F_{4}\right]$,
$\mathrm{HNiPr}_{2}, \mathrm{DMSO}$

2. ) $\mathrm{NaOH}$$$
\text { 2. ) } \mathrm{NaOH}
$$

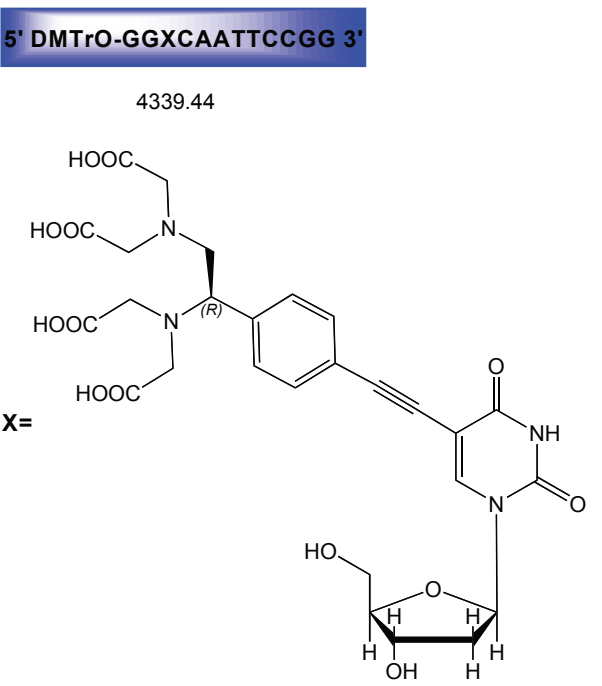

$1 \mu \mathrm{mol}$ festphasengebundenene, DMTr-geschützte DNA (35 mg) wurde unter Argonatmosphäre mit 4.4 mg Natriumtetrachloropalladat(II) (15 $\mu$ mol, 15 Äq.), 2.8 mg Kupferiodid (15 $\mu \mathrm{mol}, 15$ Äq.),5.8 mg Tri-(tert-butyl)phosphonium)-tetrafluoroborat (20 $\mu \mathrm{mol}, 20$ Äq.)

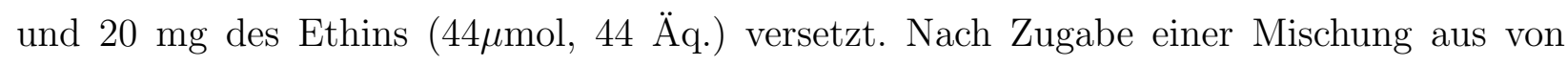
$78 \mu$ l Diisopropylamin und $400 \mu$ l Dimethylsulfoxids wurde die Suspension $3 \mathrm{~h}$ bei $50{ }^{\circ} \mathrm{C}$ geschüttelt. Anschließend wurde das Reaktionsgemisch filtriert und der Rückstand je dreimal mit $100 \mu$ l Dimethylsulfoxid und Wasser gewaschen. Die festphasengebundene DNA wurde anschließend mit einer Lösung aus 0.4 M Natronlauge in Wasser/Methanol: 1/4 $16 \mathrm{~h}$ bei Raumtemperatur geschüttelt. Die DNA-haltige Lösung wurde anschließend mit HPLC und ESI-MS analysiert. Die Retentionszeit entsprach dabei der ioddesoxyuridinhaltigen DNA und im Massenspektrum wurde auch nur dessen Masse detektiert. 


\subsubsection{Sonogashira-Reaktion an der festphasengebundenen DNA mit 5-Ethin-2'-desoxyuridin}

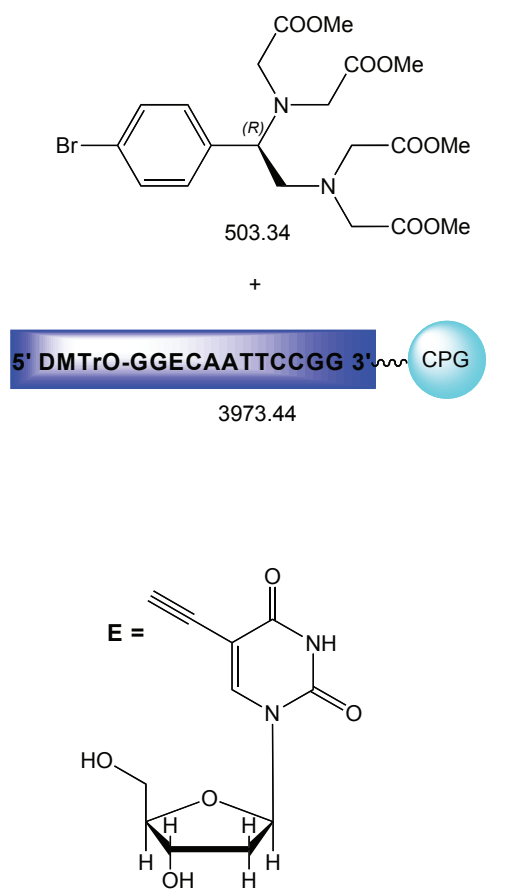

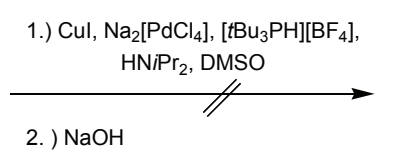

5' DMTrO-GGXCAATTCCGG 3'

2.) $\mathrm{NaOH}$ 4339.44

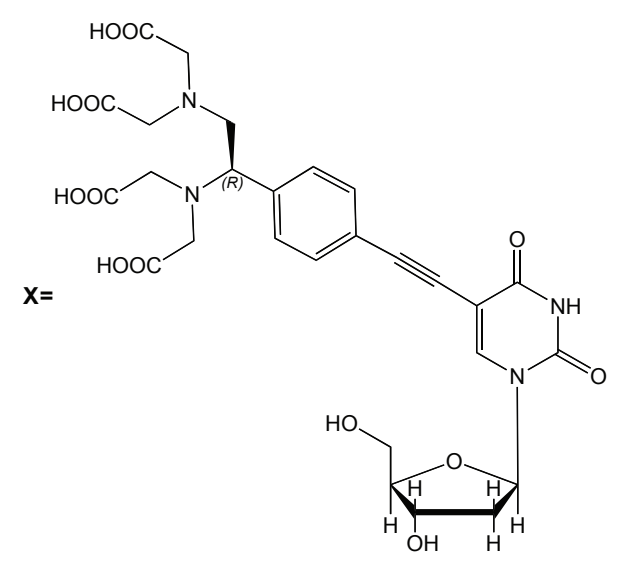

$1 \mu \mathrm{mol}$ festphasengebundenene, DMTr-geschützte DNA (35 mg) wurde unter Argonatmosphäre mit $8.1 \mathrm{mg}$ Natriumtetrachloropalladat(II) (28 $\mu \mathrm{mol}, 28$ Äq.), 4.19 mg Kupferiodid (22 $\mu \mathrm{mol}, 22$ Äq.), 12.7 mg Tri-(tert-butyl)phosphonium)-tetrafluoroborat (44 $\mu \mathrm{mol}, 44$ Äq.) und $25 \mathrm{mg}$ des Ethins (50 $\mu \mathrm{mol}, 50$ Äq.) versetzt. Nach Zugabe einer Mischung aus von $100 \mu \mathrm{l}$ Diisopropylamin $200 \mu \mathrm{l}$ Acetonitril und $200 \mu \mathrm{l}$ Dimethylsulfoxids wurde die Suspension $16 \mathrm{~h}$ bei $60{ }^{\circ} \mathrm{C}$ geschüttelt. Anschließend wurde das Reaktionsgemisch filtriert und der Rückstand je dreimal mit $100 \mu$ l Dimethylsulfoxid, Dichlormethan und Wasser gewaschen. Die festphasengebundene DNA wurde anschließend mit einer Lösung aus 0.4 M Natronlauge in Wasser/Methanol: 1/4 16 h bei Raumtemperatur geschüttelt. Die DNA-haltige Lösung wurde anschließend mit HPLC und ESI-MS analysiert. Die Retentionszeit entsprach dabei der ethindesoxyuridinhaltigen DNA und im Massenspektrum wurde auch nur dessen Masse detektiert. 


\subsection{Pulssequenz des NOESY-Spektrums für die Mes- sung der DNAs in $\mathrm{D}_{2} \mathrm{O}$}

PPNOESY

Saved: Dienstag, 19. Mai 2009 18:49:18 Uhr

noesyetgp

; avance-version (00/04/28)

;2D homonuclear correlation via dipolar coupling

; dipolar coupling may be due to noe or chemical exchange.

;phase sensitive using Echo/Antiecho-TPPI gradient selection

;

;\$CLASS=HighRes

; \$DIM=2D

\$TYPE =

; \$SUBTYPE=

; \$COMMENT=

\#include <Avance.incl>

\#include <Grad.incl $>$

\#include <Delay. incl>

"p2=p1*2"

"d0=3u"

"d11=30m"

"DELTA=p16+d16+d0"

"DELTA1=p16+d16+8u"

"TAU=d8-p16-d16"

1 ze

2 d11

$3 \mathrm{~d} 1$

50u UNBLKGRAD

p1 ph1

DELTA

p2 ph2

d0

p16:gp1*EA

d16

p1 ph3

TAU

p16:gp2

d16

p1 ph4

DELTA1

p2 ph5

$4 \mathrm{u}$

p16:gp3

d16

$4 \mathrm{u}$ BLKGRAD

go $=2$ ph31

d11 mc \#0 to 2 F1EA(igrad EA, id0 \& ip1*2 \& ip31*2)

exit

ph1=0 2

$\mathrm{ph} 2=0$

ph3 $=000000000002222222222$

ph4=0 $0 \begin{array}{lllllll}0 & 2 & 2 & 3 & 3 & 1 & 1\end{array}$

ph5 $=0$

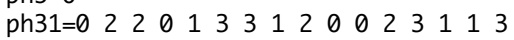




\subsection{Pulssequenz des COSY-Spektrums für die Mes- sung der DNAs in $\mathrm{D}_{2} \mathrm{O}$}

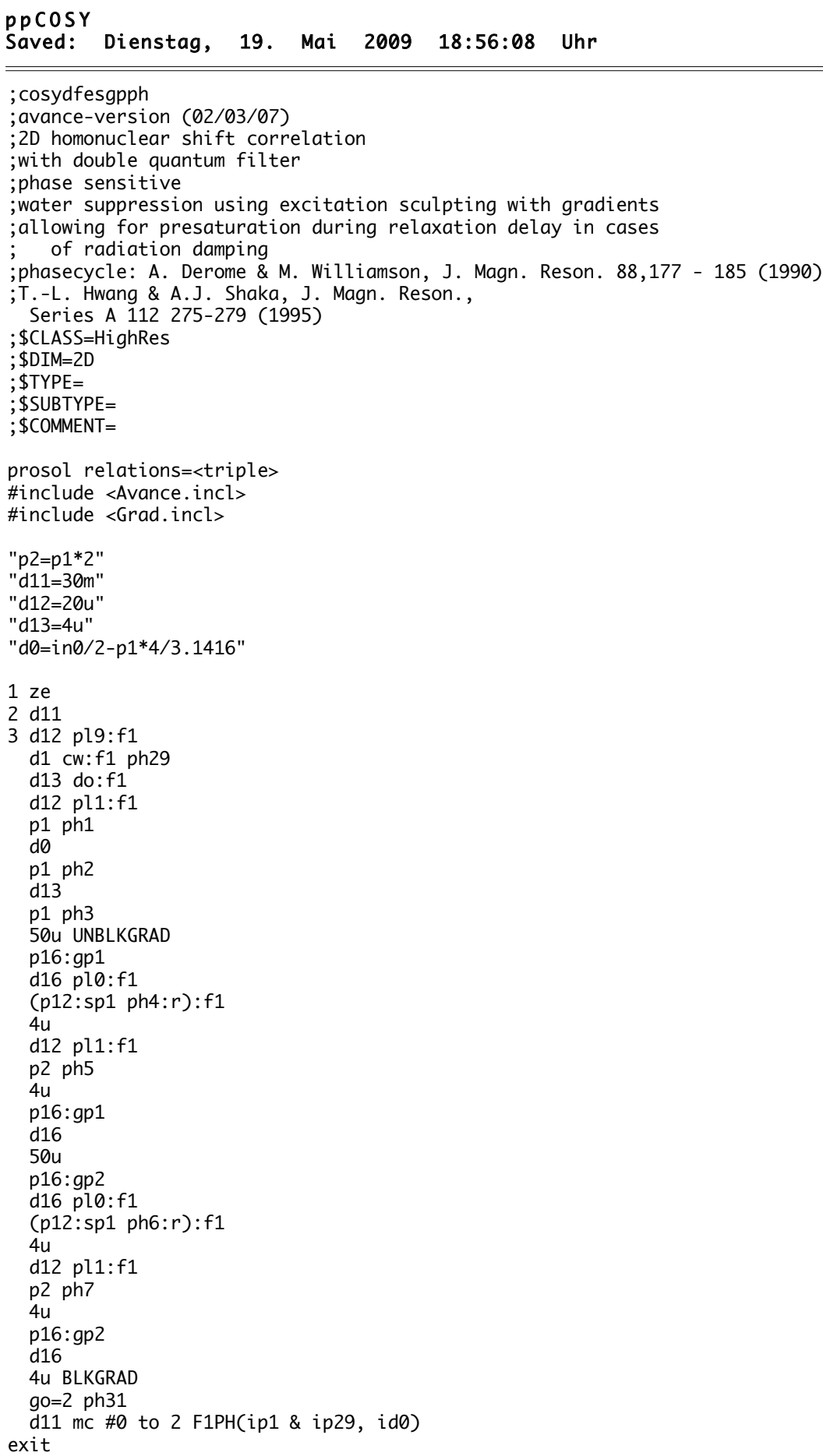


pPCOSY

Saved: Dienstag, 19. Mai 2009 18:56:08 Uhr

Page 2 of 2

ph1=1 1111111111110000000000

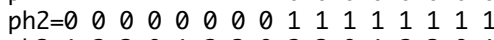

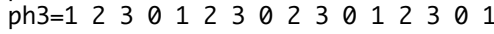

ph4=0 $00 \begin{array}{llllllllllllllllllll}0 & 0 & 1 & 1 & 1 & 1 & 1 & 1 & 1 & 1 & 2 & 2 & 2 & 2\end{array}$

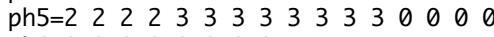

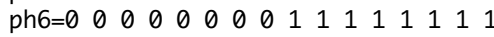

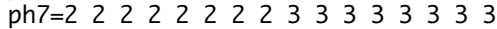

ph29=0 00000000000111111111111

ph31=0 32121210032321010032 


\subsection{Pulssequenz des TOCSY-Spektrums für die DNA- Proben in $\mathrm{D}_{2} \mathrm{O}$}

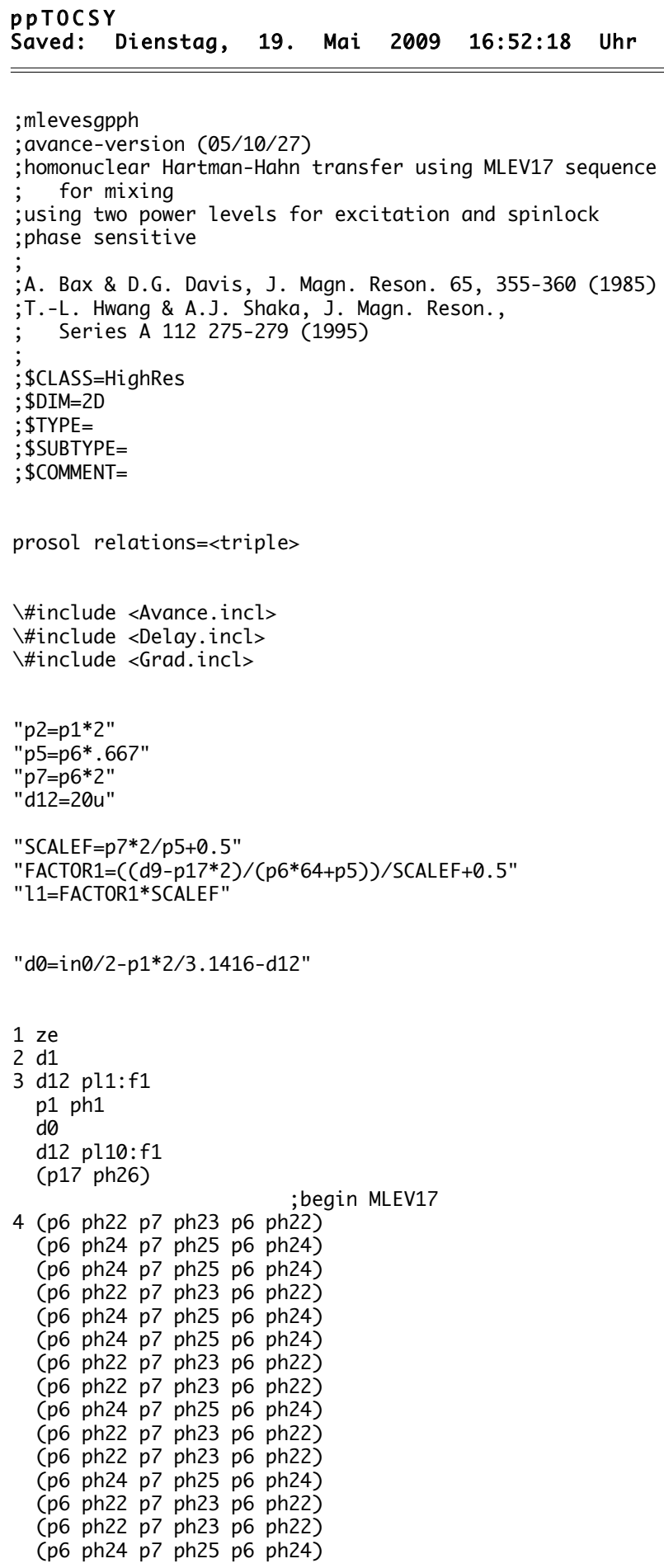




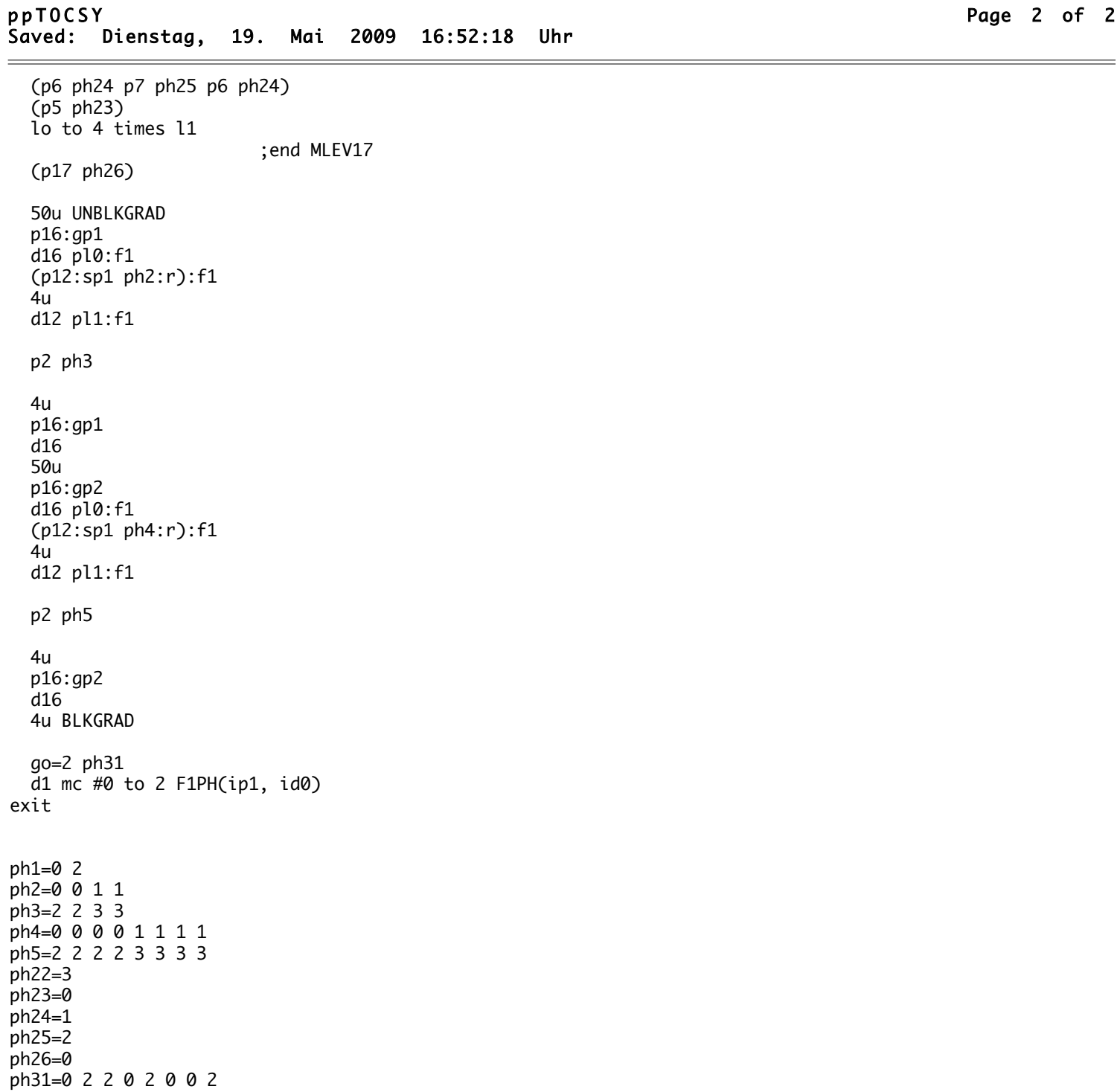




\subsection{NOESY-Pulssequenz mit watergate-Wasserunter- drückung für die Messung der Proben in $\mathrm{H}_{2} \mathrm{O}$ mit $10 \% \mathrm{D}_{2} \mathrm{O}$}

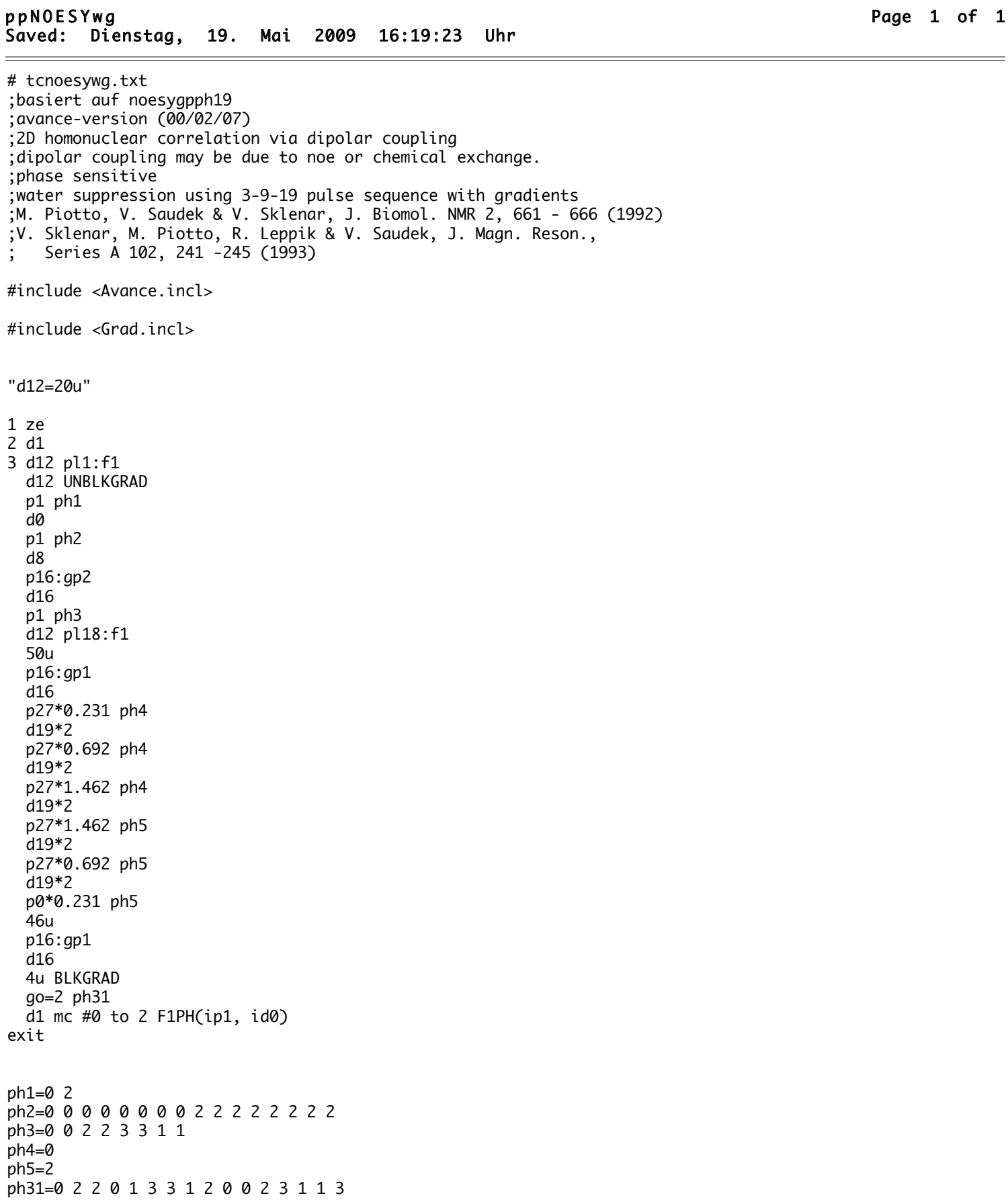




\subsection{Pulssequenz zur Messung der entkoppelten HSQCs der C1'-H1'-Kreuzsignale der gelabelten RNAs}

zuckerentkoppelt.txt

Saved: Dienstag, 19. Mai 2009 15:57:40 Uhr

Page 1 of 4

\# 1 "/opt/topspin_2.1/exp/stan/nmr/lists/pp/user/vshchsqcrdc1dec.txt"

; hsqc to measure rdc on RNA, $\mathrm{c}^{\prime}$ + $\mathrm{c5}$ resonances

\#1 "/opt/topspin_2.1/exp/stan/nmr/lists/pp/Avance.incl" 1

;Avance2.incl

; for 1

; avance-version $(07 / 08 / 21)$

;\$CLASS=HighRes Incl

; \$COMMENT=

; \$Id: Avance2.incl,v 1.17.2.1 2007/09/14 16:17:35 ber Exp \$

\# 10 "/opt/topspin_2.1/exp/stan/nmr/lists/pp/user/vshchsqcrdc1dec.txt" 2

\# 1 "/opt/topspin_2.1/exp/stan/nmr/lists/pp/Grad.incl" 1

; Grad2.incl - include file for Gradient Spectroscopy

; for 1

; avance-version $(07 / 01 / 17)$

; \$CLASS=HighRes Incl

;\$COMMENT=

define list $<$ gradient $>\mathrm{EA}=<\mathrm{EA}>$

; \$Id: Grad2. incl, v 1.12 2007/01/22 14:22:35 ber Exp \$

\# 11 "/opt/topspin_2.1/exp/stan/nmr/lists/pp/user/vshchsqcrdc1dec.txt" 2

\# 1 "/opt/topspin_2.1/exp/stan/nmr/lists/pp/Delay.incl" 1

;Delay.incl - include file for commonly used delays

; version $00 / 02 / 07$

;

; \$CLASS=HighRes Incl

; \$COMMENT=

; general delays

define delay DELTA

define delay DELTA1

define delay DELTA2

define delay DELTA3

define delay DELTA4

define delay DELTA5

define delay DELTA6

define delay DELTA7

define delay DELTA8

define delay TAU

define delay TAU1

define delay TAU2

define delay TAU3

define delay TAU4

define delay TAU5

; delays for centering pulses

define delay CEN_HN1

define delay CEN_HN2 
zuckerentkoppelt.txt

Saved: Dienstag, 19. Mai 2009 15:57:40 Uhr

define delay CEN_HN3

define delay CEN_HC1

define delay CEN_HC2

define delay CEN_HC3

define delay CEN_HC4

define delay CEN_HP1

define delay CEN_HP2

define delay CEN_CN1

define delay CEN_CN2

define delay CEN_CN3

define delay CEN_CN4

define delay CEN_CP1

define delay CEN_CP2

; loop counters

define loopcounter COUNTER

define loopcounter SCALEF

define loopcounter FACTOR1

define loopcounter FACTOR2

define loopcounter FACTOR3

;\$Id: Delay.incl,v 1.12 2005/11/10 12:16:58 ber Exp \$

\# 12 "/opt/topspin_2.1/exp/stan/nmr/lists/pp/user/vshchsqcrdc1dec.txt" 2

"p2=p1*2"

"p4=p3*2"

"p22=p21*2"

"d11=30ms"

"d12=20u"

"d0=4u" ;a shorter $d \theta$ gives too short a delay between consecutive sp

"d20=d0*2-4u"

"d4=1s/(cnst2*4)" ;172 Hz is fine for C1r and C5

"d14=d4-p16-d16-50u"

"in $0=\inf 1 / 2$ "

"CEN_HC1=p3-p1"

"CEN_CN2=(p12-p22)/2"

"CEN_HC2 $=(p 12-p 2) / 2$ " ; specific for decoupled version

\# 1 "mc_line 34 file /opt/topspin_2.1/exp/stan/nmr/lists/pp/user/vshchsqcrdc1dec.txt expanding definition $\mathrm{f}$ define delay MCWRK

define delay MCREST

define loopcounter ST1CNT

"ST1CNT = td1 / (2)"

"MCWRK $=0.333333^{*} d 1$

"MCREST $=\mathrm{d} 1-\mathrm{d} 1 "$

dccorr

\# 34 "/opt/topspin_2.1/exp/stan/nmr/lists/pp/user/vshchsqcrdc1dec.txt"

1 ze

\# 1 "mc_line 34 file /opt/topspin_2.1/exp/stan/nmr/lists/pp/user/vshchsqcrdc1dec.txt expanding definition c

\# 35 "/opt/topspin_2.1/exp/stan/nmr/lists/pp/user/vshchsqcrdc1dec.txt"

20u pl3:f3 pl12:f2

\# 1 "mc_line $36 \mathrm{file} /$ opt/topspin_2.1/exp/stan/nmr/lists/pp/user/vshchsqcrdc1dec.txt expanding start label 


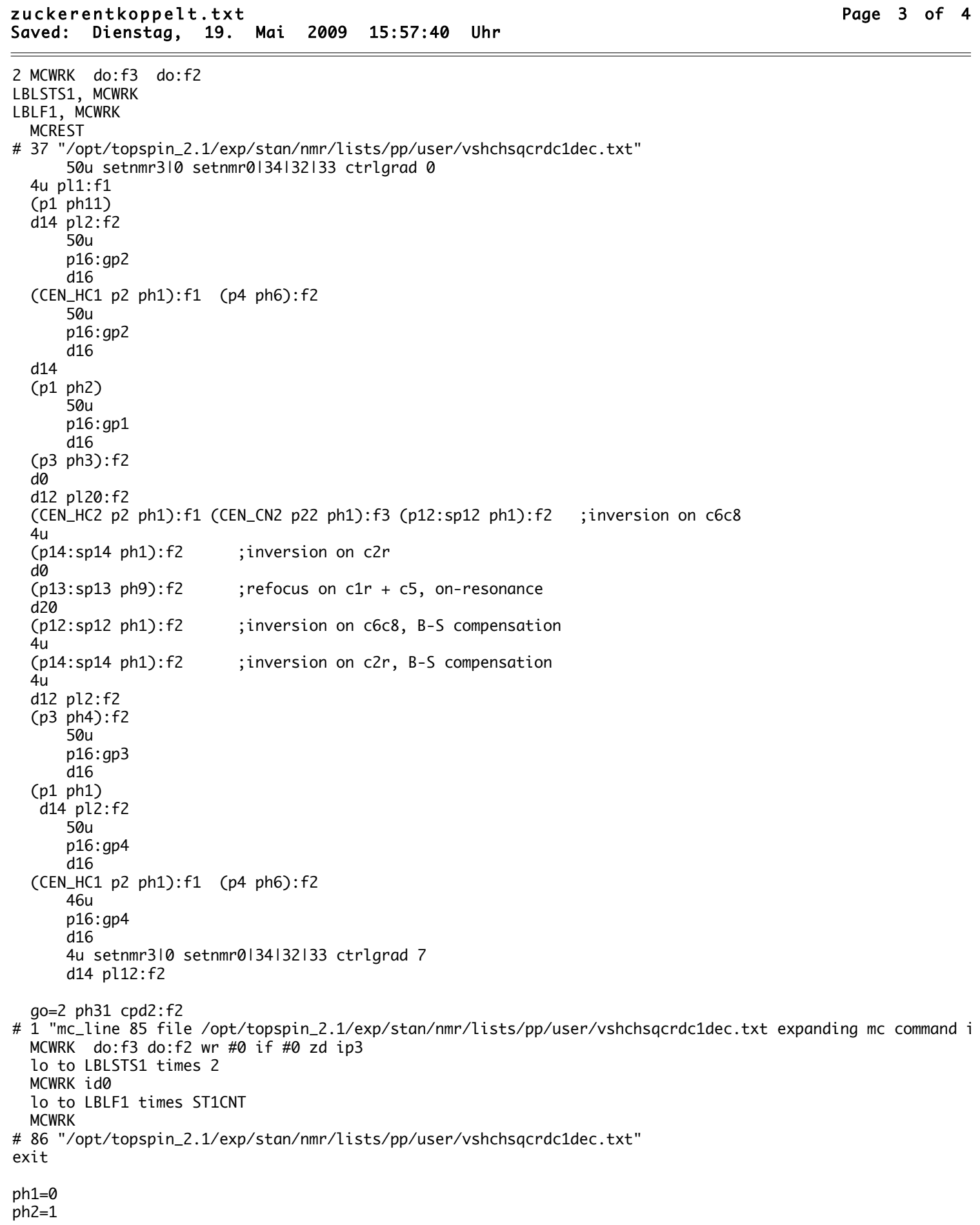


zuckerentkoppelt.txt

Saved: Dienstag, 19. Mai 2009 15:57:40 Uhr

Page 4 of 4

ph3 $=02$

ph4=0 $0 \begin{array}{lll} & 2 & 2\end{array}$

ph6 $=0$

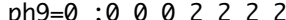

ph11=0 $0 \begin{array}{lllllllll}0 & 0 & 0 & 2 & 2 & 2\end{array}$

ph12 $=0$

ph31=0 220020002

;pl12: f2 channel - power level for CPD/BB decoupling

;pl20: f2 channel - power level (dummy) for shaped pulse

; cnst2 : J(CH) $=160-180 \mathrm{~Hz}$ for base $\mathrm{C} 6 / \mathrm{C} 8,150 \mathrm{~Hz}$ for $\mathrm{c} 1 \mathrm{r}$

; $d 4: 1 /(4 \mathrm{~J}) \mathrm{XH}$

; in0: $1 /(2 * \operatorname{SW}(X))=D W(X)$

;nd0: 2

;States-TPPI

; cpd2: GARP for this HSQC

;gradient: SINE.100

;gpz1: $45 \%$

;gpz2: $12 \%$

;gpz3: $57 \%$

;gpz4: $10 \%$

; most of the gpz can be altered because they are not related among them

; The shaped pulses allow the refocusing of the Jcc.

; The third sp hits C5 but does not do anything. It simply compensates the

; Bloch-Siegert phase shifts. Possibly, it inverts the $M$ on $C 5$, but this $M$ will not

; become detectable. 


\title{
9.10 Pulssequenz zur Messung der entkoppelten HSQCs der C8-H8- und C2-H2-Kreuzsignale der gelabelten RNAs
}

\author{
baseentkoppelt. txt \\ Saved: Dienstag, 19. Mai 2009 15:42:42 Uhr \\ Page 1 of 4
}

\# 1 "/opt/topspin_2.1/exp/stan/nmr/lists/pp/user/vshchsqcrdc2.txt"

; hsqc with watergate

\# 1 "/opt/topspin_2.1/exp/stan/nmr/lists/pp/Avance.incl" 1

;Avance2.incl

; for 1

;

; avance-version $(07 / 08 / 21)$

; \$CLASS=HighRes Incl

; \$COMMENT =

; \$Id: Avance2.incl, v 1.17.2.1 2007/09/14 16:17:35 ber Exp \$

\# 7 "/opt/topspin_2.1/exp/stan/nmr/lists/pp/user/vshchsqcrdc2.txt" 2

\# 1 "/opt/topspin_2.1/exp/stan/nmr/lists/pp/Grad.incl" 1

; Grad2.incl - include file for Gradient Spectroscopy

; for 1

; avance-version $(07 / 01 / 17)$

; \$CLASS=HighRes Incl

;\$COMMENT=

define list $<$ gradient $>E A=<E A>$

; \$Id: Grad2. incl, v 1.12 2007/01/22 14:22:35 ber Exp \$

\# 8 "/opt/topspin_2.1/exp/stan/nmr/lists/pp/user/vshchsqcrdc2.txt" 2

\# 1 "/opt/topspin_2.1/exp/stan/nmr/lists/pp/Delay.incl" 1

; Delay.incl - include file for commonly used delays

;

; version $00 / 02 / 07$

; \$CLASS=HighRes Incl

;\$COMMENT =

; general delays

define delay DELTA

define delay DELTA1

define delay DELTA2

define delay DELTA3

define delay DELTA4

define delay DELTA5

define delay DELTA6

define delay DELTA7

define delay DELTA8

define delay TAU

define delay TAU1

define delay TAU2

define delay TAU3

define delay TAU4

define delay TAU5

; delays for centering pulses

define delay CEN_HN1

define delay CEN_HN2

define delay CEN_HN3

define delay CEN_HC1

define delay CEN_HC2 
baseentkoppelt. $t$ xt

Saved: Dienstag, 19. Mai 2009 15:42:42 Uhr

define delay CEN_HC3

define delay CEN_HC4

define delay CEN_HP1

define delay CEN_HP2

define delay CEN_CN1

define delay CEN_CN2

define delay CEN_CN3

define delay CEN_CN4

define delay CEN_CP1

define delay CEN_CP2

; loop counters

define loopcounter COUNTER

define loopcounter SCALEF

define loopcounter FACTOR1

define loopcounter FACTOR2

define loopcounter FACTOR3

;\$Id: Delay.incl,v 1.12 2005/11/10 12:16:58 ber Exp \$

\# 9 "/opt/topspin_2.1/exp/stan/nmr/lists/pp/user/vshchsqcrdc2.txt" 2

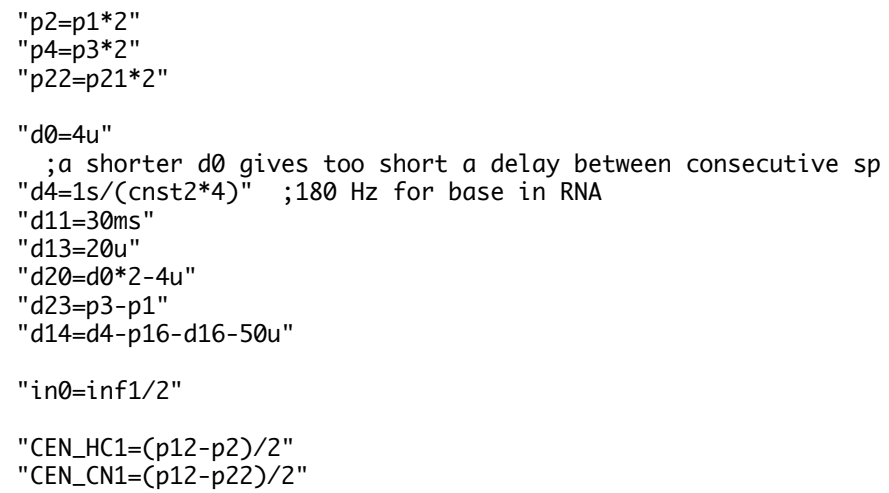

\# 1 "mc_line $30 \mathrm{file} /$ opt/topspin_2.1/exp/stan/nmr/lists/pp/user/vshchsqcrdc2.txt expanding definition part define delay MCWRK

define delay MCREST

define loopcounter ST1CNT

"ST1CNT = td1 / (2)"

"MCWRK $=0.333333^{*} d 11 "$

"MCREST $=\mathrm{d} 11-\mathrm{d} 11 "$

dccorr

\# 30 "/opt/topspin_2.1/exp/stan/nmr/lists/pp/user/vshchsqcrdc2.txt"

1 ze

\# 1 "mc_line $30 \mathrm{file} /$ opt/topspin_2.1/exp/stan/nmr/lists/pp/user/vshchsqcrdc2.txt expanding definition of n

\# 31 "/opt/topspin_2.1/exp/stan/nmr/lists/pp/user/vshchsqcrdc2.txt"

20u pl12:f2 ; pl3:f3

\# 1 "mc_line 32 file /opt/topspin_2.1/exp/stan/nmr/lists/pp/user/vshchsqcrdc2.txt expanding start label for 2 MCWRK do:f2

LBLSTS1, MCWRK

LBLF1, MCWRK

MCREST 


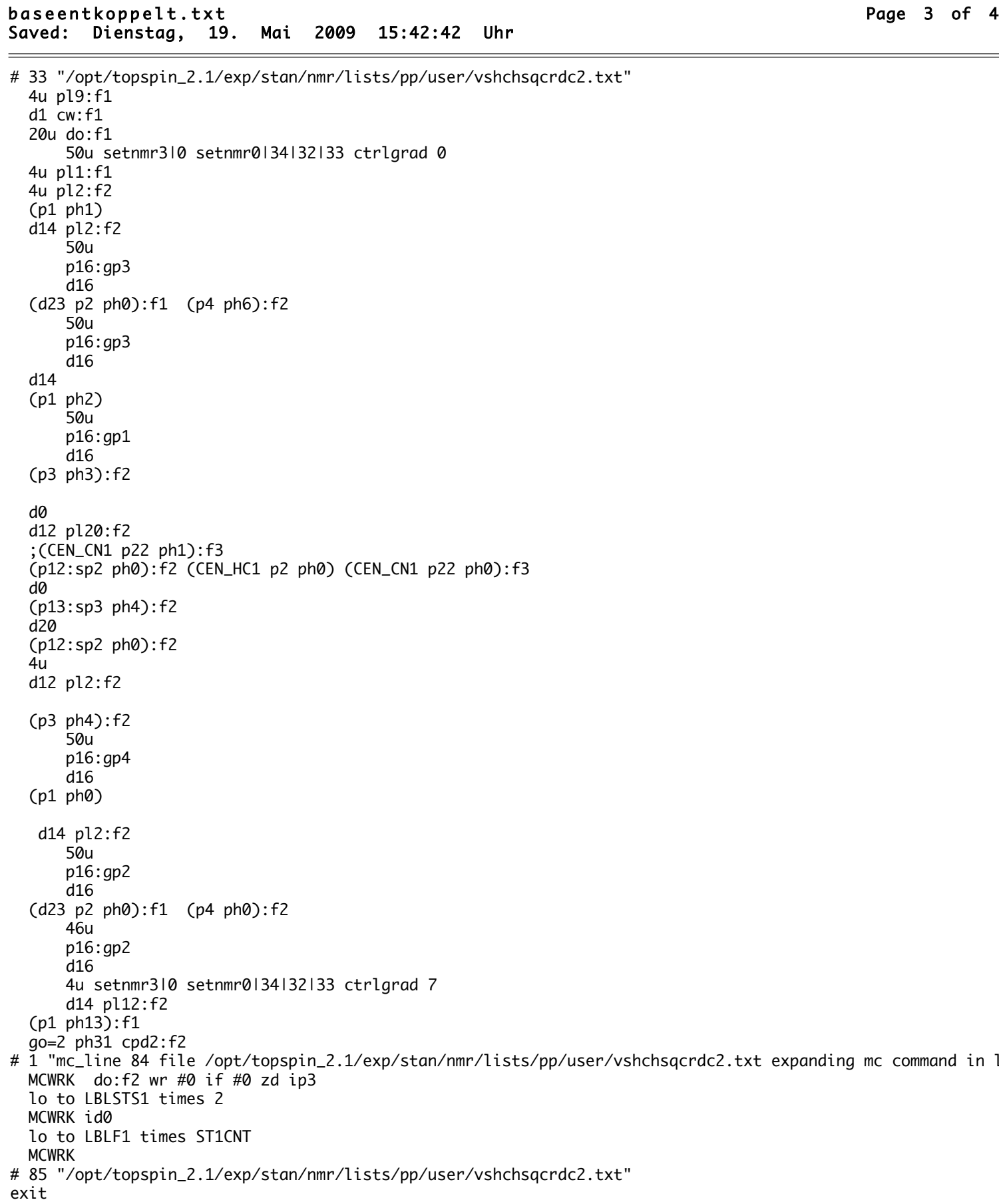


baseentkoppelt.txt

Saved: Dienstag, 19. Mai 2009 15:42:42 Uhr

$\mathrm{ph} \theta=0$

ph1=0 0000022222

ph2 $=1$

ph3 $=02$

ph4=0 $0 \begin{array}{lll}0 & 2 & 2\end{array}$

ph6 $=0$

ph12=0

ph13=2

ph31=0 2220020002

;pl1 : f1 channel - power level for pulse (default)

;pl2 : f2 channel - power level for pulse (default)

;pl12: f2 channel - power level for CPD/BB decoupling

;p1 : f1 channel - 90 degree high power pulse

;p2 : f1 channel - 180 degree high power pulse

;p3 : f2 channel - 90 degree high power pulse

;p4 : f2 channel - 180 degree high power pulse

;p16: homospoil/gradient pulse

; cnst2 : $\mathrm{J}(\mathrm{CH})=160 \mathrm{~Hz}$ for base $\mathrm{C} 6 / \mathrm{C} 8$

;d0 : incremented delay (2D)

[3 usec]

;d1 : relaxation delay; $1-5 * \mathrm{~T} 1$

;d4 : 1/(4J)XH

d11: delay for disk I / 0

;d13: short delay (e.g. to compensate delay line) [3 usec]

;d16: delay for homospoil/gradient recovery

; d24: 1/(4J)XH for XH

1/(6J)XH for all multiplicities

in0: $1 /(2 * \operatorname{SW}(X))=D W(X)$

;nd0: 2

;States-TPPI

; cpd2: decoupling according to sequence defined by cpdprg2 [GARP for this HSQC]

; gradient: $\sin .100$

;gpz1: $50 \%$

;gpz2: $20 \%$

;gpz3: $15 \%$

;gpz4: $40 \%$

;most of the gpz can be altered because they are not related among them 


\subsection{Pulssequenz zur Messung der in $t_{2}$-gekoppelten HSQCs der C1'-H1'-Kreuzsignale der gelabelten RNAs}

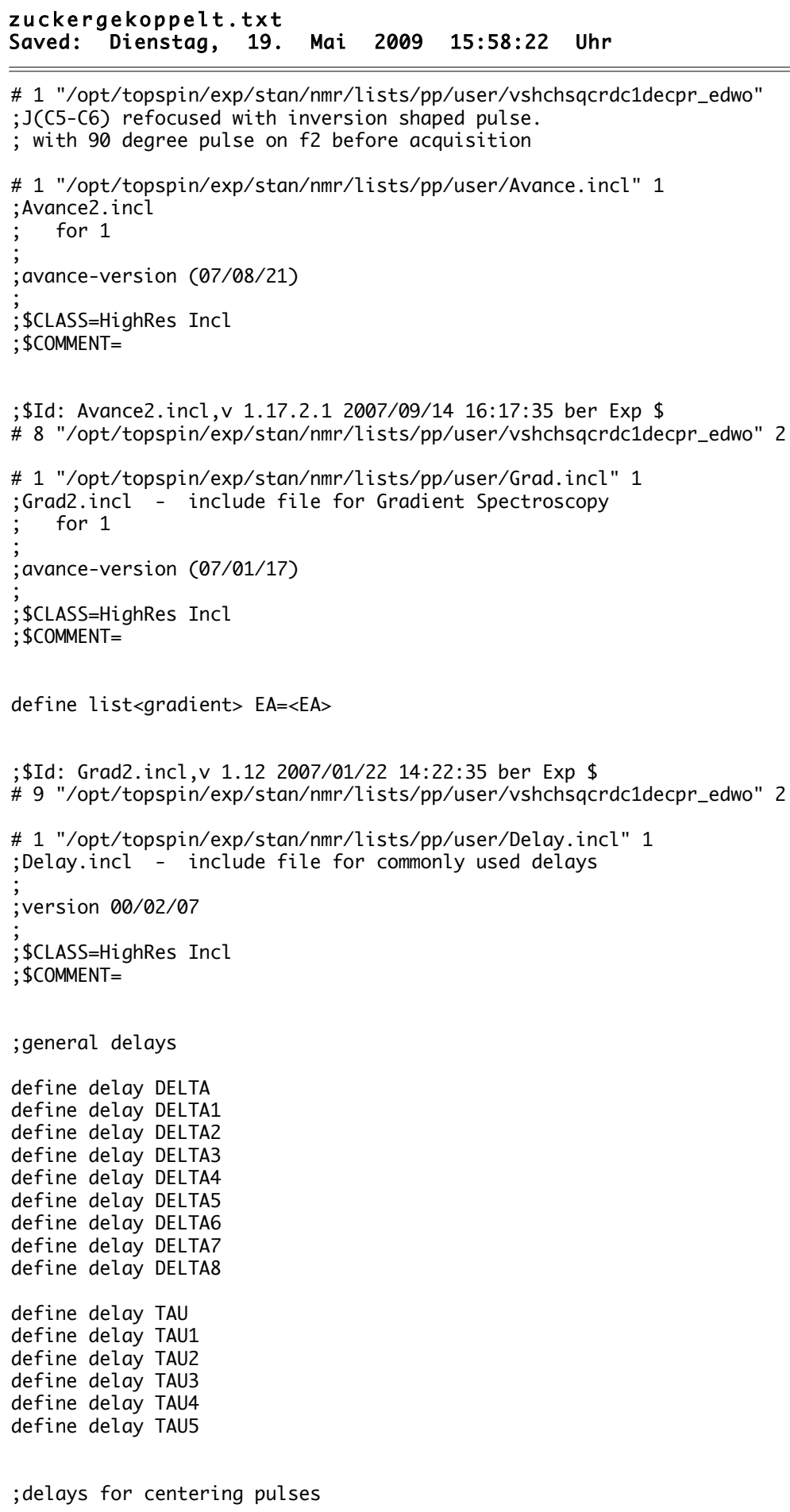


zuckergekoppelt.txt

Saved: Dienstag, 19. Mai 2009 15:58:22 Uhr

define delay CEN_HN1

define delay CEN_HN2

define delay CEN_HN3

define delay CEN_HC1

define delay CEN_HC2

define delay CEN_HC3

define delay CEN_HC4

define delay CEN_HP1

define delay CEN_HP2

define delay CEN_CN1

define delay CEN_CN2

define delay CEN_CN3

define delay CEN_CN4

define delay CEN_CP1

define delay CEN_CP2

; loop counters

define loopcounter COUNTER

define loopcounter SCALEF

define loopcounter FACTOR1

define loopcounter FACTOR2

define loopcounter FACTOR3

;\$Id: Delay.incl,v 1.12 2005/11/10 12:16:58 ber Exp \$

\# 10 "/opt/topspin/exp/stan/nmr/lists/pp/user/vshchsqcrdc1decpr_edwo" 2

"p2=p1*2"

"p4=p3*2"

"p22=p21*2"

"in $0=$ inf1/2"

"d0=4u"

"d4=1s/(cnst $2 * 4) "$

"d11=30ms"

"d12=20u"

"d20 $=d \theta * 2-4 u "$

"d23=p3-p1

"d14=d4-p16-d16-50u"

"CEN_CN1 $=(p 12-p 22) / 2 "$

"CEN_HC1=(p12-p2)/2" ; specific for decoupled version

\# 1 "mc_line 31 file/opt/topspin/exp/stan/nmr/lists/pp/user/vshchsqcrdc1decpr_edwo expanding definition pc define delay MCWRK

define delay MCREST

define loopcounter ST1CNT

"ST1CNT = td1 / (2)"

"MCWRK $=0.333333^{*} d 11 "$

"MCREST = d11 - d11"

$$
\text { dccorr }
$$

\# 31 "/opt/topspin/exp/stan/nmr/lists/pp/user/vshchsqcrdc1decpr_edwo"

$1 \mathrm{ze}$

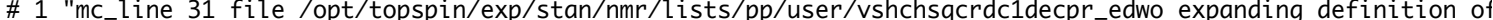
\# 32 "/opt/topspin/exp/stan/nmr/lists/pp/user/vshchsqcrdc1decpr_edwo"

20u pl3:f3 ;pl12:f2

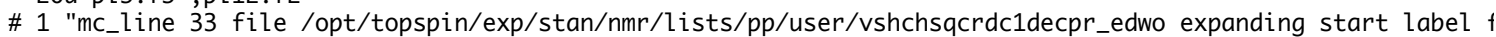

2 MCWRK do:f3 do:f2

LBLSTS1, MCWRK

LBLF1, MCWRK 
zuckergekoppelt.txt

Saved: Dienstag, 19. Mai 2009 15:58:22 Uhr

MCREST

\# 34 "/opt/topspin/exp/stan/nmr/lists/pp/user/vshchsqcrdc1decpr_edwo"

20u pl9:f1

d1 $\mathrm{cw}: \mathrm{f1}$

20u do:f1

$50 u$ setnmr310 setnmr0|34|32|33 ctrlgrad 0

4u pl1:f1

(p1 ph1)

p16:gp3

d16

(d23 p2 ph1):f1 (p4 ph6):f2

$50 \mathrm{u}$

p16:gp3

d14

d16

(p1 ph2)

p16:gp1

p16:g

(p3 ph3):f2

d0

d12 pl20:f2

(CEN_HC1 p2 ph1):f1 (CEN_CN1 p22 ph1):f3 (p12:sp2 ph1):f2

$4 \mathrm{u}$

(p14:sp4 ph1):f2

d0

(p13:sp3 ph4):f2

d20

(p12:sp2 ph1):f2

$4 \mathrm{u}$

(p14:sp4 ph1):f2

d12 pl2:f2

(p3 ph4):f2

$50 \mathrm{u}$

p16:gp4

d16

(p1 ph1)

d14 pl2:f2

$50 \mathrm{u}$

p16:gp2

d16

(d23 p2 ph1):f1 (p4 ph6):f2

$46 \mathrm{u}$

p16:gp2

d16

4u setnmr310 setnmr0|34|32|33 ctrlgrad 7

d14 ;pl12:f2

(p3 ph1):f2

go=2 ph31; cpd2:f2

\# 1 "mc_line $89 \mathrm{file} /$ opt/topspin/exp/stan/nmr/lists/pp/user/vshchsqcrdc1decpr_edwo expanding mc command ir

MCWRK do:f3 do:f2 wr \#0 if \#0 zd ip3

lo to LBLSTS1 times 2

MCWRK idO

lo to LBLF1 times ST1CNT

MCWRK

\# 90 "/opt/topspin/exp/stan/nmr/lists/pp/user/vshchsqcrdc1decpr_edwo" 
zuckergekoppelt.txt

Saved: Dienstag, 19. Mai 2009 15:58:22 Uhr

exit

ph1 $=0$

ph $2=1$

ph3 $=02$

ph4=0 $0 \begin{array}{lll}0 & 2 & 2\end{array}$

ph $6=0$

ph12=0

ph31=0 2220

;pl1 : f1 channel - power level for pulse (default)

;pl2 : f2 channel - power level for pulse (default)

;pl12: f2 channel - power level for CPD/BB decoupling

;p1 : f1 channel - 90 degree high power pulse

;p2 : f1 channel - 180 degree high power pulse

;p3 : f2 channel - 90 degree high power pulse

;p4 : f2 channel - 180 degree high power pulse

;p16: homospoil/gradient pulse

; cnst2 : $\mathrm{J}(\mathrm{CH})=160 \mathrm{~Hz}$ for base $\mathrm{C} 6 / \mathrm{C} 8$

;d0 : incremented delay (2D)

; d1 : relaxation delay; $1-5 * \mathrm{~T} 1$

;d4 : 1/(4J)XH

;d11: delay for disk I / 0

[3 usec]

;d16: delay for homospoil/gradient recovery

[30 ms]

; d24: $1 /(4 \mathrm{~J}) \mathrm{XH}$ for $\mathrm{XH}$

; $1 /(6 \mathrm{~J}) \mathrm{XH}$ for all multiplicities

; in $0: 1 /(2 * \operatorname{SW}(X))=\operatorname{DW}(X)$

;nd0: 2

States-TPPI

;cpd2: decoupling according to sequence defined by cpdprg2$$
\text { [GARP for this HSQC] }
$$

;gradient: sin.100

;gpz1: $40 \%$

;gpz2: $30 \%$

;gpz3: $25 \%$

;gpz4: $50 \%$

; most of the gpz can be altered because they are not related among them 


\subsection{Pulssequenz zur Messung der in $t_{2}$-gekoppelten HSQCs der C8-H8- und C2-H2-Kreuzsignale der gelabelten RNAs}

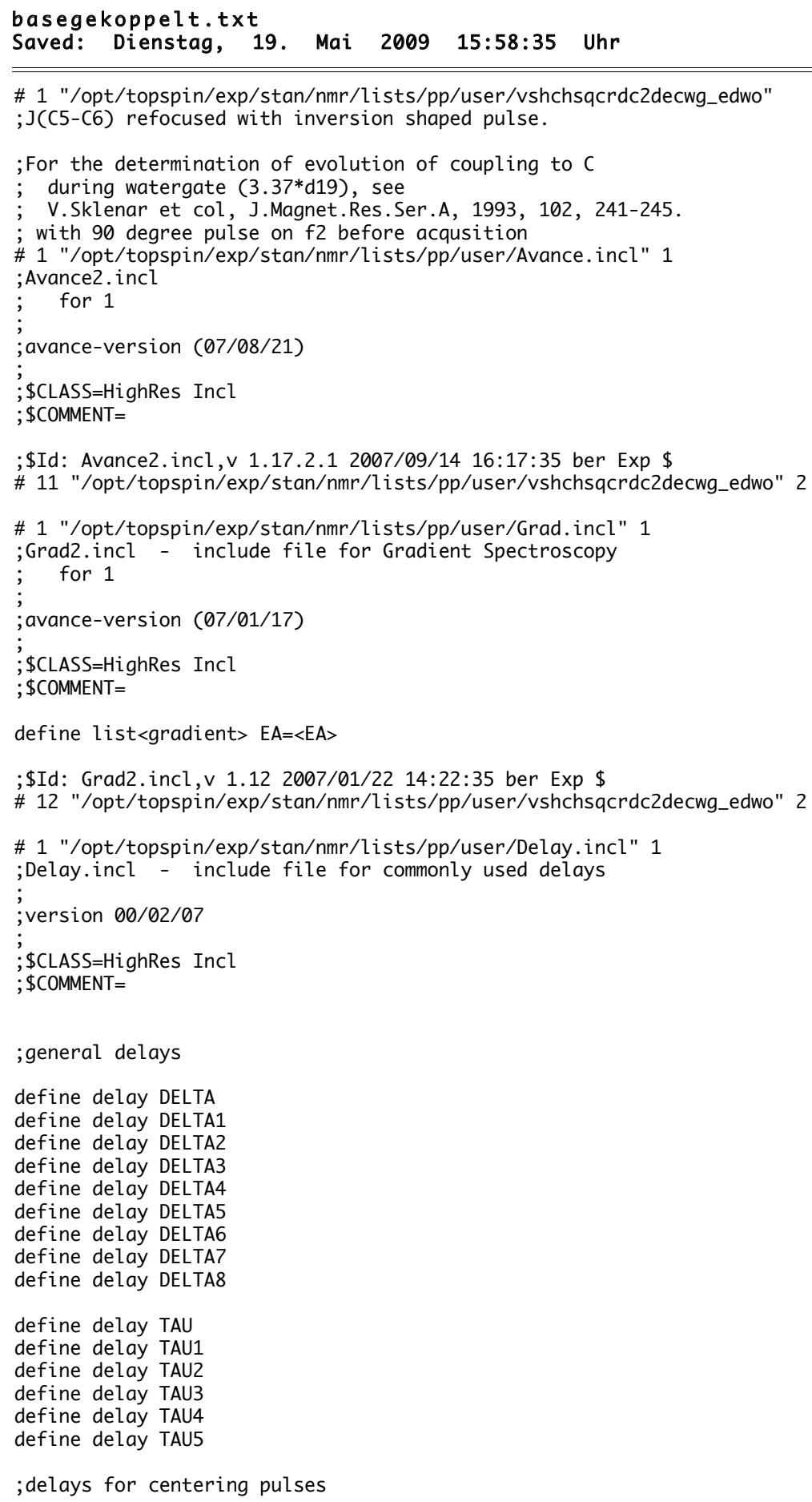


basegekoppelt.txt

Saved: Dienstag, 19. Mai 2009 15:58:35 Uhr

define delay CEN_HN1 define delay CEN_HN2 define delay CEN_HN3

define delay CEN_HC1

define delay CEN_HC2

define delay CEN_HC3

define delay CEN_HC4

define delay CEN_HP1

define delay CEN_HP2

define delay CEN_CN1

define delay CEN_CN2

define delay CEN_CN3

define delay CEN_CN4

define delay CEN_CP1

define delay CEN_CP2

; loop counters

define loopcounter COUNTER

define loopcounter SCALEF

define loopcounter FACTOR1

define loopcounter FACTOR2

define loopcounter FACTOR3

;\$Id: Delay.incl,v 1.12 2005/11/10 12:16:58 ber Exp \$

\# 13 "/opt/topspin/exp/stan/nmr/lists/pp/user/vshchsqcrdc2decwg_edwo" 2

"p2=p1*2"

"p4=p3*2"

"p22=p21*2"

"in $\theta=$ inf1/2"

"d $\emptyset=4 u$ "

"d4=1s/(cnst $2 * 4) "$

"d11=30ms"

"d12=20u"

$" d 20=d 0 * 2-4 u "$

"d23=p3-p1"

"d14=d4-p16-d16-50u"

"DELTA=d19-p4/2"

"DELTA1=d4-p16-d16-d19*3.37"

"DELTA2=DELTA1-46u-4u"

"CEN_CN1 $=(\mathrm{p} 12-\mathrm{p} 22) / 2 "$

"CEN_HC1 $=(p 12-p 2) / 2 " \quad$; specific for decoupled version

\# 1 "mc_line $37 \mathrm{file} /$ opt/topspin/exp/stan/nmr/lists/pp/user/vshchsqcrdc2decwg_edwo expanding definition pc define delay MCWRK

define delay MCREST

define loopcounter ST1CNT

"ST1CNT = td1 / (2)"

"MCWRK $=0.333333 * d 11 "$

"MCREST $=\mathrm{d} 11-\mathrm{d} 11 "$

dccorr

\# 37 "/opt/topspin/exp/stan/nmr/lists/pp/user/vshchsqcrdc2decwg_edwo"

1 ze

\# 1 "mc_line 37 file /opt/topspin/exp/stan/nmr/lists/pp/user/vshchsqcrdc2decwg_edwo expanding definition of \# 38 "/opt/topspin/exp/stan/nmr/lists/pp/user/vshchsqcrdc2decwg_edwo"

20u pl3:f3 ;pl12:f2

\# 1 "mc_line $39 \mathrm{file} /$ opt/topspin/exp/stan/nmr/lists/pp/user/vshchsqcrdc2decwg_edwo expanding start label $\uparrow$ 2 MCWRK do:f3 do:f2 


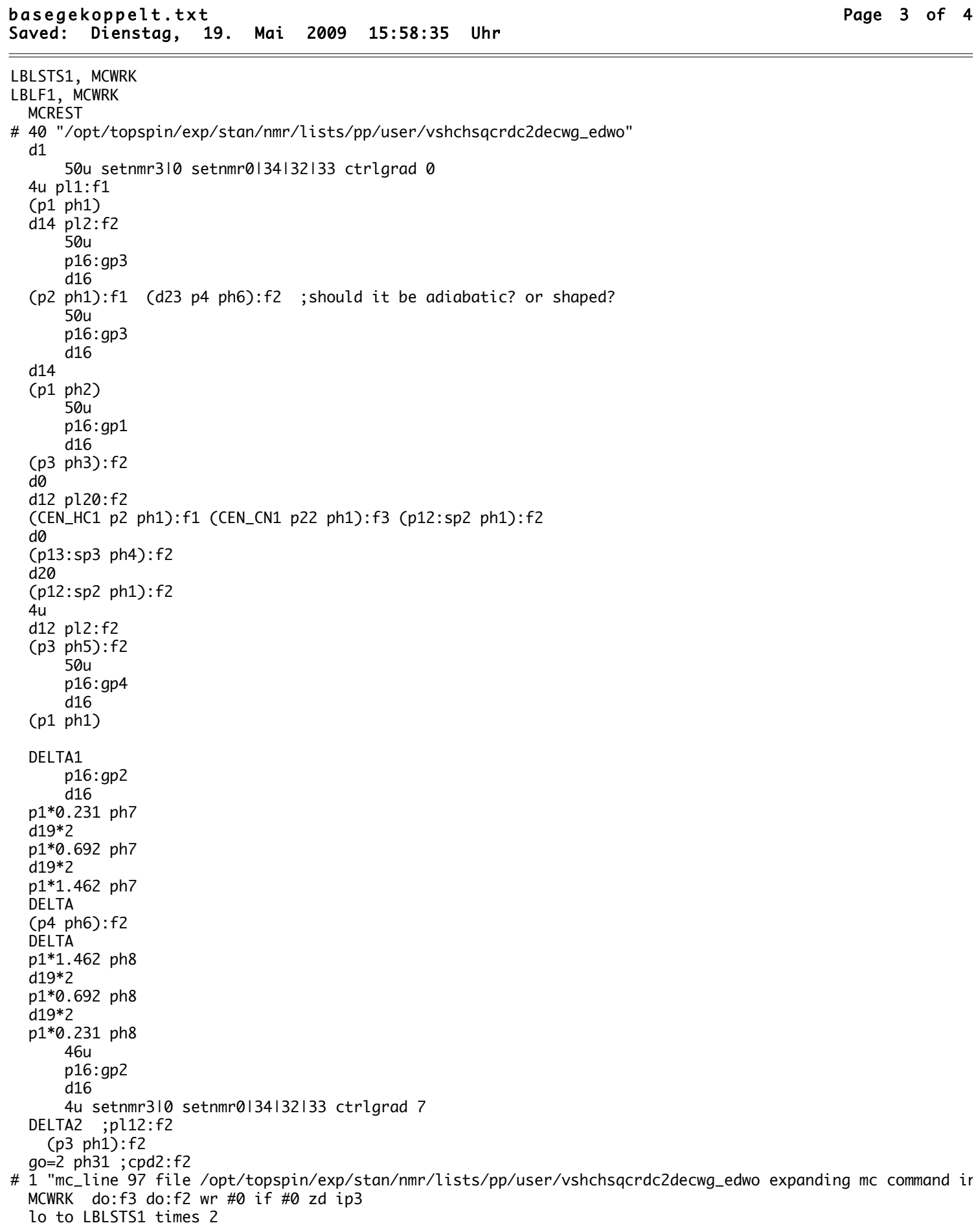

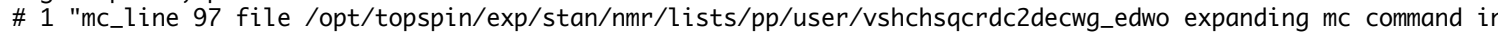
MCWRK do:f3 do:f2 wr \#0 if \#0 zd ip3

lo to LBLSTS1 times 2 
basegekoppelt.txt

Saved: Dienstag, 19. Mai 2009 15:58:35 Uhr

MCWRK idO

lo to LBLF1 times ST1CNT

MCWRK

\# 98 "/opt/topspin/exp/stan/nmr/lists/pp/user/vshchsqcrdc2decwg_edwo" exit

ph1 $=0$

ph $2=1$

ph3=0 2

ph4=0 0022

ph5=0 $0 \begin{array}{llll}0 & 2 & 2\end{array}$

ph $6=0$

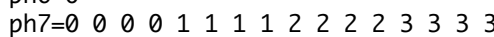

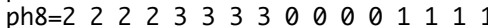

ph12=0

ph31=0 2220220002

;pl1 : f1 channel - power level for pulse (default)

;pl2 : f2 channel - power level for pulse (default)

;pl12: f2 channel - power level for CPD/BB decoupling

;p1 : f1 channel - 90 degree high power pulse

;p2 : f1 channel - 180 degree high power pulse

;p3 : f2 channel - 90 degree high power pulse

;p4 : f2 channel - 180 degree high power pulse

;p16: homospoil/gradient pulse

; cnst2 : $\mathrm{J}(\mathrm{CH})=180 \mathrm{~Hz}$ for base $\mathrm{C} 6 / \mathrm{C} 8$

;d0 : incremented delay (2D)

[3 usec]

; 11 : relaxation delay; $1-5 * \mathrm{~T} 1$

; d4:1/(4J)XH

;111: delay for disk I / 0

;d16: delay for homospoil/gradient recovery

[30 $\mathrm{ms}]$

; 24 : $1 /(4 \mathrm{~J}) \mathrm{XH}$ for $\mathrm{XH}$

; $1 /(6 \mathrm{~J}) \mathrm{XH}$ for all multiplicities

in $0: 1 /(2 * \operatorname{SW}(X))=D W(X)$

;nd0: 2

States-TPPI

; cpd2: decoupling according to sequence defined by cpdprg2 [GARP for this HSQC]

;gradient: $\sin .100$

;gpz1: $50 \%$

;gpz2: (20\%) 60\% for watergate version - try lower values

;gpz3: $15 \%$

;gpz4: $40 \%$

; most of the gpz can be altered because they are not related among them

; The shaped pulses allow the refocusing of the J-CC.

; The third $\mathrm{sp}$ hits $\mathrm{C} 5$ but does not do anything.

; Simply compensates the Bloch-Siegert phase shifts. Possibly, it inverts

; the $M$ on $C 5$, but this $M$ will not become detectable. 


\subsection{CNS-Skripte und Tabellen}
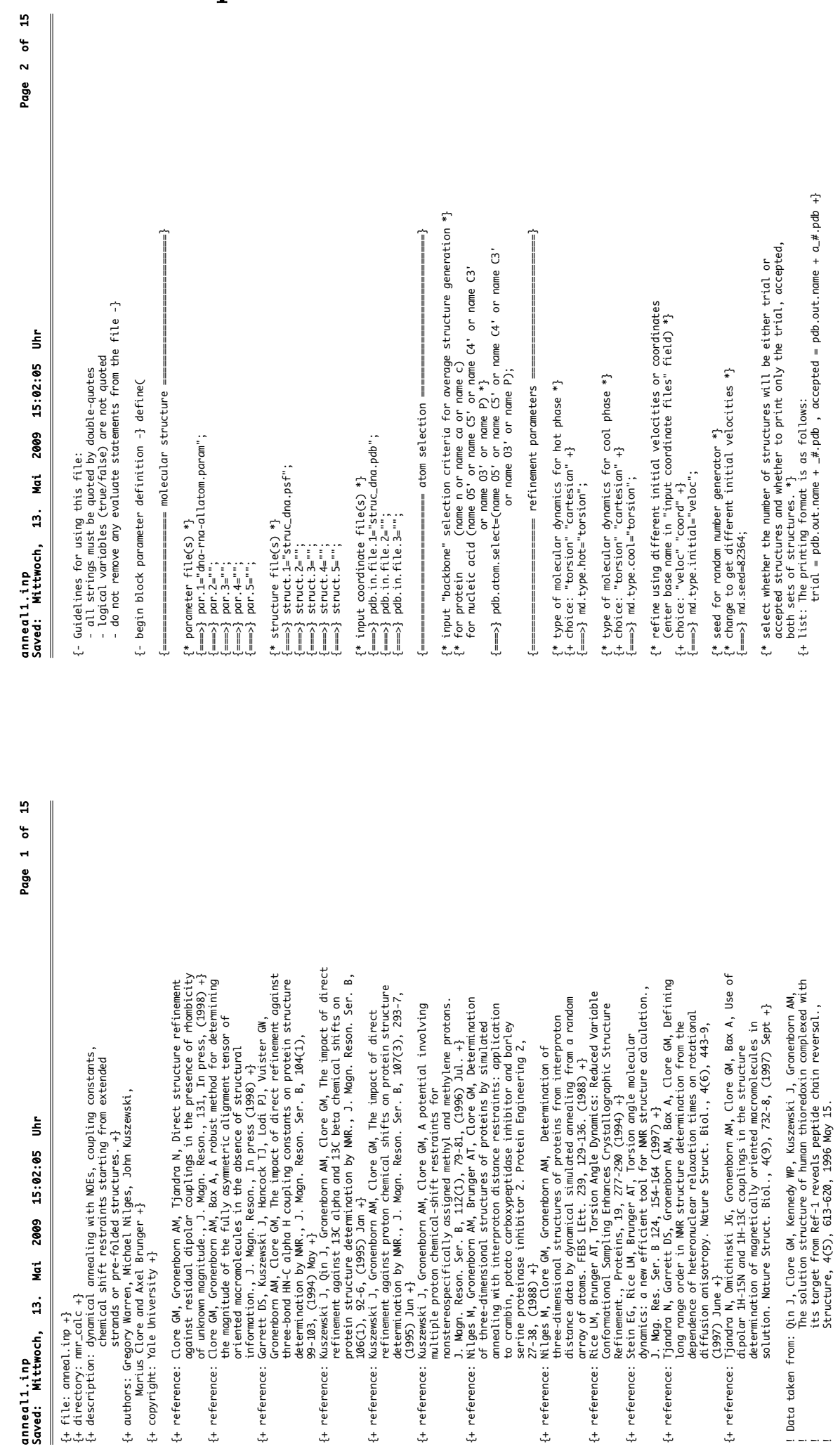

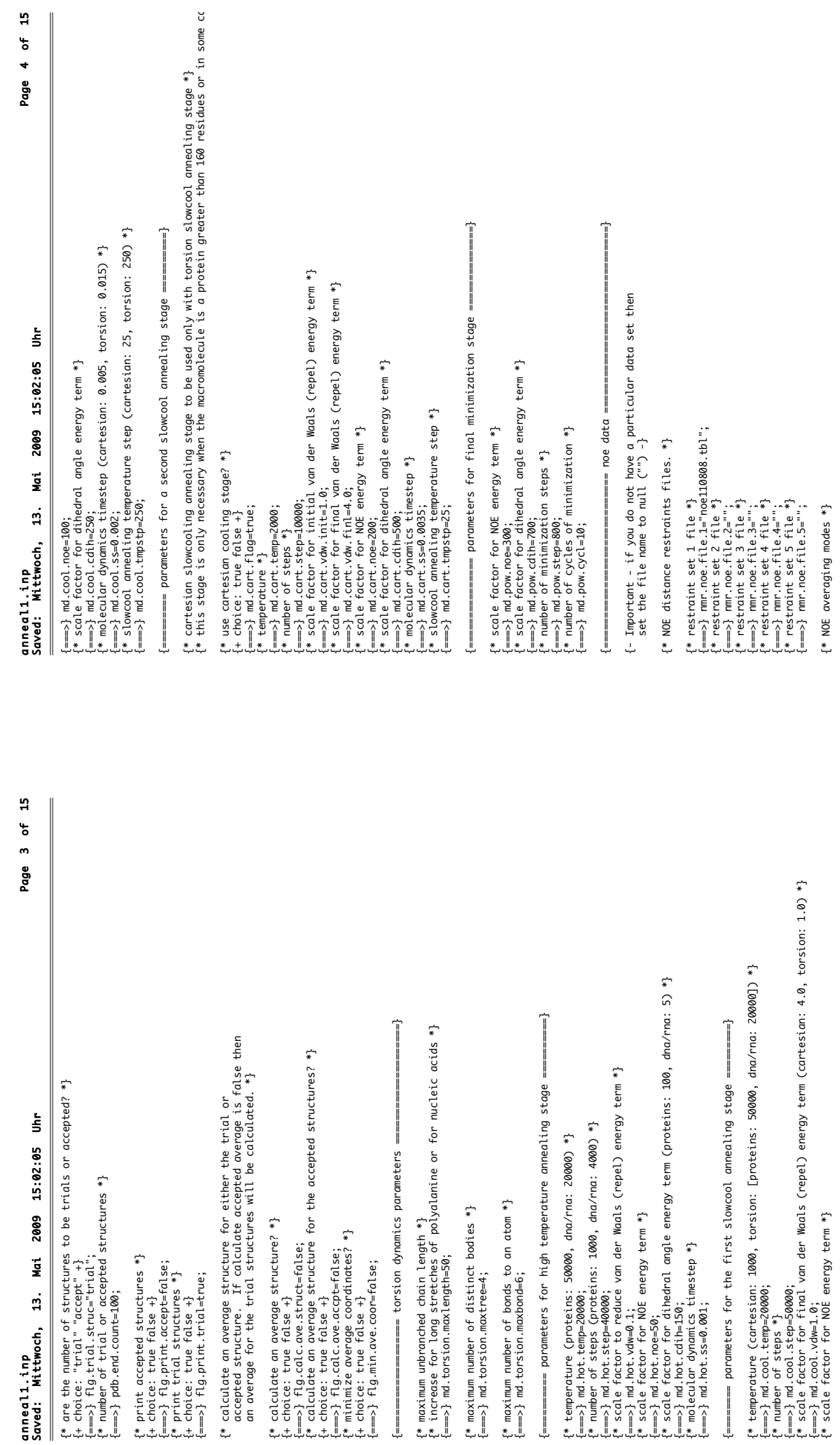

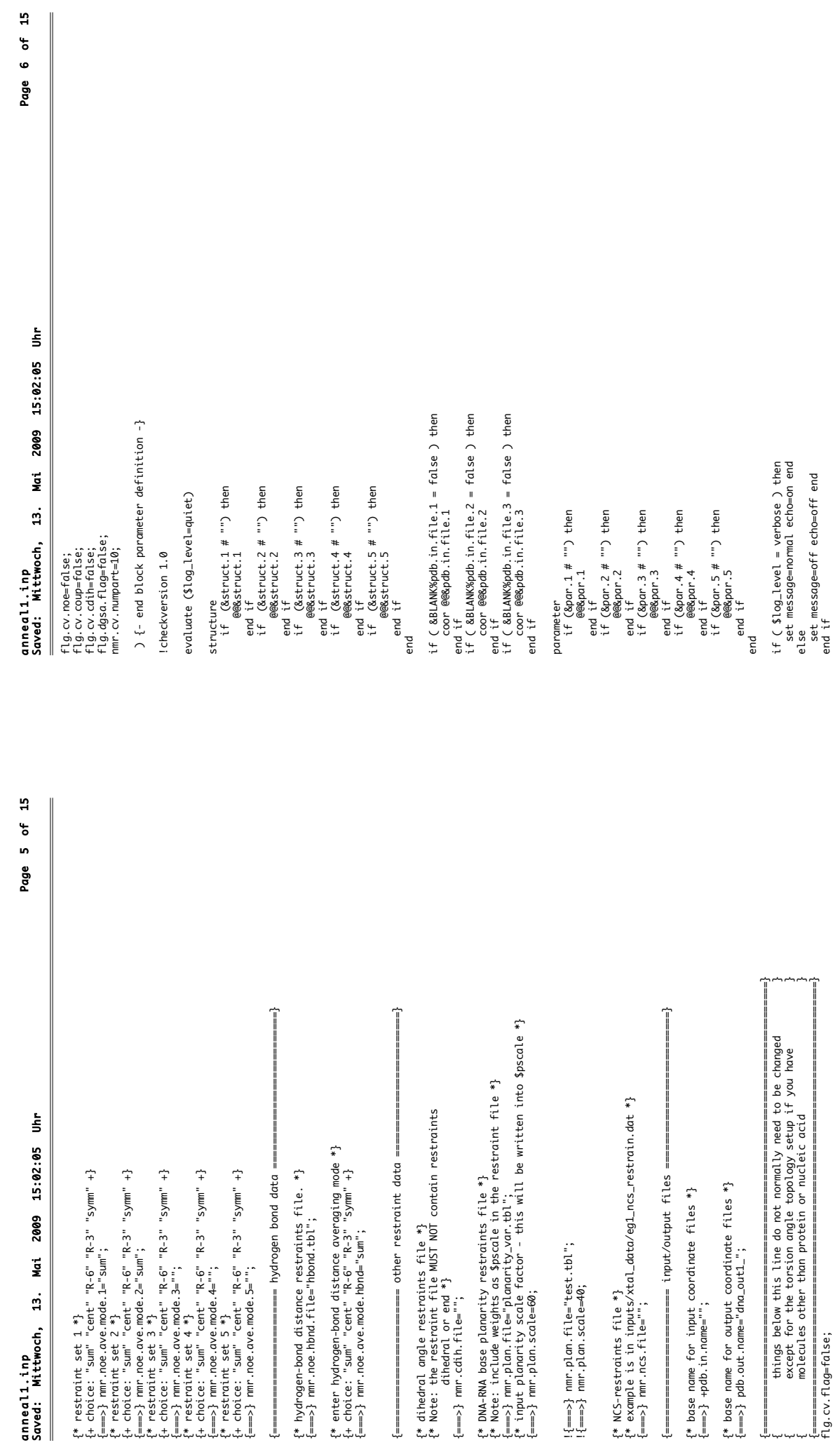

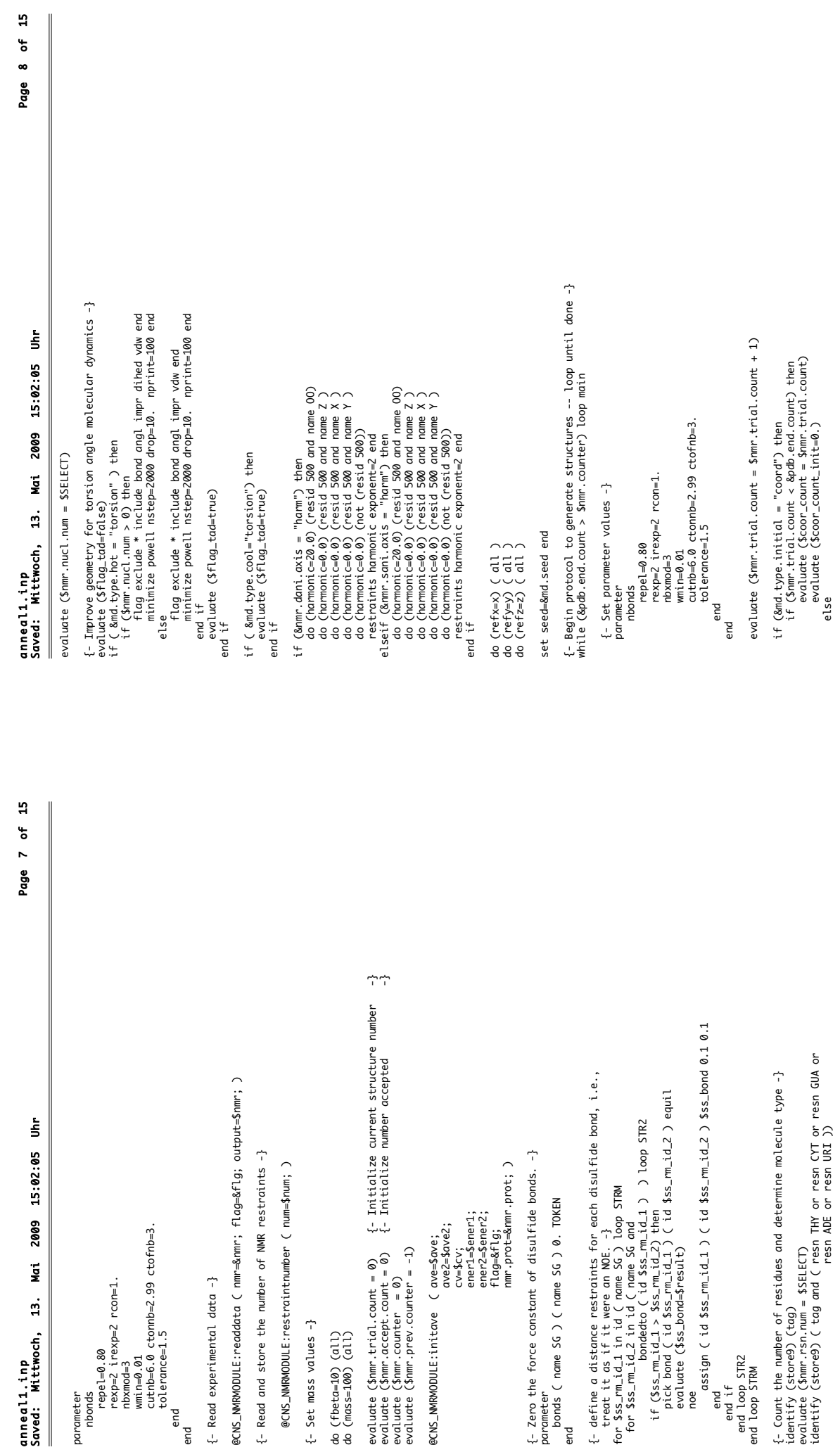

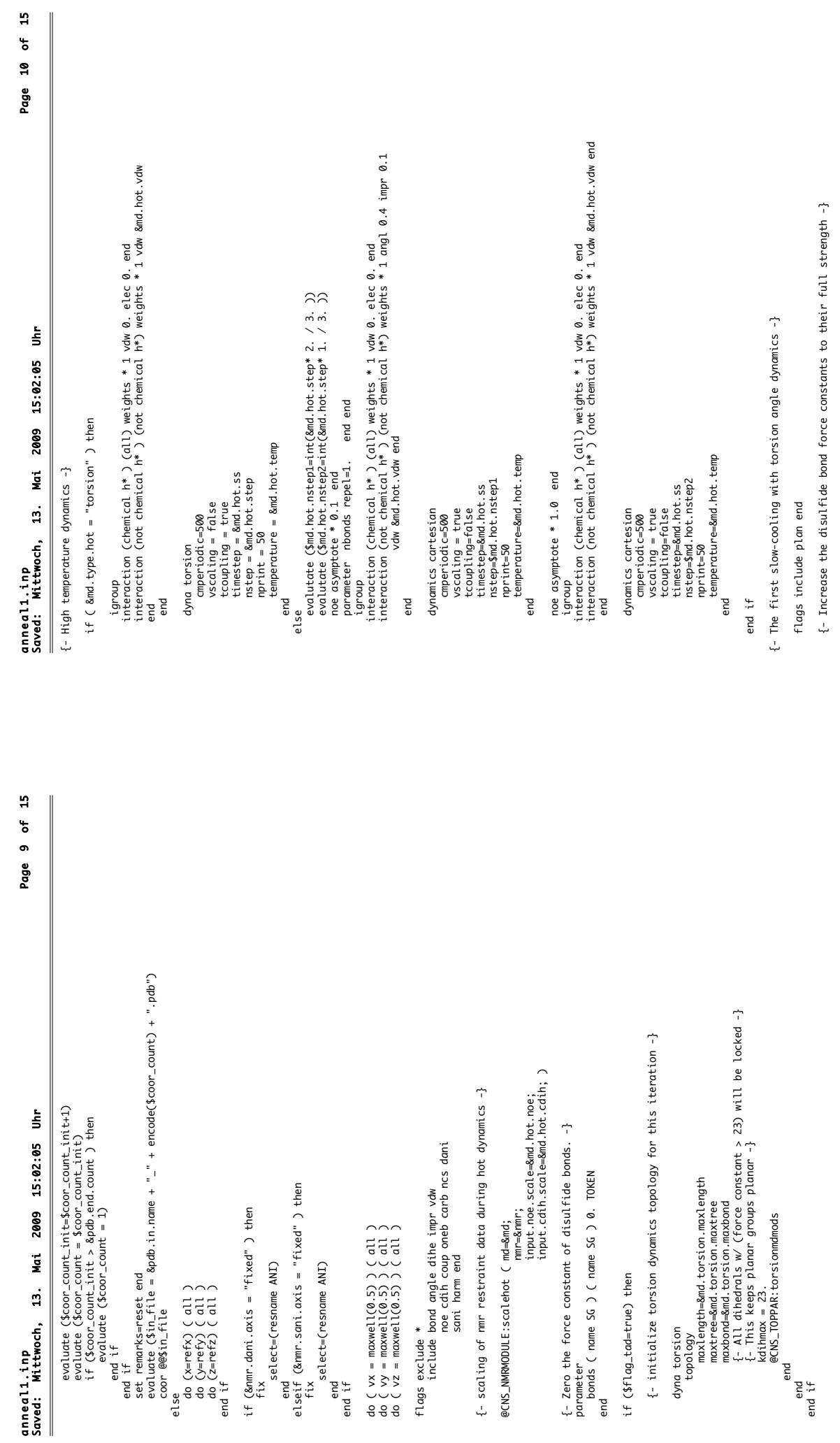

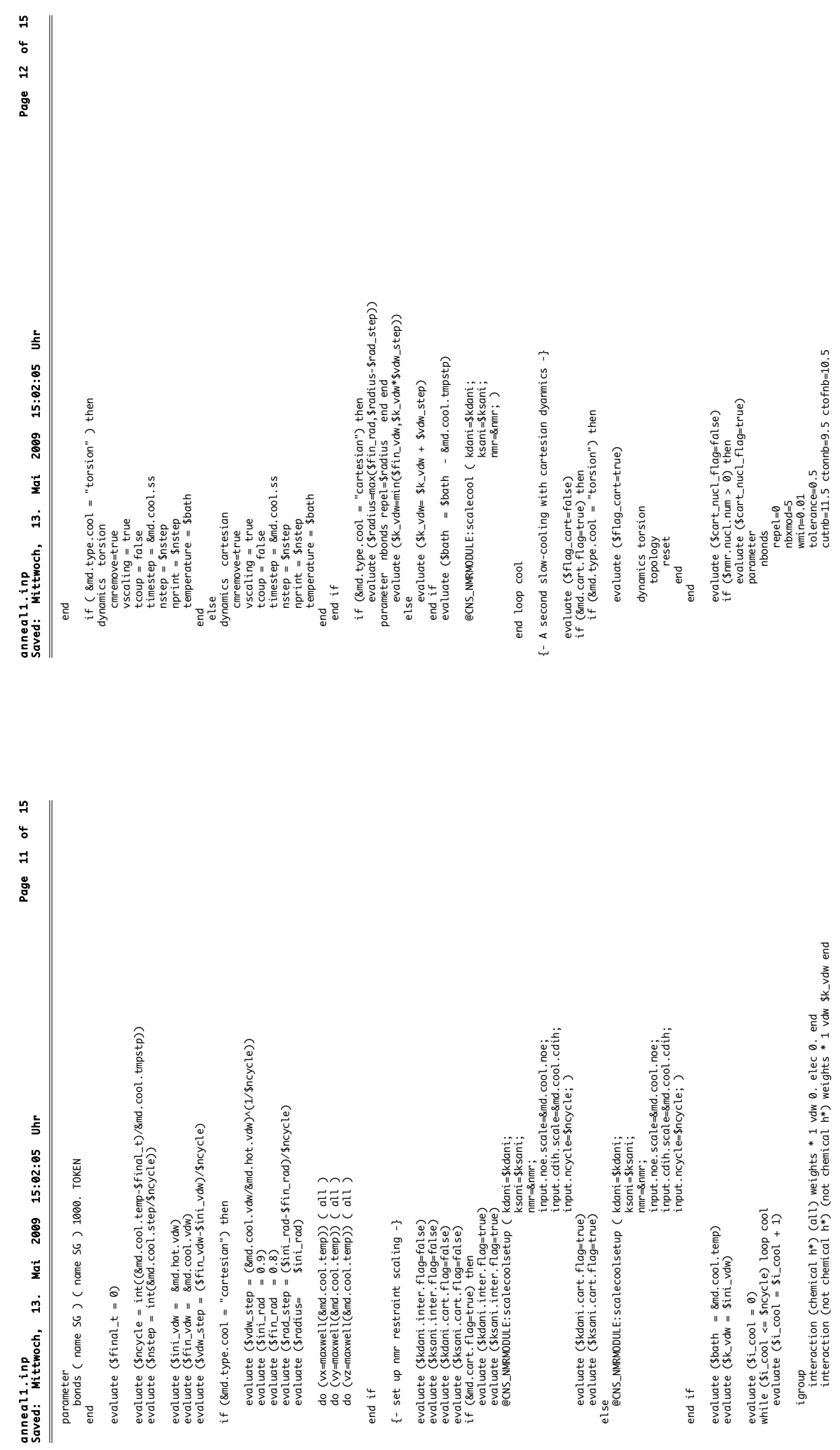

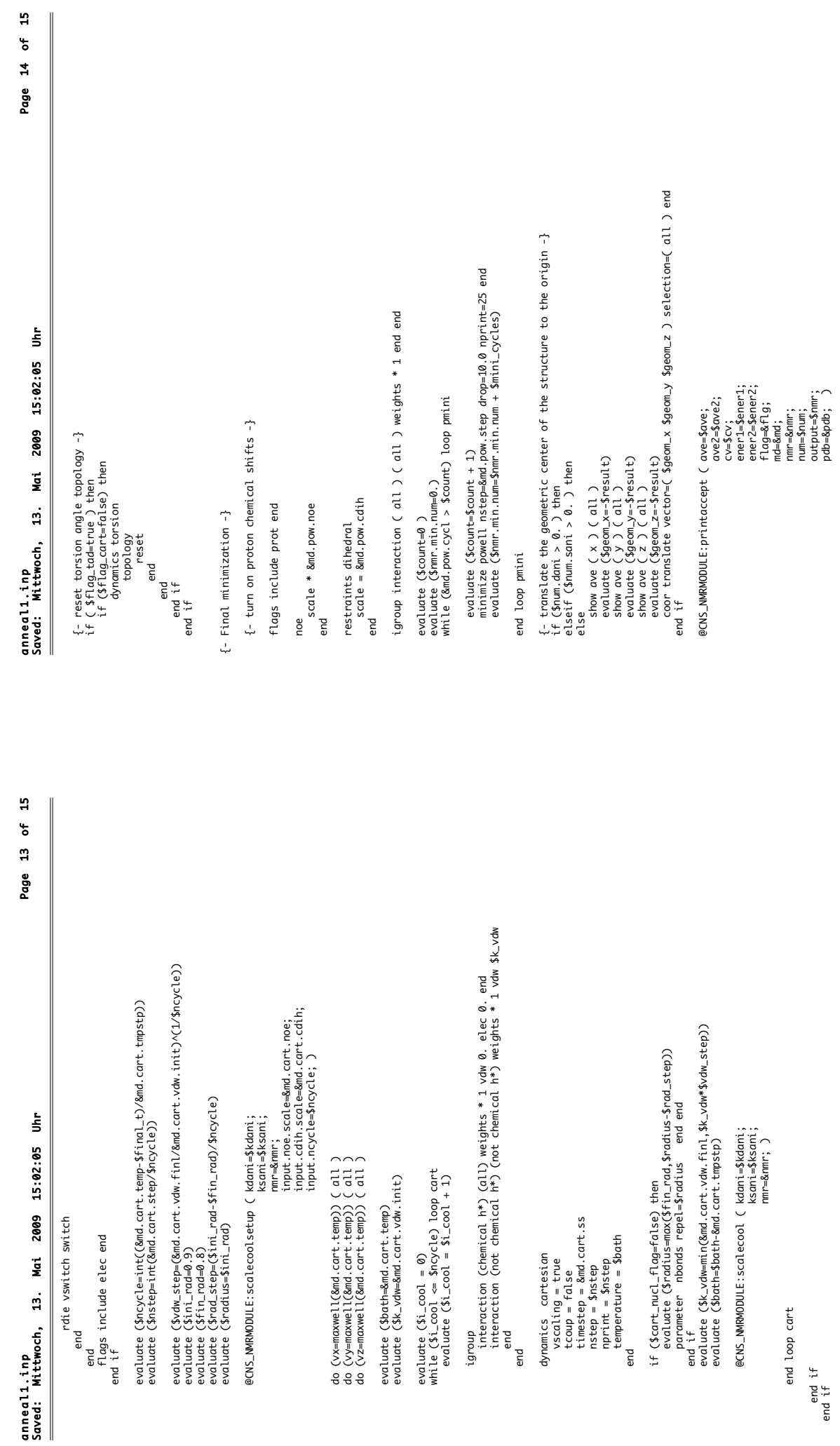


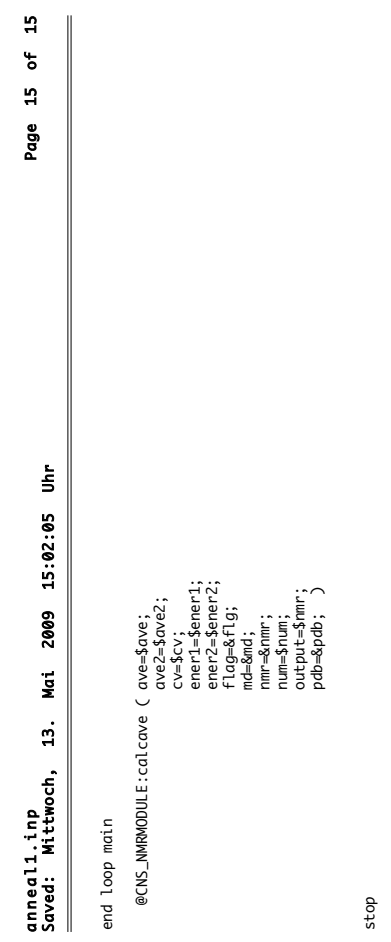



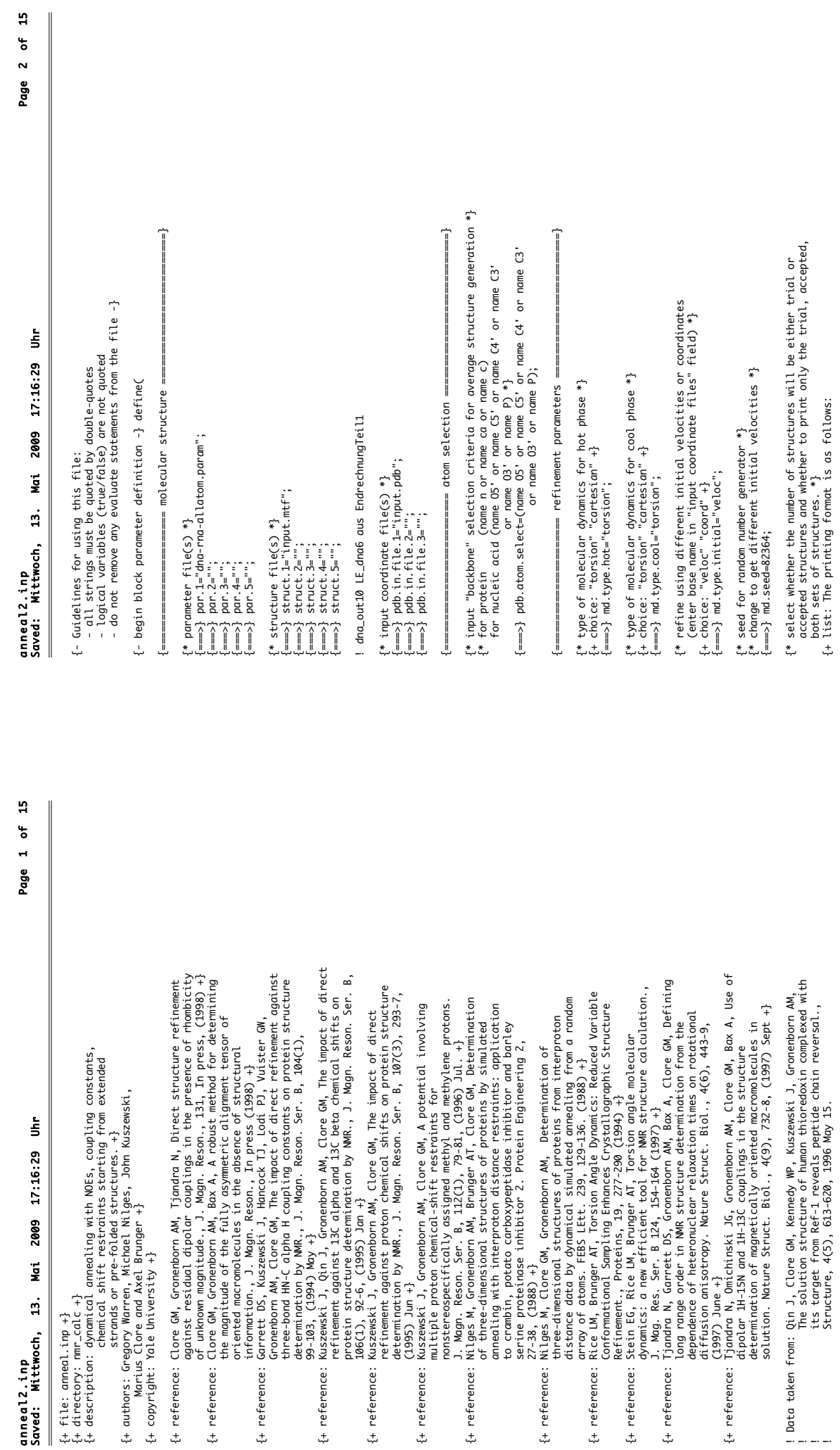

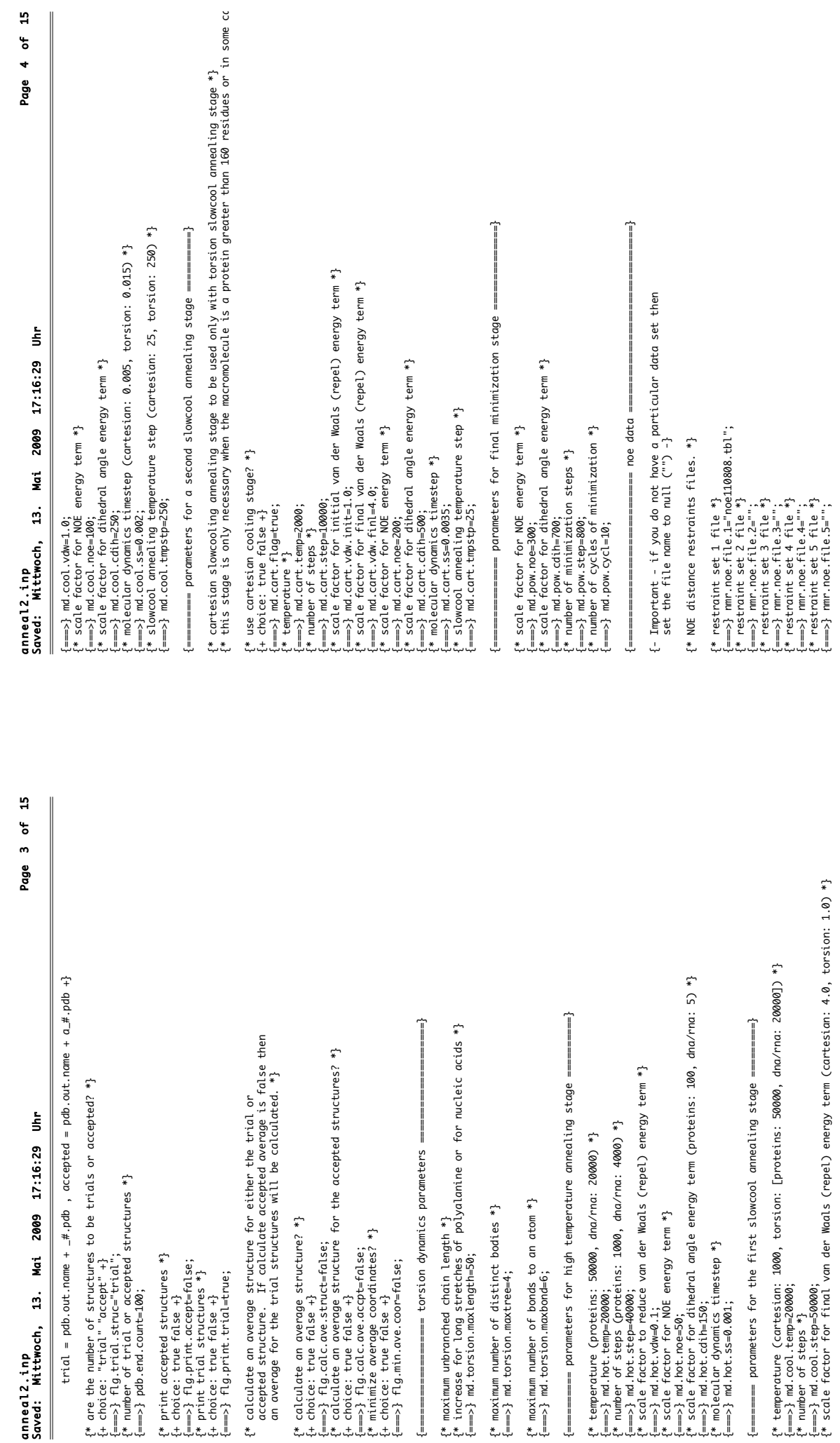

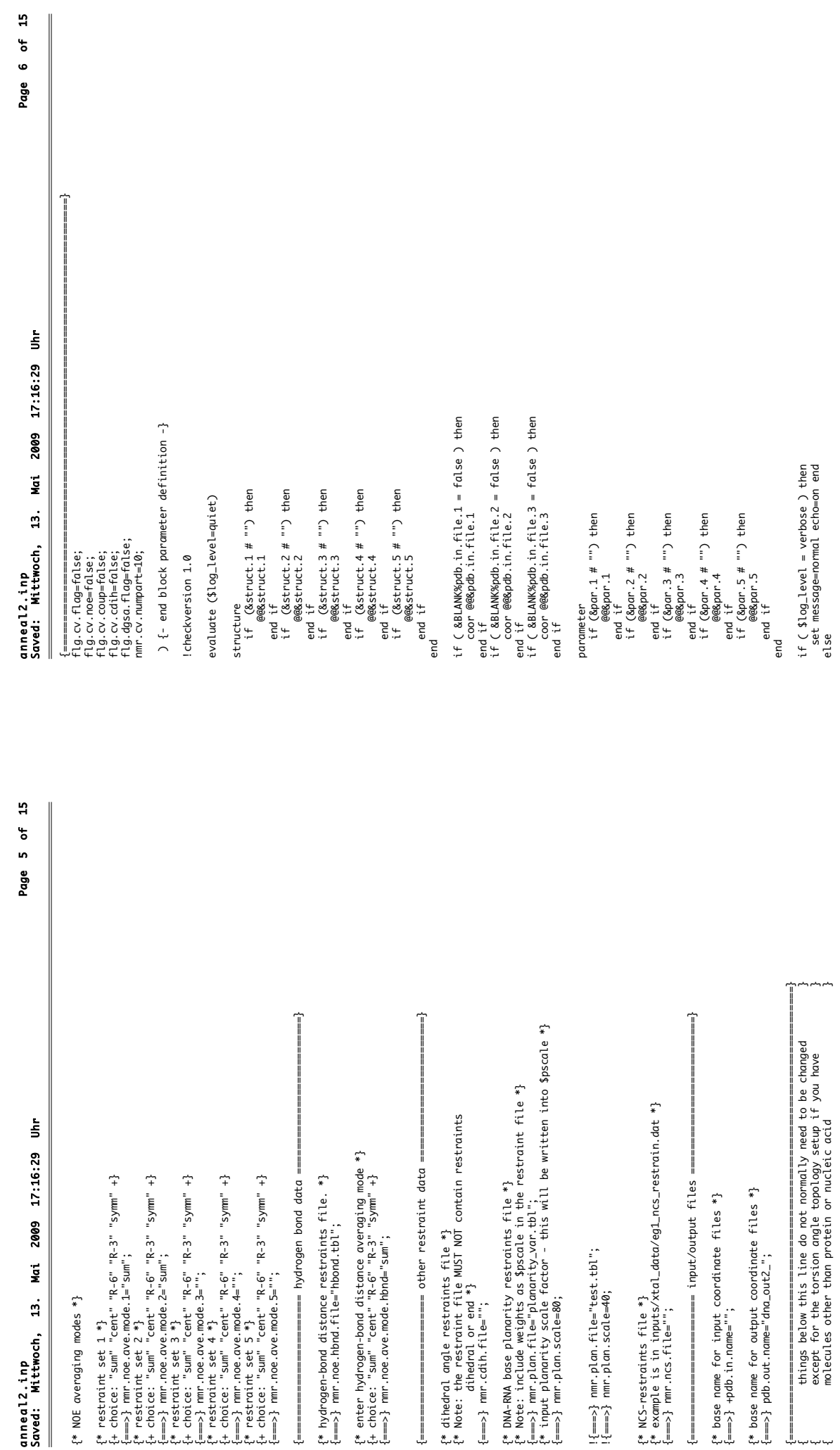

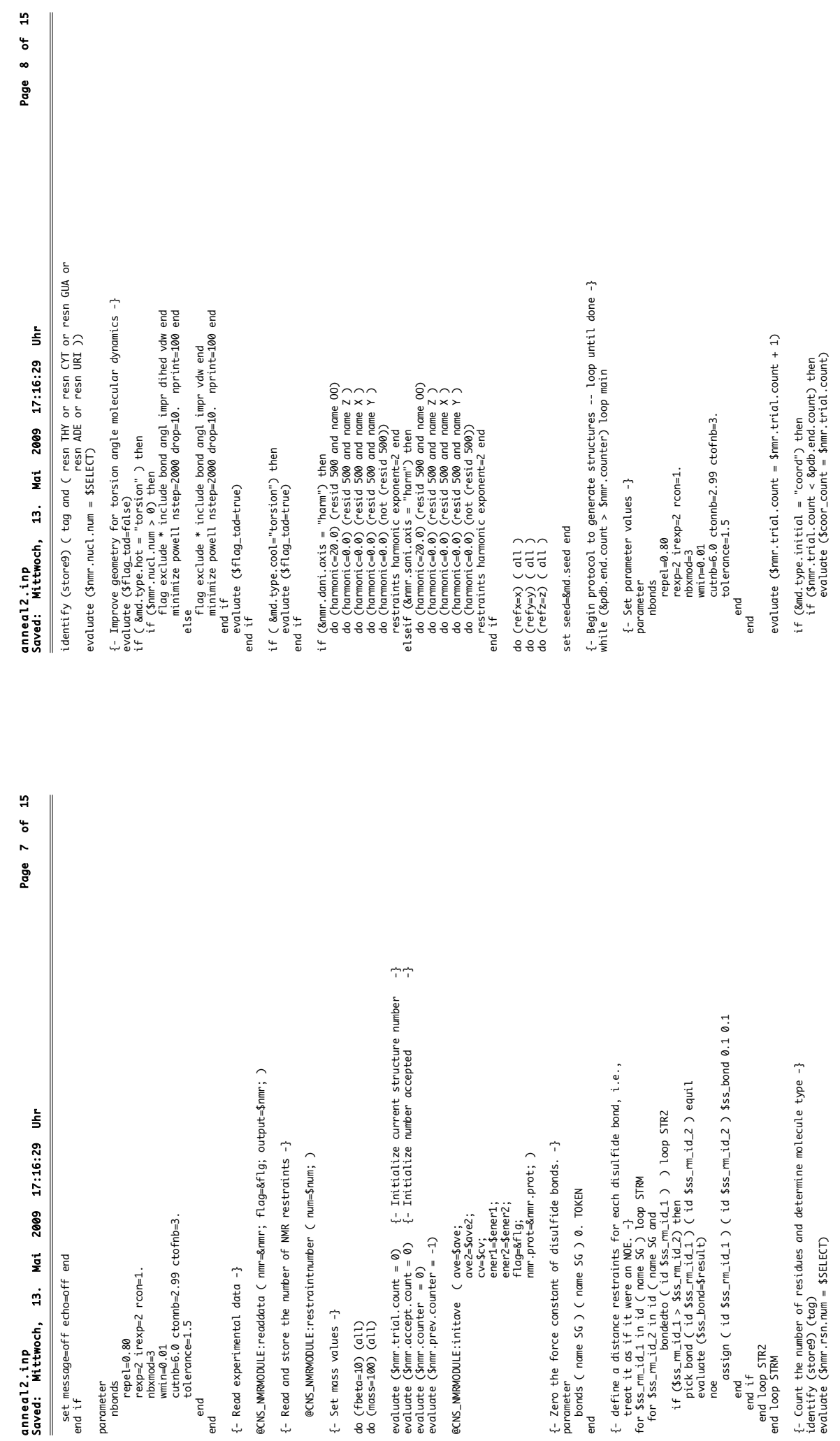

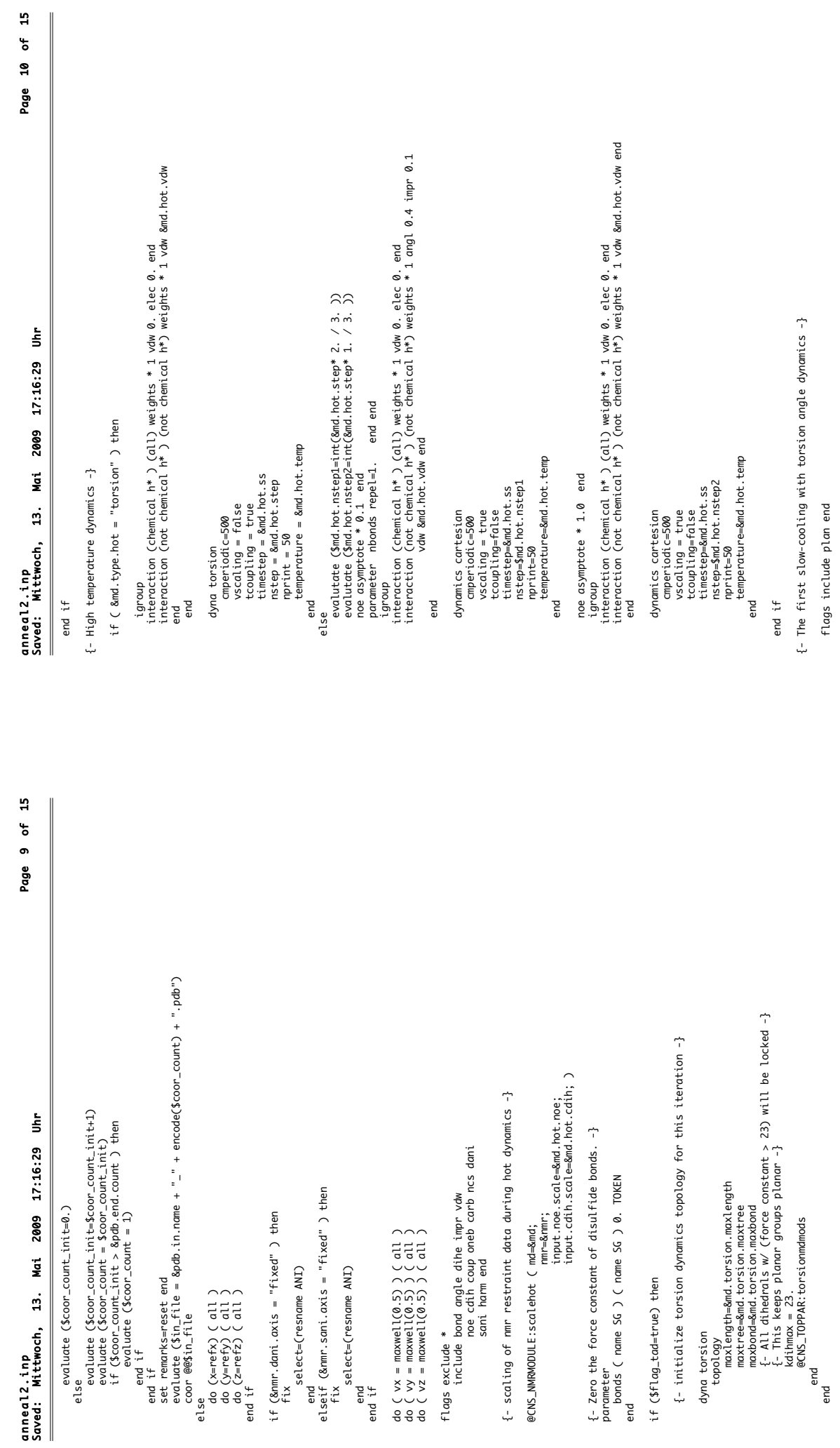

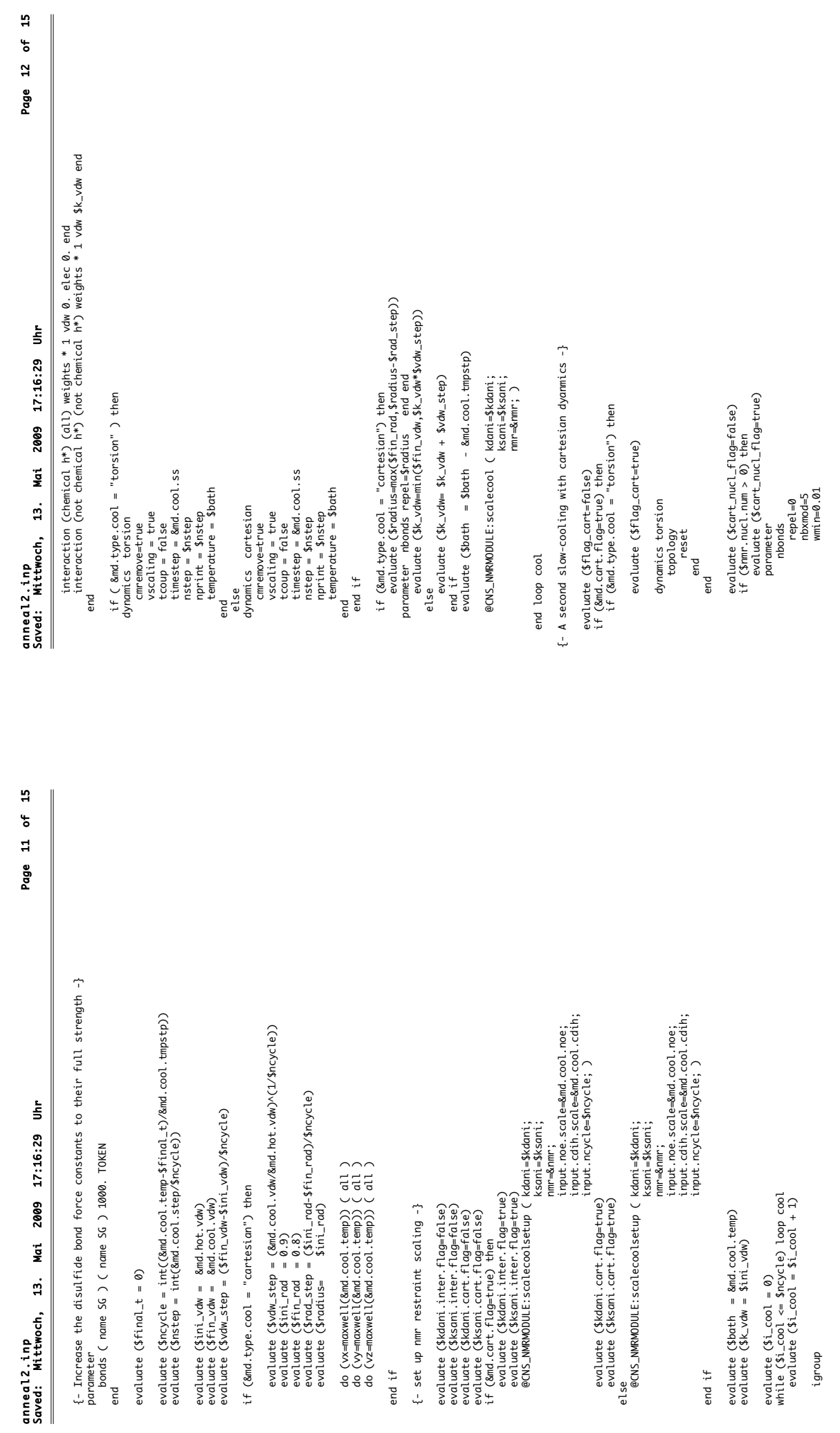

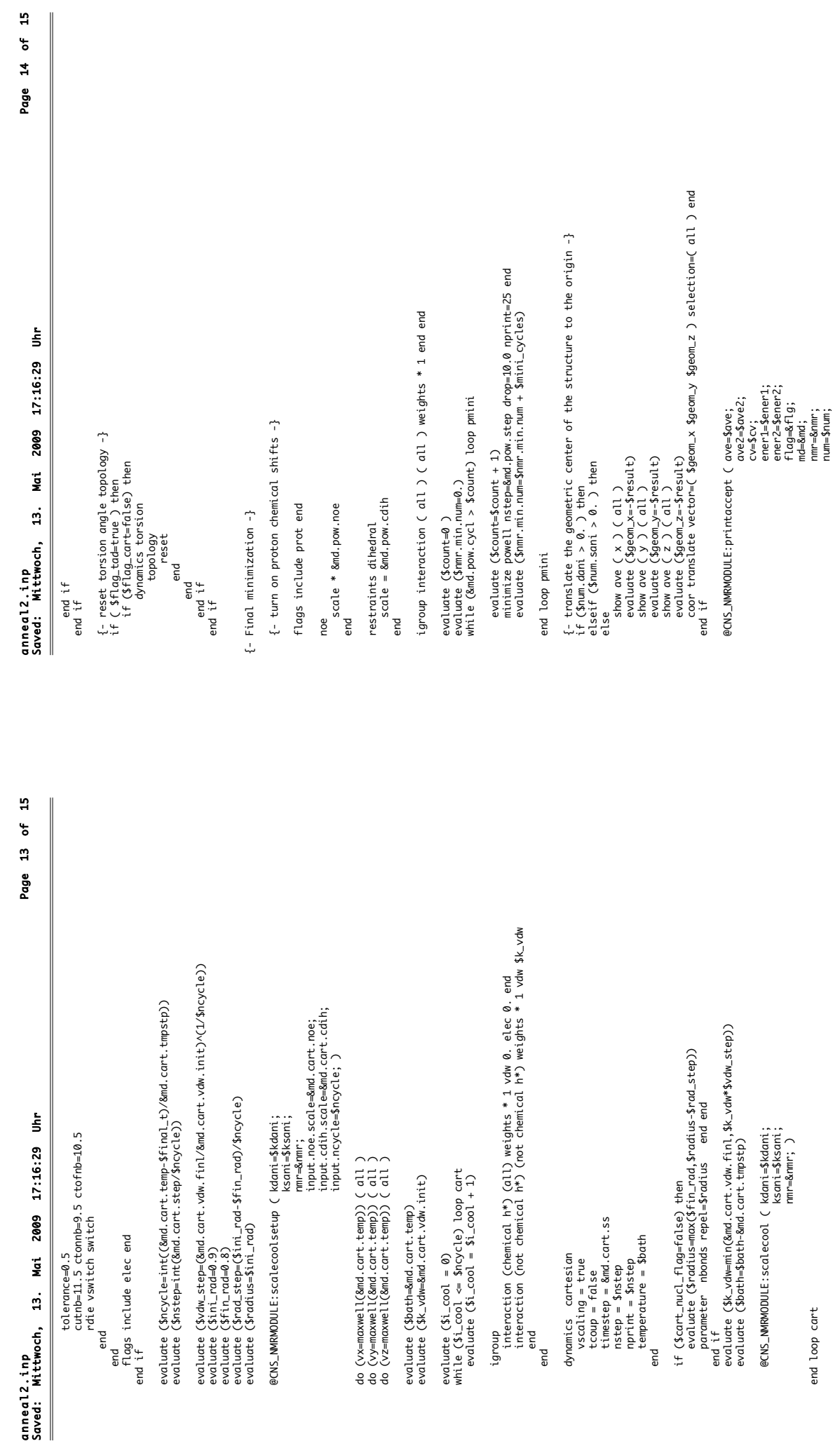


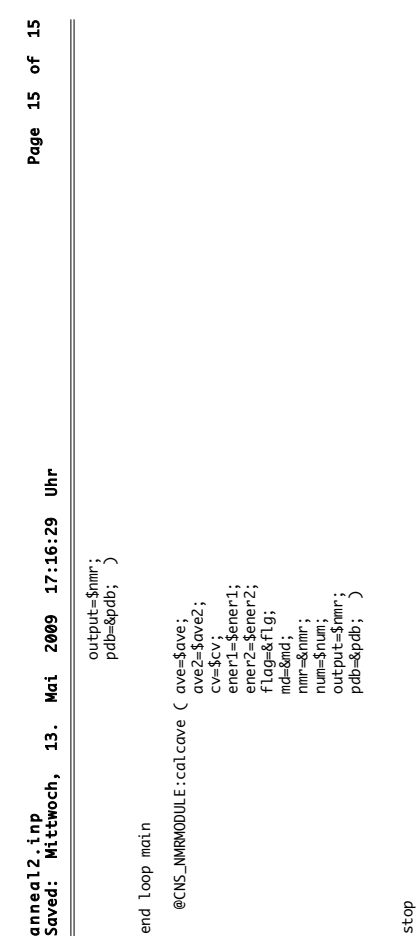



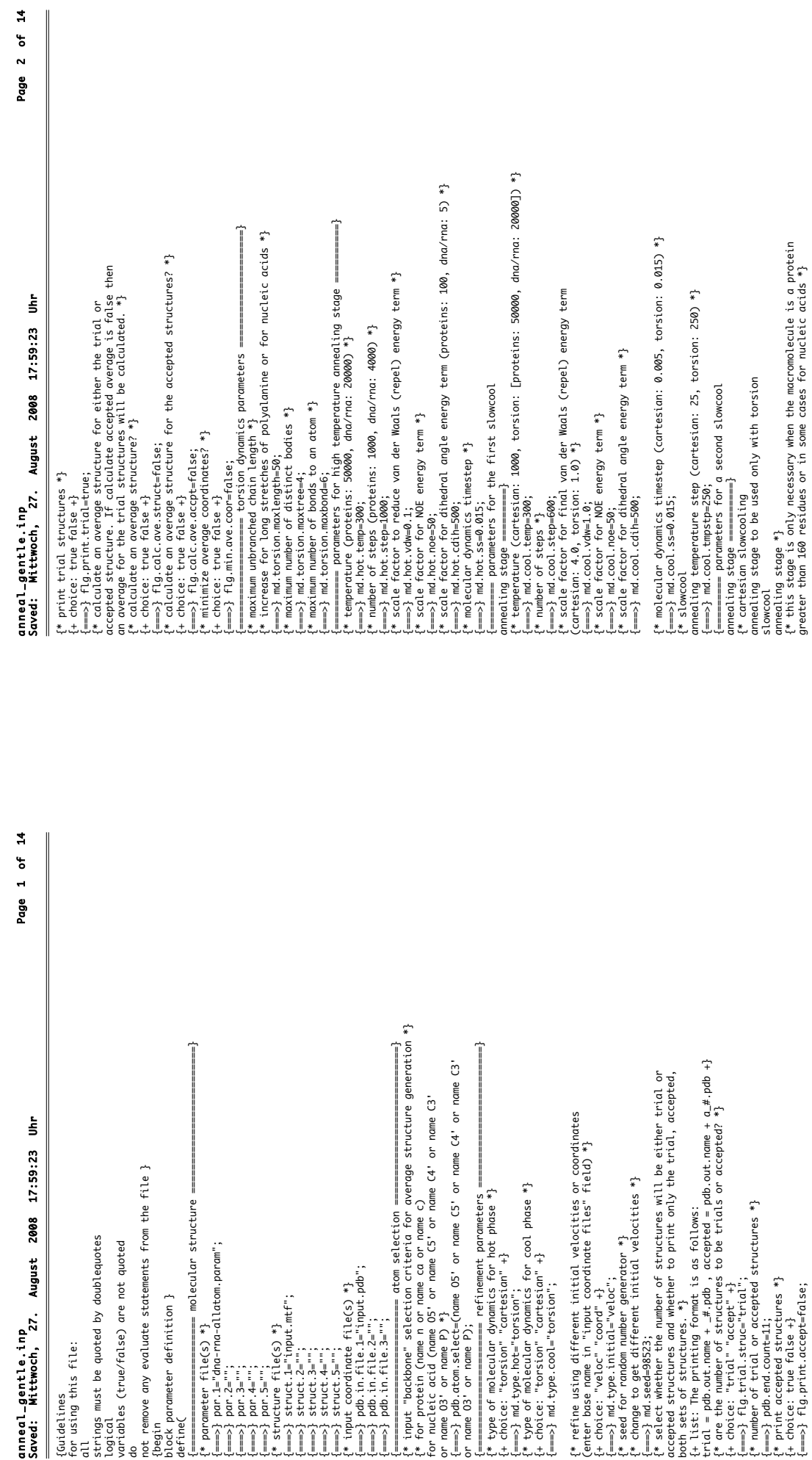

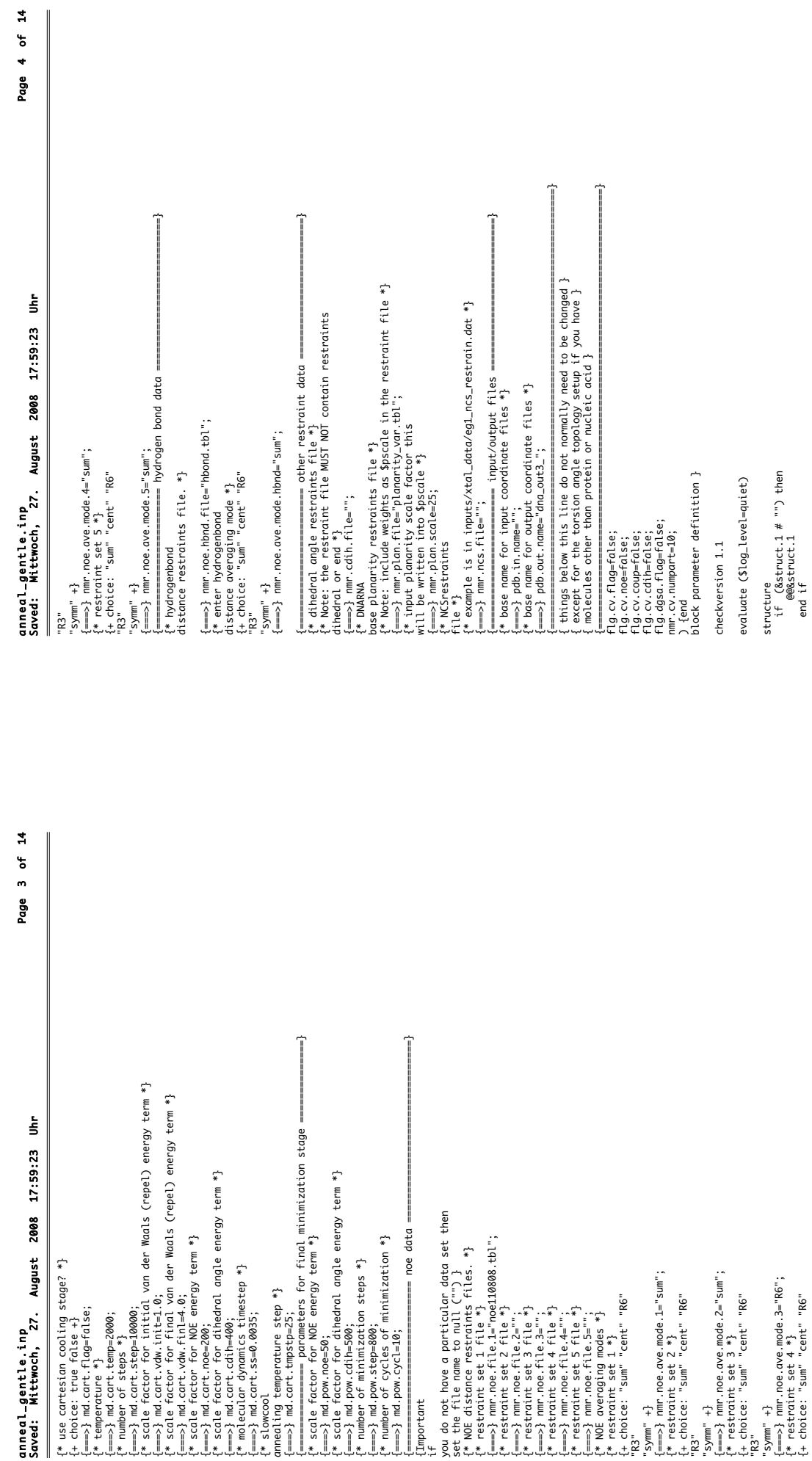

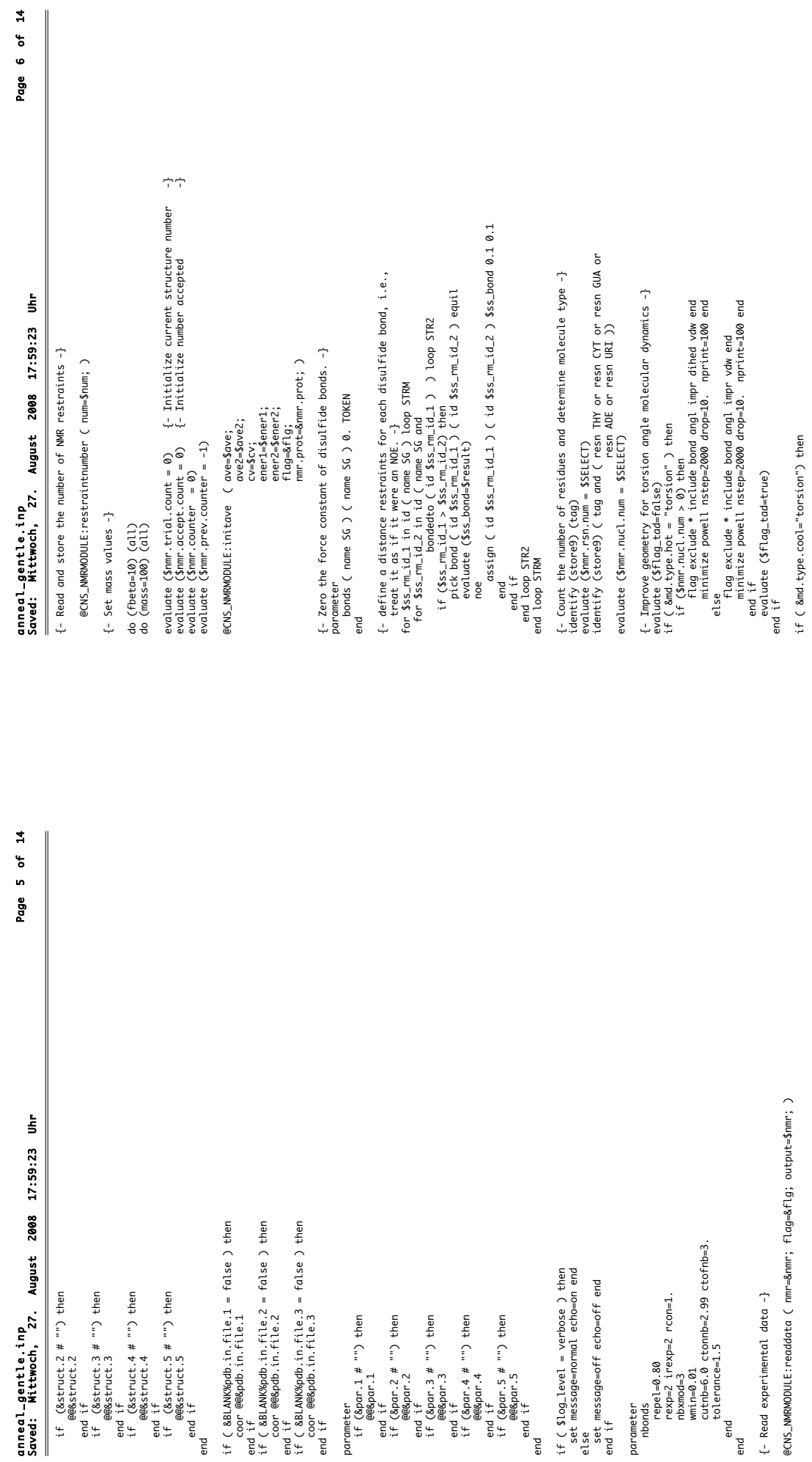

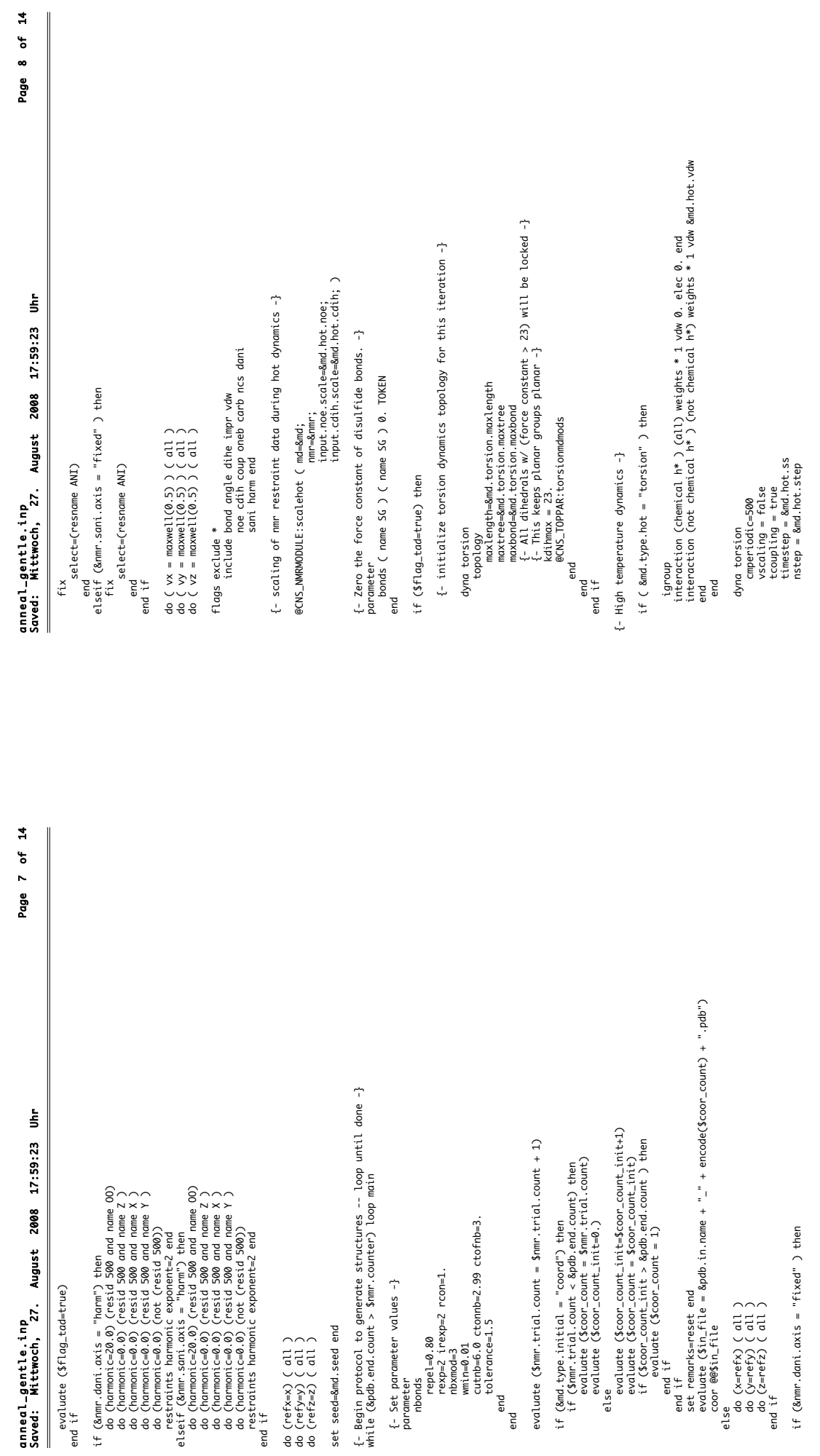

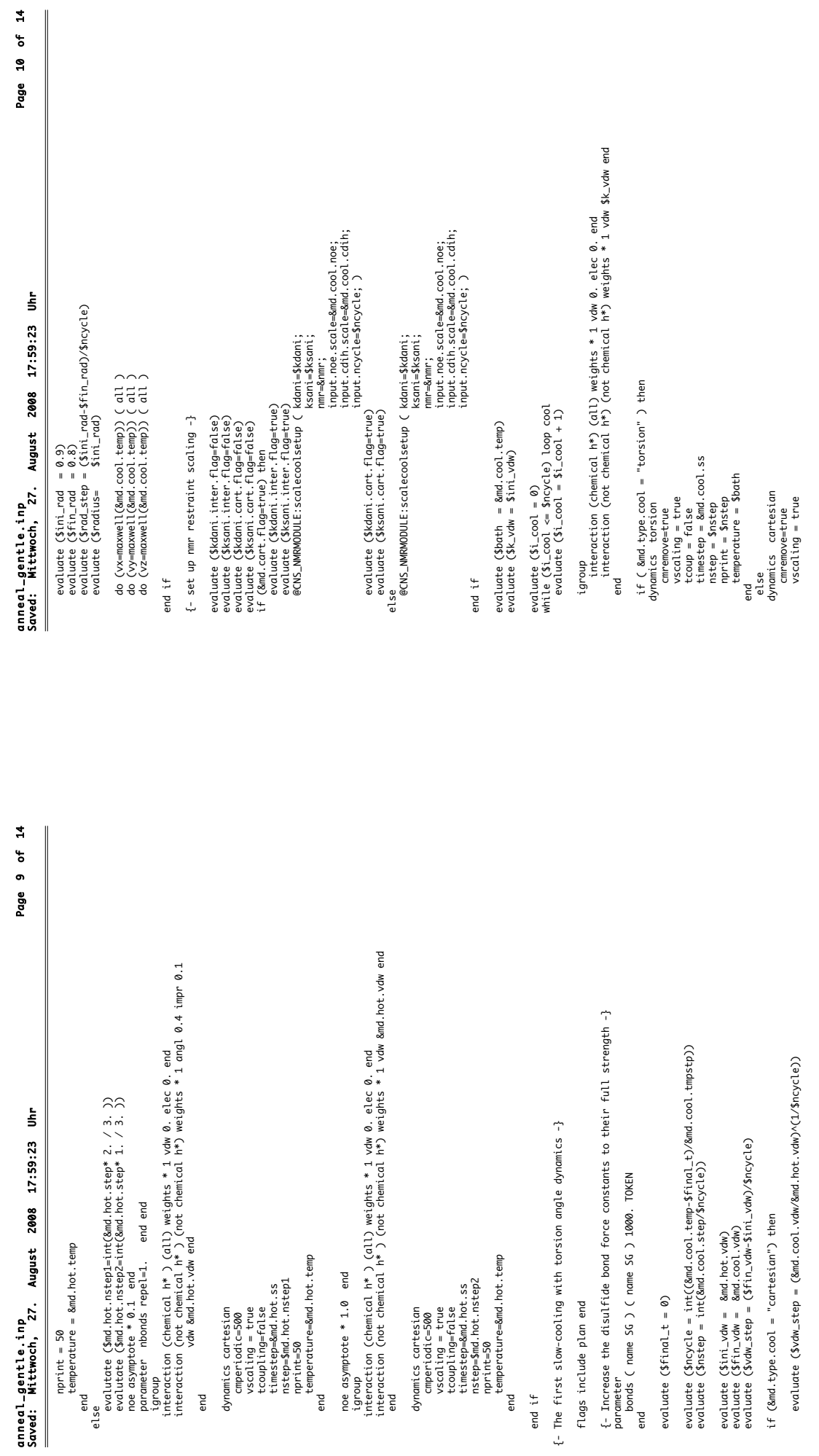

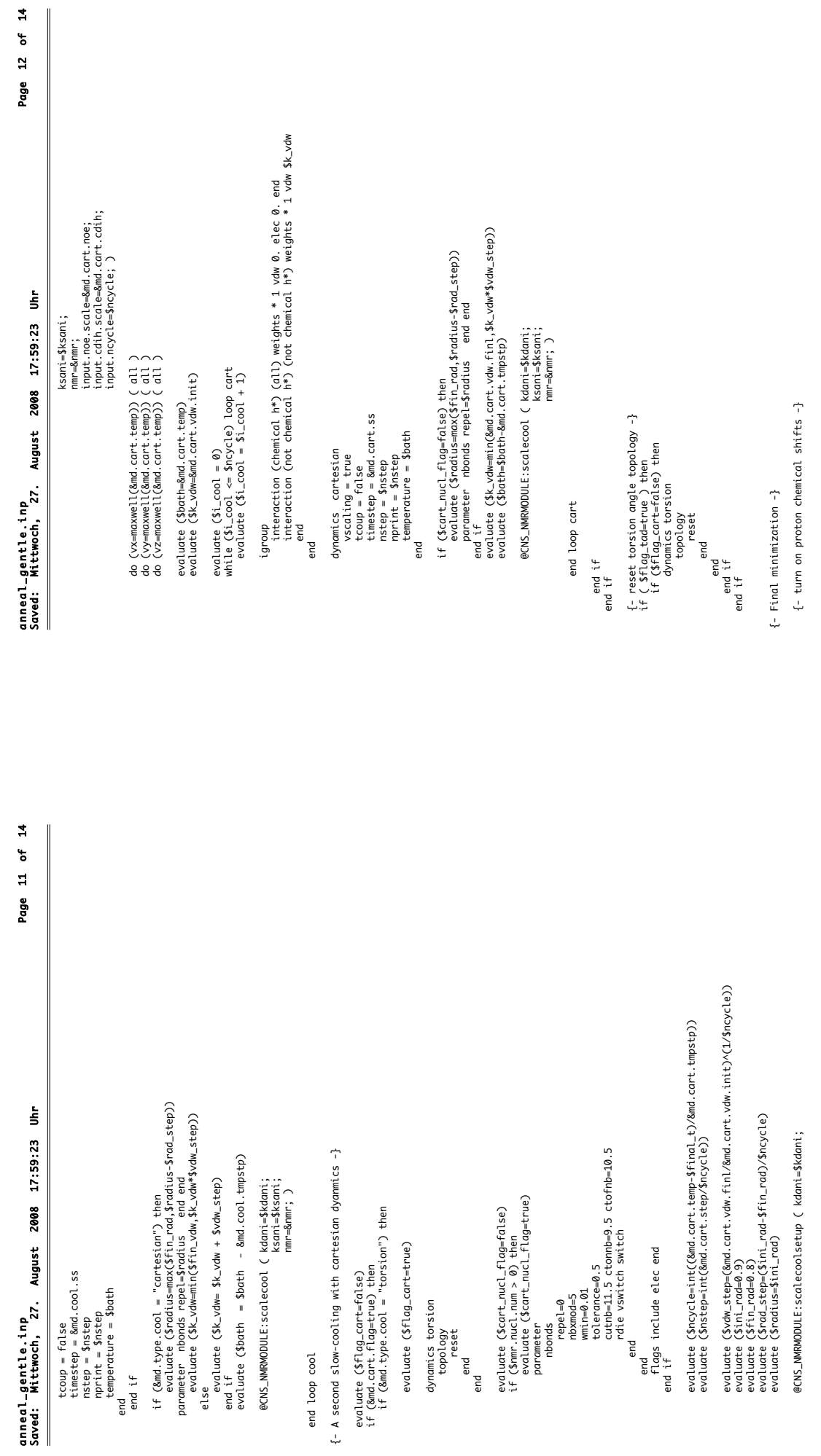

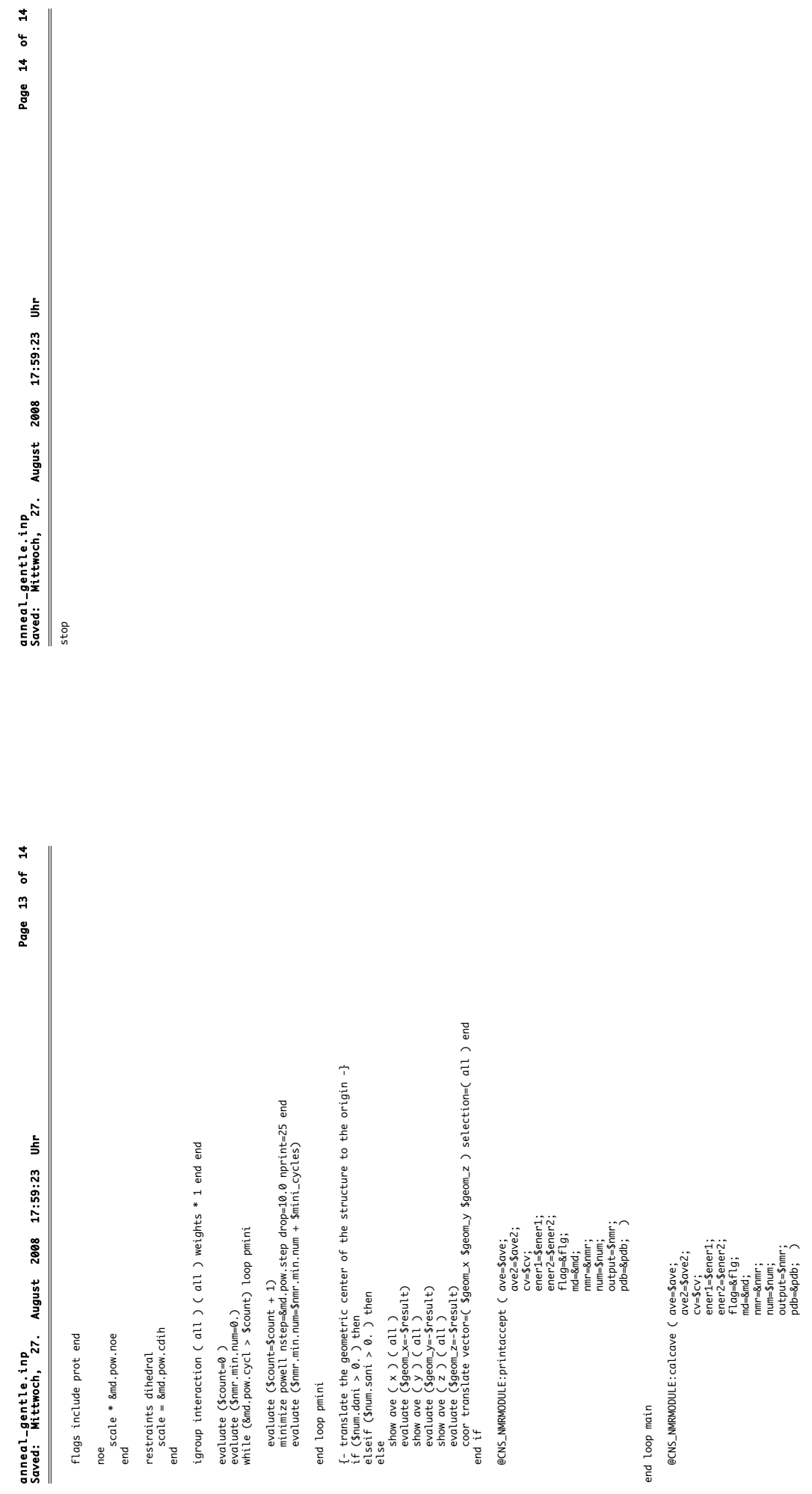

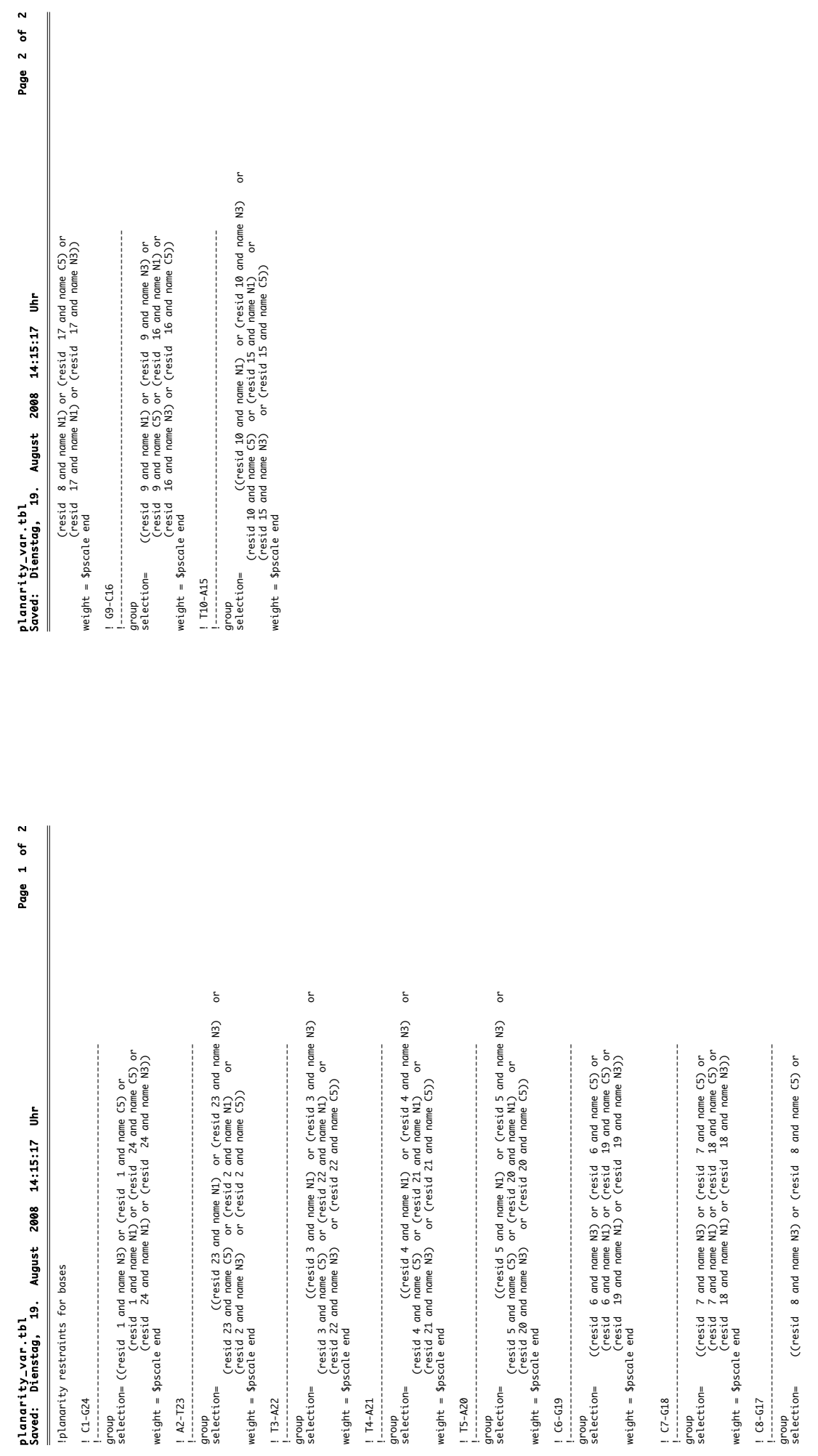

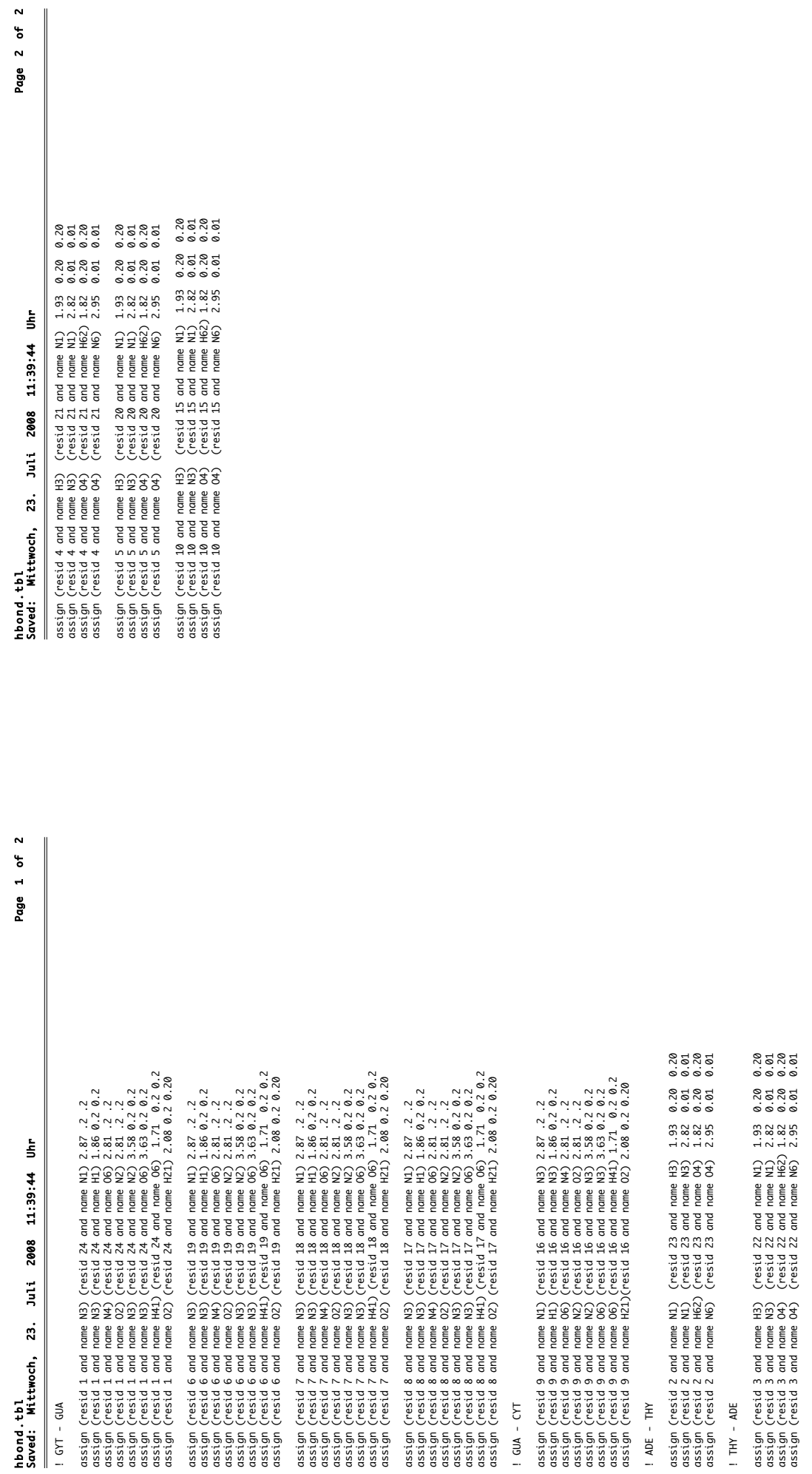

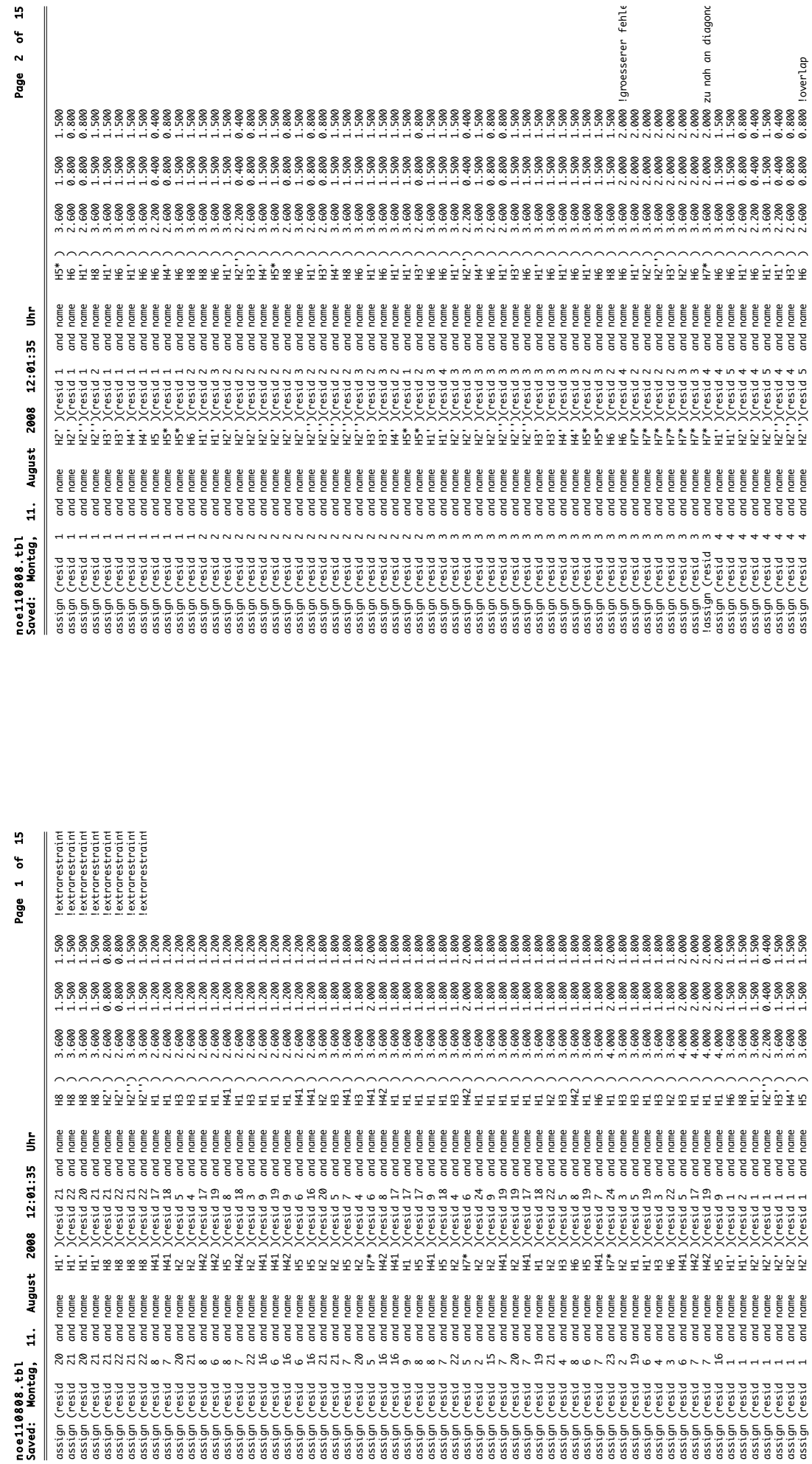

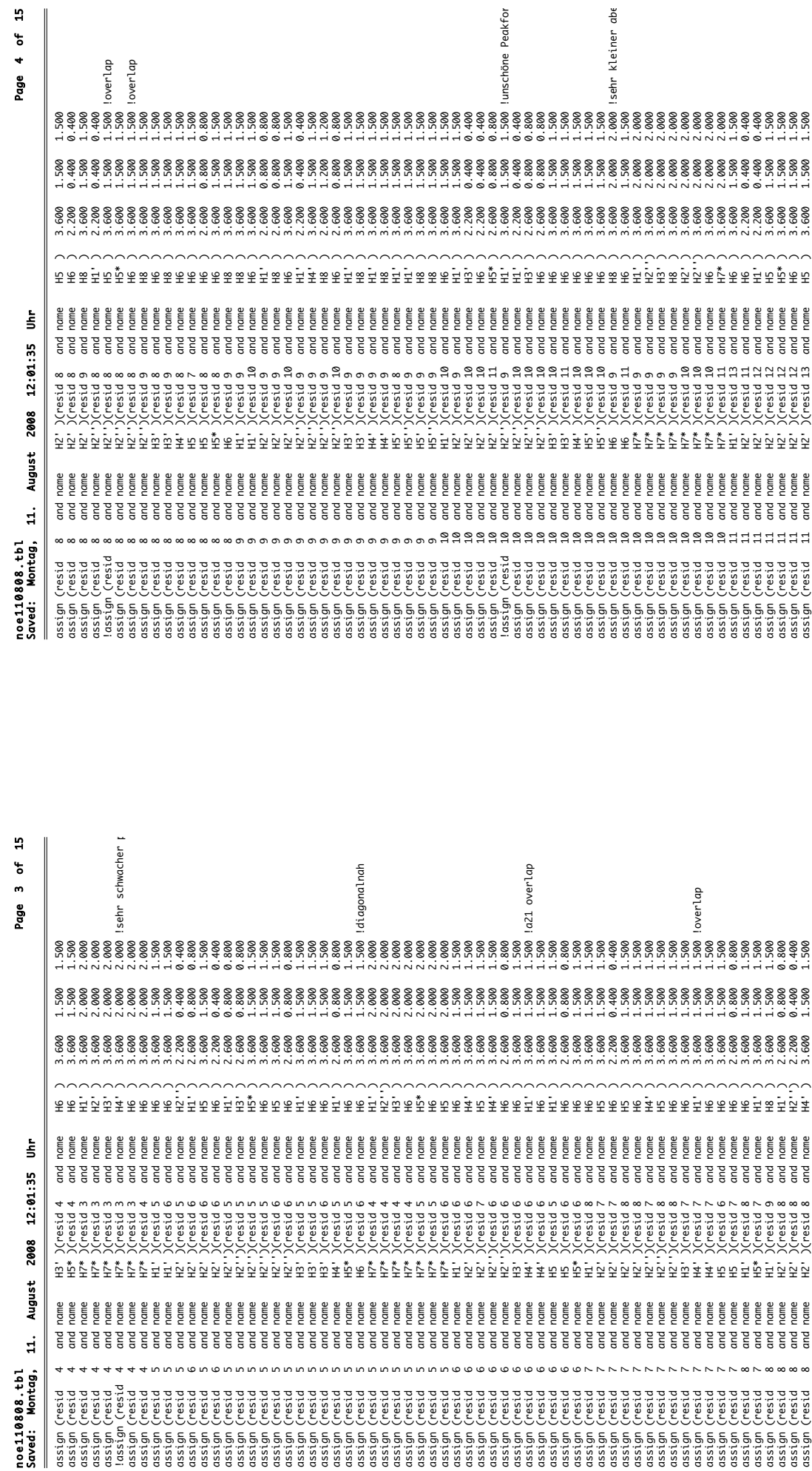

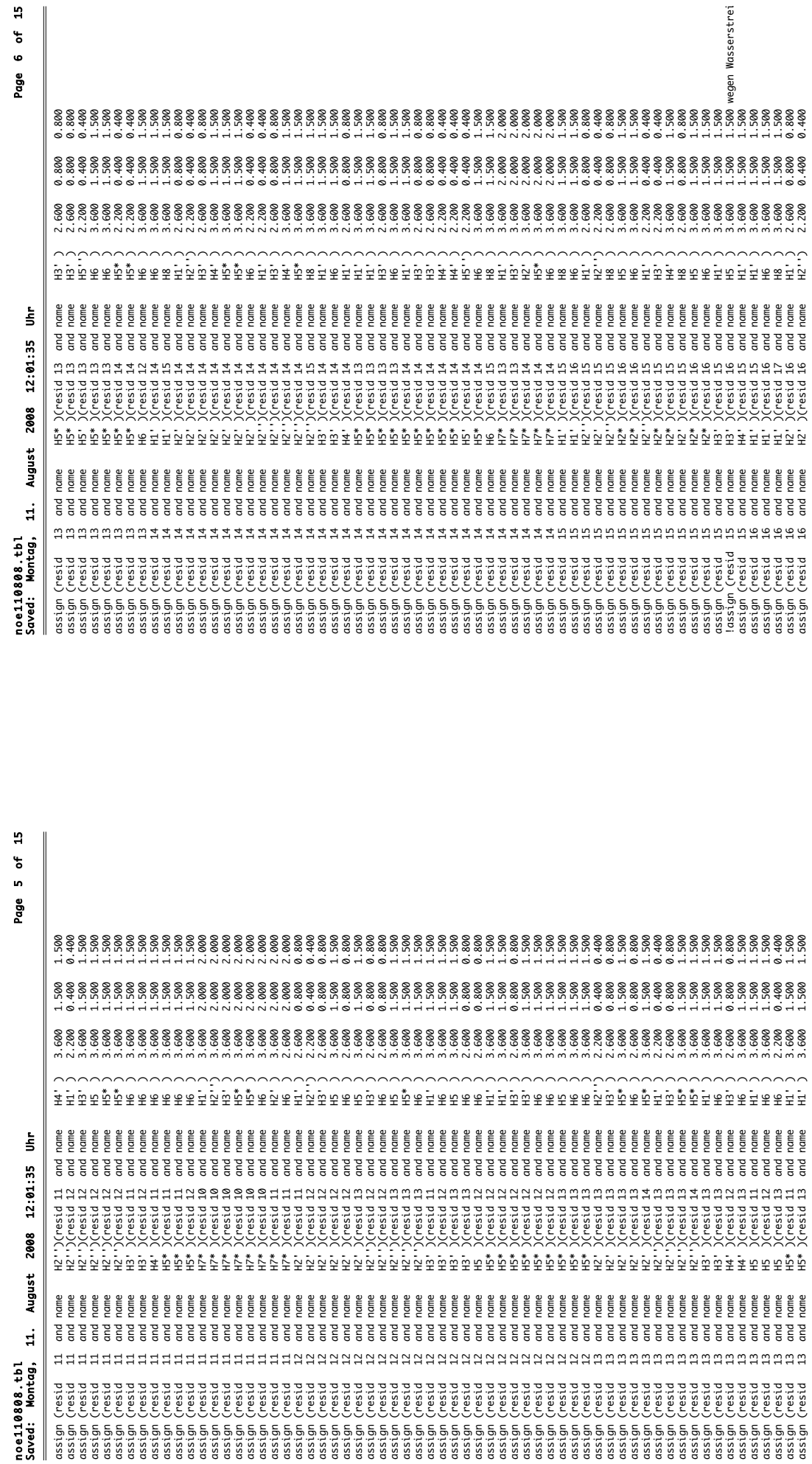

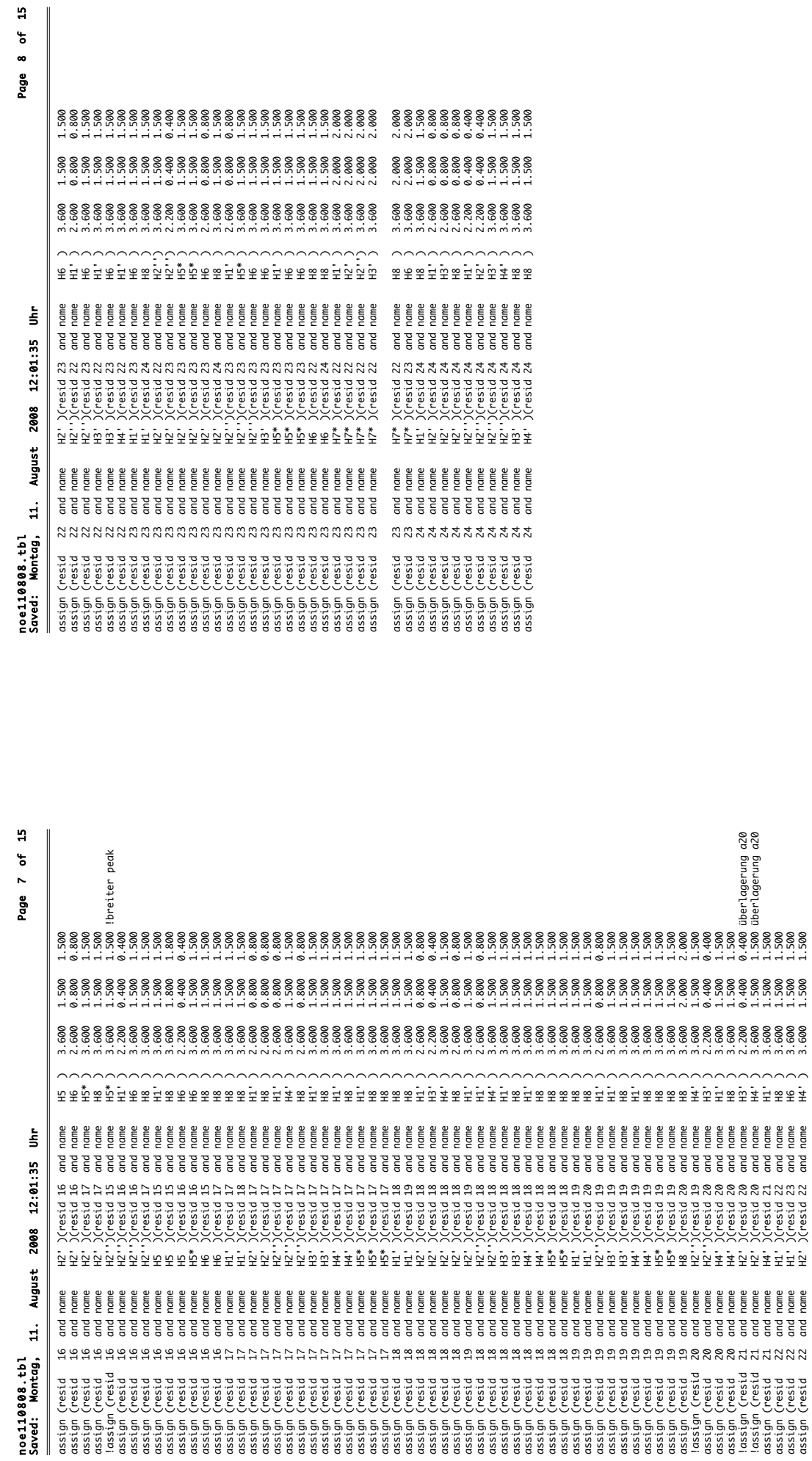


\subsection{Relax-Skript und die zugehörige PCS-Tabelle}

\begin{tabular}{|c|c|c|c|c|c|c|c|c|c|c|c|}
\hline $\begin{array}{l}\text { PCShpE } \\
\text { Saved: }\end{array}$ & $\begin{array}{l}\text { TE } \\
\text { Sor }\end{array}$ & $\begin{array}{l}\text { Anh } \\
\text { nnta }\end{array}$ & $\begin{array}{l}\text { ang } \\
g,\end{array}$ & $\mathrm{Mai}$ & 2009 & $19: 49: 09$ & Uhr & & & & \\
\hline \#Pseudol & konta & aktve & rsch & nigen & n ppm für & die DY- & -EPTE-24m & er-DNA & & & \\
\hline HETATM & 305 & Q7 & THY & 4 & 6.095 & 3.590 & 8.262 & 1.00 & 0.00 & $\mathrm{H}$ & -0.616 \\
\hline HETATM & 310 & $\mathrm{H} 6$ & THY & 4 & 8.474 & 1.597 & 6.758 & 1.00 & 0.00 & $\mathrm{H}$ & -0.424 \\
\hline HETATM & 338 & Q7 & THY & 5 & 8.263 & 1.020 & 2.854 & 1.00 & 0.00 & $\mathrm{H}$ & -0.342 \\
\hline HETATM & 343 & $\mathrm{H} 6$ & THY & 5 & 7.916 & -1.279 & 3.352 & 1.00 & 0.00 & $\mathrm{H}$ & -0.266 \\
\hline ATOM & 339 & $\mathrm{H} 2^{\prime}$ & THY & 5 & 7.305 & -3.492 & 2.259 & 1.00 & 0 & $\mathrm{H}$ & -0.218 \\
\hline АТОМ & 58 & $\mathrm{H} 5$ & $\mathrm{CYT}$ & 6 & 4.809 & -0.800 & 1.133 & 1.00 & 0.00 & $\mathrm{H}$ & -0.322 \\
\hline ATOM & 59 & $\mathrm{H} 6$ & CYT & 6 & 4.629 & -3.194 & 1.082 & 1.00 & 0.00 & $\mathrm{H}$ & -0.229 \\
\hline ATOM & 89 & $\mathrm{H} 5$ & $\mathrm{CYT}$ & 7 & 1.756 & -1.051 & -1.922 & 1.00 & 0.00 & $\mathrm{H}$ & -0.136 \\
\hline ATOM & 90 & $\mathrm{H} 6$ & $\mathrm{CYT}$ & 7 & 0.475 & -3.024 & -2.301 & 1.00 & 0.00 & $\mathrm{H}$ & -0.120 \\
\hline ATOM & 82 & $\mathrm{H} 1^{\prime}$ & CYT & 7 & -3.277 & -3.031 & -2.64 & 1.00 & 0 & $\mathrm{H}$ & -0.101 \\
\hline АТОМ & 117 & $\mathrm{H} 2^{\prime \prime}$ & $\mathrm{CYT}$ & 8 & -7.308 & -3.194 & -6.397 & 1.00 & 0.00 & $\mathrm{H}$ & -0.043 \\
\hline ATOM & 120 & H5 & CYT & 8 & -1.730 & -2.905 & -7.461 & 1.00 & 0.00 & $\mathrm{H}$ & -0.086 \\
\hline ATOM & 121 & $\mathrm{H} 6$ & CYT & 8 & -3.681 & -4.025 & -6.664 & 1.00 & 0.00 & $\mathrm{H}$ & -0.073 \\
\hline HETATM & 369 & $\mathrm{H} 1^{\prime}$ & GUA & 9 & -8.199 & 1.094 & -6.902 & 1.00 & 0.00 & $\mathrm{H}$ & -0.009 \\
\hline HETATM & 377 & $\mathrm{H} 8$ & GUA & 9 & -6.787 & -2.196 & -8.477 & 1.00 & 0.00 & $\mathrm{H}$ & -0.023 \\
\hline HETATM & 405 & Q7 & THY & 10 & -9.124 & -1.358 & -11.485 & 1.00 & 0.00 & $\mathrm{H}$ & -0.003 \\
\hline HETATM & 407 & $\mathrm{H} 2^{\prime}$ & ' THY & 10 & -10.816 & 3.952 & -12.583 & 1.00 & 0.00 & $\mathrm{H}$ & -0.006 \\
\hline HETATM & 410 & $\mathrm{H} 6$ & THY & 10 & -9.711 & 0.899 & -11.061 & 1.00 & 0.00 & $\mathrm{H}$ & -0.003 \\
\hline HETATM & 501 & $\mathrm{H} 1^{\prime}$ & $\mathrm{ADE}$ & 15 & 0.146 & 6.610 & -13.194 & 1.00 & 0.00 & $\mathrm{H}$ & -0.026 \\
\hline HETATM & 505 & $\mathrm{H} 2^{\prime}$ & 'ADE & 15 & 0.681 & 5.925 & -10.929 & 1.00 & 0.00 & $\mathrm{H}$ & -0.035 \\
\hline ATOM & 504 & $\mathrm{H} 2^{\prime}$ & $\mathrm{ADE}$ & 15 & 1.784 & 4.65 & -11.51 & 1.00 & 0 & $\mathrm{H}$ & -0.037 \\
\hline HETATM & 508 & $\mathrm{H} 8$ & $\mathrm{ADE}$ & 15 & 1.597 & 3.294 & -14.342 & 1.00 & 0.00 & $\mathrm{H}$ & -0.0354 \\
\hline АTOM & 209 & $\mathrm{H} 2^{\prime}$ & CYT & 16 & $-0,267$ & 8,176 & $-6,889$ & 1.00 & 0 & $\mathrm{H}$ & -0.083 \\
\hline ATOM & 213 & $\mathrm{H} 5$ & $\mathrm{CYT}$ & 16 & 1.623 & 4.136 & -8.071 & 1.00 & 0.00 & $\mathrm{H}$ & -0.080 \\
\hline ATOM & 214 & $\mathrm{H} 6$ & CYT & 16 & 1.206 & 6.500 & -8.063 & 1.00 & 0.00 & $\mathrm{H}$ & -0.068 \\
\hline HETATM & 705 & $\mathrm{H} 2^{\prime}$ & $\mathrm{ADE}$ & 22 & 2.362 & -8.692 & 11.635 & 1.00 & 0.00 & $\mathrm{H}$ & -0.2425 \\
\hline HETATM & 706 & $\mathrm{H}^{\prime}{ }^{\prime}$ & 'ADE & 22 & 4.120 & -8.790 & 11.465 & 1.00 & 0.00 & $\mathrm{H}$ & -0.237 \\
\hline ATOM & 702 & $\mathrm{H} 1^{\prime}$ & $\mathrm{ADE}$ & 22 & 4.084 & -7.326 & 9.501 & 1.00 & 0 & $\mathrm{H}$ & -0.277 \\
\hline HETATM & 709 & $\mathrm{H} 8$ & $\mathrm{ADE}$ & 22 & 0.773 & -6.852 & 11.492 & 1.00 & 0.00 & $\mathrm{H}$ & -0.2915 \\
\hline HETATM & 738 & Q7 & THY & 23 & 1.130 & -7.015 & 15.945 & 1.00 & 0.00 & $\mathrm{H}$ & -0.284 \\
\hline HETATM & 743 & $\mathrm{H} 6$ & THY & 23 & 3.562 & -8.683 & 14.312 & 1.00 & 0.00 & $\mathrm{H}$ & -0.259 \\
\hline АТОМ & 740 & $\mathrm{H} 2^{\prime \prime}$ & THY & 23 & 5.88 & -9.973 & 15.148 & 1.00 & 0 & $\mathrm{H}$ & -0.245 \\
\hline ATOM & 734 & $\mathrm{H}^{\prime}{ }^{\prime}$ & THY & 23 & 7.108 & -7.895 & 14.572 & 1.00 & 0 & $\mathrm{H}$ & -0.295 \\
\hline
\end{tabular}

Page 1 of 1 
analysis 77 neu $4-a 20 \mathrm{~g} 24$. py

Saved: Samstag, 9. Mai 2009 16:33:50 Uhr

\# Script for determining populations for lactose conformations using RDCs and PCSs.

from random import uniform

\# relax imports.

from data import Relax_data_store; ds = Relax_data_store()

from generic_fns.mol_res_spin import spin_loop

from specific_fns.setup import n_state_model_obj

\# Create the data pipe.

pipe.create('dna', 'N-state')

\# Load the structures.

NUM_STR $=77$

for $i$ in range(NUM_STR)

structure.read_pdb(file='HPEPTEconf_Hpepte-CS2-out.' +`i+1', set_mol_name='DNA', set_model_num=i+1, pars

\# Load the sequence information.

atom_list $=$ ["H1'", "H2'", "H2'"", "H5", "H6", "H71", "H72", "H73", "H8"]

for atom in atom_list:

structure.load_spins(spin_id="@"+atom, ave_pos=False)

\# Create the pseudo-atoms.

for $i$ in $[4,5,23,10]$ :

id $=$ ': $+{ }^{\prime}+{ }^{\prime}+$ '@H7

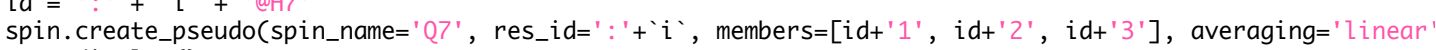
sequence.display()

\# The PCS.

pcs.read(id='pcs1', file='PCShpEPTETneu4-a20g24.txt' , mol_name_col=None, res_num_col=4, res_name_col=3, spi

\# The temperature.

temperature (id=' pcs1' , temp=298)

\# The frequency.

frq. $\operatorname{set}\left(i d={ }^{\prime} p \operatorname{cs} 1^{\prime}\right.$, frq $\left.=700 * 1 \mathrm{e} 6\right)$

\# Calculate the paramagnetic centre, using a pseudoatom (from the structures in the 'tag' data pipe).

structure.load_spins(spin_id=' :34@01' , ave_pos=False)

structure.load_spins(spin_id=':36@01', ave_pos=False)

structure.load_spins(spin_id=':39@01', ave_pos=False)

structure.load_spins(spin_id=' :41@01', ave_pos=False)

residue.create(100)

spin.create_pseudo(spin_name='Ln', res_id=':100', members=[':34@01' , ':36@01', ':39@01', ':41@01'], averagi sequence.display()

pcs.centre(atom_id=' :100@Ln')

\# Set up the model.

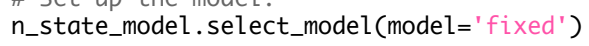

\# Minimisation.

minimise('simplex', constraints=True)

\# Write out a results file.

results.write('results77neu4-a20g24', dir=None, force=True)

\# Show the tensors.

align_tensor.display() 


\title{
9.15 Lebenslauf
}

\author{
Name: $\quad$ Edith Wöltjen \\ Geburtsdatum: $\quad$ 07.12.1980 \\ Geburtsort: Braunschweig \\ Staatsangehörigkeit: deutsch
}

\section{Ausbildung}

seit Okt. 2005

Mai 2005

Jul. 2004 - Jan. 2005

Okt. 2002

Aug. 2000

Jun. 2000

Aug. 1997 - Dez. 1997
Dissertation am Max-Planck-Institut für biophysikalische Chemie bei Prof. Griesinger gefördert durch ein Stipendium des Fonds der Chemischen Industrie zum Thema „Paramagnetisch markierte Oligonukleotide"

Diplomprüfung mit Auszeichnung (Note 1,0)

Externe Diplomarbeit am Max-Planck-Institut für biophysikalische Chemie zum Thema „Synthese eines paramagnetischen Tags zur NMR-spektroskopischen Untersuchung von Oligonukleotiden“ Betreuer: Prof. Griesinger und Prof. Diederichsen

Okt. 2003 - Jan. 2004 Forschungsaufenthalt bei Prof. Malacria an der „Université Pierre et Marie Curie" in Paris

Okt. 2000 - Mai 2005 Studium der Chemie an der Georg-August-Universität Göttingen unterstützt durch ein Stipendium nach Bayerischem Begabtenförderungsgesetz

Vordiplomprüfung (Note 1,1)

Praktikum bei der Schwan-STABILO Cosmetics GmbH \& Co. KG in Heroldsberg im Bereich Qualitätsentwicklung

Allgemeine Hochschulreife am Albert-Schweitzer Gymnasium Erlangen (Note 1,3)

Dreimonatiger Schulbesuch in Calgary (Kanada) im Rahmen eines Austauschprogramms des Bayerischen Jugendrings 